\title{
STUDIES ON THE FAMILY PERIDINIDAE AN UNFINISHED MONOGRAPH ON THE ARMOURED DINOFLAGELLATA
}

$\operatorname{AUTHOR(S):~}$

Abe, Tohru H.

\section{CITATION:}

Abe, Tohru H.. STUDIES ON THE FAMILY PERIDINIDAE AN UNFINISHED MONOGRAPH ON THE ARMOURED DINOFLAGELLATA. Publications of the Seto Marine Biological

Laboratory. Special Publication Series 1981, 6: 1-409

\section{ISSUE DATE:}

1981-02-25

URL:

http://hdl.handle.net/2433/176462

RIGHT: 


\title{
STUDIES ON THE FAMILY PERIDINIDAE AN UNFINISHED MONOGRAPH ON THE ARMOURED DINOFLAGELLATA
}

\author{
THE LATE TOHRU H. ABÉ, D.SC.
}

\section{CONTENTS}

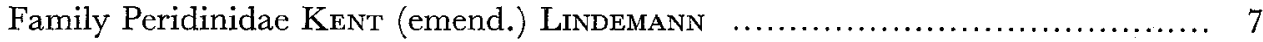

Subfamily 1. Glenodiniopsinae n. subfam............................... 8

Subfamily 2. Dinosphaerinae n. subfam. ….......................... 8

Subfamily 3. Diplopsalinae n. subfam. ................................... 9

Historical account and consideration ..................................... 9

General characteristics .............................................. 13

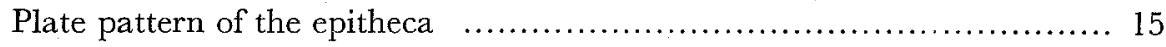

Distal displacement of the girdle ...................................... 18

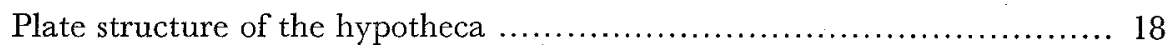

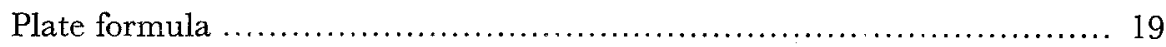

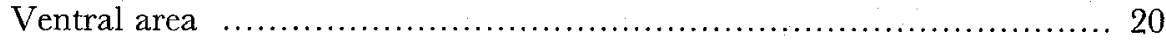

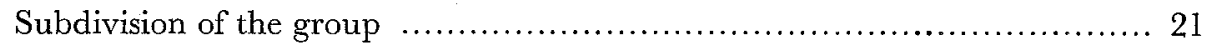

Interrelationship between subgroups and species ........................ 22

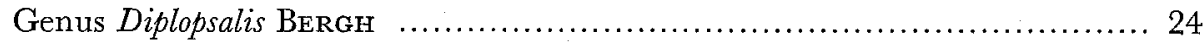

Subgenus 1. Diplopsalis n. subgen. ................................... 25

1. Diplopsalis lenticula BeRGH ...................................... 26

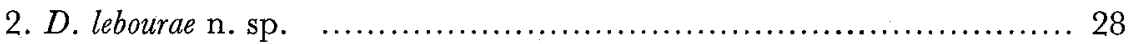

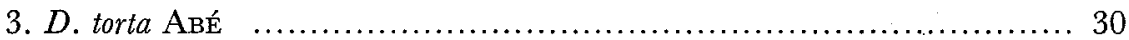

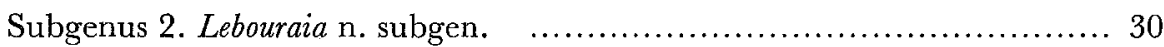

4. D. minuta AвÉ.............................................. 31

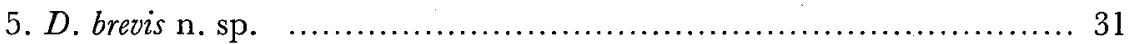

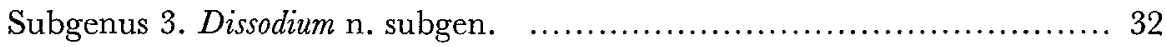

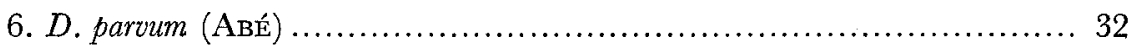

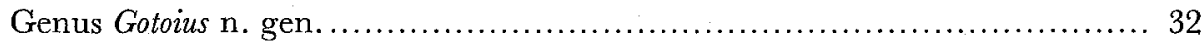

1. G. mutsuensis n. gen. n. sp. ................................... 33

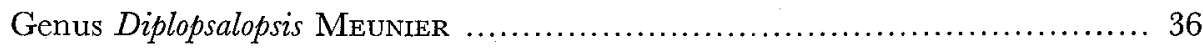

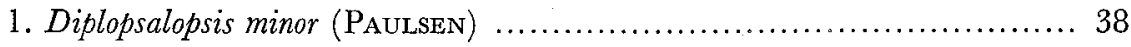

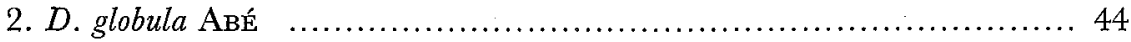

3. D. asymmetrica (MANGIN) ......................................... 44

4. D. steinii ABÉ ...................................................... 44

5. D. orbicularis (PAULSEN) ......................................... 44

var. orbicularis $\mathrm{n}$. nom. ............................................. 45

var. ovata $\mathrm{ABÉ}$..................................................... 47 
Genus Apsteinia n. nom. ........................................ 49

Subfamily 4. Chalubiskinae $n$. subfam. .................................. 49

Subfamily 5. Minusculinae $n$. subfam. ................................ 49

Subfamily 6. Peridininae n. subfam. ................................... 50

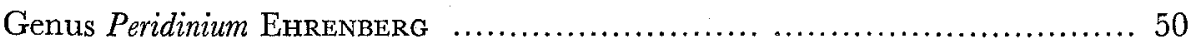

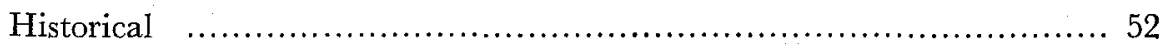

Polymorphism and general organization of the body $\ldots \ldots \ldots \ldots \ldots \ldots \ldots . \ldots 54$

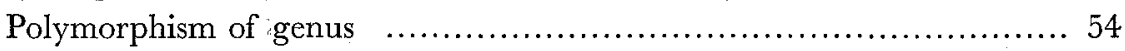

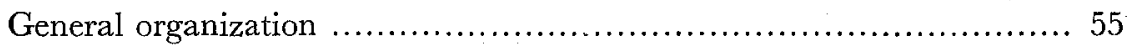

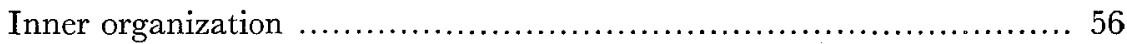

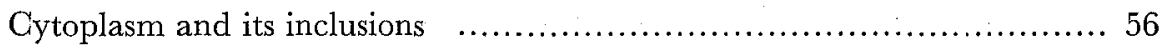

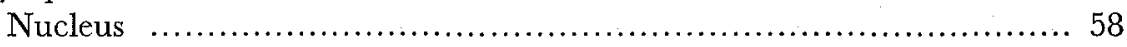

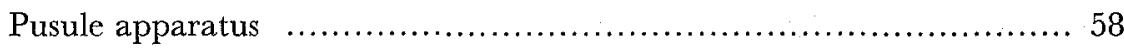

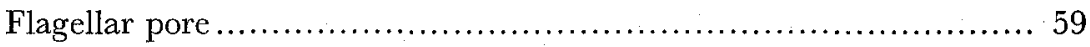

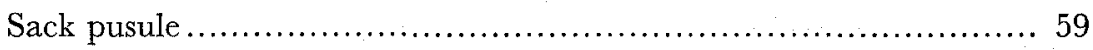

Collecting vacuole .............................................. 65

So-called accessory and daughter pusules .........................6 67

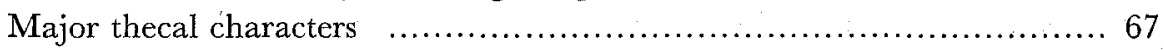

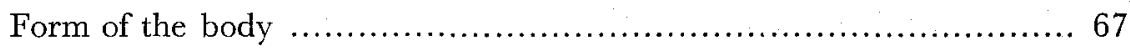

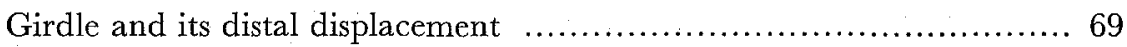

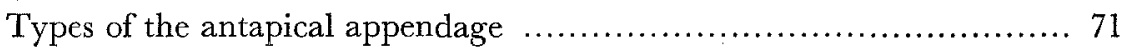

Spine or wing-complex ...................................... 72

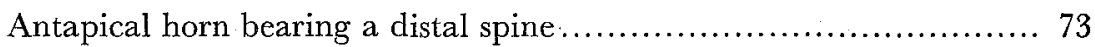

Antapical horn ................................................. 74

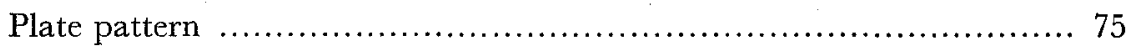

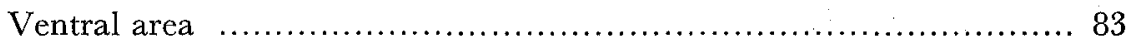

Steinii-type ................................................. 85

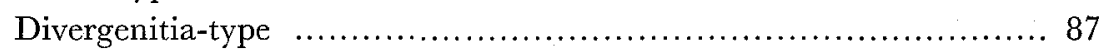

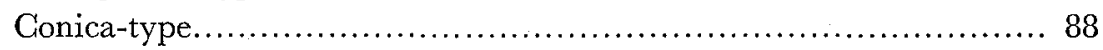

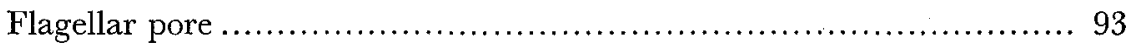

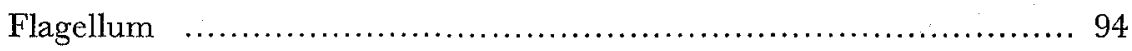

Thecal wall .................................................... 94

Correlation between different thecal characters ........................ 97

Ventral and dorsal plate patterns of the epitheca ..................... 97

Ventral plate pattern and hypothecal appendage ....................... 99

Ventral plate pattern and cingular displacement ........................ 100

Cingular displacement and antapical appendage ......................... 101

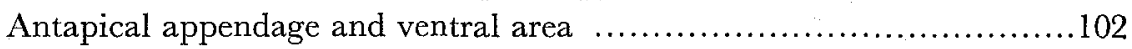

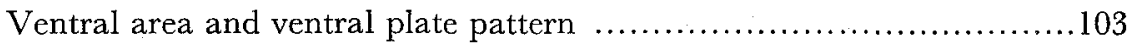

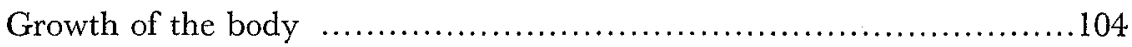

Growth of thecal plates............................................ 108

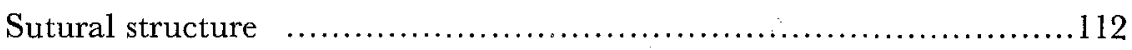

Distribution, irregularity and differentiation of the sutural zone .......119 
Longitudinal sutural zone...................................... 120

Apical region ...................................................... 120

Antapical region................................................... 121

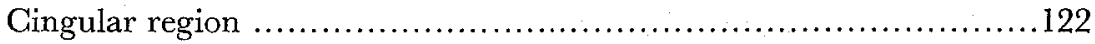

Structural Differentiation ......................................... 126

Girdle ........................................................... 127

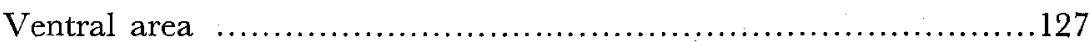

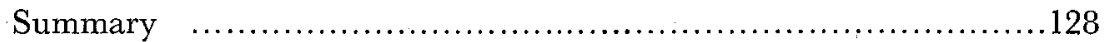

Reproduction ...................................................... 129

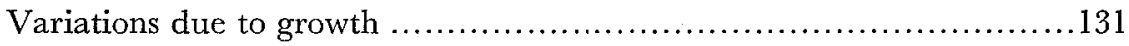

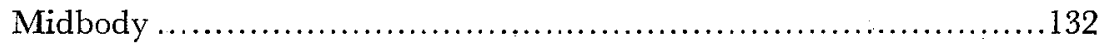

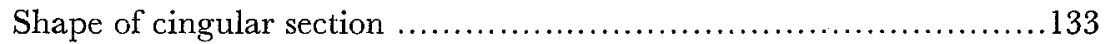

Size ............................................................. 133

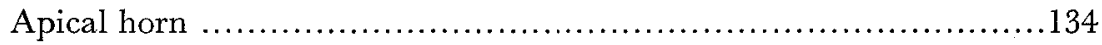

Girdle ............................................................. 134

Antapical spine or horn .......................................... 135

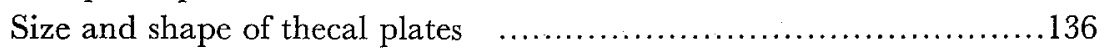

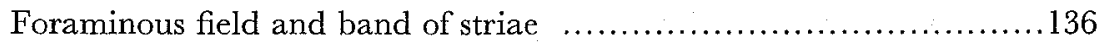

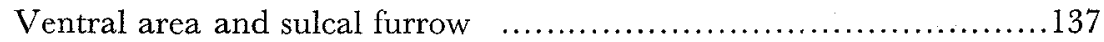

General variations of thecal characters .............................. 137

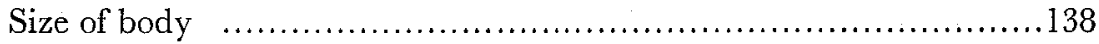

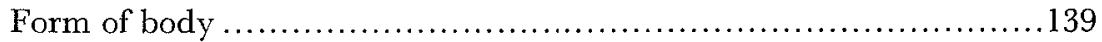

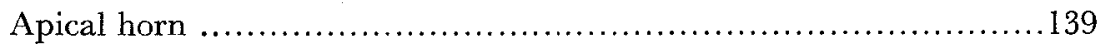

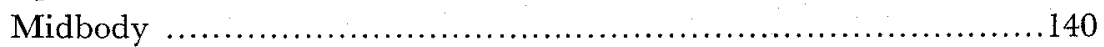

Girdle ............................................................ 141

Cingular displacement .......................................... 142

Antapical elongation or extension ................................... 142

Structure of the thecal plate ....................................... 144

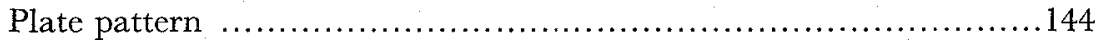

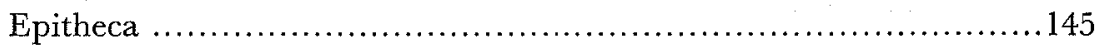

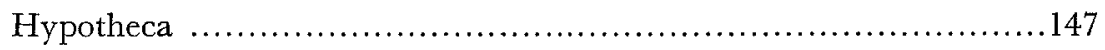

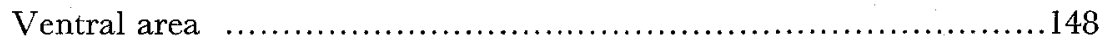

Discussion ................................................................ 150

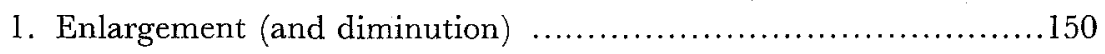

2. Splitting .................................................. 150

3. New formation ................................................151

4. Fusion ...................................................... 151

Combination of characters, basis for subdivision of the genus

Peridinium .............................................................. 161

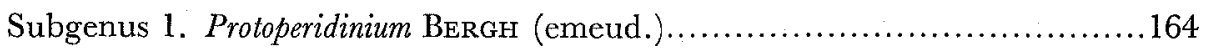

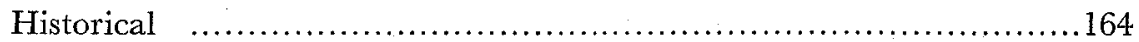

Group 1. Humilia Jörgensen (emend.) ................................168

Historical ..........................................................170 
General discussion on the major thecal characters $\ldots \ldots \ldots \ldots \ldots \ldots \ldots \ldots 171$

Section 1. Heteracantha n. sect. .................................. 174

1. Peridinium decipiens Jörgensen ................................ 176

Section 2. Moacantha AbÉ.......................................... 177

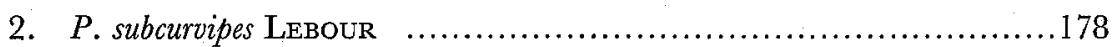

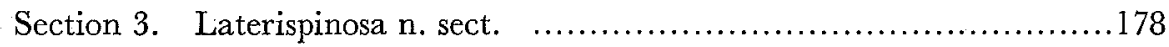

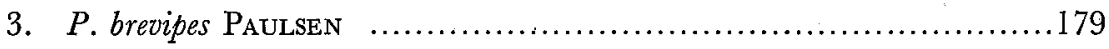

4. P. granii Ostenfeld ............................................. 182

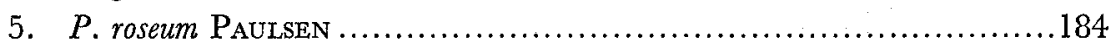

6. P. solitarum AвÉ ................................................186

Section 4. Bispinosa n. sect. ...................................... 186

7. P. marukawai АBÉ .................................................. 187

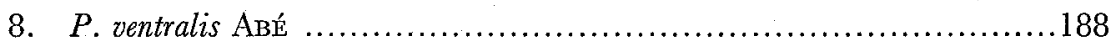

Section 5. Globula ABÉ ............................................. 188

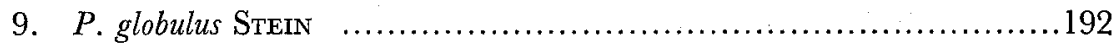

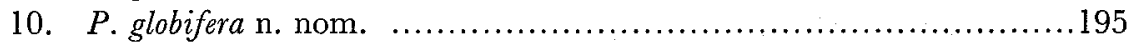

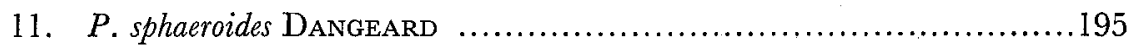

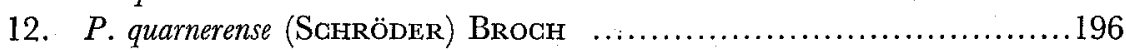

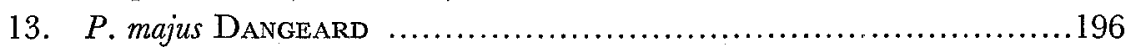

Group 2. Pyriformia Jörgensen (emend.) ..............................200

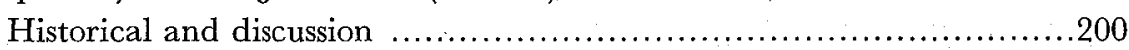

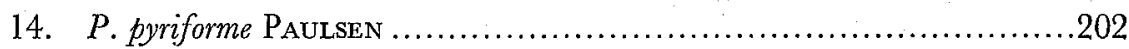

15. P. rectum KofoID ................................................203

16. P. subpyriforme DANGEARD............................................204

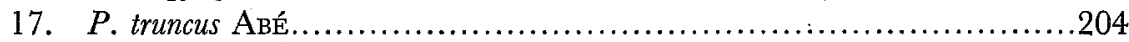

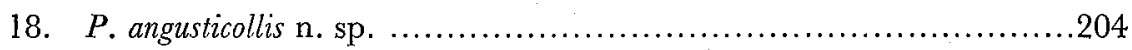

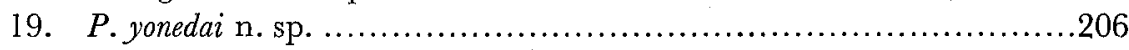

Group 3. Pellucida JögneSEN (emend.) ….............................208

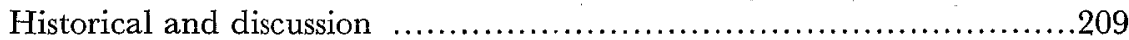

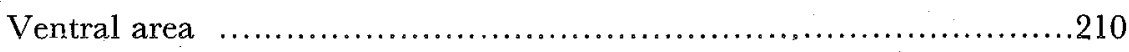

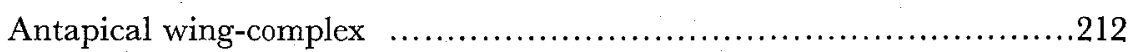

Thecal plate and sutural zone ....................................213

Characterization of the group ......................................217

Section 1. Metapellucida n. sect. ...................................220

20. P. acutum FAURÉ-Fremiet .......................................220

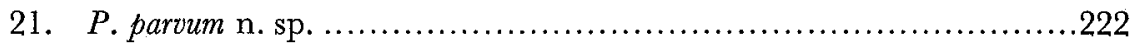

22. P. hirobis AвÉ ...................................................224

23. P. brachypus n. sp. .........................................224

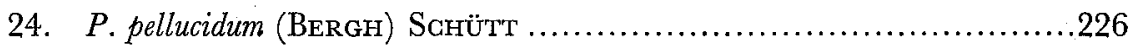

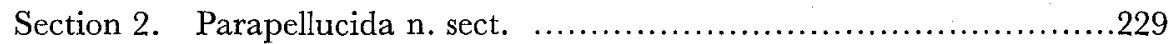

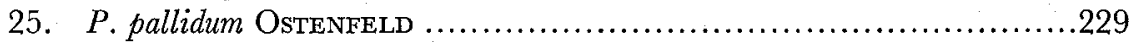

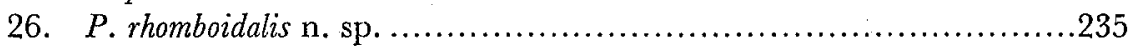

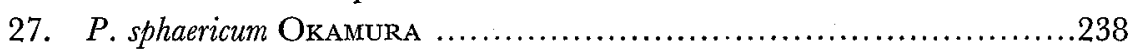

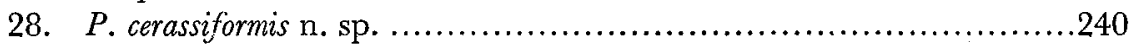




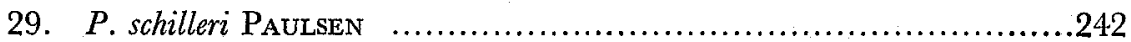

forma complexum n. f. ........................................244

Subgenus 2. Mesoperidinium n. subg.....................................247

Group 1. Paradivergentia (emend.) …...............................248

30. P. isthmus n. sp...............................................250

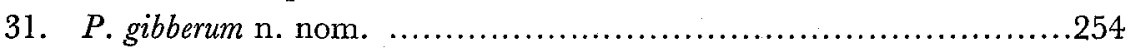

32. $P$. globosum (GoURRET) ........................................254

Group 2. Divergentia FaURÉ-Fremiet (emend.) ........................256

33. P. spinulosum SaHILER .......................................262

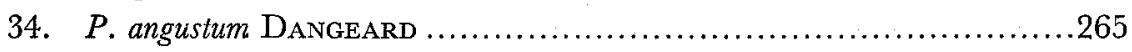

35. P. crassipes KofoId ..........................................268

36. P. grande KofoId .............................................271

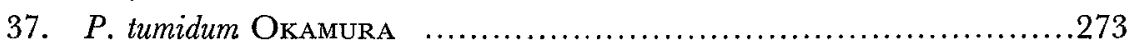

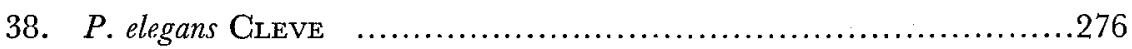

Subgenus 3. Veroperidinium PAUlSEN (emend.) ...............................279

Group 1. Tabulata Ehrbnberg (emend.) ..................................286

Section 1. Tatrica n. sect. ............................................28

Section 2. Tabulata n. sect. ..........................................289

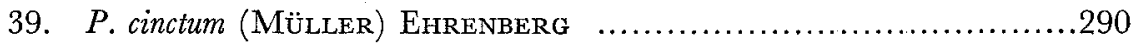

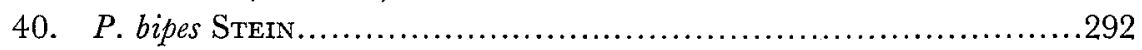

41. P. volzii Lemmermann ..........................................293

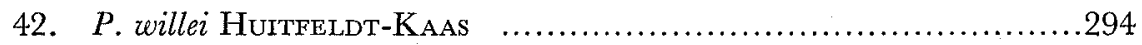

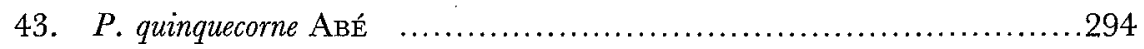

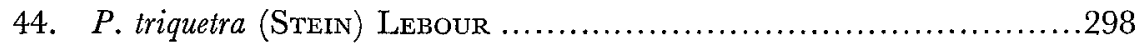

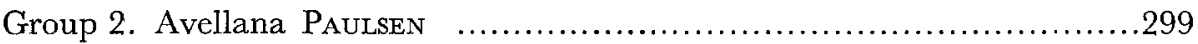

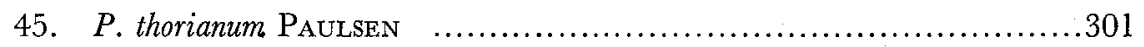

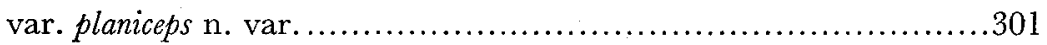

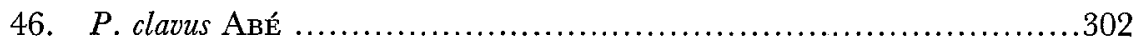

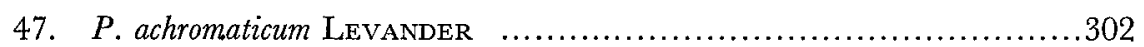

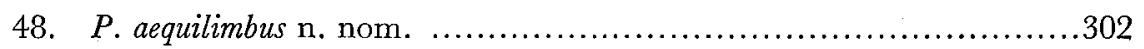

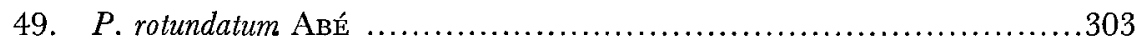

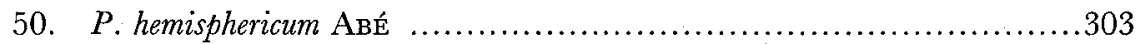

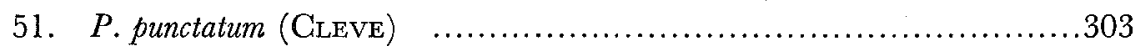

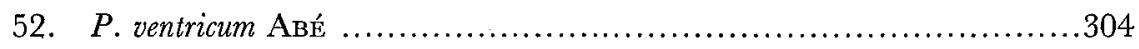

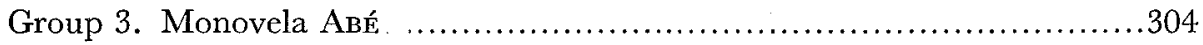

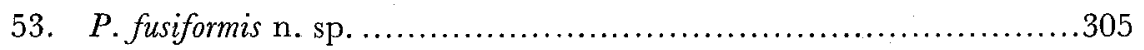

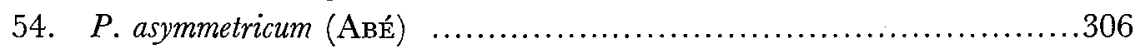

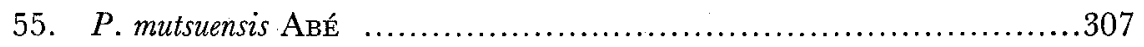

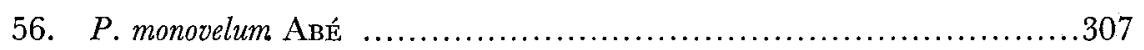

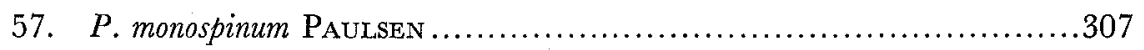

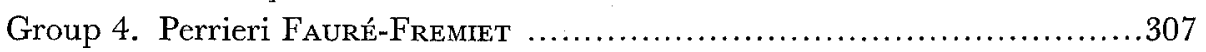

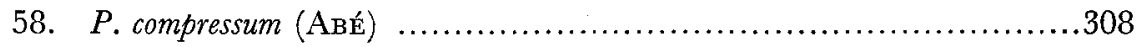

59. P. excentricum PAULSEN .................................................. 


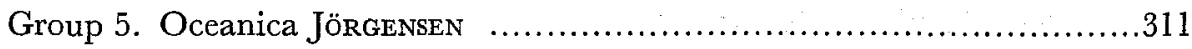

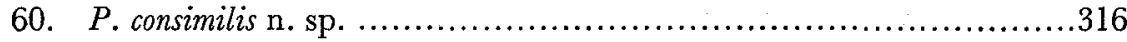

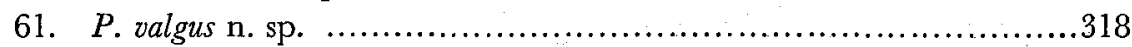

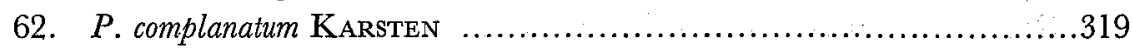

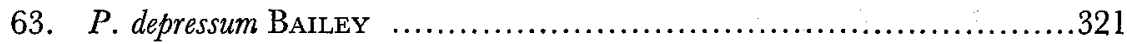

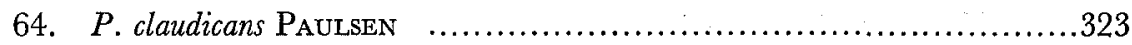

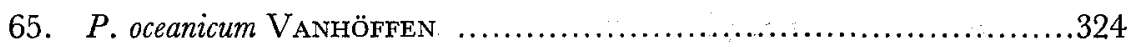

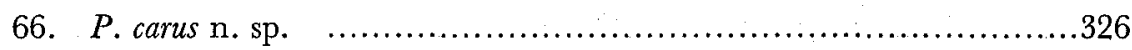

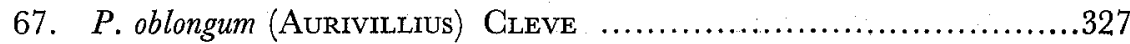

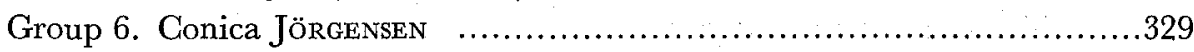

Historical account on the characterization of group .................... 330

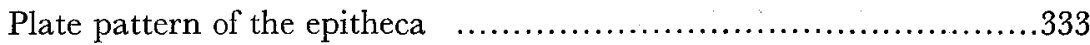

Cingular displacement and torsion of the body due to growth .........335

Asymmetry in the cingular section and torsion of the body axis .......336

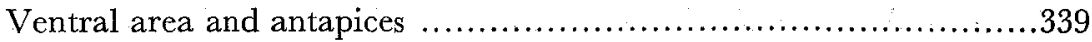

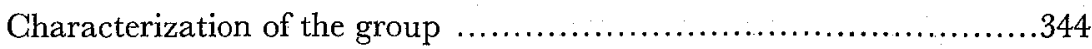

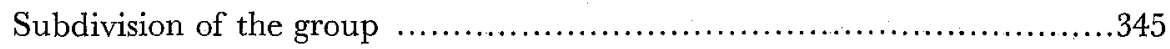

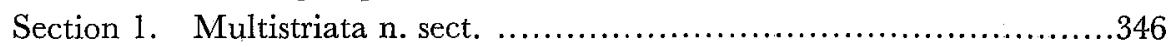

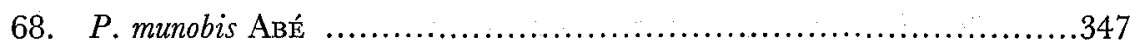

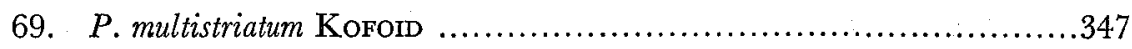

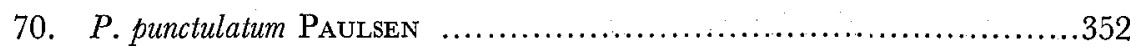

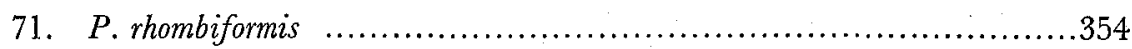

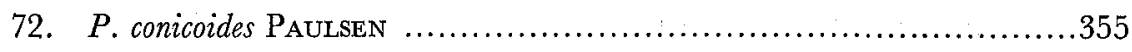

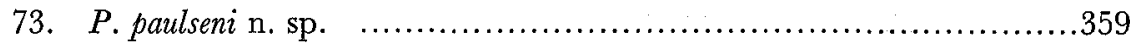

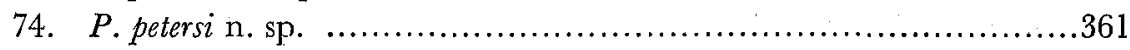

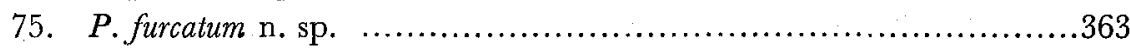

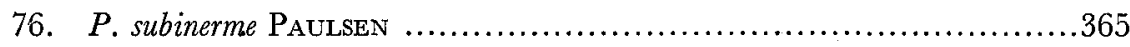

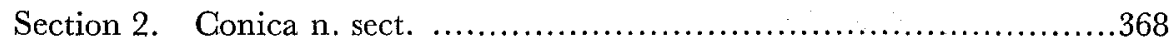

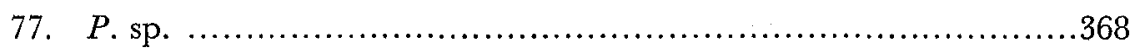

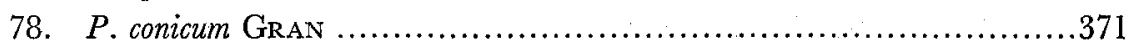

79. P. deficiens Meunier ............................................... 374

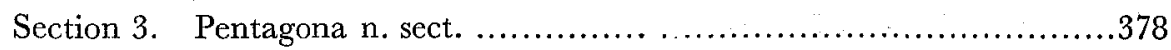

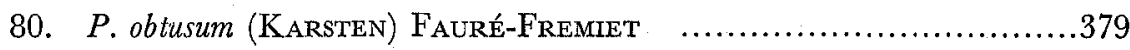

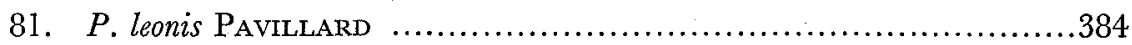

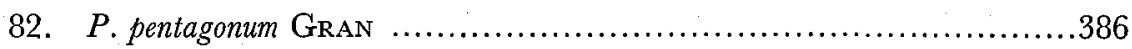

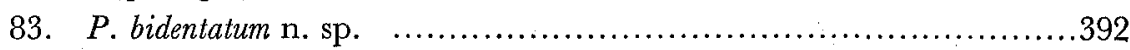

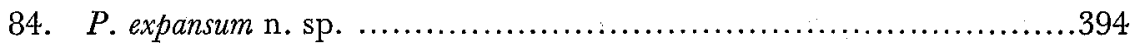

85. P. sinuosum (LermmermanN) JörgenSEn............................396

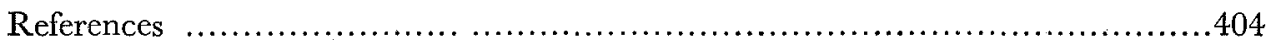

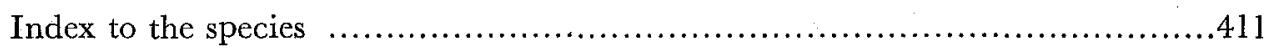




\section{Family Peridinidae Kent (emend.) LINDEMANN}

Peridinidae, Kent 1880; in part, Pouche 1913.

Peridinida, BERgr 1881.

Peridiniaceae, Paulsen 1908; Lindemann 1928.

Ceratidae, in part, KoFord 1907.

Body is typically globular, lenticular, pyriform, rarely peculiarly flattened, and generally provided with two antapical spines or horns. Two or three circular rows of plates are comprised in the epitheca. Hypotheca consists of a circular row of postcingular plates and antapical plates which are rarely a single but typically two, bilaterally arranged.

Ventral area consists of four sulcal plates, anterior three of which are arranged directly around the flagellar pore.

The present family is subdivided in this paper as follows:

Subfamily 1. Glenodiniopsinae n. subfam.

Genus Glenodiniopsis WoloszynskA

Subfamily 2. Dinosphaerinae n. subfam.

Genus Dinosphaera KofoId and Mrahner

Subfamily 3. Diplopsalinae n. subfam.

Genus Diplopsalis BeRGH (emend.)

Subgenus Diplopsalis (BERGH)

Subgenus Lebouraia (ABÉ)

Subgenus Dissodium (АВÉ)

Genus Gotoius AвÉ

Genus Diplopsalopsis Meunier (emend.)

Genus Entzia Lebour (=Apsteinia n. nom.)

Subfamily 4. Chalubinskinae n. subfam.

Genus Chalubinskia WoLoszynskA

Subfamily 5. Thaurileninae n. subfam.

Genus Minuscula Lebour

Genus Thaurilens PAscher

Subfamily 6. Peridininae n. subfam.

Genus Peridinium Ehrenderg

Subgenus Protoperidinium Bergh (emend.)

Subgenus Mesoperidinium n. subgenus

Subgenus Veroperidinium Paulsen (emend.)

Key to subfamilies

1. The postcingular series of plates comprises three plates

Chalubinskinae n. subfam.

2. The series consists of three typical plates and an atypical one and coupled with much irregularity in the arrangement of the plates in the epitheca.

Thaurileninae n. subfam. 
3. The series comprises five plates

a. Gentral major portion of the epitheca is covered with three subequal plates Dinosphaerinae n. subfam.

b. The dorsal plate among the four apical ones is separated from the apical pore and the distinct left sulcal list is the sole surface extension of the hypotheca........................................... Diplopsalinae n. subfam.

c. The four apicals are arranged in close contact with the apical pore......... Peridininae n. subfam.

4. The series comprises six or seven plates

Glenodiniopsinae n. subfam.

\section{Subfamily 1. Glenodiniopsinae n. subfam.}

The thecal wall is divided into plates of three circular series, of which the apical four plates are displaced ventrally as a whole and are arranged so as to separate $3^{\prime}$ from 1', and scarcely exceeds in length the precingular plates covering basal small length of the epitheca. The hypotheca is covered with 7 postcingulars and two antapicals. The ventral area does not indent the epitheca and is bilaterally expanded posteriorly, where it is covered with a large posterior sulcal plate. Several minute plates lie in the inter-cingular part of the ventral area.

One genus and one species, Glenodiniopsis steinii, is included.

The genus Glenodiniopsis was established by WoLoszynska, and a single species, G. steinii, is included as valid. The epitheca consists of three series of plates, of which the intercalary has four plates arranged bilaterally. The four apicals include a minute midvental plate, which scarcely exceeds in length any of the precingular plates covering ventral median of the epitheca. Two laterals of them border on each other separated a little from the others. The genus is, therefore, related in these regards partly to Gotoius and Dinosphaera and also partly to Goniodoma.

Judging from published figures, at least three small plates are seen in the intercingular part of the ventral area covered by far the majority with a huge plate. A close relative of the genus in this connection can be sought in Goniaulax. However, our knowledge about the genus Glenodiniopsis is allied to Peridinium in general features of its ventral area. Structural relations of the ventral area of the present genus are, however, far from complete at the present time.

\section{Subfamily 2. Dinosphaerinae (n. subfam.)}

Dinosphaeraceae Lindemann, 1928, p. 84.

The epitheca consists of two circular series of plates, and is covered its central major region with three of four apical plates, of which the dorsal is much separated 
from the small ventral apical. The hypotheca is covered with 5 postcingulars and a single antapical plate. The sulcal plates are four in number, lying two bilaterally and two at the two ends of the ventral area for a short distance where it is covered with a distinct sulcal plate.

One genus and one species, Dinosphaera palustris, is included.

A peculiar form, D. palustris, had been described for the first time as a Goniaulax species by Lemmermann (1910) and was remexamined by Kofoid and Miahner (1912) by whom the genus Dinosphaera was established for this species. The species has the hypotheca allied to that of Poroceratium or some of the Diplopsalis group. On the other hand, the three central plates coupled with a midventral one of the epitheca lead us to suggest close relationships of this with Goniodoma or more probably with Glenodiniopsis and most of the Diplopsalis group. American authors contend that the ventral area is covered with 6 plates, one of which corresponds in situation to the transitional plates of Peridinium and one of the others lies at the distal end of the girdle, where it is expanded distally. Judging from published figures, we are forced to assume, differing from the American authors, that those lying closest being in contact with the flagellar pore are three in number just as in Peridinium and these three forms, together with the posterior one, the ventral area proper.

Koford and Michner (1912) enunciated that the genus in question is related most closely to Goniaulax. In contradiction to their conclusion, all of the considerations given above lead us to presume that Dinosphaera is the closest relative of the Diplopsalis group or of Glenodiniopsis but is the least related to Goniaulax or its allies.

\section{Subfamily 3. Diplopsalinae n. subfam.}

ABÉ 1936. p. 747.

The body is globular or lenticular and with or without a distinct apical or antapical elongation. Apical series of plates consists of four plates, the dorsal of which is separated variously from the ventral and often so strongly that it may be worth regarded as an intercalary plate. Rarely, this dorsal apical is formed. Antapical series consist regularly of a single plate lying mostly on the left but rarely on the opposite side of the dorsal apical plate. Ventral area is narrow and short, expanding typically towards the right in its hind end, and the posterior sulcal plate is small lying asymmetrically in the pointed hind end of the ventral area or is transversely elongated, expanding diagonally between two ventral postcingular plates.

\section{Historical account and consideration}

The genus Diplopsalis was established by R. S. BERGH in 1881 with the following diagnosis: "Die Körper linsenformig, im Querchnitt rundlich. Die Membran aus 
Tafeln zusammengesetzt. Von dem Begrenzungsapparat der Längsfurche finden sich nur die zwei schwach brechenden Leisten." In describing D. lenticula from Skaggerak, he gave three figures which, so far as diagnostic details are concerned are ,so far from complete that actual identification of the species is hardly possible. Therefore, taxonomic positions or relations of the origical species and its relatives have been left in a state of confusion.

A number of lenticular or globular forms have been recorded after him, and the majority are characterized by a distinct left sulcal list. We can see among them a surprising variety of plate arrangement, and, what is worse, they are mostly described or figured only very incompletely owing partly to their smallness and partly to their rare occurrence or sparse distribution. Different opinions as to allocation or grouping of these various forms have been introduced by some investigators, while most of the earlier and also of the later authors agree in allocating them collectively in BERGH's original genus.

According to Lebour (1922), Stein was the first to figure a plate structure of species certainly of this group, and his species had been identified as BERGH's original by many subsequent authors. Pavillard and Lebour suggested that his figures included two different forms and BERGH's specific name was retained for the smaller one of them.

In the same year, Pouchet (1883) gave a drawing of a lenticular species with distinctly ascending and deeply overhanging girdle, which was wrongly identified as Glenodinium lenticula. Judging from its characteristic spiral girdle, it is certainly a Peridinium species belonging particularly to the Globula group. Two years later, two figures were given by the same author who considered them as identical with BERGH's original species. However, they agree apparently with STEIN's larger form.

Murray and Whitting described Diplopsalis saecularis those figure was reproduced by PAULSEN (1908), and this has been left as an uncertain species. However, this may be a Peridinium-species of the Globula group and not a Diplopsalis.

In 1892, ApsteIn described Glenodinium acutum, which is characterized by its single antapical plate and its Peridinium-like epitheca. This species was interpreted variously, some authors allocating it to Diplopsalis while others to Peridinium, and Lebour (1922) separated it into a new genus Entzia.

Lemmermann (1904) established a new genus Peridiniopsis for a fresh-water species $P$. borgei, and $P$. cunningtonii was added by the same author (1907). This genus was characterized by the plate formula of $3^{\prime}, \mathrm{la}, 6^{\prime \prime}, 5^{\prime \prime \prime}, 2^{\prime \prime \prime \prime}$. Most of the species had been described or figured to have invariably five precingulars coupled with or without an intercalary plate, and the antapical was regarded as consisting of a single or double plates.

Okamura (1907) gave four figures of a lenticular species from Prov. Tosa in Japan and identified them with Diplopsalis lenticula. His figures show that it is 
furnished with the plate structure apparently similar to $D$. orbicularis.

Ostenfeld (1908) recorded in 1908 Diplopsalis caspicum and D. pillula from the Aral Sea, the first of which was re-described by Lindemann (1927), but the other species has never been re-discovered by subsequent authors except PAUlsen (1908) who saw it in the Zuiderzee, and its plate structure $\left(3^{\prime}, 1 \mathrm{a}, 5^{\prime \prime}\right)$ is now seemed doubtful.

Besides D. lenticula, D. saecularis and D. pillula, Paulsen (1908) described Peridinium orbiculare and $P$. latum (Diplopsalis acuta) in "Nordisches Plankton". He further recorded $D$. lenticula var. minor which was regarded afterwards as BERGH's original species by the Scandinvaian authorities such as Pavillard (1912, 1913), Paulsen (1912), Jörgensen (1912) and OSTENFELD (1915) and some others.

A broadly lenticular form was figured by FAURÉ-Fremiet (1908) and iendified with Pougher's Glenodinium lenticula. But its very narrow ventral apical plate illustrated in his figure is characteristic only of PAULSEN's Gl. minor.

Lemmermann (1910) allocated Peridinium latum, P. caspicum, P. pilula, P. borgei and $P$. cunningtonii collectively to Peridinium. Similarly Ostenfeld (1915) regarded all the known species as belonging to the same genus.

In the same year, Meunter separated Diplopsalis orbicularis into a new genus Diplopsalopsis, characterizing it with the plate formula of $3^{\prime}, 2 \mathrm{a}, 7^{\prime \prime}, 5^{\prime \prime \prime}, 2^{\prime \prime \prime \prime}$. In addition, he described Diplopsalis lenticula and $D$. spherica, both of which were identified later by Lebour (1922) as Paulsen's D. minor.

MANGIN gave, in 1911-12, three papers on this group of dinoflagellates, and the following species were described: Peridinium lenticulatum ( $=G l$. minor), P. paulseni, Diplopsalis minima and Peridiniopsis asymmetrica. The third of them is characterized with five precingulars and was separated into a new genus by LEBour (1922). A similar form occurs in Mutsu Bay (ABÉ 1927). P. paulseni was interpreted by Lebour as identical with Paulsen's Diplopsalis minor, and the last species of the four corresponds to STEIN's larger form.

Jörgensen (1912) proposed to resuscitate for StEIN's larger form in the manuscript name of Stern, Diplopelta bomba, subdividing the group into four genera, Diplopsalis, Diplopsalopsis, Peridiniopsis and Diplopelta. And this was followed by PAvILLARD (1912), and Diplopelta was later regarded by LEBour (1922) as a subgenus of Peridiniopsis. Pavillard (1912) described Peridinium meunieri, which however, was later claimed by LeBour as identical with Paulsen's Diplopsalis minor. The same author considered the epitheca of Diplopsalis lenticula consisting of nine plates, but in the next paper (1913), he failed to show an intercalary plate in the same species.

In 1913, Mangrn transferred Peridiniopsis asymmetrica to a new genus Properidinium, but this has not been supported by subsequent authors. In the same year, Pavillard distinguished Paulsen's $D$. minor into a new genus Diplopeltopsis and followed by Jörgensen in the distinction of Diplopelta. Ostenfeld (1915) regarded Peridiniopsis asymmetrica and all its relatives as Peridinium. 
All the previous authors except some of the earliest who described or figured none, considered the antapical of $D$. lenticula as double, but PAvillard (1916) saw specimens from the Mediterranean, which have no intercalary, five precingulars and a single antapical.

An important contribution to our knowledge about the classification of this group was given by LeBour $(1922,1925)$ who reviewed most of the published figures and descriptions and paid due considerations on seasonal and geographical distributions of some species, and also designated Pavillard's Dipiopsalis lenticula, MAngIn's Peridiniopsis asymmetrica and PAulsen's Diplopeltopsis minor as BerGH's original. And giving brief reviews on recorded species, she distinguished and rediagnosed following three genera, Diplopsalis, Peridiniopsis, Diplopeltopsis, and she created a new genus Entzia for EnTz's Diplopsalis acuta (=Apstern's Glenodinium acutum). But as the generic name Entzia has been preoccupied with Foraminifera by DADAY in 1883 , it must be replaced by another generic name.

Lindemann (1923) and ENTz (1926) gave good figures of Peridiniopsis borgei, one of which can support its correct allocation to the genus Peridinium. And further, the former author gave the description and figures of Peridinium limnophilum which is identical with Lebour's Peridiniopsis rotunda.

In 1927, the author saw globular forms with plate formula of $3^{\prime}, 1 \mathrm{a}, 5^{\prime \prime}, 5^{\prime \prime \prime}$, 1-2"'"', and allocated them in Diplopsalis lenticula. Lindemann $(1927,1928)$ recognized only a single genus Diplopsalis and described $D$. acuta EnTz fil. var. halophila and $D$. caspica. He saw in the last species a variation in shape (quadrangular or pentagonal) of it sintercalary plate and also in number (5-6) of the precingular ones. The first species is very peculiar and characteristic in its plate pattern and plate formula of the epitheca but its ventral area is wholly unknown.

Koford enumerated in the text of his lectures on marine planktons delivered in 1930 at the Asamushi Marine Biological Station, Tohoku University, the following three genera; Diplopsalis (3', la, 6", $\left.5^{\prime \prime \prime}, 1^{\prime \prime \prime \prime}\right)$, Peridiniopsis $\left(3^{\prime}, 1-2 \mathrm{a}, 6^{\prime \prime}, 5^{\prime \prime \prime}, 2^{\prime \prime \prime \prime}\right)$ and Diplopsalopsis (3', 2a, 7", $\left.5^{\prime \prime \prime}, 2^{\prime \prime \prime \prime}\right)$.

PAULSEN (1931) also regarded most of the reported genera of the group as synonyms of Diplopsalis, conforming to LINDEMANN (1928), gave it the following plate formula; $3-4^{\prime}, 0-2 \mathrm{a}, 6-7^{\prime \prime}, 5^{\prime \prime \prime}, 1-2^{\prime \prime \prime \prime}$, and distinguished that of the genus Peridinium as $2-5^{\prime}, 0-8 \mathrm{a}, 6-7^{\prime \prime}, 3-6 \mathrm{~g}$ ? $, 5(-6)^{\prime \prime \prime}, 2^{\prime \prime \prime \prime}$.

Judging from the historical accounts given above, it is clear that most of the earliest workers defined the taxonomic position of a given species belonging to this group basing on its distinct left sulcal list, the plate pattern and the plate formula of the epitheca were taken afterwards into consideration for the characterization and subdivision of the group, the antapical was regarded additionally as of taxonomic importance, and recently some authors came to consider the group corresponding as a whole to the single genus Peridinium, admitting distinct variations in both of them. 
Owing to insufficient definition or lack of detailed morphological study of most of the reported species, the specific name Diplopsalis lenticula has been applied to various forms on one hand and PAUlsen's Diplopeltopsis minor has been named variously on the other. And different authors characterized a given species variously, some including in it a single form, while others more than two different forms. And it is due to these inconsistencies that LEBour (1922) divided the group into five genera while Lindemann (1927, 1928) and PAulsen (1931) allocated them to a single genus.

We have here an important fact to be recollected in relation to the historical account of this group. Among the important morphological features which have been considered generally as of taxonomic importance in Peridinium and its relatives are the general shape of the body, spiral or circular girdle, the plate pattern of both epitheca and hypotheca, and the plate formula. Among them, much stress is laid on the plate pattern of the epitheca in the subdivision of Peridinium but not so in that of Goniaulax which also displays as in the other genus a wide range of variation. In spite of the fact that Peridinium borgei, $P$. penardii and $P$. elpatiewskyi have a similar plate pattern, the former two have been repeatedly discussed in relation to the present group because of their six precingular plates, while the other was given no attention owing to its seven precingulars. Diplopsalis acuta is included generally in the present group in spite of its Peridinium-like epitheca. BARrows (1918) considered the hypotheca as less variable than the epitheca in Peridinium, and this has been followed by many workers. While all the recorded species of this group were allocated to a single genus by some recent investigators in disregard of their single or double antapical. And different genera, groups or species were characterized variously. And these puzzles cannot be answered without taking other important characteristic features such as the ventral area into considerations.

That in Japan were found several forms yet unrecorded appears to indicate the possibility that there may be in nature much more various forms than ever recorded and that they have mostly escaped our observations owing to their exceedingly sparse distribution. These additions lead us to reexamine the definitions of the Diplopsalis group and its subdivisions. It is imperative for this purpose to study the thecal morphology of species one encounters inquiring into their details as far as possible.

\section{General characteristics}

The present group includes various forms as stated above, and some considerations must be given on their doubtful but interesting forms in order to establish the characterization of this group.

OSTENFELd's Diplopsalis caspica was regarded by LeBour as an uncertain form. But judging from published figures, its ventral area is apparently characteristic of this 
group because of the fact that the flagellar pore lies in its sinistro-posterior corner. The same author's $D$. pilula, whose plate formula is $3^{\prime}, 0 \mathrm{a}, 5^{\prime \prime}, 5^{\prime \prime \prime}, 2^{\prime \prime \prime}$, is not so sufficiently known as to be discussed here. Lebour (1922) suggested that its precingulars may be six. Anyhow, it may be a true member of the present group so far as Ostenfeld's figures indicated. Together with these two species, Peridiniopsis borgei was transferred to Peridinium by Lemmermann (1910) who had separated it to a new genus Peridiniopsis in his earlier paper. His earlier separation was followed by Jörgensen (1912) and Lebour, but recently Lindemann (1923) and ENTz (1926) agree in its correct allocation in Peridinium conforming to LemmermanN's later opinion. And in our opinion, together with its allies, $P$. penardii, $P$. cunningtonii and $P$. elpatiewskyi are in reality Peridinitm-species, forming a connecting link between the present group and the genus. Judging from Lebour's citation, Mangin's D. minima also may be an ordinary member of this group though its correct position in our classification is uncertain. Lindemann (1928) recorded Diplopsalis behemingi from Volga, in which the epitheca consists of three central and three peripheral plates in addition to an extremely minute midventral one. A similar plate pattern is known from Dinosphaera palustris (Lemm.) Koford et Miarner but the two species differ profoundly in the structural relations of their ventral area. We are unable to follow Lindemans's interpretation of the plates in the epitheca, and this shall be discussed later. Diplopsalis saecularis Murray and Whitting (PAulsen, 1908, p. 36) was regarded by LEBOUR (1925) as 'not sufficiently known as regards plate structure to be assigned to any definite position.' However, it is certainly a Peridinium related closely to $P$. globulus, judging from its distinctly spiral girdle and its plate arrangement. But this does not mean that the spiral girdle cannot be seen in this group, for a single uncertain species belonging to this group was found, furnished with the distinctly ascending girdle and the left sulcal list.

Other species such as Diplopsalis spherica, D. meunieri and D. asymmetrica var. spherica may be out of the scope of this paper because we have not been fortunate to see either original descriptions nor references of these species. Therefore we shall follow Lebour in regard to the identification of them.

From these, the following ten species are regarded in this paper as valid for this group or at least as worthy of consideration here: Diplopsalis acuta, D. behemingi, D. caspica, D. lenticula, D. minima, D. pilula, Diplopsalopsis minor, D. orbicularis, D. asymmetrica and Peridiniopsis rotunda. And to these are added de novo the following seven new species and one new variety; Diplopsalis brevis, D. lebourae, D. minuta, D. torta, Diplopsalopsis globula, D. steinii, D. orbicularis var. ovata and Gotoius mutsuensis. Among them, Diplopsalis minuta, D. parvum, D. rotunda, D. torta, D. minima, Diplopsalopsis asymmetrica, D. globula, D. orbicularis, D. orbicularis var. ovata, D. steinii, Peridiniopsis rotunda resemble Peridinium in their double antapicals, while Diplopsalis acuta, D. lebourae and Diplopsalopsis minor are related to the genus in some points of the epitheca. And $D$. orbicularis and its variety have a similar resemblance to Peridinium both in the 
epitheca and hypotheca. As to the plate pattern of epitheca, the present group can be divided into several different groups. These patterns of epitheca are each combined with either of the two types of the hypotheca. Consequently, it appears to us unjustifiable to make a sweeping statement of the present group.

Plate pattern of the epitheca No definite conclusion has ever been proposed by former investigators as to the number of the apical series. Some believed it to be three, while others regarded it as four in the case that of Peridinium. Although the apical series of PAulsen's f. minor is generally described as four, his Fig. $45 \mathrm{~g}$ indicates that a broad transverse sutural zone passes just across the dorsal side of the apical pore without any interruption there. From the basis of this as well as the distribution and growth of this zone, it is clear that the apical process of this species has no direct connection with a plate lying just dorsal to it. And this suggestion was confirmed in this paper as true in our material. From these, it appears as if the apical series of this group has three plates and the other dorsal is an intercalary one. On the other hand, in Gotoius of this subfamily and in the two subfamilies of Glenodiniopsinae and Dinosphaerinae, there are in the apical region four plates, the ventral and dorsal of which are separated from each other by the other two apicals just as in other species of the present subfamily. In these cases, it may be allowed to conclude that only ventral three of them are to be distinguished as apicals from the other, as there is no structural differentiation between them to suggest their distinction. If this conclusion is to be verified, the four central plates of the epitheca or their morphological equivalents in this group are regarded as a whole as apicals, because of the consideration that the four of this might had been derived from those of the other subgenera considered above. And the only difference is the apical pore which is clearly of secondary origin, formed presumably at the intersection of three thecal plates. It may be allowed to suggest, therefore, that intersection of four apical plates at the apical pore as seen in Peridinium is derived from a type which is prevalent in this subfamily and two plates of which are separated by a sutural line which is reduced in later stage of phylogenetic development. It is due to these considerations that the four plates are regarded as originally apicals in disregard of the separation of the dorsal one from the apical pore. It is to be regarded, however, that it is very often convenient in description to denote the dorsal one as an intercalary plate. These two methods of denotation are used in this paper. In this regard it is to be added that Diplopsalis acuta and D. brevis have typically formed four apical plates arranged closely around the apical pore.

The present group displays a surprising variety of the plate pattern of the epitheca, which can be divided into three or five types. To the first type belong $D$. behemingi and $D$. pilula (Fig. $1-$ c, d), either of which lacks entirely the intercalary plate. They have five and three precingulars respectively. It is interesting that they have the least number of plates in the epitheca in this group, but they are known only too insufficiently to allowing any discussion here. 


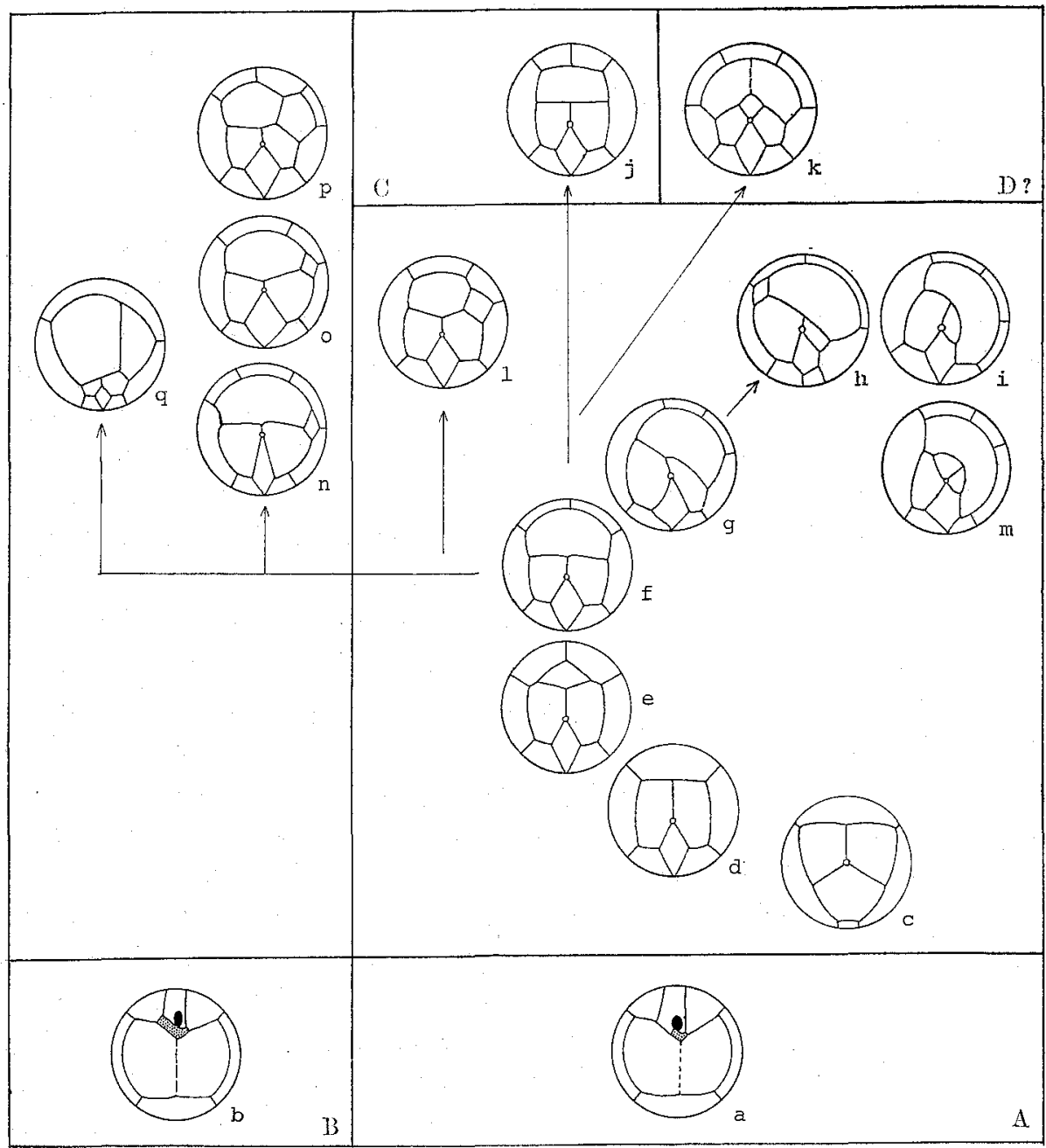

Fig. 1. Interrelationship among the thecal plate pattern in various forms of Peridinidae. A: Caspica-type. a-Hypothecal plate pattern and ventral area. $\mathrm{c}-\mathrm{i}, \mathrm{l}, \mathrm{m}$--Epithecal plate pattern in various forms. B: Asymmetrica-type. b-Hypothecal plate pattern and ventral area. n-qEpithecal plate pattern of various forms. C: Epithecal plate pattern of Peridinium-type. D: Epithecal plate pattern in a type in which ventral area is unknown. c-Diplopsalis behemingi. $\mathrm{d}-D$. pilula e-D. caspica. $\mathrm{f}-D$. lenticula. $\mathrm{g}-D$. torta. $\mathrm{h}-$ Lebouraia minuta. $\mathrm{i}-$ Peridiniopsis roturda. $\mathrm{j}$ Glenodinium borgei. k-Apsteiniaacuta. 1-Dissodium parvum. m-Sp. No. 2-25. n-Diplopsalopsis minor. $\mathrm{o}-D$. asymmetrica. $\mathrm{p}-D$. orbicularis. $\mathrm{q}-$ Gotoius mutsuensis.

The second type has a single intercalary plate lying more or less symmetrically, and comprises the following five species; D. caspica, D. lebourae, D. lenticula $D$. torta and Lebouraia minuta (Fig. 1-e-h). It is interesting to note that $D$. caspica exhibits varieties in the shape, size and position of the intercalary plate and varies in the number of its precingulars (Lindemann, 1927). Mangin's D. minima and D. lebourae n. sp. have five precingulars as in $D$. pilula and also one of Lindenmann's $D$. caspica, 
while $D$. torta and $D$. lenticula have six in the same series. Their intercalary plate is much larger than that of $D$. caspica, lying symmetrically on the dorsal half $(D$. lenticula) or variously displaced towards the left side of the body (D. lenticula, $D$. lebourae and D. torta, Fig. $1-\mathrm{g}$ ). D. borgei and its allies form a link between this type and the typical Peridinium.

There is another type in which a single intercalary plate is distinctly elongated transversely and much asymmetrical in position lying around the dorsal and left sides of the epitheca, and other plates are arranged irregularly (Fig. 1-i-m). LEBour's Peridiniopsis rotunda is comprised in this and two other species L. brevis and L. minuta are reported de novo. In association with this asymmetry, the ventral apical is peculiarly pentagonal and contiguous with the intercalary plates in two of them but separated in others. The last of the three species in which the intercalary is the smallest (Fig. 1-e) is related most closely in plate structure to $D$ : torta of the previous type, from which it differs particularly in its much reduced left apical plate which makes the ventral apical plate contiguous with the left ventral precingular one $\left(2^{\prime \prime}\right)$. Stronger displacement of the plate is seen in P. roiunda (i) in which it is not the left ventral precingular but the intercalary that borders directly on the pentagonal ventral apical. In $L$. brevis, the apical series consists exceptionally of four plates. If one suppose the huge intercalary of $L$. brevis is arranged symmetrically on the
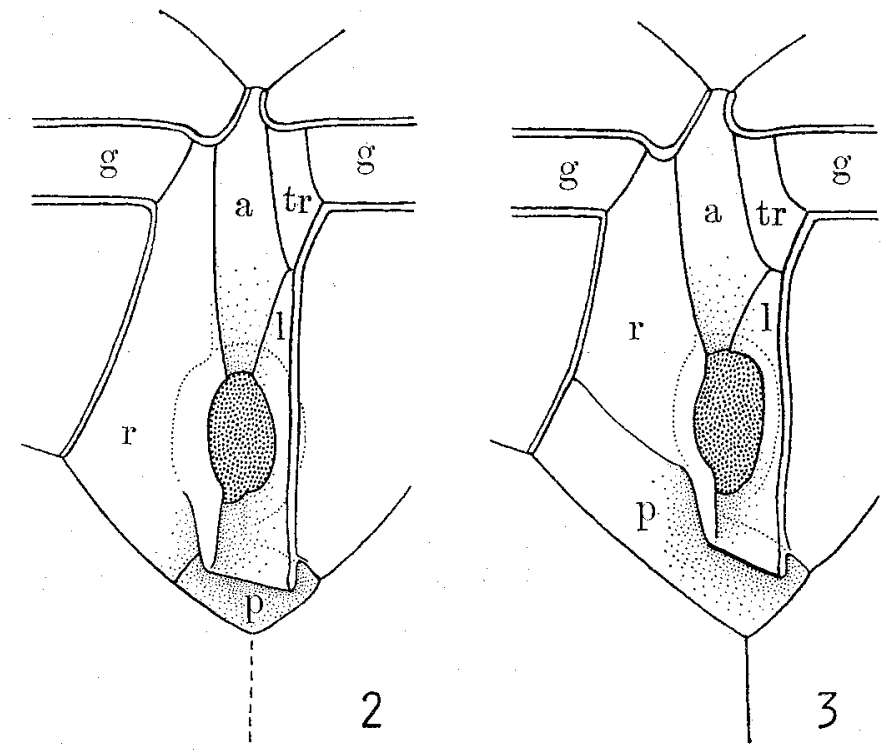

Fig. 2. Diagrammatical illustrations of plate pattern in ventral area. 2-Caspica-type. 3-Asymmetrica-type. a-Anterior sulcal plate. g-Girdle. 1-Left sulcal plate. r-Right sulcal plate. p--Posterior sulcal plate. tr-Transitional plate. 
dorsal side, he can imagine a plate structure almost identical with that of $D$. acuta whose intercalary is sometimes split into two.

The fourth type includes D. parzum, Diplopsalopsis minor, D. globula, D. asymmetrica, $D$. steinii, and $D$. orbicularis, each furnished with a small left and a larger right intercalary plates. An additional small intercalary is recorded very rarely. The smaller left intercalary is either diamond-shaped or pentagonal, which is seen in different species or even within a single species. The left intercalary is removed slightly from the apical process in the case when it is pentagonal but much more distinctly when it is diamond-shaped. The ventral margin of the right intercalary or dorsal apical plate is fairly straight or nearly so in apical view when the left intercalary is small and rhombic, while distinctly angulate at the apical process, when the other is larger and pentagonal. The species D. minor (Fig. 1-n) is interesting in this regard, showing the closest resemblance to the second type in which the ventral margin of the plate is not distinctly angulate. From these, the present type appears to be closely related to the second type.

Closely related to this is Gotoius mutsuensis (Fig. 1-q) in which the two intercalaries are peculiarly shaped and the three small apicals gather closely in its ventro-median portion. The ventral margin of the larger right intercalary (3a) is also straight, and the precingular is only five in number.

If the first is combined with the second, and the fourth with the fifth, we shall have only three types. This subdivision is, however, not conclusive because of the fact that more important structural relations such as the hypotheca and the ventral area were not taken into consideration.

Distal displacement of the girdle Most of the recorded species have a circular girdle with exception of Glenodinium lenticula Pouchet and Diplopsalis saecularis M. and W. whose correct taxonomical allocation to Peridinium especially to its group Globula was pointed out of the present group and found its girdle to form a distinctly ascending spiral. Thus, this is an exceptional case in this group.

Plate structure of the hypotheca In contradiction to the great variability of the epitheca, only two forms are seen in the plate structure of the hypotheca, one with a single and the other with two antapicals. The postcingulars are invariably six in number. Whether the antapical is single or double is not related with the types of plate arrangement in the epitheca and also with the structural relations of the ventral area. These two types of the hypotheca are seen associated with every type of the epitheca except the fifth which composes only a single species. The double antapical is seen though very rarely in $D$. minor which has been regarded generally as furnished with a single one. It is interesting to note that the first and the second types of the epitheca, which exhibit the most primitive structural features, have 
mostly a single antapical, while the fourth displays the most highly developed ventral area and the most complex plate arrangement in the epitheca, and in addition to these, it has generally two antapicals. Each of the other second and the third types has partly a single and partly a double antapical suggesting their positions in these regards between the above two. These relations can be established also from the structural features of their ventral area.

Plate formula The plate formula has been so highly estimated by some investigators as the most important character for generic distinction. In our opinion, however, two same formulae do not necessarily indicate their close relationships. Although Lebour described that "I should suggest regarding the intercalaries as variable within the genus, the apicals, antapicals and precingulars as constant generic feature," a variation in number of plates was reported by Lindemann (1927) on $D$. caspica and we saw two types of the antapical in D. minor. However, it is only the postcingular series in which hardly any variation takes place not only in this group but also in Peridinium. Lebour (1925) included in the subgenus Peridiniopsis of the genus Peridiniopsis, $P$. borgei, $P$. penardii and $P$. rotunda basing only on the plate formula. But the first and the last species of them differ profoundly in their plate arragement in the epitheca. They differ also in the shape of the ventral apical, which has generally been esteemed as a character worthy of subgeneric distinction. The plate formulae of this group hitherto described and recorded de novo are twelve as shown in Table 1 . If that character is to be esteemed too much, the present group must be divided into so many different genera, which will result in much taxonomic confusion and difficulty. On the other hand, it appears to us unreasonable to allocate in a single genus so many different forms or groups each worthy of generic distinction.

Table 1. Plate formulae of Diplopsalis and its allied genera and species

\begin{tabular}{rccccc}
\hline \hline I & $3^{\prime}$ & $0 a$ & $3^{\prime \prime}$ & $5^{\prime \prime \prime}$ & I $^{\prime \prime \prime}$ \\
II & 3 & 0 & 5 & 5 & 2 \\
III & 3 & 1 & $5-6$ & 5 & 1 \\
IV & 3 & 1 & 5 & 5 & 2 \\
V & 3 & 1 & 6 & 5 & 1 \\
VI & 3 & 1 & 6 & 5 & 2 \\
VII & 3 & 2 & 5 & 5 & 2 \\
VIII & 3 & 2 & 6 & 5 & 2 \\
IX & 3 & $2-3$ & 7 & 5 & 1 \\
X & 3 & 2 & 7 & 5 & 2 \\
XI & 4 & 1 & 6 & 5 & I \\
XII & 4 & I-2 & 7 & 5 & I \\
\hline Total range & $3-4^{\prime}$ & $0-3 a$ & $3-7^{\prime \prime}$ & $5^{\prime \prime \prime}$ & I-2 \\
\hline
\end{tabular}


From what was considered above, we can agree neither with LEBOuR nor Lindemann (1927, 1928) and Paulsen (1931). Before introducing final conclusions, however, we have to consider here a structure of so much taxonomic importance but hitherto not taken into consideration.

Ventral area Hardly anything has ever been described about the structural features of the ventral area of this group. OsTENFELD (1908) figured that of $D$. caspica fairly accurately but did not give any elucidation about it. A minute plate lying at the hind end of the ventral area of Diplopsalopsis asymmetrica was noticed by MANGIN (1911), Pavillard (1913) and Lebour (1922), but was suggested only as an accessory plate. Judging from Text-figure 3 of ENTz (1926), Peridinium borgei has the ventral area, related more closely in structural relations to that of Archaeperidinium of the genus Peridinium than to that of the present group, and apparently suggestive of its correct allocation in the genus.

Occurrence of a large left sulcal list had been recognized by BERGH on $D$. lenticula, and has been regarded by most of his followers as a structural feature worthy of characterization of this group. Among them is Lindemann (1927) who esteemed this as worthy of separation of this group from Peridinium. But such a structure is not a characteristic confined to this group. In Asamushi, two globular and one trochoidal small forms are found, all of which are apparently Peridinium-species not yet recorded and furnished with the narrow ventral area and the left sulcal list. In two of them, the posterior sulcal plate lies obliquely at the hind end of the ventral area, and their flagellar pore has a stout flange about it and a distinct flagellar trough-like those of the present group.

The ventral area of the present group can be divided, so far as our analyses are concerned, into two types, one with a minute posterior sulcal plate at its sinistroposterior end (Figs. 1-A, 2) and the other with a much larger one lying transversely across the entire breadth of the hind end of the ventral area (Figs. 1-B, 3). The former type is seen in association with the second and the third types of the epitheca and the latter is accompanied generally with the fourth or fifth type. In regard to the hypotheca, the former is related to either of the single or the double antapical while the latter generally with the double one.

In all the species of this group, we have analyzed invariably four sulcal plates $(\mathrm{a}, \mathrm{r}, \mathrm{l}, \mathrm{p})$ as shown in Peridinium, in Podolampinae and also in Dinophysioidae. And the anterior three of the four are arranged just like those of Peridinium, and a minute transitional plate (tr) is seen generally in its ordinary position at the proximal end of the girdle. The posterior sulcal plate $(\mathrm{p})$ is the one showing a distinct variation. OSTENFELD's D. caspica has the flagellar pore at the sinistro-posterior end of the ventral area. A similar structure is seen, as stated above, in most lower forms of our materials, in which a minute posterior sulcal plate is seen lying just below the lip-like extension of the flagellar trough. We shall call this in what follows 'Caspicatype'. While, this plate is seen most distinctly developed in $D$. asymmetrica on which species it was recorded for the first time. Then it may be convenient to call this 
'asymmetrica-type'.

The well known species, $D$. minor, has been doubtful to us as in the structural relation of its ventral area. We have long been anxious to know about it because of the fact that the species is the only one furnished generally with a single antapical among those belonging to the fourth type of the epitheca. Its ventral area is very narrow and the flagellar pore lies just in front of its hind end occupying its major breadth. From these peculiarities it was surmised to take a considerable period of time to form a distinct type, but our repeated analyses succeeded finally in confirming it to belong to the asymmetrica-type. Peridinium borgei and its allies are important in this regard. Judging from ENTz's figure, in which the sulcal plates are partly illustrated, it is apparent that the species has the posterior sulcal plate of the asymmetrica-type but of much larger size.

It may be very interesting to recollect here the facts that the genus Peridinium has several types of the ventral area, each associated with some different characteristics of the body, that the genus can be divided into so many groups each accompanied with a definite type of the ventral area and that a type of the ventral area is characterized by the posterior sulcal plate which varies distinctly in the genus but is characteristic of a given group and is related with a given type of the antapical appendage such as the spine or horn.

\section{Subdivision of the group}

From the facts and considerations given above, it may clearly be noted that the present group is in a state of much taxonomic confusion and is full of inconsistencies. If we conform to the generally accepted principle of subdivision, we have to subdivide the group into more than twelve genera. On the other hand, it may hardly be reasonable to allocate all of these remarkably various forms to a single genus.

Reviewing through various forms of this subfamily we are led to suggest that the two lateral apical plates border on each other not at a point but along a sutural line of a certain length and that the ventral area has structural relations of a particular type. The dorsal of the four apical plates is variously separated not only from the ventral apical but from the apical pore, and not a single case was found in which the dorsal apical extends to the apical pore. In association with this, a great range of variation regarding its plate pattern was found in this subfamily in the epitheca. Regions of the greatest variation are not in the ventral half or in the peripheral region but in the central region covered with the apical and intercalary plates. Variations are brought about by differences in relative sizes, shapes and lateral displacement of the apical plates and in number, arrangement, size and shape of the intercalary plate. With a few exceptions, the ventral plate pattern is fairly constant throughout the subfamily. In the hypotheca, the antapical series of plates consists typically of two plates but rarely of a single one. In the ventral area is fairly uniform in shape and in its side list shows a distinct variation in size and lateral expansion of the posterior sulcal plate. 
From these, it is clear that there are three regions showing prominent variations in this subfamily, one in the epitheca, another in the ventral area and the other in the hypotheca. The variation is most prominent in the first of them and that in the latter two is distinct and of more taxonomic importance. According to differences in combination of these major characteristics of the three regions, the present subfamily is divided in this paper into three genera and three subgenera as follows:

\section{Genus Diplopsalis BeRGH}

Subgenus Diplopsalis n. subgen.

Subgenus Lebouraia (ABÉ)

Subgenus Dissodium (АBÉ)

Genus Gotoius ABÉ

Genus Diplopsalopsis Meunier

\section{Interrelationship between subgroups and species}

It is believed by some investigators that in Peridinium, the majority of species with larger number of the thecal plates are derived from species with fewer plates. The same appears to hold true in the present group.

In the major species of this group, the epitheca consists of three circular series of plates. But the intercalary series is absent from $D$. pillula and D. behemingi. All of the other species are related directly to the former of them in regard to the plate patterns of the epitheca, and the latter, which manifests relationships with Dinosphaera palustris (LEMM.) Koford is related with them only through the former. From this, it may be allowed to suggest that either of these two represents the least advanced type of the plate pattern in the group, and $D$. orbicularis or its allies stand at the other extremity of a series of variation in the plate pattern, displaying some closest relationships to Peridinium.

In Diplopsalis, D. pillula, D. caspica and $D$. lenticula are closely related with one another in a single antapical plate. In the latter two of them, the single intercalary plate lies in the middorsal, while it is displaced towards the left side in D. torta. Lindemann's $D$. caspica is interesting in this regard because of its displaced intercalary plate. In $D$. lebourae, $D$. torta and three species of Lebouraia, the antapical series consists of two plates, and the intercalary plate is much displaced. D. brevis may be related closely to $D$. acuta, because the intercalary of the former is restored to its presumably regular (middorsal) situation, so we can get the plate pattern of the latter, which is also characteristic of the Avellana group of Peridinium. Consequently, we can establish in Diplopsalis a series of the plate patterns, ranging from $D$. pilula to Peridinium, suggesting their natural affinities.

We can establish a different relationship between Diplopsalis and Peridinium, which is represented by $D$. lenticula and $P$. borgei, the latter of which is clearly a Peridinium-species judging from its ventral area.

The species $D$. parvum forms a third type of the genus, related most closely to 
Diplopeltopsis. In this latter genus, Diplopsalopsis minor can be separated from other species in its narrow ventral area and in its single antapical plate, presumably suggestive of its lowest type in the genus. Gotoius is related most closely to $D i$ plopsalopsis and partly to Diplopsalis, suggesting that it is a descendant of a form closely allied to Diplopsalopsis. We have to recollect here the epithecal plate pattern of $P$. excentricum and its allies, which has also a smaller left and a much larger right intercalary plates.

From these comparisons and considerations, we may be led to the question how the number of plates are increased in the apical and intercalary series of the present group. From comparison of Peridiniopsis rotunda with Diplopsalis brevis, we can establish the increase in the number of plates of the apical series. And from comparison of $D$. brevis with $D$. acuta or of $D$. lenticula with Diplopsalopsis minor or $D$. asymmetrica, we may be informed of the manner by which the number of plates is increased in the intercalary series.

In relation to Diplopsalis behemingi, we have to recollect the fact that in Goniodoma, the epitheca consists only of the apical and precingular series of plates, and the former of them has three component plates arranged around the apical pore.

We have to pay due considerations to the well-known but least established species, D. acuta APsTEIN (1896) described this as a Glenodinium-species. A distinct genus, Entzia, was created for it by LEBour (1925) basing on its single antapical plate, while ENTz (1927) still contends that it is a Diplopsaliswspecies. This inconsistency is apparently due to its single antapical plate and lack of our knowledge about structural relations of its ventral area. The plate pattern of the epitheca of this species is characteristic not of Diplopsalis and its allies but clearly of Peridinium. This may be justified when one recollects that of Peridinium hemisphaericum or P. clavus (AвÉ, 1936, Figs. 26, 28-29, 41-44). Nothing has been described about the ventral area. However, it can be said with certainty based on published figures that the ventral postcingular plates expand posteriorly only about one-half as long as the ventral area which has a broadly rounded hind end. This peculiarity just considered cannot be established in any of the Diplopsalis group but more or less distinctly in most of the subgenus Archaeperidinium, of the genus Peridinium. From these, we are led to suggest that $D$. acuta may justify its generic separation from Peridinium. Basing on these facts and considerations, we intend here to propose a new generic name, Apsteinia, for the place of Entzia.

Key to genera and subgenera

I. The posterior sulcal plate is minute and confined in the rear of the ventral area .. Gen. Diplopsalis

A. The ventral apical plate is rhombic

a. No intercalary plate is formed

b. A single intercalary is formed Subgen. Diplopsalis Subgen. Dissodium 
B. The ventral apical is pentagonal

Subgen. Lebouraia

II. The posterior sulcal plate expands along entire breadth of the ventral area

A. An apical pore is typically formed

Gen. Diplopsalopsis

B. No apical pore is formed and ventral three apical plates are exceedingly small in size, lying in the ventro-median region

Gren. Gotoius

\section{Genus Diplopsalis BERGH}

Bergh, 1881; Bütschli, 1889; Ostenfeld, 1901; 1908; Paulsen, 1908; 1912; Mangin, 1910; 1911; Pavillard, 1912; Lebour, 1925, in part; Stein, 1883; Ostenferd, 1901; 1908; 1915; Lemmermann, 1910; 1928; Meunier; 1910; 1919; Pavillard, 1913; 1916; Jörgensen, 1913; LinDEMANN, 1928.

Diplopeltopsis Pavillard, 1913; Lebour, 1925.

Glenodinium FAURE-FREMIET, 1908, in part.

Peridiniopsis Lemmermann, 1904, in part; Lebour, 1925; Kofold, 1930.

The body is globular or lenticular and is furnished with a minute apical process but not with antapical elongation nor appendage. The equatorial girdle is subcircular. The ventral area is short and narrow, expanding asymmetrically towards the right and bears a distinct list along its straightened left edge. The epitheca consists of 3-4 apical, $0-1$ intercalary and 5-6 precingular plates. The ventral apical plate is rhombic or pentagonal. In typical cases, the lateral apical plates expand dorsally beyond the apical pore. In case the intercalary series consisting of a single plate, it lies either symmetrically in the middorsal or asymmetrically displaced towards the left side of the epitheca. The hypotheca consists of 5 postcingular and 1-2 antapical plates. The ventral area is covered with four sulcal plates, arranged around the posteriorly displaced, ovoidal flagellar pore. The posterior sulcal plate is exceedingly small, lying in the rear of the flagellar pore and in contact with the left ventral postcingular plate.

According to the plate patterns of the epitheca, the present genus is divided into three subgenera which were dealt with the author in 1941 as three distinct genera.

LEBOUR's form of $D$. lenticula differs in some points from ours, but they are considered in this paper as identical owing to lack of our knowledge about the variation of its thecal structure. Lindemann (1927) illustrated two forms of $D$. caspica, one with five and the other with six precingulars.

Lebour's Peridiniopsis rotunda belongs to a different genus as was discussed in another paragraph. The epitheca of $D$. behemingi is described as consisting of three precingulars, one 'Rautenplatte', one ventral apical and two dorsal apicals. Considering the central three plates shown in his figure around the apical pore as the apicals, the midventral minute plate should be the one meant by LindemanN as 'Rautenplatte'. It appears highly probable, however, that the structure is not a member of the epitheca but an anterior elongation of the ventral area indenting 
the epicaeca, although such is not figured in his Fig. 12. Judging from his Figs. 12 and 14, it is highly probable that this species has the ventral area either of this genus or more probable of Diplopsalopsis. Its correct taxonomic position can be decided only when the structural relation of its ventral area is studied, but it is allocated here provisionally. On the other hand, it may be allowed to suggest that peculiar species may be the one related more closely to Pyrophacus or Goniodoma than the present genus.

Key to species

I. The apical series consists of three plates and no intercalary plate is formed

A. All of the three plates are subequal in size and similarly triangular in shape (doubtful species for the genus)

Diplopsalis behemingi

B. The ventral apical is typical in shape and much smaller than the others D. pilula

II. The apical series consists of four plates, the dorsal of which is separated from the apical pore (species is valid of the genus)

A. The dorsal apical or intercalary plate (3) is placed in dorsomedian

a. The plate is transversely rhombic

D. caspica

b. The plate is rectangular or similarly shaped

$a^{\prime}$. The body is spheroidal

D. lebourae

$\mathrm{b}^{\prime}$ The body is flattened in axial direction

D. lenticula

B. The dorso-median apical (3') is hexagonal and is associated with a smaller left dorsal intercalary s. str.

D. parvum

C. The dorsal apical $\left(3^{\prime}\right)$ or intercalary plate is irregularly shaped and is displaced more or less distinctly towards the left

a. The ventral apical plate is rhombic

D. torta

b. The ventral apical plate is pentagonal

$a^{\prime}$. The dorsal apical is separated from the ventral apical, and a small intercalary s. str. is formed on the right of it

D. minuta

$b^{\prime}$ The dorsal apical or its morphological equivalent extends to the ventral apical

a" The apical pore is surrounded with three plates

D. brevis

$b^{\prime \prime} \quad$ The apical pore is surrounded with four plates

D. rotunda 


\section{Subgenus 1. Diplopsalis n. subgen.}

Genus Diplopsalis AвÉ, 1941.

The body is globular or lenticular. The elongated ventral area extends to the center in front of the hypotheca. The plate formula is $3-4^{\prime}, 0,3-5-6^{\prime \prime}, 5^{\prime \prime \prime}, 1-2^{\prime \prime \prime \prime}$. The apical pore lies at the intersection of three plates, and is separated shortly or distinctly from the dorsal apical plate which lies in the middorsal or is displaced towards the left side of the body.

In this subgenus are included the following six species: Diplopsalis behemingi Lindemann, D. pillula (Ostenfeld), D. caspica Ostenfeld, D. lenticula Bergh, D. lebourae n. sp. and D. torta ABÉ. Of these, the first is doubtful for this genus.

\section{Diplopsalis lenticula BERGH}

Fig. $3(4-6)$

BerGH; 1882, p. 246, Figs. 60-62; Lebour, 1922, p. 795, Figs. 6-10; 1925, p. 99, Pl. XV, Fig. 1a-e; Paulsen, 1931, p. 40.

non Pouchet, 1885; Pautsen, 1908; Jörgensen, 1913; Ostenfeld, 1915.

We found only a single specimen of this small species, which to our regret was partially crushed before completion of its sketches. Consequently, the following description is incomplete but serves to characterize this form.

The lens-shaped body has a minute but fairly elevated apical process and the subequatorial girdle: The cingular section is circular without ventral flattening except at the ventral area.

The plate pattern of its epitheca is nearly the same as that of the Atlantic form but displays some differences in details. Fig. 3-4 is an apical view of an isolated epitheca. The rhombic ventral apical tapers more anteriorly than posteriorly, and its greatest width is 0.6 total transverse length of the two ventral precingulars or 0.4 of transverse diameter of the body. Of the two lateral apicals, the left is smaller than the right partly in accord with the asymmetrical extension of the large intercalary plate which covers by far the dorsal majority of the epitheca. The apical pore occupies the ventral half of the median suture between them, which is slightly oblique with its dorsal end deflected towards the right. All the precingular plates are very small in length, particularly distinctly in their dorsal two members $3^{\prime \prime}$ and $4 "$, which lie just below the intercalary plate.

Fig. 3-5 is an antapical view of an isolated hypotheca. The left ventral postcingular is shorter and broader than the right ventral, extending almost to the hind end of the ventral area. The other three postcingulars are subequal in length, covering about anterior one-third of the hypotheca. The antapical is very irregular in shape in its ventral margin which is provided with a large triangular notch formed at the posterior extension of the ventral area and of the left ventral postcingular plate. 

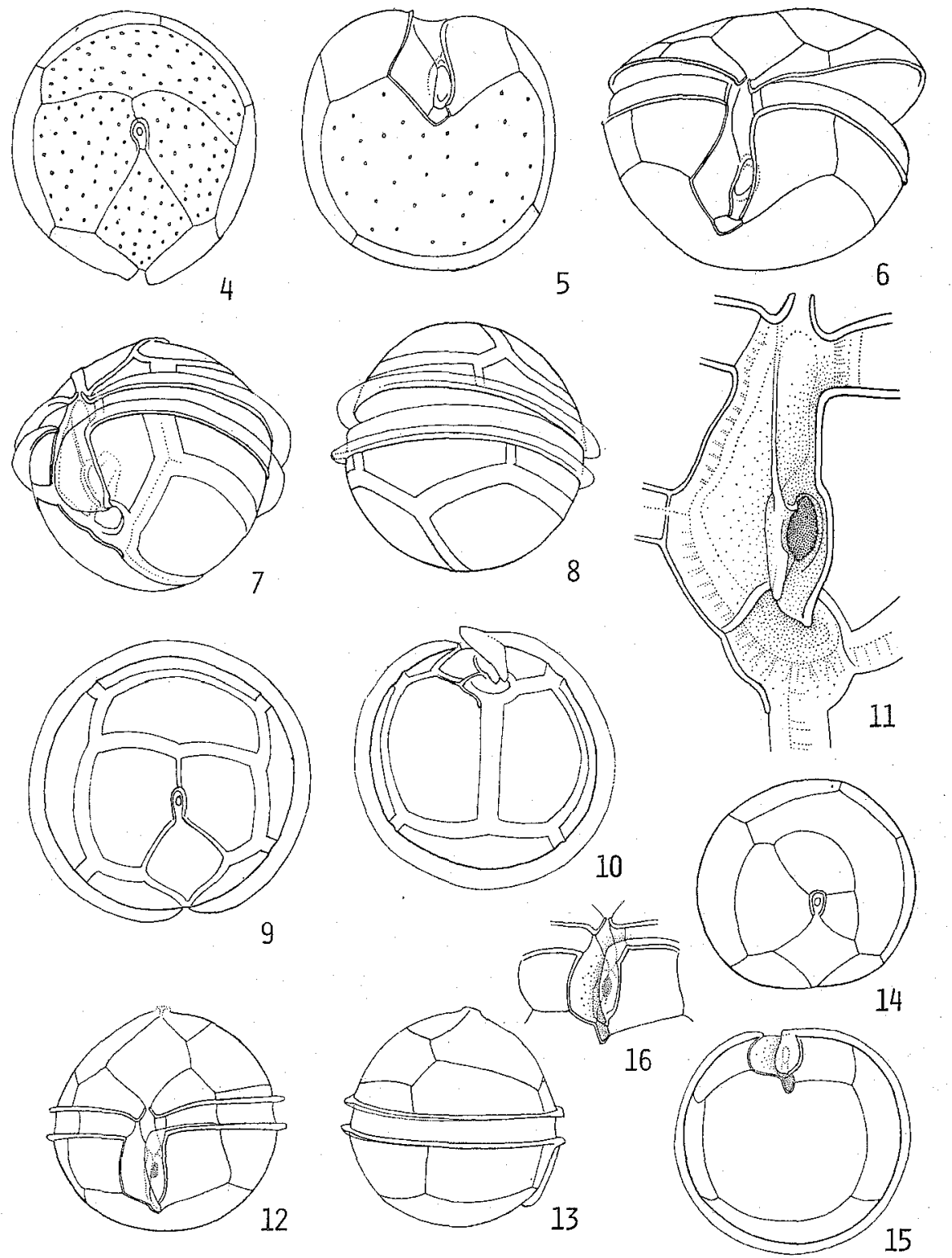

Fig. 3 (4-6): Diplopsalis lenticula BERGH. 4-Apical view. 5-Antapical view. 6-Postero-ventral view of a partially splitted specimen.

(7-11): Diplopsalis lebourat n. sp. 7-Posterior sinistro-ventral view. 8-Posterior dorsal view. 9Apical view. 10-Antapical view. 11-Ventral area.

(12-16): Diplopsalis brevis n. sp. 12-Ventral view. 13-Side view. 14-Apical view. 15-Antapical view. 16-Ventral area and its surrounding plates. 
The ventral area is elongated triangular in shape with its largest side on the left, and ends posteriorly in front of the center of the hypotheca. It tapers more anteriorly than posteriorly, and is broadest at two-thirds from the anterior end, where the ovoidal small flagellar pore lies close to the base of the left sulcal list. Over the flagellar pore and flagellar trough lies a deep longitudinal furrow by which we failed to establish the exact shape and size of the left sulcal plate. Peculiar is the fact that the posterior sulcal plate is very minute, lying just at the hind end of the ventral area and in the rear of the flagellar trough. It is broader and much shorter than the flagellar pore, and distinctly separated from the right ventral postcingular plate bordering directly on the left ventral one of the same series. Subdivision of the cingular wall could not be established, but a very narrow transitional plate was seen lying transversely across the proximal end of the girdle.

The thecal surface is sparsely distributed with speckles.

Dimensions: Length of body, ca. $40 \mu \mathrm{m}$. Transverse diameter of body, $47 \mu \mathrm{m}$. Locality: Asamushi.

Since the description by BERGH in 1881, as was described above, much has been discussed about the characterization of this species because of entire lack of our knowledge about the plate pattern of the original species. STEIN did not figure nor describe any about the hypotheca. Pavillard is another to be considered here. Of these latter two authors, the former could not confirm the existence of the intercalary plate, while the latter did not agree in this regard in his different papers. They agree, however, in that the precingular series consists of five plates. Lebour (1922) described this species from Plymouth Sound and defined its plate formula as $3^{\prime}$, la, $6^{\prime \prime}, 5^{\prime \prime \prime}, 1^{\prime \prime \prime \prime}$, believing that Stein and Pavillard probably had failed to detect the differentiation of the extremely narrow dorsal precingulars ( 3 " and 4"). We are, however, in doubt now as to whether or not all these forms described by different authors are regarded as belonging to a single species. Judging from our discovery of many allied species from Asamushi and Shimoda, which were not recorded as yet and are closely related in some but differ distinctly in other characters. The Asamushi form agrees with most of the Atlantic ones in measurements, and with Lebour's characterization and her interpretation of old literatures, we intend here to identify this Pacific form provisionally with the Atlantic one. Lebour's form appears, however, to differ from the present one in its smaller intercalary plate and in its much broader ventral apical plate. But extreme rareness of our material led us to refrain from separating them as different species.

\section{Diplopsalis lebourae n. sp.}

Fig. $3(7-11)$

D. lenticula ABÉ, 1927, p. 386, Fig. 4; LeBour, 1922, in part.

This globular species is seen very sparsely in association with the more flattened and larger species, Diplopsalopsis minor, but can be diffentiated from it by its different 
body shape and by its two antapicals.

The globular body has no distinct ventral flattening. The apical pore is displaced ventrally, and the thecal wall is elevated around it to form a minute but abrupt apical process. The circular girdle is equatorial. The triangular ventral area extends posteriorly but not to the center of the hypotheca, and bears a large list on its left side. The plate formula is $4^{\prime}, 5^{\prime \prime}, 5^{\prime \prime \prime}, 2^{\prime \prime \prime \prime}$. The ventral area is usually with 4 plates, and the posterior sulcal plate is very minute lying just below the flagellar pore.

The rhombic ventral apical is small both in length and breadth, and 0.3 transverse diameter of the body in breadth. Of the other two apicals, the left is smaller than the right, and the large intercalary is separated slightly from the apical pore. The precingular series appears to consist of five plates instead of six, and its middorsal portion lying just below the intercalary plate has the length subequal to the breadth of the girdle. We have failed to confirm the division of this narrowest middorsal portion of the series into two components, and extreme scarcity of the material did not allow us to make further analyses.

Among the five postcingulars, the lateral one is equal or a little larger than the girdle in length, but the dorsal $3^{\prime \prime \prime}$ extends twice in the length of the lateral.

The girdle usually consists of three plates, and their ventral component corresponds in transverse length to the ventral pre- or postcingular plate. The transitional plate was not differentiated, but its existence may be highly probable.

The ventral area is elongated triangular, tapering more anteriorly than posteriorly, and broadest at two-thirds from its anterior end. The left sulcal list is formed along the median margin of the left ventral postcingular plate, extending obliquely towards the right, and covers almost entire breadth of the ventral area. The right sulcal list is very indistinct lying along the median margin of the right ventral postcingular plate. There is another smaller one along the ventro-median margin of the right antapical plate. Close to the base of the left sulcal list and just at the brodest part of the ventral area is the ovoidal flagellar pore furnished with a short inner tubule leading into the body. The sulcal furrow lies in the left half passing over the flagellar pore. There is a distinct longitudinal ridge just on the right of the pore, and it continues further anteriorly and can be traced to the epitheca althouth it is dying out distally. The flagellar trough is subequal with the pore in breadth and projects posteriorly over the posterior sulcal plate. There is another short ridge extending oblique-posteriorly from the flagellar pore. This, together with the longitudinal ridge, demarcates the deeper furrow. The small and fan-shaped posterior sulcal plate expands slightly towards the left beyond the hind end of the left sulcal list.

Dimensions: Length of body, $42-44 \mu \mathrm{m}$. Transverse diameter of body, $43-$ $45 \mu \mathrm{m}$.

Locality: Asamushi.

Coupled with the general plate structure of the body, smaller size of the posterior sulcal plate serves to separate this from all other allied species, justifying at the 
same time its allocation in this genus. The present form can be distinguished from $D$. lenticula by its globular body and by its double antapical plate. From the other larger species of the genus, this can be separated by its smaller size and globular shape of the body and in its regular plate pattern of the epitheca. In addition to the usual flattened form of $D$. lenticula, LEBour (1922) saw very rarely a much rounder form which may probably be identical with the present one.

\section{Diplopsalis torta ABÉ}

ABk, 1941, p. 122, Figs. 1-6.

\section{Subgenus 2. Lebouraia n. subgen.}

Genus Labouraia ABÉ, 1941.

The body is globular and is furnished with a minute apical process but without any antapical elongation nor appendage. The equatorial girdle is nearly circular. The ventral area is elongated triangular, expanding towards the right, and bears a distinct list along its left side. The plate formula is $4^{\prime}, 1-2 \mathrm{a}, 6^{\prime \prime}, 5^{\prime \prime \prime}, 1-2^{\prime \prime \prime \prime}$. The ventral plate pattern is 'meta'. A huge intercalary plate is much displaced towards the left side, covering the major dorsal and left portion of the epitheca, and two or three precingular plates lying below it have exceedingly small and subequal length. Rarely another minute intercalary plate is seen on the right of this, when the apical pore is surrounded with 3 plates. In the rear of the much posteriorly displaced flagellar pore lies a small posterior sulcal plate which covers the pointed hind end of the ventral area, lying in contact with the left ventral postcingular plate.

To this subgenus are allocated following three species; Diplopsalis minuta (ABÉ), Peridiniopsis rotunda LEBOUR and $D$. brevis n. sp.

LEBour had reported in 1922 a peculiar small peridinian, Peridiniopsis rotunda from Plymouth Sound, and the same was redescribed in 1925 by LINDEMANN as Peridinium limnophilum. These can be distinguished only by size; the former being about $22 \mu \mathrm{m}$ and the latter $40 \mu \mathrm{m}$ in length. They are characterized by the peculiar asymmetrical arrangement of the plates in the epitheca, and the ventral plate pattern is peculiarly 'meta'. Her species was transferred to Diplopsalis by PAursen (1931). A small from was found in Shimoda and a different, larger one in Asamushi, both agreeing with her form in the characters just considered. The antapical is single in the smaller and double in the larger form. They differ so distinctly not only from each other but also from $P$. rotunda that each of them are to be separated as a distinct species. We shall call the smaller one $D$. minuta and the other $D$. brevis. The ventral area of our two species is of the Caspica-type, and the same is suggested also in Lebour's species judging from her Figs. 4b and 4c. The above suggestion may be supported by distinctly asymmetrical posterior extension of the two ventral postcingulars in her Fig. 4c.

All the three species are characterized similarly by the pentagonal ventral 
apical and the huge and asymmetrically expanded intercalary plate. With respect to the plate pattern of the epitheca, it is interesting to note that $D$. minuta is most closely related to Diplopsalis while $D$. brevis stands at the opposite end nearest to $D$. acuta and $P$. rotunda is intermediate between the two subgenera. The huge intercalary plate is much displaced towards the left, bordering directly on the ventral apical plate similarly in $P$. rotunda and in $D$. brevis while still separated from it and yet bordering on the precingular $2 "$ in $D$. minuta. From these facts, it seems to us to be the best to separate them collectively from all other members of the Diplopsalis group, because they are more closely related with one another than with any other subgenus or genus.

\section{Diplopsalis minuta (ABÉ)}

Lebouraia minuta AвÉ, 1941, p. 126, Figs. 7-13.

\section{Diplopsalis brevis n. sp.}

Fig. $3(12-16)$

The spheroidal body is provided with an equatorial circular girdle and a minute but abruptly differentiated apical prominence which stands just on the ventral of center of the epitheca. The ventral area is broad but short, terminating just in front of half-way between the girdle and the antapex. The cingular section is circular.

The epitheca consists of four apicals, one intercalary s. str. and six precingulars Among the four apicals, the ventral one is broadly pentagonal, and the quadriangular left is much smaller than the hexagonal right, while the biconvex dorsal apical lies diagonally along their dorsal side. A peculiarly elongated huge intercalary plate lies asymmetrically around the dorsal and left sides of three of these four plates extending from the right precingular $5^{\prime \prime}$ to the left ventral precingular $1^{\prime \prime}$. It lies so closely along the girdle that it is hardly possible to see. In apical view, these three precingular plates $\left(2^{\prime \prime}-4^{\prime \prime}\right)$ lying below it, owing to their exceedingly reduced length (0.3-1.2 width of the girdle in length). Among the precingulars, the right $5^{\prime \prime}$ is the largest both in length and breadth, and the left ventral $2^{\prime \prime}$ is the smallest in length.

The girdle is circular and its wall is flat, and its ventral component does not expand laterally beyond the ventral pre- or postcingular plate. The cingular list is very narrow and hyaline, and apparently devoid of ribs.

The hypotheca is characterized by a single antapical plate which covers its central half. The postcingular series except its left ventral member covers a little less than the upper half of the hypotheca.

The ventral area is short but wide, tapering abruptly at the hind end where it forms a minute elongation at the flagellar trough (Fig. 3-16). A very small flagellar pore lies close to its left side, and the flange of the pore elongates posteriorly forming the short and narrow flagellar trough. The left sulcal list is short and nar- 
row. Major right portion of the ventral area is covered with the right sulcal plate, and sheltered under the flagellar trough lies the minute posterior sulcal plate which occupies the abruptly differentiated minute posterior elongation. The left sulcal plate extends anteriorly to half-way between the flagellar pore and the girdle, and the posterior margin of the transitional plate is oblique as shown in the genus Peridinium.

Dimensions: Length of the body, $40 \mu \mathrm{m}$. Transverse diameter of the body, $40 \mu \mathrm{m}$. Dorso-ventral diameter of the body, $38 \mu \mathrm{m}$. Width of the girdle, $5 \mu \mathrm{m}$.

The only known species related to the present species is Peridiniopsis rotunda (LEBOUR), to which it has closest resemblance in the plate pattern of the epitheca. However, it can be distinguished by its rounded apex, its four apicals, shorter ventral area, less distinct sulcal list, larger size of the body and particularly by its single antapical. The species differs from $D$. minuta not only in the size of the body but also in the plate pattern of the epitheca.

\section{Subgenus 3. Dissodium n. subgen.}

Genus Dissodium AвÉ, 1941, p. 129.

The body is globular, bearing a minute apical process but no antapical one. The equatorial girdle is nearly circular. The plate formula is $4^{\prime}, 1 \mathrm{a}, 6^{\prime \prime}, 5^{\prime \prime \prime}, 2^{\prime \prime \prime \prime}$. The left of the two intercalaries or intercalary s. str. is rhombic and about one-half as large as the other (or the dorsal apical).

One species, Diplopsalis parvum, is included in this genus.

\section{Diplopsalis parvum (ABÉ)}

Dissodium parvum ABÉ, 1941, p. 129, Figs. 14-19.

\section{Genus Gotoius n. gen.}

The body is lenticular and bears no apical and antapical process nor apical pore. The equatorial girdle is nearly circular. The ventral area is very short, and has its greatest breadth just in front of its hind end. The plate formula is $4^{\prime}$, la, 5", $5^{\prime \prime \prime}, 2^{\prime \prime \prime \prime}$. The exceedingly small ventral apical plate is rhombic. Together with two ventrals of the precingular plates, the three apical plates are closely crowded in a small midventral portion of the epitheca. Central major portion of the epitheca is covered with a smaller left and a much larger right intercalary (or dorsal apical) plates. The posterior sulcal plate is rectangular, lying diagonally along the hind end of the ventral area and in contact with the two ventral postcingular plates.

One species, G. mutsuensis, is allocated to this genus.

An abundance of poreless lenticular species were found in planktons collected on April 19, 1927 (specimen bottle No. 62). It appeared as a larger form of Diplopsalopsis minor, but closer examinations revealed many peculiar characteristics 
disagreeing with that and also with any other known species, suggesting its apparent distinction from them. Peculiar is the fact that it is characterized by a lower type of the epithecal plate pattern coupled with the most advanced type of the ventral area, and also by the lack of the apical pore. In the texture of the thecal wall, it resembles Diplopsalopsis minor, but its two intercalaries are markedly enlarged in inversed proportion to its much reduced three apicals displaced ventrally. It may be characterized also by its larger dorsal precingular plate which covers the region represented in $D$. minor by its $3^{\prime \prime}, 4^{\prime \prime}$ and $5^{\prime \prime}$. This combination of the characteristics both of the epitheca and of the hypotheca sets the present poreless form apart from all the other known species and genera of the Diplopsalis group. In general shape of the body, this poreless form is related most closely to Coolia monotis MEUnIER, which can be distinguished from this by its irregularity in shape of the body, and this seems to be quite unrelated to it in the number and arrangement of thecal plates and in the shape of the ventral area. Our poreless form may be worthy of generic distinction. And the generic name is dedicated to the late Professor S. Gotô of the Tokyo Imperial University, by whose recommendation this study was undertaken.

\section{Gotoius mutsuensis n. gen., n. sp.}

Fig. $4(17-22)$

The body of this large discoidal species is markedly flattened in antero-posterior direction especially in its anterior half. The epitheca is broadly rounded and has no apical prominence nor its opening. The girdle is premedian and circular for the most part, forming a slightly ascending spiral by means of its weak proximal arch. The cingular section is circular. The hypotheca has no surface extension except the left sulcal list. The ventral area extends posteriorly to half-way between the girdle and the center of the hypotheca, and its posterior sulcal plate is elongated obliquely across its hind end.

The epitheca consists of four apicals, one intercalary and five precingulars. Arrangement and shapes of these plates are very peculiar and characteristic. The rhombic ventral is very small, one-tenth of the transverse diameter of the body in breadth and one-third of the surface radius of the epitheca in length. The left apical, which is hexagonal or rather triangular with truncated three ends, is a little larger than either the pentagonal right or the ventral apical. Common dorsal side of these lateral apicals is fairly short and straight but distinctly diagonal, and the two plates are contiguous with each other, separating the ventral apical completely from the larger right intercalary or dorsal apical plate. The trapezoidal ventral precingular plates are nearly equal in size and shape with each other, and do not extend laterally beyond the lateral apicals. These five small plates are arranged closely together within a small ventral median part, about one-third in width and one-fourth in depth of the epitheca. The other three precingulars are much larger 


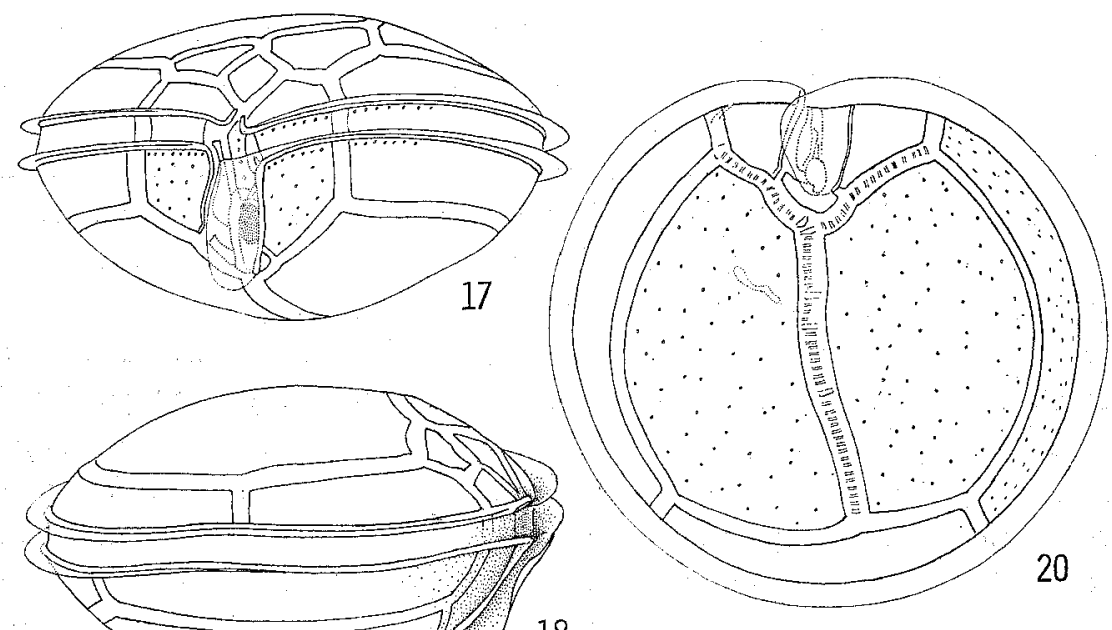

18
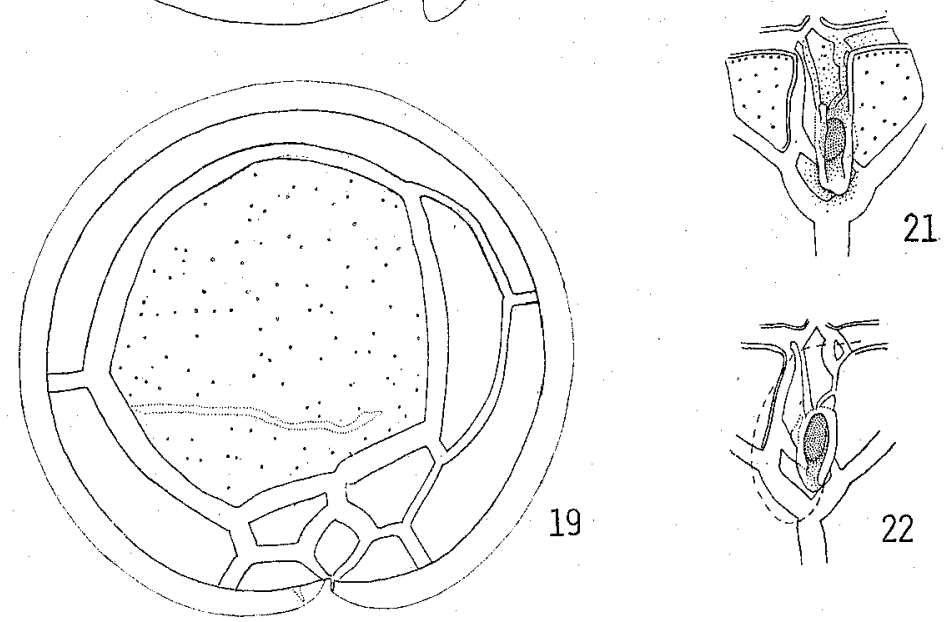

Fig. 4 (17-22): Gotoius mutsuensis n .gen., n. sp. 17-Sinistro-ventral view. 18-Side view. 19-Apical view. 20-Antapical view. 21,22--Two examples of the ventral area different in shape and development of some sulcal plates.

in length than the ventral two, and cover peripheral one-fifth of the epitheca. The dorsal precingular is the largest in the series and occupies a dorsal half of the row to which it belongs. The major central portion is covered with a crescent smaller left (la) and a much larger right intercalaries $\left(3^{\prime}\right)$. The latter plate is three-sided ventrally but broadly convex dorsally. Concerning most of the specimens, broad sutural zones were examined, and the apical pore or any structure to be interpreted as such was not visible between the two lateral apicals and in any other part of the epitheca.

The girdle has flat or faintly convex wall and is guarded with broad side-lists. Its wall consists of three plates as in other genera, and its ventral members do not expand laterally beyond the ventral pre- or postcingulars. The cingular section is circular with a small and indistinct ventral indentation. 
The hypotheca has five postcingulars and two subequal antapicals. The former plates cover anterior one-third or one-fourth of the hypotheca. The two ventral postcingulars are nearly equal in breadth, but the left of them is slightly longer than the other.

The ventral area is short and narrow and completely sheltered under its left sulcal list. The right sulcal list is indistinct. Peculiar is the fact that the four sulcal members are unusually separated more or less distinctly from one another in those specimens with broad sutural zones, so that we can easily establish their shape and extent (Fig. 4-21, 22). There is a minute triangular plate at the point where the transitional plate lies in other genera. It is at the proximal end of the girdle and close to the posterior cingular ridge, and it does not extend to the opposite side of the girdle, ending variously in different heights in different specimens. On the right of this is the irregularly shaped anterior sulcal plate. The right sulcal plate is triangular in shape, tapering anteriorly, and extends slightly beyond the posterior cingular ridge but not to the epitheca. It extends posteriorly to the middle of the flagellar pore. The flagellar pore is ovoidal, lying in the left posterior portion and just in front of the broadest part of the ventral area, and its flange is fairly stout, opening posteriorly to form the flagellar trough which protrudes over the posterior sulcal plate. The left sulcal plate is seen extending anteriorly beyond the flange in a small triangular elongation which is peculiarly separated from the transitional plate. The posterior sulcal plate is J-shaped or elongated rectangular, lying obliquely across the hind end of the ventral area, but does not expand towards the left much beyond the flagellar trough. The ventral postcingular plates are shortly truncated obliquely in their postero-median end where they border on the posterior sulcal plate. It is very interesting to re-note that the present species is furnished with all the important sulcal structures seen in other genera, that the transitional and the right sulcal plates are not as yet wholly developed and that all the sulcal plates are separated more or less distinctly from one another by sutural zones.

The thecal wall is either thin or distinctly thick and scattered with minute pores. A closely arranged line of pores lies on either side of the base of the cingular lists on the pre- or postcingular plates and also on the cingular wall. The anterior and the right sulcal plates are each furnished with a similar but short line of pores. The thecal wall is coloured or distinctly hyaline according to its thickness. The thicker thecal wall of this species resembles very closely that of Diplopsalopsis minor in texture especially with the fixation of formalin. And a similar relation exists between them in the structure of the sutural zone.

Dimensions: Length of body, $42-47 \mu \mathrm{m}$. Transverse diameter of body, 71-79 $\mu \mathrm{m}$. Width of girdle, $4-5 \mu \mathrm{m}$.

Locality: Asamushi.

The present species can be distinguished from all the other genera and species of the Diplopsalis group by its entire lack of the apical pore and by the peculiar plate pattern of its epitheca. It resembles Coolia monotis in the shape of the body, but according to Meunier's which was reprodeced by Lebour (1925), his species has the 
apical pore and profoundly different plate pattern not only in the epitheca but also in the hypotheca. Pyrophacus horologicum is another to be considered here, but it can separated from this at once in its different plate arrangements, its apical pore and its much smaller and different structure of the ventral area.

\section{Genus Diplopsalopsis MeUnIER}

Preperidinium MANGIN 1911.

Diplopelta Jörgensen 1913.

Diplopeltopsis Pavillard 1913; LeBour, 1922; 1925.

The body is globular or lenticular and with a minute process at the apical pore. Neither antapical process nor appendage is formed. The equatorial girdle is nearly circular. The ventral area is widest just in front of its hind end, and does not extend to the center of the hypotheca. The plate formula is $4^{\prime}, 1 \mathrm{a}, 6-7^{\prime \prime}, 5^{\prime \prime \prime}, 1-2^{\prime \prime \prime \prime}$. The ventral apical plate is rhombic, and the two intercalary plates are subequal or differ remarkably from one another in size, consisting always of a smaller left (la) and a larger right ones $\left(3^{\prime}\right)$. The ventral area covered with four sulcal plates are arranged around the flagellar pore which is ovoidal in shape and displaced posteriorly. The posterior sulcal plate is short but transversely elongated, lying along the hind end of the ventral area more or less diagonally with its right end deflected anteriorly, and extends between the two ventral postcingular plates.

To this genus belong D. minor (PAULSEN), D. globula ABÉ, D. asymmetrica (MANGIN), D. steinii ABÉ and D. orbicularis (PAULSEN).

Diplopelta bomba was a manuscript name of STEIN to denote a form, but later was given by the same author in favor of Diplopsalis lenticula. Jörgensen (1913) gave it again STEIN's name and this was followed by Pavillard. Lebour (1925) regarded Diplopelta as a subgenus of Peridiniopsis and included in it only a single species $D$. asymmetrica. On the other hand, PAulsen's D. orbicularis, as it is characterized by its so-called single intercalary plate, was transferred to a newly created genus $D i$ plopsalopsis by Meunier (1910). The latter species has, however, in reality, three apicals and two intercalaries instead of one judging from Paulsen's as well as LEBour's figures, by which we can support MEUnien's distinction of this from Peridinium. Consequently, these two species differ only in number of the precingular plates. In addition to them, a spherical and a larger lenticular species were found in Shimoda, and all these four species agree well in the structural relations of their ventral area, by which we can distinguish them from all other members of the Diplopsalis group and also from the so-called Archaeperidinium and other subgenera or groups of Peridinium. Closer examinations could not distinguish any special correlation between the structural features of the ventral area and the difference in the number of the precingular plates. From these, it seems relevant to unite the two genera into the MeUnIER's Diplopsalopsis.

Paulsen's var. minor is another to be considered here. Fauré-Fremier's Gle- 
nodinium lenticula is, in our opinion, identical with PAulsen's because of its strikingly narrow ventral apical plate and also of its similarly depressed ventral area. The species was studied afterwards by Meunier (1910), Mangrn (1911), Paulsen (1912), Pavillard (1912, 1913), Jörgensen (1913), Ostenfeld (1915), Meunier (1919) and Lebour (1922). Most of the earlier workers allocated it alone or together with D. lenticula either in Peridinium or in Diplopeltopsis, and this was followed by LEBour (1922, 1925).

Paulsen's species can be distinguished, in practice, from all the other species of the present group by the characteristics considered above and a single large antapical plate. Its ventral area is peculiar and characteristic in that the flagellar pore occupies its major median breadth, while in all other species, the ventral area is much broader expanding distinctly towards the right. This species is therefore unparalleled in these regards in the Diplopsalis group, and appears to be worthy of generic distinction. One has to consider here, however, the fact that the plate pattern of this species agrees in the main with that of $D$. asymmetrica or D. orbicularis, indicating their natural affinities. This suggestion is supported by the structural relations of their ventral area. PAULSEN's D. minor has, so far as our analyses are concerned, the posterior sulcal plate lying, similarly as that of asymmetrica, across the entire breadth of its ventral area. Consequently, it differs from other species of Diplopsalopsis only in its single antapical plate and smaller breadth of the ventral area.

To this genus belong D. minor (Paulsen), D. orbicularis (PAulsen), D. globula Abé, D. asymmetrica (MANGiN) and D. steinii ABÉ.

Key to species

I. The body is globular or nearly so

A. The left ventral postcingular plate is distinctly broader than long

B. The plate is longer than broad D. globula D. orbicularis

II. The body is lenticular

A. The thecal wall flares strongly along the girdle

D. steinii

B. The thecal wall do not flare so distinctly along the girdle

a. Ventral margin of the dorsal apical is straight and transversal or distinctly concave

D. minor

b. The ventral margin is distinctly convex

D. asymmetrica 


\section{Diplopsalopsis minor (PAULSEN)}

Figs. 5, $6(23-38)$

Diplopsalis lenticula BERGH, 1881, in part; JörgENSEN, 1913, p. 6.

Diplopsalis lenticula f. minor Paulsen, 1908, p. 36, Fig. 45.

Diplopeltopsis minor Pavillard, 1913; Lebour, 1922, p. 801, Figs. 11-15; 1925, p. 102, Pl. XV, Figs. 2 a-e; Lindemann, 1924, p. 133, Figs. 11-15.

Diplopsalis minor Lindfmann, 1927, p. 419; Paúlsen, 1931, p. 40-41.

The body is broadly but variously flattened ovoidal in side view, and has a circular equatorial girdle and a minute apical elevation. The apical process lies on the ventral of the center of epitheca and is, in most cases, hardly differentiated from the body (Figs. 5-24; 6-32). The epitheca contracts very rarely distally to form a short conical process there (Fig. 6-31). The broadly rounded hypotheca forms, in some cases, a broad longitudinal bulge along the ventral area. The ventral area is very narrow and subequal in breadth throughout its entire length ending posteriorly in front of the center of hypotheca. It has a broad but distinctly oblique sulcal list along its left side. In addition to this, a narrower right list which continues posteriorly and then turns towards the left along the hind end of the ventral area (Fig. 5-24). All of the precingular plates and most of the postcingular ones have a small length subequal with or only slightly larger than the breadth of the girdle. The ventral apical is very narrow, subequal with the ventral area, and the right intercalary plate is so large as to cover by far the dorsal majority of the epitheca. The antapical is single but very rarely double.

The present species displays a remarkable variation in the shape of the body or rather in length-breadth ratio $(0.73-0.87)$ and also in size (36-77 $\mu \mathrm{m}$ in transverse diameter). Smaller specimens are generally more flattened than larger ones, some of the largest specimens having strongly swollen body (Fig. 5-24). The cingular section is generally circular but has sometimes a ventral flattening which varies only slightly in different specimens.

As to the shape and arrangement of the plates in the epitheca, much has been discussed and described by some former authors, and there remains only a little to be mentioned here. One of the most distinct and remarkable features of practical importance is not only the diamond-shaped smaller left intercalary plate but also the extremely small width of the ventral apical plate as well as the ventral area. The ventral apical tapers more anteriorly than posteriorly and has its largest width just above its hind end where it measures generally $6-10 \mu \mathrm{m}$ and much rarely $20 \mu \mathrm{m}$ (including its sutural zones) and is only 0.11-0.15 of transverse diameter of the body. Together with the very small ventral precingular plates, these features help us in the identification of this species. Furthermore, a fairly straight and long suture passing transversely across the epitheca is also helpful.

The two lateral apicals form apical process laterally extending further dorsally slightly beyond it. This dorsal expansion can be seen more distinctly in younger specimens owing probably to smaller breadth of the sutural zone which blurres the 
actual margin of the plates.

In the hypotheca is seen generally a single antapical plate, but very rarely was found a large specimen with two antapicals (Fig. 5-28). However, we could not establish any difference worthy of specific separation between those with a single and with a double antapical. The typical antapical is a huge plate covering by far the major part of the hypotheca, and has a broadly triangular notch in its ventral
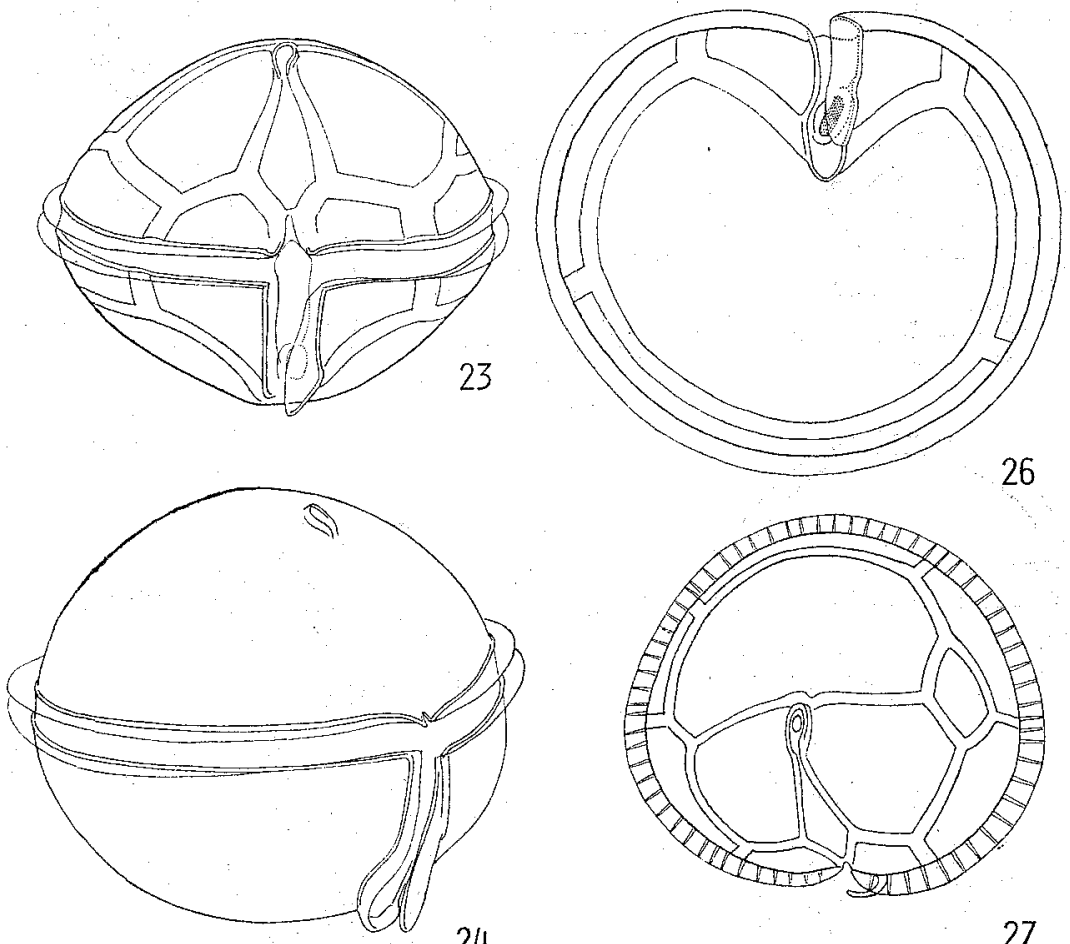

24

27
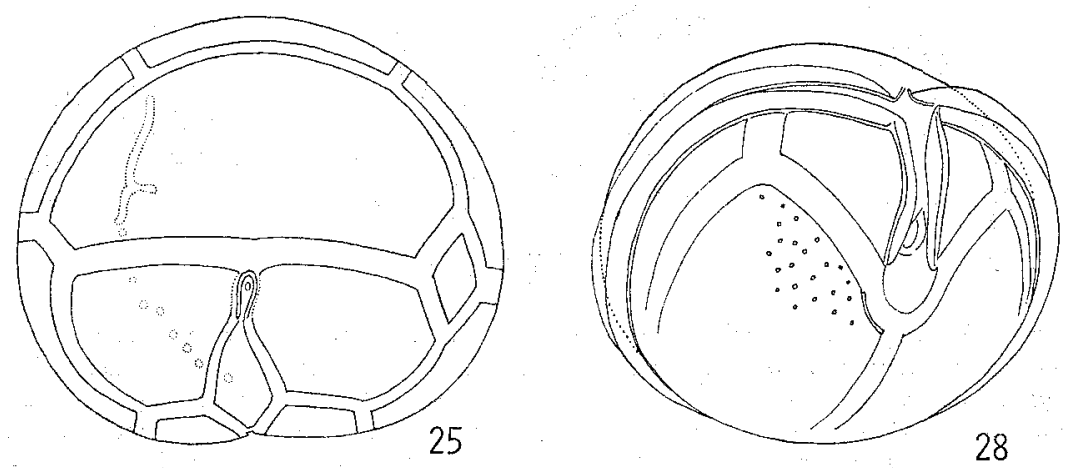

Fig. 5 (23-28): Diplopsalopsis minor (PAULSEN) (1) Larger forms. 23-Ventral view of an ordinary specimen. 24-Sinistral side wiew of a swollen specimen. 25-Apical view. 26-Antapical view. 27-Apical view of a little smaller specimen showing slight irregularity in the plate pattern. 28Sinistro-ventral view of specimen having two sulcal lists. 

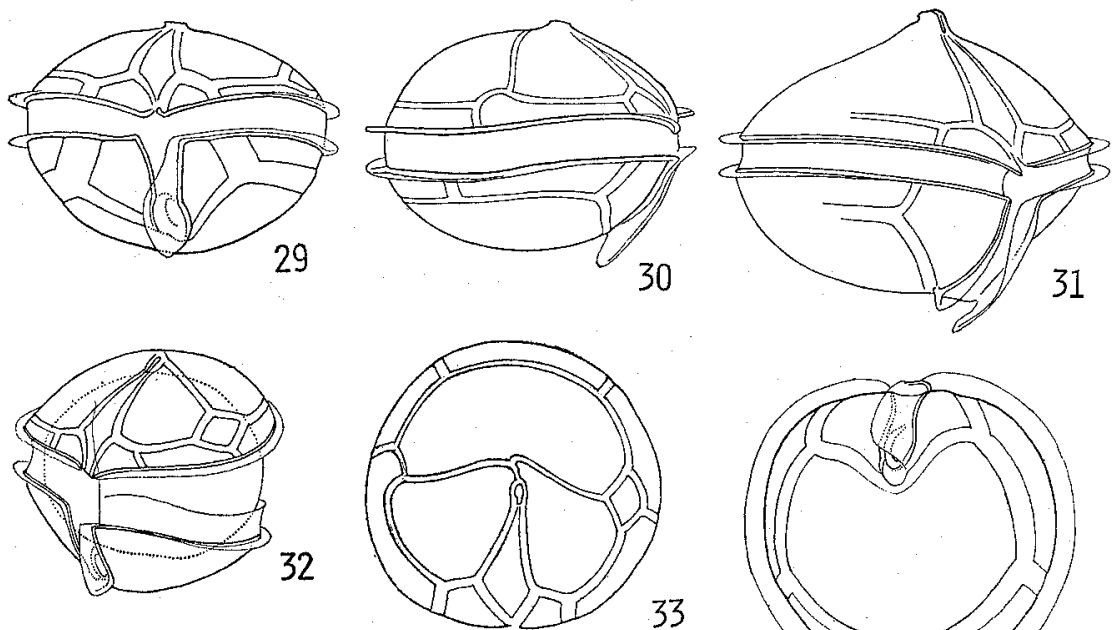

33
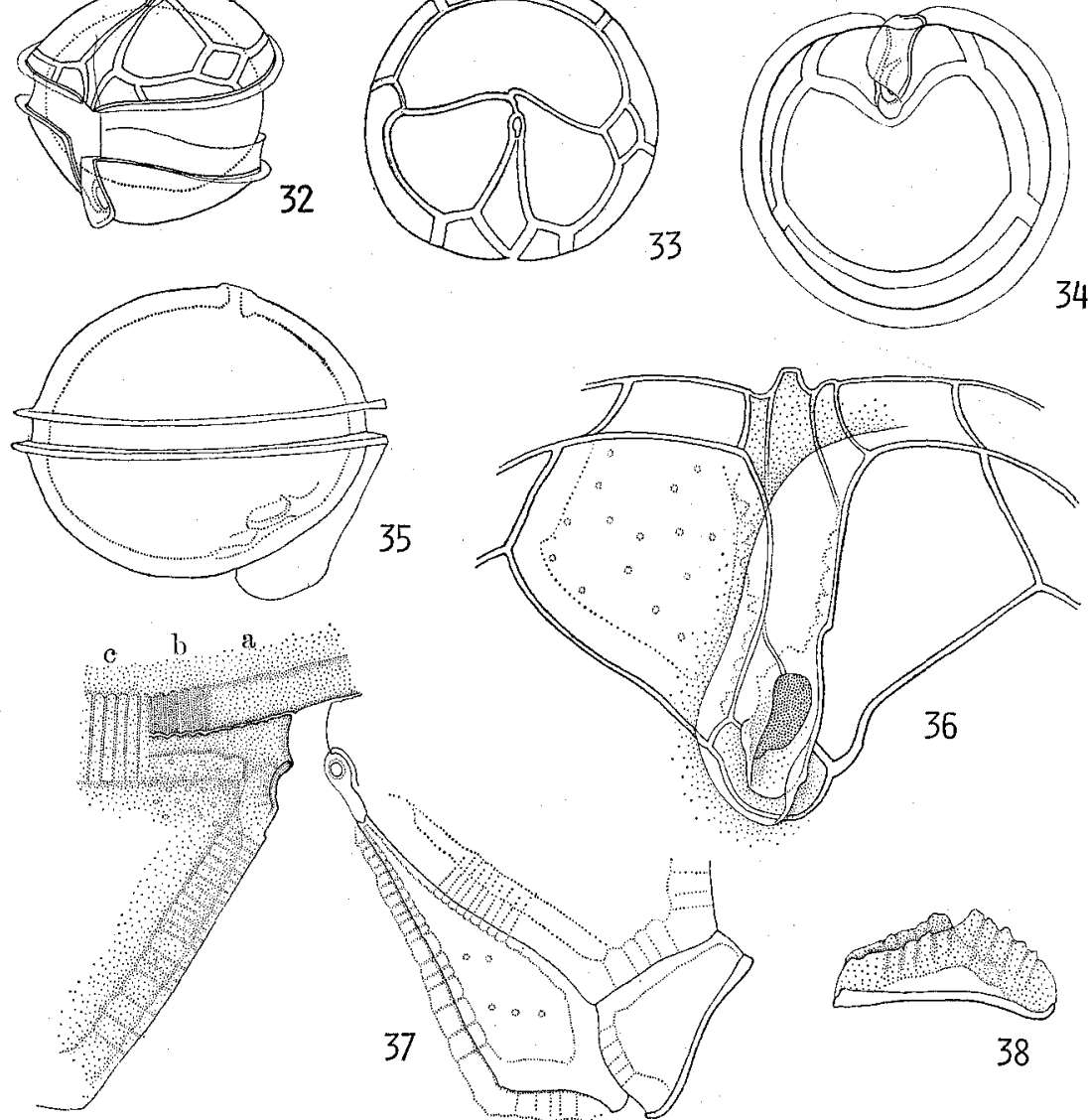

38

Fig. 6 (29-38): Diplopsalopsis minor (PAuLsen) (2) Smaller forms. 29--Ventral view. 30-Side view. 31-Dextro-ventral view of a rare specimen with contracted apex. 32-A minute specimen formed a cyst in the theca. 33--Apical view of a smaller form showing much irregularity in the plate arrangement. 34-Antapical view. 35-A medium-sized specimen with thicker thecal wall. 36Ventral part of a larger specimen. 37-Ventral part of the same specimen. Epitheca splitted along the right edge of the ventral apical plate. Finer structures of the sutural zones are illustrated. 38An isolated right ventral precingular plate. 
side, brought about by posterior elongation of the ventral postcingular plates and the ventral area. The left ventral postcingular plate is smaller in width than the right ventral, both extending similarly to the hind end of the flagellar pore. The other three postcingular plates are very small in length, covering anterior one-sixth or a little less of the hypotheca. The two ventral cingular plates agree with the two ventral pre- or postcingulars in their lateral ends.

The ventral area of this species (Fig. 6-36) is characteristic in its subequal small width throughout its entire length, not reaching the center of hypotheca. Strictly speaking, it is slightly compressed bilaterally in its middle just in front of the flagellar pore and expands laterally only slightly in its hind end below the flagellar pore, and has a rounded hind end.

The minute and elongated ovoidal flagellar pore lies longitudinally in the left half and just in front of the hind end of the ventral area. The flagellar trough is very distinct forming a large lip-like projection over the posterior sulcal plate, and occupies the major breadth of this part of the ventral area. The left sulcal list is developed in its hind end along this projection and extends further posteriorly. It extends obliquely towards the right, sheltering under it the entire breadth of the ventral area. The right sulcal list is narrow and has subequal breadth throughout its entire length. It takes reversed J-shaped course, standing for the most part along the right side of the ventral area and bends towards the left along its rounded hind end.

Anterior major part of the ventral area lying in front of the flagellar pore is covered for the most part with the anterior sulcal plate. Its anterior end is shortly truncated, extending beyond the anterior cingular ridge. On the left of this and at the proximal end of the girdle is the transitional plate, extending posteriorly far beyond the posterior cingular ridge. However, it is not certain whether or not this is contiguous posteriorly with the left sulcal plate, though there are some reasons to believe that the left sulcal plate which we failed to separate from the anterior sulcal one, is ordinary in its position, extension and structural relations, lying around the left and posterior sides of the flagellar pore and forms the lip-like flagellar trough. On the right of the flagellar pore is the right sulcal, anterior narrower portion of which extends anteriorly to the distal end of the girdle lying closely along the median margin of the right ventral postcingular plate. It extends posteriorly to the posterior sulcal plate. Posterior to the flagellar pore is the small and irregularly curved posterior sulcal plate expanding towards the left beyond the flagellar trough. It lies between the postero-median ends of the two ventral postcingular plates and is sheltered for the most part under the flagellar trough. The posterior end of the right sulcal list stands along the dorsal (posterior) margin of this plate. From these, it may be apparent that the strikingly narrow ventral area of this species has usually four plates but is characterized by distinct posterior displacement of the flagellar pore and proportionately elongated right and anterior sulcal plates.

The thecal wall is generally thin but often of considerable thickness. And in specimens preserved with formaline, there appears often a cleft-like structure or a 
series of poroid-like ones in the thecal wall (Fig. 6-37). The thecal plate is scattered densely with extremely minute circular speckles. In addition, the thecal plate is scattered sparsely with slightly larger specks of a different kind.

Larger specimens have generally broader sutural zone sometimes of considerable breadth. Repeated careful examinations reveal the fact that the sutural zone or rather sutural cleft is much more complex in structural relation than generally considered. The sutural zone between the right and dorsal apical plates is shown in Fig. 6-37. Careful focussing reveals us, on either side of a sutural line, narrower or broader marginal zone, which differs in texture form other part of the plate to which it belongs, and has no poroids. The sutural line between them is minutely undulated. Further focussing downwards reveals different structures on either side of the suture. Just immediately below the surface of the intercalary, there appears a broad striated band along its ventral margin. The band consists of darker blocks alternating with very narrow lighter bands of subequal breadth. This band has minute dents along its dorsal margin, and the lighter striations extend between the dent and the sutural line. Further focussing downwards causes a some changes of image. The band becomes as a whole rather lighter than the plate proper and there emerges a series of transverse darker striations each corresponding exactly in position with the lighter striation of the previous. In this deeper layer, the sutural line already disappears and the darker striation much elongates ventrally lying half in the intercalary and half in the apical plates but not interrupted at the point where the surface sutural line is seen. This deeper striated zone expands ventrally, much beyond the marginal (surface) poroid-free zone of the apical plate lying on the under side of its plate proper scattered with the poroids. The breadth of this deeper zone varies distinctly in different specimens in accord with age of the organism.

The ventral apical plate has its marginal poroid-free zone all around it, and it is broader posteriorly than anteriorly. Slightly focussing downwards in the free margin of the plate, we can see a much broader striated zone expanding strikingly beyond the poroid-free zone (Fig. 6-37). The striation can be seen for the first time only in this zone, but slight lowering of the focus reveals the occurrence of the poroid-free marginal zone. While the lateral apical plate has a broad band of striac lying just below its surface along its median margin opposite to the ventral apical plate. The band is subequal in breadth with the similarly striated band of the ventral apical just described. The number and distribution of the striae are similar in both plates. On further lowering of the focus, we can see similarly but less distinctly striated another band lying on the underside of that just described. The latter is slightly narrower than the former.

From these, it may be said with certainty that the ventral apical plate has a single marginal lamina striated similarly on its both surfaces, and its under-surface band of striae is broader than the upper-surface one, expanding into the plate proper, and that the lateral apical plate has two laminae of subequal breadth along its median margin, each lamina is striated on its one side lying opposite to each other. Before 
separation of the plates, the marginal lamina of the ventral apical is apparently put between the two laminae of the lateral apical plate, thus connecting tightly together the two contiguous plates. This reversed relation is made between the right and dorsal apical and the intercalary plates. The striae may be interpreted in this case as to represent closely folded fine canalicules or ridges passing along the sutural cleft which is deeply $\mathrm{V}$-shaped in its course. The marginal double laminae can be seen clearly in Fig. 6-37 in which the two laminae differ in shape, breadth and in direction of expansion. It is interesting to note that a similar but much simpler sutural structure was found in the subfamily Podolampinae (ABÉ, 1940), in which the sutural cleft is distinctly oblique for the most part and a marginal overlap of the plate fits into a shallow furrow lying along the outer margin of the other plate.

We have often seen larger or smaller specimens with one or two cysts in it. The cysts has a byaline and refractive surface layer of considerable thickness, and two of them are enveloped by a common but much thinner membrane. This cyst formation appears to be unrelated with growth of the body because of its occurrence within a small specimen with very narrow sutural zones.

Dimensions: Length of body, 33-60 $\mu \mathrm{m}$. Transverse diameter of body, 36$78 \mu \mathrm{m}$. Width of girdle, 5-6 $\mu \mathrm{m}$.

Locality: Asamushi.

PAUlsen's species was regarded as Bergh's original by Scandinavian authorities such as Pavillard (1912), Paulsen (1912), Jörgensen (1913) and Ostenfeld (1915) as well by some others such as Mangin (1911) and Meunier (1919), because of its being the commonest species in that region collected by BERGH. But Pavillard (1913), Lebour (1922, 1925), Lindemann (1928), Kofoid (1930) and Paulsen (1931) agree in distinguishing it into a different one.

In two out of the three figures of BERGH is illustrated the very narrow ventral area which is subequal in width throughout its length. Careful examination of the figures reveals the fact that the ventral area is slightly constricted at the middle and the flagellar pore lies in its posterior region where it widens a little bilaterally instead of asymmetrically towards the right. This structural feature of BERGH's species, which has not been taken into consideration by former investigators, is characteristic only for PAULSEN's form so far as our observations and published literatures are concerned. Further, the postero-sinistral continuation of the right sulcal list in its hind end in our form answers well to BERGH's description that "Die zwei Leisten, welche von der hinteren Querfurchenleist (rechts und links an der Ventralfläche) entspringen, scheinen sich ganz nach hinten zu vereinigen;..." In no other species of the Diplopsalis group can be seen an exactly corresponding structure so far as our analysis and published literatures are concerned. On the other hand, the present form appears to differ from BERGH's in its much shorter ventral area.

BERGH saw seven plates in an isolated single hypotheca of his peculiar form (p. 276). This appears to indicate that in the region he investigated, there is at least another form furnished with five postcingulars and two antapicals, although it is somewhat doubtful whether or not the incomplete specimen is to be regarded as 
identical with those figured by him. It is also uncertain whether or not the incomplete specimen is to be assigned to $D$. asymmetrica or to the rarer specimens of the present species. It may be mentioned in this connection that $D$. asymmetrica was found in Shimoda but not in Asamushi. At any rate, it is a well known fact that the present species is found commonly in the region investigated by BERGH. The species name $D$. minor is retained in this paper for this species because of the fact that it was elucidated exactly for the first time by PAulsen.

\section{Diplopsalopsis globula ABÉ}

ABÉ, 1941, p. 132, Figs. 20-23.

\section{Diplopsalopsis asymmetrica (MANGIN)}

ABÉ, 1941, p. 134, Figs. 24-31.

Diplopsalis lenticula Pouchet, 1885, p. 57, Pl. III, Fig. 12; SchütT, 1895, p. 21, Fig. 31; PaUlSEN, 1908, p. 39, Fig. 44 in part; Gran, 1915 in part; Lindemann, 1927, p. 93, Fig. 77.

Peridiniopsis asymmetrica MANGin, 1911, 1913; Lebour, 1922, p. 798, Figs. 6-10; 1925, p. 101, Pl. XV, Figs. 3 a-e; LINDEMANN, 1924, p. 132, Figs. 6-10.

Diplopelta bomba JörgensEn, 1913, p. 6.

Paraperidinium asymmetricum MANGIN, 1913.

Peridinium asymmetricum OstenfeLd, 1915.

Diplopsalis asymmetrica Lindemann, 1928, p. 91; Paulsen, 1931, p. 40.

\section{Diplopsalopsis steinii ABÉ}

AвÉ, 1941, p. 137, Figs. 32-39.

\section{Diplopsalopsis orbicularis (PAULSEN)}

Meunier, 1910; Lebour, 1922; 1925, p. 103, Pl. XVI, Fig. 1, a-e; Jörgensen, 1913, p. 6.

Diplopsalis lenticula Okamura, 1907, p. 131, Pl. V, Fig. 44; a-d.

Peridinium orbiculare PAULSEN, 1908, p. 42, Figs. 50; a-k.

Diplopsalis orbicularis PaUlsen, 1930, p. 42.

The body is globular or swollen lenticular with equatorial circular girdle and circular or broadly oval in cingular section. The apical prominence is hardly elevated, lying slightly ventral to the center of epitheca. The ventral area is elongated triangular with its maximum breadth just in front of its hind end, and extends posteriorly for about two-thirds or slightly more from the girdle to the center of hypotheca. The left sulcal list is fairly distinct extending almost to or slightly beyond the hind end of the body. The plate formula is $4^{\prime}, 1 \mathrm{a}, 7^{\prime \prime}, 3 \mathrm{~g}, 5^{\prime \prime \prime}, 2^{\prime \prime \prime}$. The quadrilateral or pentagonal left intercalary is not much smaller than the pentagonal, hexagonal or heptagonal right intercalary or dorsal apical one. Either all the precingulars or most of the postcingulars are very small in length, not much exceeding the breadth of the girdle. The precingular $5^{\prime \prime}$ is either fairly larger or subequal 
with $3^{\prime \prime}$ of the same series.

OKAMURA (1907) figured a flattened globular species with three apicals, two intercalaries, seven precingulars, six postcingulars and two antapicals and identified it with Diplopsalis lenticula referring it with SchürT's figures. In the same and the next years, PAULSEN described a small globular species with a pentagonal smaller left and a hexagonal larger right intercalary plates and regarded it as a Peridinium. Its body is only slightly broader than long, and his Fig. 50a indicates that this species is furnished with a large posterior sulcal plate lying obliquely across the hind end of its ventral area. Meunier (1910) transferred it to a new genus Diplopsalopsis and this was followed by Jörgensen (1913) and Lebour (1922, 1925). The last author's species includes at least two forms in regard to the plate pattern of its epitheca, one with that agreeing with PAULSEN's and the other with a different one. Fig. $1 d$ in her latter paper may be identical with her former one and further with PAuLsEN's original. But the other figures a, $\mathrm{c}$ and e differ from them in the larger size of its two precingulars $4^{\prime \prime}$ and $5^{\prime \prime}$, coupled with the pentagonal right intercalary plate. Furthermore, her two forms are more strongly flattened than PAULSEN's which is only very slightly broader than long.

One globular and another flattened forms were found in Asamushi, and a different flattened form in Shimoda. They agree in size of the body and also in the structural relations of the ventral area, but differ in the plate pattern of the epitheca. However, the materials we examined are so few and the variations they display appear to be so trivial, that it appears advisable to allocate them collectively in this species for the sake of convenience. This, however, does not mean that their taxonomic unity is established in this paper.

Almost all the specimens examined display slight variations in some or other points. This, together with the occurrence of the two forms, appears to suggest distinct variabilities of this species in regard to the shape of the body and the plate arrangement of its epitheca. So far as our materials are concerned, it seems to be convenient to divide it, for the sake of description, into two varieties, one with globular and the other with swollen lenticular body.

var. orbicularis n. nom.

Fig. 7 (39-43)

D. orbicularis LeBour, 1925, p. 103, Pl. 16, Figs. a-e.

The body is globular and furnished with the equatorial girdle and a minute but distinct apical process. The rhombic ventral apical plate is $0.3-0.36$ in breadth of transverse diameter of the body. The left hexagonal and the right pentagonal apicals are subequal in size, and they are longer than wide, extending dorsally only slightly beyond the apical process. The smaller left intercalary is either pentagonal or diamond-shaped, and the other right $\left(3^{\prime}\right)$ is accordingly hexagonal or heptagonal. Correlated with this variation, the dorsal precingulars $3^{\prime \prime}$ and 4 " differ in shape in 
the two cases (Fig. 7-40, 41). All the precingular plates are fairly small in length, decreasing their length from ventral to dorsal. The ventral cingular plate agrees in lateral extremity with the ventral pre- or postcingular plate. Among the postcingulars, the ventral two are usually longer than the others.

The ventral area is broader posteriorly than anteriorly and abruptly pointed posteriorly. The large left sulcal list covers the left two-thirds of this area, while the right one is very narrow and indistinct. The flagellar pore varies in size, lying usually at.two-thirds from its anterior end and just in front of its broadest portion. The flagellar trough varies also in size and shape (Fig. 7-39, 43). The minute transitional plate lies transversely across the proximal end of the girdle, extending slightly posteriorly beyond the posterior cingular ridge to meet the left sulcal plate.
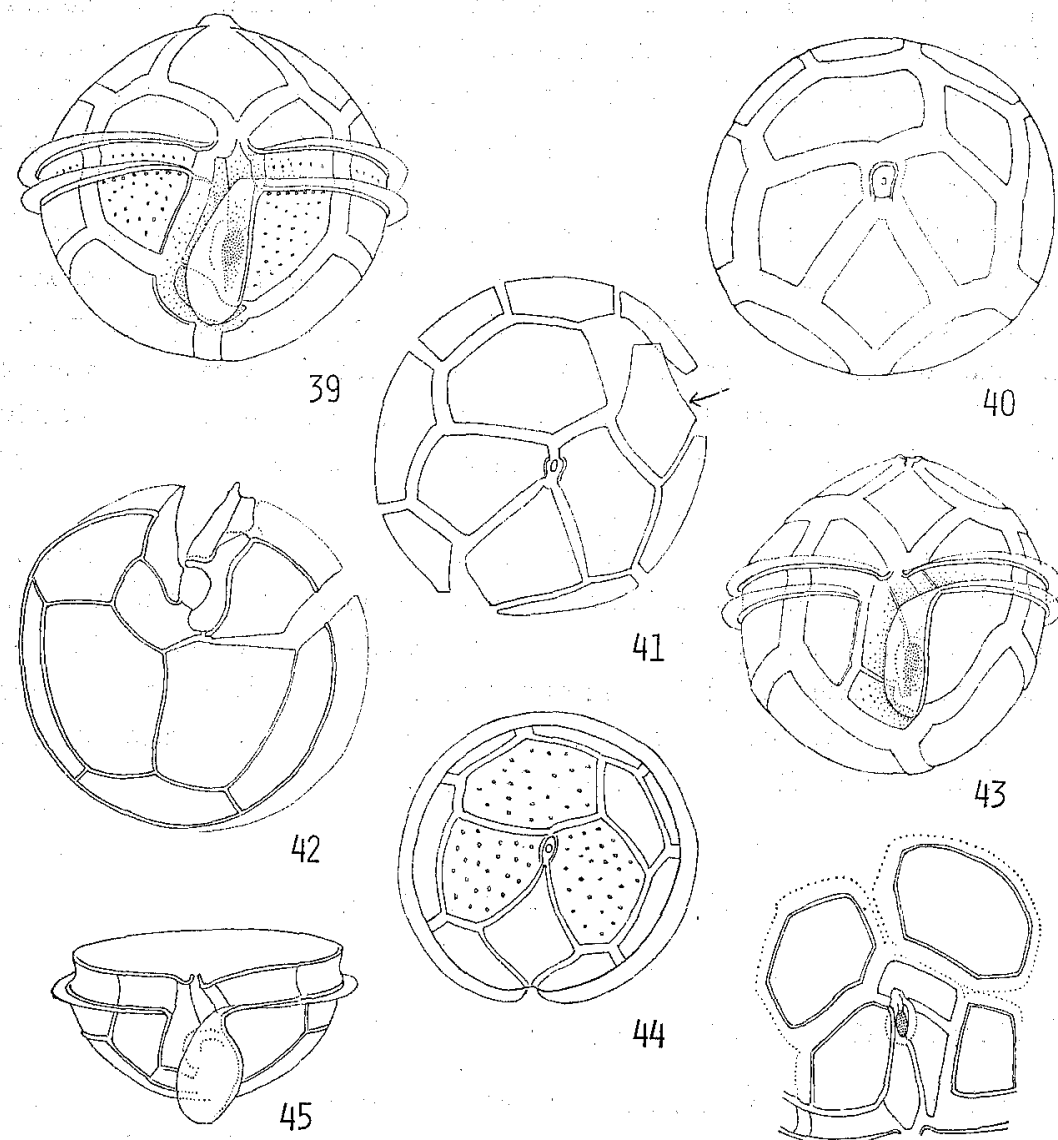

40

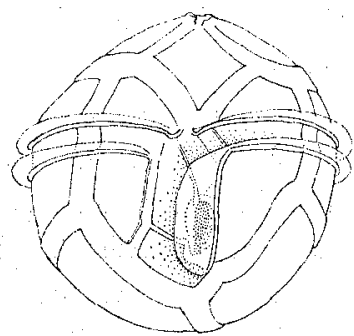

43

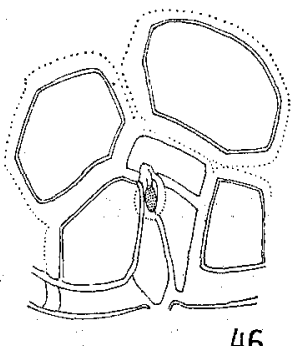

46

Fig. 7 (39-43): Diplopsalopsis orbicularis var, orbicularis n. nom. 39-Ventral view. 40-Apical view. 41-Apical view of another specimen, partially splitted, with pentagonal left intercalary plate (arrow). 42-Antapical view of a partially splitted specimen. 43-Ventral view of a specimen different in some points from 40.

(44-46): Diplopsalopsis orbicularis var. ovata ABt. 44-Apical view. 45-Ventral view of isolated hypotheca and girdle. $46-$ Ventral area and its surrounding plates. 
The posterior sulcal plate is obliquely rectangular lying across the entire breadth of the ventral area. It is 1.5-2 times broader than its long and expands towards the left slightly beyond the posterior end of the left sulcal list or rather that of the flagellar trough. These relations can be clearly established in Fig. 7 (43) which shows a partially splitted hypotheca.

The thecal plate is scattered with minute pores. A close line of similar pores lies along the middle of the cingular wall, and a similar one along the base of the cingular list either in the pre- or postcingular plate (Fig. 7-39).

Dimensions: Length of body, $47-50 \mu \mathrm{m}$. Transverse diameter of body, 45$52 \mu \mathrm{m}$. Breadth of girdle, $4-5.5 \mu \mathrm{m}$.

Locality: Asamushi.

var. ovata $\mathrm{ABE}$

Fig. 7 (44-46)

ABÉ, 1941, p. 143, Figs. 40-45.

We found a single specimen with smaller body flattened in axial direction. It can be differentiated from the other variety only by its flattened body and its smaller size, and resembles the Shimoda-form more closely than the previous. Extreme scarsity of the material leads us to abandon further comparison, but it seems highly probable that this Asamushi-form may be identical with Shimoda-form.

Dimensions: Transverse diameter of body, $40 \mu \mathrm{m}$.

Locality: Asamushi.

In both varieties, the right intercalary plate appears to be hardly separated from the apical process, but closer observation indicates that it has no part in the formation of the apical process. This, together with the seven precingular plates, suggests a close relationship between this species and the genus Peridinium. Except for this structure, the present species may be allocated in that genus.

As stated partly at the beginning of this description, LEBOUR's form appears to differ in some points from PAulsen's original one. We described in 1927 a small globular variety temaris in Asamushi and separated it from the original species. In this paper, two other forms are dealt with, one in the same locality and the other in Shimoda and Asamushi. Thus there are five forms in all, similar in the main but different in some or other points. The variety temaris can be differentiated from the others by its single intercalary plate (la) and its small ventral apical one separated completely from the girdle. PAULSEN reported his globular form in the North Sea, the Dainsh water and Ireland, and Leвouk reports her lenticular form in the English Channel. Our globular form is seen in Mutsu Bay while the other is mainly in Shimoda. This parallel occurrence of the globular form from northern seas and of the lenticular one in southern regions of the two oceans may be interpreted as to indicate their respective habitat and also their taxonomic unity. Extremely rare occurrence of the lenticular form in Mutsu Bay may be elucidated 
in the currents of the Tugaru Strait.

During the investigation of Asamushi planktons, many small forms related very closely to them were found in addition to those described in this paper. They agree in the body shape and in the lack of distinct apical elongation and of any antapical appendage except the distinct left sulcal list. But closer inquiry revealed a surprising variety of plate arrangement particularly in the epitheca, though they have not yet been fully worked out. Most of them were confirmed to be provided with an elongated posterior sulcal plate lying obliquely across the hind end of the ventral area. So far as our observations are concerned, they can be divided into three groups in regard to the body shape and structural relation of the ventral area.

The first group is characterized by globular body and the ventral area, typical of the asymmetrica-type. The ventral area can be divided further into two types, one with and the other without rightward expansion in its posterior portion occupied by the posterior sulcal plate. Several forms were found belonging to this group but they are entirely unknown as to their thecal structure.

The second group has small and rounded pentagonal body, a broader left and a much indistinct right sulcal lists and distinctly elongated ventral area. This plate pattern is typical of the genus Peridinium being provided with symmetrically arranged three intercalary plates. Its ventral area has a large posterior sulcal plate lying obliquely as in the former, but the two ventral postcingular plates extend only to half-way between the girdle and the hind end of the ventral area, ending similarly in front of the posterior sulcal plate.

The first group certainly includes those species of the Diplopsalis group, judging from the structural relations of the ventral area and the characteristic broad left sulcal list, but the second is to be allocated undoubtedly to the genus Peridinium. There are some reasons to believe that some of these two groups, particularly of the first may be younger or larval forms of other larger species, but others are undoubtedly adult ones judging from their more or less distinct sutural zones.

In addition, a peculiar form of the Diplopsalis group was found, and it is here separated into the third group. It is characterized by its lenticular body, its short but distinctly differentiated apical horn, its equatorial but distinctly ascending girdle and particularly by its narrow ventral area provided with a large left sulcal list (Fig. 7-45). Among described species, Glenodinium lenticula Pouchet (1883, p. 442, Pl. XX-XXI, Fig. 35, not FAURÉ-Fremie'r, 1908) has similarly a distinctly spiral girdle, but this is apparently a Peridinium certainly of the Globula group. Diplopsalis saecularis MURR. and WHITT. is another to be considered here, but its belonging to the same genus was established in this paper. Thus, the present form is unparalleled in the Diplopsalis group in regard to the structures just considered.

Universal occurrence of these smaller and insufficiently known species may be suggested from the fact described by LeBour (1922). And this forces us to infer that the species undoubtedly of the Diplopsalis group must be more numerous in nature than ever recorded. 


\section{Genus Apsteinia n. nom.}

Entzia LEBOUR, 1922.

Much has long been discussed about the taxonomic allocation of Entzia acuta, some regarding it as a Peridinium-species and others as a Diplopsalis-species. Judging from its markedly formed left sulcal list and a single antapical plate, the species is clearly more closely related to the Diplopsalis group than to Peridinium. But it can not be allocated to note of the group because of its typically formed four apical plates. And in addition, structural relations of its ventral area are entirely unknown. Consequently, it may be least unreasonable to conform to LEBOuR in distinguishing it as a distinct genus and placing it in the Diplopsalis group. The generic name, Entzia was, however, proposed for a group of the Foraminifera.

\section{Subfamily 4, Chalubinskinae n. subfam.}

The epitheca has three circular rows of plates, of which the apical consists of four plates arranged directly around the apical pore.

The hypotheca is covered with three postcingulars and a single antapical. The ventral area is strongly elongated anteriorly.

Only one genus and one species, Chalubinskia tatrica, is comprised.

On the basis of the existence of three postcingulars and one antapical, WoLOsZYNsKA (1916, 1922) separated Chalubinskia from Peridinium. General plate pattern of the epitheca and striking anterior elongation of the ventral area which is fairly simple in contour cleary suggest some close relationship of her genus to some of fresh-water species of Peridinium. A peculiar bending of the cingular tract on the dorsal side of the body leads us to recollect a similar peculiarity in Ceratium.

\section{Subfamily 5, Minusculinae n. subfam.}

The hypotheca consists of 4 postcingulars and two antapicals, and the left ventral of the precingular series is elongated irregularly to the result of separating the next postcingular from the left antapical plate. This has only one genus, Minuscula (PAulsen) Lebour.

Pascher (1922) described a peculiar form manifesting so strikingly unusual irregularity in the arrangement of the thecal plates both in the epitheca and hypotheca that its taxonomic allocation can hardly be established. Careful study of his descriptions and figures, suggests that the plate formula of Thaurilens ${ }^{\circ}$ denticulata may be $4^{\prime}, 3 \mathrm{a}, 6^{\prime \prime}, 4^{\prime \prime \prime}, 2^{\prime \prime \prime \prime}$. Judging from this, it is clear that the genus is related most closely to Chalubinskia or to Peridinium. It is interesting to note that re-adjusted arrangement of the thecal plates seen in some higher forms of Peridinium is seen also in this species but peculiarly only in the apical and intercalary series. Regions of the irregularity are the precingular and postcingular series, and in the latter $2^{\prime \prime \prime}$ is separated from the antapical plate by irregular development of 1 "', Scarcely 
any has been illustrated about structural relations of the ventral area. But so far as his figures are exactly drawn regarding the shape and the bilateral subdivision in the hind end, ventral area of this form may be allied to the Tatrica type of Peridinium.

Though detailed accounts are not given, Glenodinium bipes of PAULSEN $(1904,1908)$, for which LeBour (1925) established the genus Minuscula, corresponds in all probability with the PASCHER's.

\section{Subfamily 6, Peridininae n. subfam.}

The body is globular, flattened or elongated and often bears the antapical spine or horn. Thecal wall consists typically of four apical, seven precingular, five postcingular and two bilaterally arranged antapical plates. Well differentiated ventral area has four sulcal plates.

This subfamily includes a single genus Peridinium Ehrenberg.

\section{Genus Peridinium EHRENBerG}

Ehrenberg, 1880; 1883; Bergh, 1881; Klebs, 1882; Gourret, 1883; Pouchet, 1883; 1885; Stein; 1883; BÜtSChLI, 1885; 1889; SCHÜTT, 1896; GRAN, 1902; KARSTEN, 1905; 1906; Kofold, 1907; 1909; 1911; Okamura, 1907; 1912; Faurf́-Fremiet, 1908; Paulsen, 1908; 1911 ; 1931; Ostenfeld, 1908; Mangin, 1910; Lemmermann, 1910; Broch, 1910; Meunier, 1910; Hensen, 1911 ; Kofoid and Michner, 1911; Schillek, 1911; 1929; 1935; JöRGENSEN, 1912; SaHILlING, 1913; WoloszYNSKa, 1916; 1928; Pavillard, 1916; LindeManN, 1918; 1924; 1925; 1928; 1929; Barrows, 1918; Forti, 1922; Fauré-Fremiet et Puigaudeau, 1922; Lebour, 1922; 1923; 1925; Dangeard, 1923; 1927; NyGAARD, 1926; ENTZ, G., 1927; ABÉ, 1927; 1936; 1940; Holl, 1928; KisseLEv, 1928; 1930; Peters, 1928; Böhm, 1931; 1933; Wang and Nie, 1932; Diwald, 1939.

Heterocapsa Stein, 1883; PAulsen, 1908.

Vorticella (cincta) O.F. MÜLLER, 1773.

Protoperidinium Bergh, 1881; POUChet, 1885.

Staszicella Woloszynska, 1916; Pascher, 1922; Lindemann, 1925.

Sphaerodinium Woloszynska, 1916; PAscher, 1922.

Amphidiniopsis WoloszynsKa, 1928.

The body is remarkably polymorphic in shape, ranging from globular to pyriform or to biconical and furnished with or without one or both of an apical horn anteriorly and a double set of antapical spines, wing-complexes or horns posteriorly. It is flattened usually on the ventral but rarely strongly compressed dorso-ventrally or antero-posteriorly. The girdle and ventral area are well differentiated. The general thecal plates are grouped into three circular rows in the epitheca and into two in the hypotheca. Of them, the apical consists typically of four plates closely arranged around the apical pore which is rarely absent and two represented by a short sutural line. The antapical row has two laterally arranged plates, and the preand postcingular rows comprises in typical cases seven and five plates respectively. The ventral area is covered with four sulcal plates, the posterior one of which is of considerable size, lying in the main transversely rarely across the major but typically 
across entire breadth of the ventral area and often expands bilaterally or asymmetrically towards the left beyond the remaining part of the structure.

The present genus is subdivided in this paper as follows:

Subgenus Protoperidinium (BERGH)

Group Humilia Jörgensen (emend.)

Section Heteracantha n. sect.

Section Monacantha ABÉ

Section Laterispinosa n. sect.

Section Bispinosa n. sect.

Section Globula n. sect.

Group Pyriformia Jörgensen

Group Pellucida Jörgensen (emend.)

Section Metapellucida n. sect.

Section Parapellucida n. sect.

Subgenus Mesoperidinium n. subgen.

Group Paradivergentia PAULSEN (emend.)

Group Divergentia Fauré-Fremiet (emend.)

Subgenus Veroperidinium Paulsen (emend.)

Group Tabulata EhrenberG (emend.)

Section Tatrica n. sect.

Section Tabulata n. sect.

Group Avellana Paulsen

Group Monovela n. gr.

Group Perrieri FAURÉ-Fremiet

Group Oceanica Jörgensen

Group Conica Jörgensen

Section Multistriata n. sect.

Section Conica n. sect.

Section Pentagona n. sect.

According to Lebour (1925, pl. 18, fig. 2), the species, $P$. triqueta, which has long been allocated to a distinct genus, Heterocapsa, is a typical species of Peridinium. Woloszynska (1916) created a new genus, Staszicella, for a minute species, S. dinobryonis, which according to the author has two antapical plates but according to LINDEMANN (1925a), single plate of the series. Some other characters recorded by the two authors also differ from each other, suggesting their taxonomic distinction. WoloszynSKA's species is described to have five apical plates, which have often been established in Peridinium. Though hardly any was given about the structural relation of its ventral area, other general properties of its hypotheca puzzled us in finding any reason for separating it into a distinct genus. Lindemann's form clearly suggests a large plate in the posterior half of its ventral area, which is characteristic for the Tabulata group of Peridinium. Sphaerodinium was distinguished by Woloszynska from Peridinium by its four intercalary plates and its hexagonal dorsal apical plate. In other respects, all of the three species recorded by the author are apparently Peridinium 
species. Judging from some figures of them, reproduced by PAsaHer (1924), these recorded species have the ventral area, clearly allied in the structural relation to that of Peridinium tatricum and its allies, suggesting their closest relationships. The same author's Goniaulax kofoidii, for which a new genus, Amphidiniopsis, was established, has, judging from her Figures 2, 10-12 and 15, the posterior sulcal plate expanding laterally beyond the anterior narrower half of its ventral area. This is the characteristics we have established in the subgenus Veroperidinium of Peridinium. According to some of his figures, this species appear to have peculiarly an apical pore in its ventral apical plate which is illustrated as if extending dorsally beyond the pore. But in her Fig. 13 is illustrated a slight constriction of the plate on its left side and just on the ventral of the pore. If this incompletely illustrated structure can be presumed to suggest the site of a suture, it may be concluded that the ventral apical plate of this species is pentagonal, coming in contact with a smaller left one of two asymmetrically arranged intercalary plates. And if these suggestions are allowed, this species agrees in these characters apparently with Peridinium grenlandicum.

\section{Historical}

It was O.F. MülLER (1773) who had found for the first time a peridinian species belonging to Peridinium, describing it as Vorticella cincta which was afterwards identified as $P$. tabulatum. He ascertained at the same time the transverse girdle, and regarded the transverse flagellum as consisting of a circular row of cilia.

About sixty years later, Ehrenberg (1830) established the present genus for two species and contributed much to our knowledge about morphology of it, ascertaining the thecal wall. But his genus was heterogeneous because of its comprising Gymnodinium and Ceratium. Glaparede and LAGHManN (1858-61) conformed to him in this regard.

In 1878, STEIN proposed to exclude these species with structureless theca from EHRENBERG's genus and to limit the genus only to those covered with definite thecal plates. His recharacterization of the genus has long been accepted generally with or without emendation.

BERGH (1881) established a new genus, Protoperidinium, for these species with distinct sulcal lists, such as $P$. michaelis and $P$. pellucidum. At the same time, he included the other genus Peridinium, those species with antapical horns or without the sulcal lists, such at $P$. tabulatum and $P$. divergens. He put stress in distinguishing species of the latter genus upon slenderness of body form, breadth and length of body, length of horns and some others, and he took into considerations the numbers of the thecal plates. Yet, according to our principle of subdivision, his species, $P$. divergens, is a collective species because of its including several different species belonging to the Divergentia, Occanica and Conica groups. In his species, P. pellucidum, are also included at least two different species. It may be interesting to note that a variously formed water pusule, which had been regarded as stomach of the organism, was 
ascertained by BERGH in various species as connected with the flagellar pore by means of five canals, and was suggested as an organelle of assimilation, absorbing water from outside of the body. BERGH's principle of distinguishing Protoperidinium from Peridinium was supported by Poucher $(1883,1885)$ and some others.

Conforming these earlier investigators, BüTsGHLI (1889) distinguished Peridinium from Diplopsalis by its seven precingular plates, admitting on the other hand identity of them in regard to numbers and arrangement of the thecal plates in their hypotheca. These two genera were distinguished at the same time by body form, girdle, sulcal lists and types of the antapical appendage or elongation.

Contrary to these investigators, GRAN (1902) divided the genus itself into two subgenera, Protoperidinium BERGH and Euperidinium GRAN, according to the ascending girdle coupled with the antapical spine for the former and the descending one coupled with the antapical horn for the latter. And this was followed by Karsten (19051907), Paulsen (1908), Broch (1910) and Fauré-Fremiet et O. du Puigaudeau (1922). A different system of subdivision was proposed in 1908 by FAuré-Fremiet, who divided the genus abruptly into four groups of Tabulatum, Divergens, Cinctum and Perrieri.

From these considered above, it may be manifest that the genus Peridinium had been fairly well established in an earlier time, and that the thecal structures of the epitheca and hypotheca were brought to light gradually. In addition, Koford (1909) gave fuller accounts of the thecal morphology of $P$. steinii, greatly contributed to the advancement of protozoology in this field.

In 1913, JörGENSEN proposed an epoch-making new system of subdivision, in which he separated these species with two epithecal intercalary plates to a new genus, Archaeperidinium, and subdivided, mostly conforming to FAURÉ-Fremiet, the genus Peridinium into groups according to different combinations of the ventral and dorsal plate patterns of the epitheca. His principle of subdivision has generally been accepted by most of subsequent investigators. We can deduce from his suggestion three conclusions.

In the first place, he ascertained three types of the ventral plate pattern, including all the possible patterns occurring in the genus. Particularly, Barrows (1918) considered the different plate patterns as to manifest relationships of the genus, and discussed probable natural affinities among them, putting much taxonomic stress upon the ventral plate pattern.

Secondly, he apparently separated these species with two intercalary plates into a distinct genus, because of the consideration that the type with three intercalary plates is derived from that with two. Conforming to this, the genus has been divided by some of his followers such as Broch (1910), Pavillard (1916), Lebour (1925), Peters (1928) and Böhm (1931), according mainly to the ventral plate patterns into Meta-, Para- and Ortho-peridinium, which were accepted either as group-names or as three subgenera.

This was followed with some emendations by Lebour (1925) and PAulsen (1931). They agree in regarding Archaeperidinium as a subgenus of the genus. And 
JöRgEnSEN's Peridinium was accepted as such by LEBOUR in reducing it to a subgenus, while Paulsen proposed in place of it a new subgeneric name, Veroperidinium. From these, it is manifest that they agree in placing more stress upon whether the intercalary row consists of two or three plates than upon the ventral plate patterns and other structural characteristics.

Thirdly, it is to be highly esteemed that he, conforming to FaURÉ-Fremiet, subdivided the genus into sections or groups. This system was adopted concomitantly with or independently of the subgeneric division by the majority of subsequent investigators because of its simplicity and practical convenience.

In spite of these far reaching discussions and considerations about taxonomy of the genus, hardly any detailed account has ever been given, except by Koford (1909), on the thecal morphology, on which the taxonomy bases. This clearly accounts for the fact that it has been hardly possible for any of the former investigators to propose a system of subdivision of the genus, without allowing smaller or larger numbers of exceptional cases.

There is another fact by which the taxonomy of the genus has not been much advanced. There have been recorded, so far as our studies on published literatures inform us, more than two hundred species or so many recorded specific names of the genus, the majority of which are, however, very insufficiently figured and described. Many of them, particularly those recorded in an earlier time of the study of the genus, are so insufficiently described and figured that later investigators can hardly know what subdivision of the genus they are to be allocated, or whether or not they are really the Peridinium-species, by inaccurately drawn contours of them. This naturally made it exceedingly difficult or more probably hardly possible to establish the taxonomy of the genus with accuracy. It appears to us then that not a single thorough study of the genus has ever been given by any of former investigators, though importance and need of study of the genus has long been much estimated and generally expected. The only way by which one can deal with this difficulty is to study as far as possible details of the thecal morphology of so many species covering all of possible subdivisions of the genus.

\section{Polymorphism and general organization of the body}

\section{Polymorphism of the genus}

Within the armored dinoflagellates, together with the genus Ceratium, the genus Peridinium is most polymorphic in regard to the general form of the body, ranging from an almost perfectly spherical form to a plate-like, flattened one, a pear-shaped or biconical one, and a pentagonal or starshaped form with or without a small or large postmedian indentation. A globular form is in most cases furnished with two shorter or longer antapical spines or wing- complexes and a pentagonal one similarly with two hollow antapical horns. Often the apical horn is strikingly elongated in close association with remarkable elongation of the antapical spine or 
horn. The girdle is often post-equatorial but generally sub equatorial, forming a fusiform, ovoidal, reniform or circular cingular section lying horizontally or tilting up dorsally. The thecal wall is broadly rounded or bulges remarkably along the girdle. The midventral part of the body is either flattened or longitudinally indented more or less strongly, and the ventral area is highly polymorphic regarding its shape and structural differentiation, lying in the ventral depression, and is indented partly or as a whole. The genus Peridinium is then unparalleled in the armored dinoflagellates regarding its astonishing wide range of variations in the form of the body.

\section{General organization}

The body is generally globular or pear-shaped with or without an apical elongation and two antapical spines, or biconical or alike, furnished with two antapical horns, but rarely polyhedral or strkingly flattened antero-posteriorly or dorso-ventrally. The median or entire breadth of the body is typically flattened or lon gitudinally indented. Coupled with this feature, the body is often flattened slightly or remarkably in dorsoventral direction. In any case, the body is divided by an ascending, circular or decending girdle into mostly subequal but rarely markedly unequal epitheca and hypotheca:

The epitheca is either concave, flat or convex conical or hemispherical, tapering distally into a minute or strikingly elongated apical elongation, at the distal end of which opens typically an apical pore bearing a shorter or longer apical trough or ventral slit. But often some trace of the apical pore is formed in the fresh-water species. The cingular wall is flat or indented and is guarded on either side with a cingular list whose width decreases gradually from its proximal end to its distal extremity and is furnished generally with many closely set ribs.

The hypotheca is generally broadly rounded posteriorly bearing two shorter or longer antapical spines or wing-complexes, or bicuspidate conical with concave, convex or flattened surface and two antapical horns of smaller or greater length, but it is often typically conical tapering to a pointed or rounded end. Along the ventro-median region of this lies the ventral area which has a subequal breadth throughout its length and is more or less deeply indented as a whole, or consists of a narrower anterior and a broader posterior parts, deeply excavated similarly or partially in the anterior left half. In any case, it is strongly indented in the part lying between the proximal end of the girdle and the flagellar pore, forming there the flagellar furrow which often extends more posteriorly beyond the pore.

The ventral depression or flattening of the body is greater in extent than the ventral area which shows an astonishingly wide range of variations in size and shape. And the sulcal furrow is weakly or strongly formed, occupying the entire or major portion of this ventral area. A part of this furrow is particularly strongly indented to form the flagellar furrow. The ventral area can be divided into several types regarding its various shapes and structural differentiations just considered. Each of them is coupled with indefinite type of the antapical extension or elongation.

The hypotheca is, thus, much more polymorphic than the epitheca, forming several different types. Consequently, the genus Peridinium is unparalleled in this regard in the armored dinoflagellates, except the genus Ceratium. This polymorphism 
of the genus is mainly or exclusively due to its hypotheca.

Much taxonomic stress had been put by some of the earlier investigators of this group of protozoa upon the form of the hypotheca. But this structural feature has long been disregarded since JöRGENSEN (1912) proposed a new principle of subdivision of the genus, basing upon the combinations of the ventral and dorsal plate patterns of the epitheca. Contrary to this long prevailed principle, we came to the conclusion that the type and structural differentiation of the hypotheca and particularly of the ventral area are of paramount taxonomic significance, serving for the subdivision of the genus and at the same time for characterization of a given species, because of their diversity and constancy and also of their trustworthiness in representing natural affinities among subgenera, groups, sections and species of the genus.

On the basis of this structural diversity of the hypotheca established and partly upon the plate pattern of the epitheca which hitherto has been accepted generally as of taxonomic significance, the genus can be divided into three series of species. In the first series (subgenus Protoperidinium and a part of subgenus Mesoperidinium), the globular or pear-shaped body is furnished generally with two antapical spines or wing-complexes. The second series (consisting of subgenera, Mesoperidinium and Veroperidinium), presumably derived from the previous one, has the hollow antapical horn covered entirely with the antapical plate. In the third series, a part of subgenus Veroperidinium) the conical antapical horn is covered except its median surface with the posterior sulcal plate. On the other hand, three subgenera just cited are characterized by three different types of the ventral area respectively. And spineless or hornless forms are comprised partly in Protoperidinium and partly in Veroperidinium.

\section{Inner organization}

The most conspicuous structure seen in the living body of the marine species is the sack pusule which displays a wide range of variation in its size and form. It occupies in some extreme cases such greater central part of the body that the general cytoplasm forms a thin layer sticking to the thecal wall, filling at the same time the apical and antapical hollow horns. But generally the body is filled mostly with the cytoplasm, and a smaller or larger sack pusule lies in it asymmetrically. In the cytoplasm, at least two different regions can be distinguished. The majority of it is granular, containing a large nucleus, chromatophores, rhabdosomes, trichocysts, small vacuoles and some metabolic products such as starch grains and oil droplets. Just along the anterior bottom of the sulcal furrow or flagellar pore, hyaline smaller portion is differentiated, and the collecting pusule is comprised in it.

\section{Cytoplasm and its inclusions}

The granular region of the cytoplasm is much greater in proportion than the hyaline region, filling up the apical and antapical horns and by far the majority of 
the mid-body. Sometimes it is crowded with minute or larger vacuoles. In most species, short and very fine thread-like trichocysts are arranged at random beneath the inner surface of the thecal wall. However, when the cytoplasm shrinks and is separated from the thecal wall, they form a radially striated peripheral layer of considerable thickness. Regarding the relationship between the trichocyst and the thecal wall, we agree with KRUGER's interpretation that "Doch möchte ich daran erinnern, dass bei sehr vielen beschalten Peridineen der Panzer von Poren durchsetzt ist, die möglicherweise als Austrittstelle für die Trichocysten dienen können, ..." The fluid vacuoles are scattered throughout the remaining inner layer of the cytoplasma and do not display any definite arrangement. Their size and number are partly subject to individual variations but are partly fairly constant for a given species. The oil droplets are seen mostly in and at the base of the apical and antapical horns and along the girdle where the thecal wall bulges more or less distinctly. They are also scarcely distributed along the body surface of the other portion. Many rod-like rhabdosomes can be established in many species. And those of $P$. oceanicum are arranged so as to converge towards the flagellar pore or towards the collecting pusule.

When the cytoplasm of $P$. oceanicum was stained vitally with gentian violet or neutral red, minute and weakly stained granules make their appearance throughout a middle layer of the granular cytoplasm. A thin peripheral layer is free of the granules and this corresponds with the trichocyst-layer. Just beneath the layer are seen granules most densely crowded, transforming into the inner half of the cytoplasm in which more densely stained granules of different sorts can be established throughout. They consists of a small number of larger granules of lighter colour and smaller, more numerous but deeply coloured granules. They are scattered most densely along the surface of the sack pusule and more scantly towards the middle layer.

This characteristic arrangement of the two sorts of the granule is not disturbed immediately after the death of the body nor by the discharge of the sack pusule, which brought forth striking increase in thickness of the granular plasm. This feature suggests high viscosity or rather rigidity of the cytoplasm.

The hyaline cytoplasm is restricted in the midventral part of the body and just along the dorsal of the ventral area, forming a sharply differentiated region which is longer than wide, extending anteriorly beyond the ventral area but posteriorly to the hind end of the flagellar pore and never beyond it. In these species with the bilobed sack pusule, this small mass of hyaline plasm is bordered on its three sides with the wall of the pusule as it lies at the base of the two lobes. In others with the spherical or spirally elongated sack pusule, this hyaline mass is partly or largely contact with the pusule. Presumably in normal and active specimens, this mass of plasm is completely hyaline and free from any trace of granule or vacuole. But in those in which degenerative changes ensue, it is filled with small vacuoles of very weak refractivity. In case the sack pusule vanishes or the body is dying, this mass of the cytoplasm becomes several times larger than the original size, and yet retains its definite surface bordering on the granular cytoplasm. In disregard of this swell- 
ing, fairly strong rigidity of the hyaline cytoplasm can clearly be established by the fact that we can see in its ventral portion a peculiarly diffrentiated structure corresponding exactly in size, shape and mutual relations with the flagellar pore and the collecting vacuole. Further this can be confirmed by an interesting fact exhibited during discharge of the active collecting vacuole, which shall be given in a later paragraph.

\section{Nucleus}

The nucleus is generally of considerable size but not so conspicuous. It is either spherical or more generally oval, and commonly contains numerous, very fine tangled threads, the optical section of which is easily misinterpreted as granular. Among the thread are seen one or more nucleoli. The nucleus is located generally in the dorsal or sinistral part of the body when the sack pusule is smaller. But often it is strongly compressed against the thecal wall when the cytoplasm forms a thin layer and a huge sack pusule occupies by far the central majority of the body.

\section{Pusule apparatus}

The pusule apparatus is characteristic of marine species of the dinoflagellates and was examined so extensively for the first time by Sснӥтт (1892, 1895) that other investigators after him have studied the structure only to verify his account of its characteristic structure. But different investigators have given different interpretations to its functions. And no final conclusion on this contested point has ever been proposed.

The extreme sensitiveness of the dinoflagellates to the slight changes of environmental conditions such as brought forth during collection and examination forces one to examine as fast as possible the normal structures of these delicate inner organellae such as water pusules and general microscopical structures of the cytoplasm. If not examined immediately after the collection, degenerative changes immediately ensue and the inner organellae begin to show abnormal changes.

The study of the water pusules of the dinoflagellates to be given here was carried out in the summer of 1938 at the Misaki Marine Biological Station of Tokyo University. And the collected samples were examined within two hours in order to avoid misinterpretations of structures and functions of the organellae.

It has been generally established that the pusule apparatus of the marine dinoflagellates consists of a sack pusule and a collecting pusule, either of which has a short canal leading to the flagellar pore. Most of former investigators have discussed these two sorts of the pusule collectively without paying due considerations on their morphological as well as physiological differences they exhibit. In contradiction to them, we came to the conclusion that the collecting pusule is morpholologically and functionally different from the sack pusule.

Before going into discussions of these organellae, it may be necessary to give here a brief note on the structural relation of the flagellar pore which has the closest relationship with either of the two sorts of the pusule. 
Flagellar pore The flagellar pore is an ovoidal or elongated depression lying along the bottom of the sulcal furrow. In most species of the genus Peridinium, it is elongated and characteristically twisted, opening in its anterior end obliquely towards the left and in its posterior end directly ventrally. It is not a mere aperture of the thecal wall but has a short canal leading into the body. The side-wall of the canal is built with interior extensions of the right and left sulcal plates, and the canal is, in side view, C-shaped, forming two pits, each at its anterior and posterior end. The anterior pit caves in either straightly or obliquely posteriorly in its distal half, and ends blindly. But the posterior pit differs, opening interiorly directly to the leading canal of the sack pusule. And the major middle portion of the flagellar pore lying between these two pits forms a flat bottom of subequal depth.

Though we cannot establish the point from where the posterior flagellum originates, it can be said with conviction that the transverse flagellum can be traced proximally into the anterior pit. These features were established mainly in $P$. oceanicum.

Sack pusule A smaller or greater central portion of the body is occupied by a sack pusule which shows a fairly wide range of variations in size and shape not only in the genus Peridinium, but also in its allies. Its shape and size are in the main fairly constant not only for a species but also for a group or section of the genus, while its size varies individually and further according to different physiological conditions of a given specimen. Often it disappears completely before or after some degenerative changes. The pusule is globular, ovoid, balloon-shaped, spirally winded or bilobed. And a given group, section or subgenus of the genus is correlated with either of them.

Before going further, it may be necessary to give here brief notes on the sack pusule of the Diplopsalis group, the closest relative of the genus Peridinium. In Diplopsalis globula ABÉ, D. asymmetrica (MANGIN) and D. steiniz ABÉ, the pusule is globular or ovoid, lying mostly in the right half of the body and opens to the flagellar pore by means of a narrow canal of considerable length springing from the ventromedian or dextro-posterior end of the pusule.

The sack pusule of the Humilia group is closely related to that of the Diplopsalis group just given. In P. majus Dangeard of the Globula section, the central majority of its body is occupied with a huge pusule which has, in apical view, a deep notch just at the ventral area in its ventro-modian region. The glanular cytoplasm is pressed against the thecal wall, along which it forms a thin peripheral layer, while the hyaline mass of the cytoplasm occupies the ventral notch of the pusule, lying along the ventral area. And the leading canal of the pusule is very short, passing through this hyaline cytoplasm. The sack pusule of this species may be regarded through hasty observations as flattened globular, but in reality is a modified one of the horse-shoe type because of the fact that its leading canal springs asymmetrically from its right lobe. 
This relation can be established more clearly in P. sphaeroides DANGEARD of the same group. The pusule in this appears as if reniform in apical view, but is in reality twisted horse-shoe shape, with its right lobe extending obliquely in antero-ventral direction. A short leading canal springs from the dextro-posterior portion of the pusule.

In $P$. yonedai n. sp. of the Pyriformia group of Protoperidinium, we have been able to verify almost every detail of KofoID's accounts (1908) given for the sack pusule of Diplopsalopsis steinii. In this, the pusule is asymmetrically bilobed, consisting of a smaller left and a larger right lobes, either of which extends obliquely in anterosinistral direction. This corresponds exactly in structural relations with that of $D$. steinii illustrated in Fig. 9 (plate 2) of Korom, but differs from that given by HAYE (1930). The leading canal is short and thick, and this U-shaped pusule is not compressed dorso-ventrally in any point. There observed an optical dorso-ventral section of the bridge connecting the two lobes, where it opens by a short funnelshaped canal leading ventrally to the flagellar pore.

The organelle of $P$. spheroidea ABÉ belonging to the Parapellucida section of the Pellucida group, is much simpler in structure, resembling that of the Diplopsalis group but rather more closely to that of the Paradivergentia group of the subgenus Mesoperidinium. It is balloon-shaped, lying entirely within the right half of the body. It is elongated longitudinally, contracting towards the opposite direction to form a funnel-shaped canal leading to the flagellar pore.

In the subgenus Mesoperidinium, a shorter or longer balloon-shaped pusule is established, lying in the right half of the body. In P. crassipes, the pusule is globular or nearly so, and its short leading canal is more or less abruptly differentiated from the sack springing from its ventro-posterior end. That of opening is much smaller, tapering postero-ventrally to a fine leading canal of considerable length. A large and remarkably elongated pusule is seen in $P$. grande in which it is subject to individual variation in size and elongation. In some it is banana-shaped lying mostly along the dextro-dorsal side of the body and extends anteriorly to the antero-median part of the body. But in some others, it extends further towards the left and almost to the sinistral end of the body, forming an ascending spiral tract. Often this pusule bulges anteriorly in its middle, extending into the apical horn.

In general, the pusule of the other subgenus, Veroperidinium, is fairly simple in structure. That of $P$. excentricum is small globular, but that of $P$. pentagonum GRAN is ovoid and its short leading canal is subterminal. On the other hand, $P$. oblongum, $P$. oceanicum and their allies have similarly a large, horse-shoe shaped or bilobed pusule, flattened in dorso-ventral direction. It occupies by far the major central portion of the body, and the cytoplasm is then more or less strikingly compressed against the thecal wall. In some extreme cases, the pusule is so great in size in ventral view that the cytoplasm forms a thin film along the thecal wall except at the three apical and antapical horns. The leading canal is subterminal, springing from the right lobe of the pusule. The Oceanica section to which these species are 
allocated is closely related to the Diplopsalis group regarding the sack pusule.

On the basis of these structural differences given above, the sack pusule is divided into two types, one with a terminal and the other with a subterminal leading canal. In other words, the pusule of the genus is elongated either towards one direction opposite to the leading canal forming the elongated form or towards two directions opposite to each other bringing forth the bilobed pusule. The elongated form is seen in the two groups of Mesoperidinium and the Parapellucida section of Protoperidinium, all of which are furnished similarly with an asymmetrically expanded posterior sulcal plate. The bilobed pusule is established in the Humilia and Pyriformia groups of Protoperidinium, and is developed most highly in the latter group of them. The sack pusule of Veroperidinium is intermediate between them in this regard. It is generally ovoid and not bilobed but has a subterminal leading canal. The Oceanica group of the subgenus exceptionally has a typically bilobed pusule. It is interesting to describe that the posterior sulcal plate in Protoperidinium is interrupted on either side from contact with the ventral postcingular plate, while in Veroperidinium, it borders on either side directly on the postcingular plate. If the major case of Veroperidinium is distinguished from the typically bilobed form, we have then three forms of the sack pusule, which are coupled respectively with the three forms of the posterior sulcal plate. In any of them, highly differentiated types may be derived from a simpler form which is common to the three forms and can be sought in a globular sack pusule established in some of them and also in the Diplopsalis group. A parallel relation is clearly established between Blepharocysta and Podolampas of the Subfamily Podolampinae. In the former genus, the sack pusule is globular, while in the latter, it is balloon-shaped.

Whether or not the sack pusule communicates with the apical pore by a canalicule is an interesting but still unsolved question. We can see in apical view of the body a minute pore at the distal end of the apical horn, and from which a delicate canalicule can be traced for a short distance. But the fate of this canalicule has not been established. With the intention to solve this question, we contrived to see if there is a fine canalicule extending anteriorly from the pusule into the apical horn. In most cases the efforts were in vain. But in a single case, a short and fine canal-like extension was observed at the antero-dorsal end of the pusule in P. oblongum. Between this and the apical pore is seen a bundle of fine striations. But we are not conclusive as to their direct communication.

That the sack pusule communicates with the hind end of the flagellar pore by a shorter or longer canal of considerable diameter was established in all the species examined. This leading 'canal is in all cases oblique in direction of extension, as it can be traced from the flagellar pore obliquely towards the right or dextroanterior direction.

Along the surface of the sack pusule, KoforD (1909) saw 'a sharply defined plasmal wall'. And HAYE (1930) had also a similar conclusion. According to the latter author, "..., um der Wand der Pusule, welche ziemlich dick und schwarz gefärbt ist, liegt einer Plasmazone von dunklerer Färbung also die des übrigen Plas- 
mas. Diese Zone häuft sich besonders in den Einbuchtungen an." and further "..., sicht man deutlich, dass dieses Plasma von dichterer Konsistenz ist als das übrige Plasma." However, in almost every case a very thin, hyaline layer over the surface of the pusule was found. And this layer has a considerable thickness around the inner opening of the funnel-shaped leading canal and along the wall of the canal itself. In Oceanica and Conica in which the canale is fairly short, fine striations were very often seen arranged along the hyaline wall of the pusule and radiating dorsally from the inner end of the posterior pit of the flagellar pore. In the portion where these striations are seen, the pusule wall is fairly tough and elastic, and appears as if it consists of a rigid membrane. The striations are often due to wrinkles of the pusule wall itself. This suggestion is supported by another fact. In contriving to separate the sulcal plates from the body content in order to examine the plates, a block of these sulcal plates were often seen around the vental area stuck so firmly on the ventral surface of the content that the attempt was utterly in vain with all our efforts and contrivances.

Even when the cell was crushed, the sulcal plates were still sticking to the cell content and never detached. Repeated and careful observations lead us to establish that the interior extension of the flagellar pore is deeply inserted into the cell. These repeated experiments lead us finally to the conclusions that the sticking is so firm that the interior extension is formed only along the side-wall of the shallow excavation of the pore and that there must be some structures firmly connecting the side-wall of the excavation with the interior of the cell content. Fortunately, we had an observation answerable to the above expectation. In a single case of $P$. conicoides, a wrinkled bundle of extremely thin and hyaline membranes is still sticking partly into a bared mass of the cell content, when we succeeded in drawing apart for a short distance a block of the ventral thecal plates including the sulcal ones. The wrinkled membrane was seen springing from the interior edge of the flagellar pore, and its other end was still buried in the bared mass.

From these considerations and observations, it can be concluded without uncertainty that the sack pusule has, at least in its larger or smaller proximal portion, a definite and rigid membrane which becomes thicker towards the flagellar pore. The thickness of this membrane varies apparently not only in different parts of a single pusule but also between different individuals of a single species and further between different species. If the pusule is deprived of its rigid surface membrane it has to take a spherical form. But the pusule has often uneven surface when the cytoplasm is filled with more or less larger granules. This, however, does not necessarily indicate development of the solid membrane all over the pusule surface. The pusule actually changes its size and shape, and often disappears. When it vanishes, a faintly striated structure can be traced often for a short distance extending dorsally from the flagellar pore. But no trace of the distal major portion of the pusule remains. This probably suggests posterior restriction of the rigid membrane.

The fluid filling the pusule is in any case completely free from any solid particle and appears to have a rosy tint. In connection with this, there arose a question 
as to the origin, nature and fate of this fluid, which shall be discussed in the next paragraph.

When a specimen of $P$. spinulosum was rolled around its body axis under the coverglass, the pusule collapsed almost completely at the moment when the body was compressed bilaterally. At this moment, the entire length of the pusule including the leading canal was represented by a fine canal-like structure. At the next moment when the body was rolled further on, the pusule regained its original size and shape. And the pusule fluid has again a rosy nuance, just as that seen before the collapse. The flagella regained their activity. From this, we are informed undoubtedly of the facts that the pusule has some sort of value or similar structure to regulate inflow or discharge of the fluid, that the content is nothing but the sea water taken in through the flagellar pore, and that the rosy nuance the content display is at least partly due to some other causes, such as refractivity and interferences of light, or more probably due to the thick layer of the cytoplasm through which one examines the pusule. The suggestion given last may be supported by the fact that when the huge pusule occupies by far the major portion of the body and the cytoplasm forms an extremely thin outer layer, the pusule is always colourless or almost nearly so. From these given above, one can conclude that the content of the pusule can easily alternate with the sea water without distinct changes of its chemical nature and presumably the vitality of the body itself as well.

The size of the pusule be in the normal specimen appears to fairly constant and characteristic to a certain degree for a given species, but varies distinctly within a single specimen in case the body was subjected to abnormal conditions such as caused by light, temperature or salinity or physical disturbance of the sea water in which it lives. The pusule of $P$. oblongum had already vanished in the major specimens examined when they were collected in a stormy weather. The cytoplasm was seen to shrink away from the thecal wall to form a globular mass, and the central major portion of the mass is filled with hyaline substance. The granular cytoplasm which is very thin in normal specimens is in this case considerably thickened. No trace of the pusule membrane remained between the granular and hyaline zones. Some of these specimens were stained with neutral red to the result suggestive of no trace of degeneration leading to death. The same suggestion may be true regarding the change of salinity of the sea water. If the salinity of the sea water in which the organism lives was lowered or when the organism was drifted into such water, it can regulate the size of the pusule by osmosis and sink further into a deeper level of higher salinity.

The peripheral and subsulcal differentiation of the cytoplasm still remains, each of which retains characteristic structure but apparently swells distinctly. That liquefaction of the cytoplasma is not occurring can be established by the fact that the individuality in relative size and extent of the two sorts of the cytoplasm is still retained and that the traces of the collecting pusule and the flagellar pore can clearly be established in the ventral depression of the plasmic mass, exactly corresponding to that of the thecal wall. All these facts just considered apparently point 
to the fact that the pusule vanished by discharging its content, that the space preoccupied by the pusule content was filled at least for the majority by swelling of the cytoplasm and that the whole mass of the cytoplasm decreased its volume but inversely increased its specific gravity by sacrifice of the pusule content. Thus, by increasing the specific gravity of the body in the case of the stormy weather as in some other unfavourable conditions, these organisms can sink into a deeper level to get rid of the disturbance of the sea as far as possible leading to the destruction of the body and to final death.

One has to recollect here the fact that the surface of the sack pusule is, on the one hand, covered for the major portion with the granular cytoplasm and on the other hand has a more or less closer relationship with the differentiated sub-sulcal mass of the hyaline cytoplasm. In species with the bilobed or U-shaped sack pusule, the two lobes border directly on this hyaline mass of the cytoplasm, which, as shall be discussed in later paragraphs, is clearly associated with the excretory function. If this relationship between these two organellae is established more or less clearly in regard to the two other types of the sack pusule, one would naturally be led to suggest that the sack pusule takes part in the excretory function.

From these observations and considerations given above, we have been led to the conclusion regarding the function of the sack pusule that the organelle changes its size presumably regulating buoyancy of the body, and is indirectly associated with the excretory function. This suggestion is based mainly on morphological facts, and is therefore not conclusive. But there is another fact lending support to this view. The sack pusule, filled with sea water and occupying more or less larger portion of the body content, lies exclusively or at least for the major portion in the right half of the body in all the species and genera examined. If this sack pusule acts weakly or strongly as a buoy, the body may be thrown into a slightly tilting posture with its right side higher than the other. This is the case actually seen in nature either in floating or swimming of the organism so far as the observations on actively swimming organisms inform us. The organisms swim in typical cases upwardly along a left-hand spiral in a posture with their right shoulder elevated slightly above the other. This tilting posture may also be correlated with the bilateral asymmetry of the body, most of the dinoflagellates display. In case the apical horn is elongated, it curves or bends always towards the right but never towards the opposite direction. And in case the epitheca is conical, its right side is always more strongly concave than the other and its short apical process inclines in like manner towards the right.

In regard to the function of this organelle, Koforv (1909) suggested that water and nutrient pass through the pusule wall into the cytoplasm to form the so called daughter vacuole which discharges its content peripherally by passing through the cytoplasm. His presumption has, however, no trustworthy observational basis. Much earlier than him, ScHÜTr $(1892,1895)$ conjectured that the pusule is a pulsating vacuole. Following him, HAYE (1930) regarded the pusule as 'eine Art Exkretionsorgan', basing only on its histological study, and suggested homology of its 
surface layer with the 'Exkretionsplasm' established generally in the protozoa. KoFOID (1908) and HAYE (1930) are then opposed to each other in regard to the function of the organelle, the former regarding it as of absorbing and the latter as of excretive function. As was given above, we have been led to the conclusion parly conforming KofoID's suggestion and partly disagreeing with either of the two.

Collecting vacuole In the ventral median portion of the body and just anterior to the flagellar pore is a small vacuole with a fine, short duct leading posteriorly to the anterior pit of the flagellar pore. ScHütz called this a "collecting" pusule, and the other investigators followed him. Around this are closely arranged minute vacuoles, and similar but somewhat larger vacuoles are seen scattered throughout the general cytoplasm. KoFoID (1905) called them collectively a "daughter pusule". But they differ from each other morphologically and physiologically and hardly comparable with the sack pusule because of their evanescent character. Therefore, these two sorts of evanescent structures might better be classed as vacuoles than as pusules. Consequently, we would limit, in contradiction to Koford, the use of the word "daughter vacuole" to those having a definite limitation of emergence around the main collecting vacuole.

Contrary to the polymorphic sack pusule, this collecting pusule is fairly constant in form and structural differentiation not only throughout the genus Peridinium, but also in some of its allied genera.

The pusule or more exactly vacuole is globular, ovoidal or irregularly balloonshaped, inclining or elongating more dorsally than ventrally, and opens by a short and fine canalicule leading to the anterior wall of the anterior pit at a short distance from its bottom. The vacuole continues to regain a rounded contour so long as the organism is active, but becomes rugged as soon as degenerative changes ensue, and disappears earlier than the sack pusule. Long continued observations informed us of the fact that the vacuole changes its size very slowly from time to time. When the vacuole vanishes, there remains a hyaline and lighter area, corresponding in size and shape with the swollen vacuole but distinguishable from its surrounding cytoplasm. This leads us to suggest that the vacuole has no rigid membrane but is surrounded with highly specialized plasm of high rigidity, through which more liquid substance may flow out to fill the space of the contracted vacuole. This suggestion may be supported by the fact that during the course of collapse of the vacuole we can see for the first time a hyaline lighter layer around the vacuole and then increase of its thickness from around to fill finally the space, preoccupied by the vacuole.

This vacuole is closely crowded with minute daughter vacuoles of high refractivity. They are more closely arranged anteriorly than posteriorly. And often one side (right) or ventral and dorsal ends of the main vacuole are left free from them. They are either balloon-shaped, tapering towards the surface of the main vacuole or spherical with extremely fine canalicules converging also towards the same direction. Different forms of this daughter vacuole are seen generally between different specimens but often within a single one. Actual communication of the 
daughter and the main vacuoles was not established but is highly probable. Though it was not possible to trace the entire course of the contracting movement of this daughter vacuole on account of slowness of the process, repeated and long continued observations led us to the conclusion that an extremely fine, spherical vacuole makes its appearance just on the surface of the main vacuole or at a short distance from there, and grows larger very slowly. Then, there develops a fine canalicule which grows longer, and the daughter vacuole becomes balloon-shaped. And finally the daughter vacuole becomes thinner slowly and vanishes at the end.

We never met a case in which a minute vacuole migrating through the cytoplasm reaches the main vacuole. It is hardly probable even to think of it, because the dauthter vacuole can be seen exclusively within a thin layer of a definite thickness lying around the main vacuole, and not a single vacuole of high refractivity can be established beyond it. From this it can be concluded that the dauthter vacuole is formed within a thin granular layer of cytoplasm lying around the collecting vacuole, and never passes through the cytoplasm as had been suggested by KoForD (1909). In one case a bacterium was found swimming actively to and fro within the collecting vacuole. This, together with other facts mentioned above, suggests free communication of the main vacuole with the flagellar pore allowing inflow of sea water.

That the activity of the collecting and daughter vacuoles depends only on the physiological conditions of the body and not in the least on some physical effects exerted from outside of the body, may be suggested by the fact that contrary to the collapse of the sack pusule, these evanescent vacuoles do not vanish nor become smaller when the body is compressed from above the cover glass. Regarding this, one has to recollect in mind that these vacuoles vanish before some other degenerative changes can be established.

The collecting pusule is thus hardly comparable morphologically and functionally with the sack pusule. The restriction of the daughter vacuole only around the surface of the collecting vacuole, and the extremely slow change or movement of the daughter vacuole clearly point to the conclusion that the collecting and the daughter vacuoles are certainly an excretory organ. From these, we are led to suggest that there is a differentiated layer of plasm around the collecting vacuole, homologous with the excretory cytoplasm surrounding the contractile vacuole of other fresh water protozoa, and in this layer situated closely to the wall of the main pusule is formed the daughter vacuole which discharges its content into the collecting vacuole, driving the fluid from its surrounding plasm, and further the collecting vacuole discharges its fluid through the leading canal into the anterior pit of the flagellar pore, partly by means of its slow contracting movement and partly presumably by negative pressure which may be caused and strengthened by the active movement of the flagellar springing from the anterior pit.

It may be interesting to note that the transverse flagellum is then associated with the excretory function of the body, springing from the anterior pit of the flagellar pore, and the longitudinal flagellum is associated with a certain other func- 
tion, probably regulating the buoyancy of the body but morphologically correlated, probably, with the posterior pit of the flagellar pore. The two flagella in the dinoflagellates, as has generally been established, have different functions, one driving the body forwardly and the other around the body axis, and cooperate in driving the body along spiral course. At the same time, two currents of water caused by them help, thus respectively or co-operatively, to strengthen the two different but partly associated functions occurring within the body.

So-called accessory and daughter pusules The emergence of the so-called "accessory" and "daughter" vacuoles described by Kofom on P. steinii is apparently due to degenerative changes, judging from the shrinkage of the outer plasmic zone away from the thecal wall, which is caused by some abnormal conditions, brought forth during observation under the microscope.

So far as our observations on $P$. oblongum indicate, some small vacuoles can be established in the outer plasmic zone, and they increase in size and become more numerous as the observation goes on. In the presumably normal specimen when observed immediately after its removal from the sea, there can be established a few vacuoles only in the outer zone which is fairly granular. And these vacuoles are less refractive than the daughter ones sticking to the collective vacuole, and are either arranged mostly peripherally along the striated surface layer filled with the trichocyst, or distributed evenly through the entire thickness of the outer zone. The discharge of their contents peripherally, as presumed by KoFord, seems to us to be hardly possible, judging from their interruption by the thickly striated surface layer from contact with the peripheral fluid zone, which is in reality a degenerative product. Any fact suggestive of their centrifugal migration or increase of their sizes peripherally was hardly be ascertainable. On the other hand, the differentiated sub-sulcal mass of the hyaline plasm surrounding the collective vacuole is, in most of the presumably normal specimens, entirely free from any granular or vacuolar inclusion. But in those in which degenerative changes ensue, there begin to emerge minute vacuoles of weak refractivity, which are seen growing larger in our observation. And yet, they can be distinguished at once from the daughter vacuole by its different refractivity. In some species such as $P$. yonedai $n$. sp. and Diplopsalopsis asymmetrica (MANGin), we often saw in the outer plasmic zone many large vacuoles, several times larger than the collecting vacuoles. In these cases, no trace of degenerative change could be established.

All these facts considered above point out to the conclusion that the so-called daughter vacuole is to be regarded at least partly as a normal morphological constituent of the outer-plasmic zone, and it grows larger and more numerous as the degenerative changes and liquefaction of the plasm ensue.

\section{Major thecal characters}

\section{Form of the body}

The genus, displaying a wide range of variation in regard to the form of the 
body, can be divided into two types, one with globular or pyriform and the other with biconical.

An almost perfectly spherical body bearing a minute and abruptly differentiated apical prominence, from which other, more or less highly differentiated forms can be derived, is seen in some of the Humilia, Pyriformia and Pellucida group of Protoperidinium and the Monovela group of Veroperidinium. But in most of the others, the transition between the apical elongation and midbody is less abrupt, bringing forth a pyriform body. Generally a stronger elongation of the apical horn is coupled with longer antapical spine, but the reverse is not necessarily followed. In a few species of the Humilia and Pellucida groups, the thecal wall bulges slightly at the base of the spine to form a minute conical elevation. This structure is particularly distinct exceptionally in $P$. granii of the Humilia group. A corresponding but much distinct structure is established generally in the Divergentia group of Mesoperidinium. The fresh-water species may be comprised mostly in this globular type, though their epitheca is often distinctly conical. Some of the Avellana group of Veroperidinium form a connecting link between the two types because of the cingular bulge of their thecal wall.

The typical biconical form is seen in $P$. biconicum of the Conica group and in $P$. punctata $(=P$. abei) of the Avellana group of Veroperidinium. As a result of dorsal extension of the sulcal furrow beyond the antapex, the postero-median indentation of the body is brought forth. Such is the case invariably in all the species of the Conica group, in which the magnitude and breadth of the indentation are highly various, bringing forth remarkably polymorphic forms, ranging from a lenticular to a pentagonal or star-shaped ones. The two antapical horns in the Divergentia group of Mesoperidinium is formed mostly in this manner, but smaller or larger distal ends of them extending beyond the posterior sulcal plate have hardly any relation with the sulcal furrow. The shorter or longer antapical horn established invariably in the Oceanica and partly in the Divergentia group may be one corresponding in structure to the conical antapical bulge of $P$. granii.

Along the girdle the thecal wall bulges more or less remarkably in the major species of the typically or modified biconical type, particularly distinctly in some of the Divergentia and Oceanica groups, such as $P$. crassipes, $P$. elegans and $P$. depressum. When this cingular bulge of the thecal wall is coupled with variously formed tilt of the cingular plane, remarkable variation in the form in ventral view of the body is brought forth.

In the majority of the species, the ventral side of the body is weakly or strongly flattened by means of the ventral depression in which the sulcal furrow is formed. In the extreme cases, the cingular section is sickle-shaped with a broad and deep triangular indentation on the ventral. Such is the case with $P$. elegans of the Divergentia or $P$. sinuosum of the Conica group. Unusually strong dorso-ventral compression of the body is seen in $P$. compressum of the Perrieri group of Veroperidinium. In many species of the Humilia group, the body is flattened more or less remarkably in the axial direction. This is particularly distinct in $P$. monacanthum in which the body is discal. A similar compression is seen also in $P$. excentricum of the Perrieri 
group.

From these considerations given above, it is clear that the major thecal characters having marked influences on the form of the body are the apical and antapical extension or elongation, thecal bulge along the girdle, tilt of the cingular plane, ventral depression and flattening of the body in either direction.

\section{Girdle and its distal displacement}

The girdle encircles the body along its largest portion, and is either equatorial or pre- or post-equatorial, and it is intercepted at the mid-ventral by the ventral area. Its two ventral ends, often lie symmetrically but in the major species asymmetrically, forming an ascending or descending spiral. Coupled with diagonal extension of the ventral area, the two ends often overlap each other. It is guarded on either side by a cingular list and has a flat or concave wall, forming a cingular furrow. Its width appears subequal throughout the entire length, but in reality decreases very gradually from its proximal (left ventral) end towards its distal (right ventral) end.

Lying more or less asymmetrically on either side of the sulcal furrow, the two ends of the girdle have different relations with it. In some of the fresh-water species particularly of the Tabulata section, the left edge of the furrow is distinctly diagonal instead of longitudinal for a considerable length in the portion lying between the two ends of their remarkably descending girdle. By means of this, the sulcal furrow merges into the indented proximal end of the cingular furrow, or in other words, the flagellar pore is connected with the proximal end, while the distal end of the cingular furrow is hardly indented and sharply differentiated from the sulcal furrow by a ridge. Exactly corresponding structural relations can be established also in the Avellana group. But in this case, the diagonal edge of the furrow is very short, lying just at the proximal end of the girdle. In all of the other groups or species examined, this diagonal ridge is invariably formed independently of the types of the distal displacement of the girdle. By means of this, the proximal end of the sulcal furrow increases its width towards the sulcal furrow, the former merging into the latter in regard to their depth. The cingular furrow itself is almost subequal in depth and width throughout its major length, but is less indented in its distal quarter. And its distal extremity is partly constricted from the sulcal furrow by a minute jut of the right ventral precingular plate, springing from its postero-median end.

The distal displacement of the girdle has long generally been regarded as of taxonomic importance by most of the former investigators. This structure serves in the characterization of groups. On the other hand, it has been more clearly established that the distal displacement is in many cases subject to individual variation in regard to its magnitude. And in addition, so far as our study reveals, even the type of the displacement varies in some cases.

There have generally been established three types of the distal displacement, 
one with circular and the other two with spirally wound girdle. In the case of the so-called circular girdle, we have hardly saw a case in which the two ends of the girdle are exactly symmetrical. It is due partly to the distal constriction of the girdle and partly due to the diagonal edge in the proximal end, by which a slight difference in the width of the two ends of the girdle is brought forth. Even when the anterior cingular edges of the two ends are symmetrically arranged, the proximal end of the posterior cingular edge is displaced more posteriorly than its distal end. Furthermore, the postero-median jut of the right ventral precingular plate varies in size and length not only between different species but also within a single species. And often an exactly corresponding structure is formed also at the proximal end of the girdle. We are liable to be led to misinterpretation about the exact type of the cingular displacement in case the two ends are arranged more or less symmetrically.

If we disregard these trivial differences, we are often puzzled about a varying distal displacement. In $P$. rhomboidalis $\mathrm{n}$. sp. the girdle is obviously circular in some, clearly ascending in some others and often distinctly descending. The ascending girdle in this case is correlated with asymmetrical posterior expansions of the two ventral precingular plates. In spite of symmetrical expansion of the two plates, the girdle often forms a descending spiral by means of its proximal arch, limited mostly in its first quarter.

The type of the distal displacement appears to be correlated with the symmetrical or asymmetrical posterior expansion of the two ventral precingular plates, in other words, with the lengths along which the two plates extend beyond the ventral apical plate. This is actually the case only when the hind end of the ventral apical plate is transversely truncated. The hind end of this, on the contrary, is often diagonal to either direction in $P$. crassipes and $P$. depressum, bringing forth some variations in the magnitude and type of the distal displacement.

All of these discussed above, in which certain magnitudes of the characters have effects upon the type of the distal displacement of the girdle, are concerned with the circular or subcircular girdle. Regarding this, it may be concluded then that the distal displacement of the girdle varies, when it is slight, from one type to the other, that the so-called circular girdle is a character, not yet firmly established and still displaying a lingering variation, and that the type of the displacement may be exactly defined in the case of a single individual but not so in a given species without thorough examinations over fairly large number of its specimens.

A more or less strongly descending girdle is coupled generally with a narrow and distinctly indented sulcal furrow, as is seen generally in the Divergentia, Tabulata, Avellana and Oceanica groups. The sulcal furrow extends anteriorly for a considerable length beyond the proximal end of the girdle in some of the second, but hardly beyond it in the third group. And the others are intermediate between them. In this case, the sulcal furrow merges into the proximal end of the cingular furrow but is sharply differentiated from its distal end which opens normally to the sulcal one. A fairly remarkable variation in the amount of the distal displacement is also seen in this type, but the amount is always not so great as to alter the type of 
the distal displacement.

The differentiation of the distal end of the girdle from the sulcal one is generally much less distinct in the case of the ascending girdle which is wound most strongly in the Globula section of the Humilia group. In the section, the girdle is least indented, forming a strikingly ascending spiral of more than one turn around the body. The distal end of the girdle makes then an acute angle with the ventral area which is somewhat diagonal particularly in its anterior half.

In the case of the typically circular girdle, it may be regarded as lying every point along a flat plane. But when the girdle forms an ascending or descending spiral, it runs partly out of the plane. In either case, the portion deviating from the circular course is rarely at the two ventral ends but generally at the proximal part of the girdle, which bends invariably posteriorly but never anteriorly, thus bringing forth a stronger or weaker ventral or distal arch of the girdle. In any case, the proximal arch is much more distinct than the distal one, and is particularly remarkable in $P$. crassipes, $P$. depressum, $P$. pentagonum and some others. By means of this asymmetrically formed ventral arch, the distal displacement or the ventro-median deviation of the girdle from the cingular plane has no great influence upon the ordinary course of the girdle. In such an extremely ascending spiral as seen in some of the Globula section, the deviation is limited within a ventral half of the cingular plane, the other forming a typical plane.

The cingular wall is either flat or concave, presumably according to weaker or stronger indentation of the sulcal furrow. In case of the indentation, the furrow thus formed decreases in its depth gradually from its proximal end towards the distal end. The cingular list, lying along either side of the girdle, also decreases in its breadth in like manner. This list has generally a close set of ribs along its outer surface. Consequently, its inner surface facing to the girdle is smooth. The two cingular lists, thus standing parallel with each other, have generally smaller thickness along their free margins, towards which they often converge but never diverge.

\section{Types of the antapical appendage}

The most prominent feature by which the hypotheca is characterized may be sought in the antapical spine or horn. Fither of them had been regarded by former investigators as of taxonomic importance. Since JörGENSEN (1913) proposed a new principle of subdivision of the genus, basing on different combinations of the plate patterns of the epitheca, the hypothecal feature was not so much estimated as before. This is partly due to the wrongly prevailed consideration that the antapical spine is remarkably subject to seasonal, local and also individual variations in length and development, and more clearly partly due to the fact that exact and detailed structures of the spine and its side-wings have not been studied so suffciently as to serve for its subdivision.

To study and discuss the structures alone are almost fruitless if due considerations were not given for other structures so closely related with it that they cannot 
be discussed separately or independently from the spine or horn. Such are the ventral area and the sulcal list. Although accounts on the ventral area will be given in the later paragraphs, the sulcal-list cannot be discussed separately from the antapical spine.

The antapical appendage can be divided into three types, one represented by the spine and its side-wings, another with the horn and the other with both of them.

Spine or wing-complex The antapical spine and its side-wings, more or less closely connected with the sulcal list but distinct from the antapical horn, are characteristic mainly of Protoperidinium and partly of Mesoperidinium, and can be divided on the basis of their structural relations or differentiations into several subtypes, ranging from a solitary spine to a highly advanced wing-complex closely connected with the left sulcal list.

In the first (Heteracantha) sub-type, two sulcal lists are formed along either side of the ventral area, and the left of them has a rib in front of its hind end, not much extending beyond the list. Such is characteristic of $P$. curvipes and its allies of the Himilia group.

In the second (Monacantha) sub-type, a single solitary spine is seen standing independently from either of the two sulcal lists and on the right antapical plate. Such is the case with $P$. monacanthum and $P$. subcurvipes belonging to the Monacantha section of Humilia.

Two short spines are in the third (Laterispinosa) sub-type, separated for a short distance from the hind end of the ventral area, springing respectively from an antapical plate. In some species, such as $P$. incurvum, $P$. finlandicum and $P$. pedunculatum, the thecal wall bulges slightly at the base of the spine to form a minute conical process, which is particularly distinct in $P$. granii in which this structure is highly variable in size.

These two spines are set, in the fourth (Bispinosa) sub-type, closely by the sulcal list, from which they are distinct. Among the recorded species $P$. ovatum, $P$. lenticulatum, $P$. ventralis and $P$. sphaeroides are deemed to bear the antapical spine of this sub-type.

In all of these four sub-types given above, the antapical spine is fairly short, discussed bearing in most cases hardly developed narrow side-wings. But in the three to be discussed below, the antapical spine is longer and furnished with well-formed three side-wings, forming a wing-complex, and is connected directly or indirectly with the sulcal list. Morphological account of this wing-complex was fully given for the first time by Koford (1909) on P. steinii and by the author (1936) on P. pyriforme.

The ventral and dorso-median side-wings of the spine in the fifth (Pyriformia) sub-type stand basally along the very edge of the ventral area, while the other lateral one extends laterally, standing basally on the antapical plate. The ventral one in the left wing-complex forms, together with a posterior continuation of the proximal part of the posterior cingular list, the broad left sulcal list. On the other hand, that in the other is generally interrupted at the postcingular-antapical 
suture from the posterior continuation of the distal end of the cingular list. In addition to $P$. sieinii and $P$. pyriforme, $P$. oviforme, $P$. sylvanae and $P$. longicollum are allocated to this sub-type.

A similar but slightly different relation is established in the sixth (Pellucida) sub-type in which the left antapical wing-complex or rather spine is connected transversely with the left sulcal list by a small side-wing of the former. The spine stands on the left of the hind end of the sulcal list, most of the former investigators have misinterpreted them in ventral view of the body as two distinct spines or the spine bearing an accessory one. The spine of this type is seen in $P$. sphaeroides, $P$. schilleri and some others.

All of these six sub-types are correlated with a type of the posterior sulcal plate, interrupted on either side from contact with the ventral postcingular plates, and are characteristic of Protoperidinium. But in the seventh (Paradivergentia) subtype, the well-formed left antapical wing-complex is completely separated laterally from the left sulcal list by the asymmetrically elongated posterior sulcal plate, which extends with its left lobe to the left ventral postcingular plate. The spine of this type is seen in $P$. okamurai and $P$. longipes belonging to Mesoperidinium.

It has been generally believed that the antapical spine is a support for the sulcal list, originating independently of the hollow horn, as described by BARrows (1918). Contrary to this, the facts given above led us to a somewhat different conclusion. It may be allowed to suggest that if the higher sub-types of the spine may be ones derived from some of the lower sub-types, they can be traced to two origins, one represented in the first and the other in the second or third sub-types. In other words, the antapical spine directly connected with the sulcal list such as seen in $P$. steinii and its allies is regarded as derived from the rib of the sulcal list, but that standing separately from the sulcal list as established in $P$. schilleri or $P$. longipes is originated from a spine formed independently of the sulcal list.

Antapical horn bearing a distal spine A small conical bulge of the thecal wall at the base of the antapical spine is seen exceptionally in connection with the third sub-type, but more often in the sixth sub-type, particularly in P. pellucidum and $P$. pallidum. A much larger conical bulge is formed invariably in the Divergentia group of Mesoperidinium, in which the spine is less evolved but more strongly separated from the sulcal list than in the Paradivergentia group. In these cases, the spine is coupled with the hollow horn and they are formed independently of the ventral area. And these two structures are inversely related with each other regarding their length and build. A smaller conical bulge is furnished generally with a longer and well-formed wing-complex while a larger one with a less evolved spine. And in an extreme case, the antapical horn is fully formed without bearing a distal spine. In $P$. pellucidum and $P$. pallidum, the antapical conical bulge is very small in size while the wing-complex is fully formed. Either of the horn or wing-complex is of considerable length in $P$. solidicorne. In $P$. crassipes, $P$. adriaticum and their 
allies, the antapical horn is fairly well-formed while the spine is much shorter and its side-wings are hardly formed. A distal half of the antapical horn in $P$. grande is covered with many distinct longitudinal ridges, which are apparently morphological equivalents of the side-wing of the antapical spine. This suggestion is based upon the fact that the side-wings or side-ridges of the antapical spine in $P$. crassipes and its allies can be traced basally to the polygonal meshes covering the antapical plate. These longitudinal ridges are seen also in $P$. fatulipes but are less distinct, and fail to develop entirely in $P$. elegans. The antapical horn is longer in the order of $P$. crassipes, $P$. grande, $P$. fatulipes and $P$. elegans, and it is elongated finger-shaped in the last species of them as in P. oceanicum and its allies. All of them are so closely related to one another regarding the structural differentiation of their ventral area that they are allocated collectively in this paper to the Divergentia group. Further, among them, the latter one is a higher type than its preceeding one regarding the same structure. From these it is clear that the antapical horn of $P$. elegans is derived from the horn bearing a distal spine such as seen in $P$. crassipes or $P$. solidicorne.

From these it may be allowed to suggest, opposing Barrows' conclusion, that the antapical hollow horn in the genus Peridinium, is at least partly directly derived from the conical bulge of the thecal wall at the base of the typical antapical wing-complex, and that the horn might have grown longer in the course of its phylogenetical development by sacrifice of the antapical spine standing at its distal end.

Antapical horn The antapical horn of $P$. elegans is covered partly in its basal median portion with the posterior sulcal plate, but that of $P$. oceanicum and its allies differs in its sharp differentiation from the ventral area. In this regard, the antapical conical bulge of $P$. pellucidum and $P$. pallidum may be related more closely to that of $P$. granii and its allies than to $P$. crassipes and its relatives.

In $P$. oceanicum and its allies, the sulcal furrow is sharply differentiated as considered just above from the base of the antapical horn. But owing partly to much advanced differentiation of the flagellar furrow from the sulcal furrow in $P$. crassipes and its relatives, which shall be fully elucidated in later paragraphs, the sulcal furrow of them is inversely less differentiated from the general thecal surface and also from the base of the antapical horn. Consequently, in this case the indented posteromedian margin of the body formed by the sulcal furrow lies, partly or mostly along the median base of the antapical horn.

Next, the horn extends partly or mostly beyond the sulcal furrow. In other words, the antapical horn of the former type is covered exclusively with the antapical plate, while that of the latter is covered partly with the posterior sulcal plate and mostly with the antapical one. For the sake of brevity we shall call that of the former type 'typical or simple horn' and that of the latter 'semisulcal horn'.

Differing from either of them, the conical antapical horn of $P$. conicum and its allies is covered along its entire median half with the posterior sulcal plate, which 
extends invariably to the pointed tip of the horn. The conical horn of this does not extend beyond the sulcal furrow. In what follows we shall call this 'pseudomorphous horn'.

The typical horn is covered exclusively with the antapical plate. The semisulcal horn, on the other hand, is formed partly by the bulge of the antapical plate and partly by the dorsal extension of the sulcal furrow. The pseudomorphous horn is to be regarded as a part of the mid-body left on either side of the sulcal furrow. In other words it is formed entirely by the sulcal furrow. These three sub-types of the antapical horn, then, differ profoundly from one another in their property and origin, and the antapical horn of any species of the genus Peridinium can be classed without exception to one or the other of them. The same conclusion can be drawn regarding the seven types of the antapical spine given in the previous paragraphs.

These various sub-types of the antapical spine or horn are correlated singularly or in groups to different types or sub-types of the ventral area. In practice, the type of the ventral area of a given species can be established by means of its antapical spine or horn. Combined with the ventral area, the sub-types of the antapical spine or horn are regarded as not only of morphological significance but also of taxonomic importance, affording one of the most trustworthy bases not only for ready identification of a given species but for correct appreciation of the natural affinities of different species, sections, groups or even subgenera of the genus.

\section{Plate pattern}

The morphological significance of the plate pattern of the epitheca was established for the first time by Jörgensen (1912) who recorded three ventral plate patterns of 'Meta', 'Ortho' and 'Para'. Estimating the first two of them, he subdivided the genus into Metaperidinium and Orthoperidinium, and considered the third as of infrequent occurrence. At the same time, he also ascertained three different shapes in the middle one of the three intercalary series. He accordingly redivided each primary subdivision of the genus on the basis of the dorsal plate pattern.

This principle of subdivision proposed by JörGENSEN has been accepted generally by his followers with or without a little emendation. The ventral pattern in the genus is limited only to the three types recognized by Jörgensen and a fourth type which is reversed in bilateral relations to 'Meta' has never been established to occur. On the other hand, a wide range of variation in number of the intercalary series of plates was confirmed afterwards, and JörGEnSEN's system of subdivision was emendated by some authors for those species with a single, two or more intercalary plates. BARRows (1918), studying thecal variations in the genus mostly in literatures, concluded that the greatest variation in the plate arrangement is located in the anterior portion of the body whereas is more conservative in the posterior portion. He is correct in this regard, though his conclusions are in many other points apparently too speculative. The only thecal character that was known at that 

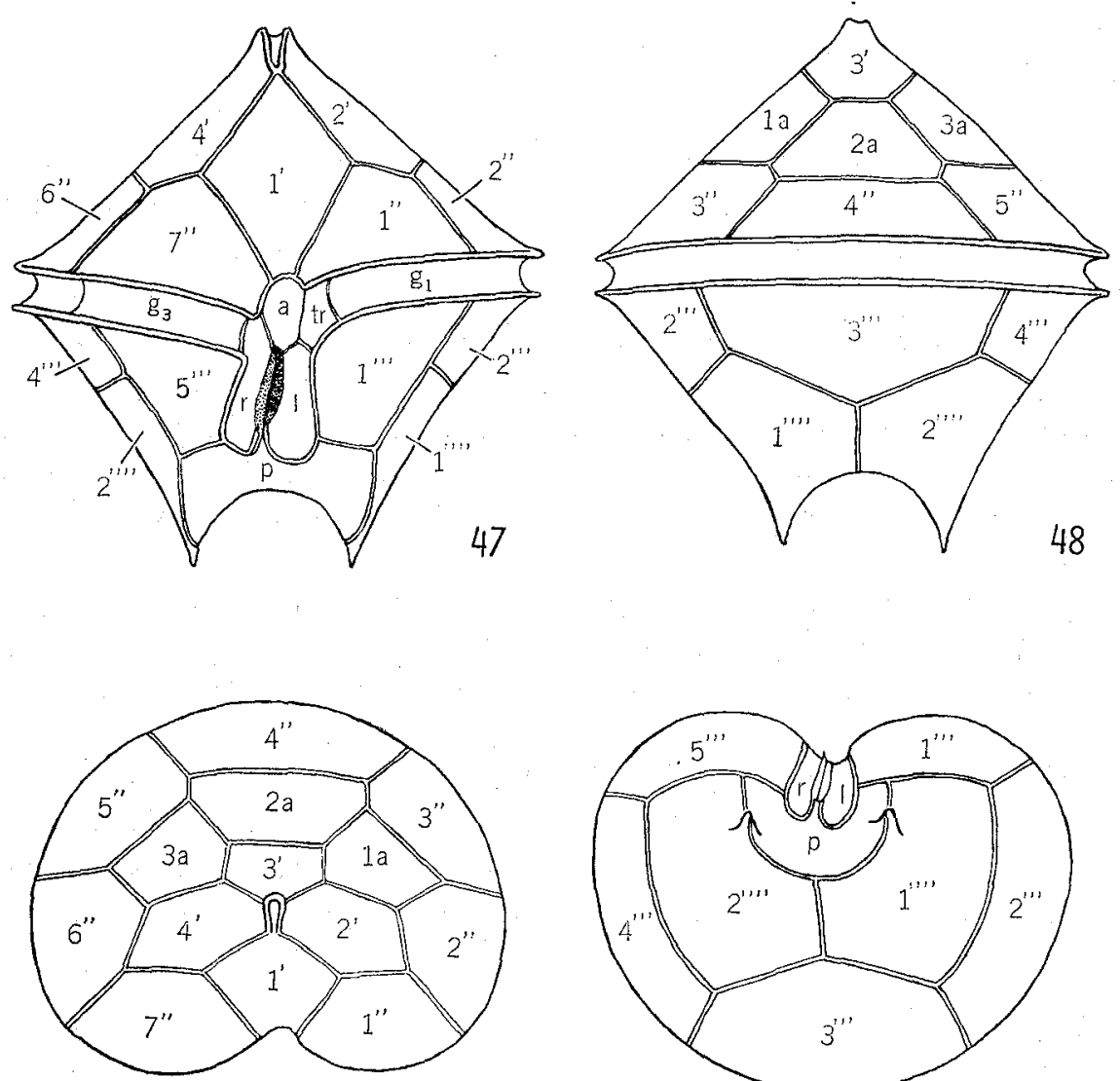

49

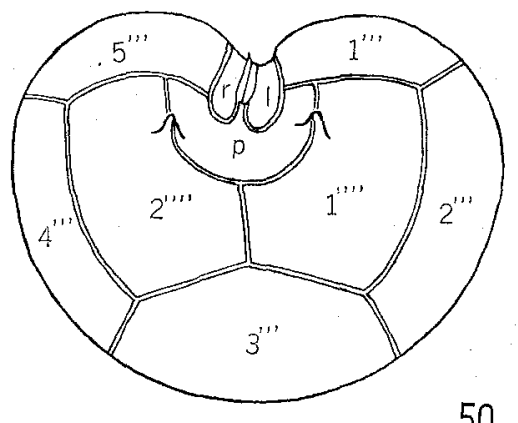

Fig. 8 (47-50): Schematic illustration of epithecal and hypothecal plate patterns. 47-Ventral view. 48-Dorsal view. 49-Apical view. 50-Antapical view. 1'-4'-Apical plates surrounding a poreplate. 1a-3a-Anterior intercalary plates. $1^{\prime \prime}-7^{\prime \prime}$-Precingular plates. $1^{\prime \prime \prime}-5^{\prime \prime \prime}$-Postcingular plates. $1^{\prime \prime \prime \prime}, 2^{\prime \prime \prime \prime}$ - Antapical plates. a, 1, r, p-Plates of ventral area (see Fig. 9). tr--Transitional plate. $\mathrm{g}_{\mathrm{x}}-\mathrm{g}_{3}-$ Girdle plates.

time so accurately as to characterize a group of species, was the plate pattern of the epitheca, and hardly anything was known about the thecal morphology of the hypotheca. It is probable that if the thecal details of the hypotheca, especially of the ventral area and its surroundings, had been worked out at that time, Barrows' conclusions might have been altered in part.

The thecal plates of the genus can be divided into six circumferential and one longitudinal series. Among them, the apical, intercalary and precingular series of plates cover the epitheca, and the major portion of the hypotheca is covered with the postcingular and antapical series of plates. The cingular plates are arranged around the body between the epitheca and the hypotheca, and the sulcal plates are arranged longitudinally along the midventral portion of the hypotheca and in close connection with the girdle and the flagellar pore.

The apical pore is absent in some of the fresh-water species but is established in 
the majority of the genus. In typical cases, it consists of a narrower ventral and a broader dorsal portion and is covered with a pore plate, in the dorsal portion of which is seen a minute hole. This apical pore has in typical cases a shorter or longer ventral slit which extends ventrally to the anterior end of the ventral apical plate and is longer generally in long-horned species. In some marine species, particularly in the Avellana group, a similar structure is seen extending dorsally beyond the apical pore which, then, is seen to lie at the middle of an dorso-ventrally elongated furrow. In what follows this structure is called 'apical trough'. 'The apical pore is encircled by a low collar-like structure which consists of anterior extensions of the lateral and dorsal apical plates and continues often ventrally along the ventral slit. The ventral slit is in most cases longitudinal in direction of extension, but is often deflected diagonally towards the left and rarely towards the opposite direction. It is peculiar that when the ventral slit is deflected towards the right, the ventral apical plate in its posterior end is very often deflected towards the opposite direction.

The apical row of plates is arranged around the apical pore, and consists typically of four but rarely of three or five plates. In the case of three plates, a fourth plate is seen displaced dorsally for a short distance from the pore. And such species are in most cases allocated in this paper to the Diplopsalis group. From some freshwater species, five apical plates are recorded regularly, and the same number of plate appears in some marine species as a sport. In the species with a long apical horn, the structure is covered mostly or entirely with the apical plates. And the three or five apical plates are seen so far as our observation goes only in short horned or hornless species.

The ventral apical plate extends invariably anteriorly to the ventral slit of the apical pore and generally posteriorly to the girdle except in a few species in which it is intercepted from contact with the girdle by the juxtaposed two ventral precingular plates. Three shapes of this have been established in the genus, and a fourth shape has never been recorded. Regarding shape of this plate, the three ventral plate patterns of 'Ortho', 'Para' and 'Meta' have been confirmed since Jörgensen. The first two of them are in the main symmetrical as the plate is surrounded with four or six plates. On the other hand, the plate pattern of 'Meta' is asymmetrical and has been considered as bordering on the left on two precingulars and a single apical plates as in 'Para' and on the other side of the precingular and apical ones as in 'Ortho'. But this type of the pattern is to be divided into two sorts, so far as our study indicates, because of the fact that the ventral apical plate comes to contact on the left with an intercalary plate instead of the precingular $2^{\prime \prime}$ in Lebouraia brevis AвÉ of the Diplopsalis group and in Peridinium grenlandicum Wolosz. Although one has to submit some exceptions, all these ventral patterns are generally accepted as of utmost morphological significance, and almost every investigator has made it a practice to allocate these forms with different ventral patterns to different species or even to different subgenera. But in practice, an unusual pattern makes it appearance though very rarely as a sport in some species in which a given pattern is generally established. Such is the case with $P$. granii. 
The precingular series regularly consists of seven and rarely six or eight plates, arranged along the anterior edge of the girdle, and is interrupted in the midventral by the ventral apical plate. These plates have along their hind margins transversely arranged surface extensions which are formed into the anterior cingular list. There is a peculiar structure. The right ventral plate of the series has at its postero-median corner a minute jut extending into the distal end of the girdle. Though a similar structure was rarely found at the proximal end of the girdle, this dextral one is more abrupt and prominent. By means of asymmetrical development of this structure, the girdle is constricted at its distal end partially from the ventral area. An exactly corresponding structure can be established in Diplopsalis and its relatives and also in Dinophysioidae. In Podolampas in which neither the cingular list nor the cingular furrow devolved, this dextral jut is formed fairly strikingly.

The intercalary row of plates or dorsal part of the epitheca is the formost in the peridinian body in manifesting remarkable variations in number and arrangement of the plates. It is due to this that almost all the recent investigators have laid much stress upon the variable number and arrangement of the intercalary series in the taxonomy of the genus Peridinium. On the other hand, it was gradually known that the series under consideration varies often in number within a single species and has not so profound correlations with other thecal characters as has generally been considered.

Whether the series consists of two or three plates has been regarded since JöRGENSEN as of much taxonomical as well as morphological significance and also as two opposed characters by means of which we can divide the genus into two large groups or subgenera. But in reality, there have been recorded, in contradiction to some investigators' conclusions, many fresh-water species with a single or no intercalary plate or with more than four, sometimes eight intercalary ones. This unusual number of the plate is known also from the two groups of Avellana and Monovela of the marine species. Seventy species bearing two or three intercalary plates are taken out of the three groups, and were arranged in Table 2 according to the number and arrangement of their intercalary plates.

Under the column of 'uncertain allocation' in the Table 2 is included these species which are still uncertain as to their allocation (Tatrica or Tabulata) judging from structure of their ventral area so far as manifested in published figures. There are following five species with no intercalary plate; $P$. cunningtonii LEMM., P. elpatievskyi (Ostenf.), P. goslaviense Wolosz., P. kulczynskii Wolosz. and $P$. penardii Lemm. Two species of $P$. polonicum Wolosz. and $P$. quadridens STEIN have a single plate of the series. It is uncertain whether or not a dorsal one of so-called four apical plates of $P$. anglicum WEST and $P$. marssoni LEMM. is to be regarded as an intercalary one. These latter two species are regarded here as uncertain species. Three species of the Perrieri group, all furnished with two juxtaposed plates, are not taken into consideration here because of their unusual thecal structures. A tetragonal middle intercalary plate is known only from P. robustum (LeBour 1925, Fig. 36 e).

In the case of double component, the two plates are either juxtaposed or sepa- 
Table 2. Development of intercalary plates in some groups of Peridinizm

\begin{tabular}{|c|c|c|c|c|c|c|c|c|c|}
\hline & & & \multirow{2}{*}{\multicolumn{3}{|c|}{$\frac{\text { Fresh-water species }}{\text { Tabulata }}$}} & \multicolumn{2}{|c|}{ Marine species } & \multirow{3}{*}{$\mathrm{F}$. } & \multirow{3}{*}{ M. } \\
\hline \multirow{2}{*}{\multicolumn{3}{|c|}{ Intercalary }} & & & & Avellana & Monovela & & \\
\hline & & & Tatrica & Tabulata & $\begin{array}{l}\text { Uncertain } \\
\text { allocation }\end{array}$ & & & & \\
\hline \multicolumn{3}{|c|}{ undeveloped } & 2 & 2 & 1 & - & - & 5 & \\
\hline \multicolumn{3}{|c|}{ a single plate } & 1 & 1 & - & - & - & 2 & \\
\hline \multirow{2}{*}{ double plate } & \multicolumn{2}{|c|}{ juxtaposed } & 5 & 2 & 2 & 8 & 4 & 9 & 12 \\
\hline & \multicolumn{2}{|c|}{ separated } & 8 & 2 & 4 & - & - & 14 & \\
\hline \multirow{3}{*}{ triple plate } & \multirow{3}{*}{ 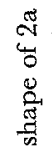 } & tetragonal & - & - & - & 1 & - & & 2 \\
\hline & & pentagonal & 一 & 8 & 2 & 一 & 2 & 10 & 2 \\
\hline & & hexagonal & - & 9 & 2 & 3 & - & 11 & 3 \\
\hline \multicolumn{3}{|c|}{ Total number of species } & 16 & 16 & 11 & 6 & 6 & 51 & 19 \\
\hline
\end{tabular}

rated, and both of these types are found in the fresh-water species while only the former can be established from the marine species. In regard to the shape of the middle plate of the triple, the marine species are more variable than the fresh-water ones. This, together with the fact that the majority of the marine species are furnished with three intercalaries, appears to suggest that the triple intercalary might have been established mainly in the marine species in the course of the phylogenetical development of the genus. Further it is to be noted here that the triple intercalary can not be established in the Tatrica section, while the character is found not rarely in the Tabulata section. This difference may be interesting when one recollects the structural difference of the ventral area the two sections display.

It was suggested by Barrows (1918, p. 447) that the full complement of the three intercalary plates might have developed from the pattern with two juxtaposed plates. In the majority of species with two intercalary plates, the series consists of subequal plates. And there is a small group of species in which the two intercalaries are of considerable difference in size and coupled with some peculiarities in other parts of body. This group may be of different origins and consists of three species of $P$. compressum, $P$. excentricum and $P$. grenlandicum. In all of them, the right intercalary is much larger than the left. The difference of them in size is so remarkable that the dorsal pattern of $P$. excentricum was suggested by BARRows as that transferred from the triple one by secondary fusion of the right and middle intercalary plates. But it may be allowed to suggest here another consideration about the asymmetry in size and development of the two intercalaries.

In the genera of Gotoius, Diplopsalopsis and Dissodium, the intercalary series consists invariably of a smaller left and a larger right plate. On the other hand, Lebouraia minuta has a minute intercalary plate on the right of a much larger one. In 
all of them, the apical series consists of three plates instead of four. Belonging to the Monovela group of Peridinium, P. mutsuensis has a smaller right and a larger left intercalary in addition to the four apicals. A similar but much less unequal intercalary is seen in the ventricum of the Avellana group. If BARRows' suggestion is established, all these species and genera just considered are to be regarded as derived from these with three intercalaries. On the contrary, all of these are in reality related more closely in general thecal features to these species with a single or two intercalaries than to those with three plates.

Furthermore, in some of them, the intercalary row of plates is displaced as a whole to the left side of the body even when a smaller plate lies on the right side of the body. In some of Diplopsalis and Lebouraia, a single intercalary is displaced more or less remarkably towards the left. A similar asymmetrical displacement of the intercalary row is not rare and often fairly remarkable in these species with three intercalaries. In such forms as Lebouraia rotunda, L. brevis and $P$. grenlandicum, the displacement is so conspicuous that an intercalary plate extends ventrally around the left side of the body to the ventral apical plate, forming there the plate pattern of 'Meta'. In any case and so far as our studies on literatures and materials in-

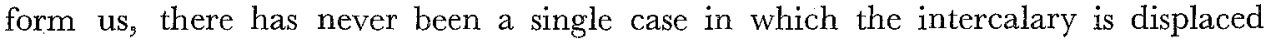
towards the right. From these it may be allowed to conclude that the leftward displacement of the intercalary row of plate is a character of intrinsic subordination of the genus Peridinium and its closest relatives. And the remarkable difference in size of the two intercalaries considered before may be a character introduced in correlation with the asymmetrical development of the intercalary row of plates.

In case the intercalary series consists of three plates, one can divide it into three types regarding the shape of the middle 2a. The plate is either tetragonal, pentagonal or hexagonal. Among them, the first is generally accepted as of a primitive type and the last as of the most highly specialized one derived from the other. These differences in shape of the middle intercalary plate has generally been regarded as of highly morphological as well as taxonomic importance. But, comparative studies of many species inform us of the fact that the shape and size of the middle intercalary is to be considered not alone but together with the shape, size and arrangement of the entire intercalary row of plates.

The tetragonal middle intercalary can be ascertained to occur in all the sections of the Humilia group of Protoperidinium, in the Divergentia group of Mesoperidinium and in the Avellana and Oceanica groups of Veroperidinium. In some of the Heteracantha, Laterispinosa and Bispinosa sections, all of which are of primitive types in the group, and middle plate is fairly small and longer than wide while the other lateral ones of the same series are of considerable size. In some other advanced species of the same sections, the middle one is much larger and broader than long and the bilateral ones are elongated more or less remarkably in dorso-ventral direction. The intercalary row of plates is, then, sharply bent and broadly U-shaped in apical view, and covers large dorsal and lateral portions of the epitheca. Though this characteristic type of the dorsal pattern can be established partly in the pyrifor- 
mia group, it is fairly predominate in the Humilia group, and particularly distinct in $P$. subcurvipes and $P$. monacanthum of the Monacantha section, in $P$. cerasus and $P$. roseum of the Laterispinosa group, in $P$. ovatum, $P$. lenticulatum and $P$. marukawai of the Bispinosa group and in $P$. quarnerense and $P$. simulum of the Globula group.

Belonging to the same type of the intercalary row, the middle plate is often penta gonal in $P$. majus and $P$. quarnerense. The pentagonal middle intercalary is more widely known than the tetragonal one, and can be seen in all the groups and sections of Protoperidinium except Monacantha and Parapellucida sections which represent either the most primitive or the most specialized form of the subgenus. In Mesoperidinium, the Divergentia group is known to have the pentagonal one, and the most specialized Conica group is the sole one in Veroperidinium besides the Perrieri group, in which the pentagonal 2a can not be established. And the Pyriformia group is peculiar in that the middle intercalary is invariably pentagonal, as a different pattern has never been established. In this type of the pattern, the middle intercalary is regularly displaced more towards the left beyond the mid-dorsal precingular $4^{\prime}$, and only very rarely as a sport towards the opposite direction. This displacement may be explained when one recollects the intrinsic feature of the intercalary row of plates considered above.

In the Humilia group, this tetragonal intercalary $2 \mathrm{a}$ is in most cases more or less transversely elongated. But in other groups it is more rotund, and is coupled in Pyriformia with subequal and in Divergentia with larger laterals as in Humilia. Regarding the shape and relative size of this plate, Oceanica is more closely related to Divergentia than to Humilia.

The hexagonal shape of the middle intercalary often presents itself in some sections or groups with the tetragonal or pentagonal one, and not rarely in a species regularly furnished with a pentagonal one, such as $P$. quarnerense. The consideration generally accepted that the hexagonal shape of this plate is the highest type and might have been derived from the pentagonal one, may be supported by the facts that the Parapellucida section, the Paradivergentia group and the Conica group, every one of which is a higher type in the subgenus to which it belongs are furnished exclusively or by far the majority with the hexagonal intercalary 2a. Further, it is interesting in this regard to know that the hexagonal one presents itself in the Humilia group only in association with the most bighly differentiated type of the ventral area, that is, in the Globula section. The hexagonal middle intercalary is in most cases transversely elongated and broadest at or more often slightly below its middle and is characteristic in shape and range of variation for every section or group. In some of the Tabulata section, this plate is remarkably elongated transversely, covering by far the major anterior breadth of the epitheca, and the other lateral intercalaries are much smaller, not expanding laterally beyond the middle, on the ventral of which they lie. In the Conica group, the plate is in most of the advanced species trapezoidal or nearly so with the largest breadth at its hind end or just in front of it. This peculiar shape of the plate in the group can be explained only when we consider the re- 
arrangement of the epithecal plates, which is characteristic of the group.

In some highly advanced species such as $P$. conicum, $P$. pentagonum and $P$. sinuosum of the Conica group, the pattern of the sutures of articulation in apical view of the epitheca is so re-adjusted that the entire epitheca or epithecal plates are divided into six longitudinal sections or groups by six longitudinal sutures extending more or less straightly from apex to girdle. Among the three pairs of the sutures, the dorsal one is least straight as it bends sharply at the hind end of the dorsal apical plate and is slightly zigzag at the postero-lateral corner of the middle intercalary plate. On the other hand, in such species as $P$. anthonyi or $P$. punctulatum, the pattern of the sutures of articulation is not re-arranged as in the major species of the genus. And that of $P$. conicoides is intermediate between the two forms. In consequence of this progressive development of the re-adjustment, the hexagonal middle intercalary plate is forced to reduce length of its postero-lateral sides, and finally becomes trapezoidal, partly in consequence of reduced difference in the anterior expansion of the three dorsal precingular plates. Presumably correlated with this re-adjustment, there can be established in $P$. pentagonum and $P$. sinuosum a peculiarity in the epithecal plate pattern that the ventro-lateral pair of the longitudinal sections is remarkably reduced in breadth, particularly strikingly on the left. It is to be recollected in this place that all these species with re-adjusted epithecal plate pattern are furnished invariably with a large posterior sulcal plate. Just a corresponding correlation between the advanced re-adjustment of the epithecal plate pattern and greater development of the posterior sulcal plate can be established in $P$. elegans of the Divergentia group.

In most cases of the re-adjusted patterns, the longitudinal sutures are furnished with narrow lists which make the longitudinal sutures more prominent and thicker than the transverse ones connecting them. This feature leads us to the suggestion that a plate within a single longitudinal section or zone of the re-adjusted pattern is related more closely with other members of that zone than with its neighbours belonging to the same circumferencial row of plates and lying in the next longitudinal zones. The principle, proposed by KororD, of subdivision of the epitheca into three circumferencial rows is of great practical convenience and indeed appears to accord with reason in representing natural relations and affinities of the plates. But, the fact established on the Conica group leads us to suggest here that the epithecal plates in some higher forms of the Conica group are so related as to form six longitudinal or radial groups. That this grouping is not only of morphological significance but also of physiological importance is supported by the fact that fusion of plates within a single longitudinal zone occurs often in some species such as $P$. deficiens, $P$. expansa and some others.

No plate variation nor plate pattern has ever been discussed by any of former investigators regarding the hypotheca. But the variations of the plate arrangement are seen practically on the ventral side of the hypotheca within the ventral area. This, however, shall be discussed in other paragraphs. 


\section{Ventral area}

Along the midventral portion of the body is generally a longitudinal groove which is wider and more conspicuous in the hypotheca than in the epitheca. And the ventral area lies along the bottom of this groove, particularly of the hypotheca, and can be distinguished into several types or subtypes in regard to its shape and structure, each characteristic for a group or section. The structural relations and differentiations of this ventral area seem never to have received an extended morphological study because of the great difficulty in determining its structural details which, however, were partly illustrated by some investigators. Kofold (1908) is the only one who has analysed the fine structures of the ventral area of the genus Peridinium. The result of his study is far reaching but is unsatisfactory regarding the relation between the flagellar pore and the sulcal plates, especially the posterior sulcal one. On the other hand, this posterior sulcal plate is, according to the morphological study, of utmost morphological significance exhibiting astonishingly various modifications in shape and size among different species, and at the same time afford us one of the most trustworthy basis for the ready diagnosis of a group or section of the genus.

The ventral area, as was pointed out for the first time by KoForm (1907) and later by ABÉ (1936), consists of four sulcal plates which are arranged around the flagellar pore. The right and left sulcal plates lie bilaterally on either side of the flagellar pore, forming at the same time largely the wall of its tubular inner extension. The anterior sulcal plate extends between the flagellar pore and the epitheca, and further dorsally with its attenuated hind end along the anterior wall of the tubular part of the flagellar pore. The postero-median ends of the right and left sulcal plates border directly each other at the hind end of the flagellar pore, where they form a short and narrow depression, the flagellar trough, extending from the pore to the posterior sulcal plate. These flagellar pore and flagellar trough lie in a more or less sharply differentiated furrow, the flagellar furrow, which extends anteriorly to the proximal end of the girdle but posteriorly hardly beyond the flagellar trough. And along the posterior sides of these two sulcal plates lies transversely the posterior sulcal plate which expands laterally either symmetrically or asymmetrically and is separated from the pore by the length of the flagellar pore.

In most of the groups of the genus, the ventral area is excavated as a whole, but in some others the furrow is limited only in its smaller portion. In either case, the depth of the furrow lies invariably in the left half extending from the proximal end of the girdle posteriorly to or somewhat further beyond the flagellar pore.

Examinations of large number of species inform us of the fact that the ventral area of the genus displays the same structural relations between the flagellar pore and the sulcal plates. However, a wide range of variation in shape and structure of this region may be established. The various modifications in the ventral area are shown in size and shape and relation between the posterior sulcal plate and the ventral two of the postcingular ones. In regard to these relations, the ventral area 

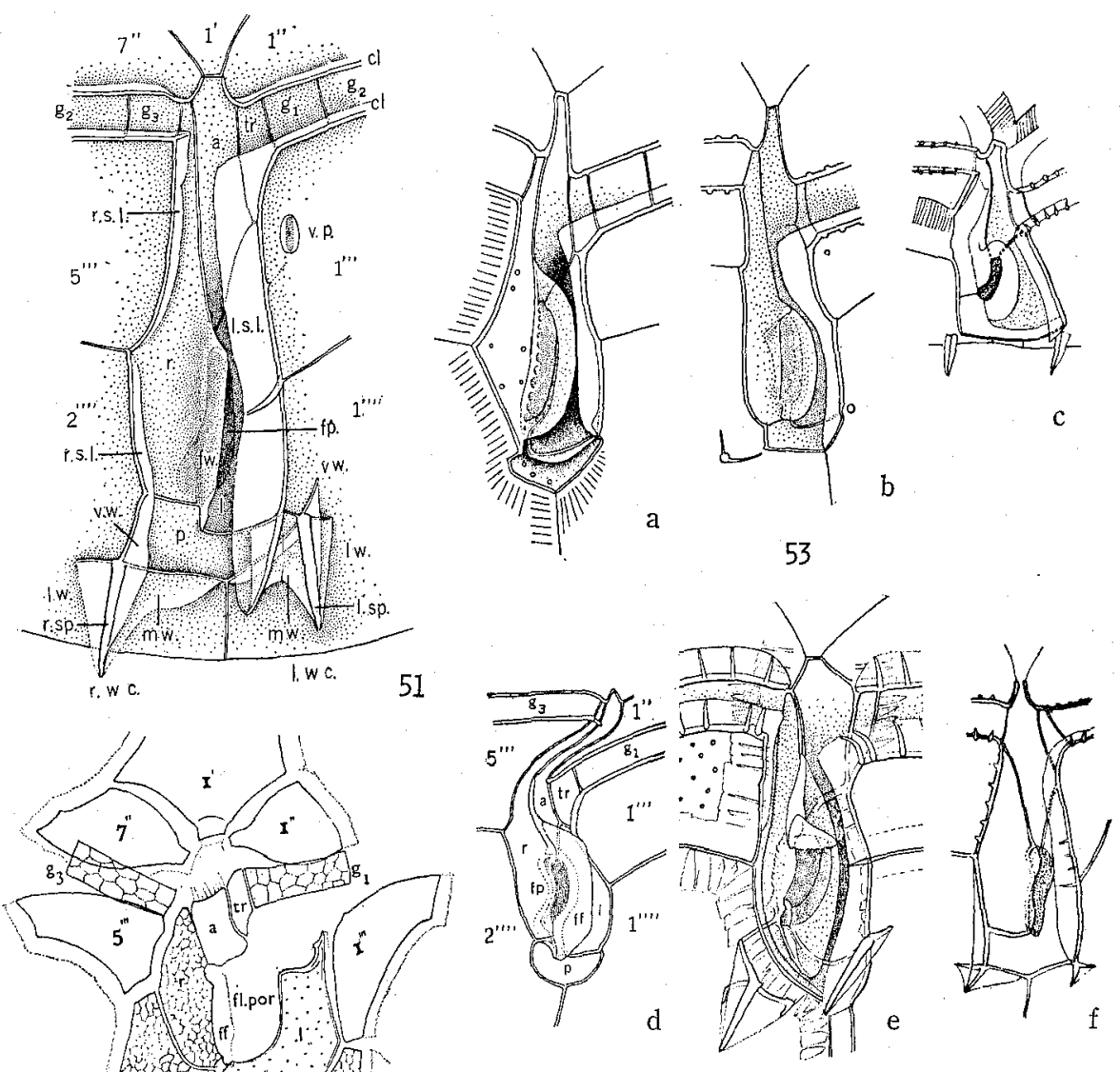

52
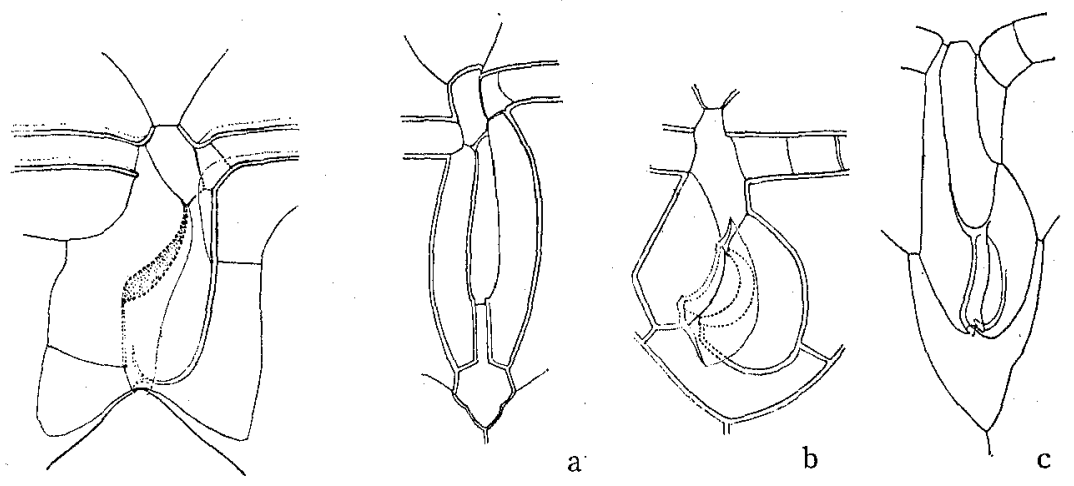

54

55

Fig. 9. 
of the genus is divided into three types as follows.

Steinii type This type was characterized for the first time by Kofom (1909) under detailed morphological analysis of $P$. steinii. And some accounts on the structure of several other species allied closely to this type were also given by ABÉ (1936). All these species agree in that the posterior sulcal plate has no direct relation with either of the two ventral postcingular plates, expanding laterally hardly beyond the two middle sulcal plates, and covers a smaller posterior portion of the ventral area. The ventral area of this type is found only in species with rounded hypotheca bearing generally antapical spine or wing-complex.

On the basis of the general shape, structural differentiation of the ventral area and posterior sulcal plate and the antapical spine or wing-complex, this type can be subdivided into six sub-types as follows.

1. Monacantha sub-type. The ventral area of $P$. subcurvipes tapers anteriorly to a pointed end, expanding towards the right at its posterior two-thirds where it is broadest, and tapers posteriorly to a bluntly pointed end of a considerable breadth. Its larger left half is indented to form the flagellar furrow, which is guarded on the left with a narrow sulcal list and on the right with a large flagellar wing which can be traced anteriorly and posteriorly beyond the flagellar pore. The posterior sulcal plate is in the main triangular, lying transversely along the hind margin where the ventral area is much less in breadth than at the postcingular antapical suture. The ventral area of this sub-type is coupled with a single right antapical spine standing at a short distance from the ventral area.

2. Laterispinosa sub-type. In $P$. rosezm, the posterior half or a little less of the ventral area is broader than the other part, but its hind end has a little smaller breadth. The ventral area is indented as a whole but particularly deeply in its left half the flagellar wing is indistinct. Two short antapical spines are separated shortly from the ventral area.

3. Bispinosa sub-type. The ventral area of $P$. marukawai and its allies has

Fig. $9(51-55)$ : Ventral area. 51-Diagrammatic illustration of ventral area and its appendages. a, $r, 1, p$-Anterior, right, left and posterior sulcal plates. fp-Flagellar pore. fw-Flagellar pore wing. 1.s.l., r.s.l.-Left or right sulcal list. cl--Cingular list. 1.w.c., r.w.c.-Left or right wingcomplex. mw-Median wing. lw-Lateral wing. vw-Ventral wing. 1.sp., r. sp.-Left or right antapical spine. $\mathrm{l}^{\prime}$-Ventral apical plate. $\mathrm{l}^{\prime \prime}, 7^{\prime \prime}$-Precingular plates. $\mathrm{g}_{1}$ - $_{3}$-Cingular

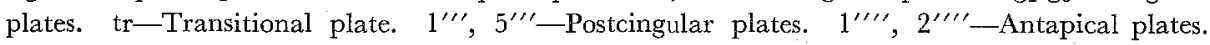
52-Isolated ventral portion of $P$. sp., strongly flattened and partially disjoined. $1^{\prime}$-Ventral apical plate. $1^{\prime \prime}, 7^{\prime \prime}$-Ventral precingular plates. $\mathrm{g}_{1}, \mathrm{~g}_{3}$-Cingular plates. 1"', $5^{\prime \prime \prime}$-Ventral postcingular plates. $1^{\prime \prime \prime \prime}, 2^{\prime \prime \prime \prime}$-Antapical plates. tr-Transitional plate. a-Anterior sulcal plate. 1-Left sulcal plate. r-Right sulcal plate. ff-Flagellar fin. f. por.-Flagellar pore. 53: Ventral areas of Steinii type. a-Monacantha sub-type; $P$. subcurvipes. b-Laterispinosa sub-type; $P$. roseum. c-Bispinosa sub-type; $P$. marukazai. d-Globula sub-type; $P$. globifera. C-Pyriformia sub-type; P. pyriforme. f-Pellucida sub-type; P. pellucidum. 54. Ventral area of Divergentia type-Divergentia sub-type; $P$. elegans. 55. Ventral area of Conica type. aAvellana sub-type; $P$. thorianum. b-Monovela sub-type; $P$. monovelum. c-Conica sub-type; P. excentricum. 
its greatest breadth at its hind end, and tapers towards the other end. The posterior sulcal plate is transversely elongated and has no distinct bilateral differentiation. The left of the two short antapical spines is formed near the hind end of the left sulcal list. In most cases, an anterior half of the ventral area bends somewhat weakly towards the left at the proximal end of the girdle.

4. Globula sub-type. This diagonal extension of the anterior half is particularly remarkable in the ventral area of $P$. globulus and its close relatives. In all of them, the girdle forms an unusually ascending and overhanging spiral. These two overhanged ends of the girdle are connected diagonally by an extraordinarily elongated anterior part of the ventral area, where it consists exclusively of the anterior and a part of the right sulcal plates. The other posterior part of the ventral area is much broader, lying longitudinally, and has a narrow sulcal list on the left and along its median a large flagellar wing which can be traced anteriorly to the proximal end of the anterior cingular list. The major part of the ventral area is least indented and has no circumjacent list, distinguishing the sulcal furrow from the general surface of the body. The sulcal furrow thus fails to develop completely in this sub-type, but the flagellar furrow is formed faintly between the left sulcal list and the flagellar wing. The posterior sulcal plate is triangular, lying with its pointed end dorsally, and has the breadth subequal with or a little smaller than the greatest breadth of the ventral area at the girdle. Thus, the ventral of this sub-type displays many characteristic peculiarities of the sub-type. The most distinct feature of this is sought in its strongly overhanging girdle and <-shaped ventral area. But regarding these, the present sub-type is connected with the previous one through $P$. ventralis and some other species belonging to that sub-type. The present one is unparalleled in the Steinii-type with respect to the entire disappearance of the sulcal furrow. On the other hand, the present one is rather a lower type in the Steinii type regarding its triangular posterior sulcal plate. This suggestion is supported by the fact that the antapical spine or list in this sub-type is least formed and separated from the ventral area. From these, it is apparent that the present sub-type is related more closely to the three given above than to the other higher ones to be given below, with which it has hardly any direct relationship.

5. Pyriformia sub-type. Related somewhat to the Laterispinosa sub-type, the ventral area of $P$. steinii, $P$. pyriforme and allies has the greatest breadth at the postcingular antapical suture, where it expands towards the right, and tapers slightly at the hind end. It is indented as a whole, and the left sulcal list connects the left antapical spine directly with the posterior cingular list. The posterior sulcal plate is $\mathrm{V}$-shaped or alike, showing indistinct bilateral differentiation.

6. Pellucida sub-type. Hardly decreasing in its breadth posteriorly, the ventral area of $P$. pellucidum and its many closest relatives has a broader posterior half, along the hind margin of which lies transversely the posterior sulcal plate which is more or less highly differentiated bilaterally. It is weakly or hardly indented as a whole, but in any case the flagellar furrow is conspicuously distinguished and sharply confined within the small portion represented by the left sulcal plate. The posterior 
sulcal plate lies transversely across the hind end of the ventral area, and its left half is generally indented by the flagellar furrow. Thus the plate has a narrower left and a broader right half. The degree of this bilateral differentiation is various. In some smaller species, the plate is transversely oblong displaying hardly any bilateral difference, while in others it consists of a large rectangular right half bearing a narrow neck on its left. And almost every intermediate form is established between them. When the plate is highly differentiated bilaterally in company with stronger differentiation of the sulcal furrow, it is generally coupled with a more well formed antapical wing-complex. In any case, the left antapical spine stands on the left of the left sulcal list which is connected transversely with the other by a narrow side list.

In typical cases, the posterior sulcal plate terminates on the left at the base of the left antapical spine, but extends exceptionally further beyond it to the left ventral postcingular plate. This unusual extension can hardly be established in ventral view of the body, but is clearly suggested from the fact that when the plate is separated from its surroundings a posterior half of the left sulcal list is seen firmly stuck to its narrower neck. The asymmetrical expansion of this plate is characteristic of the Divergentia type in which the left sulcal list has no direct connection with the left antapical spine. In this regard, some highly advanced ones of this Pellucida sub-type form a connecting link between the Steinii and Divergentia types.

We have to draw attension here to a peculiar structure generally seen in this Pellucida sub-type and rarely in the Conica sub-type of the Conica type. There is a small but conspicuous dent in the right sulcal list at a short distance from its anterior end. This is far separated either from the distal and proximal ends of the transverse flagellum or from the flagellar pore, and clearly has no influence upon the water currents caused by the two flagella. Then, there is no means to suggest its morphological significance.

Divergentia type Coupled either with the semisulcal horn or with the antapical wing-complex distinct from the left sulcal list, the posterior sulcal plate displays conspicuous lateral difference, expanding asymmetrically towards the left where it extends to the left ventral postcingular plate, separating the left antapical spine or horn from the left sulcal list, while it is completely separated on the other side from the right ventral postcingular plate. Regarding the sulcal indentation and antapical appendage, this type is subdivided into two sub-types.

1. Paradivergentia sub-type. The ventral area of $P$. okamurai is broader posteriorly than anteriorly and expands towards the left beyond the left sulcal list. It is indented as a whole. But that of $P$. longipes differs a little, coming gradually broader posteriorly on the right side while abruptly on the opposite side, and is hardly indented except in the flagellar furrow which is strongly differentiated. In either case, the antapical wing-complex is well formed, instead of a hollow horn, and is separated completely on the left from the left sulcal list. 
2. Divergentia sub-type. A similarly asymmetrical posterior sulcal plate is coupled with a more or less distinct sulcal furrow and hollow antapical horn in $P$. crassipes, $P$. solidicorne, $P$. fatulipes, $P$. elegans and their allies. In the first two of them, the left lobe of the posterior sulcal plate is fairly narrow, while it is much more broader and greater in size than the other half in $P$. elegans. And there are many intermediate species between them regarding the structural feature just considered. In them, it is clearly established that the increase in the relative size of the left lobe of the plate is followed by longer antapical horns and wider opening of the sulcal furrow. In $P$. elegans, the sulcal furrow is so excessively expanded that it merges imperceptibly into the general ventral depression of the body, losing at the same time its circumjacent list and ridge by which the sulcal furrow is differentiated from the general surface of the body. On the contrary, the flagellar furrow is strongly confined and differentiated into a smaller portion lying between the girdle and the flagellar pore. Exactly a parallel variation can be established in the Conica sub-type of the Conica type, as shall be given in later paragraphs.

In any case, however, an anterior half of the right sulcal ridge is fairly diagonal while the other posterior half is longitudinal. This feature helps us in practice in diagnosing the species belonging to this sub-type.

As described before, this Divergentia type is related to the Steinii type through the Parapellucida sub-type of the latter. On the other hand, the present type has close relationships with the Conica type through the Tatrica sub-type of the latter, in which the posterior sulcal plate covers partially the hind end of the ventral area and is intercepted by posterior elongation of the right sulcal plate from contact with the right ventral postcingular plate. Thus, the present type is related partly to the Steinii and partly to the Conica types. This may be suggested also from the fact that it is coupled partly with the antapical spine and partly with the horn. Further it may be interesting to recollect here that the Steinii and Conica types of the ventral area are coupled with the rhombic and hexagonal ventral apical plates respectively, while the present type is also intermediate in this regard because of its being accompanied typically with the pentagonal ventral apical plate.

Conica type In all of the groups of Veroperidinium except the Tatrica section of the Tabulata group, the posterior sulcal plate expands laterally slightly or strikingly beyond the two middle sulcal plates, and the two ventral postcingular plates extend posteriorly lying along either side of the ventral area to this sulcal plate. This posterior sulcal plate is unusually polymorphic in its shape, size and lateral expansion, and can be divided in these regards into six sub-types, each coupled with a characteristic structural differentiation of the ventral area.

So far as published figures can reveal, the ventral area of fresh-water species is fairly polymorphic, as it forms a narrow furrow of subequal small width along the midventral of a broadly rounded hypotheca, or expands slightly or strikingly towards 
the left, bringing forth in some extreme cases an irregularly angulated hypotheca. But hardly any account has ever been given about the structural relations within the ventral area itself. No one has ever described about the structure, but in some of published figures are illustrated some lines or alike features within the area of the sulcal furrow, suggestive of the sutures and flagellar pore. Judging from these, the ventral area of fresh-water species can be divided into two types or groups, one clearly furnished with the posterior sulcal plate occupying the entire breadth of the ventral area and the other with the plate intercepted from contact with the right sulcal edge by the right sulcal plate.

1. Tatrica sub-type. Judging from Woloszynska's figures (1916, Fig. 7), $P$. tatricum has a large ventral area, in which the left sulcal plate extends posteriorly to its hind margin, separating the posterior sulcal plate from the right sulcal edge. Just a corresponding structure can be ascertained clearly in some published figures of $P$. goslaviense, $P$. elpatievskyi, $P$. steinmanni and $P$. dzieduszyckii, and more or less vaguely from $P$. cunningtonii, $P$. penardii, $P$. marchicum and $P$. umbonatum. Among them, the first four were recorded by the same author and the latter four were recorded by others. They agree in large width of their ventral area.

2. Tabulata sub-type. The ventral area of $P$. cinctum is narrow throughout its entire length, and is weakly constricted from either side shortly in front of its hind end. The posterior sulcal plate lies in rear of this constriction, expanding over entire width of the ventral area. An exactly corresponding structure can be clearly ascertained in published figures of $P$. aciculiferum, $P$. marssoni, $P$. polonicum, $P$. lubioniense, $P$. veestii, $P$. tabulatum, $P$. volzii, $P$. willei and some others, in all of which the ventral area is fairly small in breadth and does not display a distinct asymmetrical expansion.

3. Avellana sub-type. In $P$. thorianum and its allies, the ventral area is deeply excavated as a whole and has a small and subequal breadth throughout its length. The furrow is bilaterally compressed weakly just in front of its hind end. The posterior sulcal plate is small and pentagonal, lying in rear of the constriction, just as in the previous sub-type. The sulcal furrow forms a weakly undulating tract, bending elegantly towards the left in its anterior end where it merges into the strongly descending sulcal furrow. This sub-type is related most closely to the previous one in all respects but for the fact that the right sulcal plate extends anteriorly to the epitheca in the previous sub-type but ends in front of it in the present sub-type. With exception of the two given above, the present one is the lowest one in the subtypes of the Conica type regarding structural differentiation of the ventral area, particularly its posterior sulcal plate.

4. Oceanica sub-type. The closest relative of this third sub-type is to be sought in the ventral area of $P$. oceanicum and its allies. In this sub-type, the straightly elongated, narrow sulcal furrow is deeply indented as a whole and has a subequal width throughout its length except its hind end where it often expands abruptly towards either side slightly beyond the other portion. The left sulcal list is fairly narrow and does not extend to the expanded posterior portion, and there is 
a much narrower and serrated list standing around the furrow. The ventral area of this type is accompanied invariably with the typical hollow horn, and is fairly constant in shape and structural relation throughout different species, without showing, so far as our study goes, evidence of such a distinct variation as seen in the Conica sub-type.

5. Monovela sub-type. Differering profoundly from these given above, the ventral area of $P$. monovelum and its relatives display peculiar and characteristic features. It is symmetrically formed, expanding laterally below the girdle in like manner. Just as in P. globulus and its allies, the ventral area of this is hardly indented except in the weakly formed flagellar furrow which covers the left sulcal plate and a part of the anterior sulcal one, and has no circumjacent list except along the flagellar furrow. The left sulcal list is very indistinct, while the broad flagellar wing is unusually great in size extending obliquely towards the left, over the major breadth of the flagellar furrow. The ventral area is slightly constricted at the anterior end of the transversely elongated triangular, or rather broadly V-shaped posterior sulcal plate. The ventral area of this type is coupled invariably with a circular girdle and globular midbody but never with either antapical spine or horn. Judging from general thecal features, the species bearing the ventral area of this subtype is to be regarded as a lower type, and the closest relative of this may be sought in the fresh-water species. The same may be said also of the features displayed in the ventral area, but for the complete disappearance of the sulcal furrow. On the other hand, this is related closely to the Avellana sub-type regarding its right sulcal plate which hardly extends anteriorly beyond the posterior cingular ridge.

6. Perrieri sub-type. Regarding the posterior sulcal plate, $P$. excentricum is closely related to $P$. monovelum and its allies. But the ventral area of this species has a subequal width and is deeply indented as a whole as shown in the Monovela sub-type. While the flagellar furrow is clearly differentiated within the sulcal furrow which extends dorsally for a short distance beyond the ventral area and over ventro-median portion of the antapical plates. In this regard, the species is related to the Conica group.

7. Conica sub-type. In all species of the Conica group, the posterior sulcal plate is constricted more or less distinctly into two subequal lobes, by means of which the plate expands laterally abruptly beyond the two middle sulcal plates. The ventral area itself is divided into a narrower anterior and a broader posterior half. The former is covered mostly with the right and left sulcal plates and the latter exclusively with the posterior sulcal plate. The structure displays an unusually wide range of variations regarding the shape, width, size and antero-posterior differentiation. Species bearing the ventral area of this sub-type form an uninterrupted series, ranging from a biconical one furnished with a narrow sulcal furrow as in the case of the Avellana sub-type to a pentagonal or star-shaped one bearing an extremely differentiated ventral area. At one end of the series lies $P$. punctulatum in which the ventral area forms a deep furrow of a small subequal width expanding slightly to either side in its small hind end. In spite of the smaller size, the posterior sulcal plate of 
this species is typically of the present sub-type and not of the Avellana sub-type, to which the species is closely related in regard to the ventral area. At the other extremity stands $P$. sinuosum in which the antero-posterior differentiation is astonishingly advanced. The posterior sulcal plate covers an entire breadth of the dorso-ventrally flattened hypotheca while the anterior narrower half of the ventral area is much smaller in breadth. The sulcal furrow is hardly formed over the major portion of this markedly expanded ventral area, and the flagellar furrow is also confined within a left half of the anterior narrower part of the ventral area. Between these two extremities can be established almost every intermediate form in which the pseudomorphous antapical horn is formed variously according to different size of the posterior sulcal plate and also to different extent of development of the sulcal furrow. It is to be reminded that the width and depth of the postero-median indentation of the body depend upon those of the sulcal furrow. Typical of this sub-type may be sought in the ventral area of $P$. conicum.

The ventral area of this type is coupled with a circular or descending girdle and a conical epitheca. One of the closest relatives of this is, as suggested before, the Avellana sub-type, through which this is related to the Tabulata sub-type. It may be recollected here that $P$. elegans of the Divergentia type and $P$. sinuosum of this Conica type appear to be related closely with each other in regard to their superlatively confined and differentiated flagellar furrow, almost entire disappearance of the sulcal furrow and their extraordinarily expanded posterior sulcal plate which is deprived of its intrinsic (sulcal) nature. As a result of these parallel differentiations in the two species, the flagellar pore in them is formed in like manner, lying diagonally and twisted along its axis. Their apparent resemblance is further supported by their similarly re-adjusted epithecal plate pattern. These peculiar structural correspondences between them do not necessarily show their taxonomic affinity, but are to be explained as a result of parallel phylogenetical developments carried forth distinctly in the two groups.

It may be granted from these to conclude that higher structural differentiation of the ventral area is accompanied with some advanced modifications in other parts of the body. This suggestion is further supported by the fact that the midbody of $P$. compressum is unusually strikingly flattened dorso-ventrally while its ventral area is highly differentiated just as similarly as that of $P$. sinuosum. The ventral area of this species is largely deprived of its sulcal nature, showing at the same time a strong antero-posterior differentiation, and the minute flagellar furrow is confined into a small sinistro-anterior part of the ventral area. In this regard, $P$. compressum appears to be allocated to this Conica sub-type. But the species is to be regarded as of a lower type, judging from other thecal structures including the posterior sulcal plate.

In many of the species furnished with the ventral area of this Conica sub-type, one can establish a peculiar structure lying along dorsal side of the posterior sulcal plate. A small ventro-median part of the antapical plate is differentiated from the rest by a curved or zigzag ridge, along which the thecal plate is faintly folded. Two 
of them lying bilaterally form a sickle-shaped area collectively, distinguishable from either the ventral area or the general dorsal side of the hypotheca. We shall call this 'postsulcal area'. This structure is most distinct in the species furnished with well-formed sulcal furrow. Judging from this and other available facts, it is clearly due to dorsal continuation of this sulcal furrow beyond the posterior sulcal plate. It is, then, morphologically equivalent to that formed typically in $P$. excentricum.

The ventral area of the genus Peridinium is divided, as given above, into three types, one with an asymmetrically expanded and the other two with symmetrically formed posterior sulcal plate. We have, then, the fourth asymmetrical type hidden behind the mist of unsolved mystery. Not a single case of the posterior sulcal plate extending asymmetrically towards the right and interrupted on the opposite side from contact with the left ventral postcingular plate has ever been recorded to occur in the genus. So far as literatures inform us, the ventral area of $P$. divergens figured by MANGin (1910, pl. 11, figs. 10, 11,13) has the structural relation just expected. But no other investigator has supported him nor recorded a similarly inversely formed ventral area. There are some reasons to believe that these drawing are due to the misinterpretation. They might have been drawn either without due morphological analyses or from inside of the body, instead of the correct orientation.

In this regard, the ventral area of the Diplopsalis group is interesting in that the posterior sulcal plate lies diagonally with its right end more anteriorly than the other, and that the plate borders broadly on the right ventral postcingular plate, while it is connected with the left ventral of the same series only with its pointed end. This bilateral relation is very akin to that expected in the fourth type.

In each of the three types, sub-types are related more closely, with exception of the two cases already referred, to one another than to these of different types, and they display ranges of parallel variations. They can be arranged in any case from the deeply indented, narrow ventral area, furnished with a least differentiated posterior sulcal plate to that furnished with the most conspicuously differentiated sulcal furrow, hardly formed sulcal furrow and excessively differentiated posterior sulcal plate. Coupled wiit some other structural features, these just given clearly suggest their phylogenetical relationships. The ventral area of small and subequal breadth and with the least differentiated flagellar furrow and a small and simply shaped posterior sulcal plate may be taken to represent the least advanced type. On the other hand, the highest type is to be sought clearly in that with the most highly differentiated flagellar furrow coupled with complete or partial disappearance of the sulcal furrow and the well-formed and best differentiated posterior sulcal plate.

From these we have been led to conclude that the presumably best taxonomic stress is to be put upon the structural relations or differentiations of the ventral area but not upon the plate pattern and the type of the cingular displacement. Further, another reason why we dare to suggest this is that the types and sub-types of the ventral area are related so closely to those of the antapical spine or horn that the former can afford us the best means by which we can establish the latter without 
any misinterpretation.

\section{Flagellar pore}

Along the bottom of the flagellar furrow opens the flagellar pore, from which two flagella spring out, one anteriorly to the girdle and the other posteriorly. This flagellar pore has various shapes, ranging from short ovoidal to elongated and twisted form. A small ovoidal flagellar pore is seen in the ventral area of some lower subtypes of the Steinii type and in most of the fresh-water species. In other words, the flagellar pore of this least advanced type is correlated to the least differentiated ventral area. A longitudinally elongated flagellar pore, opening ventrally as a whole, is established to occur in the ventral area of the Avellana and Oceanica subtypes of the Conica type and in some of the Steinii type. In all of these cases just referred to, the flagellar furrow is not yet well differentiated from the sulcal furrow, and then the flagellar pore opens directly ventrally. But in other higher sub-types, the flagellar pore is more or less conspicuously differentiated, and the flagellar pore lies along its dextral wall, partly or entirely hidden behind the base of the flagellar wing. The ventral area in them is slightly or remarkably elongated, lying somewhat diagonally, and opens partly ventrally but mostly obliquely towards the left. In some extreme cases such as seen in $P$. elegans, $P$. pentagonum, $P$. sinuosum $P$. compressum and the Monovela sub-types and some highly advanced species of the Parapellucida group, the flagellar pore is strongly elongated diagonally, lying with its hind end deflected towards the right. It is remarkably twisted along its axis, opening towards the left in its anterior end and oppositely to the proximal end of the girdle, but oblique-ventrally in its hind end where it is deeply retreated behind the edge of the flagellar furrow.

In any case, the dextral edge of the pore is markedly elevated than the other, and along this stands the flagellar wing extending obliquely towards the left. The pore itself is wider posteriorly than anteriorly, and is connected anteriorly with the proximal end of the girdle by a narrow furrow and posteriorly with the posterior sulcal plate by the flagellar trough which also displays some variations in length and breadth. The flagellar pore is not a simple opening of the thecal wall but forms an abruptly indented furrow with a flat bottom covering its major portion and two deeper pits at its two ends. The anterior pit ends blindly and is communicated with the collecting vacuole by a short and fine canal opening normally to the anterior wall of the pit. But the posterior one is a little larger, opening dextro-dorsally to the water pusule. The side-wall of this furrow consists mostly of interior (median) extensions of the right and left sulcal plates, and the anterior sulcal plate lies with its posterior extension tapered along the anterior wall of the anterior pit.

Thus the two ends of the flagellar pore or pore furrow differ from each other not only morphologically but also physiologically. The water pusule is supposed to serve at least partially as an absorbing organelle while the collecting vacuole is clearly an excretory one. In addition, the transverse flagellum springs from the 
bottom of the anterior pit while the longitudinal one is supposed to come out of the posterior one. This relation is supported morphologically by the specimen having well formed groove connecting the pore with the proximal end of the girdle and posteriorly by the flagellar trough.

The sulcal furrow is a narrow and short groove, covered mostly by the left sulcal plate and partly by the right sulcal one. The furrow can be traced anteriorly to the ridge of the flagellar pore, where it bends dorsally, and further along the posterior wall of the posterior pit.

\section{Flagellum}

The fine structure of the flagella was given on Goniaulax polygramma, in which the transverse flagellum is band-shaped, springing from the anterior end of the sulcus and extends around the body to the distal end of the girdle. The inner margin of the band lies closely along the bottom of the girdle, while its outer free margin along which is seen an axis of the flagellum is undulating as it is longer than the other margin.

A corresponding structure is established on Peridinium oblongum. In this species, the transverse flagellum is also band-shaped throughout its major length except a short proximal portion, lying diagonally between the flagellar pore and the girdle. It can be clearly traced proximally into the anterior pit of the flagellar pore and closely along its anterior wall. The flagellum has a circular cross section within the pit. But it is flattened already at the opening of the flagellar pore. The flagellum in this portion is free from contact with the thecal wall; but as soon as it goes out of the pore it is stuck to the wall. It terminates distally at the dextro-ventral part of the body, and never extends beyond these to the distal end of the girdle. This leads us to recollect that the sulcal furrow is confluent with the proximal end of the girdle but is differentiated more or less abruptly from the distal end.

Along the free margin of the band is seen a fine, highly refractive thread which displays in active organisms a characteristic spiral movement usually in anticlockwise direction. The pitch of this spiral movement is about $3-5 \mu \mathrm{m}$ and is fairly constant throughout the length of the flagellum. The movement is seen to occur in either direction but begins or ends always at a short distance from the girdle, and it can hardly be established in the proximal portion lying diagonally between the girdle and flagellar pore and where the full breadth of the band is not formed as yet. During observations we often saw the flagellum getting loose from the cingular wall, contracting to form a shorter and irregularly tangled thread.

\section{Thecal wall}

The thecal plate is generally covered with meshes or poroids and often scattered with spinules or circular specks, and further it is perforated irregularly in most portion but partially with great regularity.

In some smaller species of Protoperidinium, the thecal plate is hyaline and without 
any structure such as pores or specks. But in some others such as $P$. acuminatum and its allies, it is distributed sparsely or closely with minute circular specks. It is not certain whether such is a surface structure or a texture of the thecal wall. The same structure can be ascertained also in $P$. monovelum and its allies; much distinct one is observed closely arranged all over the thecal plates of $P$. excentricum. In some smaller species of Veroperidinium, such as $P$. punctulatum and $P$. paulseni, the thecal plate is crowded densely with short spinules which are shorter and more sparsely distributed in the epitheca than in the hypotheca. It is presumed that the spicule might have been derived from the speck.

In all the species of the Avellana group of Veroperidinium, the thecal plate is covered sparsely or densely with rounded or slightly angulated poroids of subequal diameter. They are circular and arranged fairly sparsely in $P$. clavus, while they are slightly angulated and more densely crowded in younger specimens of $P$. thorianum and $P$. punctata (CLEve). In grown ones of the latter two, the poroids are often conspicuously polygonal and much densely crowded, displaying mesh-like appearance. When they are thus densely arranged, the thecal surface is distinctly corrugated. It is due to this that the thecal wall displays in polar view a regularly wavy optical section. In the cingular wall, the poroids are elongated transversely across the girdle, forming alternating ridges and grooves. The poroids are subequal in diameter within a single specimen but fairly various between different ones.

The other structure of the thecal wall, generally established in the genus is the so-called reticulation or meshes. But so far as the observations inform us, this cannot be elucidated with a sweeping discussion because of its being derived presumably from different origins. In $P$. crassipes, $P$. grande, $P$. elegans and others, the thecal surface is corrugated according to its typical meshes. But the meshes are not necessarily coupled with the corrugated surface. Such is the case with $P$. schilleri and its relatives, in which the reticulation is not the surface structure but is clearly the texture of the thecal wall. This suggestion is based on the fact that when focussing down the focus reveals for the first time an entirely smooth surface scattered with minute pores and then the meshes, and finally the under surface of the thecal wall after the disappearance of the meshes. Clearly this suggests the fact that the thecal wall in these species consists of three layers, in the middle of which is confined the reticulated structure.

In addition to these apparently different two sorts of the reticulation, there is a third one, established in $P$. obtusum. In this, the marking varies according to the age of organisms. In grown specimens fully formed meshes are seen in either of the epitheca or hypotheca. But the meshes are incompletely formed in various degrees in the epitheca of younger specimens. The structure is formed at the beginning from many scattered centers, each consisting of two or three short ridges radiating from a speck. These ridges grow longer and thicker, and are finally connected each other to form the complete meshes.

All of these considered above have the meshes consisting invariably of conspicuous and more or less regularly formed polygons of considerable diameters. 
On the other hand, we often saw in some smaller species a sort of the meshes consisting of extraordinarily minute and weakly formed polygones. This can be ascertained only when the thecal plate was separated from the cell content and was examined with great care. It is liable to be overlooked under superficial observation.

The fifth type of the reticulation is that established in $P$. sinuosum, in which the meshes are partly complete and partly incomplete. The meshes in this case are irregular in shape, partially consisting of undulating, branched or interrupted veins, and have often a shorter or a longer branch extending into a large mesh. It is to be noted that minute thecal pores are arranged along the vein, and the branch of the vein terminates invariably at a thecal pore. In any case, the vein goes around the thecal pore, and it never passes along its side. In other words, the pore is formed invariably within the vein itself.

A closely related but somewhat differently formed reticulation is established in $P$. rhomboidalis. The meshes in this case is less complete, consisting of very irregularly undulating and branched veins which are formed distinctly from another and connected partially in later stages of growth but never form complete meshes. A similar structure is established in the cingular wall of $P$. sinuosum, in which the meshes consists of many distinct curved veins lying transversely across the girdle. In either case, the vein is also closely connected with the thecal pores. Judging from these, this sort of reticulation may be a variation of the previous forms.

From these, it may be concluded that the so-called surface marking of the thecal plate in the genus consists at least of two sorts, one brought forth by the surface structure and the other with the texture formed in the middle layer of the thecal wall.

The thecal wall is generally perforated with minute pores which pass its entire thickness and opens normally to its surface. They can not often be established, however, in small species, presumably owing to too small thickness of its thecal wall. This thecal pore is related variously to the different types of the marking of the thecal plate. In the case of areolation, the thecal pore is generally arranged between the poroids. In most species of Protoperidinium and Mesoperidinium, in which is established regularly the reticulation, one or several thecal pores are seen lying within a mesh.

In the case of the incomplete or irregular reticulation, the thecal pore is distributed, as given above, along the vein. If we suppose that the typical reticulation is derived from the areolation by too dense arrangement of the areoles, the reticular portion lying between poroids may be a morphological equivalent of the vein in the complete or incomplete reticulation. We have then two sorts of the marking regarding the relation between the thecal pore and the vein. In one of them the pore is seen within the vein and in the other it lies outside of it. One has to recollect here that the vein or its equivalent structure is generally more refractive than the mesh itself. This, together with the differentiated three layers of the thecal wall established on $P$. schilleri, presumably suggests that the thecal wall consists at least of two different substances regarding refractivity. If we assume that the more refractive substance or portion is higher in rigidity than the other less refractive one, which is highly probable, it may be allowed to regard the vein as serving as a support 
against pressure, which will clearly elucidate a close relation between the vein and the pore.

But that these two structures are not necessarily connected is shown above. This is further suggested by the fact that the thecal wall lying within the conspicuously differentiated sulcal or flagellar furrow has generally no surface marking but is furnished invariably with the thecal pore. In case the furrow is less abruptly indented, the marking is formed variously in that part of the thecal wall according to the varying degree of differentiation. In any case, the transitional and two anterior and left sulcal plates, all of which lie within the flagellar furrow, have invariably no reticulation. In other words, the marking of the thecal wall is formed only in the part of the wall, lying along the outer surface of the body. This clearly supports the suggestion that the vein is skeletal in function.

Here we have to add a few words about the thecal pore. Along the outer layer of the cingular wall is seen generally a close set of the pores in most of the species examined. Another line of less closely arranged pores is established invariably in every species along its cingular wall, particularly often along its middle. Further, the thecal pores arranged along one side of a sutural line disappear as the striated sutural band grows broader. Consequently, the pores in a more grown thecal plate are confined into a smaller portion than in a younger one. The distribution and probable function of this thecal pore has to be re-discussed in later paragraphs in relation with the growth of the thecal plate.

\section{Correlation between different thecal characters}

The major thecal characters thus, can be subdivided into certain numbers of types and sub-types, according to their structural differences. Among all probable combinations of them, some was ascertained while others have not been certified to occur in the genus. In addition, some of the characters are fairly conspicuous while others are not. This naturally leads us to some misinterpretations about morphological and taxonomic importance of some structures or their certain combinations, which are distinct but subordinate in property.

Regarding the subdivision of the genus, some of the earliest investigators took into consideration certain structural features both of the epitheca and hypotheca. But many investigators followed JörGENSEN (1913) in placing much taxonomic stress mainly upon the characters of the epitheca, and have thought little of those of the hypotheca.

\section{Ventral and dorsal plate patterns of the epitheca}

The three ventral plate patterns of 'meta', 'para' and 'ortho' were ascertained by JöRGENSEN (1913) and have generally been accepted by his followers as of taxonomic importance. The fourth type, reversed para, has not been established, though some uncertain figures of it were given by some authors. 
On the dorsal half of the epitheca, the intercalary row of plates displays conspicuous variations in the number of its component plates and their arrangement. This row very rarely fails to develop but generally has a single, two or three and often more than four plates. Disregarding this wide range of variation, that the intercalary row consists of two or three plates has generally been believed as of taxonomic importance, and was regarded by some as worthy of subgeneric division of the genus. Furthermore, the shape of the middle one of the triple intercalary plates has generally been highly estimated, while juxtaposition or separation and shapes of the plates in the case of the double intercalary have been hardly thought of. Consequently, nine combinations between the three ventral plate patterns and the three (tetragonal, pentagonal and hexagonal) shapes of the middle intercalary have been discussed as of taxonomic importance.

Table 3. Combinations of plate patterns between dorsal and ventral sides in the epitheca

\begin{tabular}{|c|c|c|c|c|c|c|c|}
\hline \multirow{3}{*}{$\begin{array}{l}\text { Ventral } \\
\text { pattern }\end{array}$} & None & Double & \multicolumn{4}{|c|}{ Triplet } & $\begin{array}{c}\text { Quartet, pentad } \\
\text { or more }\end{array}$ \\
\hline & \multirow{2}{*}{ Single } & \multirow{2}{*}{$\begin{array}{c}\text { Juxtaposed } \\
\text { or } \\
\text { separated }\end{array}$} & \multicolumn{4}{|c|}{ Shape of $2 a$} & \multirow{2}{*}{$\begin{array}{l}\text { Reg. or irreg. } \\
\text { arranged }\end{array}$} \\
\hline & & & Tetra & Penta & Hexa & $\begin{array}{c}\text { Higher } \\
\text { polygonal }\end{array}$ & \\
\hline Meta & & . & 0 & $\mathrm{O}$ & 0 & $\mathrm{O}$ & \\
\hline Para & & , & 0 & - & 0 & & \\
\hline Ortho & 0 & 0 & 0 & $\bigcirc$ & 0 & & $\mathrm{O}$ \\
\hline
\end{tabular}

Reviewing through published figures available at hand and our own drawings, we summarized various combinations between the dorsal and ventral plate patterns of the epitheca (Table 3). From this, it is clear that the ventral plate pattern of 'ortho' is associated with almost every possible dorsal plate pattern ever ascertained, while the other two ventral ones are coupled only with the dorsal triplet. In these two patterns, that of 'meta' is combined with all of the four shapes of the middle intercalary, particularly with two of them (tetragonal and pentagonal). That of 'para' is combined mainly with either of the tetragonal or hexagonal middle intercalary. The ventral plate pattern of 'ortho' differs from them profoundly in that it is combined, in addition, with fewer or more numerous dorsal intercalaries. Among the three (tetragonal, pentagonal and hexagonal) shapes of the middle intercalary, the hexagonal one is predominantly associated with the ventral pattern of 'ortho'. From these, it may be suggested that lower types of the middle intercalary are associated mainly with the ventral plate pattern of 'meta', while its higher type is coupled with that of 'ortho', and either of the lower or higher type is accompanied with that of 'para'.

Thus, each of the three ventral plate patterns has one or two predominant dorsal plate patterns, regarding the middle of the triplet intercalary. On the other hand, there has never been certified a single case in which a single ventral plate pattern 
is combined exclusively with a given dorsal plate pattern.

From these discussed above, it is clear that the ventral and dorsal plate patterns are of morphological significance, but any combination of them is not of taxonomic importance in such a degree as has ever been generally estimated. Contrary to the prevailing belief, much stress is to be placed upon the fact that cases of fewer or more numerous intercalary plates are seen exclusively in the combination with the ventral plate of 'ortho'. This can not be explained, however, before morphological accounts on other more important thecal structures are given.

\section{Ventral plate pattern and hypothecal appendage}

In the ventral and the dorsal plate pattern of the epitheca, the latter has much more various sub-types than the former and is very often subject to individual variation, while the former is fairly well established and has fewer sub-types. Consequently, the ventral plate pattern, as generally accepted now, is more trustworthy and also of practical convenience than the dorsal one in the subdivision of the genus. As pointed above, no one has given, particularly recently, due considerations on the correlation between the structures of the epitheca and those of the hypotheca. But, in view of finding some correlation between them, the ventral plate pattern was examined in conjunction with the antapical appendage, one of the most conspicuous structures in the hypotheca, and interesting results were found which are summarized in Table 4.

The ventral plate pattern of 'meta' is typically accompanied with the rounded or angulated hypotheca furnished regularly with, but often without, the antapical

Table 4. Correlation between hypothecal appendages and ventral plate pattern in Peridinium

\begin{tabular}{|c|c|c|c|c|c|}
\hline \multicolumn{5}{|c|}{ Hypotheca } & \multirow[b]{2}{*}{ 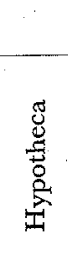 } \\
\hline Ortho & Meta & Para & \multicolumn{2}{|l|}{ Ventral plate pattern $\begin{array}{c}\text { Hypothecal } \\
\text { appendage }\end{array}$} & \\
\hline 0 & & o & \multicolumn{2}{|l|}{ Spineless } & 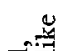 \\
\hline - & $\mathrm{O}$ & 0 & Winged spine & \multirow{3}{*}{ 芯 } & $\int_{0}^{\pi} \frac{\pi}{6}$ \\
\hline & 0 & 0 & Wingless spine of Steinii-type & & 蛋 \\
\hline & 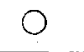 & O & Wing-complex & & 昶 8 \\
\hline & o & - & Typical horn coupled with distal spine & & \\
\hline \multirow[t]{2}{*}{0} & & & Typical horn & \multirow{3}{*}{ 莒 } & \multirow{3}{*}{ 范 } \\
\hline & () & & Semisulcal horn & & \\
\hline () & & & Pseudomorphous horn & & \\
\hline
\end{tabular}


spine. The only exception of this is seen in $P$. granii in which the thecal wall bulges on either side of the ventral area to form a small conical process bearing a distal spine. In all other respects, this species is related most closely to other typically spined species.

The ventral plate pattern of 'para' is united partly with the semisulcal horn and partly with the wing-complex and exceptionally. with that of Steinii-subtype. This agrees with the relation established between the ventral and dorsal plate patterns of the epitheca.

The other ventral pattern is associated partly with the rounded and spineless hypotheca and the typical antapical horn and exceptionally with the rounded hypotheca bearing wingless spine. It is to be reminded that the ventral plate pattern of 'ortho' is never coupled with the typically spined hypotheca. Further, it is to be estimated that three sub-types of the antapical horn are fastened respectively to a single ventral plate pattern of either 'para' or 'ortho', and that the antapical spine or wing-complex is coupled more frequently with the ventral plate pattern of 'meta' than that of 'para' but never with that of 'ortho' except a single case. And the spineless hypotheca is established in association with that of 'meta' or 'ortho' but not 'para' (Table 4).

From these it is clear that a given type or sub-type of the antapical appendage is coupled either with a single or with two of the three ventral plate patterns. We can establish, then, exactly or approximately the ventral plate pattern of a given specimen judging from the structure of its antapical appendage.

\section{Ventral plate pattern and cingular displacement}

Together with the plate pattern of the epitheca and the type of the antapical appendage, the type of the distal displacement of the girdle has long been taken into consideration in the characterization of the subgenera and groups of the genus. As described in previous paragraphs, the girdle indication is related more closely with the antapical appendage through the ventral area than the other structure of the

Table 5. Correlation between the thecal plate pattern and the cingular displacement

\begin{tabular}{l|c|c|c}
\hline Ventral plate pattern & Meta & Para & Ortho \\
\hline Strongly ascending & 0 & & \\
\hline Slightly ascending & 0 & 0 & 0 \\
\hline Circular & 0 & 0 & 0 \\
\hline Slightly descending & & & 0 \\
\hline Strongly descending & & & 0 \\
\hline
\end{tabular}


epitheca. As is given in Table 5, there are some correlation between the types of the ventral plate pattern and the girdle.

The tilt of the girdle is divided, for the sake of convenience, into five grades regarding degrees of its distal displacement. No definite or characteristic correlation is certified between the circular or slightly ascending girdle and the three types of the ventral plate pattern. It may be worthy to note that the strongly ascending girdle is coupled with only the ventral plate pattern of 'meta' while the descending girdle mainly with that of 'ortho'. This inclination, together with the variableness of the cingular displacement in many species, leads us to the conclusion that the type of the cingular displacement in conjunction with the ventral plate pattern of the epitheca can not be too much estimated as of taxonomic importance.

\section{Cingular displacement and antapical appendage}

The girdle and the antapical appendage such as spine or horn lie at either end of the ventral area, by which they are connected with each other. Then they may be expected to display some correlation. The circular girdle is seen associated with almost every type of the antapical appendage, while the ascending girdle is correlated more frequently with the antapical spine and the descending girdle with the antapical horn. This is clearly due to the fact that a certain type of it has closer relationship to the ascending or descending girdle but never in like manner with both of them. And closely related two or three types of the appendage display parallel relationships in this regard. Regarding the spineless hypothecae, it is to be recollected that they are seen mostly in Veroperidinium and only partly in the Glo-

Table 6: Correlation between antapical appendages and cingular displacement

\begin{tabular}{|c|c|c|c|c|c|c|c|c|}
\hline Hypotheca & & \multicolumn{4}{|c|}{ Hemispherical, conical or alike } & \multirow{2}{*}{\multicolumn{3}{|c|}{$\frac{\text { Bi-horned }}{\text { Horn }}$}} \\
\hline & & \multicolumn{3}{|c|}{ Spine } & \multirow[b]{2}{*}{ 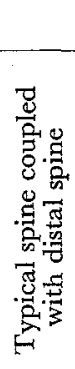 } & & & \\
\hline $\begin{array}{l}\text { Type of } \\
\text { cingular } \\
\text { displacement }\end{array}$ & 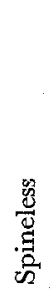 & 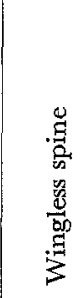 & 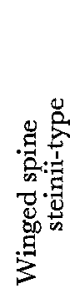 & 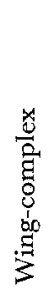 & & है & 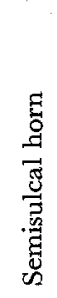 & 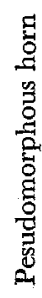 \\
\hline Strongly ascending & O & $\mathrm{O}$ & & & & & & \\
\hline Slightly ascending & - & 0 & $\mathrm{O}$ & $\mathrm{O}$ & 0 & & O & $\bullet$ \\
\hline Circular & 0 & $\bullet$ & 0 & 0 & & 0 & 0 & ० \\
\hline Slightly descending & 0 & & & - & & 0 & 0 & 0 \\
\hline Strongly descending & 0 & & & & & 0 & 0 & 0 \\
\hline
\end{tabular}


bula section of Protoperidinium. The former is furnished generally with the circular or descending girdle and the latter exclusively with the conspicuous ascending girdle.

As given just above, this feature agrees in the main with the correlation between the types of ventral plate pattern and those of the cingular displacement. It may be suggested, therefore, that the types of the ventral plate pattern and those of the antapical appendage also show a certain correlation.

\section{Antapical appendage and ventral area}

Although the antapical appendage has generally been fairly well estimated and the ventral area was hardly been brought under extended morphological study, these two structures are similarly of utmost taxonomic importance as well as morphological significance. Roughly speaking, either of them can be divided into three types as elucidated before, and they are associated with one another as given in Table 7.

Table 7. Antapical appendages and types of the ventral area

\begin{tabular}{|c|c|c|c|}
\hline$\underbrace{\begin{array}{c}\text { Antapical } \\
\text { appendage }\end{array}}_{\begin{array}{c}\text { Ventral } \\
\text { area }\end{array}}$ & Extensionless & Spine & Horn \\
\hline Steinii type & 0 & 0 & - \\
\hline Divergentia type & 0 & 0 & 0 \\
\hline Conica type & 0 & - & 0 \\
\hline
\end{tabular}

As far as indicated in this table, any particular correlation appears to be hardly certified between any two types of the structures. But when sub-types of them are examined, they display definite correlations as given in Table 7. As the structural relation of the ventral area is hardly known regarding the Heteracantha subtype, it is excluded partly from the table. Regarding the minute conical bulge of the thecal wall at the base of the antapical spine as a short or a primordial form of the typical or semisulcal horn, it is marked in conjunction with the Laterispinosa and Pellucida sub-types of the ventral area. The fresh-water species have often one, two or several spinules or horn-like structures, but they are excluded from the table because we have not examined their property with sufficient accuracy. Before going into examination of this table, it is to be recollected that the Tatrica and a part of the Pellucida sub-types of the ventral area are more closely related to the Divergentia type than to others regarding the plate pattern of the structure; notwithstanding they are allocated in this paper to the Conica and the Steinii type basing on the structural relations of their hypotheca and its appendage.

With exceptions of the Heteracantha and Conica sub-types and the other type having no antapical appendage, every sub-type is correlated exclusively with a single sub-type of the ventral area. In the case of the minute conical bulge considered above, it is always accompanied with a well formed wing-complex, which 
Table 8. Correlation between types of antapical appendages and those of ventral area

\begin{tabular}{|c|c|c|c|c|c|c|c|c|c|c|c|c|c|c|c|c|c|}
\hline & Ventral & Type & \multicolumn{6}{|c|}{ Steinii } & \multicolumn{3}{|c|}{ Divergentia. } & \multicolumn{6}{|c|}{ Conica } \\
\hline \multicolumn{2}{|c|}{$\begin{array}{l}\text { Antapical } \\
\text { appendage } \\
\text { or elongation }\end{array}$} & $\begin{array}{l}\text { Sub- } \\
\text { type }\end{array}$ & 䔍 & 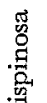 & 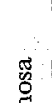 & $\frac{\pi}{\pi}$ & · ્ָّ & $\underset{\mathbb{Z}}{\mathbb{D}}$ & 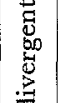 & . & $\pi$ & $\underbrace{\pi}_{\pi}$ & đ్ల & 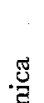 & $\frac{\pi}{8}$ & $\vec{y}$ & \\
\hline Type & Sub & pe & $\stackrel{0}{\Sigma}$ & 䔅 & 獣 & $\frac{0}{0}$ & I & 䓌 & 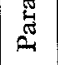 & 足 & 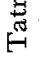 & 产 & $\stackrel{\square}{8}$ & ठัّ & $\stackrel{ह}{B}$ & 峛 & ठี \\
\hline \multirow{7}{*}{ Spine } & \multicolumn{2}{|c|}{ Heteracantha } & $?$ & $?$ & & & $?$ & & & & & & & & & & \\
\hline & \multicolumn{2}{|c|}{ Monacantha } & O & & & & & & & & & & & & & & \\
\hline & \multicolumn{2}{|c|}{ Laterispinosa } & & $\bigcirc$ & 0 & & & & & & & & & & & & \\
\hline & \multicolumn{2}{|c|}{ Bispinosa } & & & & & & & & & & & & & & & : \\
\hline & \multicolumn{2}{|c|}{ Pyriformia } & & & & & 0 & & & & & & & & & & \\
\hline & \multicolumn{2}{|c|}{ Pellucida } & & & & & & 0 & & & & & & & & & \\
\hline & \multicolumn{2}{|c|}{ Paradivergentia } & & & & & & & 0 & & & & & & & & \\
\hline \multirow{3}{*}{ Horn } & \multicolumn{2}{|c|}{ Semisulcal } & & - & & & & - & & 0 & & & & & & & \\
\hline & \multicolumn{2}{|l|}{ Typical } & & - & & & & - & & & & & & O & & & \\
\hline & \multicolumn{2}{|c|}{ Pseudomorphous } & & & & & & & & & & & & & & & \\
\hline \multicolumn{3}{|c|}{ Extensionless } & & & & 0 & & & & & 0 & $\mathrm{O}$ & O & & 0 & 0 & \\
\hline
\end{tabular}

has predominance over that basal one. The hypotheca is often hemispherical, conical or alike, and is ascertained to occur most frequently in Veroperidinium and partly in Protoperidinium. This is clearly heterogenous in origin and can be subdivided as shown in the table. Conforming to the highly polymorphic posterior sulcal plate in the Conica group of Veroperidinium, the hypotheca in that group is unusually various, ranging from hemispherical to typically bi-horned. Then, the Conica sub-types of the ventral area is illustrated in the table, for the sake of brevity, as associated with two forms of the hypotheca.

From the relationships established just above, it is clear that the ventral area and the antapical appendage are related so closely with each other that we can certify with great exactness the sub-type of one of them through that of the other.

\section{Ventral area and ventral plate pattern}

The ventral plate pattern has been estimated generally as the character of the paramount taxonomic importance, and the utmost taxonomic stress is laid in this paper upon the structural relation of the ventral area. Associations between them are given in Table 9.

It is interesting that in the table the three types of the ventral area is correlated in the main with the three types of the ventral plate pattern. The 
Table 9. Correlation between ventral area and ventral plate pattern.

\begin{tabular}{l|c|c|c}
\hline & Meta & Para & Ortho \\
$\begin{array}{l}\text { Ventral } \\
\text { plate pattern }\end{array}$ & 0 & $\bullet$ & $\bullet$ \\
\hline Steinii-type & - & 0 & 0 \\
\hline Divergentia-type & & & 0 \\
\hline Conica-type & & & \\
\hline
\end{tabular}

Meta-Steinii combination is connected with the Para-Divergentia combination through the Meta-Divergentia type. And the Para-Divergentia and Ortho-Conica combinations are fastened with each other by means of the Ortho-Divergentia combination.

So far as published figures inform us, all of the three ventral plate patterns are ascertained in the Heteracantha section of Protoperidinium. As these published figures of the species comprised in that section are drawn very insufficiently and are not described in detail, they are not trustworthy as for their ventral plate pattern. But this does not mean that either the Para-Steinii or Ortho-Steinii combination is unthinkable in nature, as we certifed a single case of the Ortho-Steinii combination in $P$. granii which is characterized typically by the Meta-Steinii combination.

Together with the close relationships between the ventral area and the antapical appendage, the present one is the most trustworthy one among possible combinations of the major thecal characters given above. These two combinations are not only of practical convenience but also of profound taxonomic importance because of the great regularity of the previous and the apparent simplicity of the present ones. They not only clearly suggest taxonomic relationships or natural unities of the species groups represented by the combinations but also help us in proposing a new principle of subdivision of the genus, with which we can answer some important problems which have not been solved nor even investigated with trustowrthy accuracy.

\section{Growth of the body}

It has long been known that some peridinian bodies have narrower or broader zones of striae along the sutures. As to the morphological significance of this structure, STEIN elucidated for the first time that the thecal plates are brought together by means of this. He was followed by SaHütт (1895) and KoFoId (1909). The former of them regarded the structure as due to thickening of the thecal wall so as to strengthen the thecal wall along the junctions of plates, believing that growth of the peridinian body does not depend solely upon the marginal growth of the thecal plates because of the fact that if that is the sole agent, the thecal plate of 
grown spherical bodies must have unusually convex surface bringing forth some distortions of the body contour. Studying upon structural details of the thecal wall of $P$. steinii KoFOID (1909) came to a different but somewhat similar conclusion. According to him, "The correlation of the increased width of the intercalary bands with the thickening of the wall and reduction in the porulate areas of the plates leads us to infer that they are neither growth zones nor peculiar types of membrane thickenings" and further that "the striae are modified pores or canals lying in the wall, or on the oblique faces of the overlapping margins of the plates," and "may be structural adaptations facilitating the communication of the inner and outer plasma, the transfer of fluids through the substance of the wall, and also the union of the opposed surface."

Gontrary to them, BüTSGHLI $(1885,1889)$ came to the consideration that "die Interkalarstreifen dem Zuwachs der Fläche bezeichnen, welchen die Tafeln nach ihrer abgrenzung noch erfahren haben." BROGH (1910) followed him regarding the sutural zone as formed by marginal growth of the thecal plate, and saw older thecal plates bulging unusually in $P$. ovatum, $P$. curvipes and $P$. depsessum. Lemmermann (1910) saw in $P$. willei that the striated zone is very narrow in younger specimens but grows broader as the growth of the body goes on. But marginal parts of the thecal plate have, according to him, often "dünne, durch Querleisten verstärkte Membranfortsätz." BüTsGHII's suggestion was supported by BARRows (1918) who, giving extended considerations on the thecal variations of the genus, described as follows: "The joint at the sutures is beveled and corrugated (KoFoID, 1909) and it seems probable that limited growth with age is permitted by the widening of this beveled edge through the addition of shell material on the margin of the plate. The great differences in the appearance of the sutures varying in different individuals from narrow, highly refractive lines to wide, striated tracts are regarded as due to the widening of the sutures to accommodate the internal pressure of growth with age." This was confirmed as such by Peters (1928) who, taking into considerations the distribution and arrangement of the sutural striae and marginal laminae of the thecal plate, came to the conclusion, supporting BürschlI's suggestion, that 'Die Vergrösserung des Panzers geschieht sicherlich zum grössten Teil, wahrscheinlich sogar ausschliesslich, durch Wachstum an der Rändern der Platten" and further that "Es ist sehr wahrscheinlich, dass die leistenformigen Verdickungen,..., zur Versteifung derselben dienen und es ist ferner möglich, dass die schräg verlaufenden, kanalartigen Gängen,..., der Verbindung des inneren und äusseren Plasmas dienen." Ascertaining on one hand variations in the size of body between different specimens furnished with sutural zones of similar breadth, he established on the other hand that a given plate of a smaller specimen with narrow sutural zones corresponds exactly in size and shape with its corresponding one of a much longer one with broadest sutural zones, both belonging to the same species, $P$. subinerme. This comparison appears to support decidedly Bütschli's as well as Peters' conclusion that enlargement of the thecal plate is carried out exclusively by means of marginal addition but not of interstitial deposition of thecal substance. 
So far as our studies upon materials in both Asamushi and Shimoda are concerned, Peters' conclusion is correct in the main but appears to be wrong in some details. Distinguishing 'Falzstreifen' from 'Zuwachsstreifen', PÉTERs apparently confused them in some cases such as in Fig. $27 \mathrm{~b}$ and Fig. $28 \mathrm{~h}$. The apicals 2 ' and $4^{\prime}$, the intercalary $2 a$ and all of the precingulars differ in shape between figures $b$ and c of Fig. 27. And the hind margin of the middle intercalary plate, 2a, is illustrated in Fig. 28 h as shorter than the anterior margin of the precingular, 4'. . These inconsistencies, though they are trivial in property, are improbable in nature and may clearly be due to his misinterpretation or misdrawing. It is highly probable that total breadth of 'Zuwachsstreifen' and 'Falzstreifen' are called by him as 'Interkalarstreifen' which overlap partially with the reticulated areas of the thecal plates. Some wrong conclusions may likely be introduced unless one carefully distinguishes seeming width of 'Falzstreifen' from the actual breadth of the sutural zone. The latter is represented by a structureless or striated band of a certain breadth, lying between two reticulated or areolated areas, while the former is striated and often greater in breadth than one-half of the sutural zone, and it lies partially below marginal parts of the reticulated or areolated area. Magnitudes of growth is represented by the sutural zone but by 'Falzstriefen'. It is requested, then, that when one discusses the growth of the thecal plate in relation to the arrangement and variation in breadth of the sutural structure, he has to confine his considerations only upon the sutural zone or 'Zuwachsstreifen' lying between two reticulated or areolated areas, distinguishing it as the same time from 'Falzstreifen' or 'Interkalarstreifen'.

Distinction from one another of these three sutural structures is absolutely necessary in the review of published figures in order to get correct conclusions about the distribution or development of the sutural structure. If due considerations were not given, 'Interkalarstreifen' may probably be misinterpreted as to represent the real magnitude of growth, as was often done by many former investigators. As may be clearly understood from Peters' Fig. 28, 'Interkalarstriefen' is practically often much more, and in extreme cases, several times greater in breadth than 'Zuwachsstreifen'. Consequently, if one regards the striated structures illustrated in published figures as to represent actual magnitude of growth, he may likely be led to wrong conclusions or overestimations about the magnitude of growth.

It is apparent that any peridinian body increases its size or diameters during entire course of its growth. But, it is utterly impossible for us at present to calculate the growth-rate or actual magnitude of growth by tracing a single individual or a herd of given species throughout the entire course of its growth period because of lack of our cultural technique of the armoured peridineans. Further, the sutural zone of a given thecal plate is various in breadth in different portions of a plate and further of a body, and the total sum of these zones represent the circumferential growth but not the actual growth in diameter, length or volume of the body. On the other hand, as was pointed out by PETERs (1928), there is very often a wide range of variation within a single species in the size or diameter of bodies with extremely narrow or similarly grown sutural zones. Within a given species, the epitheca or hypotheca 
is divided into a difinite number of plates or series of plates, every one of which occupies a fairly constant ratio of its entire surface, which is characteristic of a given species. Naturally a given plate of a originally larger specimen is larger in absolute size than its corresponding one of a smaller specimen. All these facts point to the conclusion that it is utterly impossible to show the growth rate by calculating either the breadth of the sutural zones or the diameters of different specimens in case their corresponding plates do not coincide exactly with each other in size. Peters' Fig. 27 is uncertain in this regard. But in spite of these, it may be possible, on the other hand, to calculate the original size or diameter of a grown specimen of a given well known species from an exactly drawn, apical view sketch of its epitheca, by reducing the sutural zones and then re-arranging originally formed parts of the thecal plates represented by the reticulation or areolation. Selecting from drawings of the apical view drawn as exactly as possible of specimens with extremely broad sutural zones, we then contrived with greatest care to re-arrange their reduced thecal plates, keeping at the same time from distortion of the body contour. The transverse diameter of these well-grown specimens may be reduced by this method of re-drawing to $67-77 \%$. If it is assumed that this method does not introduce many errors or misinterpretation, it appears to suggest that these species just measured come during their growth period to 1.3-1.5 times larger in transverse diameter than their original size. Regarding the volume of the body, they become 2.20-3.4 times as large as their original ones.

It may be allowed to say with certainty that these species just considered have each a certain limit of its growth, characteristic of the species. And the maximum growth-rate of these species may be ca. 1.5, judging from the fact that these specimens given here are unparalleled regarding the breadth of their sutural zone not only in the published figures but also in our materials. Examination of a vast number of specimens of the genus informs us of the fact that comparatively broader sutural zone presents itself rather in some smaller species than in larger ones. So far as our material is concerned, the most remarkable example of this is either $P$. conicoides or $P$. brevipes in which especially the body contour of the cingular section is modified by over-development of the sutural zone. A similar modification can be established also in other larger species but this shall be considered in a later paragraph. Another example of this is $P$. multistriatum of Kofold, although actual breadth of its striated sutural zone may be much inferior than figured because of his confusion of 'Falzstreifen' with 'Zuwachsstreifen', which seems to be highly probable.

The development of the sutural zone is, as shall be discussed in other paragraphs of this paper, irregular in some species or in some individuals of certain species. And often we saw a case in which the latitudinal sutural zone is remarkably broader in proportion to the longitudinal one. In such cases, it may naturally be concluded that the growth is greater in length than in depth or breadth. Presumably as a result of this different growth ratio of the body in the two directions, relative length of the body is often larger in well-grown specimens than in younger ones in some species such as $P$. brevipes, $P$. thorianum and others. 


\section{Growth of thecal plates}

Growth of the body is accompanied naturally with that of the thecal plates, which has been regarded due either to the intermolecular (interstitial) deposition or to the marginal addition of thecal substance. The latter way of consideration has generally been accepted recently, and was strongly supported by Peters (1908). Long period of study on this problem led us also to support Peters' conclusion except for some points which are emended in this paper.

Against Bürschlı's suggestion of marginal growth of the thecal plate, SaHÜtT demonstrated because of the consideration that if that occurs it must follow that the thecal surface of well-grown specimens is unusually convex in the portion covered with every thecal plate. This uneven contour which was unacceptable for ScHÜTT, was afterwards proved true in some species by Broch and others. And PeTers elucidated it as due presumably to the elasticity of the thecal wall (KOFOID).

The irregularity of the body contour due to development of the intercalary zone can not be established in our materials as the zone is too narrow. Particularly the knurled surface which may be the ultimate form of the irregularity has never been ascertained notwithstanding careful investigation. The most common case ever seen in our materials is that the cingular edge in apical or antapical view is straight or weakly concave instead of convex at the distal end of the longitudinal sutural zone, where the cingular list has no rib at all.

Over-grown specimens of $P$. brevipes and $P$. conicoides usually have along their cingular edge two broadly rounded indents each at its dorso-lateral portion. The cingular section of them is then weakly three-lobed owing to the two indents and the mid-ventral indentation of the body. The dorso-lateral indent in this case is seen at the intrapostcingular sutural zone lying on either side of the dorsal postcingular plate. Further, in well-grown specimens of some of much larger species such as $P$. crassipes and $P$. conicum, there can be seen two additional indents each on either side of the mid-ventral one at the sutural zone between $1^{\prime \prime \prime}$ and $2^{\prime \prime \prime}$ on the left or $6^{\prime \prime \prime}$ and $7^{\prime \prime \prime}$ on the right. From these, it may be apparent that over-grown sutural zone brings forth along it a flattening or weak depression which is particularly strong along the intrapostcingular suture or at its distal end. There can be no other elucidation for this but for interpreting it as due to increased rigidity of older thecal plates, by which original surface curvature of a thecal plate is kept as far as possible throughout its growth.

The reason why this irregularity or dent around the cingular section of the body is not formed in specimens with narrower sutural zones may be that younger or thinner thecal plate has higher elasticity, yielding to the pressure caused by the growth of body content. Contrary to this postcingular one, no dent is formed in any case along the anterior cingular edge, that is, at the distal end of the intraprecingular sutural zone. This, however, may be accounted as due partly to closer arrangement of the intraprecingular sutures than the intrapostcingular ones. In other words, as the precingular row is divided into smaller and more numerous plates than the post. 
cingular rows, a precingular plate or intraprecingular sutural zone receives a smaller proportion of inner pressure or power of torsion of the thecal wall, which may be the same or at least subequal in strength on either side of the girdle. Consequently, the distortion due to growth may present itself more readily and distinctly in the postcingular row than in the precingular row of plates.

A similar but much less distinctly formed depression may be formed along every sutural zone in case it grows to strikingly greater breadth. But such can hardly be certified in surface view or optical section because of too small distortions formed there. If the distortion or irregularity in surface curvature is small, it can hardly be established either in surface view or in optical cross section normal to the surface, but it can often be readily certified in a cross section cutting the surface at a smaller angle. Such may be the case with the cingular section of the body. Along the girdle, the thecal wall flares more or less remarkably in many species, particularly in those in which the dents are easily ascertained along the girdle. In them, the cingular plane cuts the thecal wall remarkably obliquely all around the body. These may be the reasons why the distortion of the thecal wall due to the growth can be established most readily along the girdle, particularly distinctly along its posterior ridge.

The suggestion that the thecal plate has a property to maintain its original curvature throughout the growth period may be supported by the fact that the dorsal portion of the epitheca in a over-grown specimen of $P$. marukawai, where the surface curvature is strongest in the body, is more convex than in younger ones (ABÉ 1936 b, p. 28, Figs. 9-11).

Interesting in this regard is the fact discussed for the first time by PETERs (1928) that some of the intraprecingular sutural zones lying in the dorsal side of the body taper towards the girdle instead of towards the apex. Similarly either or both of the dorsal intrapostcingular sutural zones are in some rare cases narrower towards the girdle. This irregularity thus occurs in either or both of the pre- and postcingular rows. This fact is apparently inconsistent with Peters' opinion, so is to be elucidated in a different way, which shall be discussed in other paragraphs. It shall briefly be given here that so far as our study reveals, this irregularity is correlated to the swelling or flaring of the dorsal portion of the body as given just above but not to the posterior or anterior displacement of the growth-equator as suggested by Peters. Though the distribution of the sutural zone throughout the major portion of the body was already given by Peters, and also shall be re-considered in other paragraphs of this paper, almost nothing has ever been given about that in and around the ventral area. In all species of the genus, a narrower or broader sutural zone makes its appearance along the right and dorsal (posterior) sides of the ventral area, and does not present itself between the sulcal plates until extremely broad zones are formed in other part of the body. This fact, which shall be given in detail later, clearly supports BÜTSCHLI's and PETERs' opinion of marginal growth.

If we assumes, contrary to Bütschli's or Peters' conclusion, that the interstitial growth of the thecal plate goes on during entire period of growth either in 
addition to or instead of the marginal growth, it must follow that absolute magnitude of growth is greater in an originally larger plate than in a smaller one and also becomes greater towards the girdle from the apex or antapex. In other words, if the two sorts of the growth are carried, two opposite sides of a transverse suture, which lie closely together along their entire length and have exactly the same length before development of the sutural zone which gradually puts them apart wider as the zone grows on, have to grow differently. But this is not the case in nature so far as our careful investigation reveals. It has generally been established that in some species the sutural zone has closely arranged transverse striae across its entire breadth. In most cases, these striae are arranged, as has often been described, transversely across the zone, but not rarely they are oblique to the sides of plates. In any case, however, any two striae or groups of striae are always parallel with each other so far as they belong to a single sect of the sutural zone, in disregard of straight or curved tract of the zone. We have not yet seen a single case in which the striae belonging to one sect of the zone converge or inversely diverge towards one of the two juxtaposed plates. In Fig. 35 (231), in which is shown the zone of striae lying between some plates of $P$. crassipes, one can clearly ascertain the facts that the striae lying on the left hand are arranged normally to the side of either of the two plates, but those on the other end of the zone are set diagonally across the zone. And yet, these two groups of the striae are parallel with each other. Together with this fact, the same figure gives us an impression as if the striae are a trail of the two plates left behind when they were pulled apart from each other without any change in size and shape of them. In such a case as this curved one, the breadth of the zone differs in its different portions but its two sides correspond exactly with each other in shape and length. From these, it may be concluded that the two opposite sides of a single sect of the sutural zone are left unchanged in their shape and length throughout entire period of the growth, that is, there is no trace of different growth between adjoining margins of two juxtaposed plates, and that two ends of a single stria of the zone may be regarded as representing the two points standing side by side before separation of the two original plates.

The sutural zone thus formed does not always have the same breadth all around the thecal plate, being narrower in some while broader in other sides. This irregularity in the directions of stronger growth is characteristic of a given plate of a given species. The rhombic ventral apical plate of $P$. depressum has, according to Peters' Fig. $28 \mathrm{c}$, two narrower antero-lateral and two broader postero-lateral sutural zones, each of which agrees in breadth laterally. But that of $P$. subcurvipes has remarkably broad marginal zones in its posterior half, which develop particularly more strongly towards the left than towards the right. The left ventral precingular plate of $P$. schilleri has along its either side a broader right and a narrower left sutural zones, but no visible zone is formed along its posterior side along which stands the cingular list and by which it borders on the girdle. These structural features just given for $1^{\prime \prime}$. hold true for every plate of the pre- and postcingulars. The cingular plates expand between the inner bases of the two cingular lists, and the zone of 
striae does not appear along either side of the girdle until strikingly broad sutural zones are formed in other portions of the body. In such a well-grown specimen, when the theca is splitted along the girdle, a narrow and striated lamina can be established extending from the base of the cingular list. This lamina, on the other hand, cannot be established in specimens with narrow or no sutural zone, and does not extend, even when it develops to its maximum breadth, beyond the middle of the girdle. Furthermore, the breadth of the girdle is fairly constant throughout the genus, and does not become larger in broadly sutured specimens of any species. From the fact considered at the last, it is apparent that there never occurs marginal growth along the sutures lying on either side of the girdle, and that the cingular plate does not become broader by means of either the marginal growth or the interstitial deposition, notwithstanding of apparent formation of a broad band of striae between any two of the cingular plates. In short, along the cingular edge of the pre- or postcingular plate is never built the sutural zone but is formed in a later stage of the growth a narrow marginal laminae, and the cingular plate itself is not capable of growing broader. These peculiar and interesting features of the cingular plate are to be regarded as extreme cases of the irregularity of the growth, being checked partly or entirely in one or two directions.

Partly in relation to this extreme irregularity of growth in the cingular region and partly to the differences in the number of the longitudinal sutures among the precingular (6), cingular (2) and postcingular (4) series of plates, there occurs a peculiar fact that so long as the growth goes on, very gradual shift of plates is carried on differently between the precingular and cingular plates on one hand and between the cingular and postcingular plates on the other, in each case one sliding in transverse direction along the other. This peculiarity can not be elucidated without considering the fixed breadth of the girdle throughout the entire period of growth in any species and also throughout the genus. And this regularity has a profound relation with the morphological as well as physiological singificance of the transverse flagellum.

All these facts and considerations given above lead us to suggest that the thecal plate grows larger by means of marginal addition of thecal substance. But there is one fact presumably against this conclusion.

The surface meshes of the thecal plate are in typical cases regularly subequal all over a single plate when the sutural zone is narrow. But in some broadly sutured specimens of $P$. angustum, $P$. crassipes and $P$. depressum, a single or double row of larger meshes more often seen arranged along marginal portions of a plate, lying above the broad zone of striae. Further, we saw a case in which a narrow median margin of the left ventral postcingular plate of an over-grown specimen of $P$. angustum is covered with remarkably smaller meshes consisting of unusually thick laces which irregularly fill up some of the meshes. It is to be reminded that either of these irregularities is always seen associated with development of unusually broad zone of striae, and that the irregularity of this sort can not be seen, so far as our study reveals, in younger specimens with narrower bands of striae. If this change of structure occurs during 
growth of the body, it must follow that the interstitial deposition of the thecal substance or partial reorganization in the texture of the plate must have took place in these portions of plates, lying over the sutural striae. We have, however, no other datum to lend support to this view.

\section{Sutural structure}

The sutural structure has been interpreted variously by some of former investigators such as Stein, Bütschli, Schütt, Kofoid, Lemmermann, Broch, Peters and some others.

Regarding the structure of the intercalary striae, BürschlI (1889) described on Gonyaulax polyedra and Peridinium divergens as follows: "... dass die feine Querstreifung nicht auf der äusseren, sondern der inneren Fläche der Streifen ihre Sitz hat, wenigstens finde ich bei Peridinium, dass die äussere Flache dieselben Netzfeldchen deutlich aufweist, wie übrige Tafelfläche; die aufeinander stossenden Feldchen benachbarten Tafeln zeichnen sich nur dadurch aus, dass sie ziemlich regelmässig senkrecht zur Grenz der Tafeln gerichtet sind, ....." His observations are in the main correct and accurate. He regarded the intercalary zone as "die neuhinzutretenden Randverbreiterung" believing on the other hand "die Mäglichkeit eines äusseren Wachstums...."

To this author's interpretation SсHÜтT (1895) dissented, regarding the intercalary band of striae as thickening of the thecal wall, by means of which the wall is mechanically strengthened along the suture, and with which at the same time the thecal wall is secured from breakage. He further believed that the growth of the thecal plate is fulfilled by intermolecular deposition of thecal substance, basing on the consideration that if the marginal growth occurs alone as was suggested by BürsGHLI, these must follow in spheroidal forms distortion of the body contour caused by original surface curvatures of the thecal plate.

Inquiring into the thecal morphology of P. steinii, KoFord (1909) conjectured that "the band of intercalary striae is not surface thickening either upon the outer or inner face of the wall but is an oblique structure in the substance of the wall itself in and beyond the region of overlapping on the margin of the plates, passing from the outer to the inner surface...," suggesting at the same time that "the striae are modified pore or canals lying in the wall, or on the oblique faces of the overlapping margins of the plates," and further that "the structures are continued beyond the edges of the overlapping plates...." In the main he conforms to STEIN's suggestion, but one year later BROGH (1910), acknowledging BürsaHLr's conclusion, admitted remarkable convexity of grown thecal plates, which SGHÜтT regarded as improabale in $P$. ovatum, $P$. curvipes? and $P$. depressum. On the other hand, Lemmermann (1910) remarked that the band of intercalary striae is a "dünne, durch Querleisten verstärkte Membranfortsätze..., , and that "Manchmal besitzen die verfalzten Fläche auch noch besondere, ineinander grèifende Riefen, die eine ausserordentliche feste Verbindung ermöglichen." 
Studying the thecal structure of $P$. depressum, $P$. subinerume and others, Peters (1928) certified the fact that a well-grown thecal plate is encircled with either or both of Zuwachsstreifen and Falzstreifen. According to him, "Der Falzstreifen, der unter die Nachbarplatte mit dünner Leiste hinunter fasst, zeigt häufig eine Querstreifung, die durch Versteifungsrippen entsteht." Regarding the sutural structure of an uncertain species, presumably belonging to Protoperidinium, he described that "Die Plattenränder liegen mit der Oberfläche der erhaben Leisten aufeinander, so dass die Einsenkungen neben den Rippen Kanäle oder Gänge mit Verbindungsbrücken an der Unterbrechungen der Leiste darstellen." Further he saw in P. subinerme that "die Rippen des einen Falzstreifens nicht in vertiefungen der Nachbarplatte hineinfassen, sondern wo Leiste auf Leiste liegt, so dass auch Gänge vorhanden sein müssen, die vielleicht mit den Kanälen (KofoID) homolog sind."

In other paragraphs detailed accounts are given on the structural relations of the sutural cleft in a Blephalocysta species of Podolampinae and Diplopsalopsis minor of the Diplopsalis group. In the former, the sutural cleft or plane of contact is somewhat J-shaped in its course, passing for the major breadth obliquely through the thecal wall and bends along its one end more or less normally to the outer surface of the thecal wall. On the contrary, that of the latter is remarkably complex, being deeply folded along its middle. The former has, then, around its thecal plate an oblique surface of contact, by means of which any two plates are connected. In the latter case, one of two juxtaposed plates has along its outer margin an inner and an outer laminae and the other plate has a single one which is inserted originally between the two of the other plate.

The genus Peridinium lies, so far as our studies on several species revealed, between these two examples regarding the complexity of the sutural structure. By almost all the former investigators who discussed this structure, it has been suggested and generally accepted that two thecal plates are united with each other by means of cohesive substance. Such may be a natural interpretation if we accept SaHÜtT's or Peters' conclusion about the sutural structure. To this, however, we dissent from a peculiar fact which led us to suggest that there must be in some species another structure by which two thecal plates are mechanically united. While examing the sutural structure of $P$. depressum preserved in alcohol or formaline for a long time, sometimes for several years long, two juxtaposed plates are often seen separated from over-grown specimen hardly separable from each other. They have between them an unusually broad band of striae, which can be split with easely longitudinally along the suture into two halves. These two halves could be separated from each other for a short distance, sometimes for about one half of the original breadth of the zone, but could not be put apart completely, in spite of repeated contrivances and efforts to bring them apart. They keep moving to and fro without changing their mutural relation, that is, holding between them a narrower or broader structureless zone of fixed breadth. These two plates can be separated only after they are pulled apart further than one half and often a little more of the breadth of the original sutural zone. It would hardly be possible to elucidate this, then, by assuming the cohesive substance alone. 
The precise relations of these sutural structures were studied on several species belonging to the three subgenera of the genus Peridinium. It differs in some or other points between different subgenera, agreeing fairly remarkably on the other hand among the species of a given subgenus, and so cannot be elucidated with a sweeping description.

A thecal plate isolated from an over-grown specimen of $P$. subcurvipes has around it either a striated band consisting of darker blocks alternating with lighter striae or a broad band of darker colour. The darker blocks of the former are generally slender and fairly regular in breadth and arrangement but often irregular in shape and breadth. They differ in these regards from portion to portion of a single band and also from plate to plate. Within a single band of striae, these blocks run parallel with one another or arranged normally or make a certain angle to the edge of the plate to which they belong. Between two bands of striae, each lying along two margins of a single plate, is seen a large triangular block or a similarly shaped group of slender blocks, which lies then at the junction of three thecal plates. These darker blocks are separated from one another by lighter bands of a similar width, which are connected transversely by a band of lighter colour, this latter is set off from the punctured area of the plate by a fine striae of darker colour.

Along other margins of the plate lies a broad band of darker colour, which is sharply differentiated from the plate proper by a straight or undulating line but has along its other side sharply pointed irregular serrae.

These two sorts of the marginal band are ascertained along different sides of a plate, but are certified respectively invariably on opposite sides of two adjacent plates when they are connected to form the thecal wall of the body. In the former case, the band of striae is ascertained to lie in a particular portion under the broad band of darker colour, while in the latter case it lies partly or entirely over the darker band.

Judging from these it can be suggested that the thecal plate has around it two sorts of wedge-shaped edge of considerable width, one with a flat outer and an oblique inner surfaces and the other reversely with a flat inner and an oblique outer surfaces, that the two thecal plates come to contact with each other by means of their marginal oblique surface, that the band of striae represents the oblique inner surface while the broad band of darker colour represents the outer oblique surface or entire thickness of the marginal edge. And the darker blocks are often seen extruding beyond the sharply edged margin of the plate to which they belong. These facts given above lead us to conclude that the bands of these two sorts represent two different faces of the plane of contact or sutural cleft, by which two adjacent plates are combined with one another and that the sutural cleft is strongly oblique to the surface of the thecal wall. Judging from some of the facts given above and other available facts, it may be suggested that the darker blocks represent thicker portions while the lighter striae correspond to narrow furrows lying between them. These fine furrows formed along one of the two planes of contact represent the sutural canalicules connecting inner and outer surfaces of the thecal wall.

Along a sutural line, one of the two juxtaposed plates lies, then, over the other, 
and three thecal plates at their junction are arranged with their edged margins one over or below the other, forming their three layers. These relations were established on every epithecal plate and their junctions of $P$. subcurvipes. In most cases, a thecal plate is covered with some of its adjacent plates and expands at the same time over some other ones. From the figure it may be apparently suggested that a thecal plate is covered by some lying on its ventral, ventro-lateral or ventro-median sides and expands over some others lying on its dorso-lateral, dorsal or dorso-median sides. Peculiar in this regard is the ventral apical and the dorso-median precingular plates. The former is covered on all sides by its neighbouring plates, while the latter expands invariably over its surroundings on all sides.

Certifying the same relationships at every junction of the three plates connecting at a junction, each plate is numbered one by one in the order from upper to below. Three numerals thus obtained are arranged in surface view either in clock-wise or in anticlock-wise direction. From the figure, one is informed then of the fact that the direction of rotation thus illustrated is the same on either side of the apical pore, but is generally reversed between two adjacent junctions, and that these two sorts of rotation thus marked are arranged more or less symmetrically in either lateral half of the epitheca.

The same relations were established also on some other species, and found that the regularly alternating arrangement of the two different directions of rotation is certified so far as all of the intercalary and two lateral apical plates have in every case even number on its side. Regarding the dorsal or ventral apical plate, its anterior end serves in this regard as two adjacent corners or junctions because of the fact that there are two different rotations there. When the rotations are arranged regularly, the direction of rotation at a given junction can be calculated from that of the apical pore. But derangement in the distribution occurs around an oddly angulated plate.

Belonging to the same subgenus Protoperidinium, $P$. schilleri has the sutural structure corresponding in the main to that just described on $P$. subcurvipes. In this species, a grown thecal plate has around its reticulated field a narrower or broader structureless zone. Two structureless zones are seen, then, on either side of a sutural line, from which the sutural cleft can be traced obliquely inwardly. This sutural cleft is very oblique for its major breadth, but in its outer margin it normally turns to the outer surface of the thecal wall. In surface view of the thecal wall, we can establish along one side of the sutural line a broader or narrower band of striae, which represents the sutural cleft. Along this cleft are formed fine canalicules lying parallel with one another but strongly obliquely for their major length to the surface of the thecal wall. These sutural canalicules are represented in the band of striae by fine striae of lighter colour alternating with broader blocks of darker colour. And these two sorts of the sutural structures are ascertained mainly on one of the two planes of contact, that is, on the inner oblique face of the wedge-shaped edge of one of the two juxtaposed plates.

In other words, along the inner oblique face of the wedge-shaped edge are formed 
broader ridges and finer grooves alternating one another. On the outer oblique face of the wedge-shaped ridge belonging to the adjacent plate are formed fine ridges, corresponding exactly in length, breadth and arrangement with the grooves of the other plate. By means of these grooves and ridges lying correspondingly on the two oblique faces of the different thecal plates, two juxtaposed thecal plates are united with each other and the sutural canalicules are formed along the sutural cleft. Detailed accounts of this structure are given in regard to the species.

From these it is clear that the band of striae is entirely distinct from the structureless marginal zone, the former represented by the plane of contact or the sutural cleft and the latter formed around the outer margin of a thecal plate.

Judging from these two cases, one belonging to the Laterispinosa Section of the Humilia Group and the other to the Parapellucida Section of the Pellucida Group, it may be granted to conclude that the structural relations of the sutural cleft and the sutural zone given above are characteristic of the subgenus Protoperidinium.

The structural relation of the sutural cleft in $P$. curtipes which belongs to subgenus Mesoperidinium, is the same in the main with these given above. The main difference we can establish between them is the transverse striations in the sutural (growth) zone of $P$. crassipes, which fails to develop in the other. Very fine and straight or slightly undulating striations are irregularly but more or less closely arranged transversely across the sutural zone. They are restricted only in the sutural zone and differ profoundly from the sutural striae seen along the sutural cleft. This structure corresponds to Peters' 'Zuwachsstreifen'. They extend across the entire breadth of the two sutural zones lying side by side, but are interrputed at the sutural line which runs along the middle of the entire sutural zone. These striae are arranged normally in most cases to the sides of the zone, but are oblique when the zone curves or is undulating. Yet, these within a single sect of the zone are parallel with one another. Further, they correspond partly or mostly in arrangement with the meshes lying closely along either side of the zone. These features just given above lead us to recollect striated mark left behind on the sand when two closely set plates were dragged apart. Distinctness of the striae is subject to individual variations. They are fairly distinct in some specimen while hardly distinguishable in others. Not rarely is found a case in which the striae develop differently on either side of the sutural line. In most cases, they are irregularly and more or less coarsely arranged. But in broad sutured specimens, one to several weaker and equidistant striae are formed secondarily between the original ones. In scarcely grown specimens, the structure differs entirely from that given above. As was established by PETERs on $P$. depressum, we can see in this species also a double set of a weaker and a thicker striae along the sutural line. The weaker one is undulate according to the meshes along which it lies, while the other is several times thicker.

By carefully focussing down the lens, we can firstly ascertain on the surface of thecal wall irregularly distributed pores on one side of the vaguely emerged thicker stria and a regular line of similar pores closely along the other side. Then there emerge clearly the thinner and thicker striae between which lies the regular line of 
pores, and at the same time the reticulation of the thecal plate appears. Tracing down these sutural canalicules which are represented in the band of striae as lighter striae, one can ascertain the fact that the sutural cleft of $P$. curtipes turns just below the surface of the thecal wall abruptly towards one side opposite to the thicker stria, and that this can be traced for a short distance.

In $P$. angustum, belonging also to Mesoperidinium, the sutural striation is less distinct. These sutural striae are faintly zigzag, extending across the entire or major breadth of the sutural zone, but are not necessarily correlated in arrangement with the meshes. The sutural canalicules are, one the contrary, more distinct and appear to be less closely arranged.

Regarding the sutural structure of the subgenus Veroperidinium, Peters described fairly minutely on $P$. depressum. But we often saw the case, as was given in a previous paragraph, which can not be elucidated by his interpretation alone and suggests some sort of mechanical connection of the thecal plates instead of some cohesive substance. In view of this fact, we contrived as far as possible to examine the sutural structure of the species.

$P$. depressum or $P$. oblongum has often the sutural zone of considerable breadth, divided into two halves of subequal or remarkably unequal breadth. Across the entire breadth of this extend a set of closely arranged parallel striae. This zone is subject to individual variations in breadth, and is scarcely formed in some younger specimens, in which the sutural zone is represented by a thicker and a thinner striae lying closely on either side of the sutural cleft. When the zone becomes broader, the transverse striae are always thicker on the side along which the thicker one of the double striae is established. These double striae correspond apparently to Peters' 'Randleisten'. There is another band of striae, twice or more as broad as that just considered, and lying just beneath the surface of the thecal wall. And this lies along one side of the sutural cleft and can be traced further beyond the sutural zone into the reticulated field of the thecal plate. This latter band of striae clearly represents the plane of contact. When two juxtaposed plates are separated from each other, they show some differences in the structure of these sutural striae. In either half of the sutural zone is seen, in addition to the transverse striae, several longitudinal ones parallel to the side of the reticulated field, along which the zone is formed. There is then formed on the surface of the sutural zone a sort of grating, consisting of so many nodules arranged regularly along each of the transverse straie and connected transversely by fine striae. One half of the sutural zone furnished with the thicker one of the double striae bears along its distal margin a much broader and thinner lamina. And the transverse striae lying along the sutural zone appear to extend into this lamina though they come to thinner distally. In this lamina, the longitudinal parallel striae were not ascertained. It is peculiar that the sutural zone in this case has often weakly convex surface, and this together with the lamina is bent very often along its base towards interior direction. This appears to suggest that the sutural zone and the lamina are two distinct structures. Further, one of the two interlaced sets of the parallel striae can not be ascertained when 
two juxtaposed plates or their marginal sutural zones are tightly combined. In view of these peculiarities, we contrived to examine the cross section of this part of the thecal plate, and found that this part consists of a narrower and a much broader laminae, the former lying on the outer surface of the latter. These two laminae correspond in breadth with the sutural zone and the lamina respectively. Further it was ascertained that the narrower one is often convex towards the outer direction while the broader one is flattened. These two laminae are typically fairly parallel with each other and often the narrower one comes to contact with the other by its distal end, but they were never seen opening wider distally. In the marginal view of them, it was ascertained that they are seen as two, closely set, parallel laminae, each bearing along its inner surface a set of minute dents, arranged equidistantly and correspondingly between the opposite surfaces. It is clear from this that the lamina has along its one surface closely arranged parallel ridges which are represented in the surface view as the transverse striae. This structural relation can be certified by the facts that when we examine the sutural zone under great magnification, we can establish firstly the transverse striae confined within the sutural zone, and again at a slightly lower level different set of striae extending further into the broader lamina, and that the latter (longer) striae make their appearance sharply after the former (shorter) ones disappear, while the thicker one of the sutural double stria from which these two sers of the transverse striae spring does not display a corresponding change.

The other half of the sutural zone belonging to the next thecal plate has not a lamina corresponding to the broader one of the other. Though it is not ascertained there are some reasons to believe that this also consists of a double laminae of subequal breadth.

From these considered above, we came to the conclusion that the two juxtaposed thecal plates of $P$. oblongum are united tightly together with each other by means of their double laminae formed along their margin. The sutural canalicules were not ascertained in this species but was suggested from the fact that the thicker one of the double striae lying along outer border of the reticulated field, has along its one side opposite to the meshes, along which the sutural cleft is regarded as strongly folded, a close set of minute dents, each lying between adjoining two of the transverse striae.

All these facts and considerations given remind us of the exactly corresponding sutural structures of Diplopsalopsis given by the author.

In $P$. sinuosum and its allies, all belonging to the Conica Group of Veroperidinium, a linearly arranged set of pores and the sutural cleft are seen along the sutural line. The former lies along the middle of the sutural zone, and along the latter expand the sutural canalicules towards one side of the sutural line, and towards the other side expands the thicker ones of the double striae.

Regarding the structural relations of the sutural cleft given above, the genus Peridinium may be divided into two, one furnished with an oblique sutural cleft and the other with a strongly folded one. In the former, the marginal parts of the two juxtaposed plates are similarly wedge-shaped. But in the latter, one of them has 
a double lamina and the other bears a single one. These two appear to differ profoundly from each other, but in reality are to be regarded, so far as our interpretation goes, as representing two different forms of a varying structure. One has to recollect in this regard that the sutural cleft is folded in one (former) case along its one end while in the other (latter) along its middle or just on one side of it. The former can therefore be derived from the latter.

\section{Distribution, irregularity and differentiation of the sutural zone}

The suture may be classed into two sorts, one running mainly from either end of the body to the girdle and the other connecting them transversely. They agree in the main with each other in their structures but display some differences in some particular cases. In the epitheca of species with three intercalary plates, there are six or eight longitudinal sutural zones, only four (ventro-lateral and dorso-lateral) of which extend from the apex to the girdle and the others (ventral and dorsal) branch off from the formers at a short distance from their anterior ends. They display either zigzag or straight tracts. In the hypotheca, arrangement of the sutural zone is in most cases irregular. In the postcingular region, we can ascertain five longitudinal ones, four lying within the postcingular row and one between it and the ventral area, and in the distal half of the hypotheca, there are three, one lying between the two antapical plates and two between these and the ventral area. In a few groups of the genus, ventral two of the four intra-postcingular ones form, together with the ventral two of the three lying on either side of the posterior part of the ventral area, straight tracts extending along the entire length of the hypotheca.

It has generally been ascertained and figured that the sutural zone increases its breadth from the apex or antapex towards the girdle. But detailed accounts of their arrangement and growth were not brought forth until Peters (1928) whose conclusions in these regards may be summarized as follows:

1. The longitudinal sutural zone increases its breadth from the apex or antapex to the girdle.

2. The growth in breadth of the zone is always repressed at the apex, and rarely strengthened around it.

3. The zone is broader in the hypotheca than in the epitheca, and regarding the latter in its ventral side than in its dorsal.

4. The growth-equator coincides typically with the girdle but is exceptionally deflected posteriorly in the dorsal side.

5. Amount of growth is equal both in the epitheca and the hypotheca.

Of these, the first four (1-4) deal with the longitudinal sutural zone and the last (5) is concerned in the transverse and latitudinal zones. These conclusions are correct in the main but must be subjected to re-examination or re-discussion because of many exceptional cases. Before going further, it must be noted here in order to avoid confusion that the sutural zone dealt in what follows represents the 
growth zone built between two thecal plates and not the band of the sutural striae. Almost all of the former investigators had discussed them without distinction, and Peters himself confused one with the other in some paragraphs of his paper while distinguished them in others.

Longitudinal sutural zone The longitudinal sutural zone extending from the apex to the girdle typically increases its breadth towards the girdle. In one specimen of $P$. pallidum its ventral apical plate is seen divided into subequal halves by an unusual, oblique sutural zone. In this case, the sutural zone is formed across a single plate and is typically broader posteriorly. But the general longitudinal sutural zone passes in the major cases across two or three circular rows of plates, and differs in breadth from part to part according to the rows it passes.

It may be granted to assume that the amount of growth differs from place to place according to various diameters or circular lengths of the body. Consequently, at the slender part of the body it is smaller than at a thicker part. In other words, the peridinian body is greatest at the girdle and smallest at the apical end and is various between them according to different diameters in different parts of the body. From these it is clear that a given longitudinal sutural zone differs in the manner of increasing or decreasing its breadth towards one end according to various forms of the epitheca. So long as a distal part of the epitheca is cylindrical, the longitudinal sutural zones lying in this portion do not display variations in breadth, and as the diameter of the body grows greater it is followed by increase in breadth of the sutural zone.

Apical region There are four sutural zones around the apex, two extending to the dorso-lateral and the other two to the ventro-lateral directions. Of these, the dorsal pair differs from the other in that it springs directly from the apical pore, lying between the lateral and dorsal apical plates, while the ventral springs from the distal end of the ventral slit of the apical pore, lying on either side of the ventral apical plate. This difference is of morphological significance because of the facts that the apical pore is hardly subject to variation in size or rather in breadth due to growth, that around the apical pore is hardly allowed growth in breadth of the sutural zone so as to increase the diameter of the apical pore, and that contrary to the apical pore, the ventral slit increases its length by allowing growth in breadth of the anterior ends of the two ventral sutural zones, that is, by wider displacement of the ventral apical plate from the apical pore.

This and other available facts lead us to suggest that in the peridinian body there is a strong tendency to keep the apical pore fairly constant in breadth throughout growth period of the body, presumably owing to some physiological want. But this does not hold true with such species of an elongated apical pore or apical trough such as $P$. pentagonum, $P$. thorianum and their allies, in which the two dorsal sutural zones extend to the apical trough normally or nearly so, allowing the apical trough 
to grow longer but never to become broader. In either of the dorsal or ventral pair of the sutural zone, the breadth is generally subequal in the two sutural zones. But we saw a single case of $P$. spheroides in which the left dorsal one has smaller breadth than the other three.

In well grown specimens, the apical trough or ventral slit of the apical pore appears to be much elongated ventrally, extending invariably directly to the apical plate, and the sutural zone is never formed between the apical pore-plate and the reticulated or poroided field of the ventral apical plate. From this, it is suggested that the newly elongated, ventral part of the apical structure is formed partly by the ventral apical and partly by the lateral apical plates, at the junction of which it lies. This is supported by the facts that the sutural zone of any breadth has hardly been ascertained, so far as our examination on several species inform us, around the apical pore-plate or at its either end, and that when the three ventral and lateral apical plates of a grown specimen of $P$. tumidum are separated from another, the ventral slit of the apical pore is ascertained to be sticking to the ventral apical plate as if it were its narrow extension.

Antapical region As seen in the epitheca, it may be expected also in the hypotheca that the intra-antapical suture decreases in its breadth posteriorly. But such is not the case in practice. This sutural zone has generally a subequal breadth throughout its length, and the difference in breadth of its two ends, if it can be ascertained, is very slight. It is only rarely found in some of $P$. brevipes, $P$. conicoides and $P$. pentagonum, that the sutural zone is narrower towards its posterior end. But we have never ascertained a single case in which the intra-antapical sutural zone displays the structural feature just described on the dorsal intra-apical sutural zone. If Peters' conclusion is correct, this intra-antapical is also expected to taper towards its hind end. But that this is not the case is clarly due to the fact that there is at the hind end no special structure, comparable to the apical pore of the epitheca, strongly limiting the growth of the sutural zone. The sole agency or factor exerting influences upon the breadth of this intra-antapical sutural zone is to be sought only in the forms of the hypotheca. In species with a typically semispherical hypotheca, the amount of surface growth is filled mostly with the marginal additions (sutural zones) of the thecal plates and partly by sliding apart but not by rotation of the plates. If the two antapical plates are separated from each other in order to answer the growth in volume of the body content by rotation of them around the hind end of the intra-antapical suture, there must follow some deformities or torsions in shape or structural relation of the ventral area or sulcal furrow, which may be fatal to the organism in extreme cases.

As is considered in other paragraphs of this paper, we have to admit the fact that the structural relations within the ventral area is least disturbed by the growth of the sutural zone. In the ventral of the hypotheca, a broad sutural zone is formed longitudinally along the right side of the ventral area, and this continues further 
along the hind end of the ventral area, where it meets with the intra-antapical sutural zone. This ventral, circum-sulcal sutural zone has a subequal breadth througout its length, presumably so as not to bring forth disturbance in the structural relations within the sulcal furrow. It seems that this naturally lends forces to make broader at the hind (ventral) end of the intra-antapical sutural zone. If not so, some structural inconsistencies may be brought forth between the ventral and dorsal sides of the antapex. In horned species, the hypotheca has still a considerably large breadth or transverse diameter at the hind end of the intra-antapical suture owing to the conical bulges of the thecal wall standing on its either side. The intraantapical sutural zone is naturally forced to grow at its hind end to a certain breadth. Even when the hypotheca is typically conical as shown in $P$. punctulatum $(=P$. abei $i$, the intra-antapical sutural zone has a considerable breadth at its hind end. This cannot be justified correctly without taking into due considerations the morphological significance of the ventral area or sulcal furrow, that of the apical pore of the epitheca and that of the sutural zone in the hypotheca.

Cingular region In typical cases, the longitudinal sutural zone has its greatest breadth at its hind end just at the anterior cingular ridge. As has been established by PETERs, the zone is generally broader in the hypotheca than in the epitheca and in the ventral than in the dorsal of the epitheca. But so far as the analysis reveals, the relations are more complex than suggested by him, displaying many exceptional cases.

In the precingular part of the body are seen generally eight longitudinal sutural zones, six of which lie between the precingulars and two on either side of the ventral apical plate. They form then four pairs, which for the sake of brevity, are called in what follow, ventral, ventro-lateral, dorso-lateral and dorsal pairs.

Among these, the ventral pair $\left(1^{\prime \prime} / 2^{\prime \prime}, 6^{\prime \prime} / 7^{\prime \prime}\right)$ has typically the greatest breadth, and the other three pairs have either subequal or various smaller breadths. Whether they are subequal or different in breadth is not characteristic of a species but apparently subject to individual variation. In a specimen of $P$. crassipes are seen eight sutural zones of subequal breadth, while in a different specimen, the dorso-lateral pair is the broadest. In a case of $P$. brevipes, the dorsal pair has the greatest width, while in another the ventral pair is broadest. A specimen with the broadest dorsal pair was found in $P$. crassipes and also in $P$. pentagonum. A similar dorso-ventral irregularity can be established often in the hypotheca in which four longitudinal zones lie within the postcingular row of plates and the ventral pair of them is generally broader than the dorsal one. But in some of $P$. multistriatum and $P$. thorianum, the left-hand zone of the ventral pair was broader than the other right one. Further, we often saw an over-grown specimen with the broadest dorsal pair in P. brevipes, P. crassipes and $P$. yonedai. It is noted here that these irregularities in the distribution of the greatest breadth of the longitudinal sutural zone are seen invariably in specimens furnished with unusually broad sutural zone, and not a single case of irregularity was 
established in specimens with narrow sutural zone. This appears to suggest that the irregularity occurs only after the growth of the body has advanced beyond a certain limit which may be characteristic of a given species and correlated to the original size of the body.

There is another irregularity, which is often ascertained in practice. Peters described a case of $P$, depressum in which the dorsal intra-postcingular sutural zones are unusually narrower towards the girdle, and he elucidated it as follows: "dass bei diesen Art der Wachstumsäquator nicht mit der stark geneigten Querfurche zusammenfällt, sondern auf der antapikalen Seite bedeutend unter derselben liegen muss, etwa nahe den hinteren Enden der beiden Nähte $2^{\prime \prime \prime} / 3^{\prime \prime \prime}$ und $3^{\prime \prime \prime} / 4^{\prime \prime \prime}$." We have seen, however, many examples contradictory to his suggestion. In them, the inversely shaped sutural zone is ascertained not only on the dorsal side of the hypotheca but though very rarely on its ventral side. It is distributed symmetrically or asymmetrically on the dorsal side of the epitheca, and sometimes simultaneously on either side of the girdle of a single specimen. PETERs was the first and sole investigator who found and discussed this peculiarity. His consideration is far reaching but contradictory to the facts established by us as shall be arrayed below.

In the precingular row, the inversed zone is established most frequently on either or both sides of the dorsal precingular plate $4^{\prime \prime}$. So far as our observations revealed, the inversed zone is seen on the right of the plate in $P$. majus, on the opposite side in $P$. conicoides and further more frequently on its both sides in $P$. conicum and $P$. pentagonum. Less frequently it is seen to occur in other places, namely on either side of the precingular $3^{\prime \prime}$ in P. obtusum and on the left of $4^{\prime \prime}$ and on the right of $5^{\prime \prime}$ in $P$. thorianum. From these, it is clear that the irregularity does not occur along the ventral and ventro-lateral pairs of the precingular longitudinal suture but appears in the dorso-lateral and dorsal pairs, particularly frequently in the suture mentioned at the last. In other words, occurrence of the irregularity is confined typically in the dorsal half of the epitheca, and its frequency is greater in its dorso-median region than in its lateral.

More rarely the irregular changes in the reversed direction can be established in the hypotheca. In this, the zone becomes narrower towards the anterior direction. Such irregularity is seen on the right of the dorsal postcingular plate in $P$. obtusum and $P$. pentagonum and simultaneously on its either side in $P$. conicum, $P$. pentagonum and $P$. longipes. Not a single case in which it occurs on the left of the plate was found in our materials. Peculiar and interesting is the case in which the irregularity was established to occur laterally along the two ventral intra-postcingular sutures in an extremely over-grown specimen of $P$. brevipes.

From these it is to be reminded here that occurrence of the irregularity is regularly limited in the portion of the body lying next to the girdle. Not a single instance of the irregularity was established only along the suture lying between or along the intercalary plates.

If we accept Peters' explanation of this, asymmetrical occurrence of the irregularity both in the epitheca and hypotheca can not be explained. Furthermore, 
we cannot explain the fact that the inversed zones were established in $P$. pentagonum simultaneously and strikingly symmetrically on either side of the precingular 4 " and somewhat asymmetrically on either side of the postcingular $3{ }^{\prime \prime \prime}$. This latter fact is thinkable only when one assumes either partial displacement of a single growth equator to either side or splitting of it into two daughter ones, each lying on either side of the girdle.

Before going further into discussions about this irregularity, we have to recollect the fact that increase in circular length of the thecal wall due to growth of the body may be equal or at least subequal in the girdle itself and on its either side, while the cingular and pre- or postcingular rows of plates differ from one another in number of their intraserial (Jongitudinal) sutural zone. These three series of plates have to cover, then, by the same amount of the circular growth with their intraserial sutural zones of different number. In other words, a definite magnitude of force or stress due to the growth of the body is subdivided variously in the three different rows. On the other hand, there are reasons to believe that a thecal plate has inclination to keep, as far as possible, its original surface curvature or convexity throughout the growth period, while the sutural part of the thecal wall is rather liable to yield to the stress. The magnitude of the stress or amount of the sutural growth, against which a single sutural zone has to withstand or cover, is then inversely proportionate to the number of the zones lying within a single circular row. In this regard, the cingular row of plates is the foremost, because of the fact that the thecal wall bulges more or less remarkably along the girdle where the diameter or circular length is greatest in the body, while only two intraserial sutural zones are formed in the girdle. One has to recollect in this regard that, in the precingular and postcingular regions, there are five light longitudinal sutural zones respectively. Consequently, the zone within the girdle is greater in breadth than any of the preor postcingular ones. From these facts and considerations, it seems highly reasonable to suggest that there may be a stronger inclination to repress the circular growth of the body in the girdle than in the pre- or postcingular region when we consider that a single sutural zone can withstand a certain magnitude of stress, whether it lies in the cingular or in the pre- or postcingular row of plates.

In typical cases, in which the circular growth increases relatively and also absolutely from the apex to the girdle, all of the longitudinal sutural zones lying in the pre- or postcingular region increase in their breadth towards the girdle. In this case, total sum of the breadths of the longitudinal sutural zones lying in the pre- or postcingular region is greater in their cingular end than in their opposite end. But when the circular growth of the body is carried out repressively along the girdle. The total sum may be in inversed relation or at least subequal between the two ends, and furthermore the repression may be stronger on the dorsal half than on the ventral side of the pre- or postcingular region judging from the fact that the cingular wall is allowed to grow longer only in its ventral side where the two sutural zones lie. 
This suggestion is strongly supported by the observations partly given above and also by actual measurements of the total breadth of the sutural zones. In the specimens in which the inversely broadened sutural zones are ascertained in its preor postcingular region, the total sum of the breadth of the longitudinal sutural zones is larger in the anterior end of the precingular ones and also in the posterior end of the postcingular ones than in their cingular end respectively. An example of our measurements, carried on a single specimen of $P$. pentagonum is given in Table 10.

Table 10. Sum of breadth of longitudinal sutural zone at cingular and opposite ends in P. pentagonam

\begin{tabular}{ccc}
\hline Amount of circular growth & precingular row & postcingular row \\
\hline at cingular end & $70 \mu \mathrm{m}$ & $67 \mu \mathrm{m}$ \\
\hline at opposite end & $83.5 \mu \mathrm{m}$ & $75 \mu \mathrm{m}$ \\
\hline
\end{tabular}

From this and also other unpublished measurements, it may be apparent that the difference or amount of disturbance in the growth between the two ends is greater in the epitheca than in the hypotheca. It is correlated with the fact that in many cases the body flares more strongly dorsally than ventrally, and in the dorsal side it bulges more in the epitheca than in the hypotheca. Careful observations lead us to conclude that the convexity of the dorsal thecal wall is generally strongest in the epitheca just along or in front of the anterior margin of the precingular row of plate, and in the hypotheca along the hind end of the postcingular row or in rear of it. It may be granted to suggest that in a part of the body where surface curvature is stronger than in surroundings the thecal wall has inclination to bulge more strongly as a result of the growth than elsewhere. This suggestion is supported by the facts that in many species, grown specimens have generally more strongly convex thecal wall or swollen body than younger ones, and that an unusually stronger flaring of the thecal wall is ascertained on the dorsal side of the epitheca in an over-grown specimen of $P$. marukareai (ABÉ, 1936). Coupled with the inclination to repress the circular growth in the girdle, this stronger flaring of the thecal wall in the middle of the epitheca or hypotheca clearly explains the occurrence of the inversely broadening, longitudinal sutural zone on one side or on both sides of the girdle.

These just considered deal with the species with convex thecal wall. Contrary to them, it is often observed that the breadth of the sutural zone is smaller in the middle than in the hind end of the epitheca in such species as $P$. crassipes and its allies in which the epitheca or hypotheca has generally strongly concave surface. In a single case of $P$. majus (ABÉ, 1940, p. 37, figs. 20-23) an irregularly bending broad sutural zone is found lying diagonally across the left dorsal of its epitheca. In this case, this sutural zone has the greatest breadth in its middle just in the middorsal of the epitheca and tapers distally in its two ends. These strongly support the above suggestion.

It is interesting to note in this regard that the body wall has in the horizontal 
section of any species the strongest curvature at the ventro-lateral region where the longitudinal sutural zone grows generally broader than elsewhere. Further, the curvature of the thecal wall in these two regions differs in any species on either side of the body. This corresponds exactly to the fact that the ventro-lateral pair of the longitudinal sutural zone differs in breadth between its two members.

Structural differentiation In addition to many typical cases completely explained on the fifth law of Peters', we often saw a case in which the epitheca grew stronger than the hypotheca. In $P$. rotundata, $P$. brevipes and $P$. angustum, the total sum of the bread ths of the two dorsal transverse sutural zones, measured at either side of the middle intercalary plate, was approximately equal with the breadth of the single one lying between the dorsal postcingular and antapical plates. But in a case of $P$. tumidum, the total sum of the epithecal dorsal was $21 \mu \mathrm{m}$ while that of the hypothecal dorsal was only $13-15 \mu \mathrm{m}$.

In many of published figures, the longitudinal and transverse sutural zones were illustrated with different strength or different breadths. In some of them, the longitudinal one is shown with a stronger line or the transverse one is represented with a double line of greater separation. A corresponding differentiation between the longitudinal and transverse zones were established, so far as our materials are concerned, in $P$. compressum, $P$. conicoides, $P$. conicum, $P$. clavus, $P$. deficiens, $P$. obtusum and $P$. rotundata, all belonging to the subgenus Veroperidinium. In some of them, the longitudinal one is represented by a narrow but distinct ridge of stronger refractivity, but in others by a narrow sutural zone. On the other hand, the transverse zone has exclusively a definite breadth of weaker refractivity. From this, it may be suggested that the growth of the thecal plate in these species is greater in the longitudinal direction than in the transverse one. One has to recollect, in this regard, the facts that all of these species are furnished with a convex or flat conical epitheca, that more or less distinct readjustment in the arrangement of the epithecal plate can be established in most of these species, and that in such a conical epitheca, the convexity of the thecal wall is stronger in the circular direction than in the longitudinal one. If these longitudinally arranged plates grow on keeping their original convexity and if their yielding power to elasticity is kept small throughout, torsion or deformity of its surface must follow. But this is not generally the case in nature.

Somewhat a modified form of this differentiation between the longitudinal and transverse sutures is seen either all over the surface of the epitheca or only in a part of it. A broader sutural zone is formed along the anterior margin of the precingular row, as was illustrated by BRocH (1910, fig. 11) and Вӧнм (1935, fig. c, e) and was established by us on $P$. conicoides, $P$. conicum and $R$. obtusum. In the species mentioned at the last, we saw a case in which the sutural zone failed to develop only around the ventral apical plate. In some of $P$. clavus and $P$. rotundala, a broad transverse one is seen lying along the anterior margins of the ventral apical and all of the precingular plates. 
Girdle Within the girdle is formed invariably a broad sutural zone between two cingular plates; but any trace of the zone can be ascertained along their anterior or posterior margins, next to the pre- or postcingular plates. This may be suggested also from the fact that the growth of the body has no effect upon the breadth of the girdle. On the other hand, the girdle of an over-grown specimen was found furnished, along its either side, with a narrower or broader band of striae. In such a specimen, we can ascertain a narrow, wedge-shaped lamina springing from the base of the cingular list. This lamina, lying closely along the inner surface of the cingular wall, grows broader without forming the sutural zone or its homologue between it and the pre- or postcingular plate. From these, we can conclude that cingular plate is allowed to grow only in one (circular) direction and that the sutural growth between the cingular and the pre- or postcingular plates is represented only by the lamina of the latter plate.

Ventral area Hardly anything has ever been discussed, so far as published literatures inform us, about the sutural zone lying in and around the ventral area. This is clearly due to difficulties of analysing thecal components of the sulcal furrow which is highly various and strikingly complex in structural relations. Contriving to bring out the structural relations of the ventral area, we ascertained in all sections. and groups of the genus that the ventral area consists of four sulcal plates lying around the flagellar pore, and that bringing forth and arrangement of the sutural zone in and around the ventral area are the same in the main throughout the genus.

Prior to emergence of the sutural zone of conspicuous breadth within the ventral area, a broad one is formed along the entire length of its right side. Anteriorly it extends across the girdle and around the anterior end of the anterior sulcal plate, where it forms a falciform end, and posteriorly it lies further around the posterior sulcal plate. It has a subequal breadth throughout its major length, and continues on the left to the suture lying between the left ventral postcingular and left antapical plates. Not a distinct sutural zone can be established along the suture between the left sulcal plate and the left ventral postcingular plate until a later period of growth. But we can certify there a band of striae along the inner base of the left sulcal list. The sutural zones of perceptible breadth are ascertained among the transitional and sulcal plates long after broad ones are formed in general parts of the body. As a consequence of this, the four sulcal plates and the transitional one are displaced as a whole more and more strongly towards the proximal end of the girdle so long as the growth of the body goes on. The sulcal plates have in younger specimens subequal relations with their surroundings, but are interrupted in grown specimens from contact with most of them and even from the distal end of the girdle, and are closely kept only with the proximal end of the girdle throughout the entire period of growth. 
Clearly correlated with this asymmetrical displacement of the sulcal plates, around the anterior end of the ventral area, is often formed a large semicircular or strongly. curved band of radially arranged striae. This band of striae is overlapped with the ventral apical and two ventral precingular plates but consists mostly of the marginal lamina of the anterior sulcal plate. Apparently as a result of development of the falciform sutural zone around the anterior end of the ventral area, the sulcal furrow of well-grown specimens often extends anteriorly beyond the ventral area into the epitheca. Such an unusual elongation of the sulcal furrow is ascertained most frequently in the Oceanica and Conica groups and often in some other groups of Veroperidinium and less remarkably in some of Protoperidinium. In any case, this unusual elongation does not generally extend beyond the band of striae anteriorly and agrees in breadth with the transverse length of the anteriormost falciform part of the circumsulcal sutural zone.

This peculiar structure was first described by Peters (1928) on $P$. pyriforme, $P$. subinerme and $P$. variegatum. However, he wrongly regarded its formation due to unusual growth of the sutural zones lying on either side of the ventral apical plate. But as described above, this structure is rather related much more closely to the asymmetrical displacement of the sulcal plates, or in all probability due to strain caused by the peculiarly shaped anterior end of the circumsulcal sutural zone. This suggestion may be supported by the fact that this elongation is formed by abrupt folding of the hind end of the ventral apical and the median ends of the two ventral precingular plates, which lie along the anterior and lateral sides of the depression whose bottom is covered with the falciform part of the circumsulcal sutural zone.

Within the ventral area, a narrow sutural zone is first formed along the anterior margin of the posterior sulcal plate and also along the right of the transitional plate, both of which are not connected directly with the flagellar pore. Only in strikingly over-grown specimens, the zone of perceptible breadth can be established between the sulcal plates lying directly around the flagellar pore.

Summary With regard to the development and distribution of the sutural zone, observations and discussions given above are summarized as follows:

1. The sutural zone is formed along any of the sutures except that lying on either side of the girdle and that around the apical pore plate.

2. The sutural zone can be divided into longitudinal and transverse ones, which differ from one another in some points.

3. The longitudinal one is generally broadest at its cingular end and becomes narrower towards the other end. Growth of it is not permitted at the apical pore when it brings forth increase in breadth of the pore. In the hypotheca, it has invariably a certain breadth at its hind end.

4. The longitudinal sutural zone of considerable breadth often comes narrower towards its cingular end. This is apparently due to the probable repression of cir- 
cular growth in the girdle and at the same time owing to stronger bulge of the thecal wall in the dorsal middle part of the epitheca and hypotheca.

5. Growth in length is generally subequal both in the epitheca and hypotheca, but often a little greater in the former than in the latter. Growth of a thecal plate differs often in two directions, particularly distinctly in some of Veroperidinium. An extreme case of this irregularity can be sought in the cingular plate in which only the circular growth is permitted.

6. The pre- or postcingular plate forms a narrow lamina along its cingular margin, but not the sutural zone.

7. The four sulcal plates and the transitional one are closely related with one another and also with either the flagellar pore or the proximal end of the girdle, and their interrelations are least disturbed by development of the intra-sulcal sutural zone which comes to have perceptible breadth only after broad sutural zones are formed in general part of the body.

8. Asymmetrical over-growth of the circumsulcal sutural zone at the anterior end of the ventral area often brings forth an unusual anterior elongation of the sulcal furrow beyond the ventral area.

We have to call attention here to the following similarities and dissimilarities between the apical pore and the flagellar pore.

1. Either of these two pores is encircled with four plates, the dorsal and anterior three of which are the least separated from one another and also from the opening of the pore by any structure, while the other (posterior) one is set apart in a later stage of growth from the others and also from the opening by a narrower or broader sutural zone.

2. The sutural zones radiating from the apical pore extend to the girdle, increas" ing in their breadth gradually towards their distal ends. While these radiating from the flagellar pore have hardly perceptible breadth throughout and do not extend beyond the circumsulcal broad one.

From these just considered, it may be allowed to suggest that the apical and flagellar pores are of morphological equivalent. The difference between them is suggested that the flagellar pore was confined within the particularly differentiated ventral area and sulcal furrow and is directly connected with the locomotive organellae and also with the excretory or buoyant function, while the apical pore lying on the general surface of the body has presumably some relationships with certain deep-seated functions other than these just mentioned.

\section{Reproduction}

Multiplication through longitudinal or oblique division is generally believed to be prevalent in the dinoflagellates. But not a single case of division has ever been ascertained in our materials. On the contrary, in several species a cyst was seen lying within an empty theca or floating freely in the sea water. 
STEIN (1883) and KLEBS (1884) described fairly minutely formation of the cyst within the theca after division of the body in two fresh-water species, $P$. tabulatum and $P$. cinctum. Further, in the latter of the two species, a contracted spherical body is said to escape often from the theca before the division. Judging from the present state of our knowledge about taxonomy of the genus, it is doubtful whether or not the two species upon which they described are correctly identified. A similar process of the cyst formation was recorded afterwards on a marine species, $P$. divergens, by Poughet (1885), Bütsahli (1885) and ClaApark̀de et LaGHManN (1859). According to these authors, two sorts of the cyst are known, one with a thin and the other with a thick membrane. The double cyst of $P$. ovatum described by ScHürt $(1887,1895)$ has a thick membrane around it judging from published figures.

The species that has been ascertained most frequently to form the cyst is $P$. conicoides, so far as our materials in Asamushi are concerned. The cyst of the species is seen lying within an empty theca with narrower or broader sutural zones. It is spheroidal or nearly so, having in its postero-ventral region a slight flattening or depression corresponding to the sulcal furrow of the theca. Its thick membrane is deeply coloured and has a sort of lamellate structure or of surface extension suggestive of the apical or antapical horn or cingular lists. A large nucleus lies in the center of the cyst which is filled with small granules of starch. A cyst without the theca but exactly corresponding to it in size, colour and structures is often found in the waters in which the species is distributed.

A large ovoidal cyst is found, partly escaping through the apical region of an empty theca of $P$. marukawai. In this case, a deeply coloured thick membrane and a thick layer of starch granules are also ascertained. Its larger diameter is about $77 \%$ of the transerse diameter of the theca. In P. okamurai, a similarly organized cyst was seen partly pushed out of the theca through its antero-dorsal region. In a single case of $P$. clavus, there are two smaller cysts, one lying within the empty theca and the other escaping from it. In all of these cases, the cyst is globular or alike, without forming any process or partial bulge of the wall. However, we saw often a huge one with three short but thick processes, suggestive apparently of the apical and antapical horns respectively. It was found invariably floating free in the seawater but exclusively in association with $P$. depressum with which it corresponds exactly in size and in the arrangement of the three horns.

In addition to these with thicker membrane, a different one was often seen bearing a thin membrane. Within an empty theca with broad sutural zones of $P$. rotundatum was a spheroidal cyst, subequal in diameters with the theca. This cyst has along its postero-median region a slight depression corresponding to the sulcal furrow. Its membrane is thin and has no particular differentiation suggestive of the cingular structure, and its content is shrunken to from the wall. Further in P. multistriatum was found a single case in which a similar but smaller cyst lies in an empty theca furnished with narrow sutural zones. In this latter case, the cyst has, around it, a definitely shaped cingular depression and its narrow side-lists. And in both of 
these, the empty theca is split along the postcingular ridge into two halves which are connected only in its ventral portion by the ventral area.

In any case given above, the cyst has a definite form presumably owing to its substantial membrane, and a single cyst is usually formed within a single theca. Contrary to them, in a single case of $P$. clavus were found two smaller cysts formed within a theca. One of them is globular lying in the center of the theca, while the other is dumb-bell shaped, escaping partly from the theca through its cingular region.

Judging from these given above, there are at least two sorts of the cyst in the genus, one furnished with a thicker membrane and the other with a thinner one. The former has invariably abundant granules of reserved substance while contents of the latter are fairly transparent and include hardly any of such granules and oil droplets. It may be granted to suggest that these two are to be regarded as the durable and the transient cyst respectively.

The cyst without reserved substance can be subdivided further into three forms. In most cases, the cyst has no cingular structure at all, and is supposed to be liberated sooner or later from the thecal wall through its definite portion which appears to be characteristic of a given species. Fate of the cyst after the liberation is uncertain. Rarely the cyst has the cingular structure before its liberation from the theca. In this case, we have no need to speak of its fate. Interesting is the case with $P$. clavus in which the body content divides into two within the thecal wall and appears to escape actively through it.

From these observations and also from published literatures, it may be allowed to conclude that the cyst formation may be one of the most predominant ways of multiplication in the genus, and it occurs fairly commonly in the marine species.

There has not been recorded, so far as published literatures available at hand inform us, except a single case of oblique or longitudinal division of the skeletal part in the genus. For purpose of answering this, we contrived in vain to seek after a specimen bearing over-grown and younger thecal plates or furnished partly with broader and partly with much narrower sutural zones. We are, therefore, forced to suggest here that division of the thecated body, which is commonly ascertained in some genera related closely to Peridinium, does not occur in the genus in its actively swimming state so far as our materials are concerned.

In contradiction to this prevailed belief, we can not avoid a haunting suspicion that $P$. hemisphericum and $P$. clavus have respectively an anterior and a posterior half of a chain, although we have never ascertained them actually connected with each other. The epitheca of the former and the hypotheca of the latter are so peculiarly flattened that one fits the other in every respects and a minute pore is often ascertained in the flattened hypotheca just at a place corresponding to the apical pore of the other. And further, these two species are found invariably in the same plankton sample and never in different ones.

\section{Variations due to growth}

Regarding the variations due to growth, hardly anything had been discussed 
until Broch (1910) who suggested as follows: "Überhaupt scheint gewöhnlich das Breitenwachstum schneller als das Längenwachstum fortzuschreiten und die Peridinium zelle während des Wachstums immer flacher zu werden." Peters (1925), on the other hand, did not verify BRoch's interpretation, concluding "dass im allgemeinen das gesammt Längenwachstum dem Breitenwachstum gleichen war,...". Diwald (1939) ascertained on $P$. ovum, $P$. adriaticum and $P$. subinerme that the relative breadth of the body at the girdle varies proportionately to the relative thickness, suggesting at the same time that the relative breadth or the relative thickness of the body is often related to the contour of the body. His measurement may be interpreted as to conform Peters' conclusion, as it is supposed that in his materials are included these specimens in various stages of growth.

As described partly in previous paragraphs, our observations do not conform to any of these authors' interpretations in some other points. Whether the longitudinal or transverse growth is stronger is hardly to be established by tracing through entire course of the growth of a single individual. At the same time, measurements of diameters without referrence to the original size of the body or without establishing to what stage of the growth the measured specimen corresponds is useless because of a considerable range of variations in the original shape and size of the species.

Midbody Displaying some variations in the formation and breadth of the sutural zone, the midbody itself shows a certain range of variations in form and contour due to growth, which is, however, brought forth through many factors difficult to be analyzed. In typical cases, the growth of the body may be subequal or proportionate in the longitudinal and transverse directions, as uas suggested by Peters (1925) and confirmed by Diwald (1931). But the transverse sutural zone is often, as was given above, broader than the longitudinal one. On the contrary, we have not ascertained a single case in which an inversed relation is shown. This clearly suggests stronger growth in the general thecal plate in the longitudinal direction than in the transverse one. And this can be ascertained not only on a single

Table 11. Relative length of midbody in some species of Peridinium

\begin{tabular}{lcc}
\hline & \multicolumn{2}{c}{$\begin{array}{c}\text { Relative length of midbody } \\
\text { (Length/Breadth) }\end{array}$} \\
\hline species & younger specimen & older specimen \\
\hline$P$. thorianum & 0.92 & 0.98 \\
\hline$P$. multistriatum & 0.94 & 1.00 \\
\hline$P$. conicoides & 1.00 & 1.00 \\
\hline$P$. obtusum & 1.09 & 1.02 \\
\hline$P$. furcata & 0.96 & 0.985 \\
\hline$P$. pentagonum & 0.88 & 0.95 \\
\hline
\end{tabular}


thecal plate but also generally on the midbody as a whole, as was given in Table 11 .

It is interesting to note that $P$. conicoides displays a fairly constant length-breadth ratio, though remarkably broad sutural zones are formed in many cases. In the table, the ratio appears to decrease in grown specimens of $P$. obtusum. But much stress can not be laid on this because of the fact that the specimens measured were small in number and the ratio in this species was apparently subject to a stronger individual variation than in others. Even in the case of $P$. pentagonum, in which the difference is decided, we saw an older specimen in which the ratio was 0.91 , hardly distinguishable from the mean value of younger one. All these species given in the table have invariably a conical epitheca and belong to Veroperidinium, in which the differentiation between the longitudinal and transverse sutural zones is established most readily. In some other species belonging to the other two subgenera, such as $P$. marukawai, $P$. crassipes, and $P$. fatulipes, it was ascertained that the midbody has more strongly convex or weakly concave wall in grown specimens than in younger ones.

Shape of cingular section In apical or antapical view, cingular end of the longitudinal sutural zone is generally not convex but straight or weakly concave. This naturally leads us to suggest that the sutural zone is not built so as to conform to the surface curvature of the thecal plates lying on its either side. This discrepancy in the surface curvature can be ascertained more or less clearly in many of overgrown specimens of small species. In them, one can see in apical or antapical view two or four conspicuous depressions around the girdle, each lying at the cingular end of the intra-postcingular suture and can be traced along it for a shorter or longer distance. It is the two dorsals lying on either side of the dorsal postcingular plate that emerge firstly. And in a later stage of growth the two ventrals are formed each at the ventral end of the lateral postcingular plate. This depression may be ascertained most readily in small species such as $P$. brevipes, $P$. conicoides and some others, which agree with one another in relatively small length of the body and in lack of the apical and antapical elongations. Further, these small species show a wide range of variations in size of the body owing to development of unusually broad sutural zones. A corresponding but less distinct structure can be established often in $P$. crassipes and its relatives.

Judging from these, it is apparent that whether or not the depression of this sort is formed is not characteristic of species or subgenus but is clearly due to whether the body has or has not too broader sutural zone in proportion to its size or, strictly speaking, to transverse length of the thecal plates lying on either side of the zone.

Size The most distinct variation brought forth by the growth is the increase in size of the body. The absolute amount of the growth varies proportionately to the diameter of the body, which differs in different altitudes measured. And it is generally ascertained that the greatest growth is seen in the cingular region. Judging from the original surface curvature of the thecal plate, which is not subject 
to remarkable modifications during the growth-period, and also from the structural relations of the sutural cleft which allows the growth of the plate only in a definite direction, it can clearly be suggested that a given species has its limit of growth, which is characteristic of the species.

According to Peters (1928), $P$. subinerme and $P$. multistriatum can grow larger by $60 \%$ and $130 \%$ of their original size respectively. But the measures given by him appear to us too great, and can not be accepted because of the consideration that he did not distinguish the band of striae from the zone of growth which is much narrower than the band. If we take the band of striae for the base of measurement, we may naturally be led to over-estimation. Either from calculations of the smallest and the largest specimens of some species or from measurements reproducing original size of a body from an over-grown specimen, we were led to suggest here that the body of Peridinium can grow larger by $50 \%$. When growth of the body advances nearly to or beyond this limit, there may be brought forth some torsion or deformation which in its extreme case may presumably be fatal to the organism.

Apical horn The sutural zone is not built at all at the apical pore which does not display any distinct variation in diameter due to growth. A more or less abruptly differentiated apical horn is covered with three apical plates when it is very short but with four plates when it is elongated. In either case, the horn does not vary in length but increases its diameter during the growth. As the growth continues, the ventral apical plate is more and more displaced ventrally or posteriorly from the apical pore, bringing forth stronger elongation of the apical trough or ventral slit of the apical pore. Furthermore, as a result of unequal distribution of the transverse sutures between the ventral and dorsal halves of the epitheca, growth of the sutural zone forces the apex to displace more ventrally than dorsally. Consequently, the apical horn is generally displaced more ventrally in older specimens than in younger ones. Presumably associated with the stronger dorsal bulge of the epitheca, the elongated apical horn of grown specimens often leans towards the ventral. In some species, the horn leans towards the right in narrow sutured specimens, and this leaning is apparently strengthened by the growth.

Girdle The type and amount of the distal displacement of the girdle, though they are subject to individual variations to some extent, are not disturbed by the development of the sutural zone, because of the fact that they are defined mainly by the symmetrical or asymmetrical posterior extension of the median ends of the two ventral precingular plates. But in such species in which the girdle forms a remarkable arch in its proximal portion, the arch is often made more conspicuous by the growth, giving an impression that the ascending spiral is strengthened. Such was the case with $P$. crassipes.

By the growth or development of the sutural zone, the breadth of the girdle or cingular furrow is uneffected at all, but the structure increases in its length by the breadth of the sutural zones lying across the girdle. 
Antapical spine or horn Though it is obvious that the antapical spine or wing-complex is built at the time when the general thecal plates are formed, the growth in length of the structure has not been established so far as our investigation goes. The length of the structure may be variable in certain species while fairly constant in others. In the former case, its greater length is not necessarily correlated to the. stronger development of the sutural zone. In $P$. schilleri, the structure is fairly constant in length irrespective of various breadth of its sutural zone. On the contrary, the structure is generally thicker in specimens with broader sutural zone or with thicker thecal plate. However, the mechanism by which the thickness is increased is uncertain. But regarding this, it may be reminded that a similar increase in thickness can be established in the cingular list of some species and further that narrow hyaline lists which are often established along the suture of the epitheca in some species, are more distinct in older specimens. In view of these facts, we are led to recollect the fact that fine strands of plasm are ascertained to extrude through the thecal wall of Ceratium and Podolampas. If a similar phenomenon is presumed in the genus Peridinium, the increase in thickness of the structures given above may be explained. In this regard, it is to be recollected that the thecal wall is distributed with minute thecal pores all over its surface except in the flagellar furrow where the least variation in structural relation is brought forth by the growth of the body.

Contrary to the formation of apical horn, the typical antapical horn is formed solely with a single antapical plate, and is then hardly allowed to grow not only in length but also in thickness.

In narrow-sutured specimens, the left antapical spine or horn often leans or is displaced more ventrally than the right one. And this asymmetrical displacement or inclination is apparently strengthened by the asymmetrical and irregular development of the sutural zone around or on either side of the ventral area, bringing forth at the same time stronger distal divergency of the antapical spines or horns.

In the Conica group, the circumsulcal sutural zone passes across the tip of the antapical horn, distal end of which becomes, then, more stumpy as the sutural growth goes on.

As the circumsulcal sutural zone is formed in typical cases just along the innerside of the circumsulcal edge, the sulcal furrow is made broader in older specimens by the breadth of the sutural zone. This naturally forces the tips of the horns to separate wider apart from each other, making at the same time the postero-median indentation of the body less indistinct. This correlated variation is established clearly in $P$. conica, $P$. bifurcata or their allies. In small-horned species such as $P$. multistriatum, $P$. rhombiformis, $P$. petersi, P. paulseni, P. subinerme and others, the pointed antapices become stumpy and its distal spine becomes hardly distinguishable owing to its minuteness and oblique displacement. This often brings forth so distinct differences of appearance in their hind end that some former investigators were led to misinterpretation about taxonomic allocation of some of them. 
Size and shape of thecal plates The marginal, sutural zone is not formed equally on all sides but is built more or less irregularly on different sides of a thecal plate. A grown thecal plate, then, differs from the original, non-grown one in some points, having in either of them a definite number of sides. In other words, the growth of a thecal plate brings forth a more or less remarkable variation in relative length of their sides. This, together with the different surface curvature of the newly formed marginal portions and the irregular arrangement of the sutural zones, causes some distortions which were partly elucidated in some previous paragraphs.

With all these, any of the thecal plates retains its original shape throughout entire course of the growth, as, for example, the hexagonal middorsal intercalary remains as such being never subjected to variation in shape. When the band of striae lying along under-surface of a thecal plate becomes broader expanding into its reticulated region, the shape of the reticulated area appears as if altered by the band seen through the wall of the plate. Such is clearly the case with $P$. subinerme recorded by PeTERs (1928). It may be granted to suggest that similar misinterpretations may be found not rarely in literatures and published figures in case two different plate patterns were described in a single species. In view of this misinterpretation which might have been done not rarely, it must be of utmost importance to re-examine published literatures and figures. Because too much taxonomic importance has been put upon the type of the ventral and dorsal plate pattern, we were forced, in practice, to define the plate pattern as far as possible in every case. This is liable to lead one into wrong or too hasty interpretation when the pattern is blurred by the band of distinct striae. In such cases in practice we has to pay special attention to the direction of extension of the striae which cross typically the suture at right angle even if it is very short.

The sulcal plates are the ones least modified, and the pore-plate covering the apical pore is the sole one never effected by the growth, as were given in previous paragraphs.

Foraminous field and band of striae The band of striae broadens by sacrifice of the foraminous field of a thecal plate along under-surface of which it lies. In some extreme cases of over-growth, a small thecal plate such as the left ventral precingular one is seen overlapped for the majority with the band of striae and the thecal pores which had been distributed all over the plate before the sutural growth began, are restricted only in its small portion. Regarding the cingular plate, the band of striae begins to grow broader from the two sides of the plate and finally a narrow median portion, along which is generally arranged a set of pores, is left unlined.

These apparent modifications due to development of the band of striae are often misinterpreted as due to variation of the texture of the thecal wall. The striated portion thus built is in many cases thicker than elsewhere owing to its double layer consisting of two marginal parts of different plates. The thecal wall in this region is 
generally thicker along its inner surface but often is faintly elevated towards the outer surface.

The striation in the band becomes generally more distinct as the marginal lamina grows broader. But it is indistinct generally within and at the anterior end of the ventral area, presumably suggesting weaker or least development of the sutural canalicules there. Aecording to some observations, the marginal lamina of the sulcal plates is, in most cases, unusually broad in comparison with their minuteness and with that of the general thecal plates, particularly distinctly around the anterior end of the anterior sulcal plate. It may be due to this that the sulcal plates are separated from each other only with difficulty and they are generally poreless.

Ventral area and sulcal furrow The ventral area is, as elucidated elsewhere in this paper, the portion least modified by the growth, but the sulcal furrow becomes larger as the circumsulcal sutural zone grows broader. In some of the Steinii- and Conica-types, in which the flagellar furrow is more or less sharply differentiated into a small part of the ventral area, the furrow is least modified, but in others in which the ventral area is excavated as a whole, the sulcal furrow expands towards the right and posterior directions by the breadth of the circumsulcal sutural zone. In the latter case, the sulcal furrow often extends anteriorly beyond the ventral area, forming a small but abrupt depression at the midventral posterior part of the epitheca. Detailed accounts of this were given in a previous paragraph.

\section{General variations of thecal characters}

Much had been discussed about the thecal variation of the genus by BARRows (1918) who laid special stress conforming to others upon the plate pattern of the epitheca, which has been believed generally since JöraEnSEN (1913) as of the utmost importance in the taxonomy of the genus. About ten years later, Peters (1928) discussed the same problem, taking some other characters into considerations, and yet he still esteemed above all the taxonomic importance of the plate pattern. Contrary to these and other authors, Schiller (1935) and Diwald (1939) suggested greater variableness than generally accepted of the plate pattern and other thecal characters within a single species. Regarding the probable causes of the variation, Diwald (1939) remarked that "Nicht nur in stark inhomogenen Lebensräumen, sondern auch in Biotopen mit ungüstigen Verhältnissen wird die Variabilität erhöht."

In spite of these, especially DiwALD's far-reaching discussions and considerations, we have had a strong suspicion about the property of the plate pattern and probable limit of its variations, established by the former investigators. Drwald, admitting an unusually wide range of variations within a species, defined his species as consisting of some genotypes which correspond to so many species, generally ascertained as distinct from one another. His species may be then comparable in some points to the 'collective species', accepted generally in an early time when morphological analysis of the genus had not been sufficiently advanced. His definition or principle of taxonomy, however, may be accepted if his morphological analysis would have 
been done with sufficient accuracy and the statistical methods he applied were based upon due considelations. Judging from his figures and descriptions, his morphological analysis is, however, unsatisfactory to our expectation. As a natural consequence, by the statistical methods he applied, it may hardly be possible to distinguish two different species of closely allied appearances and with wide ranges of variations, overlapping with one another. Further, it is hardly possible by his to distinguish modifications due to growth from variations due to causes other than the growth. This is by no means suggesting his wrong methods. On the contrary, this may be apparently due to insufficiency of his morphological analysis. It seems to be highly desirable that much higher morphological study of the variation should be achieved before re-application of the statistical methods and also for the advancement of the taxonomy of the genus. Regarding the plate pattern, our morphological study of its variations will lead us to a consideration of the general property and characters of the structure.

Size of body A remarkably wide range of variation in the size of the body was certified by Peters (1928) on $P$. depressum, $P$. inaequale and $P$. subinerme, among which the first is the foremost in this regard because of its displaying $40 \%$ variation in the transverse diameter on a smaller or larger size of its mean. A similar but less remarkable variation was ascertained also in our materials in the same species, and in much less degrees in $P$. clavus, $P$. crassipes, $P$. excentricum, $P$. majus and $P$. sphaeroides. All these cases are, however, by no means excluding from measurable variations due to growth. As described in previous paragraphs, within a given species the epitheca is in typical cases divided into definite number of plates which are characteristic of the species in their arrangement, shapes and relative sizes. Consequently, variation in size of the body can be calculated by comparing originally formed parts of corresponding plates from different specimens. If this due consideration were not given, results obtained from measurements would be untrustworthy or be regarded as too exaggerated.

Interesting in this regard is that in Shimoda were found a larger and a much smaller form of $P$. majus, hardly distinguishable from each other in general thecal characters but for the striking difference in size, and that none of their intermediate forms has ever been ascertained. Its larger form has by no means broader sutural zones than its smaller one. A similar relation was also ascertained on P. punctata $(=P$. Abéi). All specimens of the species collected from the Inland Sea were much larger than those found in Asamushi. Similarly we have also ascertained in several species that specimens in Shimoda are larger than those collected from Asamushi. From these it may be allowed to suggest that the northern form of certain species is often smaller than their southern form. This appears to contradict Peters' conclusion that "Die antarktischen Vertreter aus dem eiskalten Wasser fielen häufig im Durchschnitt etwas grösser aus als ihre nordische Artgenossen aus den mässig warmen Gewässern." In disregard of this inconsistency, it may be certain that in some species may be established some geographical variations in size, which may be brought 
about by different oceanic conditions. In this regard it is interesting to recollect that in Shimoda Bay where the two forms of $P$. majus were found. The deep-sea water of lower temperature is often carried upwards resulting in mixture with surface water of higher temperature.

Form of body It may be unjustifiable to show the form of the body statistically without giving due considerations to the characteristics and mutual relationships of the different parts of the body. In addition, there is no direct means or formulae to manifest simply the forms of differently moulded various parts of the body. As a result, most of former investigators drew presumably wrong conclusions, disregarding homology or analogy of some structure such as the antapical horn. Diwald (1939) was the first who contrived to adopt statistical methods in manifestation of taxonomical relationships of species. But by the methods he applied without paying due considerations on finer structures of important parts of the body, relationships between species can be ascertained to a certain degree but their distinction is often hardly possible. The typical antapical horn can be distinguished from the semisulcal one only morphologically but not statistically, and these two structures can not be subjected to a sweeping discussion because of differences in their construction and relationships with the other important structure, the ventral area. If due considerations are not given to these and allied points, our taxonomic study of organism is liable to be led to the conclusions with discrepancies, confusions or misinterpretations, contrary to our expectation.

We are then requested to analyse minutely every one of the major thecal characters and to define possible limits of its variation in order to avoid confusions and inconsistencies as much as possible.

Apical horn The anterior end of the body is typically differentiated into a very short or variously elongated apical horn. When short apical horn is associated with a rounded midbody, it is generally abruptly differentiated from the latter. But in case it is coupled with a conical or sub-conical epitheca, the transition is not abrupt. In case the apical horn is longer, it is generally less abruptly differentiated from the midbody, and a longer apical horn is coupled typically with a longer antapical spine or horn. And never was seen a species in which the elongated apical horn is coupled with the short antapical spine or horn. But the reverse is by no means wanting in nature, as, for example, $P$. spheroides and its allies have well formed antapical wing-complex and a very short and abruptly differentiated apical process. When the thecal wall of the epitheca is strongly concave, it is usually hardly possible to define the point of transition because the two structures are confluent with each other. In this case, we are often led to over-estimatation of the length of the apical horn, because of the impression that the horn is seen as if elongated by sacrifice of distal end of the epitheca. And this is the case often met with when the epithecal wall of a species is variously concaved. From these and other available facts we 
are led to conclude that magnitude of elongation and differentiation of the apical horn is in the main characteristic of the species.

There is a different sort of variation manifested in the apical part of the body. When the thecal wall of the epitheca is variously concave in its different parts, the apical elongation or apical end often leans towards one side of the body. In $P$. punctata $(=P$. Abei $)$ the epitheca is in typical cases regularly conical, but is often more strongly concave in its dorsal side than in the other sides. In this particular case which is by no means rare in nature, the apical portion curves or leans towards the dorsal side. In some of the Conica group, as the right side of the epitheca is usually more strongly concave than the opposite side; not only a short apical process but also the entire epitheca is seen leaning towards the right. A corresponding feature can be established, though in less distinctness in some other groups, and this characteristic feature is deeply correlated, as was described in a previous paragraph, with the asymmetrical structure of the water pusule lying within the body.

Midbody Garefully analyzing morphological factors powerfully affecting the form of the midbody excluding the apical and antapical elongation and extension, one can ascertain a group of characteristics, by different combinations and development of which the various forms of the body are brought forth. They are of relative breadth, relative depth, concavity or convexity of the thecal wall, type and strength of the bulge of the thecal wall along the girdle, the ventral depression, stronger dorsal bulge of the thecal wall presumably as a result of the ventral flattening, and shape and tilt of the cingular section. Some of these structural features were recently studied by Drwald (1939) whose methods of statistical study are in the main correct. We wish these various structural features were more minutely studied with finer critical analysis and on more strictly defined species. But we have to anticipate paramount efforts and difficulties in carrying it out.

So far as our materials inform us, concavity or convexity of the thecal wall and shape and magnitude of tilt of the cingular section are fairly variable in some species. The midbody of $P$. pellucidum shows a wide range of variation in shape, ranging from a flattened biconical to a spheroidal one. Yet the relative length (length/breadth) of them is fairly constant, being 1.09-1.14. A similar but less distinct variation was ascertained in $P$. pallidum. In $P$. crassipes and $P$. punctata the concavity of the thecal wall displays a fairly remarkable variation. In species with strongly tilted cingular section, the depth of the body is often affected by different degrees of the tilt which is in some species subject to individual variation to some extent. The relative breadth (breadth/ length) is to be measured only upon the midbody itself, because of high variability in some species in the length of the apical and antapical horns. But it is hardly possible to carry it out when the transition between the midbody and those horns are not abrupt. Among the three sorts of the diameter of body, the transverse one is the most trustworthy character and at the same time is of practical convenience. The bulge of the thecal wall along the girdle is fairly characteristic of species. In 
Protoperidinium and the Paradivergentia group of Mesoperidinium this structure is generally hardly be ascertained, while it is distinct in the Divergentia group of the latter subgenus and in some of Veroperidinium. This structural feature clearly serves to distinguish closely related species. In $P$. oceanicum the thecal wall flares more or less distinctly along the girdle. But in its closely related species, $P$. oblongum, was found the bulge hardly formed. In side view, dorsal side of the body is angulated at the girdle in the former species, but has no such structure in the latter species. Together with these, the ventral depression of the body is also fairly characteristic of species in its width and depth. It is weakly formed in all sections and groups of Protoperidinium with exception of the Globula section in which it fails to develop at all. Between the two groups of Mesoperidinium, this structure is formed more or less distinctly in Divergentia but not at all in Paradivergentia. In Veroperidinium, this displays a strikingly wide range of variation in development. In some groups or species, it is hardly formed while it develops variously in different species of other groups. In the Conica group, a parallel relation is ascertained between this structure and the development of the posterior sulcal plate. In $P$. sinuosum, these two structures attain their highest development. From these we are led to conclude that this structure, together with some others just considered, is characteristic of species and subject to least individual variation.

Girdle The relative depth of the body is fairly constant when the cingular section runs horizontally, but is often variable when the cingular section tilts up dorsally. This valiability in the latter case depends upon variableness in some species in the tilt of the cingular plane. Such is the case typically with $P$. crassipes, $P$. depressum and $P$. oblongum and in less distinctness with $P$. rhomboidalis, $P$. schilleri and some others. In the first of them, the relative depth (depth/breadth) of the body at the girdle varies from 0.82 to 0.98 . As the relative depth of the body is generally correlated with the relative length of the body, magnitude of the tilt is also correlated with the length of the midbody in some species as was given in Table 12.

Table 12. Relative depth and tilt of cingular section

\begin{tabular}{ccc}
\hline Species & Relative depth & Tilt of cingular plane \\
\hline & 0.76 & $12^{\circ}$ \\
P. rhomboidalis & 0.62 & $20^{\circ}$ \\
\hline & 1.03 & $8^{\circ}$ \\
& 0.75 & $12^{\circ}$ \\
\hline
\end{tabular}

This close correlation between the relative depth of the body and the tilt of the cingular plane suggests fairly invariable shape of the cingular plane, in other words, a given length of the girdle for a given species. 
Cingular displacement It has generally been believed that the type of the distal displacement of the girdle is characteristic of a species or group of species. Contrary to this, Diwald (1939) illustrated two cases in $P$. pentagonum, each displaying an ascending or a descending girdle. Strictly speaking, as was described elsewhere in this and other papers, two ventral ends of the girdle are subject to individual variations in regard to this mutual relation. Range of these variations is various in different species and also in different types of the distal displacement. Generally speaking, it is small in case the girdle form a more or less circular and horizontal tract, but it is greater when the girdle forms a remarkably ascending or descending spiral and the cingular plane strongly tilts up dorsally. In the major case, the range of the variation in the distal displacement is not greater than the width of the girdle itself, but in some exceptional cases it is much greater, as is ascertainable in some species of the Globula group. Consequently, when a circular or nearly so formed girdle displays the distinct variability, all of possible types of the distal displacement are brought about. But in case the ordinary amount of the distal displacement is greater than the width of the girdle, the type of the distal displacement is generally undisturbed. The three types of the distal displacement are established variously in different specimens of $P$. crassipes. In $P$. pallidum and $P$. rhomboidalis, the girdle is circular or remarkably ascending with distal displacement of one-half or more of its width. The strongly ascending girdle of $P$. schilleri displays a variation in the amount of its distal displacement, ranging from 1 to 1.5 times of its width. Most of these just cited and some other species have in the proximal part of the girdle an arch which is more conspicuous when the distal displacement is stronger.

Antapical elongation or extension According to Peters (1928), "Die antapikalen Fortsätze des Panzers schwanken innerhalb der Arten ausserordentlich in Bau, in Form und Grösse." This apparently represents not only his but also many other authors' opinions regarding great variability of the structure. Against this, our observations led us to a different conclusion that the structure is fairly constant and characteristic of a species in the major cases and appears to be variable in a few exceptional cases in which two types of the structure are originally combined.

We have shown that the antapical appendage can be classed into three types, spine, horn and that consisting of these two. It is the last type of these that displays apparent variation. The spine is either winged or wingless and stands at the tip of a conical bulge of the thecal wall. There are reasons to suggest that in this type the distal spine and the basal horn are inversely correlated in length or in development forming a series of variations. At one end of the series stands $P$. grande in which the distal spine is only rudimentary and at the other end lies $P$. pallidum or $P$. pellucidum in which the wing-complex is typically formed while the basal bulge is rudimentary and often fails to develop. And there are in the genus almost every intermediate form of the two. The inversed development of the basal horn and its distal spine within a species can be established further in $P$. solidicorne. Distal solid portion of 
the antapical appendage in $P$. parallelum has been much discussed and was regarded by some investigators as a character of taxonomic importance. But according to the principle given above, this may be explained as the case in which the distal spine, which is in typical cases rudimentary or hardly formed, happened to develop strongly by sacrifice of the basal horn.

The length of a typical antapical horn is in many cases subject to individual variation which differs in the range according to different species and varies in correlation with the apical horn. The distal portion of the semisulcal antapical horn extending beyond the ventral area varies in length, so far as measurements on our materials indicate, from $3 \mu \mathrm{m}$ to $7 \mu \mathrm{m}$ in $P$. solidicorne, from $16 \mu \mathrm{m}$ to $24 \mu \mathrm{m}$ in $P$. grande and from $35 \mu \mathrm{m}$ to $47 \mu \mathrm{m}$ in $P$. oblongum.

In most species the two antapical horns are separated similarly from the ventral area. But peculiar is the right-hand one of $P$. oblongum, which is more strongly removed from the ventral area than the other, and further the distance displaced is subject to individual variation.

There has generally been believed that the antapical spine displays remarkable variations in length and development. It is reported that the antapical spine of $P$. steinii is highly variable, as it is shorter in the Arctic Sea, a little longer in the Subarctic Sea and fairly elongated in the Bay of Biscay and Californian Sea. In Val di Bora, the PAULSEN-type is seen in the early spring, while the Mediterranean-type makes its appearance from late summer till autumn. Regarding the probable cause of these variations, Koforn (1916) suggested "possibly as the direct result of environmental condition."

In spite of these far reaching discussions about the apparent variation in the length of the antapical spine and the general belief resulting from them, hardly anything has been given about detailed morphological accounts of the structure itself. The only literature in this regard is that given by Korom (1908) on P. steinii, if the observation of ABÉ (1936) is excluded. We have to recollect here that some inconsistent discussions have been, and are still now, given about the specific heterogeneity of this well known species, $P$. steinii. This species-name has been given by various authors to different forms closely allied to each other. Then, the conclusions and suggestions about this species can not be accepted as such without verification, because the two types of the species cited above appear to differ from each other so remarkably in the form of the midbody that their specific distinctness has often been suggested. However much had been discussed about these, it may be of no use if the variability and diversity of the antapical spine was not established. As was described in this paper, the antapical spine of this genus is to be divided into several distinct sub-types, and they can not be brought under a sweeping discussion. We have, then, to confine discussion only on a given sub-type of it in order to avoid confusion and inconsistency. So far as our materials are concerned, each of the subtypes of the structure is fairly constant in structure and is characteristic of a species or a group of species, displaying variation only in length and development. In some larger species such as $P$. schilleri and $P$. rhomboidalis, the length of the spine is well 
defined, $12-14 \mu \mathrm{m}$ in the former and $5-9 \mu \mathrm{m}$ in the latter species. But in some smaller forms it shows generally a wide range of variation. The length of the antapical spine of $P$. acutum ranges from $7 \mu \mathrm{m}$ to $13 \mu \mathrm{m}$ while that of $P$. pellucidum from $4 \mu \mathrm{m}$ to $11 \mu \mathrm{m}$. Not only the length but also the direction of extension is subject to individual variation in some species such as $P$. rhomboidalis and $P$. pellucidum.

Structure of the thecal plate There has often been recorded that two sorts of the plate, one with speckled and the other with reticulated fields, are seen concomitantly or separately in a single species. We often found a similar case of some smaller species. But closer examination with greater magnification revealed without an exception that a seemingly speckled thecal plate has a weakly formed minute reticulation all over its surface. In some, the speckled structure was ascertained to represent an earlier developmental stage of the reticulation, and in other cases, these two differently formed structures continue as such throughout the entire course of growth. From this, it is apparent that the so-called variation in the structure of the thecal plate is brought about by difference in the development of the two structures which is intrinsic to a given species. Often minute spinules are seen closely arranged all over the thecal wall of some species belonging to Mesoperidinium or Veroperidinium, and this structure displays a distinct variation in development in different parts of a single body or in different specimens of a single species. This also may be explained similarly as the above.

Plate pattern Morphological significance and taxonomic importance of the plate pattern was ascertained by JörGENSEN (1931), and the majority of later investigators have followed his principle with or without emendation. The principle accepted by them is based upon the supposition that a given plate pattern or a given combination of the ventral and dorsal plate patterns is subject to the least individual variation and is therefore to be regarded as characteristic of a given species because of its validity and simplicity. Many of these investigators contrived to subdivide the genus according to the differences of the plate patterns or their different combinations. But contrary to their expectation, there has gradually been brought to light particularly recently, that the plate pattern is by no means well established for species but displays some variations in some or other species especially distinctly in the dorsal side of their epitheca. On the other hand, some variations were ascertained in published literatures and figures regarding the ventral plate pattern of the epitheca, which had been estimated much more as of taxonomic importance than the dorsal plate pattern. Coupled with the former, this, which was ascertained afterwards partly due to misinterpretations or misdrawings and partly due to actual variation brought forth as a sport, brought forth many abberant combinations of the patterns, inconsistent with any of the principles of subdivision ever proposed. Among these who studied along this line are Lindemann (1916, 1918, 1919), Barrows (1918), Dangeard (1926), Paulsen (1931), Peters (1928), Schiller (1935) and Diwald (1939). Barrows was the first who has given detailed accounts and discussions 
about the variability of the plate pattern in the marine species. He discussed the variation of the plate pattern of the genus from phylogenetic point of view, laying much stress upon the different plate patterns which were regarded by him as indicating various phylogenetic relationships of the species. He regarded, then, the variation of the pattern within a species as mutations suggesting the mutationary method of species formation. An entirely different interpretation was proposed by DIWALD who regarded the variation as being brought forth "durch verhältnismässige Vergrösserung einer Platte auf Kosten der Nachbarplatte (nicht durch Verschmeltzungen)." At the same time he gave important suggestions about correlations between the variability of the plate pattern and some oceanic and other environmental conditions. These two authors contradict each other in that the former put great stress upon variations in length of the sutural line and in shape of the thecal plate, while the latter author thought little of them. Most of the other investigators may be regarded as standing in this rather on the nearer side of BARRows than that of DiWALD and SChILLER.

BARrows (1918) ascertained four regions of variability in the epitheca, two on its ventral and two on its dorsal sides. In case the intercalary series consists of three plates, and regarded the epitheca as more conservative than the hypotheca conforming to GHIL's law of metabolic gradients. Although the variable regions are more numerous and more irregularly distributed over the epitheca and also the hypotheca than he expected the epitheca differs remarkably from the other half in stronger liability to the variation. Therefore, it is convenient to consider them separately.

Epitheca Variations in the plate pattern of the epitheca have been so extensively discussed from different points of view by many investigators that it seems to us of no use to give here reviews of the discussions.

The three ventral plate patterns are well established generally but display variations exceptionally. We have ascertained a singel case of the Ortho-pattern in $P$. granii which has the Meta-pattern in typical cases. In some smaller species of the Pellucida group, both patterns of Meta and Para make their appearance within a single species. According to Diwald (1939), the ventral plate pattern of $P$. ovum and $P$. adriaticum varies from Para to Meta or in reverse direction. In either species, the change of the plate pattern is coupled with variation in size of the right apical and right ventral precingular plates.

Before going further, it must be recollected that we are liable in practice to misinterpret the plate pattern, when the thecal wall is covered with the wellformed broad bands of striae. It may highly be probable, judging from this, that a similar misinterpretation may often have been done by former investigators. In view of this, we shall not enter here as much as possible into discussion of the recorded variations on account of their suspected interpretation, though admitting the preciseness of drawing in many cases. This uncertainty of occurrence of varia- 
tions, however, by no means reduce the taxonomic importance of the ventral plate pattern.

As may be conceived from the remarkably varying number and sizes of the intercalary plates in the genus, the most variable region in the epitheca is in its dorsal middle represented by the intercalary row of plates. In P. clavus and $P$. hemisphericum, this row has typically two plates but is often covered with a single huge plate, presumably by failure of splitting judging from fixed size and extent covered by the row in either case. In one specimen of $P$. ventricum were found three intercalary plates instead of typically two. In the case of the three intercalary plates, the middle $2 \mathrm{a}$ is the foremost in displaying variations in size and shape, and discussions hitherto given were mostly centered on this plate. It is in typical cases tetragonal, pentagonal or hexagonal, each of which has long been regarded as immutable and then characteristic of a section or group but recently ascertained as fairly variable. Shape of this plate is distinct, affording us a trustworthy character of ready distinction, when the plate is distinctly angulated at every intersection of three plates, lying around it. It may be the case with the tetragonal or pentagonal plate. But the plate is separated from two of its adjacent plates by a straight suture. In other words, when two of three sutures intersecting at a point are arranged in a straight line, the plate has then smaller number of its sides of contact than actual number of its adjacent plates. Such is the case typically with the middle intercalary plate of $P$. deficiens, which is typically tetragonal or trapezoidal in spite of its bordering on six plates. A similar inconsistency can be ascertained generally in those species in which the epithecal plate pattern is highly re-adjusted in arrangement and the middle intercalary plate is surrounded with six plates. In the case of this re-adjusted plate pattern, there may be no doubt that the middle intercalary is tetragonal if it does not expand posteriorly beyond the two laterals, and similarly it may be pentagonal if this over-expansion occurs asymmetrically on the side only.

In addition, we can assume another factor affecting the shape of the plate. In the ordinary or re-adjusted plate pattern, the teragonal or hexagonal shape of the plate is correlated with lateral expansion of the dorsal precingular plate on one side or on both sides beyond that lying above it.

From these, it may be granted to suggest that the shape of the plate is decided by the manner and extent of its posterior expansion, cooperated with these of the dorsal precingular plate, and is by no means to be regarded as a character of primary morphological significance. It is not, then, the shape but the manner and relative amount of the posterior expansion of the middle intercalary plate that has long attracted the taxonomist's deep interest and is to be much esteemed. In view of this, DIwALD's (1939) suggestion regarding the middle intercalary plate of $P$. globulus is interesting. But it is highly probable that his five figures (Fig. 4 a-e) are to be divided into three groups or types of $a-b, c$ and d-e. Our observations inform us that they do not form a single series but are interrupted at two points on either side of c. But we are of the opinion that when a series of varying characteristic displays some abrupt and conspicuous interruptions, each subgroup thus formed 
is to be regarded as a distinct one, because of the consideration led by our long continued observations that magnitude of the variation has a certain limit, characteristic of a species or group of species.

The apical series in $P$. avellana or in its allies often consists of five plates instead of four. In any case, however, an additional plate is brought about without re-arrangement of others, in other words, clearly by splitting of one of the three $\left(2^{\prime}-4^{\prime}\right)$ plates, which grew larger by sacrifice of its neighbours. A corresponding variation was ascertained in $P$. clavus. In a single specimen of $P$. elegans, an unusual suture was seen in the ordinary right apical plate which is split then into two smaller ones. A new suture is rarely formed in the ventral apical plate, as was seen in a case of $P$. pallidum and was figured by Diwald (1939) in $P$. pallidum and $P$. conicum. In any of these cases, the additional suture unusually formed lies always longitudinally or radially with its one end extending to the apical pore or apical trough. The formation of this unusual suture in $P$. clavus is always coupled with two intercalary plates and is never associated with a single intercalary. The same is the case between the antapical and the intercalary series of the same species.

Variation in size of the apical plate is not rare but attracts our attention particularly in case it is seen in the ventral apical one. The shape of this plate, as has long been much estimated as of taxonomic importance, is least variable, but its size or rather its transverse diameter often displays a remarkable variation in $P$. crassipes, $P$. pallidum and some others. The dorsal apical plate is mostly pentagonal and rarely tetragonal. We found a case of the triangular dorsal apical plate in $P$. crassipes. Hasty or superficial observation is apt to lead us to miss the tetragonal dorsal plate of $P$. globulus because of its minuteness. In Diwald's (1939) Figure $4 \mathrm{~d}$ and e, this plate is not illustrated. But we are still sceptic about complete disappearance or failure of development of this plate in the typical species of the genus.

So far as published figures show, this dorsal apical plate is always in any species interrupted by the intercalary series from the precingular plate. Peculiar in this regard was a specimen of $P$. clavus in which the dorsal apical plate extends directly to the left ventral precingular plate.

The precingular row of plates has typically seven and rarely five, six or eight plates. But this is the one displaying the least variation in the epitheca.

Hypotheca As was truly remarked by BARRows, the hypotheca displays features to be regarded as of more conservative than the epitheca. This, contrary to his conclusions, is by all means signifying more taxonomic importance of the structural features manifested in the hypotheca than those in the epitheca. However, hardly anything have been discussed about variations in the plate pattern of the hypotheca, partly owing to too much stress upon the plate pattern of the epitheca in the subdivision of the genus. This is by no means insignifying the variation nor suggestive of non-existence of the variation in the hypotheca.

We have not come across a single case of four postcingular plates or a single antapical plate. On the contrary, two cases of six postcingular plates, or rather an 
additional small one in the series, were ascertained in our materials. In an overgrown specimen of $P$. conicoides, a small sixth plate was established on the left of the ordinary right ventral postcingular $5^{\prime \prime \prime}$. And a small, triangular plate was seen in a grown specimen of $P$. depressum at the postero-dorsal corner of its right postcingular plate. In either of these two cases, the additional plate is exceedingly small and appears as if it were formed by splitting. Not a single case of variation in the number of the plates in the antapical series has ever been recorded so far as published literatures and figures available at hand inform us. But peculiarly in a single specimen of $P$. clavus were found three antapical plates of subequal size. The extent covered by them is a little larger than that occupied typically with two plates. It is to be noted here that an unusual suture formed de novo is longitudinal in $P$. conicoides and lies in radial direction in $P$. clavus while it is peculiarly diagonal in $P$. depressum.

There has often been described about the variation in the size and shape of the individual plate of the hypotheca which is by no means rare in the genus. In the postcingular series, the left ventral $1^{\prime \prime \prime}$ and the dorsal $3^{\prime \prime \prime}$ are the foremost in this regard. Two forms of the left ventral postcingular plate are seen in $P$. schilleri, and the plate is elongated in one of them longitudinally and in the other transversely. Several different forms of the plate were established in a small species, $P$. acutum, and yet in all cases the plate has a subequal size. Interesting in this regard is the fact that the ventral pore or rather its flange of the species has at least four different types.

In view of the fact that a distinct variation occurs in the left half of the ventral side, it has to be recollected that the cingular section is often subject to individual variation in shape and its ventral half is asymmetrically formed, as its right ventral portion is always more broadly rounded than the other.

The dorsal postcingular plate displays a variation in shape particularly in its hind end. Whether its pointed end lies on the middorsal or displaced asymmetrically to either side is clearly correlated either to the dorso-ventral or to the diagonal extension of the intra-antapical suture. The shape of this plate is in part characteristic of a species but amount of its asymmetrical distortion is often highly variable within a species. We have established an interesting variation regarding lateral expansion of this plate in $P$. conicoides. In this, four types of the plate were ascertained, two expanding symmetrically and the other two asymmetrically. In any case, however, its lateral extremity is invariably ascertained lying at either of two oxed points and never between them. This led us to suggest that there are on either side of the plate two regions, through either of which a suture is formed bringing forth four different combinations, two symmetrical and two asymmetrical.

Ventral area The structural relations and its variations regarding the ventral area are not only of utmost morphological significance but also of taxonomic importance as were discussed elsewhere in this paper, yet have long been veiled in mystery. In this paper was brought to light the structure of the ventral area which displaying 
diversity on one hand and simplicity on the other hand in its structural feature, is divided in regard to its plate pattern fundamentally into the three types, each characteristic in the main for a subgenus. Each of them can be subdivided basing on different shapes and structural relations into several subtypes, characteristic for sections or groups. Consequently, a group of closely related species has the ventral area, fairly uniform in shape and structural relation. Among the four sulcal plates, the anterior three are so closely related to the flagellar pore and girdle that the major portion of the ventral area covered with them displays hardly any variation. The variation in the ventral area, if it occurs, is exclusively or at least mostly associated with the posterior sulcal plate.

In most of Protoperidinium, one can not ascertain any distinct variation in the form of the posterior part of the ventral area, and the posterior sulcal plate of them is also fairly uniform in size within a species. But this plate displays a variation in its bilateral differentiation which is particularly distinct in most of smaller species though it is ascertained also in larger ones. A corresponding variation can be also ascertained in $P$. conicoides and $P$. multistriatum belonging to Veroperidinium, in each of which we established several different forms of the plate. And a minor variation of this can be certified almost in every species of the three subgenera. The left lobe of the posterior sulcal plate in $P$. csassipes of Mesoperidinium can be ascertained lying on the lateral base of the left sulcal list, and this shows individual variations in breadth within a certain small range. In $P$. depressum, the plate tapers towards the left, extending in typical cases to the left ventral postcingular plate. But often it terminates in short of it owing to its smaller transverse length.

With all three variations, the posterior sulcal plate does not display so distinct difference in the size within a species as to lose its proportion to the entire ventral area.

There is another sort of variation associated with this plate. In $P$. solidicorne the ventral area very often forms at the median base of the antapical horn a small lateral expansion by which it extends to the antapical spine. This structure is variously formed in different specimens and on either side of a single specimen, but often it fails to develop at all. A parallel but much less distinct variation can be ascertained exactly at the same portion of $P$. pallidum.

MAngIn's figures of $P$. divergens is interesting in illustrating its ventral area organized reversely in right-and-left relation. A similar, presumably corresponding structure was also given by Fauré-Fremiet et O. du Puigaudeau (1922) in Fig. 10 of $P$. divergens, in which is illustrated a small triangular plate lying on the left of the vertral area, just between the left ventral postcingular and the left antapical plate. A large triangular plate lying just on the opposite side of the ventral area and outside of the right sulcal list was figured by Diwald (1939) in $P$. divergens var. adriaticum (Figs. 6 a-c, 7). So far as our materials are concerned, not a single case of such unusual structures has ever been ascertained. And it is an unsurpassed interest to know exact details of these thecal structures in these unusual cases. 


\section{Discussion}

It may be useless for advancement of the taxonomy of protozoa to discuss or propose a new principle of subdivision without ascertaining accurate morphological relations of important parts of body or without establishing at the same time limits and manners of variations of the major characters. That the taxonomy of the genus is still in a state of confusion as partly elucidated above, is also, due to lack of our knowledge about these characters just considered, without which no advancement of the taxonomy can be expected.

There has generally been accepted that some characters such as length and development of the antapical spine, convexity or concavity of the thecal wall, length and distal divergency of the antapical horns and some others, are subject to geographical and seasonal variations. But, these investigators who believed in such variations have not founded their opinions upon detailed morphological study of some thecal characters, which are really more important than these ever considered generally, and also of those by which the variations are brought about. We have, then, to make every endeavour to bring to light every possible cause and explanation of its thecal variations and limits of variability.

The variations regarding the plate pattern, considered above and given in literatures manifests a remarkable diversity but can be grouped into four sorts of phenomena-enlargement (diminution), splitting, new formation and fusion.

1. Enlargement (and diminution) The majority of the recorded variations may be included in this. Imagine that small globules or cells are packed so closely together as to manifest in surface view so many meshes. If a cell or mesh in this enlarges by sacrifice of its neighbours, a variation may be brought forth in the surface pattern. A variation in shape of a thecal plate may be explained in a similar manner. Taking for example a case in which two different patterns are recorded in a certain region of a single species, we are informed of the fact that a change of the plate pattern is always coupled with variations in size of the thecal plates by which a given pattern is brought about. This suggestion may be supported by the facts and considerations given in previous paragraphs regarding the middle intercalary plate. A change from a given type to another of the plate pattern in a given region may be brought about by variation in the relative size of one or some plates lying around a given point or intersection. These lead us to the conclusion that difference in the plate pattern is not a matter of quality but that of quantity brought about by changes in relative sizes of plates formed by a given group. All the ordinary variations regarding the plate pattern can be, then, explained as due to qualitative differences within a group of plates.

2. Splitting In addition to the variation of the plate pattern just given above, we often saw that in the number of plates. As has long been discussed, it may be difficult to certify whether an unusual thecal plate is brought forth by splitting of an ordinary one or by new building. Whichever it may be granted to suggest that when unusual two plates are seen in place of an ordinary one without displaying 
much difference in size or extent occupied by them, this can be denoted as due to splitting. The unusual suture thus formed is in major typical cases so arranged as to bring forth a new thecal plate in a circular row of plates. In other words, the unusual suture is formed regularly along the longitudinal line extending from the apex to the center of the hypotheca, that is, hind end of the ventral area. This line is longitudinal in the equatorial region of the body but takes a radial arrangement in its two ends.

The case of $P$. depsessum given before is extremely of rare occurrence in the marine species, and may be regarded as modification of the typical one given above. Often a diagonal or transverse suture is established in many of fresh-water species, particularly in their apical or subapical region. They may be explained as due to varying conditions of fresh-water in which they live.

In the majority of the splitting, one is naturally led to acknowledge that splitting of a thecal plate is followed by enlargement or diminution in the size of some thecal plates including the split one.

3. New formation If emergence of an unusual thecal plate is coupled with re-arrangement or remarkable distortion in shape of some thecal plates lying around it, we have to ascribe it to new formation of a thecal plate. Such may be the case with the three antapical plates of $P$. clavus. In a single specimen of this species (ABÉ 1936, p. 664, fig. 47), were found three antapical plates instead of two, the middle of which is formed by sacrifice of two others and the posterior sulcal plate. The area covered with this middle antapical belongs largely to the ordinary right antapical plate and partly to the ordinary left one. If stress is placed upon this relation, this may be explained as being brought about by splitting of the ordinary right antapical plate. Another case worthy of consideration here may be the sixth small postcingular plate ascertained in an over-grown specimen of $P$. conicoides. This may also be explained as due to the splitting of the right ventral postcingular plate. But judging from its unusual situation and the typical size and shape of the postcingular plate, it may be justified to say that it is due to new formation.

4. Fusion Contrary to those considered above, decrease in the number of the thecal plate is brought forth clearly by fusion of more than two plates, in other words, by failure of formation of an ordinary suture. Such may be the case with the single huge intercalary plate of $P$. clavus and $P$. hemisphericum. Fusion of plates takes place not only between equivalent components of a single circular series just referred, but also, though exceptionally, between plates belonging to different circular rows. Full accounts of many instances of the latter case were given in previous paragraphs. All one of them are but established in Veroperidinium, especially in its Conica group in which the re-adjustment of the plate pattern is much advanced. By means of distinct development of six longitudinal collective sutures, the entire surface of the epitheca is divided into so many longitudinal zones, within each of which fusion took place between its two component plates belonging to different circular series. The most interesting and peculiar fact in this regard is to be sought in the fact that the posterior sulcal plate of $P$. expansa is seen fused with the two ventral postcingular 
plates of entirely different phylogenetical origin.

From these it may be allowed to suggest that in the typical cases, component plates of a circular series are assumed to be linked together more profoundly than those of their adjacent rows, and that as a result of over-differentiation of the structural relations within the ventral area or between the longitudinal and transverse sutures of the highly re-adjusted epitheca, the ordinary linkage is disturbed resulting in a new types of association.

An interesting variation just corresponding to that established by us in the Conica group was recorded already by Diwald (1939) on $P$. divergens and $P$. adriaticum (p. 156, figs. 12 a-d). The simplified plate pattern thus brought forth by remarkable reduction in the number of the thecal plates leads us to recollect that of Blepharocysta in which the epitheca is covered mostly with the precingular plates and the apical plates are strikingly reduced. This close correlation leads us to suggest that the simplified plate pattern of the genus Peridinium, brought forth by the fusion of plates, may be regarded as representing an ancestral feature but not an advanced one.

Two contradictory suggestions have been proposed regarding the variation in the number of the thecal plates. Barrows (1918) concluded as follows. "In the Peridinidae, ... progressive development seems to proceed in an ordinary fashion in the direction of an increase in the number of plates ..." His conclusion is based upon the consideration that "It is possible ... that plate multiplication takes place by the splitting of a former plate. ... new plates arise at first as small thecal elements either split off from the corner of a former plate ... or new plates arise to fill the gap left by a bulging of the internal protoplasm of the organism which would cause three plates to be pulled apart at their point of articulation." Conforming to him, ENTz (1927) described that "Formen mit vielen Panzerplatten aus Formen mit wenig Panzerplatten sich entwickelt hatten," and further that "die grösseren Platten sich auf kleinere aufgeteilt hatten." He also suggested that the variation of the plate pattern is due to change of inner pressure. Against them, a contradictory suggestion was proposed by Schiller (1935) and Diward (1939). According to the latter author, "die Formen mit weniger Platten direkt aus solchen mit mehr Platten entwickelte haben ...". This consideration is clearly based upon the facts ascertained in $P$. globulus and $P$. divergens var. adriaticum.

In practice, both of these increase and decrease in the number of thecal plates can be certified in the genus. The splitting of plates leads us to verify BARRowsENTz's suggestion, but the unusual fusion of plates appears to lead us to accept Schiller-Diwali's suggestion. Inquiring into morphological details of the major thecal characters, we came to a conclusion different in some or in other points from those just referred to.

We do not intend here to enter into discussion about this problem of phylogenetical development of the general plate pattern, though we have to admit utmost importance of it.

For a considerably long time, the occurrence of various types of the plate pattern has been relied upon by the protozoologists for their hypothetical phylogeny of this 
particular group of animalcules, so the plate pattern is indeed a distinct character displaying a remarkable diversity. Reviewing through the genus, one may be informed that almost every circular row of plates displays more or less remarkable variation in the number of its component plates. Species with the smallest number of thecal plate may be found in some fresh-water species belonging to the Tabulata group. In the Diplopsalis group, one of the closest relative of Peridinium, every circular row has the smaller number of plates than those in the present genus. From these and also other available facts, we may naturally be led to the consideration that the various types of the plate pattern of the genus might have been brought forth either by the splitting (or new formation) or by the fusion of thecal plates formed in an early age of phylogenetical development.

The fusion has been ascertained only by Diwald (1939) and by the author exclusively on a single species of Mesoperidinium and in a small specialized groups of Veroperidinium respectively. This phenomenon occurs apparently in correlation with some anomalities of environmental or inner conditions of the organism or with particular differentiations of some structures. It is then to be regarded as anomalous, specific and distinctive. On the contrary, the splitting can be established in almost every section, group, or subgenus of the genus, and occurs in correlation with no other anomaly and in every circular row of plates, though in different frequency. This, then, is to be regarded as of more sound, more general and prevailing property. In addition, the splitting is accompanied in most cases with the enlargement or diminution, which can be established in almost every part of each one of all the species of the genus. Generally the enlargement or diminution is so indistinct that we are liable to be led to the misinterpretation that a given species has a given plate pattern. But in practice, this minor variation or rather fluctuation of the plate pattern is so markedly prevailing in the genus that it is hardly possible to find any two specimens identical with each other in every respect of their plate pattern. This may be verified when one compares a given thecal plate of a specimen with its corresponding one of another specimen only to find between them some differences in relative lengths of their sides and in size. From this, we may be informed of the fact that the plate pattern of a given species is in the main fairly well established but displays minor fluctuations in every point. When the magnitude of the fluctuation grows larger beyond a certain limit, partial change of the plate pattern is naturally brought about.

Almost every one of these investigators who have given discussions on the plate pattern and its variations has had a primary consideration on the arrangement of the sutural lines and not on that of the thecal plates. But the chief fact which should receive careful consideration is the arrangement of the plate itself, because the sutural line represents the outer border of the plate. The sutural line or its arrange ment is then of secondary significance.

This may leads us to a question whether, in each particular organism, the conditions bringing forth one particular plate arrangement are invariably predominant. In short, is a particular arrangement of the sutural lines to be looked upon as a 
specific or at least as a constant or characteristic feature of the particular organism?

There may be no doubt about the fact that the thecal plates of characteristic shapes and sizes make their appearance simultaneously all over the body when a thin surface membrane of a younger body stiffens to form the thecal wall. The shapes and relative sizes of the thecal plates may be determined, then, at the time when they are formed. It may be natural to assume that it is not the number and relative lengths of the sides of plate but the extent, elongation or area to be covered by the plate, that is established in the first time when the plate is formed. In short, we may be allowed to assume a single plate to be an unit of potence by which the extent, elongation or area of the plate is established. And a given arrangement of a definite number of these centers lying within a closed surface brings about a certain arrangement of the plates, the plate pattern. When two fields are in contact, a straight or curved line of demarcation which corresponds to the sutural line, is formed between them, and in case three are arranged in close contact with each other, three sutures are formed converging to meet one another at the point of intersection. This latter fact is certainly of great and is probably of paramount importance. In any of the species of the genus as well as of other genera, we may be led to maintain that sutural lines always impinge upon one another three by three. In any case, then, the plate pattern is brought about by a group of the fields of platemaking potence, by which a closed surface is divided into so many faces, demarcated by the sutures which obey in arrangement the rule of triple intersection. The angles at which these three sutures will meet one another, will be determined and at the same time affected by the relative magnitudes or their slight variations of potences of any two of the three fields. The arrangement, number and relative length of the sutures thus to be formed may be brought about by relative magnitudes of a group of potences, established there various types of the plate pattern. Similarly, the number of interfacial contacts of a given plate may be correlatively realized by relative proportions of a group of potences lying around it. But the shape or particular elongation of a plate may be correlated to some morphological and physiological differentiation of that portion of the body covered with it.

In any case, however, when four plates are in conjunction, they are exclusively arranged so as to bring five sutures to meet, three and three, but never in such a way as to bring four sutures to meet at a point. In other words, whenever four plates may be found to be conjoined, two are found juxtaposed and the other two separated by a longer or shorter sutural line. Such can be ascertained to be constantly present in the genus whensoever four thecal plates are associated one another. There is an interesting case which appears to form an exception to but in reality obey the rule of triple intersection. In typical cases, four sutures converge to the apical pore. We have, however, to recollect that the apical pore, though it may be minute in size, has without exceptions a definite length and is covered with a pore-plate. And we are led to ascertain here that the four converge, two by two, to either end of the pore. Strictly speaking, either of the ventral or dorsal apical plate, which appears as if pointed distally, has in reality at its anterior end a definite 
breadth, by which it borders on the pore-plate. These relations can be established clearly when the apical pore is elongated to form the apical trough. Another fact to be recollected in this regard is that in all the species of so-called Clesitoperidinium, in which the apical pore is absent, a suture of a definite length can be ascertained invariably in place of the apical pore, and we have to acknowledge there that five sutures always impinge upon one another three by three and never converge to a point. Such may be a direct consequence of the law of minimal area or of the surface tension, because it is generally accepted that in dividing a closed space into a given number of smaller area by means of partition walls, the least unstable structure can only be get when the walls meet together in groups of three. If this suggestion is applicable for explanation of the plate pattern, it may be the natural consequence that the sutural line may be longer or shorter according to relative magnitudes of the potence of tension or of plate formation, and then a group of thecal plates may be set in a position of possibly greatest equilibrium.

If our suggestion that the plate formation is affected by the conditions of minimum potential energy in the system, which is the condition of equilibrium, is to be realized in the organism under consideration, it will accordingly be expected that the plate pattern of the lowest type consists of jumblingly arranged plates of subequal sizes by reason of possible uniformity of force and possible equality of individual plates, and that differentiation in the size of the plates may be attained afterwards, and its highly advanced types may be established in more advanced species. These are exactly the cases with species of the genus. In either of Protoperidinium and Veroperidinium or in any of their groups, the epitheca consists of more or less jumblingly arranged plates of subequal size in less advanced species, while it consists of plates of remarkably different sizes in much highly advanced species. This not only supports our suggestion but also well accounts for the progressive differentiation of the plate pattern, manifested throughout the genus.

We may, then, naturally be led to the conclusion that there can be distinguished four, at least three, different groups of the potence, one distributed over the epitheca, one over the hypotheca and the other over the girdle and ventral area. The last of them may be divided into two, which have markedly strong association with one another. In each of them are comprised certain numbers of the fields of potence arranged in a characteristic way, least unstable for it. Between two fields of the potence is formed the suture which is straight in typical cases. In like manner, we are inclined to suggest that two groups of the fields are to be separated also by a more distinct structure, extending straightly or lying along a plane. This suggestion can well account for the fact that the epithecal and hypothecal groups of plates are distinguished from the cingular group of plates by the straightly elongated cingular ridge, and that the ventral area of less advanced type has the least differentiated shape, displaying hardly any irregularity. But in higher forms of the genus or in certain other genera such as Ceratium or Heterodinium, in which some disturbances might have taken place in respect of the balance of forces, some irregularities may be brought forth in the boundary between two groups of forces. 
Bearing these considerations in mind, let us see how the thecal plates are arranged in the epitheca and hypotheca. Before going further it is to be recollected here that there is in the epitheca the apical pore which is conjectured to have deep physiological significance, presumably in association with the flagellar pore and through the interior of the body or more indirectly by way of the ventral area. The epithecal group of plates differs in this regard from the hypothecal one which has not such structure comparable to this.

The thecal plates constituting the epithecal wall are all alike in general characters except the ventral apical plate which connects the apical pore directly with the ventral area. If they may be equal in size, that is, if the potence of plate-formation is equal in magnitude in every plate and regular in arrangement, the epithecal plates are uniformly built and regularly arranged. Such may be sought in some other genera, far less advanced in structural differentiation than the genus Peridinium. But we have to make allowance in the present genus for some irregularities in the relative magnitude of the potences as a result of its higher structural differentiation and much advanced phylogenetical development.

Although hardly any discernible difference can be certified in different parts of the epitheca, it is no doubt true that morphological and physiological differentiation of high degree might have been brought forth within the protoplasm at the time when the thecal plates are formed. This may be surmised as such, judging from the irregular arrangement of some of the well differentiated inner organellae such as the excretory vacuole, water pusule and excretory protoplasm. A slight difference of physicochemical conditions in various portions of the protoplasm is very likely to affect its external manifestation. This, together with some other morphological differentiations such as seen in surface curvature, will lead the adjacent plates to cover different amounts of area and to take different shapes.

These main physical and chemical characteristics follow, as a matter of course, from the position they occupy and from the various consequences which their situation entails. Thus, every one of the thecal plates might have been laid down or differentiated in an early stage of its phylogenetical development and retained its characteristics which from their first appearance were marked off from the others by different morphological and physiological conditions of the situation. But since the first appearance, a plate has long been subjected to varying conditions of the position it covers and to differentiations of the body due to the phylogenetical development of the species, thus bringing forth the appearance of the plate, which it presents now. And a group of the forces or so many units of potence have associated together under restraints of their sufficient mutual interactions to bring them ultimately into a certain plate pattern as seen at present. It may hardly be possible yet to think of precisely the same conditions in two different specimens, by which an exactly identical plate pattern is brought about in either of them. These may be due to the fact that a group of thecal plates tends to assume, as far as possible, positions of equilibrium under the restraints to which they are subject and which were brought forth by relative magnitudes and arrangements of the units of potence of plate 
formation. And their interactions convert them into definite shapes, and some variations are brought about according to slight differences of the interactions or relative magnitudes of the group of forces.

Judging from the fact that the epitheca in any species is more or less conspicuously pointed at the apical pore where it is covered with a minute plate, we may be allowed to suggest that a condition such as seen just around the apical pore, where four apical plates are arranged closely around the minute pore plate or all the sutures emanate from the pore plate, would be particularly less unstable than in the region adjacent to the pore and would become more and more unstable towards the girdle. Similarly, all the sutures lying within the precingular row of plates which lie along the outer boundary of a closed space, the epitheca, converge towards the apex, displaying the arrangement of radial symmetry, suggestive of position of higher equilibrium particularly in their outer ends. From these simple and symmetrical arrangements, there would be expected comparatively little tendency to variation in these two circular series of plates. In species with an elongated apical trough, we can often ascertain an additional apical plate. And an additional suture often formed in the precingular row of plates takes invariably a radial arrangement. These may be a natural consequence partly of the law of equilibrium and partly due to discrepancy of the curvature, brought forth presumably by some morphological differentiation, between the apical furrow and apical plate or the girdle and precingular plate.

Contrary to these, the conditions in the intercalary row differ profoundly from them because of its situation. This portion is surrounded on all sides by regions of unstable conditions, and has no structure comparable to the apical pore or girdle by which variation is restrained. Consequently, there may be stronger tendency to variation than in other regions, although unusual sutures are formed as in other regions in the longitudinal direction. There the conditions by which contact of plates is effected are more complicated than in other portion, and students have found them very puzzling, largely because of the fact that variation in the pattern occurs all around with respect to the intercalary zone, while only along one side in regard to either of the apical or precingular row of plates, because the variation of the pattern occurs exclusively in the region along which two circular rows of plates interlock. Such a region as this may be found on the ventral side of the body between the apical and precingular rows, while on the dorsal side between the apical and intercalary rows, and between the intercalary and precingular rows. Naturally, the variation, if it was supposed to occur evenly all over the epitheca in contradiction to the actual case in nature, may be doubled in its conspicuousness on the dorsal surface, and in reality it is still more remarkable by the reason considered above.

In the epitheca, there is another position of highly stable condition, which is to be sought in its posterior mid-ventral part, adjacent to the anterior end of the ventral area. There the epitheca is indented by the sulcal furrow and two sutures are formed invariably converging upon the small notch formed by the sulcal furrow. This indicates cleary less unstable conditions of this region than those lying on its either 
side. From these, too much stress cannot be put upon the fact that the ventral apical plate extends between the two regions of the least unstableness, subjecting only its middle portion to the region liable to variation. In these regards, the ventral apical plate is in the position of the highest equilibrium in the epitheca, because no other plate lies over two regions of the least unstable conditions. In practice, the ventral apical plate tapers invariably towards two ends, and variation in shape, if it occurs, in confined only on either side of its middle portion, further from either of the apex and ventral area. This may be the explanation of the peculiar and interesting conditions of the ventral apical plate, which has long been regarded as representing a region of the least variability within the epitheca but is not followed with sufficiently due considerations and discussions. This, however, by no means points to the absolute stableness of the ventral plate pattern. The shape of the ventral apical plate thus formed represents a result of the conditional equilibrium, because it is brought about by relative magnitudes or relative proportions of five units of plate-formation potency, represented by the three apical and two ventral precingular plates. A slight disturbance of this proportion would bring forth variations in the transverse length of the ventral apical plate on the one hand, and in the relative lengths of the apical and precingular plates lying on either side of the ventral apical on the other. If the disturbance is greater than a certain extent, direct connection between the apical and precingular plates may be interrupted or newly formed, bringing forth change of the plate pattern. The reason why the fourth type of the ventral plate pattern, reversed in right and left relation to the 'meta' type, is not certified in the genus is uncertain, but may be sought in an asymmetry in relative magnitudes of the two groups of potence, lying on either side of the ventral apical plate, or in the probable correlation between this asymmetry and another asymmetry manifested in bilateral halves of the cingular or transverse section of the body, that is, the left ventral part of the thecal wall is more strongly folded than the other presumably in correlation to the direction of locomotion.

The rule and principle which we have arrived at from discussions on the stability in the formation of the sutures and by assuming a field of force for a single plate, have a much wider bearing than suggested above.

In the dorsal middle region, where the most remarkable variations are liable to occur, the middle intercalary plate is mostly tetragonal in the lower group of species, largely tetragonal in somewhat advanced species, and typically hexagonal in most highly differentiated ones. It must be recollected in this regard that when some discs or bodies of plastic substance are packed together, they are converted by balance of forces into hexagons which display the least unstable conditions. The progressive change of shape which the middle intercalary plate displays, indicates a vestige of evidence of support for our above suggestion that the dorsal middle region is in a state to be regarded as of smallest equilibrium and that generally the plate partitioning is affected largely by tensions or the law of equilibrium. A change of shape of a given plate can hardly be thought of itself, without being followed by correlative changes in the shapes and also correlative fluctuation in the sizes of its 
adjacent plates. These are not the problems of quality but that of quantity, and may be brought about by fluctuating relative proportions of a group of deeply associated units of plate formation potence.

It may safely be conjectured that the arrangement of the thecal plates or plate pattern of the epitheca had been established, as was given above, in an early stage of phylogenetical development. But with increasing differentiation of the body in the course of phylogenetical development, arrangement of the thecal plates or sutures might have come exceedingly unstable in some groups of highly advanced species, such as the Divergentia and Conica groups, owing to discrepancies newly built between the differential advancement of the body and that of arrangement of the sutures. In some of the Conica group, conditions of the body are complicated by the fact that the cingular section of the organism is never circular nor elliptical but distinctly irregular reniform with bilateral and dorsoventral asymmetries. Presumably in correlation to this peculiar ventral flattening, the plate pattern of the group becomes more and more strongly readjusted in accordance with higher development of the ventral depression and also in correlation with higher differentiation of the posterior sulcal plate. And in some extreme cases, the re-adjustment is so conspicuous that the conical epitheca is divided by six radial sutures extending from the apex to the girdle into so many triangular interspaces and some of the transverse sutures fail to develop.

This alteration from the jumble arrangement to the re-adjusted one of the epithecal plates appears to suggest that the thecal plates at the time of their first appearance or these of least advanced form were in all probability equipotential, being formed independently from other structures, but afterwards there might have emerged stronger coordination in the radial directions, which, calling for re-adjustment, runs its course ultimately to the fusion of plates. This ultimate form is of great importance because of its radial and at the same time bilateral symmetries, suggestive of the greatest stable conditions of the plate arrangement. The process of this alteration may be then regarded as indicating regression of complexity to simplicity of higher order. In the course of this alteration, the middle intercalary plate, which was tetragon or alike at the time of its first appearance, it is converted into hexagon of the re-adjustment resulting by way of pentagon, and finally resumes its original tetragonal shape in consequence in the fusion to form a larger plate of small surface curvature. A similar conversion may be ascertained on other two intercalary plates, each fusing finally with a precingular plate into a larger plate. Interesting in this regard is that a corresponding feature was established by Drwald (1939) on $P$. adriaticum.

There is one more peculiarity which we cannot omit to consider. That is the irregularity of the plate pattern ascertained in $P$. deficiens. In this species, all of the longitudinal sutures except the left ventral one are grouped into two, bilateral ones, in each of them, three or four sutures converge anteriorly into a single one which extends to the apical pore. This seemingly irregular pattern attracts our attention in that we can ascertain in its midventral region an symmetrical space comparable 
to what is known to students of Coelenterata as a 'fossula'. It is generally said that such is a symptom of bilaterality, and further this in turn is interpreted as an indication of a higher grade of organization than is implied in the purely radial symmetry. But the bilaterality in this case is brought about presumably by partial suppression of the radial symmetry. In this case, however, it is interesting that the pattern of the species is remarkably subject to individual variation, suggesting its being in conditions of unstable equilibrium.

The plate pattern is simpler in the hypotheca than in the epitheca, as it consists of two rows of plates, one lying along the girdle and the other arranged around the ventral area. Either of these two structures is least liable to variation, and arrangement of the thecal plates within the hypotheca is highly suggestive of stable equilibrium, because both of the intra-postcingular and intra-antapical sutures run similarly in radial direction. We may be allowed to suggest that the two of the antapical plate in the genus might have been derived in an early stage of phylogenetical development from a single one. So long as the stability of that portion is retained, the number of the component plate of the row continues as such. It may be suggested from this that the hypotheca, though it displays a wide range of variations in form in the genus, is in the main in a state of sufficiently stable condition in respect to the plate partitioning. But we by no means suggest that the plate pattern of the hypotheca is liable to no variation. When an unusual condition is brought forth by some particular differentiations, as may be seen in $P$. clavus, unusual number of the plates may be formed.

We have to give here considerations to another structure, the ventral area. Anterior three of the four sulcal plates are arranged around the flagellar pore, and two sutures lying between any two of them converge to the anterior end of the pore. This clearly accounts for the least variation in the anterior major part of the ventral area. The posterior sulcal plate differs in this regard from the others because of its separation from the pore by the length of the flagellar trough. From this and other facts and from the considerations given above, it may be apparent that the region of variation in the ventral area, if it is to be established, is to be sought theoretically and also practically in the outer border of this posterior sulcal plate because of its situation farthest from the flagellar pore on the ventral and from the girdle on the dorsal side, both of which are similarly in a state of higher stableness. However, this plate, lying nearest to the flagellar pore on one side and at the equilibrated end of the radiating intra-antapical suture on the other side, is less liable to variation in its middle region, and the liability is to become greater to its either end. This may be the explanation why the posterior sulcal plate displays remarkable variation in the manner of its lateral expansion. Form, size and structural relations of the hind end of the ventral area are fairly constant for a species, as just given, but display wide ranges of variations within the genus, as given in a previous paragraphs. This also may be accounted for from the discussions given above.

From these facts and considerations given above, the splitting or fusion may be explained on the basis of division or fusion of the centers or forces of plate formation. 
If a force is divided into two, there may be brought about some disturbances in the balance or relative magnitudes of forces because of separation of the two centers. In this case, however, a new balance may be resumed by broadening of the fields of forces beyond the old domain by sacrifice of the adjacent plates. This may be an explanation of the correlation between the splitting and the variations in the size of the thecal plates.

It is to be recollected here that the direction along which a new suture is formed is typically normal to that along which an ordinary suture in particular cases fails to develop. These two directions accord with those along which the two sorts of the sutural differentiation are ascertained. In the epitheca of the Conica group in which these differentiations are most remarkably manifested, the surface curvature is smaller in the longitudinal direction along which the fusion of plates and the stronger development of the sutural structure are ascertained, but it is greater in the transverse direction along which the splitting occurs and the sutural structure is formed weakly. In short, the splitting occurs typically in the direction of the strongest surface curvature and the fusion in that of the smallest curvature. As a consequence, a smaller plate brought force by the splitting receives a part of the old convexity, and a fused plate has by no means much greater convexity than either of its two predecessors. In this regard it is interesting that the plate pattern of $P$. elegans or $P$. sinuosum in which the ventral side of the body is broadly indented, is so adjusted as to set narrow plates longitudinally along the ventro-lateral portion of the epitheca where the surface curvature in the transverse direction is the strongest and to set some of the largest ones on its dorsal side where the curvature is the smallest in the epitheca. A similar but less distinct correlation can be ascertained in most species of the Conica group. Further, we are informed of the fact that the surface curvature of the epitheca is subject during the growth of the body to variation more strongly in the transverse direction in which a new plate is formed than in the longitudinal direction.

From these, it may be concluded that the splitting may be of a character of subordinate significance, brought forth by progressive disturbances of the balance of forces, carried forth during the ontogenetical or phylogenetical development of the organism. The fusion, on the contrary, may be explained as a manifestation of resumption of well-balanced conditions, brought about by means of the re-adjustment of the plate pattern.

\section{Combination of characters, basis for subdivision of the genus Peridinium}

The genus Peridinium is well established so far as it is concerned with the plate constitution of the hypotheca and also of the ventral area, as may be concluded from the facts and considerations given above, but manifests fairly wide ranges of variations in the plate pattern of the epitheca, form of the body and structure and development of the antapical elongation or extension. 
The least variable structure within the genus is to be sought in the plate pattern of the hypotheca exclusive of the ventral area, which serves, then, for the generic distinction. It was ascertained that the relations between the flagellar pore and the four sulcal plates are uniform throughout the genus, but the ventral area displays, on the other hand, remarkable variations, particularly in its hind end in regard to relations with its surroundings. As was given in a previous paragraph in regard to the "correlations between different thecal characters", the types of the ventral area are related so closely to those of the antapical appendage or elongation that it is hardly possible to think of them separately. The majority of the former investigators used to put taxonomic stress upon the types of the antapical appendage rather than upon the ventral area because of its stronger conspicuousness than the other. Some discussions have been given in published literatures on the antapical appendage, but structural details of the ventral area have not been brought under morphological analysis, definite nomenclature and sufficient discussion. Moreover, some have wrongly interpreted taxonomic importance of the ventral area. According to BARRows, "A system of nomenclature for the major plates of the theca in order to permit expression of the relationships of the various groups of the dinoflagellates need not include the ventral area in its consideration, for the main relationships of the dinoflagellates seems to be sufficiently if not mainly expressed in variation in the arrangement of the major plates of the theca exclusive of the ventral area." Against his interpretation, it may be sufficient only to show that not only the genus Peridinium, but also its allies including all the genera of the Diplopsalis group, Podolampinae and further all of Dinophysioidae have similarly the ventral area, consisting of four sulcal plates arranged around the flagellar pore. Among them, Peridinium is the foremost in displaying the highest diversity and specialization of the ventral area. Furthermore, every subtype of the structure is characteristic of a group of species, which manifests also some other distinct characteristics. Contrary to general expectation, the structural relations of the ventral area and sulcal furrow are so diversely differentiated that we can clearly establish basing on them probable phylogenetic relationships of the groups.

In the epitheca, much variation has been ascertained in the general plate pattern. Among the three circular rows of plates, the intercalary is the foremost in displaying variations in the number and arrangement of its component plates. And hardly established relationship can be ascertained between subtypes of their arrangement, or of a particular plate of them and either of the two well-established structures of the hypotheca. On the other hand, the ventral apical plate is the one to be regarded as not only practically but also theoretically least liable to variation. Contrary to BARRows' conclusion, there is hardly any reason to believe the three types of the ventral plate pattern as the manifestation of their phylogenetical relationships. In very many cases, geometrically akin but biologically very different patterns can be ascertained recurring again and again in all sorts of organisms, plants as well as animals, and with no relation to the lines of biological classification. This is by no means suggesting taxonomic unimportance of the plate pattern and its differentia- 
tion because of the consideration that some properties explainable on physical bases but found in organism are by no means denying manifestation of natural affinities. We have, then, to acknowledge by all means the morphological significance of the ventral plate pattern, mainly because of its least variableness and its inseparable relationships with some combinations of other characters of taxonomic importance as well as of morphological significance manifested in the hypotheca, such as the ventral area and antapical appendage or horn. The taxonomic importance of the ventral plate pattern, if manifested, is to be sought not in itself alone but in the combination of it with the ventral area, both lying in the ventral half of the body. It might be possible to subdivide the genus superficially into three groups according either to the three ventral patterns or to the three of the ventral area. But this results only in comprising some inconsistencies and many exceptions, as was the case with Paulsen (1931).

In the subdivision of the genus, we can exclude as far as possible the majority of possible inconsistencies and exceptions, when different combinations of the three important and least variable characters, the ventral plate pattern, ventral area and antapical appendage, are taken into considerations. These combinations accord at the same time with the most probable natural affinities of different groups. Among the three, structural relation of the ventral area is uniform in the main all throughout the genus, while that of the antapical structure is divided into several types and subtypes, each characteristic of a group of species. And each of the three type of the ventral plate pattern is seen throughout several groups of species, while the dorsal plate pattern is various in each of them and even in different species of a given group, and often is subject to individual variation.

Taking these relationships and diversities of the main skeletal characters into consideration, we have a broad and sound basis for the subdivision of the genus into three large groups, each characterized in the main with a given type of ventral area, a type of the antapical appendage and a type of the ventral plate pattern.

Key to subgenera

1. The posterior sulcal plate is more or less symmetrical in lateral expansion

A. The plate is completely interrupted on both sides from contact with the ventral postcingular plate ....................................Protoperidinium

B. The plate is contact on both side with the ventral postcingular plates

Veroperidinium

2. The posterior sulcal plate is distinctly asymmetrical both in its shape and extension

A. The plate expands asymmetrically towards the left to reach to left ventral postcingular plate ........................................ Mesoperidinium

B. The plate (in the case of fresh-water species) is in all probability separated from the right ventral postcingular plate by posterior elongation of the right sulcal plate

Veroperidinium 


\section{Subgenus 1. Protoperidinium BERGH (emend.)}

Genus Protoperidinium Bergr, 1881; Pouchet, 1883; 1885.

Subgenus Protoperidinium PaUlsen, 1908.

Group Tabulatum FAURÉ-Fremiet, 1908.

Subgenus Metaperidinium, in part, Jörgensen, 1913; Lebour, 1925.

The ventral plate pattern is regularly 'meta' or 'para' and exceptionally 'ortho'. The intercalary series consists of three plates. The antapical spine is mostly well formed. The ventral area tapers anteriorly and does not expand abruptly to either or both sides in its hind end. The small posterior sulcal plate is regularly interrupted from both of the ventral postcingular plates.

\section{Historical}

These species furnished with antapical spine or wing-complex have generally been separated from those with antapical horn into a distinct genus or a different group or section of the genus Peridinium. Their generic distinction had been proposed for the first time by Berah (1881) who established a new generic name, Protoperidinium, for the former, and this was followed by Pouchet $(1883,1885)$. About twenty years later, PAULSEN (1908) divided the genus into two subgenera, Protoperidinium and Euperidinium, each corresponding to the two genera of Bergir. On the other hand, the genus had been divided by EHRENBERg into groups, and FauréFremiet (1908), following him, subdivided it into four groups, one of which, $P$. tabulatum EHRENBerg, corresponds in the main to Protoperidinium.

Taking these two principles of subdivision into considerations, JöRGENSEN (1913) proposed to subdivide the genus into two subgenera of Orthoperidinium and Metaperidinium and seven sections. Among the four sections of the latter subgenus, Pyriformia, Paraperidinium and Humilia include these spined species formerly allocated to Protoperidinium. And this was conformed by LeBour (1925).

Following JÖrgensen's principle of subdivision, Peters (1928) divided the genus into three subgenera on the basis of the ventral plate pattern of the epitheca. And in this case, the species with antapical spine or wing-complex were allocated to the sections, Pellucida and Areolata of Paraperidinium and one (Pyriformia) of two sections of Metaperidinium. Proposing a new principle of subdivision, PAulsen (1931) arranged the spined species, separately from the horned species under the three sections of Pellucida, Humilia and Pyriformia of the subgenera Veroperidinium, characterizing them as follows:

\section{Sousgenre Veroperidinium PAulsen}

L'épivalve à 3 intercalaires.

Sect. 3. Pellucida. Para hexa, rarement Para penta ou quadra ou Meta hexa. Dextrogyres sans cornes antapicales, à deux ou plus souvent à trois épines antapicales. 
Sect. 4. Humilia. Meta quadra. Dextrogyres, saus eornes, mais souvent avex deux épines antapicales.

Section 5. Pyriformia. Meta penta, pulus rarement quadra or hexa. Dextrogyres, sans cornes antapicales, mais en general a deux epines antapicales.

Still conforming to Jörgensen's principle, Paulsen laid special stress upon different combinations of the ventral and dorsal plate patterns of the epitheca, although the latter has been confirmed by recent studies as unworthy for clear-cut definition of any of subgenus, group and section because of its high variability. This naturally led him to assent in his subdivision considerable number of exceptions, more numerous than ever submitted by any other investigator.

The body is generally globular, lenticular or cake-shaped with its broadly rounded hypotheca, but an indistinct conical bulge is formed rarely at the base of the antapical spines, and the thecal wall rarely flares along the girdle. The epitheca is hemispherical or convex, flat or concave conical, tapering distally to a minute or elongated apical horn. Rarely on either side (mostly on the right) and regularly on both sides of the hind end of the ventral area stands an antapical spine furnished with or without three side-wings. The girdle is circular or ascending, and the midventral depression on the body is generally indistinct. The ventral area is narrow and does not show an abrupt expansion in its hind end to either side. The left sulcal list is generally broader than the right sulcal one which is interrupted at the postcingular-antapical suture. The flagellar pore is remarkably displaced posteriorly.

The ventral plate pattern of the epitheca is generally 'meta', rarely 'para' and exceptionally 'ortho'. The intercalary series consists generally of three plates, of which the middle is tetragonal, pentagonal or hexagonal and exceptionally heptagonal. The ventral postcingular plate extends posteriorly to half-way between the girdle and antapex.

In the present subgenus are allocated all the species typically with its posterior sulcal plate interrupted on either side from the ventral postcingular plate and a few species with the narrower left lobe of the sulcal plate extending beyond the median side-wing of the left antapical spine, which together with the left sulcal list and one of the other two side-wings demarcates the ventral area from the general body surface. Basing on different structural relations of the left sulcal list with the left antapical spine, the subgenus can be divided into three groups of Humilia, Pyriformia and Pellucida. In the first of them, the spine fails to develop at all or is formed poorly, standing separately from the left sulcal list. The sulcal list continues in Pyriformia posteriorly directly to the left antapical spine, turning into its ventral side-wing. And in Pellucida the spine is connected transversely by its median side-wing with the sulcal list, sharply confining the major or entire extent of the posterior sulcal plate within the ventral area. In all of these, the ventral area agrees in its gradual posterior widening, without showing an abrupt expansion towards the left in its hind end. 
From these, it is apparent that the structural relations of the antapical spine of them become more and more advanced and the spine and sulcal list are combined more closely and more complexly in the order given above. This clearly suggests some profound phylogenetic relationships among them. This is strongly supported also by progressive differentiation in structural relations of the posterior sulcal plate. The plate is least bilaterally differentiated in Humilia but most remarkably in Pellucida.

In some higher forms of the latter group, its left half is exceedingly narrow owing to posterior extension of the flagellar furrow. And in many of them particularly of larger forms, one often sees a narrow stripe of thecal wall lying along lateral base of the left sulcal list and between the left ventral postcingular plate and the left antapical spine. This corresponds in size and in its relations to the surroundings exactly to the left narrower lobe of the posterior sulcal plate of Paradivergentia in which the plate extends to the posterior sulcal plate. In this subgenus, this structure belongs to the left sulcal plate and not to the posterior sulcal one. Higher forms of Pellucida thus manifest more advanced structural differentiations of their ventral area than any of Humilia.

A corresponding relation can be established also in the progressive differentiation of the sulcal furrow from the ventral area. A less advanced type of the antapical spine or of the posterior sulcal plate is correlated typically with plate pattern of 'meta' on the ventral and the tetragonal or pentagonal middle intercalary plate on the dorsal of the epitheca, while a more advanced type is associated partially with that of 'para' on the ventral and with the hexagonal middle intercalary on the dorsal. The para-pattern is seen only in association with the asymmetrical extension of the posterior sulcal plate. Furthermore, the ventral pore can be established only in Pellucida in the present subgenus and partially in Mesoperidinium. All these facts just considered strongly support the suggestion that these three groups are well established and are more closely related with one another than with any of the other subgenera, and that the closest relative of Protoperidinium is Mesoperidinium because a part of Pellucida forms a connecting link between them.

One of the most distinctive features of the subgenus, by means of which one can distinguish it from others is the antapical spine. In Humilia, it lies clearly outside of the ventral area, standing at various distances from it. Taking into considerations their different relations on one hand and the structural relations of the the ventral area itself on the other, the Humilia group can be subdivided further but five sections. This principle of subdivision is not only of practical convenience but also representing natural affinities of the sections. $P$. granii is unparalleled in the subgenus in its widely separated antapical spines, each standing on top of a conical bulge of the thecal wall, which is subject to individual variation in development. We may be led to misinterpretation regarding its taxonomic allocation if we lay too much stress upon the structure. Closer examinations, however, led us to conclude that the species is a valid member of the present subgenus. A corresponding but much less developed conical bulge of the thecal wall at the base of the antapical 
spine may be established very often in $P$. pellucidum and $P$. pallidum. This structure corresponds to the typical antapical horn, generally seen in other subgenera. $P$. globulus and its allies appear to form a distinct group because of its strikingly elongated and characteristically bent ventral area. But the peculiarity is found in less degrees also in some other species of Humilia. The small and triangular posterior sulcal plate of these species reminds us of its corresponding one in the Avellana group of Veroperidinium, suggesting at the same time phylogenetic relationship of the two subgenera.

Contrary to these distinct variations in Humilia, Pyriformia forms a well established group regarding the structural relations. Its left antapical spine stands, together with its side-wings, just at the edge of the ventral area, and their closest relationship is least disturbed by growth of the thecal plates. But its right antapical spine, together with its side-wings, are less closely connected to the ventral area and are often separated widely from it by a sutural zone formed partially around the ventral area.

In the Pellucida group either of the two antapical spines stands generally in close connections with the ventral area, but the right of them is rarely separated only slightly from the ventral area. Pyriformia and Pellucida are related to Paradivergentia of Mesoperidinium in having well formed wing-complex, but the last of them can be distinguished at once from the first two by lack of direct connection between the left sulcal list and left antapical wing-complex and also by an leftward abrupt expansion of its ventral area just at the base of the spine.

Another distinctive characteristic is the ventral plate pattern, which is typically 'meta' and partially 'para' in this subgenus. Some irregularities regarding this were, however, recorded in some small and insufficiently known species. In a single case of $P$. granii we saw an unusual pattern of 'ortho'. The plate pattern illustrated in some of published figures needs re-examination because of its probable misinterpretation. We may be allowed to assume the ventral plate pattern not well established as yet in some species or groups of the genus.

Among these five sections, Heteracantha is the sole one that is uncertain with regard to its taxonomical affinity to Monacantha. Laterispinosa and Bispinosa are closely related with one another, showing progressive advance or development in the order given above regarding such characters as the intercalary row of plates, the posterior sulcal plate and the hypothecal surface extensions. In this regard, Bispinosa is then the foremost, and through this the Humilia group is related to Pyriformia. Globula differs from them mainly in its peculiarly differentiated ventral area. But it is apparently related to the latter two of the three in the bending at the middle of the ventral area and also in the shape of the intercalary row of plates. As to its taxonomical relationship, it is a higher type in the group in regard to its epitheca particularly to the intercalary row of plates, whereas it is a lower type with regard to its small posterior sulcal plate and its least developed antapical extension. Reviewing through the groups and sections of the genus, we can not but point out in this place 
that the conical bulge of the thecal wall at the base of the antapical spine, weakly or strongly developed in some of Pellucida and of the subgenus Mesoperidinium, is seen already in some lower forms of this group such as Laterispinosa and Bispinosa.

\section{Key to groups}

1. The antapical spine is hardly or only poorly developed

A. The antapical spine, when it develops, is either single or double, lying asymmetrically only on the right or bilaterally on either side of the ventral area, and the left one of them is distinct from the left sulcal list......Humilia

2. The antapical spine has three, well developed side-wings

A. The left sulcal list is connected posteriorly directly with the left antapical spine Pyriformia

B. The left sulcal list is distinct from the spine, but they are connected transversely by a median side-wing of the latter Pellucida

\section{Group 1. Humilia JörgenSEN (emend.)}

The body is globular, lenticular or pentagonal, tapering anteriorly to a minute apical process. The typically hemispherical hypotheca is furnished generally with but rarely without a single (right) or paired antapical spines which are provided with or without narrow side-wings. The left antapical spine is distinct from the left sulcal list, standing either at the edge of the ventral area or displaced laterally from it. In some of the latter case, the right antapical spine is also removed laterally from the ventral area and the thecal wall bulges slightly or distinctly at the base of the spine to form a distinct conical process.

The girdle is circular or forms an ascending spiral displaced distally in most cases by its own width. In the Globula section, it forms a deeply overhanging spiral in accordance with strong bending of its elongated ventral area.

Its ventral area is generally narrow and in some peculiarly elongated, becoming gradually broader posteriorly. The structure is typically straight, lying longitudinally, but in some it is weakly or strongly bent at the proximal end of the girdle to form <-shaped tract, connecting the two ventral ends of the girdle with its strikingly elongated anterior half. The ovoidal or elongated flagellar pore lies just in front of the hind end of the ventral area which is excavated as a whole or only in its left half in which lies the pore.

The ventral plate pattern of the epitheca is typically 'meta' but rarely 'para' and exceptionally 'ortho'. Of the three intercalaries, the middle is typically tetragonal which can be seen throughout the five sections of the present group, but not infrequently it is pentagonal or hexagonal and very rarely heptagonal. The postcingular row of plates is fairly small generally in length, often corresponding with the distance between the displaced ends of the girdle or hardly exceeding the breadth of the girdle. 
The arrangement of the four sulcal plates is typical of the genus. In the case of <-shaped ventral area, its diagonally elongated anterior portion connecting the two ends of the girdle consists exclusively of anterior elongations of the right and anterior sulcal plates. The posterior sulcal plate is triangular, rectangular or irregularly shaped, lying always transversely across the hind end of the ventral area and invariably interrupted on both sides from direct contact with the ventral postcingular plate.

In the present group are included all of the smaller or larger globular species furnished with the ventral area of Steinii type and the weakly or hardly developed antapical spine which, when it is formed, is loosely connected with or is distinct from the ventral area or left sulcal list. The ventral plate pattern 'meta' is in the majority. But in a few uncertain species, all of which were very insufficiently described and figured, the other patterns of 'para' and 'ortho' have been reported. Taking into considerations the shapes and structural relations of the ventral area on one hand and the types of the hypothecal appendage on the other hand, and at the same time giving due references to the plate pattern of the epitheca, we subdivide the present group in his paper as follows.

Section 1. Heteracantha. n. sect. The ventral plate pattern is 'meta', 'ortho' or 'para'. The middle intercalary plate is tetragonal, pentagonal or hexagonal. The girdle is circular or weakly ascending. The left sulcal list extends posteriorly beyond the hind end of the body. Opposite to this and close to the hind end of the ventral area stands a short antapical spine.

Species: P. breve Paulsen, P. curvipes Ostenfeld, P. decipiens (Gran), P. variegatum Peters.

Section 2. Monacantha. n. sect. The ventral plate pattern is 'meta', and difference in size of the two ventral precingulars is striking. The intercalary row of plates is ]-shaped in apical view, bending sharply at two points, and its middle plate is small tetragonal. The girdle is circular or weakly ascending. A single wingless antapical spine stands on the right of the ventral area.

Species: P. monacanthum Broch, P. subcurvipes Lebour.

Section 3. Laterispinosa. n. sect. The body is generally globular but rarely has two, more or less distinct antapical bulges, and the equatorial or post-equatorial girdle is circular or ascending. The ventral plate pattern is typically 'meta' but excepationally 'ortho' and is coupled with two, distinctly unequal, ventral precingular plates. The middle intercalary plate is generally tetragonal but rarely pentagonal. Two winged or wingless antapical spines are displaced more or less laterally from the ventral area.

Species: $P$. brevipes Paulsen, $P$. cerasus Paulsen, $P$. finlandicum Paulsen, $P$. granii Ostenfeld ( $=P$. mite Pavillard), $P$. pedunculatum (after Shiller, 1929), P. roseum Paulsen, $P$. turgidum (var. karianum SAbelina), P. solitarium AbÉ, ?P. incurvum LindeMANN. 
Section 4. Bispinosa. n. sect. The body is globular or lenticular, and on either side and close to the hind end of the ventral area stand two short antapical spines furnished with or without side-wings. The ventral plate pattern is 'meta' and is coupled with two, distinctly unequal, ventral postcingular plates. The intercalary row of plates is angulated U-shaped in apical view, with its large quadrangular or pentagonal middle plate. The girdle is in most cases distinctly ascending and exceptionally circular or nearly so. The ventral area is short, not extending in most cases to the center of hypotheca, and forms a weakly <-shaped tract bending towards the left in its middle. The left sulcal list is distinct from the left antapical spine. Species: $P$. ovatum (Pouchet) SchÜTt, P. lenticulatum FAurÉ-Fremret, P. marukawai AвÉ, $P$. styliferum Schiller, $P$. ventralis AвÉ.

Section 5. Globula. n. sect. The body is spherical or lenticular. The ventral plate pattern is 'meta', and the wedge-shaped left ventral precingular plate is much smaller than the trapezoidal right ventral of the series. The middle intercalary plate is quadragonal, pentagonal, hexagonal or heptagonal. The girdle forms a strikingly ascending and markedly overlapped spiral. Anterior one-third or one-half of the ventral area is elongated obliquely to connect the ventral two ends of the girdle, and is remarkably bent at the proximal end of the girdle or at the postero-median corner of the right ventral postcingular plate. The ventral area becomes abruptly broader below this bending, extending posteriorly nearly to the center of hypotheca or ending in front of it. The sulcal lists are indistinct but a large flagellar wing extends obliquely towards the left. Two antapical spines or semicircular lists stand often laterally at the antapex and are shortly separated from the hind end of the ventral area.

Species: $\quad P$. globifera Abé, $P$. globulus $\mathrm{S}$ tein, $P$. majus Dang., $P$. quarnerense (SchröD.) Brogh ( $=P$. saecularis Murr. et WhitT.) P. sphaeroides Dangerad.

\section{Historical}

Humilia was established by Jörgensen (1912) to embrace $P$. ovatum, $P$. roseum, $P$. decipiens, $P$. excentricum and their allies, and was characterized by the ventral plate pattern of 'meta' combined with the quadragonal middle intercalary plate, an ascending girdle and two or three antapical spines which fail to develop completely in some cases. His characterization may be justified in the main in regard to the first three of the four species. But apparently he had misinterpreted $P$. excentricum, whose thecal structure was not known exactly at that time. The ventral plate pattern of this species is apparently 'ortho', and this is entirely different from the other three species in structural relations of the ventral area. The species is rather closely related in these regards to Conica. Following him, Lebour (1925) included in Humilia the nine species of $P$. globulus, $P$. cerasus, $P$. roseum, $P$. brevipes, $P$. varicans, $P$. breve, $P$. decipiens, $P$. monacanthum and $P$. subcurvipes. Recently, PAulsen (1931) placed under Humilia the following species: $P$. angustum, $P$. breve, $P$. brevipes, $P$. cerasus, $P$. monacanthum, $P$. simulum, $P$. subcurvipes, $P$. varicans, $P$. wiesneri, $P$. micrapium and $P$. sphaeroides. These workers placed in the subdivision of the genus Peridinium a special stress 
on the combination of the ventral and dorsal plate patterns of the epitheca, and the type of the antapical appendage was considered in the next. And in spite of it, among the species cited by them are seen some species, apparently inconsistent with their principle of subdivision: $P$. angustum has a distinct antapical horn, and the ventral plate pattern of $P$. sphaeroides is not 'meta' but 'para'. And recent advances in the study of the thecal morphology of the dinoflagellates inform us of the fact that the middle intercalary plate is highly variable in shape not only within a group or section but also in a single species.

\section{General discussion on the major thecal characters}

According to the results obtained from careful examinations over numerous species of the genus Peridinium, we came to the conclusion that it is not to the shape of a single middle plate of the intercalary row of plates but to the general contour of the row itself that one has to pay special attention in the characterization of the group Humilia. Examinations in apical view of the epitheca inform us of the fact that the intercalary row of plates in most of Humilia is of considerable size, bending abruptly at two dorso-lateral points to form U-shaped figure with its widely opened end ventral. The row consists then of three arms of subequal breadth, distinguishable from one another by a sharply turned corner. And the outer (dorsal) or inner (ventral) margin of its three lobes is fairly straight, particularly distinct in its mid-dorsal portion represented by the tetragonal or more rarely pentagonal middle intercalary plate. This abruptly bent, U-shaped intercalary row of plates often gives in apical view of the epitheca a characteristic feature, by which one can distinguish Humilia at a glance from others.

The ventral plate pattern is typically 'meta' throughout four of the five sections. But that of 'para' has been recorded from $P$. curvipes and $P$. variegatum of Heteracantha, and that of 'ortho' from $P$. decipiens of the same series and also from $P$. turgidum var. karianum (SABElina, 1930) of Laterispinosa. Though these species just cited were allocated in this paper tentatively in the sections judging from published figures. However their allocation is still uncertain because of their undetailed figures.

Judging from SABELLINA's figures, $P$. turgidum var. karianum has at least two different plate patterns of the epitheca, suggesting either her undetailed observation or higher degree of variability of the plate pattern. GRAN (1902) figured two types of 'para' and 'ortho' in $P$. decipiens. It is not improbable that two different ventral plate patterns occur within a single species. But judging from other figures given by Gran, it seems to be a matter of question whether or not his $P$. decipiens is in reality a single species. Together with these uncertain species and variety, $P$. curvipes and $P$. variegatum were included in this group only because of their incompletely formed antapical extensions. The Heteracantha section has, then, all the three types of the ventral plate pattern, and may be regarded as the least established section in the genus. The same may be suggested from the variously shaped middle intercalary plate in that section.

Throughout four sections of Monacantha, Laterispinosa, Bispinosa and Globula, 
the tetragonal middle intercalary plate can be established. On the other hand, the pentagonal one can be seen in the latter three of the four and the hexagonal one only in the last of them. And the structural relations of the ventral area and of the antapical extensions are more complex or more highly differentiated in them in the order given above. From these, it may be suggested that higher polygonal shape of the middle intercalary plate is associated in this group with more advanced type of the hypotheca. In some of Laterispinosa in which the hypotheca is hemispherical, this plate is either small rectangular or elongated trapezoidal. But in those with conical bulges of the thecal wall at the base of the antapical spine such as $P$. finlandicum, $P$. pedunculatum and $P$. granii, the plate is regularly pentagonal. In Bispinosa, the plate is a little larger and broadly trapezoidal with rounded hind margin or broadly pentagonal. This is still larger and more transversely elongated in Globula in which it displays a wide range of variations in shape, and four types of rectangular, pentagonal, hexagonal and heptagonal are known. Heteracantha is interesting in this regard. The plate in this is generally hexagonal while it is pentagonal or quadragonal in $P$. variegatum. This, together with the three types of its ventral plate pattern, seems to suggest that the Heteracantha section includes some uncertain species presumably of other sections. On the other hand, more than two shapes of this plate are known from $P$. ovatum, $P$. quarnerense, $P$. sphaeroides, $P$. variegatum and some other species.

In all of the five sections, the hypotheca is typically broadly rounded posteriorly without forming a conical elevation at the antapex. The antapical spine is absent in some species of Globula and in PAuLSEN's $P$. decipiens, but can be seen in all other species, in which it is fairly short, standing distinctly from sulcal list and furnished in a few cases with side-wing while in most cases without one. An asymmetrical single spine is seen in Heteracantha standing closely by the hind end of the ventral area, while in Monacantha fairly removed laterally from it. In these two sections, the left antapical spine fails to develop entirely. The other three sections have two spines. Either or both of the two spines are displaced laterally from the ventral area in Laterispinosa, while both of them lie closely by the ventral area in Bispinosa. In Globula they can be seen in a few cases in which they are completely removed laterally from the structure. In any case, the antapical spine is short and fairly simple in structure, and never forms a well-developed typical wing-complex such as seen generally in Pyriformia and Pellucida.

The ventral area is fairly narrow and gradually broadens posteriorly. It extends posteriorly to the center of hypotheca or terminates in front of it, and does not show a distinct rightward expansion in its middle. It is generally smaller and extending longitudinally in less advanced forms, but distinctly <-shaped in Glubula in which the girdle forms a deeply overhanging spiral, and an anterior half of the ventral area is strikingly elongated, diagonally connecting the two median ends of the girdle. The elongation and obliquity of this part of the ventral area is directly correlated with degrees of overhanging of the girdle. And this character is highly various within the section but differs slightly within a single species. It is interesting in 
this regard to note that the oblique extension of the anterior half is seen, though in less degrees, in some species of Laterispinosa and Bispinosa such as $P$. roseum, $P$. lenticulatum and $P$. ovatum and more or less distinctly in $P$. ventralis. In these species, the right ventral postcingular plate is strikingly small in length, and its median edge is oblique in harmony with an oblique extension of the precingular part of the ventral area. Further, the tendency of the obliquity can be seen in $P$. subcurvipes of Monacantha. In these species, the postcingular row of plates is so small in length and the spiral tract of the girdle is so pronounced that the postero-median end of the right ventral postcingular plate lies opposite to the proximal end of the posterior cingular ridge. And this relation gives us an impression of the ventral area bending at the proximal end of the girdle. In P. ventralis and also in all species of Globula, the ventral area bends actually at the proximal end of the girdle. Besides these, we have to draw attention to the fact that this tendency can be seen in Monacantha though faintly. In $P$. subcurvipes of that section, median edge of the plate and precingular part of the ventral area lie in an oblique line in disregard of the fact that the right ventral postcingular plate extends posteriorly further beyond the proximal end of the girdle.

From these considered above, it may be allowed to suggest that a type of the peculiar bending of the ventral area seen generally in Globula can be traced through Bispinosa and Laterispinosa and further to Monacantha. And this suggests the closest natural affinities of these four sections.

The ventral area is more or less deeply excavated as a whole in P. curvipes of Heteracantha judging from PAuLsen's figures, but in others, the sulcal furrow is restricted mainly in its left half. Correlated with this, the postero-median part of the body is generally not indented in Humilia. The left sulcal list is much broader than the right one in four of the five sections. It develops especially strongly in Heteracantha, in which it extends posteriorly beyond the hind end of the body and as far as the right antapical spine. But in Globula, the left sulcal list is narrow and the right sulcal one fails to develop, and the huge flagellar wing, which is rudimentary in most of the other sections, extends obliquely towards the left over the major part of the sulcal furrow and can be traced anteriorly to the proximal end of the anterior cingular ridge.

So far as our study is concerned, structural relations within the ventral area or arrangement of the four sulcal plates in $P$. subcurvipes of Monacantha, $P$. marukawai and $P$. ventralis of Bispinosa, $P$. grande of Laterispinosa and in all species of Globula are typical for the genus. In all of them, the flagellar pore is seen just in front of the hind end of the ventral area, along which lies a narrow posterior sulcal plate (ABÉ, $1936,1941)$. In most of published figures available at hand, the flagellar pore of species to be allocated to Humilia is illustrated similarly at near the hind end of the ventral area. From these, we may be allowed to conclude without doubt that in Humilia the flagellar pore is displaced distinctly posteriorly in harmony with much smaller size of the posterior sulcal plate which lies transversely across the hind end of the ventral area. 
In the genus Peridinium, the left sulcal plate and the anterior and right sulcal ones extend generally anteriorly to the proximal end of the posterior cingular ridge and to the epitheca respectively. Interesting in this regard is the fact that the strikingly elongated and diagonally extending inter-cingular part of the ventral area of Globula consists of the right and anterior sulcal plates, the former extending to and the latter beyond the distal end of the anterior cingular ridge.

From the considerations given above, it is apparent that at least the four sections of Monacantha, Laterispinosa, Bispinosa and Globula form a well-established group in which the meta-type of the ventral plate pattern of the epitheca is closely associated with the Pyriformia-type of the ventral area and incompletely formed antapical spine. We have not had enough data to discuss here the taxonomical relationship of Heteracantha, though its allocation to Humilia can be verified from some facts established heretofore.

Key to sections

1. The ventral area is elongated straight

A. Only the right antapical spine is formed

a. The spine stands at the edge of the ventral area .........Heteracantha

b. The spine is separated laterally from the ventral area

Monacantha

B. Two antapical spines are formed not strongly and slightly separated laterally from the ventral area

Laterispinosa

2. The ventral area is <-shaped

A. The girdle is strongly overhanged, and the ventral area is of subequal width throughout its diagonal anterior half ..Globula

B. The girdle is not much overhanged and the ventral area tapers anteriorly

Bispinosa

\section{Section 1. Heteracantha n. section}

Belonging to Humilia, this section includes these species characterized by a single right antapical spine standing at the hind end of the narrow ventral area and a broad and distinct left sulcal list extending posteriorly beyond the hind end of the body.

The body is generally small and rotund and not tapered anteriorly to a distinct apical horn. The hypotheca is hemispherical, and the narrow and deeply excavated ventral area extends to its center. The single, right antapical spine is short and rarely provided with side-wings. The left sulcal list is broad and distinct, standing basally along entire length of the ventral area, and extends posteriorly as far as or more often further beyond the right antapical spine. The left antapical spine generally fails to develop, but often is represented by a rib of the left sulcal list. The equatorial girdle is weakly ascending or circular. The ventral plate pat- 
tern of the epitheca is 'para', 'ortho' or 'meta'. And the middle intercalary plate is rarely tetragonal but often pentagonal or hexagonal.

The present section may be regarded as the least advanced type in the Humilia group because of its least developed hypothecal extension. On the other hand, we have some reasons to believe that $P$. decipiens apparently represents a lower type in regard to the character just cited but it is to be regarded as a higher type because of its highly differentiated posterior sulcal plate and its ventral pore characteristic of Pellucida and Paradivergentia. This suggestion may be supported by its tetragonal or hexagonal middle intercalary plate. Other species which have been recorded insufficiently have similarly some characters partly of lower and partly of higher types, suggesting their unestablished taxonomical allocation. In any case, however, it seems to be most justifiable and reasonable as well as practical to regard these species as the least developed antapical extension to form a more or less closely related group, distinct from others, unless their thecal morphology is studied more minutely and accurately than ever.

In this section may be included the following species: $P$. decipiens Jörgensen, $P$. breve Paulsen (1911), P. curvipes Ostenfeld and $P$. variegatum Peters.

All of these are so closely related with one another in the shape of their midbody and all of the published figures of them are so insufficently illustrated that it is difficult to distinguish them from one another according to the differences in the shape of this midbody and their plate pattern. PAulsen's (1908) P. decipiens differs profoundly from GrAN's (1902) which is deemed here provisionary to represent JörGENSEN's original species because there is no means for seeing JöRGENSEN's original figure. According to Gran (1902), the ventral plate pattern of P. decipiens is 'ortho' (Fig. 12 c) or 'para' (a). 'That of P. curvipes is 'para', 'ortho' and 'meta' according to Paulsen (1911) or Woloszynska (1928), Paulsen (1908) and Lebour (1925) respectively. These inconsistencies can be explained in two ways. It may be granted to presume that such variations of the ventral plate pattern may actually take place in these species. At the same time it may be highly probable to suppose that these authors have observed different but closely related species. The cause of these inconsistencies and uncertainties is that detailed morphological studies of these species have not been given by the former investigators.

The same is true of $P$. breve which was regarded by Paulsen $(1908,1911)$ as a near relative of $P$. steinii but was allocated by Lebour (1925) to Humilia conforming Fauré-Fremiet's opinion. But according to Paulsen's later paper (1911), this species is certainly a member of Heteracantha.

However, it can be said with certainty in any case of them that the left ventral plate of either the pre- or postcingular series is distinctly smaller in transverse length than the right ventral, and that the flagellar pore is illustrated as distinctly displaced posteriorly and the ventral postcingular plates do not extend posteriorly beyond half way between the girdle and antapex. This latter fact leads us to suggest that the posterior sulcal plate of these species cited above does not expand much anteriorly and is interrupted from contact with the two postcingulars, as was 
established in this paper in $P$. decipiens.

Key to species

1. The midbody is in ventral view a little longer than broad and its apex and antapex are displaced ventrally Peridinium breve

2. The midbody is subequal in length and breadth .................... curvipes

3. The midbody is a little shorter than broad ....................... variegatum

4. The midbody is somewhat lenticular ............................... decipiens

\section{Peridinium decipiens JÖRGENSEN (?)}

Gran, 1902, p. 187, Fig. 12 a-d; not Paulsen, 1908.

P. curvipes PAULSEN, 1911, p. 308, Fig. 6 A-F.

We saw a single specimen of this in Asamushi, but it was crushed to pieces before completion of its sketches. So, our account on its thecal morphology is far from complete but serves enough to characterize this species.

The body is broadly rounded posteriorly and tapered anteriorly to a hardly differentiated apical process. The girdle is equatorial and forms an ascending apiral with distal displacement of 0.5 of its width. The cingular section is ovoidal, tilting down ventrally.

The ventral plate pattern is 'meta'. The dorsal apical is exceedingly small while the middle intercalary is a large hexagonal plate occupying the major dorsal breadth of the epitheca. The postcingular series covers an anterior one-third of the hypotheca, and the left ventral of the series is a small plate and much longer than broad, extending posteriorly to half-way between the girdle and apex. The right ventral postcingular plate is much broader. These two ventral plates agree in breadth with the two ventral precingulars respectively.

The ventral area is excavated as a whole, and is broader posteriorly than anteriorly, extending posteriorly to the center of hypotheca beyond the antapices which are displaced somewhat ventrally. The right sulcal list is indistinct and has a distinct rib or an antapical spine at the antapex. The left sulcal list is much broader, standing basally along the entire length of the ventral area and has a short rib-like thickening at the antapex. There are several incomplete ribs in its anterior half. The ribs of the cingular list are sub-equidistant. The plate pattern of the ventral area is typical of the Humilia. The posterior sulcal plate is V-shaped and is interrupted from contact with both of the two ventral postcingulars.

Thecal plate is scattered with minute points. And the specimen has exceedingly striated broad sutural zones. The left ventral postcingular plate has the ovoidal pore in its pointed hind end.

Measurements: Length, $55 \mu \mathrm{m}$. Transverse diameter, $55 \mu \mathrm{m}$. Depth, $50 \mu \mathrm{m}$.

Locality: Asamushi. 
The present species is most closely related to $P$. decipiens of GRAN (1902) in general structural features of the body. But the ventral plate pattern is 'para' or 'ortho' according to GraN, while it is undoubtedly 'meta' in our material. This inconsistency or difference may be elucidated in two ways. It may be regarded, on one hand, as due to misinterpretation or misdrawing of the earlier investigator, or on the other hand as due to the variability of the ventral plate pattern of this species. There is no means to solve this question, but it must be recollected here that all the three ventral plate patterns are also described in $P$. curvipes of the same section. Judging from published figures, it is a question whether $P$. curvipes should be distinguished or not from $P$. decipiens, because of their closest resemblance in general features. But it is utterly impossible for now to answer the question because of extreme scarcity of this material.

\section{Section 2. Monacantha ABÉ.}

Group Monacantha ABÉ, 1936.

The body is flattened more or less distinctly in axial direction, tapering anteriorly to a minute apical process. The hypotheca is broadly rounded posteriorly, and the short ventral area does not extend to its center. A short wingless spine stands at a short distance from the hind end of the ventral area, springing from the right antapical plate. The left sulcal list is distinct but does not extend posteriorly beyond the right antapical spine. The ventral plate pattern of the epitheca is 'meta', and the left ventral precingular plate is much smaller than the right ventral of the same series. The middle intercalary plate is small quadragonal or trapezoidal, and the three plates of the series are arranged in an angulated and broad U-shape. The postcingular plates are fairly short, covering an anterior one-third or a little less of the hypotheca.

The equatorial girdle forms an ascending spiral, displaced distally by its own width. The ventral area expands in its middle more towards the right than towards the opposite direction, and is excavated more or less distinctly as a whole. The posterior sulcal plate is small lying at the hind end of the furrow.

To this section are allocated $P$. monacanthum ( $P$. complanatum MEUNIER) and $P$. subcurvipes LeBour (not WoloszynsKa 1928). Woloszynska's $P$. subcurvipes differs from LEBOUR's in the form of the body as it is less flattened, flaring more strongly along the girdle and lack of the right antapical spine. In the latter character, WoloszynskA's form may be allocated rather to Heteracantha than to the present section.

\section{Key to species}

1. The midbody is lenticular Peridinium subcurvipes

2. The midbody is strongly flattened in axial direction ............. monacanthum 


\section{Peridinium subcurvipes LEBOUR}

Lebour, 1925, p. 133, Pl. 17, Fig. 3; ABÉ, 1936, p. 22, Figs. 1-8.

\section{Section 3 Laterispinosa n. sect.}

Group Rosea AвÉ, 1936.

In the two, short antapical spines or wing-complexes, standing distinctly from the ventral area or sulcal lists, the present section is separated from the Monacantha section.

The body is grobular or pentagonal with or without a faint or distinct bulge of the thecal wall at the base of the antapical spine which is displaced laterally from the ventral area, springing from the antapical plate. The ventral plate pattern of the epitheca is typically 'meta' but exceptionally 'ortho', and the middle intercalary plate is typically tetragonal or trapezoidal but exceptionally pentagonal. The girdle is ascending or circular. The left sulcal list is distinct from the winged or wingless left antapical spine which is generally less displaced laterally than the right one. The posterior sulcal plate is distinctly small, and is completely separated from the two ventral postcingular plates.

The following species are included in this section: Peridinium brevipes Paulsen (=P. varicans Paulsen), P. cerasus Paulsen, $P$. finlandicum Paulsen, P. granii OstenFEld ( $=P$. mite Pavinlard), $P$. incurvum Lindemann, $P$. pedunculatum of Sahiller (1929), P. roseum Paulsen, $P$. turgidum var, karianum SAbelina and $P$. solitarium Abé.

It may be interesting to note here that these species cited above were reported invariably from the North Sea, the Arctic and the Antarctic Oceans and other seas of colder water, and not a single case is recorded, so far as we know, from warm or temperate seas. This appears to indicate their habitat.

All the species just cited have the ventral plate pattern of 'meta', but the pattern of $P$. turgidum v. karianum SABELINA is 'ortho', yet the species displays some structures characteristic of the section. Whether or not $P$. incurvum LindemanN is to be allocated to the present group is hard to establish, but there are some reasons to believe its closest relationships with either $P$. brevipes or $P$. granii.

These species can be arranged into a series regarding development of the antapical bulge of the thecal wall. And the character is related to lateral displacement of the antapical spine and at the same time to the form of the body. $P$. cerasus stands at one end and $P$. granii lies at the other extremity of the series. The former species has a globular body without antapical bulges, while the latter species has two, distinct, conical antapical bulges on either side of the ventral area, and its body is in ventral view distinctly pentagonal or rather star-shaped. And other species can be arranged between them regarding different degrees of the character it displays.

On the other hand, study of published figures informs us of the fact that the degree of the lateral displacement of the antapical spine is subject to individual 
variation. The antapical spines of $P$. cerasus are illustrated by LeBour (1925) and BöHм (1933) as standing just at the very edge of the ventral area, while by PAULsen (1911) as standing on the lateral of it. And the left one of them is displaced, according to Paulsen (1095) and Peters (1928), more laterally than the right one. A similar variation can be established in $P$. brevipes. But in this case, more lateral displacement is coupled with larger antapical bulges. The antapical bulge of the thecal wall at the base of the antapical spine is so strongly developed in $P$. granii that we were, at the beginning of this study, led to believe the species to form a distinct section or group. But detailed morphological study of its ventral area revealed close relationships between this species and $P$. pedunculatum or $P$. brevipes.

Another variable character worthy of consideration here is the ventral plate pattern of the epitheca, which has long been regarded generally as of least variable character in the genus Peridinium. Different plate patterns were recorded in some species of Heteracantha, but there still remain some uncertainties as to their belonging to a single species. But regarding the present section, a single specimen of $P$. granii was seen furnished certainly with the ventral plate pattern of 'ortho'. In this regard, it is intersting to recollect that $P$. turgidum var. karianum also has the plate pattern of 'ortho'.

\section{Key to species}

1. The hypotheca is broadly rounded posteriorly

A. The midbody is globular

a. The antapical spine is very short and is displaced much ventrally...... Peridinium solitarium

b. The spine, together with the apical horn, is longer.........P. cerasus B. The midbody is a little broader than long ................... roseum

2. The hypotheca is feebly indented in the postero-median region

A. Antapical spine is scarcely formed ........................... incurvum

B. The spine is exceedingly small in length $\ldots \ldots \ldots \ldots \ldots \ldots \ldots . . \ldots$ brevipes

C. The spine is well formed.

a. The thecal wall bulges more or less angularly along the girdle $a^{\prime}$ The epitheca is tapered distally to form a short apical horn $P$. pedunculatum

$\mathrm{b}^{\prime}$ The apical horn is scarcely differentiated......... finlandicum

b. The thecal wall is rounded along the girdle ...P. turgidum v. karianum

3. The postero-median indentation is so broad and distinct that the two antapical conical bulges are set wide apart, each bearing a spine at the tip ...P. granii

\section{Peridinium brevipes PAULSEN}

Fig. $10(\mathrm{a}-\mathrm{e})$

PAUlsen, 1908, p. 108, Fig. 151; 1911, p. 313, Fig. 13. 
Lebour, 1925, p. 131, Pl. 27, Fig. 2 a-d; WoloszynskA, 1928, Pl. 41, Figs. 7-11.

P. varicans Paulsen, 1911, p. 312, Fig. 12 A-F; Le.Bour, 1925, p. 132, Fig. 41 b; Woloszynska, 1928, Pl. 14, Figs. 12-13.

Peridinium sp. Lindemann, 1924, p. 223, Fig. 33.

This exceedingly minute species is pentagonal in ventral view with two short spines at either side of a short and scarcely indented postmargin, and furnished with a comparatively broad and deeply indented equatorial girdle of ascending spiral and a distinct sulcal furrow, broadening posteriorly.

Both the epitheca and the hypotheca have similarly convex surface, but the former tapers distally to a hardly differentiated apical process and the latter is rounded posteriorly. The narrow cingular list is furnished with equidistant ribs,

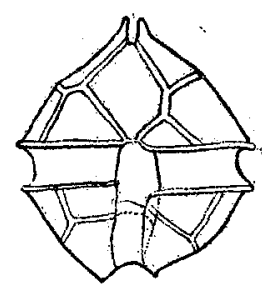

a

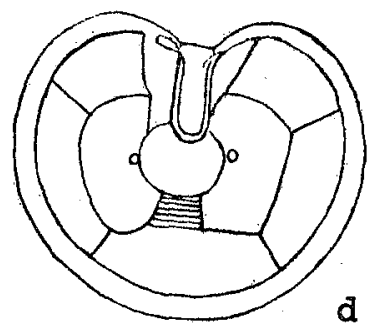

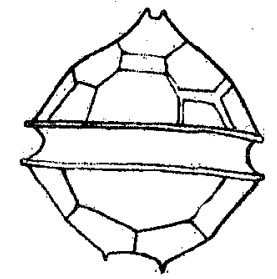

b
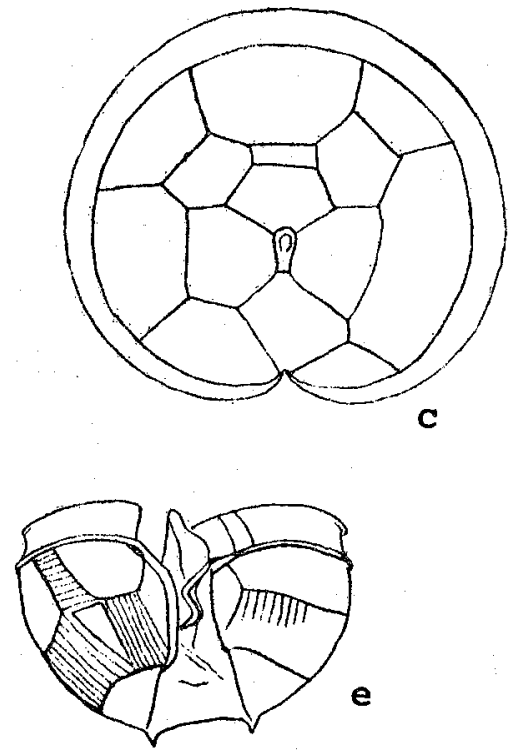

Fig. 10: Peridinium brevipes Paulsen. a-Ventral view. b-Dorsal view. c-Apical view. d-Antapical view. e-Ventral view of isolated hypotheca and girdle.

and the cingular section is more or less distinctly three-lobed with a ventral depression. The sulcal furrow is most strongly compressed laterally just below the girdle and becomes wider posteriorly. The antapical spines are separated from each other as wide as the greatest breadth of the ventral area, standing just on the edge of the furrow or on the lateral of it.

The body is colourless and is filled with a large central and many smaller subperipheral vacuoles.

The ventral plate pattern of the epitheca is 'meta', and the small but broadly pentagonal ventral apical plate is either shortly displaced from the apex or extends to it. Among the six precingulars, the ventro-laterlas, 2" and 6", are the largest. On the dorsal side, the middle intercalary is an exceedingly minute quadrangular plate lying between the much larger, hexagonal laterals of the same series. 
There appear to be two types of the plate pattern of the hypotheca, one with a narrow and the other with a transversely elongated, left ventral postcingular plate. In the former case, the plate is about one-half as broad as the right ventral of the same series. And in the latter case, they are subequal in transverse length. In either case, they extend posteriorly similarly to half-way between the girdle and antapex. Besides this, there has been established no other difference worthy of their separation. The dorsal postcingular is twice as broad as the dorsal precingular, and the two antapicals are subequal in size and shape.

In most of the specimens examined, more or less broader and distinctly striated sutural zones were seen. Measurements inform us of the fact that the epitheca or the hypotheca grows 1.38 times as long as its original length. This increase in length by $38 \%$ is measured along either side of the body where a single transverse suture is seen between the apex and girdle.

Though we could not establish the exact number of the cingular plates, there appear to be two sutural zones in the girdle, each lying in the dorso-lateral side of the body at the lateral ends of the dorsal postcingular plate, where a slight constriction or depression emerges in the cingular section of the body when the sutural zones grow broader. In addition, there is a minute plate at the proximal end of the girdle. Judging from these, the cingular wall consists at least of three plates.

The plate pattern of the ventral area is typical of the subgenus Protoperidinium. The posterior sulcal plate is transversely elongated but interrupted entirely from contact with either of the two ventral postcingular plates. The sulcal lists are indistinct, and their structural relations with the antapical spines are hardly established. The ventral area is more or less deeply excavated as a whole, and the sutural zone lying around its right and dorsal margins grows broader as the growth of the body advances. The sulcal furrow expands over into this marginal zones. Consequently, as the growth of the body advances, the sulcal furrow grows larger, expanding towards the right and posteriorly beyond the sulcal plates. This is the reason why the sulcal furrow is wider especially in its posterior half in older specimens than in younger ones.

The thecal wall is scattered sparingly with minute points.

Measurements: Body length, 27-41 $\mu \mathrm{m}$. Transverse diameter, $25-38 \mu \mathrm{m}$. Depth, 26-34 $\mu \mathrm{m}$. Width of girdle, $5 \mu \mathrm{m}$.

Locality: Asamushi.

PAUlsen (1908) gave three figures of this species without description. Detailed figures were given later by Broar and PAULSEN (1911), and further by LEBour (1925). According to LeBour, this species has been recorded in Iceland, Spitzbergen and English Channel. BROGH presumed that the present species might be "Jugendstadium" of $P$. breve. But it is interesting to note in this regard that PAULSEN, BRoGH and the author saw specimens with broad sutural zones. We agree, then, with Paulsen in the opinion that $P$. brevipes is a distinct species and not a larval form of some other species.

Paulsen described $P$. varicans found in two samples in the coastal water 
and in the pack-ice of the Greenland Seas. This differs from $P$. brevipes only in its two pointed antapices of wider separation. Its ventral apical plate is illustrated in his Fig. $12 \mathrm{~A}$ as rhombic, but the left ventral plate pattern was not given at all. Judging from his figures as well as from his description, its conical antapices stand outside of the ventral area. From these it can be said with certainty that its ventral postcingular plates do not extend to the posterior sulcal plate. On the other hand, rarely was found a specimen of the present species with antapical conical bulges or spines variously separated laterally from the ventral area. This, together with the nearly identical dorsal plate patterns of these two PAulsen's species, leads us to suggest that PAULSEN's later species may be an aberrant form of his former species.

\section{Peridinium granii OSTENFELD}

Fig. 11 (56-62)

Paulsen, 1908, p. 52, Fig. 66 a-f; Meunier, 1919, Pl. 16, Figs. 1-9, Pl. 17, Figs. 17-20; Lindemann, 1924, Figs. 54-55; Peters, 1928, pp. 47-50, Fig. 13 a-f.

Peridinium pellucidum, in part, Pouchet, 1883, Pl. 18-19, Fig. 8.

Peridinium sp. Gran, 1902, p. 188, Fig. 13 a-c.

Peridinium mite Lebour, 1925, p. 125, Pl. 25, Fig. 3 a-b; PAulsen, 1931, p. 61, Fig. 33 a-f.

Peridinium finlandicum, in part, PAuLsen, 1908, p. 51; Fig. 65 a.

The body is broadly pentagonal or rather star-shaped in ventral view, with the equatorial ascending girdle. Its conical epitheca tapers distally to a conical elongation, leaning often towards the right. A conical bulge of the thecal wall is formed on either side of the hind end of the body, bearing distally a short spine with three narrow side-wings. The cingular section is reniform or nearly so with or without a distinct ventral depression. The girdle forms an ascending spiral with distal displacement of its own width. Often diameter of the body is a little smaller at the anterior cingular edge than at its posterior edge. The ventral area is fairly narrow in its anterior half which often extends anteriorly remarkably beyond the girdle, and its posterior half is a little broader expanding asymmetrically towards the right. It is excavated deeply as a whole, and yet does not form a distinct posteromedian indentation of the body because of its ending posteirorly in front of the center of hypotheca. The left sulcal list is distinct but is separated. for a short distance from the left antapical spine.

The ventral plate pattern is typically 'meta', and two subequal ventral precingular plates are separated from each other by a narrow anterior elongation of the ventral area, which often fails to develop at all. In a single specimen we established exceptionally the plate pattern of 'ortho', which was confirmed by separating the epitheca from the hypotheca. The middle intercalary plate is typically left oblique pentagonal of various size but rarely small tetragonal. The two ventral postcingular plates agree in their posterior expansion, ending in front of half-way between the girdle and antapex, but extend anteriorly according to the distal displacement of the girdle. The rectangular distal cingular plate is one-half as large as the proximal one, but twice 

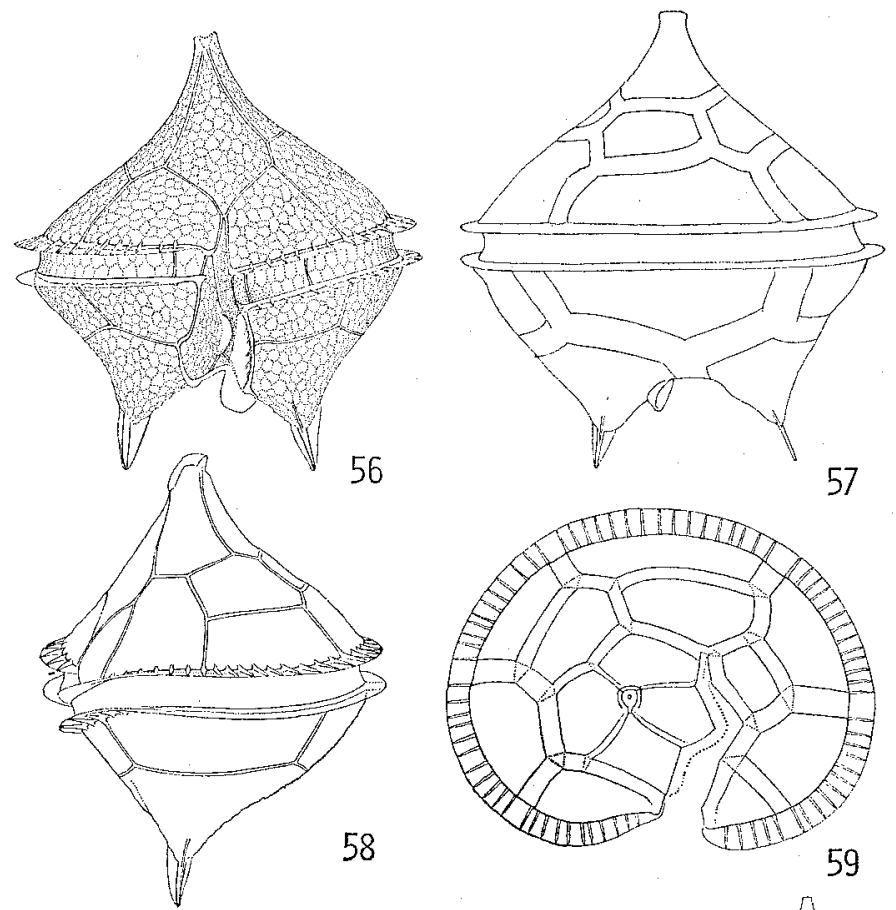

56
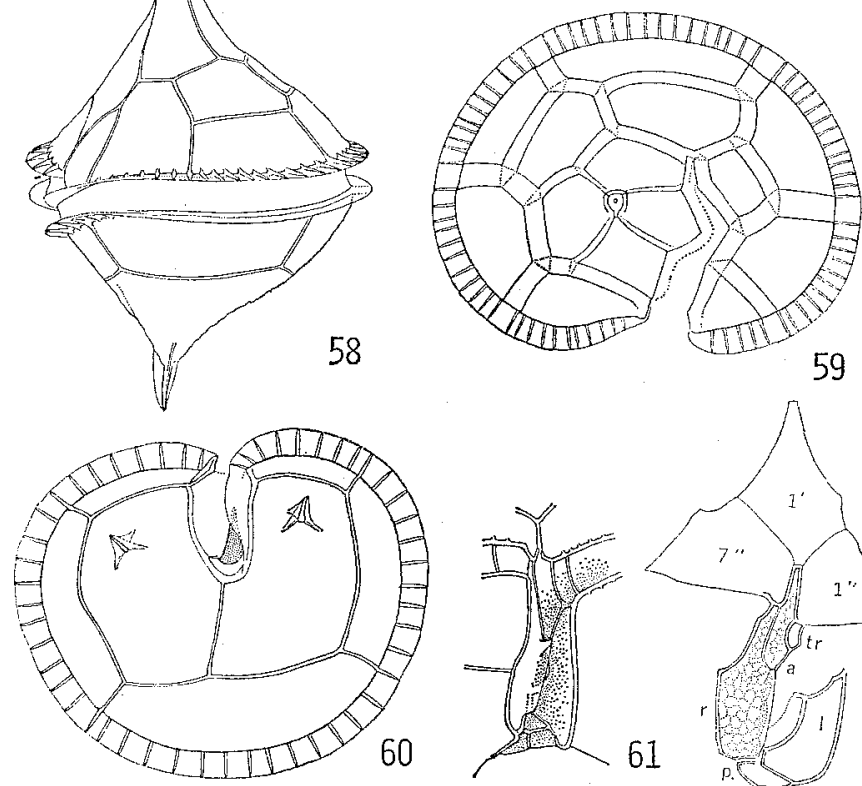

59

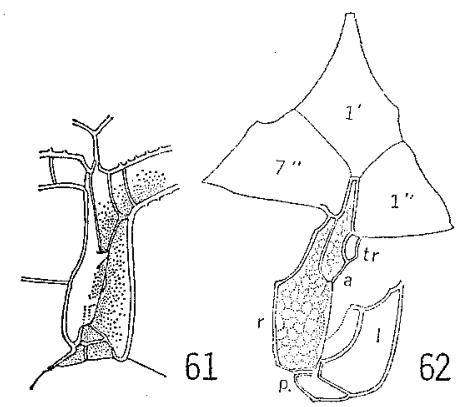

Fig. 11 (56-62): Peridinium granii Ostenfeld. 56-Ventral view showing thecal structure. 57-Dorsal view. 58-Side view. 59-Apical view, a slightly pressed specimen. 60-Antapical view. 61— Ventral area. 62-Ventral area and adjacent plates.

as large as the transitional plate. Typical is the plate pattern of the ventral area. But the posterior sulcal plate is exceedingly minute in size, lying at the posterior extremity of the sulcal furrow, and is accordingly hard to establish unless the sulcal plates are separated from the content of the body.

All of the thecal plates are finely reticulated except the left and posterior sulcal ones and the transitional one.

Measurements: Body length exclusive of antapical spine, 57-65 $\mu \mathrm{m}$. Transverse diameter, 53-58 $\mu \mathrm{m}$. Dorso-ventral diameter, $42-44 \mu \mathrm{m}$. Length of antapical spine, $6-8 \mu \mathrm{m}$.

Locality: Asamushi. 
GRAN (1902) recorded a small, broadly pentagonal species with two short antapical spines widely separated from each other and also from its narrow ventral area. In essential agreement with the original species of GRAN, some of former investigators have granted both $P$. granii and $P$. mite as two distinct species. The main differences between them consist in the shape of the body and different development of the antapical conical bulge. On the contrary, Peters (1928) proposed to unite the two species because of his establishment of variously formed antapical cone. We also saw in our materials a fairly wide range of variations in the relative breadth of the body and in the length of the antapical cone.

As regards the dorsal plate pattern of the epitheca, at least three different types have been recorded. But hardly has any variation been described about the ventral plate pattern. The only exception regarding this is the one figured by PAULSEN (1908) in which he gave a ventral pattern interpretable as 'para'. Too much significance can not be put upon this because he did not lay much taxonomic stress upon this structure, as was also pointed by Peters (1928). The plate pattern of 'ortho' which we have established is, then, the only variation ever recorded.

At the beginning of the study, we thought the present species as a close relative of $P$. divergens because of the conical antapical horn ending in a distal spine. PETERs (1928) also misinterpreted $P$. granii as a member of the Divergens section of Metaperidinium. But we found, on the contrary, the posterior sulcal plate of this species completely interrupted on either side from contact with the ventral postcingular plate. Further, we had to grant the fact that the conical bulge of the thecal wall at the base of the antapical spine is not rare in Protoperidinium, and that the spine is often separated from the ventral area in the same subgenus. These lead us to conclude, contrary to PeTERs' opinion, that $P$. granii is to be allocated to the subgenus Prntoperidinium, particularly to its Humilia group.

\section{Peridinium roseum PAULSEN}

Fig. $12(63-69)$

Paulsen, 1908, p. 44, Fig. 53; 1911, p. 307; Lebour, 1925, p. 130, Text-fig. 41 a.

The onion-shaped body has a low and swollen conical epitheca tapering anteriorly to a minute apical horn, an equatorial ascending girdle, a hemisphaerical hypotheca and two wingless antapical spines distinct from the ventral area.

The epitheca has a minute apical horn on the ventral of its center. Around the middle of the body is the ascending girdle with distal displacement of its own breadth. The hypotheca has along its ventral median a comparatively narrow ventral area which terminates posteriorly in front of its center. On either side of its hind end stands a wingless antapical spine.

The ventral apical $l^{\prime}$ is a narrow pentagonal plate, and the quadrangular left ventral precingular $1^{\prime \prime}$ is much smaller than the pentagonal right ventral of the same series. The dorsal apical $3^{\prime}$ is comparatively small, while the three subequal 

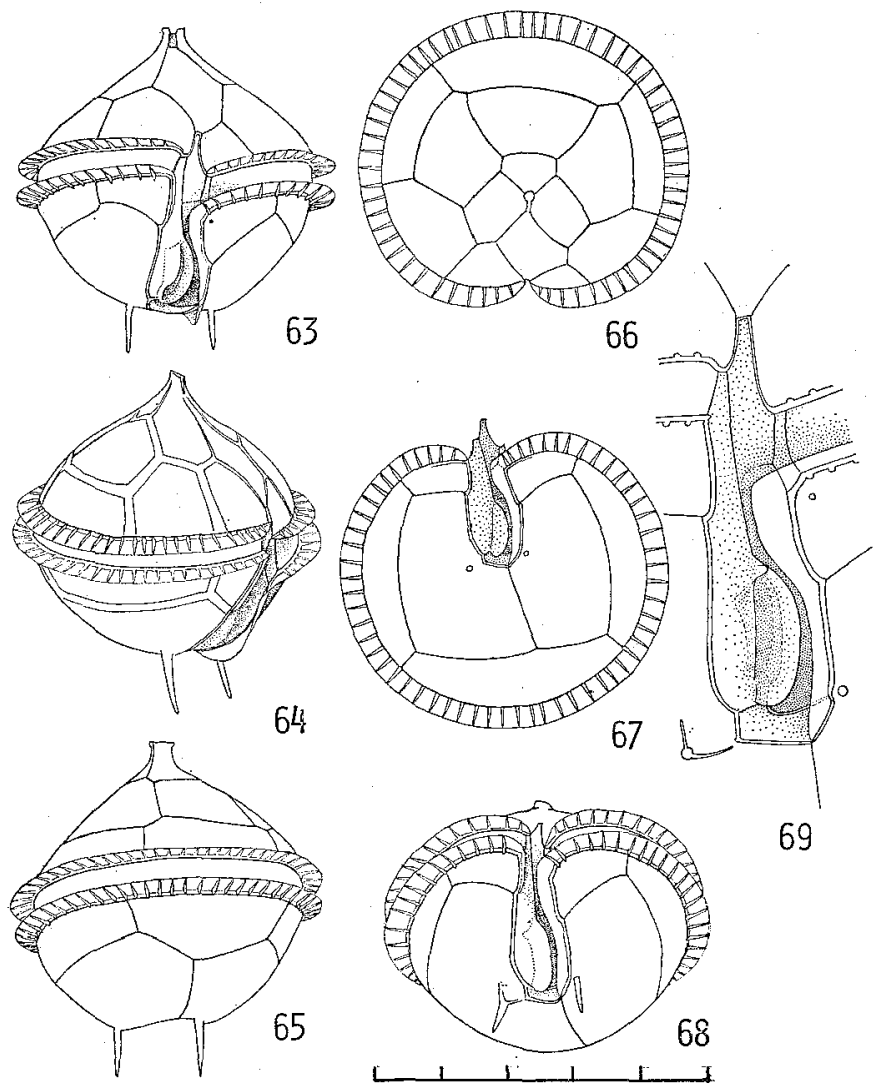

69

Fig. 12 (63-69): Peridinium roseum Paulsen. 63-Ventral view. 64 -Dextro-ventral view. 65-Sinistro-dorsal view. 66-Apical view showing Epithecal plate pattern. 67-Antapical view showing hypothecal plate pattern. 68-Postero-ventral view. 69-Ventral area. (A unit length of the scale indicates $10 \mu \mathrm{m}$. This applies to the scale in the following figures.)

intercalaries, among which the middle is broadly trapezoidal, are distinctly large. The postcingular row of plate covers an anterior one-fourth or a little less of the hypotheca, and the ventral $1^{\prime \prime \prime}$ and $5^{\prime \prime \prime}$ are similarly much shorter than broad. The antapicals then cover by far the major part of the hypotheca.

The ventral area has a distinct anterior extension with which it indents the epitheca deeply, and becomes broader in its posterior half tapering slightly in its hind end at the posterior sulcal plate. The left sulcal list is completely distinct from the left antapical spine which extends posteriorly beyond the hind end of the body, and the other sulcal list is very indistinct. Arrangement of the four sulcal plates is typical, but the posterior sulcal one is peculiar in its smaller breadth as compared with other parts of the ventral area. The flagellar fin is small and indistinct, and the sulcal furrow occupies more than the left half of the ventral area. The wingless left antapical spine is separated from the sinistral end of the posterior sulcal plate, standing on the left antapical plate, and has no direct connection either with the ventral area nor with the left sulcal list. The other stands on the right antapical 
plate and is separated more laterally from the ventral area. It is also wingless but has sometimes two or three ridges radiating from its base, which presumably represent rudimentaries of the side-wings.

The thecal wall is covered with fine meshes, and the left ventral postcingular plate has in its antero-median corner a minute ventral pore without a flange.

Measurements: Length of body exclusive of antapical spine, 39-43 $\mu \mathrm{m}$. Transverse diameter, $39-42 \mu \mathrm{m}$. Dorso-ventral diameter, $37-38 \mu \mathrm{m}$. Length of antapical spine, $6-8 \mu \mathrm{m}$.

Locality: Shimoda.

\section{Peridinium solitarium ABÉ}

ABt, 1936, p. 37, Figs. 24-29.

\section{Section 4. Bispinosa n. sect.}

The present species is less angulated than $P$. finlandicum, and is closely related to $P$. sohaeroideum, from which this can be distinguished by its larger middle intercalary plate.

The present section is distinguished from its relatives in Humilia by its two short antapical spines standing closely by the ventral area and the sulcal list from which the spine is distinct particularly on the left.

The body is globular or lenticular, and tapers anteriorly to a short apical prominence. The equatorial girdle is horizontal for the most part but forms by means of its proximal arch an ascending spiral with distal displacement of its own width.

The ventral area is rarely straight but generally <-shaped, lying longitudinally as a whole but slightly obliquely in its anterior half, and broadens posteriorly. It extends posteriorly nearly to the center of hypotheca or is much shorter, and deeply indents the epitheca anteriorly. The left sulcal list is fairly broad and distinct from the left antapical spine, which, together with the other spine, is either winged or wingless. The flagellar fin is indistinct and the flagellar pore is displaced posteriorly nearly to the hind end of the ventral area, along which lies the slender and bilaterally angulated posterior sulcal plate extending between the two antapical spines.

The ventral plate pattern of the epitheca is 'meta' and the middle intercalry plate is generally trapezoidal but rarely pentagonal. The left ventral precingular plate is distinctly smaller than the right ventral of the same series and has a length not much larger than the breadth of the girdle. The postcingular plates have length subequal with the breadth of the girdle so far as $P$. marukawai and $P$. ventralis are concerned, but are much longer in other species as published figures indicate.

In this section are included the following species: ? P. lenticulatum FAURE-FREMiet, $P$. marukawai AвÉ, $P$. ovatum (Pouchet) SGHütт, $P$. styliferum SaHILler and $P$. ventralis AвÉ. Though some uncertainties still remain, it may be suggested that 
P. sphaeroideum MANGIN may be a species of this section. The ventral plate pattern of this species is illustrated as reversed 'meta', but this may be apparently due to the author's misinterpretation.

Reviewing published figures of these species, we may be informed of the fact that the plate pattern of their epitheca displays a characteristic feature. In the major cases, the lateral and dorsal contour of either the apical or the intercalary row of plates is, in apical view, sharply angulated U-shaped. This double U-shaped sutural lines help us in practice in identifying a given species, although a similar feature is seen in some of the Globula and Laterispinosa sections.

The present section is closely related to Laterispinosa, from which this can be separated in its antapical spines standing at the very edge of the ventral area. Another characteristic of the present section is the bending of its ventral area at the proximal end of the girdle. A similar but much less distinct structure is seen in some of Laterispinosa and Monacantha, and the bending is more striking in Globula in which the anterior inter-cingular part of the ventral area is strikingly elongated, diagonally conforming the ventral overhanging of the girdle. Furthermore, the flagellar wing is unusually larger in Globula, in which it can be traced anteriorly to the proximal end of the girdle, while it is much smaller in Laterispinosa and Monacantha. The present section is intermediate between them in this regard. Then, the present section forms a connecting link in these regards between Laterispinosa and Globula. The closest relationship of this with Globula can be understood when one compares $P$. ovatum of this with $P$. majus of Globula. The two species can hardly be distinguished from each other so far as the general plate pattern of the irepitheca and hypotheca is concerned. But the characteristic bending and anterior elongation of the ventral area of the latter species serve at once to separate it from the former.

Key to species

1. The midbody is globoid

A. The ventral area is longitudinal .........................Peridinium styliferum

B. The ventral area is strongly $<$-shaped......................... ventralis

2. The midbody is lenticular

A. The apex and antapex are much displaced ventrally........P. marukawai

B. The structures are not so much displaced $\ldots \ldots \ldots \ldots \ldots \ldots \ldots \ldots \ldots . . . \ldots$ ovatum

\section{Peridinium marukawai ABÉ}

ABE, 1936a, pp. 27-32, Figs. 91-6.

P. roseum Marukawa, $1921 \mathrm{~b}$.

The plate pattern of this species is fairly constant so far as the materials are concerned. The only variation we could establish is that the tetragonal middle inter- 
calary plate is displaced slightly towards the left in some while towards the opposite side in other specimens. The cingular wall was established recently to consist of two minute and an elongated plates, the former lying at either end of the girdle and the latter covering the majority of it. In well grown specimens, the striated sutural zones between the cingular plates extend laterally nearly to the lateral extremities of the two ventral precingulars. In such a case, the total length inclusive of the sutural zone is often misinterpreted as its ordinary length. And this was the case with the author (1936, p. 28, fig. 9).

\section{Peridinium ventralis ABÊ}

AвÉ, 1936, p. 32, Figs. 17-23.

\section{Section 5. Globula ABÉ}

Group Globula ABÉ, 1940.

The body is globular or lenticular with a minute but abruptly differentiated apical process. Around the middle of the body lies a more or less deeply overhanging and distinctly ascending girdle. The ventral area is remarkably elongated forming a deeply <-shaped tract bending at the proximal end of the girdle. Its anterior inter-cingular portion is strikingly elongated and lies diagonally while the other half is much broader and extends longitudinally to the center of hypotheca or ends in front of it. A large flagellar wing can be traced anteriorly to the proximal end of the anterior cingular list, and the left sulcal list is indistinct. The right sulcal list is almost entirely absent. The flagellar pore lies just in front of the hind end of the ventral area, and the posterior sulcal plate is crescent or curved triangular point ing dorsally. The wingless or poorly winged antapical spines or semicircular lists stand in some species shortly separated laterally from the posterior sulcal plate, but in other species there is no hypothecal extension except the flagellar wing.

The ventral plate pattern is seemingly 'ortho' but in reality 'meta', because the wedge-shaped or irregularly trapezoidal left ventral precingular plate is usually very small, lying between the two ends of the deeply overhanged girdle. The intercalary row of plates is generally of large size, forming in apical view as a whole a widely expanded $\mathrm{U}$-shaped area. Its middle plate, 2a, is tetragonal, pentagonal, hexagonal or heptagonal. The postcingular row of plates has subequal bread th throughout, and the proximal end of the posterior cingular list lies opposite to the posteromedian end of the right ventral plate of the row, where the ventral area bends.

The present section is unparalleled not only in the Humilia group but also in the genus in its highly differentiated and peculiarly elongated ventral area. This peculiarity is associated largely with the striking elongation of the anterior and right sulcal plates in conformity to the strikingly overhanged ascending girdle. And the globular or rotated ellipsoidal body is not rare in the genus, but the species to be allocated to this group can be distinguished at once by the characteristics just 
considered.

The plate pattern of epitheca may be characterized at least on one hand by the left ventral precingular $1^{\prime \prime}$, trapezoidal with exceedingly smaller upper and much greater lower sides. Its median portion tapers distally, lying just above the proximal end and shortly below the other end of the girdle. Owing to this deformed precingular $1^{\prime \prime}$, the ventral apical $1^{\prime}$ is often seemingly rhombic though in reality pentagonal. It borders on the right side upon the plates $4^{\prime}$ and $7^{\prime \prime}$ while on the opposite side upon the three plates of $2^{\prime}, 2^{\prime \prime}$ and $1^{\prime \prime}$. The middle intercalary $2 \mathrm{a}$ is usually tetragonal, pentagonal or hexagonal but rarely heptagonal. This has been generally regarded as a character of taxonomical importance, but is, in reality, one of the most variable one in this group as was described elsewhere in this paper. Another portion where variation is liable to occur is the precingular row of plate, which consists generally of six plates but has rarely six or eight ( $P$. globifera and $P$. sphaeroides).

The girdle is equatorial or more generally pre-equatorial and forms a distinctly ascending spiral of more than one turn. Its distal end is displaced anteriorly owing to its proximal arch. The cingular wall is flat and consists of three plates, of which ventral two lie each just below the ventral median plate of the precingular series. The broad cingular list has generally well differentiated equidistant ribs.

The ventral area is characteristic in shape and in structural relations (Fig. 1376). It is sigmoid bending more or less distinctly at the distal end of the girdle, and its anterior end turns again anteriorly. It can be divided into an anterior slender and a posterior broader portions, the former lying between the two ends of the girdle while the latter below the girdle. The proportion in length of these two parts and the direction of their extension appear to be fairly fixed in every species, though rarely was seen specimen with less inclined one in $P$. globifera and $P$. sphaeroides. The ventral area becomes broader abruptly at its bent portion as it is confluent there with the girdle. This post-cingular part is either longitudinal or more often oblique towards the left. Obliquity of this portion appears to be associated with that of the inter-cingular part. The flagellar pore lies longitudinally or diagonally in this portion.

Interrelations of the four sulcal plates and flagellar pore are typical of the genus but it is to be noted here that the posterior sulcal plate is much reduced in size and triangular in shape pointing dorsally, and that the right and anterior sulcal plates are strongly elongated but much reduced in breadth, forming collectively the slender inter-cingular part of the ventral area. And the right sulcal plate extends to the distal end of the anterior cingular edge while the other does so more anteriorly beyond it indenting the epitheca more or less distinctly. This couple of plates lies for the most part between the precingular $1^{\prime \prime}$ and postcingular $5^{\prime \prime \prime}$. Fig. $13 \mathrm{~b}$ is the ventral area of $P$. sphaeroides, and Fig. 13b-c is its transversal optical sections in different altitudes. The longitudinal furrow is limited only in the left half of the post-cingular part of the ventral area and encircled with lists. Along the left side of this part is an indistinct but erected list which consists of a posterior extension of the posterior cingular list standing along the median margin of the left 
ventral postcingular plate $1^{\prime \prime \prime}$ and a distinct one lying along the border between the left sulcal plate and the left antapical $1{ }^{\prime \prime \prime \prime}$. The anterior cingular list extends towards the right beyond the transitional plate and transversely across the anterior sulcal plate. Just from the distal end of this horizontal list begins to extend posteriorly a large wing, the flagellar fin (ff), standing along a posterior half of the median margin of the right sulcal plate ( $r$. This wing is very distinct in all species of this group, and extends obliquely towards the left, covering major part of the longitudinal furrow. It is erected mostly in its basal narrow portion but bends abruptly towards the left, extending nearly to or partially beyond the left side of the ventral area. These relations are illustrated in Fig. C-1 $\sim 10$. Posteriorly its free end covers median major part of the posterior sulcal plate or terminates just at the hind end of the left sulcal plate. This wing is generally broadest in its posterior half where it covers the flagellar pore. The flagellar trough is short and the left sulcal plate forms a narrow lip extending over the anterior margin of the posterior sulcal plate.

The longitudinal furrow is thus restricted and framed into an incomplete tubule widely opening only posteriorly and also anteriorly into the girdle. Basal parts of the transverse and longitudinal flagella lie within this tubule, and the right sulcal plate has, then, no direct connection with them nor with the current of water that sweeps over the flagellar pore. This differentiation is also manifested in the fact that the right sulcal plate has the surface reticulation similar to that of other general thecal plates while the left and rarely the posterior ones are only distinctly porulate without surface meshes. No other lists are generally seen in this group. The inter-cingular part of the ventral area as well as the right sulcal plate is differentiated from the general thecal plate only by faint sutural lines. But in P. sphaeroides there are two additional semicircular lists ( $\mathrm{rw}, \mathrm{lw}$ ), each lying obliquely along and at a short distance from the lateral margin of the posterior sulcal plate. This structure has not been described nor figured except by DANGEARD (1927) who figured two minute antapical processes in his Fig. $3 \mathrm{D}$, corresponding in position to these fins. And further just at the same position one can see in $P$. quarnerense a slender spine with or without side lists.

The thecal plate has been described by the former investigators as being "punktiert." And our materials also show a similar structure under low magnification, but the minute granular structure that can be observed is not the structure of the plate itself. It is apparently due to their misinterpretation of the granules lying directly beneath the theca. Examination of an empty theca under high magnification uncovers general occurrence of a faint, minute but irregular reticulation with sparse population as is illustrated in Fig. 9 (53). Among the four sulcal plates, the left sulcal plate is also covered with finer meshes and the reticulation of the posterior sulcal plate is indistinct. The cingular plate is either free from it only exhibiting a crowded regular line of pores along its median or has incomplete meshes elongated transversely across the girdle.

Among described species, $P$. globifera, $P$. globulus, $P$. majus, $P$. quarnerense, $P$. 
saecularis and $P$. sphaeroides are regarded as distinct and valid species of the present section.

Schiller (1935) and Diwald (1939) are of the opinion that the body shape, development of the antapical spine, length of the ventral area and size and shape of the middle intercalary plate are variable in $P$. globulus which they divided into three variations, $P$. globulus, $P$. quarnerense and $P$. ovatum, generally regarded as so many distinct species. Carefully examining the discussions and descriptions given by the latter anthor, we have hardly found any reason for positive support of their unity but have some trustworthy data suggesting their probable specific distinction. We have to re-examine here in order to make the present group in regard to the characteristics of the major thecal features of the least established species, $P$. saecularis Murray and Whitting. Judging from its figure reproduced by Paulsen (1908, Fig. 46), this is not a Diplopsalis-species but clearly it is to be allocated to Peridinium. Its girdle forms a distinctly ascending spiral with proximal arch and has deep ventral overhanging. The left ventral precingular $1^{\prime \prime}$ is trapezoidal with its median end extending obliquely between the two ends of the girdle, especially immediately along its proximal end. A distinctly sigmoid sutural line is figured connecting the distal end of the girdle with the flagellar pore. This apparently suggests the tract of its ventral area. A small spine is said to stand at the flagellar pore and was figured to incline towards the left. This may be due to misinterpretation of the flagellar wing from its anterior end. All these structural relations given above are found exclusively in this group and are enough to allocate the species to this. The body is flattened with broadly rounded apical region and no apical horn is figured. This may be because its apical process is exceedingly minute and abruptly differentiated from the mid-body. As to the shape of its body, this species is closely related to $P$. simulum from which it can be separated in its much smaller size and its two antapical spine. The flattened body coupled with the two antapical spines serves to separate this from all the other known species of the group and is then worthy of its specific distinction.

The most distinct one of the major characteristics of this section can be sought in the peculiarly elongated and deeply bent ventral area, and the section is in this regard unparalleled in the genus. The strongly overhanged, ascending girdle, posteriorly displaced flagellar pore, triangular posterior sulcal plate and its huge flagellar wing help us above all in distinguishing this species from others. Coupled with the overhanged girdle, the striking elongation of the oblique intercingular part of the ventral area is characteristic of this section and peculiarly it consists only of the anterior sulcal plate and a part of the right sulcal one. The bending of the ventral area at the proximal end of the girdle can be seen, though in much less distinction, in some other species of the Humilia group. This clearly suggests their closest natural affinity. Further a similar relationship can be established regarding some of the other characters such as the angular U-shaped intercalary row of plates, the symmetrical posterior sulcal plate, and the laterally displaced antapical spine, 
in addition to the ventral plate pattern of the epitheca.

Key to species

1. The body is globoid

A. No antapical appendage is formed

a. The dorsal apical plate is exceedingly small tetragonal.

Peridinium globulus

b. The plate is much larger and pentagonal .................... globifera

B. Antapical appendage is formed

a. Two antapical spines are seen

$P$. quarnerense

b. Two semicircular lists are formed on either side of the hind end of the ventral area $P$. sphaeroides

2. The body is flattened in axial direction

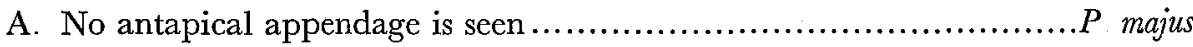

B. Two antapical spines are formed

$P$. quarnerense

\section{Peridinium globulus STEIN}

Fig. 13a (70, 71)

Paulsen, 1908, p. 42, Fig. 51; A.É, 1940, p. 28, Fig. 1.

The present species has been subjected to extended discussion and is still now in a state of confusion as to its characterization. Some included in it more than two different forms while others restricted the species name exclusively to one of them. PAULSEN (1908) separated a form with two antapical spines from STEIN's species and regarded another without the spines as the typical species. And most of the subsequent workers followed him. But two forms have been recorded in the species: one with an exceedingly smaller rhombic and the other with a larger pentagonal dorsal apical plate. In 1931, PAULSEN again characterized the species by its minute dorsal apical and included in it $P$. sphaeroides DANGeARD in disregard of its two antapical wings which were described but not figured by the latter author. This confusion is due to insufficient characterization of STEIN's or PAULSEN's former species. Judging from one of STEIN's figures reproduced by PAuLsen (1908), this species has following characters: the precingular row of plates covers nearly a lower half of the epitheca; the postcingular row covers upper one-third of the hypotheca; the ventral area extends anteriorly far beyond the distal end of its distinctly ascending girdle; and no antapical wing exists. PAulsen again illustrated this in 1931 in his Fig. 31 which appears to differ from his former in that its precingular 1 " is much elongated towards the right, its body is rotated ellipsoidal instead of spherical, and that its ventral area is much distinctly curved. At the same time he characterized this by its minute apical 3', judging from his referred literatures. Anyhow he characterizes this species, and though we are still in doubt whether or not STEIN's figure 


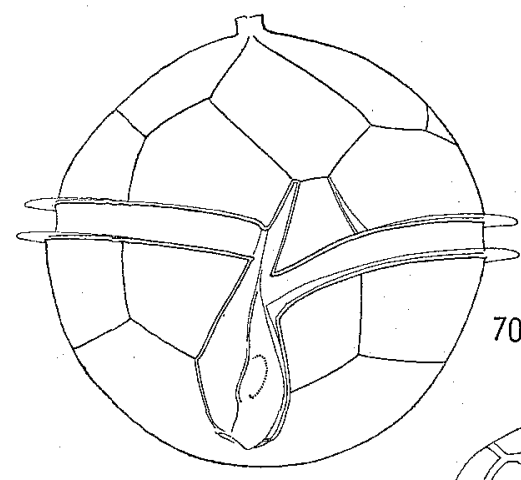

70
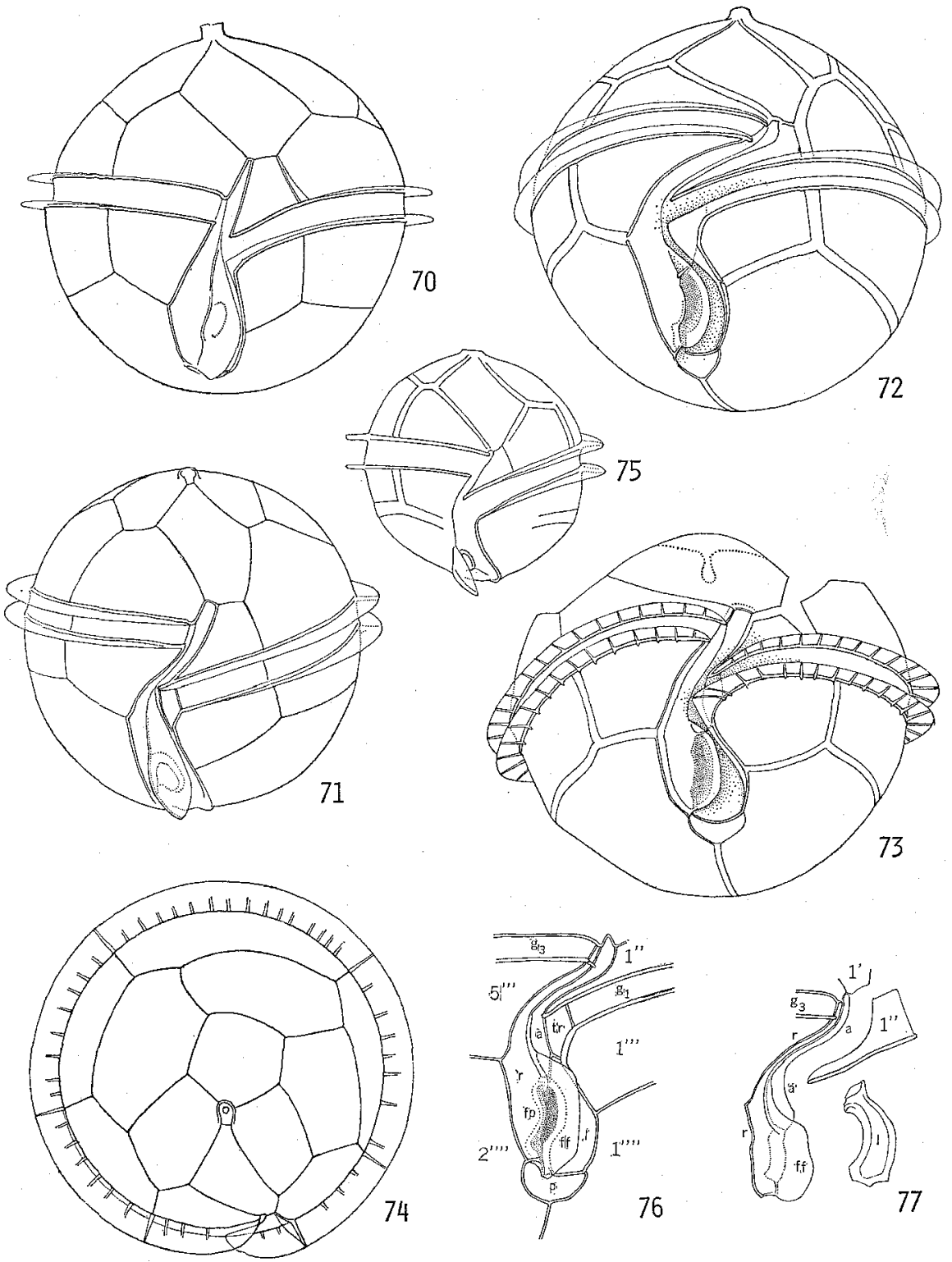

Fig. 13a $(70,71)$ : Peridinium globulus SteIN. Ventral views.

(72-77): Peridium globifera ABÉ. 72-Ventral views. 73-Ventral view, partially spiltted specimen. 74-Apical view. 75-Particularly small specimen. 76-Ventral area and its surroundings. 77Ventral area, partially analysed. $1^{\prime}$-ventral apical plate. $1^{\prime \prime}$-left ventral precingular plate. $\mathrm{g}_{1}, \mathrm{~g}_{3}$ cingular plates. $1^{\prime \prime \prime}, 5^{\prime \prime \prime}$ - postcingular plates. $1^{\prime \prime \prime \prime}, 2^{\prime \prime \prime \prime}$-antapical plates. a-anterior sulcal plate. 1-left sulcal plate. $\mathrm{r}$-right sulcal plate. $\mathrm{p}$-posterior sulcal plate. tr-transitional plate. fp-flagellar pore. ff-flagellar fin. 

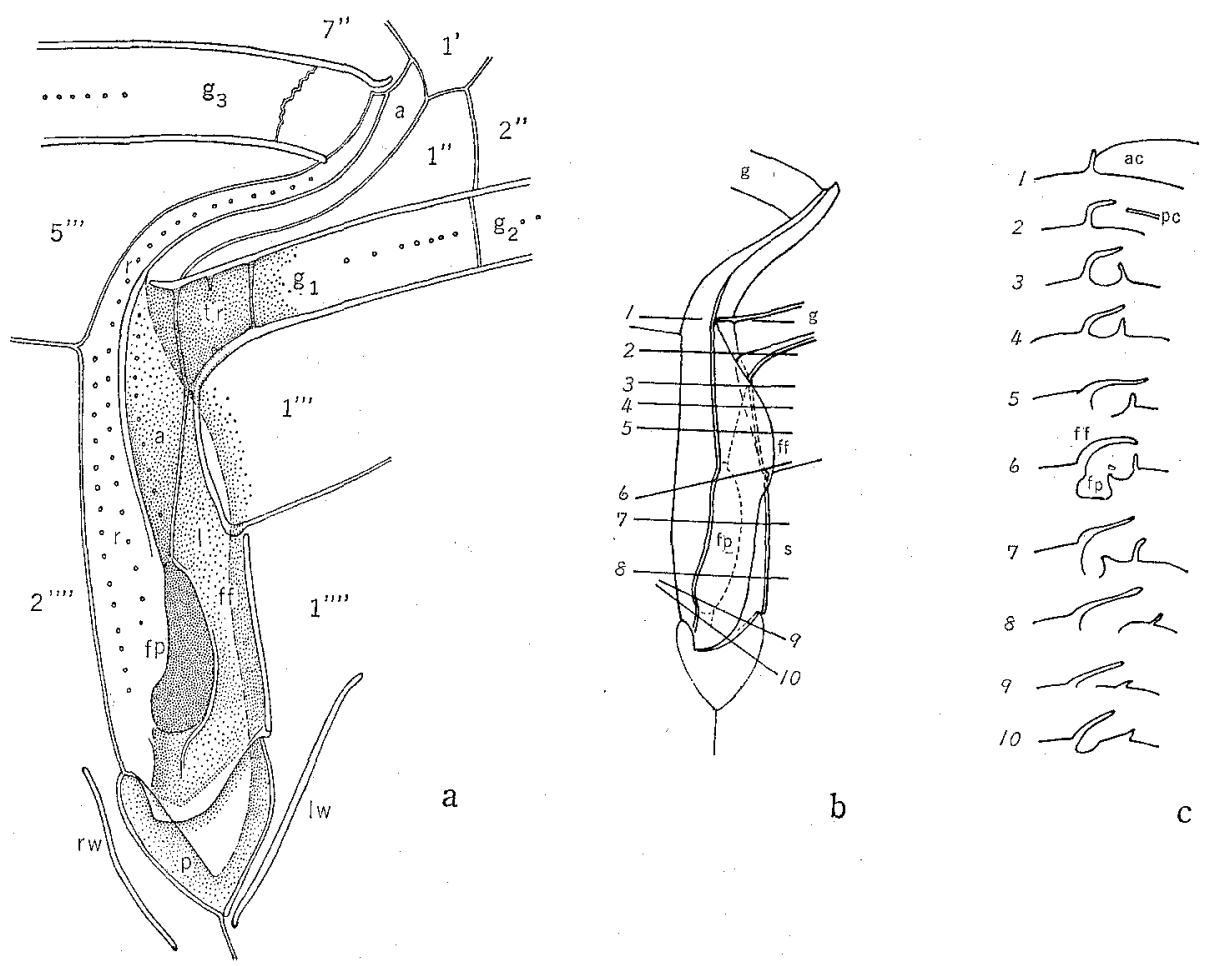

b

C

Fig. 13b: Ventral area of Peridinium sphaeroides DANGEARD. a-Surface view of ventral area. $b$-Ventral area, somewhat shematized. Transverse lines denoted in ' $b$ ' $(1 \sim 10)$ represent sites of optical sections of the ventral area. c-Optical sections of ventral area in the antapical view. Numbers denoted in figs. $b$ and $c$ correspond with each other. 1'-ventral apical plate. $1^{\prime \prime}, 2^{\prime \prime}, 7^{\prime \prime}$-precingular plates. $\mathrm{g}_{1}, \mathrm{~g}_{2}, \mathrm{~g}_{3}$ - cingular plates. $1^{\prime \prime \prime}, 5^{\prime \prime \prime}$-postcingular plates. $1^{\prime \prime \prime}, 2^{\prime \prime \prime}$-antapical plates. a, 1, $r$, $p$-sulcal plates. tr-transitional plate. fp-flagellar pore. ff-flagellar fin. Free margin of flagellar fin in ' $a$ ' is illustrated with a broken line. $\mathrm{rw}, \mathrm{w}$-right and left antapical wings. g-girdle. ac, pc-anterior and posterior cingular lists.

is correctly drawn in regard to these structures considered above, we have to regard STEIN's rather than PAULSEN's as the most reliable base for characterizing the species.

We found very sparsely a spherical form corresponding to STEIN's figure, which has, in addition to the structures considered above, a tall left ventral precingular $1^{\prime \prime}$ and straightly elongated ventral area, both of which are also illustrated in STEIN's figure. Connected with the straight elongation of the ventral area, the precingular $1^{\text {" has }}$ not its median elongation which is seen in all other species of the group. It must be noted here that we found another very closely related to one from Shimoda in a verical haul from $100-0$ meters.

From these, our present form seems to be regarded as most closely related to Stein's but not to Paulsen's nor others.

Measurements: Length, $72 \mu \mathrm{m}$. Transverse diameter, $72 \mu \mathrm{m}$. Breadth of girdle, $5 \mu \mathrm{m}$.

Locality: Asamushi, Shimoda. 


\section{Peridinium globifera n. non.}

Fig. 13a (72-77)

ABÉ, 1940, p. 29, Figs. 2, 3.

Peridinium globulus, in part, Broch, 1910, p. 182, Fig. $2_{1}$; in part, Lebour, 1925, p. 129, Fig. 40; DANGEARD, 1927, p. 12, Fig. 8.

The body is globular or a little shorter than broad and has no antapical spine. The equatorial girdle is deeply or considerably overhanged, and the vental area is then bent variously.

Either of the two ventral plates of the pre- or postcingular row is distinctly broader than long. Of the three intercalaries, all of which are also broader than long, the middle is left pentagonal. The dorsal apical is of considerable size and is more or less regularly pentagonal. Of the narrower anterior and broader posterior halves of the ventral area, the former is variously bent towards the left while the latter is weakly oblique and fairly constant in direction of extension. As a consequence, the two ventral precingular and the right ventral postcingular plates manifest concomitantly distinct variations in slenderness of their median regions while the left ventral postcingular plate is fairly constant in shape. Further, stronger obliquity of the anterior half is coupled with greater length of that part of the ventral area. A similar but much less variation is also seen in the broader posterior half of the ventral area, in which the flagellar pore lies somewhat diagonally with that part of the ventral area but parallel with the axis of the midbody.

Measurements: Length, 65-83 $\mu \mathrm{m}$. Transverse diameter, 67-80 $\mu \mathrm{m}$. Breadth of girdle, $5 \mu \mathrm{m}$.

Locality: Asamushi, Shimoda.

In addition to the ordinary specimens, we found a much smaller one $(45 \mu)$ in plankton collected from Asamushi, Aug., 23, 1927. It differs from the others only in size and in its more or less straight ventral area. The latter character is interesting in that a similarly less curved ventral area is rarely found not only in this but also in $P$. globulus and that the nearest relative of this can be seen in some other sectins of the Humilia group.

\section{Peridinium sphaeroides DANGEARD}

Fig. $13 b(a-c)$

Dangeard, 1927, p. 5, Fig. 3; 1932, p. 349, Fig. 11 a-d; AbÉ, 1940, p. 31, Figs. 8-13.

This species was rarely found in Asamushi but fairly abundantly in Shimoda. It can be distinguished from $P$. globulus mainly by its two antapical wings which are very hyaline and hard to be defined.

Measurements: Length, 65-87 $\mu \mathrm{m}$. Transvere diameter, 63-88 $\mu \mathrm{m}$. Depth, $60-86 \mu \mathrm{m}$. Breadth of girale, $5 \mu \mathrm{m}$.

Locality: Asamushimushi, Shimoda. 
Peculiarly BERGH saw seven plates in an isolated single hypotheca of his form (p. 276). This appears to indicate that in the region he investigated, there is at least another form furnished with five postcingulars and two antapicals, although it is somewhat doubtful whether or not the incomplete specimen is to be regarded as identical with those figured by him. It is also uncertain whether or not the incomplete specimen is to be assigned to Diplopsalopsis asymmetrica or to the rarer specimens of the present species. It may be mentioned in this connection that D. asymmetrica was found in Shimoda but not in Asamushi. At any rate, it is a well known fact that the present species is found commonly in the region investigated by BerGH. The species name minor is retained in this paper for this species because of the fact that it was exactly elucidated by PAULsen for the first time.

\section{Peridinium quarnerense (SCHRÖDER) BROCH}

Fig. $14(78-84)$

BROCH, 1910, p. 183, Fig. 311, III (non I).

Dangeard, 1927b, p. 14, Fig. 9; Schiller, 1929, p. 404, Fig. 18a-c; Paulsen, 1931, p. 60, Fig. 32b-d (not a); ABÉ, 1940, p. 30, Figs. 4-7.

P. globulus var. quarnernese SCHRÖDER, 1901, p. 18.

P. globulus var. STEIN, 1883, P1. 9, Fig. 8.

P. globulus SGнÜtт, 1895, Pl. 15, Fig. 48.

P. globulus, in part, Diwatd, 1939, p. 159, Fig. 13d-h.

So far as Shimoda materials revealed, the antapical spine often has narrow sidewings, and the middle intercalary plate is more often pentagonal than hexagonal, which was regularly the case with Asamushi materials. The postcingular row of plates is usually not much broader than the girdle, and the ventral one of the cingular plates is very small, lying just at the ventral end of the girdle. All of the general thecal plates are not covered with the meshes as usual but crowded with minute poroids or spots which, however, are so weakly formed and indistinct that we can established them when isolated thecal plates are examined with high magnification

Measurements: Length, 67-76 $\mu \mathrm{m}$. Transverse diameter, 68-75 $\mu \mathrm{m}$. Breadth of girdle, $5 \mu \mathrm{m}$.

Locality: Asamushi, Shimoda.

\section{Peridinium majus Dangeard}

Fig. 15 (85-94)

DANGEAkd, 1927 b; AbÉ, 1940, p. 35, Figs. 14-23.

Glendodinium lenticula Pouchet, 1883, p. 442, P1. 20-21, Fig. 35.

Peridinium globulus, in part, BROCH, 1910, p. 182, Fig. 211.

Lindemann, 1924, p. 224, Figs. 37-4; in part, Lebour, 1925, p. 129, Fig. 40 (larger form).

P. ovatum var. major DANGEARD, 1927 a, p. 6 , Fig. 4 a-d.

PAUlSEN (1931) distinguished a larger form of Broch's P. globulus and characterized it by its larger size, lenticular body, and its quadragonal middle intercalary 

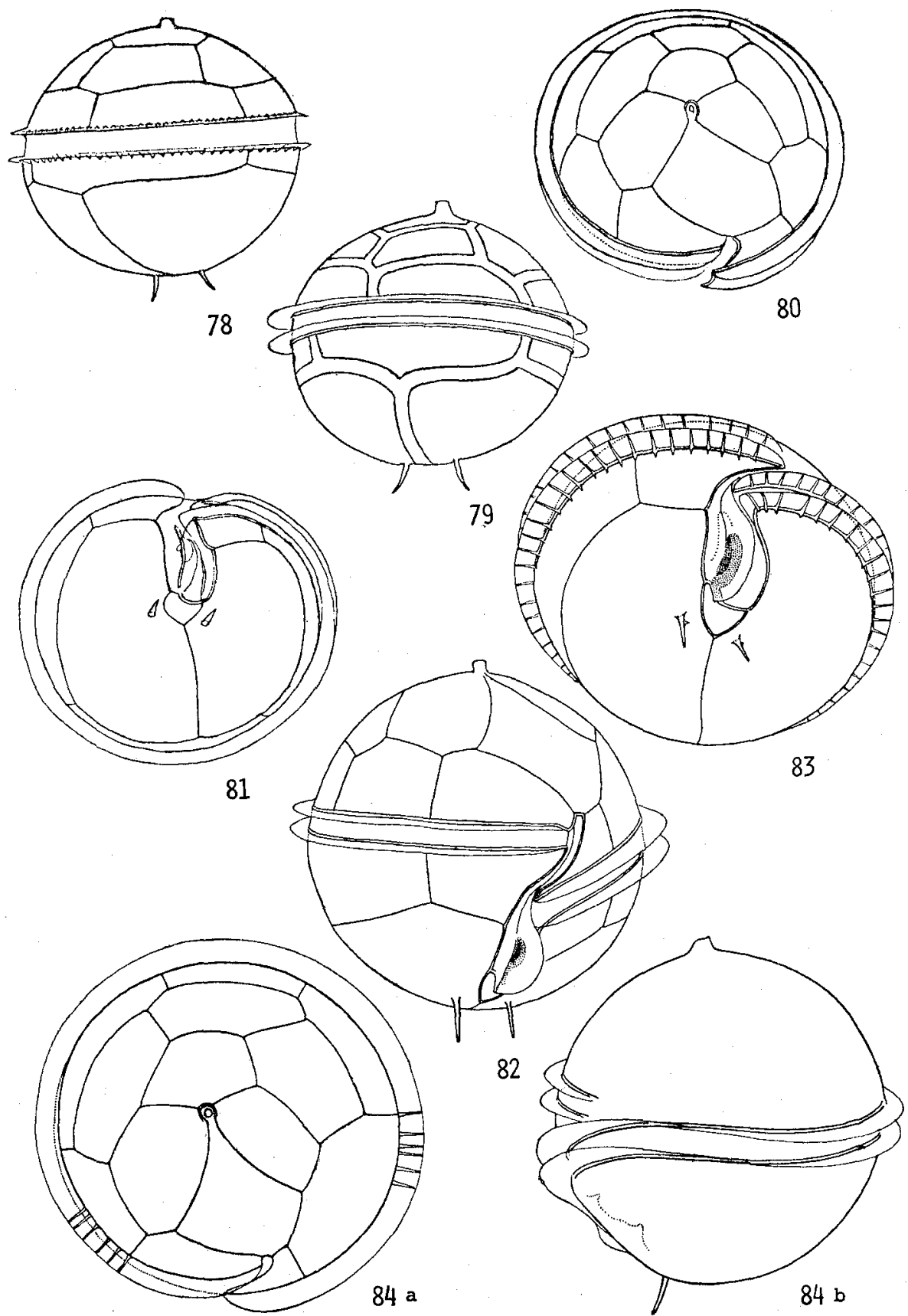

Fig. 14 (78-84): Peridinium quarnerense (SchröDER) BkoGH. 78, 79-Dorsal views of narrow and wide sutured specimens. 80-Apical view in specimen shown in 78. 81-Antapical view. 82-Ventral view of another specimen. 83-Oblique antapical view. 84a-Apical view. Ribs of cingular list are partially illustrated. $84 \mathrm{~b}$ - Side view. 


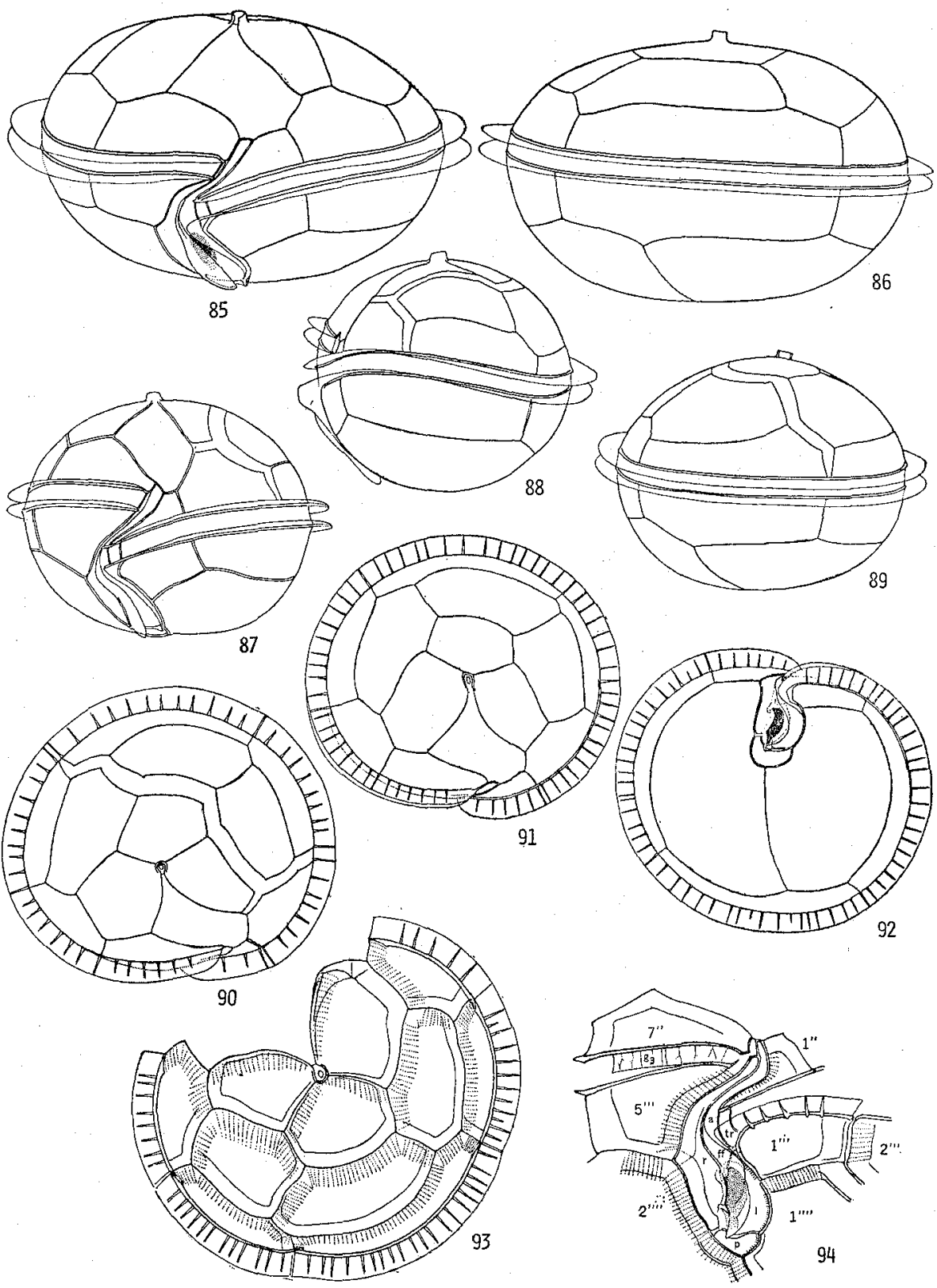

Fig. 15 (85-94): Peridinium majus DANGEARd. 85-Ventral view of larger form. 86-Dorsal view. 87-94: Smaller form, a peculiar sutural addition occurs. 87-Ventral view. 88-Side view. 89Dorsal view. 90-Apical view. 91-Apical view of larger form. 92-antapical view of the same. 93-Apical view of an isolated epitheca deprived of its three ventral plates. 94--Ventral area. 
plate. He separated further DangeARD's $P$. majus ( $P$. ovatum var. major) from it mainly by its less overhanging girdle and its pentagonal middle intercalary plate. In addition to the characters just cited, DANGEARD's species has elegantly ovoidal contour in side view while Broch's as well PAULSEN's species tapers more or less apparently towards the apical.

The elegantly rotated ellipsoidal and more or less angulate forms, each corresponding to the Paulsen's and Dangeard's, have been found respectively in Shimoda and Asamushi. The angulate form of Shimoda is intermediate between the smaller and larger ones of the Asamushi form regarding the diameter of the body, but it has a little greater length in comparison to its diameter because of the circular flare of the thecal wall along the girdle and also of stronger convexity at the two ends of the body. In other respects our Shimoda form agrees so well with either of the two Asamushi forms that these from the two regions can not be distinguished from each other by any of their major theal characters, and then they are not worthy of specific distinction. They are to be regarded, if necessary, as two varieties of the species.

The plate pattern of Asamushi form is illustrated partially in Fig. 15 $(91,92)$ which is drawn from an isolated and flattened epitheca deprived of its ventral three plates $\left(1^{\prime}, 1^{\prime \prime}\right.$ and $\left.7^{\prime \prime}\right)$. Interesting in this figure is the fact that the apical closing platelet is left detached from the ventral apical, and distribution of the striated sutural zone or plane of contact of the thecal plates is illustrated. Fig. 15(94) is the ventral area and its surroundings. Structural relations of the ventral area is typical of the group, and its anterior slender portion is subequal in length with the other broader portion. In this figure is illustrated the distribution of the striated zones around the ventral area, and we can see in this then in what manner the sulcal plates are connected with their surrounding ones and at the same time in what way the sulcal plates as a whole or the ventral area is least separated during growth of the body from the proximal end of the girdle. We have to note here the fact that the right sulcal plate is differentiated from the left and posterior sulcal plates by its surface reticulation. A part of the sutural zone between the right sulcal plate and the right antapical one, in which reticulation and porulation of the thecal plates are present, is shown. When focussing down the lens, we can see for the first time two structures of broad bands running parallel with each other and between them is a very narrow stripe along which lies a line of closely arranged pores. The broad bands represent the growth zones of the plates and the porulate stripe indicates outer margin of the plane of contact. Just beneath the growth zone of the antapical plate, we can see faintly darker transverse striations each corresponding in position to an intercalary pore. This striation, which appears to extend into the reticulated area of the plate, grows darker and outer boundary of the structureless zone becomes more and more indistinct as the focus comes down gradually. And finally the darker striations are connected each with an intercalary pore. The pore vanishes and the darker striation changes into a lighter band, and then the latter begins to fade away gradually from its median end.

Measurements: 


\begin{tabular}{l|c|c}
\hline \hline & Asamushi-form $(\mu \mathrm{m})$ & Shimoda-form $(\mu \mathrm{m})$ \\
\hline Length & $70(57-61)$ & $70-80$ \\
Transverse diameter & $105-110(75-80)$ & $83-97$ \\
Dorso-ventral diameter & $90-93(66-70)$ & $68-83$ \\
Breadth of girdle & & 5 \\
\hline
\end{tabular}

Locality: Asamushi, Shimoda.

\section{Group 2. Pyriformia JöRGESEN (emend.)}

ABÉ, 1936 (2), p. 34.

Section IV. Pyriformia, Jörgensen, 1912.

Section Pyriformia Lebour, 1925; Paulsen, 1931.

In its pentagonal middle intercalary plate coupled with two well-developed antapical wing-complexes, the left of which forms partly the left sulcal list, the present group is well established, and at the same time by these it can be distinguished from other two groups of the subgenus.

The body is globular or pear-shaped, tapering anteriorly to a shorter or longer apical horn. Its hypotheca is without a postero-median depression nor two antapical bulges. The equatorial or postequatorial girdle forms a circular or ascending spiral, and the straightly elongated, narrow ventral area does not show an abrupt lateral expansion in its hind end, on either side of which stands an antapical spine furnished with three side-wings. Either of the two sulcal lists merges posteriorly to the ventral one of the three. On the right, the sulcal list is interrupted at the postcingular-antapical suture, while the left of the sulcal list is much broader than the right and has no interruption. These two sulcal lists consist similarly of two anterior and posterior halves, springing from the ventral postcingular and an antapical plates respectively. The left antapical spine together with two of its three side-wings stands at the edge of the ventral area, while the right one is often separated shortly from the edge.

The ventral plate pattern of the epitheca is typically 'meta' but exceptionally 'ortho', and the middle intercalary plate is pentagonal. The postcingular row of plates is of considerable breadth. But its ventral components are interrupted from direct contact with the posterior sulcal plate. To the posterior one-third of the ventral area is displaced the flagellar pore, which bears a flagellar wing, extending often beyond the hind end of the body. The posterior sulcal plate is fairly small and not much differentiated bilaterally in shape. Lying in a larger left half of the ventral area, the sulcal furrow is often remarkably excavated and is wider posteriorly than anteriorly.

\section{Historical and discussion}

Jörgensen (1912) established the Pyriformia section for P. steinii, P. granii and 
$P$. calosum, and placed it under the subgenus Metaperidinium. He characterized the section with the ventral plate pattern of 'meta' coupled with the pentagonal middle intercalary plate and two winged antapical spines. According to Lebour (1925), five species of $P$. granii, $P$. mite, $P$. steinii, $P$. ovatum and $P$. pyriforme were comprised in JöRGENSEN's section. Recently definition of the section was partly emended by Paulsen (1931) as follows: "Meta penta, plus rarement quadra ou hexa. Dextrogyres, sans cornes antapicales, mais en général à deux épines antapicales." And following 17 species were included in it; Peridinium africanoides, $P$. finlandicum, $P$. granii, $P$. joubini, $P$. longicollum, $P$. majus, $P$. mite, $P$. ovatum, $P$. oviforme, $P$. pyriforme, $P$. quarnerense, $P$. steinii, $P$. subpyriforme, $P$. sylvanae, $P$. globulus, $P$. patens and $P$. dakariense.

Among the three species cited by Jörgensen, $P$. colosum is the least established one, and $P$. mite differs profoundly in the structure of the ventral area from $P$. steinii and is allocated in this paper to Humilia. The other species, P. steinii, was afterward studied elaborately by KoForD (1908) and is now generally accepted as the type species of Pyriformia. In regard to Lebour's grouping, P. ovatum is more closely related to $P$. globulus and is confirmed in this paper to belong also to Humilia. The structural relations of the ventral area and the hypothecal extensions in $P$. pyriforme were confirmed by ABÉ (1936) to correspond exactly in all respects with those of $P$. steinii described by Koford. Consequently, it may be allowed to conclude that in Pyriformia are to be comprised these species closely allied to $P$. steinii or to $P$. pyriforme. In Paulsen's 17 species, $P$. finlandicum, $P$. globulus, $P$. granii ( $=P$. mite), $P$. quarnerense are the ones to be allocated to Humilia, judging from the structural relations of their ventral area. And $P$. patens and $P$. dakariensis are not well established yet and can not be allocated then to any group or section. And the other seven or eight species are the closest relatives of $P$. steinii judging from published figures.

Taking into considerations the differences in structural relations of the sulcal lists and antapical spines, the present group can be distinguished at once in side view of the body from the Humilia group by a triangular extension of the sulcal list along the shaft of the spine. From the Pellucida group, this can be separated by the direct connection of its sulcal list with the spine. In that group, the hind end of the left sulcal list is seen in ventral view of the body on the median side of the left antapical spine, and then was generally misinterpreted as a distinct spine. While in the present group, the left antapical spine is single in all respects. In side view of the body, the left antapical spine together with its side-wings is seen in Pellucida abruptly differentiated from the free margin of the left sulcal list. By these characteristic structural differences, the present group can be distinguished from the other groups even if their plate patterns were not brought forth. Taking these into considerations, we re-examined published figures available at hand and got the following species as ones of the pyriformia group: $P$. longicollum Paulsen, $P$. oviforme $P$. africanum Dangeard, $P$. pyriforme Paulsen, $P$. rectiforme Schiller, $P$. rectum Kofoid, $P$. steinii Jörgensen, $P$. subpyriforme Dangeard, $P$. sylvanae Dangeard and $P$. truncus ABÉ. $P$. africanoides and $P$. joubini are uncertain as to their allocation to Pyriformia. In addition to these, $P$. angusticollis, $P$. microangusticollis and $P$. yonedai are given in 
this paper.

DANGEARD's $P$. subpyriforme can not be regarded as typical species of Pyriformia because of lack of the lateral side-wing of its left antapical spine and also of its wingless right antapical spine. Just the same may be said with $P$. truncus AbÉ. One has to recollect in this regard Peters' Fig. $9 \mathrm{f}$ or $\mathrm{g}$ of $P$. variegatum, in which the sulcal list ends posteriorly in a rib-like spine. These species may be considesed to form a link between Humilia and Pyriformia. P. solitarium ABÉ, which was allocated in a previous paper (1936) to Pyriformia is transferred in this paper to Laterispinosa of Humilia.

\section{Key to species}

1. The apical horn is more or less abruptly differentiated from the midbody

1'. The midbody is globoid

A. The apical horn and antapical spine are of exceedingly small length, exceedingly large in width of the girdle
a. The midbody is small (about $24 \mu \mathrm{m}$ in length)
Peridinium truncatum
b. The midbody is a little larger ( $40-50 \mu \mathrm{m}$ in length)
P. subpyriforme

B. The two structures are of much greater length

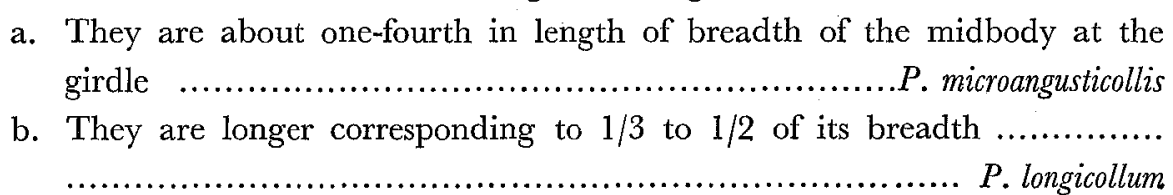

2' The midbody is cupuliform or rotated ellipsoidal

A. The apical horn is about one-third in length of midboy's breadth..P. angusticollis

B. The apical horn is much shorter

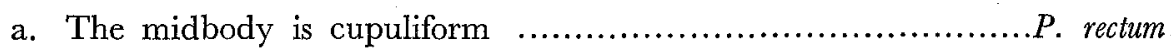

b. The midbody is rotated ellipsoidal .......................... rectiforme

2. The apical horn merges posteriorly into the epitheca

$1^{\prime}$. The midbody is short pyriform

a. The short apical horn is scarcely differentiated .............. pyriforme

b. The apical horn is elongated but merges into the epitheca through its proximal, concave conical flare ................................ steinii

2 '. The midbody is much longer than broad and a short apical horn is more or less abruptly differentiated from its convex conical epitheca.....P. oviforme

$3^{\prime}$. The midbody is in ventral view somewhat pentagonal with a short, flattened and oblique hindmargin between the two antapical spines........ . yonedai

\section{Peridinium pyriforme PAULSEN}

Paulsen, 1908, p. 46, Ftg. 57; 1911 , Fig. 8; Peters 1928, Fig. 24;

ABE, 1936, p. 44, Figs. 43-50. 


\section{Peridinium rectum KOFOID}

Fig. $16(100-102)$

KoFord, 1907, p. 311, Pl. 32, Fig. 48 (not 49).

P. oviforme Schiller, 1929, p. 403, Fig. 17 a, b.

KofoId (1907) described $P$. rectum giving its two figures, one with an abruptly differentiated and the other with a less tapered apical horn. The former corresponds in shape of the body with the present form but is a little smaller in size, while the latter has a more strongly swollen hypotheca than this. Further, a structure to be interpreted as the hind end of the left sulcal list, is illustrated in his latter figure (49) while it is absent in the former. From these, it may be granted to suggest that Paulsen's two figures may represent two different species, one belonging to Pyriformia and the other presumably to Pellucida. SaHiller's (1929) P. oviforme closely resembles the former figure of Paulsen's in body shape but is a little smaller. This is a typical species of Pyriformia in the structural relations of its hypothecal extensions so far as illustrated in his Fig. $17 \mathrm{~b}$.

The midbody is elongated ovoidal. The epitheca slightly exceeds the hemispherical hypotheca in length and is strikingly convex conical, tapering anteriorly to a short and slender apical horn. The girdle lies horizontally for the most part around the broadest part of the body, but its proximal one-fourth is weakly oblique, by means of which it forms an ascending spiral, displaced distally by its own width. The cingular section is broadly ovoidal with a slight ventral flattening. The ventral area is slightly broader posteriorly than anteriorly, extending anteriorly beyond the girdle and posteriorly to the center of hypotheca where it forms a triangular end.

The right sulcal list is narrow in its anterior half but forms in the other half a large triangular expansion, the ventral side-wing of the right antapical spine. The left sulcal list is much broader, forming posteriorly a distinct triangular extension along which lies the spine. The left antapical spine extends obliquely ventrally while the other straight posteriorly.

In ventral or lateral view of the body, one can see the flagellar wing extending posteriorly beyond the hind end of the body.

As to the plate pattern, Kororn described or figured nothing, but in ours, the ventral plate pattern of the epitheca is 'meta', and the left ventral precingular plate is much smaller than the right ventral of the same series. Among the three subequal intercalary plates, the middle is left pentagonal, and the lateral and dorsal apicals are of considerable size. The postcingular row of plates covers an anterior one half of the hypotheca. Among its components, the left ventral is distinctly slender, agreeing in lateral expansion with the precingular lying just above it.

Measurements: Length, $70 \mu \mathrm{m}$. Transverse diameter, $50 \mu \mathrm{m}$. Depth, $47 \mu \mathrm{m}$. Length of antapical spine, $15-20 \mu \mathrm{m}$.

Locality: Shimoda. 


\section{Peridinium subpyriforme DANGEARD}

Dangeard, 1927, p. 358, Fig. 21d, e; Abé, 1936, p. 40, Figs. 30-37.

\section{Peridinium truncus АвÉ}

ABÉ, 1936, p. 42, Figs. 38-42.

\section{Peridinium angusticollis $\mathrm{n}$. $\mathrm{sp}$.}

Fig. $16(95-99)$

The present species is characterized by its ovoidal midbody from which is abruptly differentiated an attenuating long apical horn, a post-equatorial girdle and two well winged antapical spines, subequal in length with the apical horn.

The apical horn is about $0.31-0.34$ in length of the midbody. Along the broadest part of the short, egg-shaped body lies the postequatorial girdle which runs horizontally for the most part, forming an ascending spiral by means of its proximal arch. The cingular plane lies horizontally for the most portion and is circular without a ventral flattening. The hemispherical hypotheca bears along its ventromedian the ventral area which becomes slightly wider posteriorly, extending almost to the center of hypotheca. The broad left sulcal list extends obliquely towards the right in its anterior half but straight ventrally in the other half, where it becomes abruptly broader, forming the ventral side-wing of the left antapical spine which stainds at the sinistro-dorsal corner of the ventral area. The right sulcal list is indistinct, being restricted only along the ventral edge of the right ventral postcingular plate. The lateral side-wing of the spine is distinctly narrow while the dorsomedian one is a little larger, extending to the ventral end of the intra-antapical suture. The right antapical spine stands at a short distance from the dextro-dorsal corner of the ventral area. Its three side-wings are subequal in size, extending in three directions. Between these two antapical wing-complexes, we can see in ventral view of the body the flagellar wing extending posteriorly beyond the hind end of the body. We can also establish this in lateral view of the body. The flagellar pore lies in the posterior half of the ventral area.

The ventral plate pattern of 'meta' is brought forth by means of the irregularly pentagonal ventral apical plate which extends with its narrow anterior neck to the ventral slit of the apical pore which lies along an anterior half of the apical horn. The tetragonal, left ventral precingular plate is strikingly smaller than the right ventral, which, together with the other two precingulars, $2^{\prime \prime}$ and $6^{\prime \prime}$, covers more than a posterior half of that part of the epitheca. The other three lateral and dorsal apical plates are much smaller in length and the left oblique pentagonal middle intercalary is smaller than the two others of the series. The postcingular row of plates covers a little less than an anterior half of the hypotheca. Its left ventral com. ponent is subequal in shape with the right ventral but is a little smaller. 


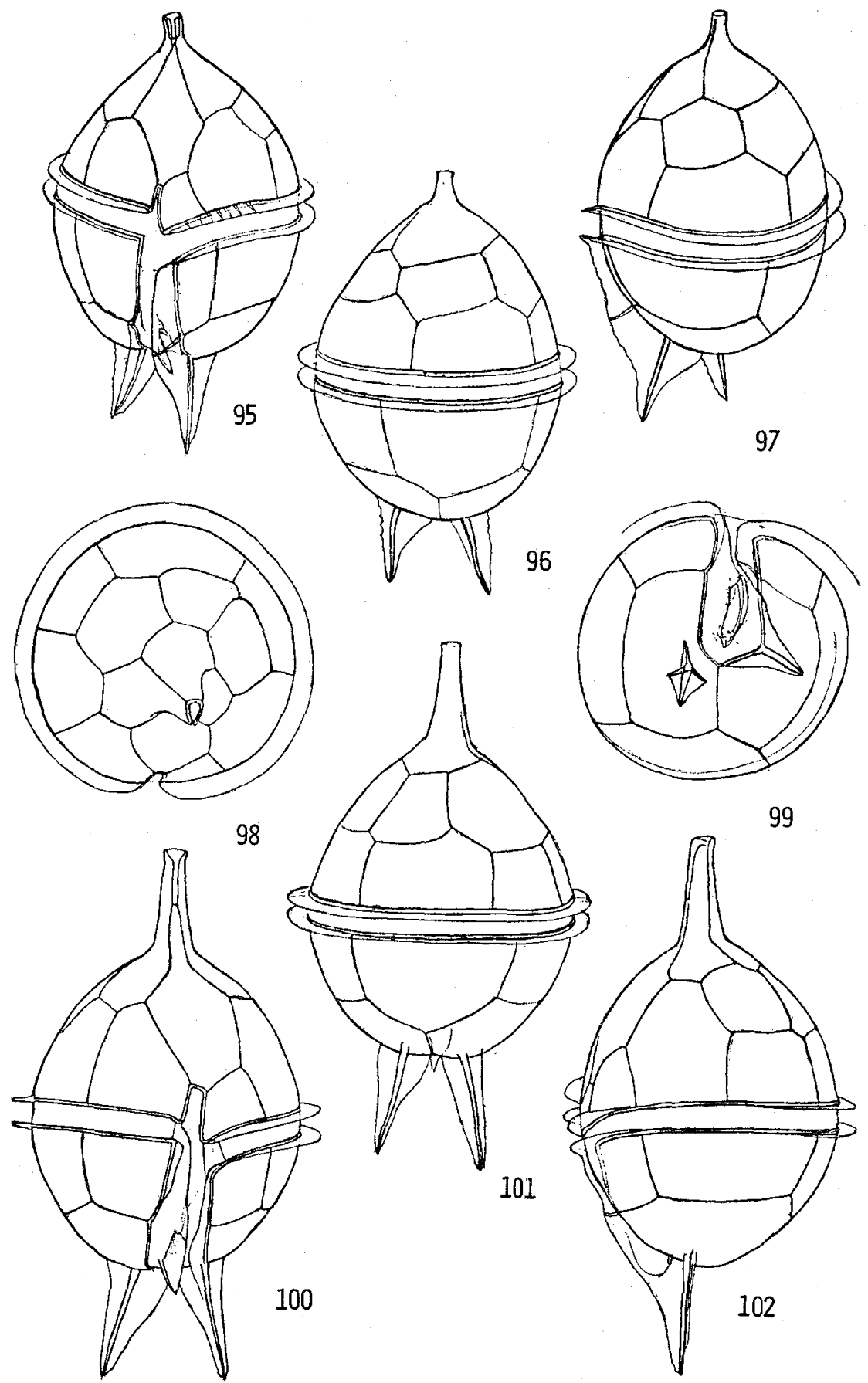

Fig. 16 (95-99): P. angusticollis n. sp. 95-Ventral view. 96-Dorsal view. 97-Side view. 98-Epithecal plate pattern. 99-Hypothecal plate pattern. (100-102): Peridinium rectum $i$ Koford. 100-Ventral view. 101-Dorsal view. 102-Side view. 
The thecal wall is minutely porulated.

Measurements: Length exclusive of spine, $85 \mu \mathrm{m}$. Transverse diameter, 55 $\mu \mathrm{m}$. Depth, $52 \mu \mathrm{m}$. Length of antapical spine, $20-24 \mu \mathrm{m}$.

Locality: Shimoda.

Only a single specimen of this was found in one of summer planktons in Shimoda. The closest relative of this, worthy to be considered, is $P$. microangusticollis $\mathrm{n}$. sp., from which this differs in its larger size, elongated body and its diverging antapical spines. From $P$. longicollum; the present one can be distinguished at once by its larger midbody and shorter apical and antapical spines and from $P$. truncus by its longer apical horn and antapical wing-complex.

\section{Peridinium yonedai n. sp.}

Fig. 17. (103-109)

P. steinii, in part, MaruKawa, 1923, p. 23, Fig. 56 e-h.

This is one of the largest species in the group. Its body is irregularly rhomboidal in side view, bulging more dorsally than ventrally and with a slight mid-ventral depression. The epitheca is weakly convex conical, tapering distally to a short spical horn. The girdle is rather pre-equatorial, lying horizontally for the most part around the broadest part of the body, and forms by means of its proximal arch a weakly ascending spiral with distal displacement of its own width. The cingular section of the body is almost circular, showing a small and weak ventral depression. In this place it is to be noted that in this species diameter of the body at the anterior cingular edge is a little smaller than that at the posterior cingular edge. The hypotheca is inversely valuted, but is in ventral view obliquely truncated at its distal end between the two antapical spines. These spines or wing-complexes are seen in ventral view fairly parallel with each other. But in reality, the left of them is displaced much ventrally and also inclines remarkably ventrally than the other. The shaft of the spine is either straight or weakly undulate, and the three side-wings have serrated free margin.

The epitheca is divided into subequal plates, and its plate pattern is typical of the pyriformia group. The postcingular row of plates covers anterior two-fifths or a little more of the hypotheca. Among the five plates of the row, the ventral two are much smaller than the others and subequal in size and shape with each other.

The ventral area is narrow, ending posteriorly in front of the center of hypotheca. It is broadest in its middle where it expands slightly towards the right, and tapers more strongly anteriorly than posteriorly. Its hind end is somewhat pointed instead of angulated, and with its narrow anterior end it extends markedly beyond the girdle. The flagellar pore lies in rear of the broadest middle of the ventral area, and the conspicuous flagellar wing extends ventrally nearly as far as the left sulcal list. The right sulcal list is represented by its anterior half lying along the median edge of the right ventral postcingular plate. Completely separated from this and 
distinctly displaced laterally from the hind end of the ventral area, there stands the right antapical spine furnished with three subequal side-wings, none of which is directly connected with the ventral area. The left sulcal list is, on the contrary, much strongly bulit, and merges posteriorly without interruption into the ventral sidewing of the left antapical spine.

The right sulcal plate is remarkably narrow in its hind end. This is directly

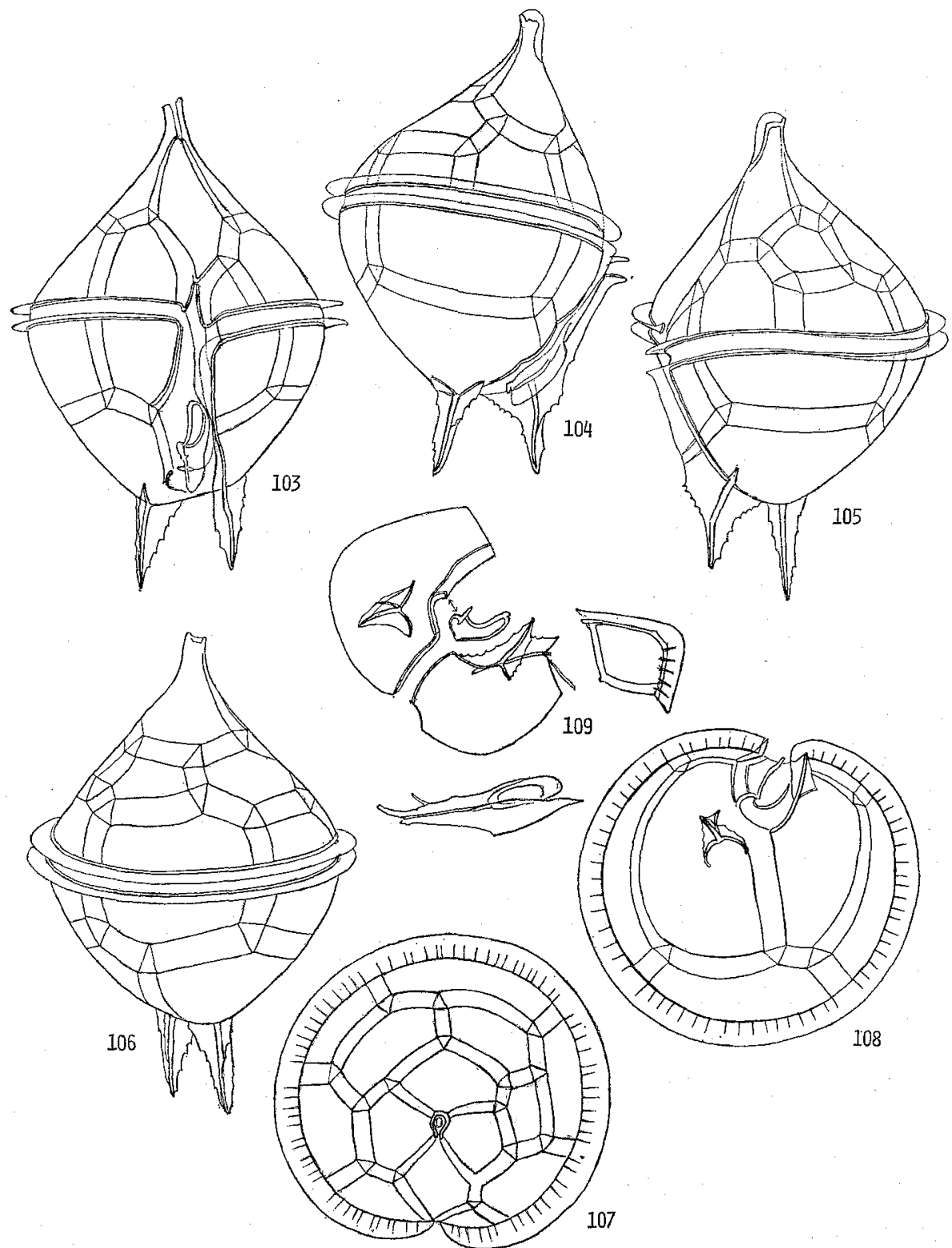

Fig. 17 (103-109): P. yonedai n. sp. 103-Ventral view. 104, 105-Side views. 106-Dextro-dorsal view. 107-Apical view. 108-Antapical view. 109-Dissociated plates the in ventral area. 
associated with the smaller breadth of the hind end of the ventral area. The posterior sulcal plate extends, then, towards the right hardly beyond the flagellar pore (Fig. 17-109).

The thecal plate is covered with small polygonal meshes. Even with closer examination of the isolated left ventral postcingular plate, no trace of the ventral pore could be confirmed.

Measurements: Length of midbody, 100-107 $\mu \mathrm{m}$. Transverse diameter, 74$78 \mu \mathrm{m}$. Depth, $70 \mu \mathrm{m}$. Length of antapical spine, $22-25 \mu \mathrm{m}$

Locality: Shimoda.

The present species may be the largest one in Pyriformia, and corresponds exactly to a part of Marukawa's $P$. steinii, of which four figures (56 e-h) drawn by YonedA are accurate so far as the characters considered above are concerned. So far as the studies go, no other described species is known comparable to the present one in regard to greater size and pentagonal shape in ventral view of its body.

\section{Group 3. Pellucida JöRgensen (emend.)}

Section Pellucida Jörgensen, 1912; Peters, 1928; Padlsen, 1931; Schillek, 1935; Diwald, 1939. Group Pellucida AвÉ, 1943.

Regarding the structural differentiations not only of the antapical wing-complex but also of the ventral area, the present group is the highest type in the subgenus Protoperidinium. On the other hand, this forms a connecting link between Protoperidinium and Mesoperidinium by means of the L-shaped posterior sulcal plate, clearly established in some higher forms of this.

The body is globular, rotated ellipsoidal, cake-shaped or irregularly biconical with or without a postero-median indentation. Anteriorly, it tapers abruptly or gradually to a shorter or elongated apical horn. The girdle is circular or ascending. The postero-median part of the body is indented more or less distinctly in angulated species in which the sulcal furrow agrees in extent with the ventral area, while the portion is rounded generally in rounded species in which the sulcal furrow is restricted generally within a left half of the ventral area, ending posteriorly in front of the center of hypotheca. The left sulcal list is distinct extending posteriorly from the left antapical spine with which it is however transversely connected by a minute sail. Two shorter or longer antapical spines stand each at the dorsolateral corner of the yentral area, and are provided in most cases with three sidewings respectively but are exceptionally wingless. The ventral and median sidewings of the right antapical spine stand along the edges of the right antapical plate, bordering directly on the ventral area. A small median one of the left antapical spine connects the spine with the left sulcal list. Consequently, there come to stand side by side the hind end of the list and the spine, which very often have been misinterpreted in ventral view as two distinct spines or a forked one. This is to be recollected when we examine inexactly drawn published figures.

The ventral plate pattern of epitheca is generally 'para' but often 'meta'. The 
middle intercalary plate is in most cases hexagonal but rarely pentagonal. The postcingular row of plates is fairly great in length, and in two ventral components of which, the left bears in its antero-median or anterior middle portion a small pore, the ventral pore, furnished with or without a flange, are subequal in length extending to half-way between the girdle and antapex.

The ventral area is in its structural relations typical of the subgenus, widening more posteriorly than anteriorly and guarded with side-lists and two spines. But in some or more probably in all of higher forms, the posterior sulcal plate has on its left a narrow extension with which it extends anteriorly around the left sulcal list to the left ventral postcingular plate, passing across the base of the small medium list of the left antapical spine, connecting it with the left sulcal list.

\section{Historical and discussion}

Jörgensen (1912) established the section Paraperidinium, allocating it to the subgenus Metaperidinium, and included in it four species of $P$. pallidum, $P$. pellucidum, $P$. islandicum and $P$. tristylum. The section was characterized by the ventral plate pattern of 'para' coupled with a hexagonal middle intercalary plate, an ascending girdle and two, winged antapical spines, of which the left has an accessory ventral spine. Conforming to him, Lebour (1925) proposed to add to the section two other species of $P$. curvipes and $P$. diabolus and further $P$. macrospinium and $P$. balticum as incertae sedis. Peters (1928), raising the Paraperidinium to a subgeneric rank, divided it into two sections of Areolata and Pellucida, the latter corresponding exactly to Jörgensen's section. And eleven species of $P$. diabolus, $P$. ellipsoideum, $P$. heteracanthum, $P$. islandicum, $P$. nipponicum, $P$. okamurai, $P$. pallidum, $P$. pellucidum, $P$. solidicorne, $P$. sphaeroidea and $P$. spinuosum were included in his Pellucida. Paulsen (1931), reviewing the principles of subdivision that generally prevailed, characterized the section as follows: "Para hexa, rarement Para penta ou quad'ra ou Meta hexa. Dextrogyres sans cornes antapicales, à trois épines antapicales." And following species were included: $P$. curvipes Ostenfeld, $P$. diabolus Cleve, $P$. islandicum PaulSen, $P$. nipponicum ABÉ, $P$. pallidum Ostenfeld, $P$. pellucidum Bergh, $P$. schilleri PaulSen, $P$. tenuissimum KoFoID, $P$. tristylum SteIn, $P$. variegatum Peters and $P$. hirobis AвÉ, and five species of $P$. ellipsoideum Dangeard, $P$. heteracanthum Dangeard, $P$. okamurai ABÉ, $P$. ovum Schiller and $P$. rectum Korord were regarded as doubtful species of the section.

From these, it is highly probable that Jörgensen's principle of subdivision is clear and simple and his section Paraperidinium is well established so far as it is represented by the four species, but afterwards some confusions and inconsistencies were introduced by some of later investigators who undoubtedly intended to cover other known species as far as possible.

Paulsen (1931) distinguished in his Pellucida section two types (Para and Meta) of the ventral and three (hexagonal, pentagonal and tetragonal) of the dorsal plate patterns. He, conforming to Jörgensen, still laid taxonomic stress upon different 
combinations of these ventral and dorsal plate patterns, bringing forth confusions contrary to expectation.

This was noted for the first time by JörgeNsEN on the four species as follows: "Gewöhnlich solid \pm geflügelte Antapikal-Stacheln von welchen der linke einen ähnlichen ventralen Nebenstachel besitzt."

According to the latter author, the groups Humilia, Pyriformia, Paradivergentia and Pellucida are characterized commonly by the winged antapical spines. The structural relations of the wing-complex of them become, according to our observations, more and more complex in the order here described. Among many species to be allocated to them, $P$. steinii is the one whose thecal morphology was studied most elaborately (KoFoIn), 1909), and in this and also in its allied species the antapical spines are two in number. On the other hand, the species allocated to Pellucida were described often to have, in addition to a single right one, a double antapical spine at the hind end of the left sulcal list. So far as the analysis is concerned, the median member of the double spine is nothing but a posterior end of the left sulcal list misinterpreted in its marginal or ventral view. This means that the left antapical spine in this group is distinct from the left sulcal list, and that both are arranged bilaterally but not antero-posteriorly. Closer observations show that this spine is connected in typical cases with the left sulcal list by a transversely arranged, minute triangular list, and further that all the species examined have in their left ventral postcingular plate, a minute pore with or without an oval flange around its opening, while the occurrence of this latter structure could not be confirmed from any of other groups except some of Paradivergentia to which the present group is closely related.

Studies on these structures lead us to suggest that it is preferable as well as reasonable to characterize the group with the structures just considered rather than with the plate pattern and other structures generally accepted. Before going further we have here to examine minutely some other thecal characters.

\section{Ventral area}

The ventral area of this group (Fig. 9-51,55) is longitudinal and comparatively the two coming gradually broader posteriorly and abruptly tapered in the rear of narrow, antapical spines which stand at the antapex where the ventral area is broadest in most cases. It is generally weakly or fairly deeply excavated as a whole, and in any case, the flagellar furrow is restricted in its left half dying out anteriorly into the proximal end of the girdle, but disappears posteriorly abruptly in front of the hind end of the ventral area. Along the dextro-dorsal side of its posterior half opens the sausage-shaped flagellar pore (fp.) which lies between the posterior halves of the right and left sulcal plates and is sheltered partly behind the flagellar wing (fw.) which corresponds in length with the flagellar pore.

The anterior sulcal plate (a.) is a small and slender one extending between the flagellar pore and epitheca, and indents the latter deeply or slightly with its an- 
terior jut. On the right of this and of the flagellar pore is the right sulcal plate ( $r$ ), the largest among the quartets. It tapers anteriorly, extending to the epitheca across the distal end of the girdle. Posteriorly it becomes broader, especially distinctly in most cases at the hind end of the right ventral postcingular plate, $5{ }^{\prime \prime \prime}$. The plate bears the flagellar wing along a posterior half of its median margin, but in reality it expands further beyond the base of the wing, and turns dorsally forming a part of the tubular structure of the flagellar pore. The left sulcal plate (1) forms by far the major part of the wall of the flagellar furrow, either ending posteriorly similarly with the right sulcal plate or extending slightly beyond it. In well-developed forms, this plate has along its hind margin a narrow lip-like extension projecting over the posterior sulcal plate. Lying along the left of the flagellar pore, it tapers anteriorly extending to the transitional plate (tr.) which is very small and narrow, lying across the proximal end of the girdle, where it expands medianwards for a short distance. The posterior sulcal plate (p.) is various in shape, lying transversely along the hind end of the ventral area, and extends generally between the two antapical spines. In smaller or lower forms, it is transversely elongated rectangular and of subequal length or has a broad but very shallow dent in its anterior left, brought forth by posterior extension of the left sulcal plate. This lateral difference in length of the plate becomes more pronounced in higher and larger forms whose antapical wing-complex is more complicated than in the lower ones. In an extreme case, the dent and the lateral difference are so conspicuous that the plate is irregularly triangular with its more or less abruptly differentiated, narrower left half. On many of larger forms, we have been informed of the fact that there is in well grown specimens a narrow stripe of thecal wall lying closely along lateral base of the left sulcal plate and extending between the left ventral postcingular plate and left antapical spine. From its situation and its relations with its surrounding, we have been led to regard it as a structure corresponding to the elongated left lobe of the posterior sulcal plate generally seen in Paradivergentia of Mesoperidinium. But repeated contrivances and efforts to separate sulcal plates from their surroundings revealed the fact that the stripe is continuous not to the posterior sulcal plate but to the posterior broader half of the left sulcal list springing peculiarly from the left sulcal plate. Belonging of the left sulcal list to the left sulcal plate may be suggested also from the fact that the list can be traced posteriorly along the suture between the left and posterior sulcal plates. These structural relations given above have never received due considerations by any of former investigators but are of taxonomic importance in suggesting some close natural affinities between Pellucida and Paradivergentia. Each of the two right (r.s.l.) and left (1.s.l.) sulcal lists, consists of two components. The narrower right is erected, standing basally in its anterior half along the median margin of the right ventral postcingular $5 "$ and in its other half along the anteromedian of the right antapical plate $2^{\prime \prime \prime \prime}$. It has ribs irregularly distributed generally along its anterior major portion, and is interrupted mostly at the postcingular-antapical suture, merging posteriorly into the ventral wing of the right antapical spine. The left sulcal list extends obliquely towards the right es- 
pecially distinctly in its anterior half where it is ribbed often along its base. Generally it has a distinct rib extending across its entire breadth at the postcingular-antapical suture, from where it can be disjoined into two halves. In less advanced species, this list is comparatively indistinct and its antero-posterior differentiation is least distinct. But in more advanced ones, its posterior half is much broader than the other, extending more or less ventrally, and covers generally a larger proportion and further in a few highly organized species even the left majority of the ventral area. The anterior half of this list is nothing but a median and posterior continuation. of the posterior cingular list, springing similarly from the anterior and median margins of the left ventral postcingular plate. Consequently, that part of the sulcal list has breadth subequal with the cingular list, and this naturally elucidates development of the ribs in it. The other broader portion of the list belongs generally to the left sulcal plate but not to the antapical one as is likely considered so. It terminates posteriorly in less advanced forms at the sinistro-ventral end of the left sulcal plate, but extending in higher forms further towards the median direction for a short distance along its hind margin. This part of the list has generally several or more numerous minute serrae along its broadly rounded free margin.

\section{Antapical wing-complex}

The antapical spine is generally furnished with but often without side-wings. The right antapical spine stands in typical at the right dorsal corner of the posterior sulcal plate springing from the right antapical plate. In well grown specimen, however, the spine is separated more or less distinctly from the sulcal plate by the breadth of the sutural zone. Of its three triangular side-wings radiating in three directions from a shaft (r. sp.), the lateral one (lw.) is the smallest, standing basally on the right antapical plate, but the others are larger, standing along the ventromedian margins of the plate, the ventral wing (vw.) is decurrent anteriorly, merging into the right sulcal list, and terminates at the postcingular-antapical suture, while the median one (mw.) extends towards the left, ending at various distances from the spine and often at the inter-antapical suture. These ventral and median side-wings lie, then, along the very margins of the ventral area when the organism has no distinct sutural zone. Peculiar is the fact found on major specimens of $P$. pallidum, that the spine stands at the tip of a small conical bulge of the thecal wall, separated at a short distance from the posterior sulcal plate (Fig. 9-51). The ventral and median wings in this case stand, then, in their proximal portions obliquely across a median half of the conical bulge and form between them a small triangular area which opens into the ventral area. This makes one liable to fall into an wrong interpretation that the ventral area expands in this species peculiarly towards the right to the tip of the bulge. A corresponding structure is seen invariably but more elucidatively in $P$. solidicorne of the group Paradivergentia. This together with the common occurrence of the ventral pore and the asymmetrical elongation of the posterior sulcal plate, apparently suggests a close relationships between the two groups, 
Pellucida and Paradivergentia.

The left antapical spine (1.sp.) springs from the left antapical plate, standing on its antero-median edge. It lies typically at the left ventral end of the posterior sulcal plate but often is displaced further ventrally (Fig. 9-51, 53f). Of the three side-wings of this, the median one (mw.) is exceedingly small and transverse, connecting the spine with the left sulcal list. Closer examinations brought to light the fact that this consists generally of two portions, a minute median one belonging to the sulcal list and the remaining majority springing from the spine. We can see a longitudinal suture in the wing running parallel with the spine and displaced much towards its median end. When the left sulcal plate was detached from the left antapical plate together with the other two side-wings of the spine, the major part of this remains attached to the latter plate, while the posterior half of the left sulcal list is found furnished with a minute triangular extension on its outer lateral surface just at the place where the median side-wings were seen. The other two side-wings (vw., lw.) extend each in ventral and in lateral (or dorso-lateral) directions.

Further in well grown specimens of larger and highly advanced species, there is a fourth list or wing in either of the two wing-complexes. In the right, there is a minute triangular list which is convex ventrally, lying at the lateral base of the spine, and stands basally on the right antapical plate. The other is a very low but much elongated one, lying along lateral margin of the slender left lobe of the posterior sulcal plate, and stands outside of the left sulcal list. Springing from the left antapical plate, this list extends between the spine and ventral end of the interantapical suture.

\section{Thecal plate and sutural zone}

SahüTt (1895), KofoId (1909) and BRoch (1910) described some about the striated zone of the peridinian body. Among them, the second author is the foremost in detailed study of the structure. Further Peters (1928) gave a detailed account of finer structure and distribution of the zone in $P$. depressum. KoFord and Peters differ in the interpretation of the striation in the zone. The former regarded it as due to differences in texture of the thecal wall but the latter described it as elevated ridges lying along the sutural face of a plate, and regarded it to serve to combine two adjacent plates. Contrary to these, ABÉ (1941) found a parallel arrangement (or nearly so) of fine tubules along the sutural cleft both in Diplopsalinae and in Podolampinae, and established it to correspond with KoforD's lighter band.

Development of this striated zone is sometimes so conspicuous that it is hardly possible to establish in surface view the exact contour of a thecal plate or the actual sutural line lying within the striated zone. In purpose of getting rid of this uncertainty or misinterpretation liable to occur, we have contrived as far as possible to study the structure on every available materials of this group.

In a well grown specimen of $P$. schilleri f. complexum we have established the inter- 
relations among reticulation, marginal growth zone, sutural striation, sutural cleft and distribution of pores of thecal plates especially on the two precingular $1^{\prime \prime}$ and $2^{\prime \prime}$. Either of the two plates is bordered with broad striated zones and covered centrally with fine meshes. Careful examinations under high magnification uncover peculiar but definite relations among the structures just considered. Gradually focussing down the lens, we can see for the first time minute pores scattered in a smaller or larger group. They are subequal in diameter and distributed over a part of a plate, free from the sutural striations. This perforated area borders posteriorly directly on the base of the anterior cingular list but is separated from the lateral or anterior margin of the plate by a broader or narrower structureless zone and is displaced as a whole towards the left side of the plate. There emerge then irregular meshes. This reticulation (Fig. 30) expands much beyond the perforated area especially distinctly towards the anterior and median directions, and yet is bordered by a distinct but much narrower structureless zone. This reticulated area is either triangular or polygonal, conforming to the characteristic shape of the plate to which it belongs, and the meshes are generally smaller in the perforated portion while much larger in other marginal parts where the reticulation laps over the sutural striations. These just considered appear to suggest the facts that the outer surface of the thecal plate is smooth instead of areolated as in other species, and that the reticulation is due to the texture of the plate and not the surface structure. Further comparative studies of younger and older specimens lead us to conclude that the reticulated area represents the original shape and extent of the plate formed at the time when it was built, and that the structureless zone lying around it is a marginal addition due to its secondary growth.

Along the boundary of any two contiguous plates, one can see on the surface a delicate groove of extremely small breadth (s.gr., Fig. 30-200). Along its base opens a line of closely arranged minute pores subequal in diameter with the groove. Further focussing down the lens, there emerges a broad band of transversely striated structure expanding to one side of this groove. This structure passes obliquely through the entire thickness of the thecal wall, getting in distally under marginal parts of the reticulated area where the meshes are larger than elsewhere. This, together with the surface groove, represents the plane of contact or the sutural cleft between the two plates, and it varies in breadth in accord with the different breadth of the marginal structureless zone lying over it. This correlation can be established not only between different specimens but also in different parts of a single individual. The striated band consists of many transverse and darker blocks of irregular shape and breadth, alternating with many single or forked, fine and lighter striations. Either of them lies across the entire breadth of the band, differing partially in direction of extension in accord with the margin of the plate, to which it is generally perpendicular. The finer, lighter striations are various in shape and breadth, some broadening in the middle while others in their inner or dorsal ends, but each of them opens at its ventral or outer end where every one has subequal breadth, so minute pores are arranged, as described above, along the bottom of the sutural groove. The 
darber blocks are also very irregular in shape and breadth. It is to be noted in this regard that there is always a large triangular block at every intersection of three striated bands. Judging from our extended studies on the homologous structures in other species of Peridinium, Diplopsalis and Podolampinae as partly elucidated above, there is no doubt of the facts that the striated zone represents the fissure or sutural plane along which the two contiguous plates rest upon each other, that the lighter striations in the band indicate the shape, size and length of the sutural tubules by which the body content communicates with the outer environment, and that the triangular darker block at the intersection represents the area where three plates overlap with one another.

On the inner surface of a plate are seen numerous minute poroids (Fig. 30197) scattered irregularly but partially in circular or linear arrangement. They are distributed over the major central part of the inner surface which is surrounded by a narrower or broader poroidless zone. Further, among them one can distinguish many pores of subequal diameter, which are communicated by fine canalicules passing through the plate with the similar structures on the outer surface. These pores are distributed over the major part of the areolated area but restricted within the reticulated part. On the other hand, the areolated area expands much beyond the reticulated one and even under the striated zone of adjacent plate. The smooth outer surface, the areolated inner surface, the thecal canalicules communicating the inner and outer pores, and distinct obliquity of the sutural plane are illustrated clearly in Fig. 30 (199). The relations between the extent and displacement of the marginal hyaline zone, the reticulated area, the striated band, the areolated part and the perforated portion, are given in Fig. 30 (198). From these and other available facts, it is apparent that the marginal hyaline zones and the striated band grow broader, and the thecal wall becomes thicker as the growth of an organism goes on, and this brings forth stronger displacement of the outer and the inner surfaces of a single plate.

Comparative study of thin-walled younger and thick-walled well grown specimens shows that the inner pitted surface is more distinct and its displacement from the reticulted area becomes more pronounced in the latter than in the former. This can not be elucidated without assuming the co-existence of both superficial and interstitial growth of the plate, because if the superficial addition is the sole agency of growth, the displacement of the inner areolated area can not be explained, on the other hand if only the interstitial one is admitted, the inner surface must have been left unchanged in relation to the reticulated area. The inner areolated surface is smaller in breadth and also in length than the reticulated polygon, and the difference in size of them becomes more and more pronounced as the striated zone grows broader. The surface pores are distributed over a major part of the reticulated area in younger specimens but become more and more strongly restricted to a smaller portion. In other words, the peripheral pores vanishe as the striated zone becomes broader. Consequently, it is to be admitted that the striated zones grow broader by the sacrifice of the inner pitted surface. This, together with the distinct development 
of the marginal structureless zone on both surfaces of the plate, strongly suggests predominance of the superficial growth at least in that part of the plate. And if solely so all over the plate, the superficial addition may be accumulated in direction nearly parallel to the sutural clefts which incline similarly on either side of a plate, and the fine thecal tubules passing through the plate have to incline also similarly. But in reality, the sutural cleft and the thecal tubule are different in degree of displacement. This appears to suggest probable occurrence, in company with the superficial one, of the interstitial growth always bringing forth partial reorgenization of the thecal tubule.

In regard to Fig. 30 (199), it must be added that the precingular plate has along its hind margin a narrow extension which projects posteriorly beyond the cingular list (cl.). The same structure can be seen on all precingulars as well as on the postcingular plates. It extends, then, from either side of the girdle, and in extreme cases backs completely the cingular wall.

Peters (1928) saw that the sutural line in $P$. depressum runs along middle of the striated zone. A similar relation was confirmed by Altmann and also by us in that and in some other species. The relation is, however, different in the species under consideration as stated above. The reticulated area of the precingular 2 " has a fairly pronounced margin along its right side, which extends anteriorly across the structureless growth zone, merging distally into the corresponding one of the left apical 2'. In lower magnification, this ridge is apt to be mistaken for a real sutural line, and thus one is liable to fall into an error, in regarding it as a real sutural line lying within the striated zone.

Interesting is the structure seen in the left ventral postcingular plate. Minute examinations reveal that there is a peculiar pore in the plate, and this is generally the case throughout the present group and also can be established in some species of Paradivergentia. To this structure we shall give in this paper the name 'ventral pore'. It is only a minute circular or elongated opening and generally accompanied with a marginal thickening of the thecal wall. we shall call the latter 'flange of the pore'. In larger species, the flange was confirmed to lie on the inner surface of the wall and to have a concave surface with its bottom bilaterally compressed, and the opening was in its depth. Not rarely, we can see several radial grooves on its depressed inner surface. The ventral pore lies always in smaller species either in the antero-median corner or in an anterior middle part of the plate, but it is distinctly displaced posteriorly in larger species in which it is generally found only shortly removed from the base of the left sulcal list. The flange is sometimes connected obliquely with the base of the list by a slender ridge. In some of the smaller species, we often saw in place of a single pore four minute and circular spots forming a regular group (Fig. 18-114). Though it is not certain whether the tetrad is due to actual openings or due to thickenings of the wall, there are some reasons to believe that the four spots are so many thickenings brought forth by splitting of a flange. In surface view of the body, one can trace a very fine canalicule from the ventral pore for a short distance into the body, but we failed to decide its morphologica! 
significance.

\section{Characterization of the group}

First of all, one has to call attention to the fact that the left sulcal list and left antapical spine are arranged longitudinally in Pyriformia and in most of Humilia, and distinct from each other in the latter of them while directly continuous in the group. But in the present group, the two structures stand bilaterally and are connected with each other by a minute list or wing. In this regard; Pellucida can easily be distinguished from the two just cited. Paradivergentia is another to be considered here because of its seemingly connected list and spine. But a closer examination shows that the median or ventral side-wing of its left antapical spine is entirely distinct from the left sulcal list, being interrupted by ventral elongation of the narrower left lobe of the posterior sulcal plate which reaches the left ventral postcingular plate.

The ventral area of Paradivergentia is excavated more or less deeply as a whole, indenting the postero-median part of the body. But in the other groups, the longitudinal furrow is generally abruptly differentiated in a smaller or larger left half of the ventral area. The posterior sulcal plate of the present group is one of the most highly advanced among the hornless groups in regard to its bilateral differentiation. This latter structure is correlated apparently with the highest structural differentiation of the ventral area, especially of its appendages in the present group. The bilateral differentiation of the plate itself is much more advanced in Paradivergentia in which the plate expands partially even into the general body surface. In this regard, Pellucida forms a connecting link between Paradivergentia and the other two groups. The next closest relative of Paradivergentia is Divergentia which is characterized, together with Conica and Oceanica, by the antapical horn.

These two major structures, antapical wing-complex and ventral area, are not only of taxonomic importance but also of morphological significance, as they serve enough to characterize the present group on one hand and they help us much on the other hand in diagnosing published figures even when they are insufficiently illustrated. In ventral view, the so-called double spine appears to diverge distally from a common base in the present group while the so-called median branch is separated more or less distinctly from the main spine in most of the others including Paradivergentia. In side view the left sulcal list is broadest in Pyriformia at the left antapical spine, along which it extends to its tip and it can be traced further posteriorly for the short distance beyond the spine. But in the present group it is broadest in front of the spine and is broadly rounded there without forming an triangular extension in its free margin at the spine. In the latter the side-wings of the spine are seen in side view as abruptly differentiated from the sulcal list.

Basing on these, we are led to suggest that $P$. heteracanthum of DANGEARD (1927 and 1932) consists at least of two different species so far as his figures are exactly illustrated. The former (1927, "Sylvana", p. 7, fig. 4) of this has the wing-complex of apparently Pyriformia group, while the other (1932, "Banyuls", p. 348, Fig. 10 a-d) 
comprises two forms, one belonging to Pyriformia and the other to Pellucida. The same author's $P$. ellipsoideum (1932) is also to be distinguished into two ones different, because his Fig. 6 c and Fig. 6 a manifest Pyriformia- and Pellucida-types respectively. A group of four antapical spines figured by KARSTEN (1907) on his P. globulus var. may be due to his misinterpretation of the so-called forked spine. This was the case also with Abé (1927) regarding P. nipponicum. And Lebour (1912), Paulsen (1931) and some others apparently misinterpreted the structures of the left wingcomplex, judging from their descriptions. In Paradivergentia the spine is in ventral view displaced laterally from the hind end of the left sulcal list. This peculiarity is of practical convenience in distinguishing Pellucida from Paradivergentia.

The ventral plate pattern, which has generally been accepted as of taxonomic importance, was regarded generally as 'para' and exceptionally as 'meta' in the present group. But so far as our materials are concerned, it is typically 'meta' and exceptionally 'para' in $P$. pellucidum. That of $P$. acutum is according to FAURÉ-Fremiet 'para' but 'meta' in our materials. We were strongly confounded in establishing that of $P$. parvum but soon found it 'meta' by separating the thecal wall from the content of the body. From these and other available facts we were led to suggest that the species manifesting partly or exclusively the plate pattern of 'meta' is generally smaller in size of the body and less advanced in the structural relations of the antapical appendage than that exclusively with the plate pattern of 'para'.

And the posterior sulcal plate of Divergentia-type is seen only in the larger and more advanced species, while that of Humilia- or Pyriformia-type is seen generally throughout the present group but typically in its smaller species.

From these, it is convenient to divide the present group into the two sections as follows:

1. Section Metapellucida n. sect.

A few small species furnished with short or feebly formed antapical wing-complex are comprised in this section. They have partly or exclusively the ventral plate pattern of 'meta', and their middle intercalary plate is pentagonal or hexagonal. The posterior sulcal plate is not much differentiated, lying invariably between the antapical spines.

To this section are included four described species as follows: $P$. acutum FaURÉFremtet, ? P. hirobis AbÉ, P. paroum AbÉ, P. pellucidum Bergh, ? P. cavispinum MANGIN.

2. Section Parapellucida n. sect.

In this are comprised a few smaller and all of larger species of the group. The antapical wing-complex is in most cases well developed. The ventral plate pattern is 'para', and the middle intercalary plate is hexagonal. The posterior sulcal plate is much more differentiated in shape than in the other section.

Following species are included in this section as its valid members: $P$. heteracanthum Dangeard, $P$. hirobis Abé, $P$. wiesneri Samlller, $P$. cavispinum Mangrn, $P$. 
acutum Fauré-Fremiet, $P$. nipponicum AbÉ, $P$. ovum Sahiller, $P$. pallidum Ostenfedd, $P$. schilleri Paulsen, $P$. sphaericum Okamura (=P. ellipsoideum Dangeard), $P$. spheroidea ABÉ, and $P$. tristylum STEIN; $P$. tenuissimum KoFord is uncertain as to its taxonomical allocation but may be a member of this so far as it is illustrated. In addition to these, $P$. brachypus n. sp., P. cerassiformis n. sp., P. parrum n. sp., and P. rhomboidalis n. sp. are given in this paper.

\section{Key to species}

1. The midbody is globoid or rotated ellipsoidal with a minute but abruptly differentiated apical horn

A. The midbody is spherical

a. The antapical spines are about one-fourth in length of the breadth of the midbody Peridinium spheroidea

b. The spines are much shorter and are much displaced ventrally P. heteracanthum

B. The midbody is longer than broad

a. The spines are longer as compared to its exceedingly smaller midbody P. ovum

b. The spines are stoutly formed and shorter as compared to its much larger midbody. .P. sphaericum ( $P$. ellipsoideum)

c. The spines are comparatively long and the midbody is rather feebly tapered anteriorly than porteriorly P. nipponicum

2. The midbody is globoid and furnished with an exceedingly elongated apical horn, subequal in length with the strongly diverging antapical spines.

a. The apical horn and antapical spine are subequal or a little less in length than the transverse diameter of the midbody.....P. tenuissimum

b. The two structures are slightly longer than one half of the breadth of

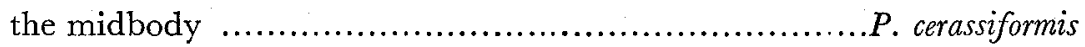

3. The midbody is pear-shaped or shortly cupuliform, tapering anteriorly into an apical horn, often hardly differentiated from the midbody

$1^{\prime}$. The hypotheca is broadly rounded posteriorly

A. The midbody is broader than long

$A^{\prime}$. The thecal wall flares more or less angularly along the girdle

a. The apical horn and antapical spine are feebly formed.....P. brachypus

b. The two structures are more strongly differentiated............. acutum

$\mathbf{B}^{\prime}$. The thecal wall is rounded along the girdle.................... parvum

B. The midbody is subequal in breadth and length

a. A minute species with a comparatively broad girdle and, a short apical horn and much elongated antapical spine P. hirobis

b. A small species with the similarly elongated, short apical horn and antapical spine P. pellucidum

C. The midbody is longer than broad 
a. A small species with sub-conical epitheca ....................... crassum

b. A large species with sub-hemispherical epitheca and elegantly rounded cingular region ............................................... schilleri

c. A large species with a subconical epitheca.................... tristylum

$2^{\prime}$. The hypotheca is indented in its postero-median region at the ventral area $A^{\prime}$. The thecal wall forms a conical bulge at the base of the antapical horn

a. The conical bulge is strongly formed and strongly displaced laterally from the ventral area...................................... cavispinum

b. The bulge is minute and is formed just on the side of the ventral area and often is not formed at all..............................P. pallidum

c. The bulge is formed asymmetrically.......................... wiesneri

4. The midbody is in ventral view distinctly rhombic or tetragonal with a narrow but deeply indented hind-margin ............................... rhomboidalis

Section 1. Metapellucida n. sect.

\section{Peridinium acutum FAURÉ-FREMIET}

Fig. 18 (110-118)

P. pellucidum var. acutum FAURÉ-FREMIET, 1908, p. 221, Fig. 7, PI. 16, Fig. 10.

FaUré-Fremiet (1908) described this as a variety of $P$. pellucidum, and Lebour (1925) suggested its specific distinction. In Asamushi, we saw, besides many small froms more or less closely related to $P$. pellucidum, a form corresponding exactly to FAURÉ-Fremiet's species.

The present species is characterized by its flattened rhombic body furnished with postequatorial girdle and slender and distinctly diverging antapical spines. Its conical epitheca is longer than hypotheca and only weakly convex posteriorly, tapering anteriorly into a distinct apical elongation. The relatively broad girdle forms a circular or ascending spiral with distal displacement of $1 / 2-1 / 3$ its own width. Its wall is flat, and the cingular list has equidistant ribs. The hypotheca is low and convex conical with broadly rounded hind end. One can rarely see a minute conical bulge of the body wall at the base of the antapical spine (Fig. 18-116).

The ventral plate pattern of epitheca is 'para' according to FAUR'́-Fremiet but apparently 'meta' in our materials, and the pentagonal ventral apical has a fairly small breadth. The trapezoidal right ventral precingular $7^{\prime \prime}$ has a very short upper side but is about twice as large both in length and breadth as the triangular left ventral of the same series. The hexagonal middle intercalary $2 \mathrm{a}$ is much larger than the other pentagonal ones of the same series. Just below this lies the trapezoidal precingular $4 "$ whose length is subequal or a little less than the breadth of the girdle. In the postcingular series, the lateral member, $2^{\prime \prime \prime}$ or $4^{\prime \prime \prime}$, is subequal in length with the dorsal precingular. The right ventral $5^{\prime \prime \prime}$ is generally broader than long, while the left ventral $1^{\prime \prime \prime}$ is various in shape, and in some it is broader than long while in others 
subequal in both dimensions; often it is much longer than wide.

The ventral area has relatively large breadth and terminates posteriorly in front of the center of hypotheca. Its plate arrangement and its structural differentiation are typical of the group. The left sulcal list is in typical cases distinctly broad in comparison to smaller size of its midbody, but it's breadth is correlated in some degree with the length of the antapical spine. Its posterior half, springing from the left

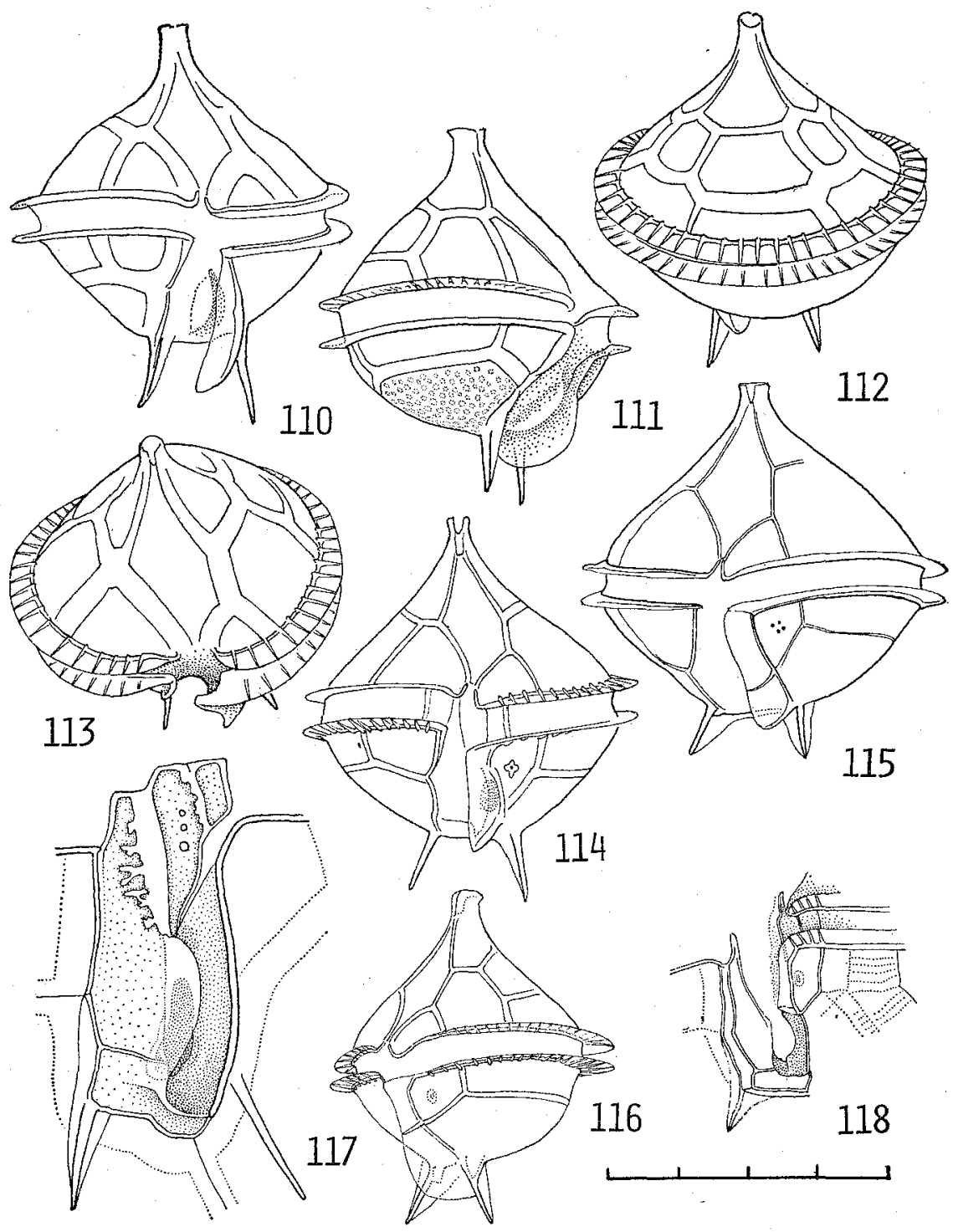

Fig. 18 (110-118): Peridinium acutum FAURÉ-FrEMIET. 110-Ventral view. 111-Dextro-ventral view. 112-Antero-dorsal view. 113-Antero-ventral view. 114-Ventral view of another specimen. 115-Ventral view of a larger specimen with shorter antapical spines. 116-A delicate specimen with slight bulge of thecal wall at an antapical spine. 117-Ventral area, partially disjoined. 118Ventral area and its surroundings. Partially disjoined. 
antapical plate, is generally much broader than its anterior half, and extends posteriorly much beyond the hind end of the body. The right sulcal list is indistinct but typical in structure. Slender but distinct are the antapical spines which diverges distally in ventral view and are relatively long although subjected to individual variations.

They stand bilaterally at the hind end of the ventral area and have generally narrow side-wings. But often one or two and rarely all of them fail to develop.

The sutural zone is often very broad, but even in such a case the shape of the body differs only slightly from that with narrower ones. This suggests that the present species has a fairly constant body-shape throughout its growth. The thecal wall is porulate, and the ventral pore is various in structure, lying either just outside of the left sulcal list or often much displaced laterally. In rare cases it has no flange but generally one can see a minute oval one with or without four constrictions around it (Fig. 18-114). Very rarely was seen a specimen with a regular group of four minute points in place of the pore and its flange. Though it is still uncertain whether there are four pores or they are only due to the misinterpretation of four minute thicker points of the wall brought forth by division of the flange, the latter of the two cases appears to me to be more probable.

Measurements: Length exclusive of antapical spine, $39-45 \mu \mathrm{m}$. Transverse diameter, $37-47 \mu \mathrm{m}$. Dorso-ventral diameter, 35-39 $\mu \mathrm{m}$. Length of antapical spine, $8-10 \mu \mathrm{m}$. Breadth of girdle, $5 \mu \mathrm{m}$.

This species is fairly constant, as described above, in the shape of the body, but displays some minor variations in the characteristics such as shape and size of the ventral postcingular plates, structure and site of the ventral pore, shape of the posterior sulcal plate, and development of the antapical spine and its side-wings. In disregard of these variations, our observations led us to conclude that it seems highly reasonable and at the same time it is of practical convenience, to regard them collectively as one and the same species.

\section{Peridinium parvum n. sp.}

Fig. 19 (119-124)

The body is flattened pear-shaped, tapering anteriorly into a minute but distinct apical horn, and furnished with a postequatorial girdle and short but stout antapical spines. Both the apex and the antapex are displaced ventrally, and the cingular plane is horizontal.

The epitheca is dome-shaped or convex conical with tapered apical horn. The postequatorial girdle forms an ascending spiral displaced distally half its breadth.

The cingular list has equidistant ribs. The cingular section is broadly ovoidal. The hypotheca is low dome-shaped and furnished with short but distinctly diverging antapical spines. The ventral area is short but broad, terminating posteriorly in front of the center of hypotheca.

The ventral plate pattern of its epitheca is 'meta', and the triangular left ventral 


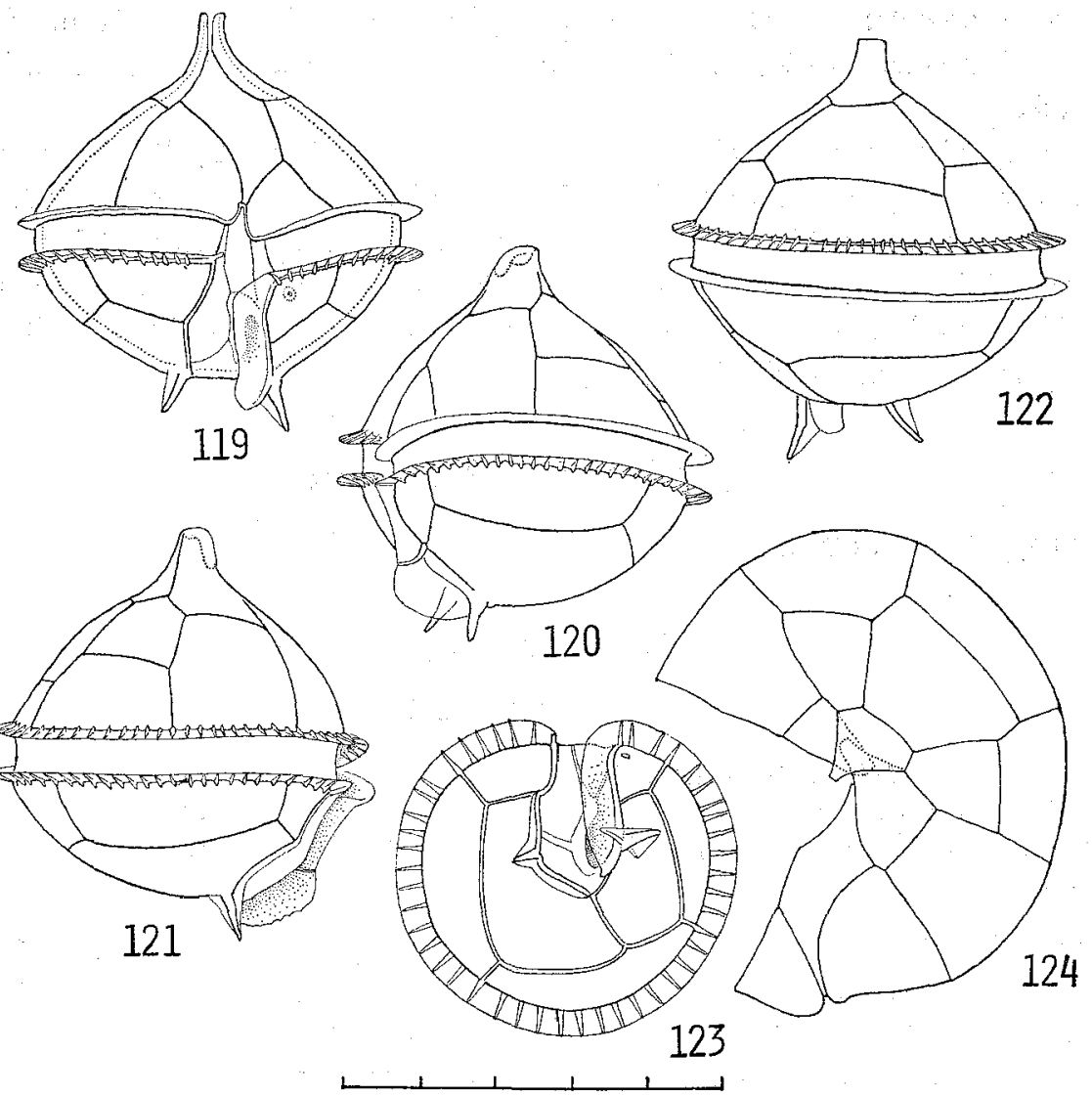

Fig. 19 (119-124): Peridinium parvum n. sp. A larger specimen. 119-Ventral view. 120, 121-Side views. 122-Dorsal view. 123-Antapical view of a smaller specimen. 124-Inside view of a partially disjoined epitheca.

precingular 1" covers lower one-third, while a similarly shaped but much larger right ventral 7" lies in the lower half of the epitheca respectively. The latter plate has a very narrow upper end, extending anteriorly as far as the ventro-lateral plates $\left(2^{\prime \prime}, 6^{\prime \prime}\right)$ of the same series. In the intercalaries, the hexagonal middle $2 \mathrm{a}$ is much larger than the lateral ones and is twice as long as the trapezoidal mid-dorsal precingular $4^{\prime \prime}$. In the hypotheca, the ventro-median postcingulars are similarly broader than long, but between them the left $1^{\prime \prime \prime}$ is smaller in breadth than the other. The dorsal postcingular $3^{\prime \prime \prime}$ is 1.5 times as broad as the dorso-median precingular $4^{\prime \prime}$, and the lateral ones of the same series are about 1.5 times larger in length than the breadth of the girdle.

The ventral area is typical for the group in its plate arrangement and its structural relations. The two distinctly diverging antapical spines have two or three narrow side-wings respectively.

The thecal wall is stout and thick, and the ventral pore has its small flange lying just below the proximal end of the girdle. 
Measurements: Length and transverse diameters of body, 37-52 $\mu \mathrm{m}$. Dorsoventral diameters, $34-47 \mu \mathrm{m}$. Length of antapical spine, 5-11 $\mu \mathrm{m}$. Breadth of girdle, $5 \mu \mathrm{m}$.

This species can not be allocated to any recorded form of $P$. pellucidum, to which this is most closely related and with which this might have been confounded. The rounded midbody of this is broader than long in its ventral view. This serves to separate this from any of them with the exception of $P$. acutum which has much flattened epitheca and elongated apical horn, and from which this differs in its more strongly swollen and broader body.

\section{Peridinium hirobis ABÉ}

ABÉ, 1927, p. 399, Fig. 18A-E.

\section{Peridinium brachypus n. sp.}

Fig. $20(125-131)$

P. pallidum Paulsen, 1911, p. 311, Fig. 9 A-G.

P. pellucidum, in part, PAULSEN, 1908, p. 49, Fig. 61 lower two; 1911, p. 311, Fig. 10; Marukawa, 1922, p. 24, Fig. 267c; Lebour, 1925, p. 134, Pl. 28, Fig. 2 a-d; Woloszynska, 1928, p. 202, Pl. 14, Figs. 1-4.

Published figures inform us of the fact that the specific name $P$. pellucidum has been used to designate at least two different forms, one with a rounded and somewhat elongated form originally figured by BERGH (1881) and the other with an angulated and rotund one described by PAulsen (1908). Both of them were examined, and the specific name was retained for the former while the latter, which corresponds to the present one, is separated here to a distinct species.

The present species has a broadly biconical body furnished with an equatorial girdle, a narrow postero-median indentation and two short antapical wing-complexes. The thecal wall flares along the girdle and is convex in the posterior two-thirds while concave in the rest of the conical epitheca. The cingular furrow is depressed, forming a weakly ascending spiral, and the cingular section is broadly ovoidal with a faint ventral flattening and tilts down ventrally. Similarly convex conical hypotheca has along its ventral median a deeply excavated ventral area which extends to its center forming there a small but fairly well formed indentation. Just on the ventral of the venter stand laterally two short antapical spines, of which the right is often removed for a short distance from the edge of the ventral area. The left antapical spine is similarly displaced towards the opposite direction from the hind end of the strongly developed left sulcal list which extends posteriorly a little beyond the spine.

The plate pattern of the epitheca is somewhat radially adjusted like that of the Conica group of Veroperidinium. Among the three pairs of the meridional collective sutures, the ventral one is fairly straight and strongly formed, and the dorsal 


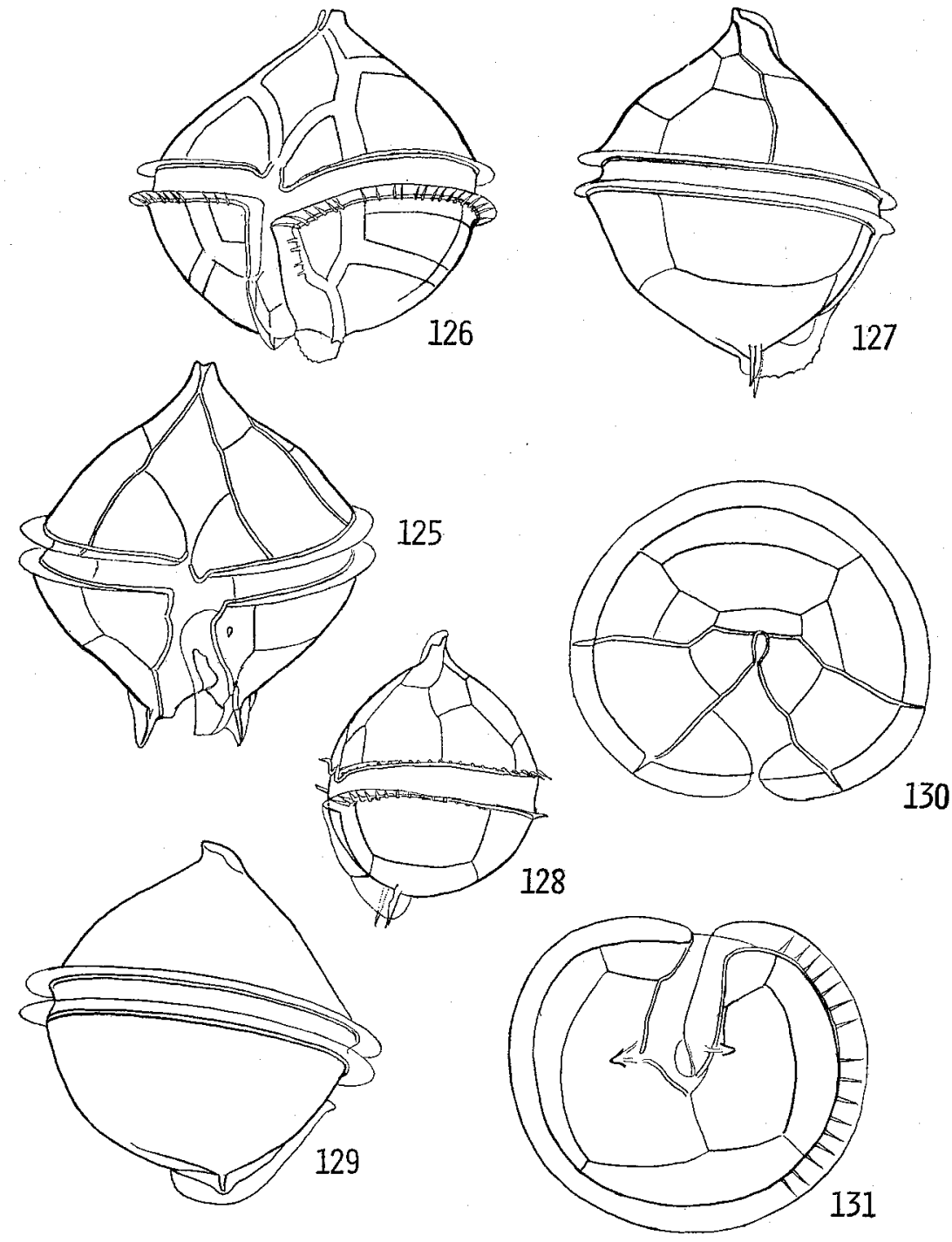

Fig. 20 (125-131): Peridinium brachypus n. sp. 125-Ventral view. 126-Sinistro-ventral view. 127129 -Side views. 130 -Apical view. 131-Antapical view.

one is weak and fairly zigzag while the lateral is intermediate between the two. The ventral plate pattern is 'para', and the middle intercalary is a large hexagonal plate. Together with the lateral intercalaries, the dorsal apical is the smallest in the epitheca. Contrary, the ventro-lateral precingulars are the largest, covering posterior two-thirds of the epitheca. In the hypotheca, the postcingular row of plates covers a little less than its anterior half. And its left ventral component is half as broad as the right ventral of the same series, both extending posteriorly similarly.

Along the lateral base of the posterior half of the left sulcal list is often seen a 
narrow stripe of thecal wall, which extends ventrally to the left ventral postcingular plate, lying between the sulcal list and the left antapical spine. This can be established only in well grown specimens and can hardly be established in specimens without sutural zones, and it is broader in more broadly sutured specimens.

The ventral pore lies in an anterior median portion of the left ventral postcingular plate.

Measurements: Length, 55-63 $\mu \mathrm{m}$. Transverse diameter, 46-55 $\mu \mathrm{m}$. Depth, 42-47 $\mu \mathrm{m}$. Length of antapical spine, 5-6 $\mu \mathrm{m}$.

Locality: Shimoda, rare in occurrence.

\section{Peridinium pellucidum (BerGH) SchÜTT}

Fig. 21 (132-145)

Paulsen, in part, 1908, p. 49, Fig. 61 upper four.

Peridinium pellucidum var. spinosa WoLosZYnsKa, 1928, pp. 202-206, Pl. 14, Figs. 5, 6 .

Peridinium huberi Schiller, 1929, p. 408, Fig. 25 a, b.

Protoperidinium pellucidum BERGH, in part, 1881, p. 227, Fig. 46 (not Fig. 47).

Since Bergh described and figured in 1881 two forms of Protoperidinium pellucidum, many small but apparently different forms has been allocated to this species by various observers. The present species is, then, left as one of the least defined in the genus, partly owing to its smaller size which has made it difficult to study minutely its thecal morphology. On the other hand, some of its formae and varieties have been established without due considerations on the characteristics of BerGH's original species.

One of his two forms has a smaller and spheroidal body furnished with an abruptly tapered, short apical horn (his Fig. 46), and the other is larger and much elongated (his Fig. 47). The former has an equatorial girdle, and its epitheca is subequal in shape and size with the hypotheca. But the latter differs in having much larger and elongated epitheca. Both of them agree in the possession of two short and well winged antapical spines. Judging from these, they are quite distinct from each other. Thus, it appears reasonable to regard Bergh's Fig. 46 to represent the typical species and at the same time to separate the other into a distinct one. FAURÉ-Fremiet (1908) described two varieties crassum and acutum of this species, both of which are also worthy of specific distinction. In the same year, PAulsen figured two forms, one corresponding to the typical species (cited from OsTENFELD, 1903) and the other has an angulated body and less developed antapical spines. The same author collected in 1911 in the East-Greenland three forms, all differing. from one another and also from either of BERGH's original but resemble more or less closely the angulated form, to which are related also Lebour's (1925) and WoLOSZYNSKA's (1928) forms. Scirrlez's huberi is probably identical with the typical form of BERGH.

Judging from these, it seems quite probable that there has been a general tendency among former investigators to allocate to this species many of small 

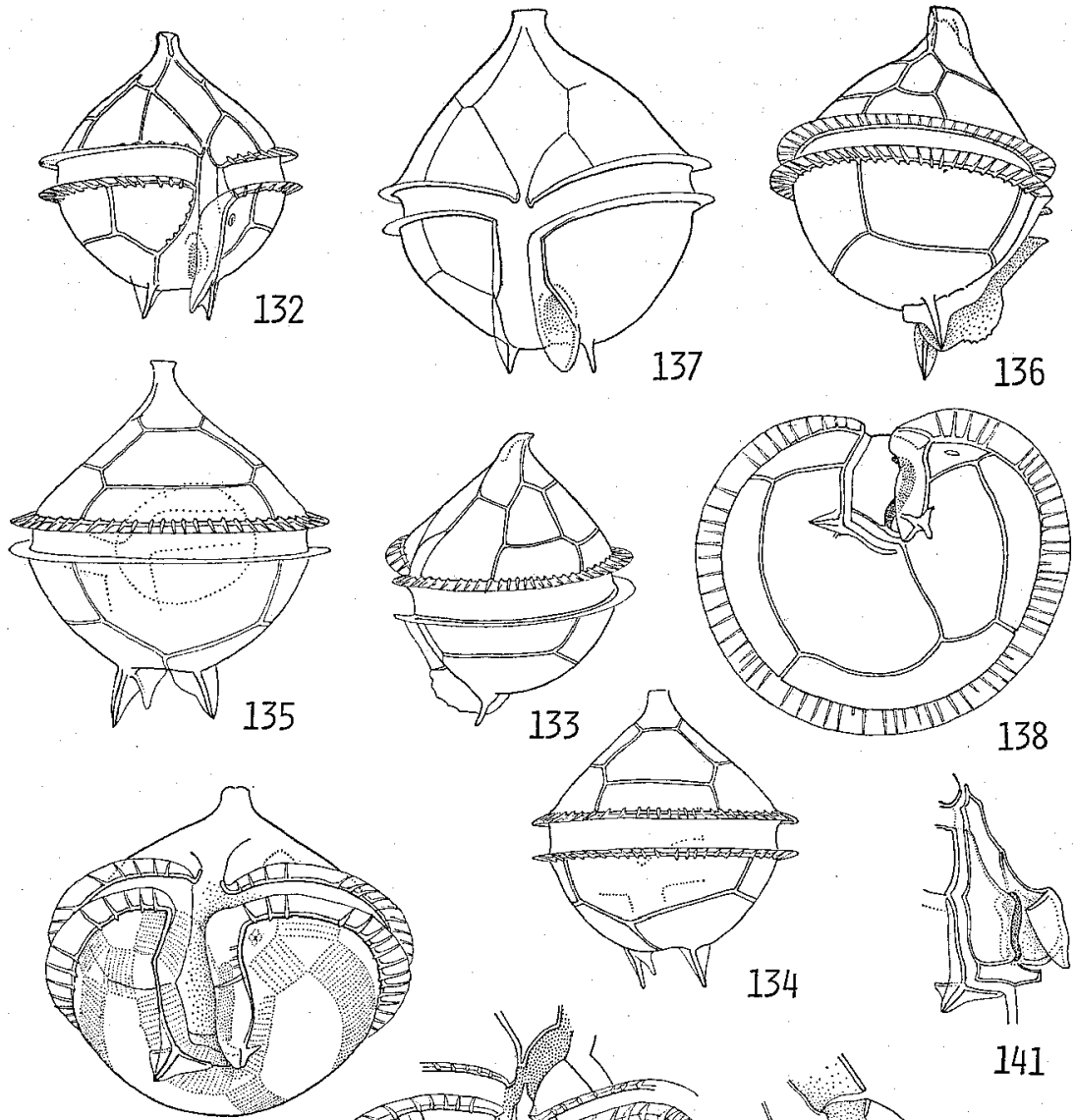

139
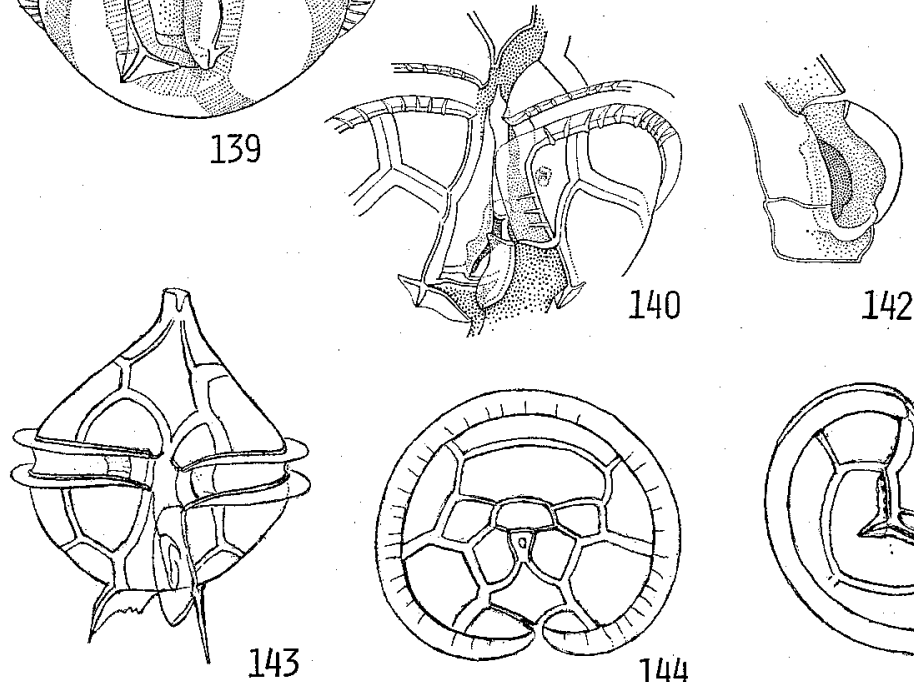

141

143
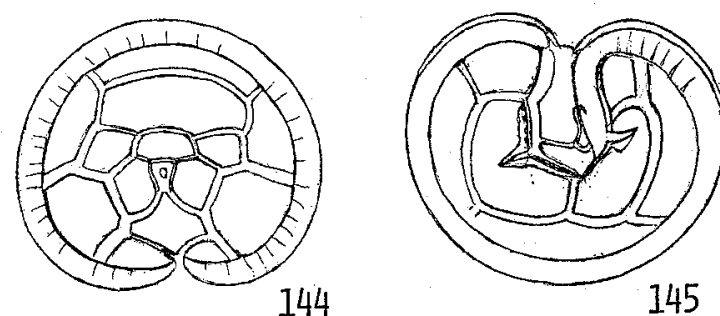

Fig. 21 (132-145): Peridinium pellucidum (BERGH) SaHÜtт. 132-134: A small rotund specimen. 132Dextro-ventral view. 133-Side view. 134-Dorsal view. 135, 136-A larger specimen with longer antapical spines, dorsal and side wings. 137-A larger specimen with shorter antapical spine in ventral view. 138-Antapical view of a larger specimen. 139-Postero-ventral view of a broadly sutured specimen. 140 -Ventral view of a partially dissociated specimen, showing disjointed two members of left sulcal list, distinct from the left antapical spine. 141-Ventral area, separated from left half of hypotheca. Posterior member of left sulcal list is folded over left sulcal plate and is distinct from posterior sulcal plate. 142-Posterior half of ventral area. Posterior sulcal plate is larger than that of 141. 143-Ventral view. 144-Apical view. 145-Antapical view. 
and rotund forms with three minute antapical extensions. In other words, the present one has been regarded apparently as a collective species. This suggestion may be strongly supported by the fact that Poucheт (1883) included in this species eight different forms, each worthy of specific distinction, but none of them can be identified with the typical species. On the other hand, separability of the species into some distinct ones was correctly suggested by some, as was pointed out already in 1912 by Jörgensen (p. 7). Fauré-Fremiet (1908), Broch (1910) Woloszynska (1928) and others subdivided it into varieties or formae. It is still uncertain whether it is to be subdivided into varieties or formae or to be distinguished into so many distinct species. Detailed morphological study of the genus leads us to the opinion that the various characteristics these minute forms display are not to be less estimated than those of the larger forms.

We found in Asamushi several small forms, all corresponding to $P$. pellucidum in some or other points. Among them is a spheroidal form corresponding exactly BERGH's Fig. 46, which is taken here to represent his species.

The body is globular with equatorial broad girdle and well winged, short antapical spines, and tapers anteriorly into a short but well differentiated apical horn. Shape of the body is fairly constant probably throughout the entire course of its growth judging from the fact and consideration that we saw almost every intermediate growth forms, that two extreme ones of them, one with remarkably broad striated zones and the other entirely without them, can be identified at once because of their closest resemblance in shape of the body, and that the above considerations naturally led us to a conclusion that the development of the growth zone does not induce any distinct deformity in body shape in such a degree as to force one to suggest their distinction. From these, it may be said with certainty that this is a well defined species so far as our materials are concerned.

The epitheca is swollen conical, tapering distally into a short apical horn by which it exceeds the hemispherical hypotheca in length. Its circular or slightly ascending girdle is relatively broad in comparison to the small size of the body. The ventral area terminates in front of the center of hypotheca (Fig. 21-138). The short antapical spine is generally well winged.

The ventral plate pattern of epitheca is generally 'meta' (Fig. 21-137) but very often 'para'. The left ventral precingular is about 1.5 times and the right ventral one is about twice as long as the breadth of the girdle. They cover lower three-fifths of that part of the epitheca. Among the three mid-dorsal intercalary plates, the middle hexagonal $2 \mathrm{a}$ is the largest, and the trapezoidal precingular 4" lying just below it is one half as long as that. In the hypotheca, the small left ventral postcingular $1^{\prime \prime \prime}$ is generally much longer than wide. The lateral ones of the same series are 1-1.5-2 times as long as the breadth of the girdle. Right antapical is larger than the left.

The cingular list has equidistant ribs, and the cingular ventral area is broader posteriorly than anteriorly, and bluntly pointed at the hind end. The left sulcal list is distinct, extending posteriorly beyond the hind end of the body and almost nearly to the tip of the left antapical spine, and has in its anterior half a set 
of basal ribs. The antapical spine has three triangular minute wings and stands just on the ventral of the center of hypotheca, and inclines weakly or hardly ventrally.

The four sulcal plates are typical in arrangement as illustrated in Fig. 22 (150). The posterior sulcal plate is somewhat variable in length, but does not extends in any case ventrally beyond the left antapical spine. Further, it may be necessary to pay attention to the fact that the posterior half of the left sulcal list belongs to the left sulcal plate and that the postero-median part of the body is not indented.

The ventral pore with its ovoidal or four-lobed flange lies either close to the base of the left sulcal list or in the anterior middle of the left ventral postcingular plate.

Measurements: Length of body exclusive of antapical spine, 38-53 $\mu$. Transverse diameter, 34-50 $\mu \mathrm{m}$. Dorso-ventral diameter, 32-48 $\mu \mathrm{m}$. Length of antapical spine, $4-8 \mu \mathrm{m}$. Breadth of girdle, $5 \mu \mathrm{m}$.

\section{Section 2. Parapellucida n. sect.}

\section{Peridinium pallidum OSTENFELD}

Figs. 22-24 (146-160)

Cleve, 1900, p. 17, Pl. 7, Figs. 21-22; Paulsen, 1908, p. 48, Fig. 60; 1931, Fig. 28; Lebour, 1925, p. 134, Pl. 28, Fig. 1; Peters, 1928, pp. 31-33, Fig. 7.

non Ostenfeld, 1911, p. 311, Fig. 9; non Böhm, 1933, p. 318, Fig. 9; non MaruKawa, 1922, Pl. 4, Fig. $59 \mathrm{i}, \mathrm{j}$ (a-h after OstenfeLd).

Peridinium divergens palididum. Karsten, 1905-1907, p. 150, Pl. 23, Fig. 13 a, b.

non $P$. pallidum var. Okamura, 1912, Pl. 4, Fig. 70.

P. pellucidum GRAN, 1902, p. 186, Fig. 10 a-c.

We found in Asamushi two forms apparently corresponding to this species. One is smaller, less broader and more rounded than the other, and minute examinations uncovered some further differences between them. Among forms described under the name pallidum, PAuLSEN's two forms correspond apparently with our larger one while Peters' agrees with the other smaller one. The former has a pentagonal body more or less angulated along the girdle and two short and winged antapical spines distinctly diverging distally. But judging from the latter author's Fig. 7a, his southern form has a minute conical bulge of the body wall at the base of its right antapical spine which stands apparently outside of its ventral area, its body is not angulate along the girdle, and its antapical spine is wingless. Our morphological study was carried out mainly on the smaller form because of its common occurrence and its displaying some peculiarities in its hind end although similar structures were also seen in the larger one in less distinctness. Further, the larger form (Fig. 22) has always thicker thecal wall, distinctly broader sutural zones and stout antapical spines. On the other hand, the smaller form (Fig. 23) has thinner and lesscoloured wall filled with less condensed content, and its sutural zones are generally less developed. In addition, some smaller specimens were often seen enveloped with a 


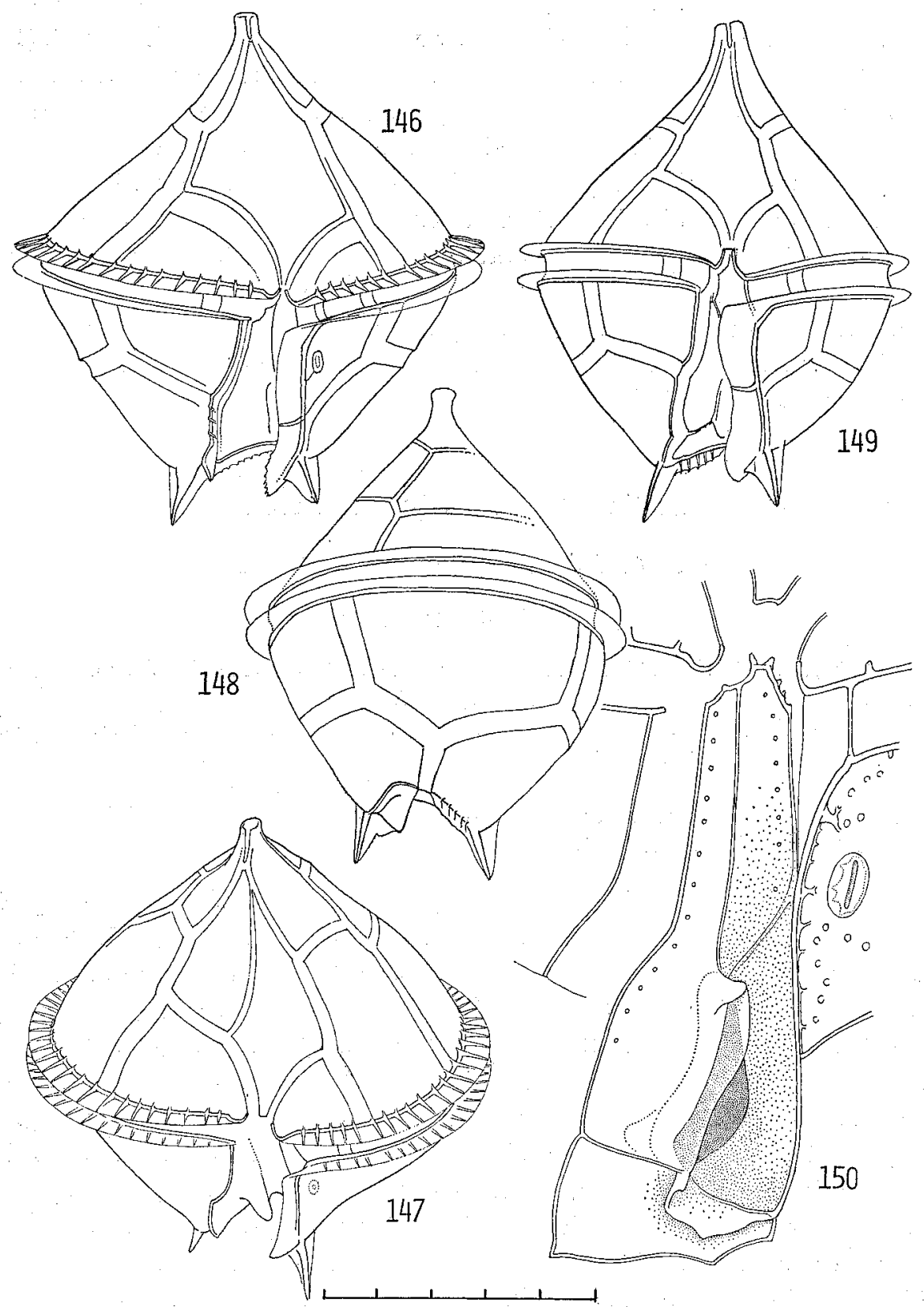

Fig. 22 (146-150): Peridinium pallidum OsTENFELD (1). 146-Angulated larger form with an entire or splitted broad ventral apical plate. Ventral view. 147-Antero-ventral view. 148-Dorsal view. 149-Ventral view of a medium-sized specimen. 150-Ventral area, partially splitted. 
thin layer of colourless substance, in all of which any of the surface extensions such as list or wing is always scarcely formed and the thecal wall is very thin. In spite of these differences, it is not a matter either of practical convenience or of taxonomical importance to distinguish them each other because of the fact that there are some

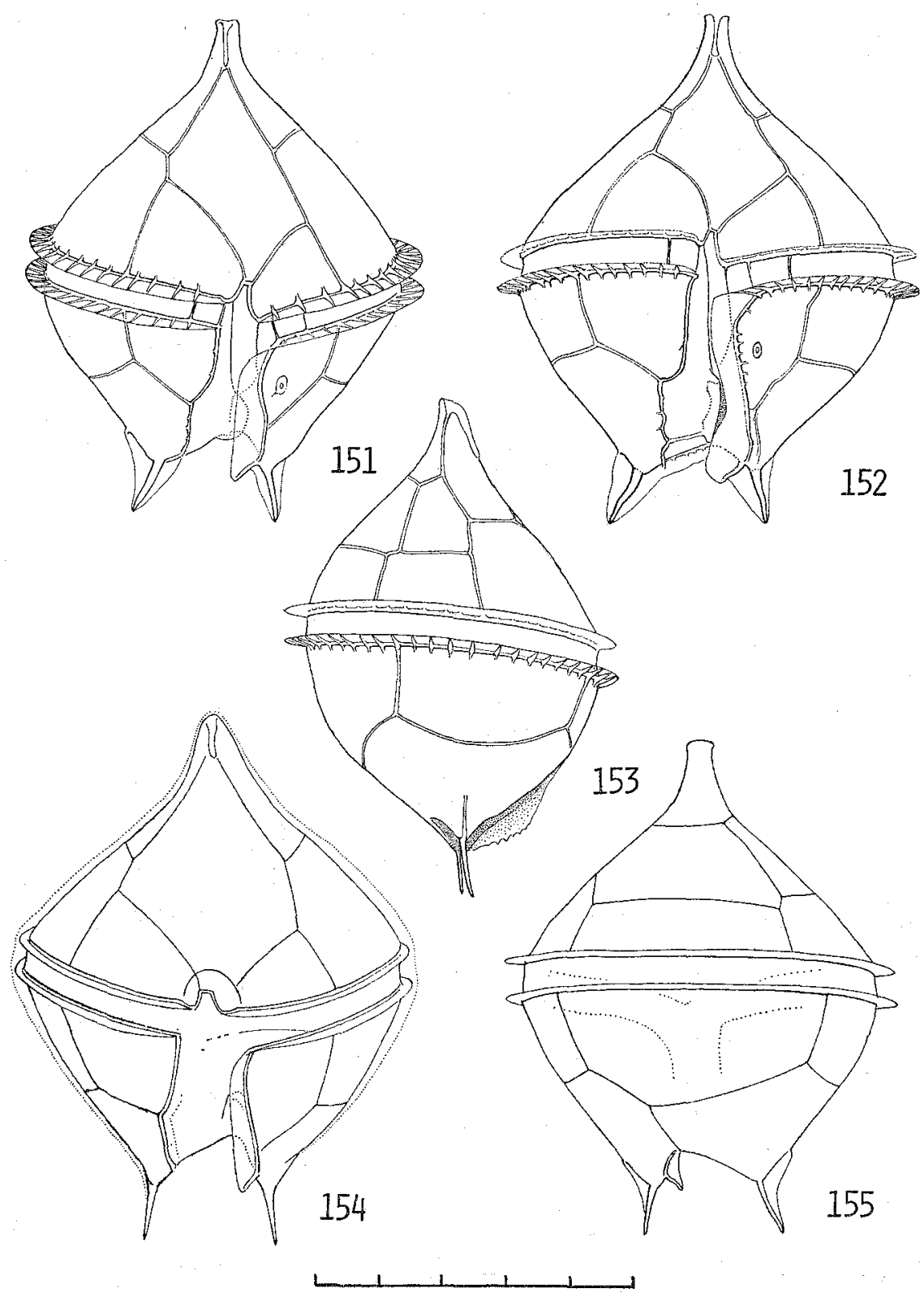

Fig. 23 (151-155): Peridinium pallidum Ostenfeld (2). 151, 152-Ventral view of two specimens each showing different shape and plate pattern of ventral area. 153--Side view of a specimen with well formed cingular list. 154-Ventral view with a narrow cingular list. 155-Dorsal view. 
intermediate forms between them suggesting their unity. Consequently, it may be granted to suggest that it is more reasonable to regard the two forms as representing different growth stages of a single species than to distinguish them from each other or to consider them as two distinct varieties.

The body is in ventral view large pentagonal with a postmedian indentation and a short apical elongation. Its equatorial girdle is circular or faintly ascending and its deeply excavated ventral area is broader posteriorly expanding towards the right
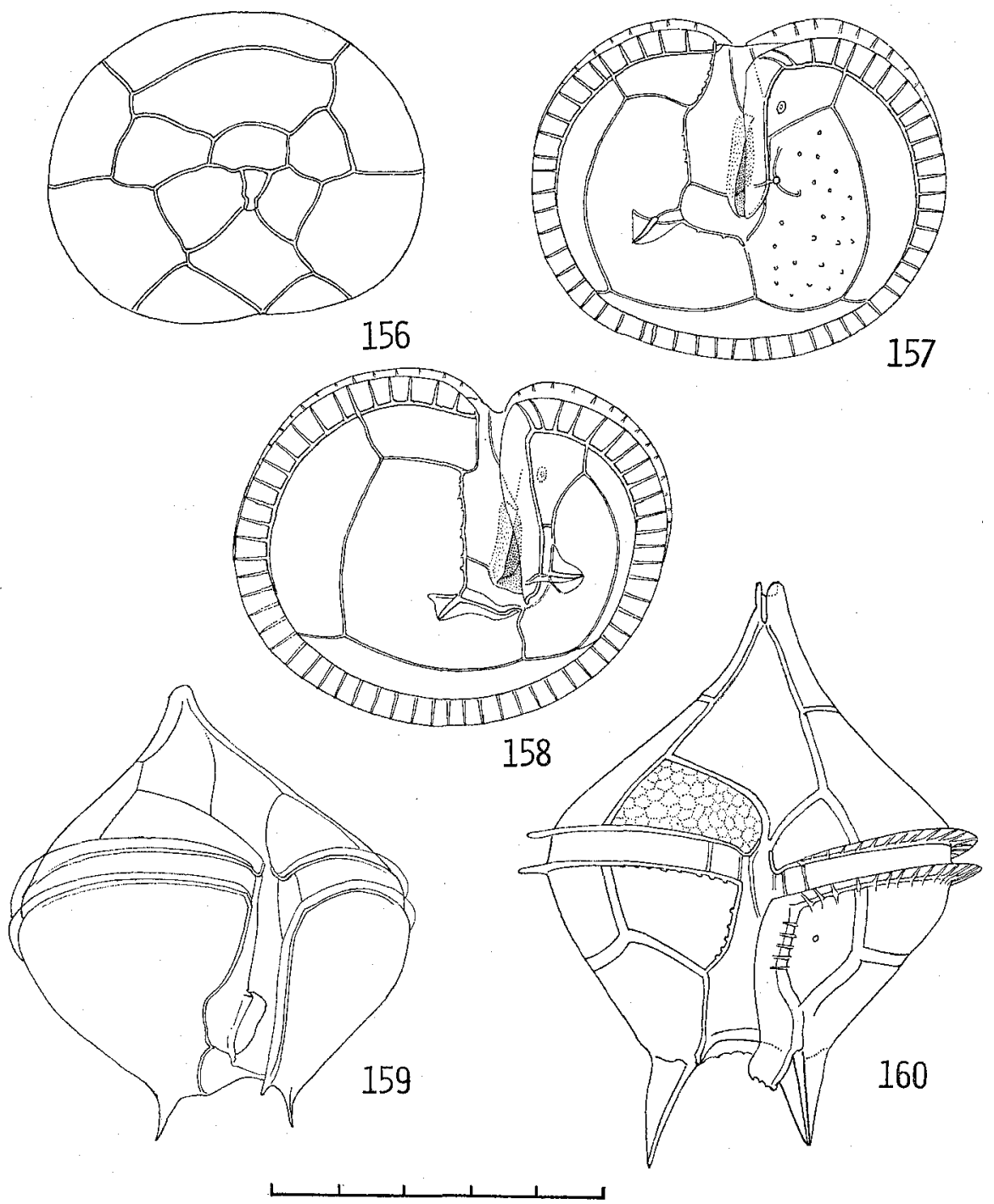

Fig. 24 (156-160): Peridinium pallidum Ostenfeld (3). Thin-walled specimen with wingless antapical spine and splitted ventral apical plate. 156-Apical view of epitheca. 157, 158: Two types of hypotheca. 157-Posterior sulcal plate ends in front of left antapical spine. 158-Sulcal plate extends beyond it to left ventral postcingular plate. 159-Ventral view. 160-Rare specimen related most closely to this species. 
in its posterior half. The left sulcal list is comparatively narrow without showing distinct antero-posterior difference in breadth. The cingular section is broadly ovoidal with a faint ventral flattening and tilts down ventrally. Distinctly diverging antapical spines, which are either winged or wingless, stand bilaterally on the antapex, and the thecal wall at the base of the spine bulges out slightly in most of the smaller forms to form a minute conical swelling which lies outside of the ventral area.

The larger form has generally broader body than the other but is variable in length-breadth ratio. In an extreme case, its breadth is subequal with its length excluding the antapical spines and the apical elongation (Fig. 22-148). But the other extremity has such a slender form (Fig. 22-154), hardly distinguishable from the smaller form in shape of the body. The short apical elongation inclines sometimes towards the right and is either distinctly differentiated from confluent basally with the midbody. The cingular list has subequidistant distinct ribs. The antapical bulge of the body wall is generally indistinct, and the antapical spines, each provided with three side-wings, stand wide apart from each other and distinctly diverge distally. Further, the left one of them inclines and is displaced much ventrally in comparison with the right.

The smaller form can be distinguished from the larger one by its less angulated body, its thinner thecal wall and much indistinct sutural zone, and especially apparently by the antapical conical bulge. The antapical spine and its side-wings are generally delicate, and often the latter of them are entirely absent. The ventral apical $1^{\prime}$ is in this from generally narrower than in the other form.

The plate pattern of the epitheca in the two forms is characterized, though it varies considerably, by its comparatively broad and hexagonal ventral apical. The plate is, in some, divided into two by an oblique suture which begins always at a short distance from the ventral slit of the apical pore, extending aslant across the plate (Fig. 22-147). The hexagonal dorsal intercalary 2a has greater length than the trapezoid precingular 4" lying just below it. The two ventral precingular plates differ distinctly in size especially in length, the right being always larger than the left. The ventro-lateral precingular covers the lower two-thirds or a little less of that part of the epitheca. The postcingular plates have fairly large length covering upper one-third or one-half of the hypotheca. The right ventral $5^{\prime \prime \prime}$ is much broader than long in the larger form but the difference between breadth and length is smaller in the smaller one. The left ventral postcingular $1^{\prime \prime \prime}$ is longer than broad, but its breadth is subject to individual variation, and extends posteriorly to halfway between the girdle and the antapical spine.

The girdle is circular or forms an ascending spiral displaced distally by its own or half of its breadth. We can see two subequal small ventral cingular plates, rectangular in the larger form while subequal length and breadth in the other.

The ventral area expands in its posterior half towards the right and is slightly constricted at the suture between the right and posterior sulcal plates. It is excavated as a whole but especially deeply in its left major part. Shapes and arrangement of the four sulcal plates are typical of the group (Fig. 22-150). The left sulcal 
plate and the transitional one meet at the level corresponding to or slightly above the ventral pore.

The posterior sulcal plate of this shows peculiarly distinct variations not only in its shape but also in its relationships with the left antapical spine and the left ventral postcingular plate. In most cases, it is irregularly rectangular or irregularly tapered towards the left, lying exclusively along the hind end of the ventral area, and either of the two antapical spines is separated laterally from this plate for a short distance. But sometimes it extends with its narrower left lobe to the base of the left antapical spine. And often particularly in broadly sutured specimens we can see a narrow stripe of thecal wall along lateral base of the left sulcal list extending between the left ventral postcingular plate anteriorly. This corresponds in situation to the left narrower lobe of the posterior sulcal plate of Paradivergentia, but it belongs in reality to the left sulcal plate and is formed in accord with considerable growth in breadth of the sutural zone.

Peculiar are the structural relations of the antapical spines and the ventral area. As elucidated above, the left antapical spine stands generally at a short distance from the distal end of the narrower left lobe of the posterior sulcal plate either just upon the median edge of the left antapical plate or immediately lateral of it. The spine is provided typically with three small side-wings, one of which connects the spine with the left sulcal list which is in this species comparatively narrow and not so distinct as in $P$. schilleri. These side-wings are various in size, and not infrequently such a specimen was seen entirely deprived of them as that recorded by Peters (1928) from the Antarctic Ocean. The small conical bulge at the base of the spine appears to be inversely correlated with the development of these side-wings. We saw a few cases of the wingless form in which the well-developed conical bulge has on its surface three radial ridges in place of the side-wings.

Just the same relations are also seen in the right antapical wing-complex as well as in its basal bulge. The right antapical spine is seen mostly at a short distance from the dextro-dorsal corner of the posterior sulcal plate, standing at the tip of a small conical bulge. Inserted between the proximal portions of its ventral and median side-wings is a small triangular patch extending between the spine and the posterior sulcal plate. This is in reality a part of the right antapical plate, distinguished from general surface of the plate by the two wings, and opening directly to the ventral area. Consequently, one is liable to misinterpret it as an unusual rightward expansion of the ventral area. This is in most cases very small and narrow, limited along the median face of the conical bulge, but it rarely expands further medianwards to the intra-antapical suture.

The thecal wall is scattered with minute points and much smaller pores. The ventral pore has an oval flange around it. The inner surface of the flange is concave with or without radial grooves.

Measurements: 


\begin{tabular}{l|c|c}
\hline \hline & Larger form & Smaller form \\
\hline Length exclusive of antapical spine & $74-86 \mu \mathrm{m}$ & $60-72 \mu \mathrm{m}$ \\
Transdiameter exclusive of list & $62-80 \mu \mathrm{m}$ & $54-60 \mu \mathrm{m}$ \\
Dorso-ventral diameter & & $42-47 \mu \mathrm{m}$ \\
Length of antapical spine & $7-12 \mu \mathrm{m}$ & $8-9 \mu \mathrm{m}$ \\
Breadth-length Ratio of body & $79-84 \cdots 93$ & $79-85 \cdots 91$ \\
Breadth of girdle & $5 \mu \mathrm{m}$ & $5 \mu \mathrm{m}$ \\
\hline
\end{tabular}

\section{Peridinium rhomboidalis $\mathrm{n}$. sp.}

Fig. $25(161-168)$

P. leonis Schiller, 1929, p. 401, Fig. 13 a.

This species is in ventral view rhombic or rather has a shape of rhomboidal pentagon with a narrow but distinct postero-median indentation. In side view, it is rhombic, bulging more dorsally than ventrally. The ascending circular or descending girdle is equatorial, and the cingular plane tilts down ventrally in various degrees in different specimens, bringing forth a variation in the flattening of the body. The distinctly diverging, short antapical spines have each generally three minute side-wings.

The conical epitheca has straight or convex contour posteriorly but is concave anteriorly. Generally, the apical horn is scarcely differentiated, but often a tapering apex, when it exists, leans towards the right. The girdle is circular for the most part but in ventral view forms an ascending, circular or descending spiral according to symmetrical or asymmetrical extension of the postero-median juts of the two ventral precingular plates. The wall of the girdle is distinctly concave. The cingular section is broadly ovoidal without distinct ventral flattening and appears to have a fairly constant breadth-depth ratio. The hypotheca is triangular in side view but is deeply excavated in ventral view in its posterior median portion as a result of dorsal extension of the deep sulcal furrow beyond the antapices where the two antapical spines stand. The posterior bilateral portions thus left are formed into two seemingly conical horns, of which the left one is displaced in most cases more ventrally than the other.

The plate pattern is typical of the group. In the ventral half of the epitheca, the lateral precingulars $2 "$ and 6" cover its posterior two-thirds, and the smaller left and the larger posterior one-fourth and one-third. The longitudinal suture extending from the ventral slit of the apical pore to the girdle is fairly straight as in the corresponding one of Conica. In the mid-dorsal region, the pentagonal apical $3^{\prime}$, the hexagonal intercalary $2 \mathrm{a}$ and the trapezoidal precingular 4 " are subequal in length and symmetrical in bilateral expansion (Fig. 25-165) The lateral postcingulars cover anterior one-third of the hypotheca. The wall of the girdle consists of three plates as usual. 


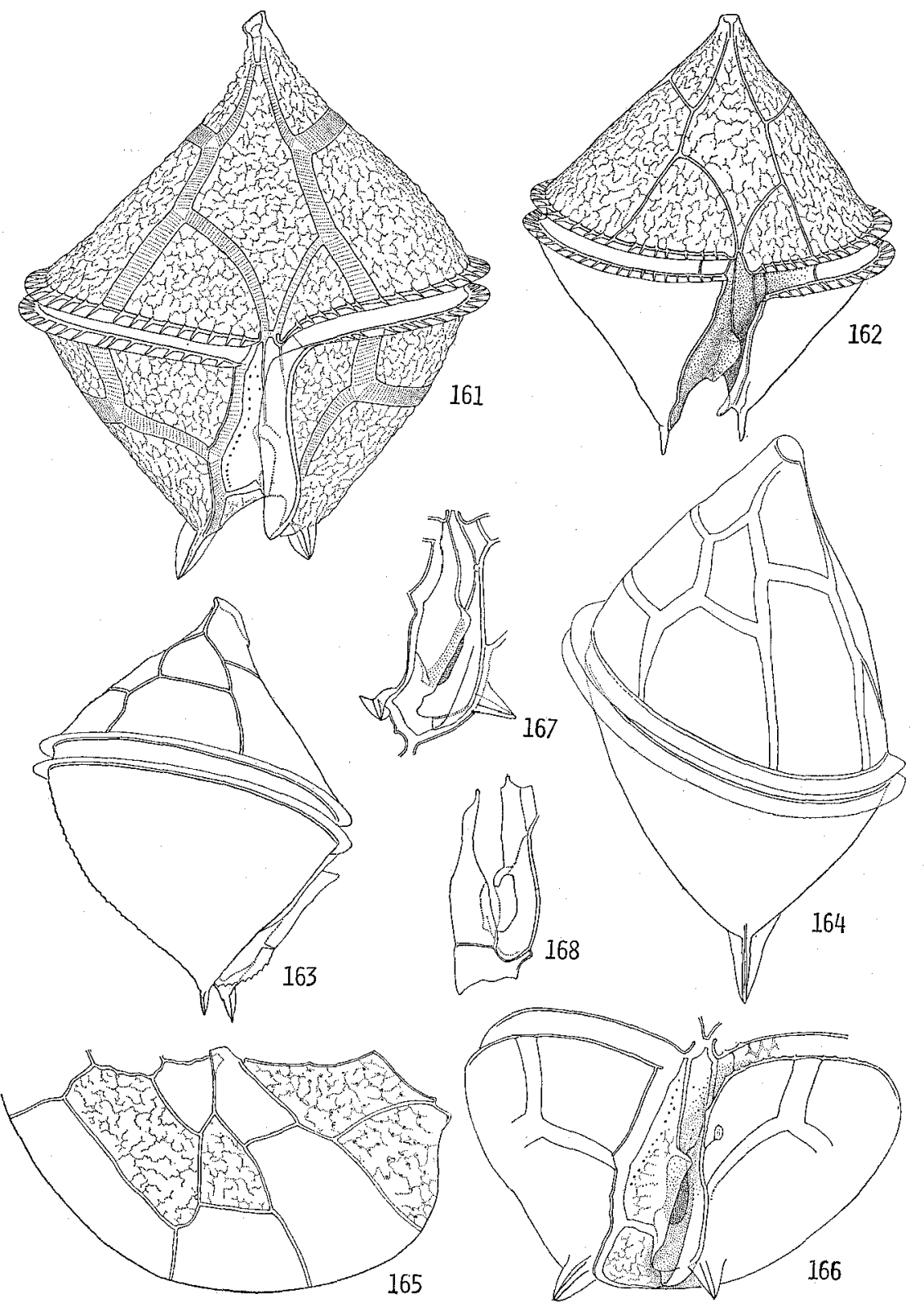

Fig. 25 (161-168): Peridinium rhomboidalis n. sp. 161-A full grown specimen, ventral view. 162Smaller specimen with wingless antapical spines. 163, 164-Side views of differently flattened specimens. 165-Surface view of an isolated flattened epitheca. 166-Ventral view of hypotheca, left sulcal list is partly illustrated. 167-Ventral area. 168-Four sulcal plates, isolated and flattened in conjunction with transitional plate. 
The deeply excavated ventral area is fairly narrow, coming broader only slightly in its posterior half.

As in some of the previous species, the present one also often has a narrow stripe of thecal wall closely along the left sulcal list. And yet the posterior sulcal plate, when isolated, does not extend anteriorly beyond the left antapical spine. The flagellar fin is small and indistinct.

The right sulcal list is very indistinct, but the left is much broader though not so distinct as in the other large species. The antapical spine is short and stout, and has in most cases three small side-wings. But the median wing of the left antapical spine is generally distinct but rarely connected with the left sulcal list. Sometimes we saw specimens with the wingless antapical spines (Fig. 25-162).

The thecal wall is thin and covered with incomplete meshes which are distributed more sparsely in younger or smaller specimens than in older or larger ones, and along the meshes minute pores are scattered irregularly. Among the sulcal plates, the anterior and the left ones, together with the transitional plate, are left free from the marking, while the cingular wall has the typical meshes. The ventral pore on the left ventral postcingular plate lies close to its median margin at one-third from its hind end. It has an ovoidal flange connected by a slender oblique ridge with the base of the left sulcal list. But frequently we failed to find the flange.

Dimensions: Body length (excluding antapical spines), 90-115 $\mu \mathrm{m}$. Transverse diameter, $75-98 \mu \mathrm{m}$. Dorso-ventral diameter, 65-73 $\mu \mathrm{m}$. Width of girdle, $5 \mu \mathrm{m}$.

This species might have been confused most frequently with $P$.pallidum from which it can be distinguished by its rhomboidal body and its deeply indented postmargin. Among published figures, one of MarukawA's $P$. pallidum (Fig. 59 i, pl. 4) is apparently the closest relative of this LeBour's P. pallidum (pl. 28, Fig. 1 a-c) which is the next to be considered here judging from its rhomboidal body. But her species corresponds apparently to the larger form of $P$. pallidum in this paper, from which this can be separated mainly in its narrower ventral apical plate, less developed antapical wing-complex, smaller transverse diameter of the body and the more deeply indented ventral area and the postmargin of body.

Judging from the deep concavity of the ventral area, which is not general in this group, it may be granted to suppose that some smaller specimen of this species might have been mistaken without due morphological analysis for a certain rhomboidal species of the group Conica such as $P$. leonis or its allies. But different structural relations of their ventral area serve to separate them at once. The present species may well be regarded as represent a type with least developed ventral area in this group, judging from its simply organized wing-complex.

But its highly differentiated posterior sulcal plate leads us to the interpretation that this species is one of the closest relatives of $P$. schilleri, one of the most highly advanced forms in the group. 


\section{Peridinium sphaericum OKAMURA}

Fig. 26 (169-175)

Okamura, 1912, p. 14, Pl. 4, Figs. 71, 72.

P. globulus var. KARSTEN, 1907, p. 416, Pl. 50, Fig. 15 a, b.

P. ellipsoideum Dangeard, 1927, p. 10, Fig. 6 A-D.

P. ovum, in part, DiwaLd, 1939, p. 167, Fig. 5.

OKamura (1912) recorded from Zenisu, south of Tokyo Bay, an ovoidal species furnished with an equatorial girdle, a minute and abruptly differentiated apical process and two wing-complexes, and DANGEARD (1927) described a similarly shaped $P$. ellipsoideum from the tropical Atlantic ocean. These two forms correspond with each other the structures just given above. Thecal details of the former given in literatures are far from complete, and can hardly be compared with those of the latter. But so far as illustrated in published figures, their specific distinction is hardly possible. The main differences established regarding DANGEARD's species are a little greater relative length of its midbody, its pre-equatorial girdle and shorter antapical spines. It is doubtful whether or not these characters were given by them with trustworthy accuracy.

We found in Shimoda an ovoidal species hardly distinguishable from either of them. Measurements on published figures and Shimoda specimens inform us that the relative length of the midbody becomes larger in the order of Shimoda form, $P$. sphaericum and $P$. ellipsoideum, as their length-breadth ratio is $1.14,1.16$ and 1.26 respectively. From these, it is apparent that they form a well established species.

The elongated globular or rotated ellipsoidal body has similarly rounded two ends, one furnished with a minute and abruptly differentiated apical process and the other with two short and well winged antapical spines inclining ventrally and diverging distally. This elongation or extension in either case lies on the ventral of center of the epitheca or hypotheca. The transverse diameter of the body is greatest in the equatorial region, shortly below the girdle. It is, then, a little smaller at the anterior cingular edge than at the other edge. Lying horizontally for the major length, the girdle forms by means of its weaker distal and stronger proximal arches an ascending spiral with distal displacement of its own width. The cingular section is circular and has no trace of the ventral flattening.

The ventral area is elongated, extending posteriorly to the center of hypotheca. It is widest in the middle, where it becomes narrower anteriorly, hardly extending beyond the girdle. In the other half it has subequal breadth throughout and is bluntly pointed posteriorly. The flagellar pore is strikingly displaced posteriorly, lying close to the hind end of the ventral area.

The right sulcal list consists of a narrow anterior half of subequal breadth and a much broader and triangular posterior half, forming an interruption between them. The latter merges posteriorly to the ventral side-wing of the right antapical spine, which has in addition a narrow lateral and a larger median sidewings. The left sulcal list is strikingly broader, particularly distinct in its posterior half where it has 
minute serrae along its free margin. Posteriorly it terminates on the median side of the left antapical spine with which it is connected transversely by a small list.

The ventral plate pattern is 'para', and two fan-shaped ventral precingular plates are subequal in size with each other. Covering by far the major portion of the dorsal face of the epitheca, the transversely elongated, hexagonal middle intercalary
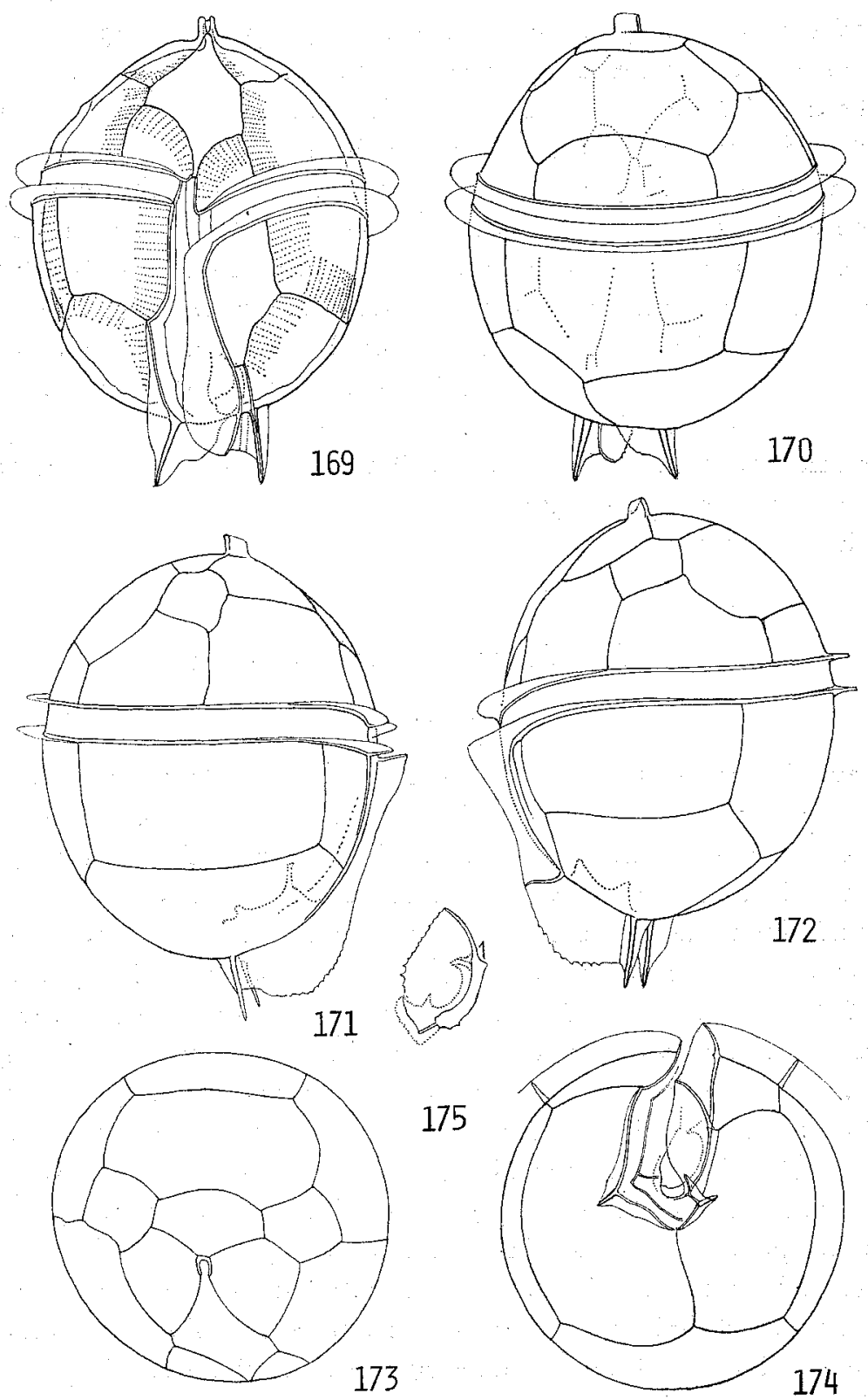

Fig. 26 (169-175) : Peridinium sphaericum OKAMURA. 169-Ventral view. 170-Dorsal view. 171, 172Side views. 173-Plate pattern of epitheca, 174-Ventral view. 175-Isolated sulcal list. 
plate is much larger than the lateral of the same series. The postcingular row of plates covers the anterior half of the hypotheca. Its left ventral component is about two-thirds as broad as the right ventral one, and is more posteriorly displaced.

In accord with the posterior displacement of the flagellar pore, three of the four sulcal plates are remarkably elongated. The other posterior sulcal plate is small and not much differentiated bilaterally. There can be established in ventral or antapical view of well grown body an exceedingly narrow stripe of thecal wall along lateral base of the broader posterior half of the left sulcal list. This structure can be traced dorsally to the posterior sulcal plate or to the small median sidewing of the left antapical spine. When the thecal plates of the hypotheca were separated from each other, this stripe was found clearly continuous to the left sulcal plate and not to the posterior sulcal one. In other words, this stripe, the broader posterior half of the left sulcal list and the posterior sulcal plate form a single unit of the thecal wall and can not be separated from one another with all repeated efforts by the author. This suggests the fact that the posterior half of the left sulcal list springs from the left sulcal plate and the stripe is nothing but a sutural addition of the sulcal plate.

Measurements: Length of body, $63-68 \mu \mathrm{m}$. Transverse diameter, $56-59 \mu \mathrm{m}$. Length of antapical spine, $10-12 \mu \mathrm{m}$.

Locality: Shimoda.

\section{Peridinium cerassiformis n. $\mathbf{s p .}$}

Fig. 27 (176-179)

The apical horn is about one half as long as the globular midbody which is slightly flattened in dorso-ventral direction by means of its weak ventral flattening. Around the equator of the midbody runs the girdle horizontally for the major length. But it forms in its first quarter a weakly oblique tract, by means of which it forms an ascending spiral with distal displacement of its own width. The hypotheca is hemispherical and has no trace of the postero-median indentation in spite of greater breadth of the ventral area which broadens posteriorly extending to the center of hypotheca. Associated with this posterior broadening, the two antapical spines are remarkably separated from each other, and further they strongly diverge distally. These spines are furnished with three narrow but well-formed side-wings respectively. The left sulcal list is strongly formed, extending much posteriorly beyond the body. The structural relations among the sulcal list, the side-wings of the spine and the sulcal plates are typical of the Pellucida group.

The ventral plate pattern is 'para'. The ventral apical plate has a narrow anterior extension, by which it extends almost to the distal end of the apical horn. The two ventral precingular plates are exceedingly small in size and subequal with each other. The two ventral postcingulars differ strikingly from each other in size and are asymmetrical in site as in the previous species. 

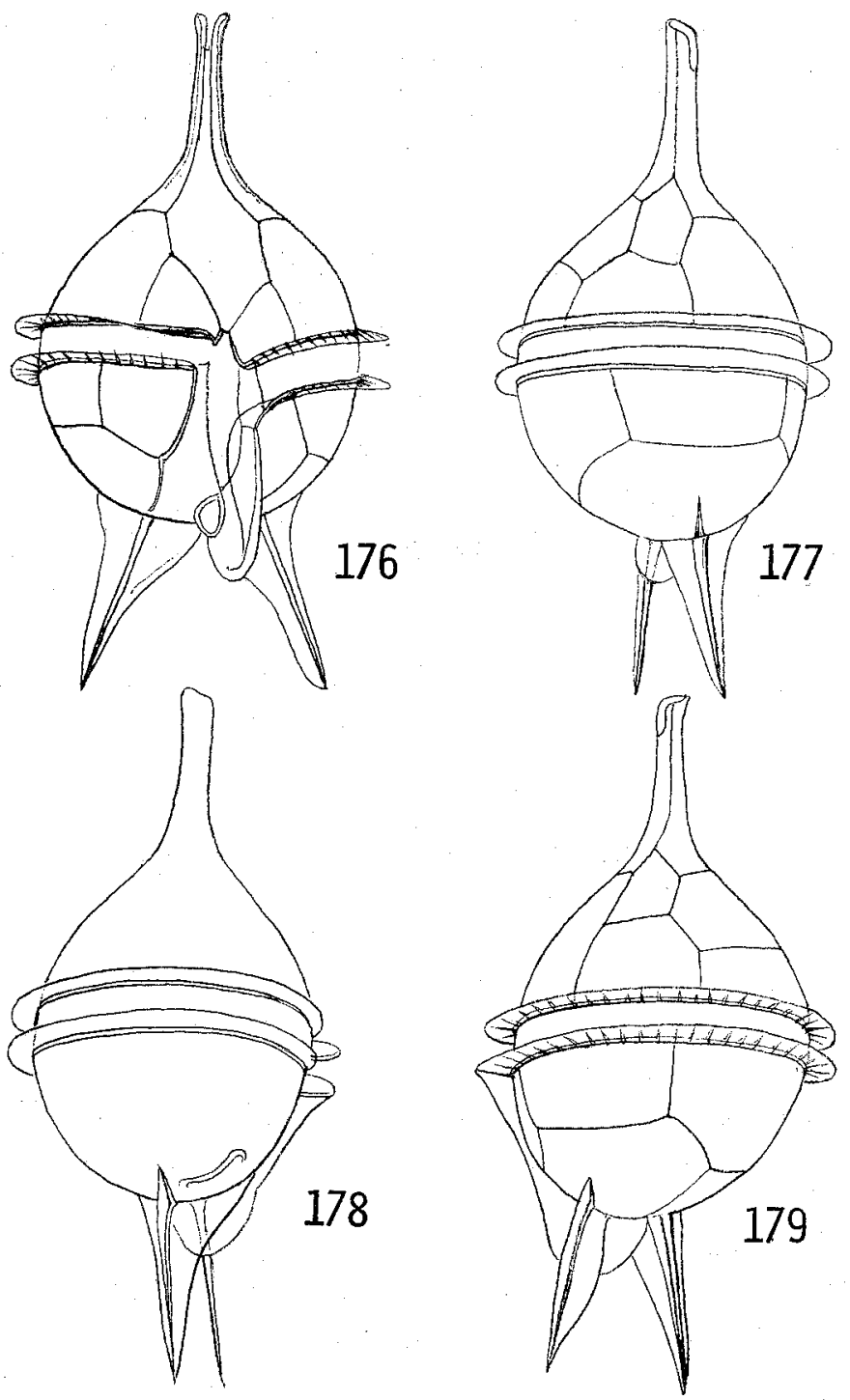

Fig. 27 (176-179): Peridinium cerassiformis n. sp. 176-Ventral view. 177-Dextral side view. 178Side view. 179-Sinistro-dosral view.

Measurements: Length of body including apical horn, $60 \mu \mathrm{m}$. Diameter, $37 \mu \mathrm{m}$. Depth, $34 \mu \mathrm{m}$. Length of antapical spine, $22 \mu \mathrm{m}$.

Locality: Shimoda.

One of the closest relatives of the present species is $P$. tenuissimum, which differs from this in its longer apical horn and smaller and more rotund midbody. Another to be considered is $P$. longicollum, from which this can be separated by its more rotund midbody and more strongly diverging antapical spines. From P. microangusticollis, to which it is also closely related, this can be distinguished by its different plate pat- 
tern of the epitheca and also different structural relation of its antapical wing-complex and further by its longer apical horn and antapical spine and more swollen midbody. By the characters given above, this can be separated from KoforD's P. steinii and its varieties.

\section{Peridinium schilleri PAULSEN}

Fig. 28 (180-185)

Paulsen, 1931, p. 56, Fig. 27 A.C.

The body is swollen rhomboid or ovoidal tapering anteriorly more or less abruptly into a short and minute apical elongation and is provided with an equatorial girdle and two well developed, fairly parallel antapical wing-complexes.

The epitheca is convex conical or dome-shaped with a tapered apex. The equatorial girdle forms an ascending spiral displaced distally its own width. Its wall is flat or slightly concave and guarded with well ribbed lists. The cingular section is nearly circular and weakly tilts down ventrally. No postmedian depression nor conical bulge of the thecal wall at the base of the antapical spine can be seen in the hemispherical hypotheca. The antapex is on the ventral of the center of hypotheca, where two well winged antapical spines stand bilaterally extending posteriorly and are fairly parallel with each other.

The ventral plate pattern is 'para', and the middle intercalary is hexagonal. The apical collar which encircles the apical pore and consists of the anterior extensions of the lateral and dorsal apical plates, is seen extending along the ventral slit of the pore and often further along the ventro-median margins of the lateral apicals. A distinct list is often seen standing along the suture between the lateral and dorsal apical plates. In the hypotheca, the right ventral postcingular is 1.5 times as broad as the left ventral of the same series, which is much longer than broad. The other ones of the series cover anterior one-third or a little less of the hypotheca.

The ventral area is narrower anteriorly than posteriorly, extending to the center of hypotheca. The four sulcal plates are typical in arrangement. But the anterior three of them are much elongated, and the other posterior member is quite small in consequence of distinct posterior displacement of the small flagellar pore. The sulcal furrow is confined to the left half of this area, dying out anteriorly and sharply differentiated posteriorly from the posterior and right sulcal plates. The two ventral cingular plates are minute and rectangular, each lying at either end of the girdle. The left sulcal plate forms in overgrown specimens a narrow stripe of thecal wall along lateral base of the left sulcal list which belongs to the plate.

The distinct left sulcal list is broader in its posterior half where it expands as far as the left antapical spine and covers the major left half of the ventral area. A parallel antero-posterior differentiation is seen also in the right sulcal list. A close line of basal ribs is often seen along the entire length of the right and in the anterior half of the left sulcal lists. 
The stout antapical spines are fairly parallel in ventral view and are furnished with three side-wings respectively. In the right wing-complex, the dorso-median wing is much larger than the lateral one, consisting of a narrower distal and a broader basal parts. In the other complex, all the three side-wings are small. We have

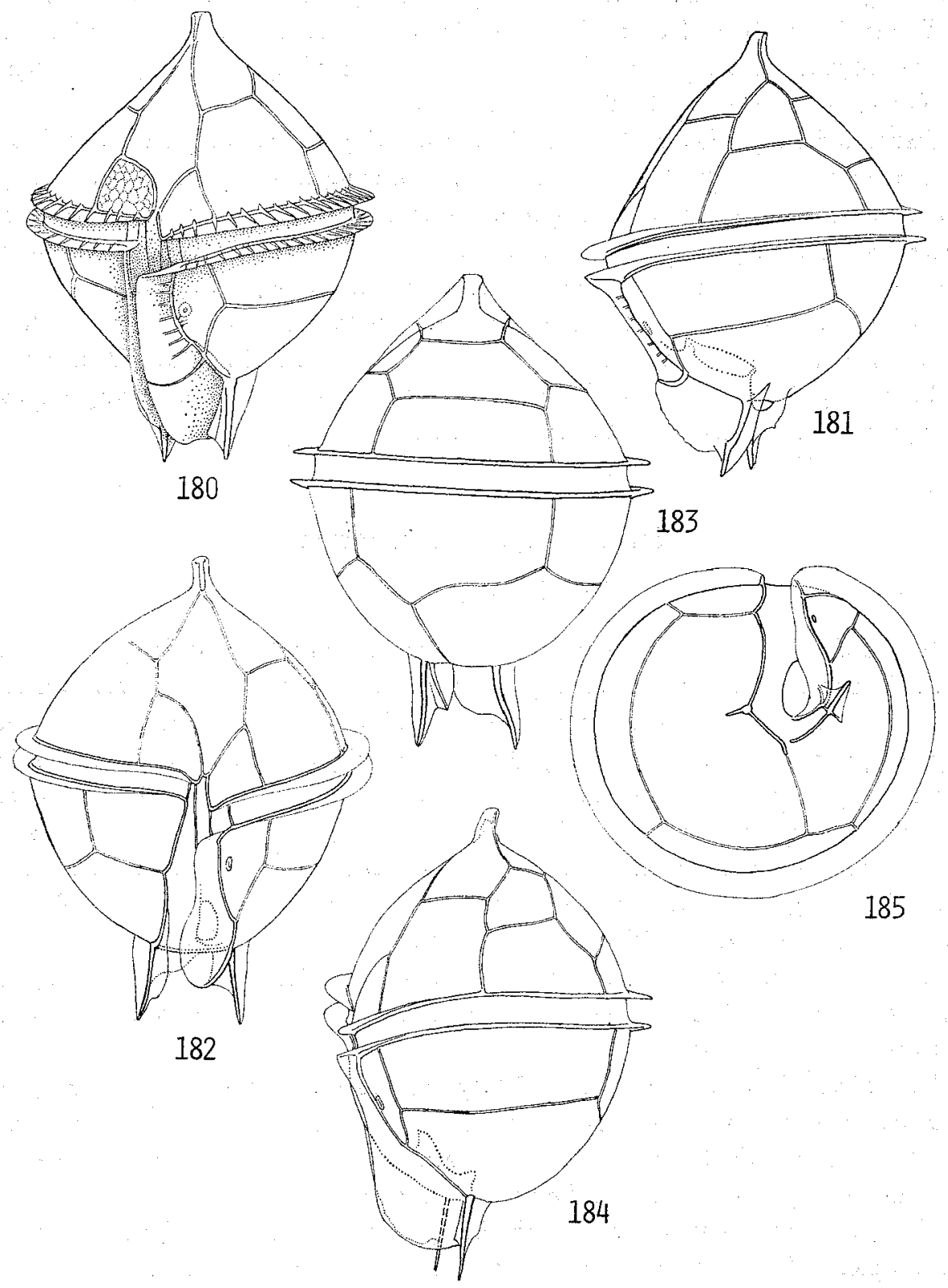

Fig. 28 (180-185): Peridinium schilleri PAulsen. 180, 181-Oblique ventral and side views of a rotund specimen with less contracted apical horn. 182-185-An elongated specimen with abruptly differentiated apical horn. 182-Ventral view, 183-Dorsal view. 184-Side view. 185-Antapical view. 
never seen in this typical species a minute accessory wing at the base of the right antapical spine as that found in f. complexum.

The thecal wall is reticulated. The ventral pore lies close to the median margin and in front of the middle point of the left ventral postcingular plate. It has a circular flange connected often with the margin of the plate by an oblique ridge.

Dimensions: Body length 67-76 $\mu \mathrm{m}$. Breadth 56--70 $\mu \mathrm{m}$. Dorso-ventral dimensions 54-64 $\mu \mathrm{m}$. Girdle breadth, 5-6.5 $\mu \mathrm{m}$, length of antapical spine, 15-16.5 $\mu \mathrm{m}$.

The present species is also found in Shimoda.

Paulsen distinguished in $1931 \mathrm{P}$. schilleri from $P$. pallidum and gave its six figures including two ventral (A, B), one dorsal (C), one antapical (D) and one lateral (F) views in addition to a ventral view $(E)$ of an epitheca. Of these, the sutural zone is represented by a single line in $\mathrm{A}$ and $\mathrm{B}$, but by a double line in C-E. So far as his figures and characterization of the species indicate, his separation appears to be correct. On the other hand, there are some reasons to doubt whether or not all the specimens illustrated are to be comprised in a single species. Our Pacific form can be distinguished, if necessary, from them by its smaller size, its larger dorsoventral diameter and its parallel antapical spines.

\section{forma complexum $\dot{\mathrm{n}}$. forma}

Figs. 29, 30 (186-201)

This differs from the typical one in its larger size, more strongly elongated but less swollen body and especially distinctly in its stouter antapical extensions, and it is furnished generally with thicker thecal wall. Judging from general features of the body, the present form is more closely related to $P$. tristylum STEIn than to the typical species just given above. But we have to consider here the fact that all of the specimens examined are invariably furnished with broad and well striated sutural zone. And we are entirely ignorant whether or not the STEIN's species has broad sutural zone. This, together with extremely scarce occurrence of the present form in Shimoda, led us to deal with this in this paper as a form of the previous one. In addition, the present form manifests some peculiarities not seen in the typical one. Consequently, it is convenient to consider this here separately from the typical one.

The distinctly conical epitheca slightly exceeds the hypotheca in length, and the cingular section is broadly ovoidal with a weak ventral flattening, tilting down ventrally especially distinctly in its ventral half. The antapical spines are furnished with well developed side-wings and do not diverge distally.

The plate pattern is the same with the typical species. The right edge of the ventral apical $1^{\prime}$ is much shorter than its left edge. This asymmetry is inversely associated with difference in length and size of the two ventral precingular plates. In this regard, this is more closely related than the typical one to PAULSEN's original species. In the hypotheca., the left-ventral postcingular $1^{\prime \prime \prime}$ appears to be variable 
in shape, as it is in some specimens much longer than wide, while in others irregularly triangular or rather crescent with its one end truncated. The antapical wingcomplex is peculiar in structure and may be thought to be the one most highly advanced in this group. The spine and its side-wings are stouter than those of the typical species. There is a very low and indistinct list standing along the lateral margin of the narrower left lobe of the posterior sulcal plate. This may be regarded as the fourth wing of the left antapical spine. Closer examination of the right wingcomplex reveals, in addition to it's typical three side-wings, a fourth minute and triangular one lying just at the lateral base of the spine (Figs. 30-144, 195, sc.w.).

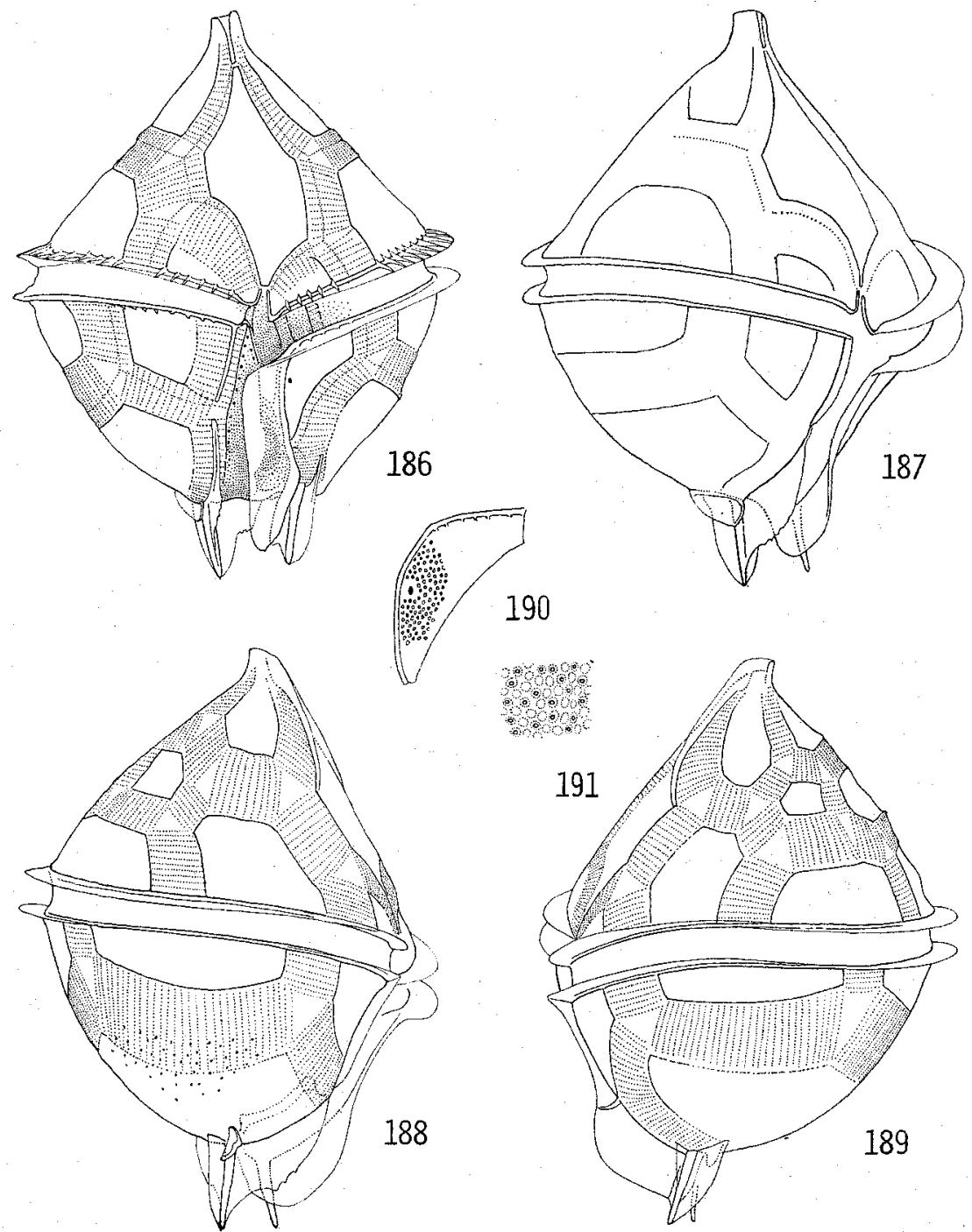

Fig. 29 (186-191): Peridinium schilleri f. complexum n. forma (1). Well grown specimen in a different aspects. 186-Ventral view. 187-Dextral ventral view. 188, 189-Side views. 190 - Left ventral postcingular plate. 191 -Inner surface structure of thecal plate, half schematized. 
It is only one-fourth of the spine in length and triangular in shape, bulging out ventrally in scoop-shape. Interesting is the fact that the former can be seen not only in this but also in the typical species, but the latter is found only in this form. As a consequence, there arises an interesting problem as to the morphological signifi-
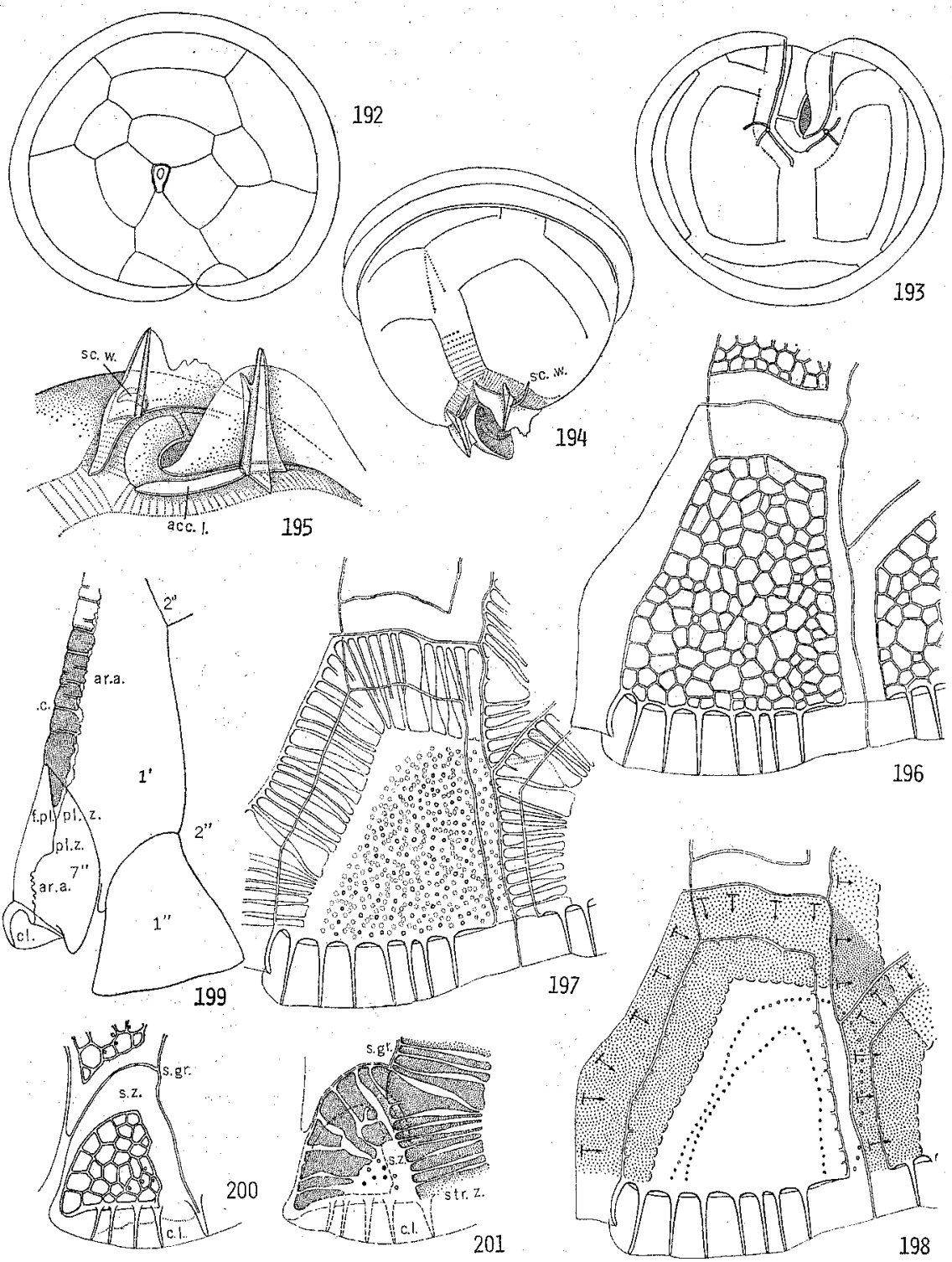

Fig. 30 (192-201): Peridinium schilleri f. complexum n. forma (2). 192-Apical view. 193-Antapical view. Sulcal lists are partially observed. 194-Postero-dorsal view of hypotheca. 195-Schematic illustration in sinistro-dorsal view of antapical and sulcal extensions. acr. 1.- accessory list of left wing-complex. sc. w.-spoon-shaped accessory wing of right wing-complex. 
cance of these structures. The antapical spines in this form have then each four wings instead of three. The accessory one in each wing-complex is exceedingly smaller than the others. In structural relations to the antapical spine and ventral area, that of the right wing-complex corresponds apparently with the ventral wing of the left wing-complex while that of the left does so with the dorso-median wing of the right wing-complex. This suggestion is based upon the fact that the ventral and the dorso-median wings of the right wing-complex stand along the very margin of the ventral area, just as the median wing and the low accesory list of the left. wing-complex do so.

The structure of the thecal wall of this species was given in previous paragraphs. In practice, the reticulation is hard to establish, and we can see more distinctly the thecal pores and poroids of inner surface of the thecal plate, presumably owing to greater thickness of the thecal wall in this species (Figs. 30-199). The ventral pore on the left postcingular $1^{\prime \prime \prime}$ is a little larger than the ordinary pore of the thecal wall and has no flange (Fig. 29-190). It lies just along the median margin of the plate and halfway between the girdle and the postcingular-antapical suture.

Dimensions: Body length, 76-97 $\mu \mathrm{m}$. Transverse diameter, 65-87 $\mu \mathrm{m}$. Dorsoventral diameter, $57-78 \mu \mathrm{m}$. Girdle width, 5-6 $\mu \mathrm{m}$. Length of antapical spine, 9-16 $\mu \mathrm{m}$.

Locality: Asamushi.

\section{Subgenus 2. Mesoperidinium n. subg.}

The ventral plate pattern is usually either 'meta' or 'para' but exceptionally 'ortho'. The intercalary series consists of three plates. The ventral area expands abruptly towards the left in its posterior half where left lobe of the posterior sulcal plate extends anteriorly along lateral of the left sulcal list to meet distally the left ventral postcingular plate. Posteriorly the body bears shorter or longer antapical wing-complex or antapical horns with or wothout forming distally short spine or wing-complex. The antapical spine, when it is formed, is separated at least by the breadth of the left lobe of the posterior sulcal plate completely from the left sulcal list with which, then, it has no direct connection. Smaller or larger median basal portion of the antapical horn, when it is formed, is covered with the posterior sulcal plate which in no case extends to the tip of the horn.

In this subgenus are comprised these species with the ventral area asymmetrically expanded abruptly towards the left in its posterior half. They may be divided into two groups, one only with the wing-complex and the other mainly or solely with the heteromorphous horn. These two types of the antapical extension are correlated principally with the ventral plate patterns of 'para' and 'meta' respectively and also with rounded or angular bulge of the thecal wall along the cingular region. Further, they are coupled with tetragonal or pentagonal middle intercalary plate in one and exclusively with hexagonal one in the other. These two groups differ remarkably from each other in these skeletal features just cited, the former showing somewhat closer relationships to Protoperidinium and the latter to Veroperidinium by way of 
Parapellucida and Tatrica respectively. This suggestion may be supported by the common occurrence of the ventral pore in Parapellucida and in one-half of this subgenus coupled with well formed wing-complex and also by its absence in the other half of this and also in Tetrica. Just a corresponding relation can be also established in regard to the shape of the water-pusule built within their body.

These species are then related partly to Protoperidinium and partly to Veroperidinium, but none of them can be allocated to either of them because of the peculiarity manifested in the hypotheca, particularly within the ventral area. On the other hand, all of them can be arranged in an uninterrupted series in regard to the relationships among the antapical spine, antapical horn and posterior sulcal plate. The antapical spine or wing-complex is only poorly or scarcely formed when the antapical horn is longer in one end of the series and vice versa in the other end. And the left lobe of the posterior sulcal plate is much smaller in breadth than its right lobe in long-spined or short-horned species, while the left is much more larger than the left in long-horned species. Two extremities of the series appear to differ thus from each other so strikingly in many respects but they are connected by intermediate forms. On the other hand, none of these seriated ones differ profoundly from any of Protoperidinium or Veroperidinium in the asymmetrical, abrupt expansion of the ventral area towards the left, which is unparalleled in the genus Peridinium. And at the same time they form as a whole a connecting link between the two subgenera of the genus.

It is, however, of taxonomic convenience to divided the present subgenus into two groups according to absence or presence of the antapical horn, because they differ from each other in some or other respects.

Key to groups

1. Shorter or longer antapical spine or wing-complex is formed

A. The thecal wall does not bulge at the base of the spine to form a conical elevation or horn Paradivergentia

B. Longer or shorter conical process is formed at the base of the spine Divergentia

2. Typical shorter or longer antapical horn is formed. Divergentia

\section{Group 1. Paradivergentia PAULSEN (emend.)}

Paulsen, 1931, p. 48, 55.

The body is pear-shaped or rotated pentagonal with or without an elongated apical horn. The equatorial or pre-equatorial girdle is circular or forms an ascending spiral, lying horizontally for the most part. The ventral depression of the body is absent or very faint. The hypotheca has no distinct horn at the base of the antapical spine which is generally elongated and well-winged but exceptionally very short and wingless. The posterior sulcal plate is Divergentia-type in shape, separating 
the left antapical spine or wing-complex from the hind end of the left sulcal list which extends posteriorly beyond the hind end of the body.

The ventral plate pattern of the epitheca is 'para', and the middle intercalary plate is hexagonal and much larger than the laterals of the same series.

Paradivergentia was established by PAulsen (1931) in these species with the ventral plate pattern of 'para' and hollow antapical horns, such as $P$. areolatum PETERs, P. spinulosum Samller and P. solidicorne MANan, and was distinguished from Divergentia by the plate pattern just cited.

By finding in Shimoda a form corresponding to the last of the three species, we were informed of the structural relations of the hypotheca, especially of the ventral area, and that $P$. solidicorne can not be distinguished from these typical species of Divergentia, such as $P$. crassipes, $P$. adriaticum or their allies. On the other hand, there are some reasons to believe that the three species cited by Paulsen (1931) may not be worthy of specific distinction.

There is another group of species, in which the posterior sulcal plate is also Divergentia-type, extending on the left to the left ventral postcingular plate, and the antapical spine or wing-complex has no direct connection with the left sulcal list. In this, however, the antapical horn fails to develop. Four species of $P$. isthmus n. sp., P. gibberum n. nom. (=P. okamurai ABÉ), P. diabolus GLEve (=P. macrospinum Mangin) and $P$. globosum (Gourret) (=P. longipes KArsten) are worthy of consideration in this regard.

In all of them, the left of the well-winged antapical spines appears in ventral view of the body as if connected to the hind end of the left sulcal list by one of its three side-wings. But so far as our morphological studies on $P$. isthmus, $P$. gibberum and $P$. globosum reveal, the two structures are separated entirely from each other by the left lobe of the posterior sulcal plate. The first of the three species is so closely related to some of Pellucida in the shape of the body and length of the antapical wingcomplex that at a glance it may be wrongly allocated to that group. The other two species are furnished similarly with extraordinary long and well developed antapical wing-complex. In $P$. globosum, the ventral area expands laterally so distinctly at the hind end of the body just between the two antapical spines that these spines appear in ventral view of the body as if displaced much laterally beyond the edge of the ventral area (Fig. 32-213). In this regard, P. diabolus Cleve is undoubtedly the closest relative of that species. This lateral expansion of the ventral area at the base of the antapical spines may be regarded as morphological equivalent of the corresponding structure seen in $P$. solidicorne of Divergentia and also in $P$. pallidum of Pellucida. Further the ventral pore established by us in most species of Pellucida can also be seen in $P$. globosum.

From these, it may be granted to suggest that these species are so closely related with one another in the structures that they can be considered to form an established group, closely related to Pellucida on one hand and to Divergentia on the other hand. As in other groups such as Divergentia and Conica, the differentiation of the flagellar furrow from the sulcal furrow is also in this group apparently correlated with higher 
lateral differentiation and development of the posterior sulcal plate which can be established most distinctly in $P$. globosum and least definitely in $P$. isthmus. In relation to this structural difference, the hind end of the body is not indented in the former species while the postero-median portion is excavated ditinctly in the latter.

There is an interesting species, P. pellucidum of PAULSEN (1911), in which the posterior sulcal plate is of Divergentia type while the general structural feature of the body is of Humilia, especially of its Laterispinosa. His species consists of two forms one with a larger (Fig. 11) and the other with a smaller body (Fig. 10). Although details of the thecal structure of this larger form is entirely unknown, his Fig. 11 c illustrate that the minute left antapical spine is apparently separated laterally from the left sulcal list by the left lobe of the posterior sulcal plate, suggesting probable correct allocation of this species to the present group. If this consideration is correct, it may be allowed to suggest that Paradivergentia is also related to Humilia from which the present group, together with Divergentia, might have been partly derived.

Though only insufficiently illustrated, both $P$. pedunculatum SaHürt and $P$. formosum PAVILLARD or only the latter of them manifests some characteristics suggesting its close natural affinity to $P$. diabolus. But taxonomic allocation of one or both of them can not be discussed here, because not examined any of these three forms cited above.

Key to species

1. The body is pear-shaped with a narrow but deep postero-median indentation but does not form an elongated horn anteriorly. The antapical spine is short and feebly formed Peridinium isthmus

2. The body is pear-shaped without a distinct postmedian indentation and an apical horn ................................................. gibberum

3. The midbody is in ventral view shortly pentagonal, forming a more or less elongated apical horn and well formed antapical wing-complexes of subequal length but no postero-median indentation

a. The epitheca passes gradually into the apical horn.............. diabolus

b. The conical epitheca is more or less abruptly differentiated from the apical

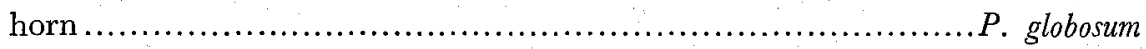

\section{Peridinium isthmus n. sp.}

Fig. 31 (202-208)

P. pallidum, in part, Marukawa, 1921, p. 24, Pl. 4, Fig. 59 j.

This huge, pear-shaped species is characterized by its very short and weakly developed antapical wing-complexes, unusually converging distally. The body is 

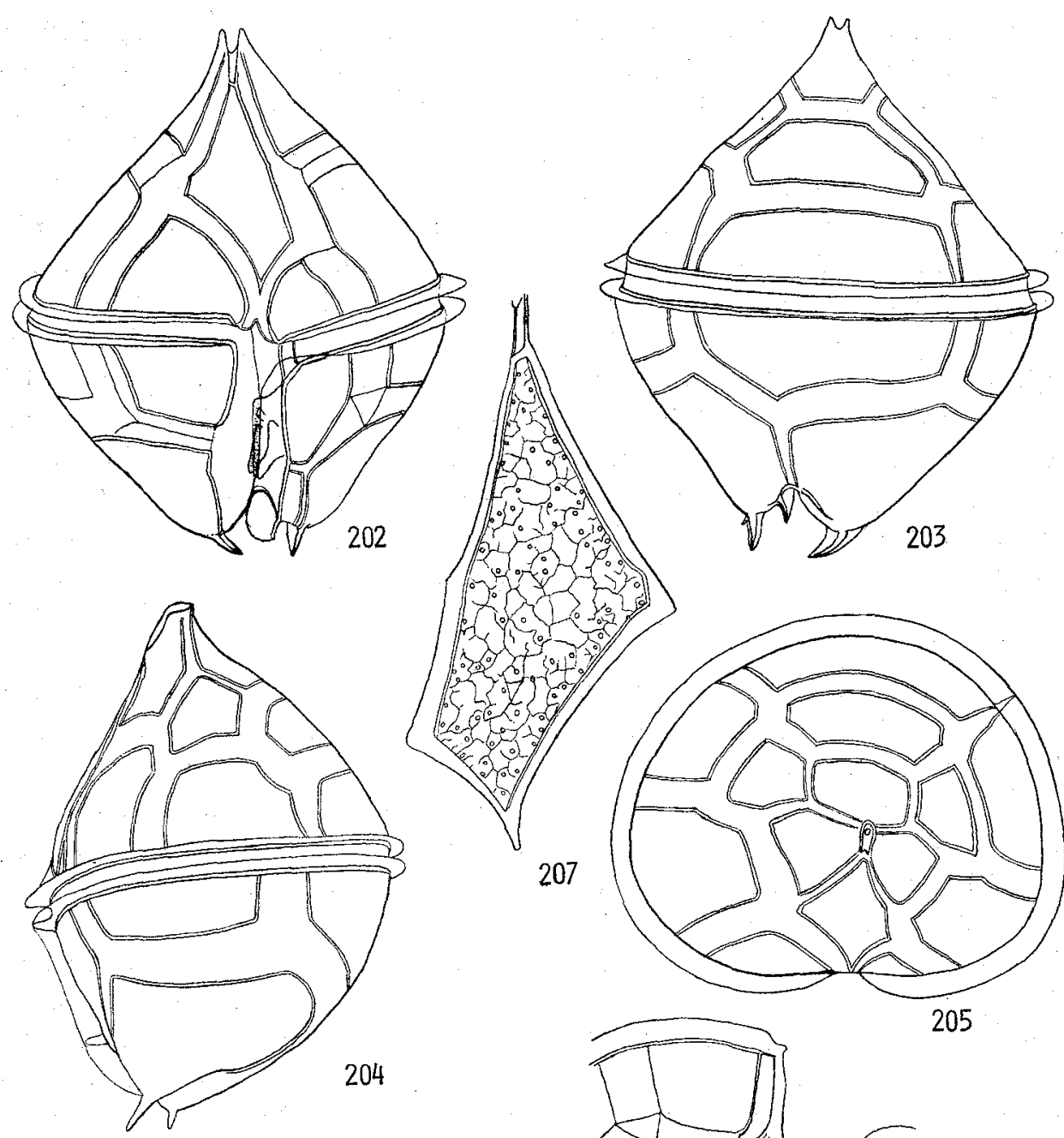

207
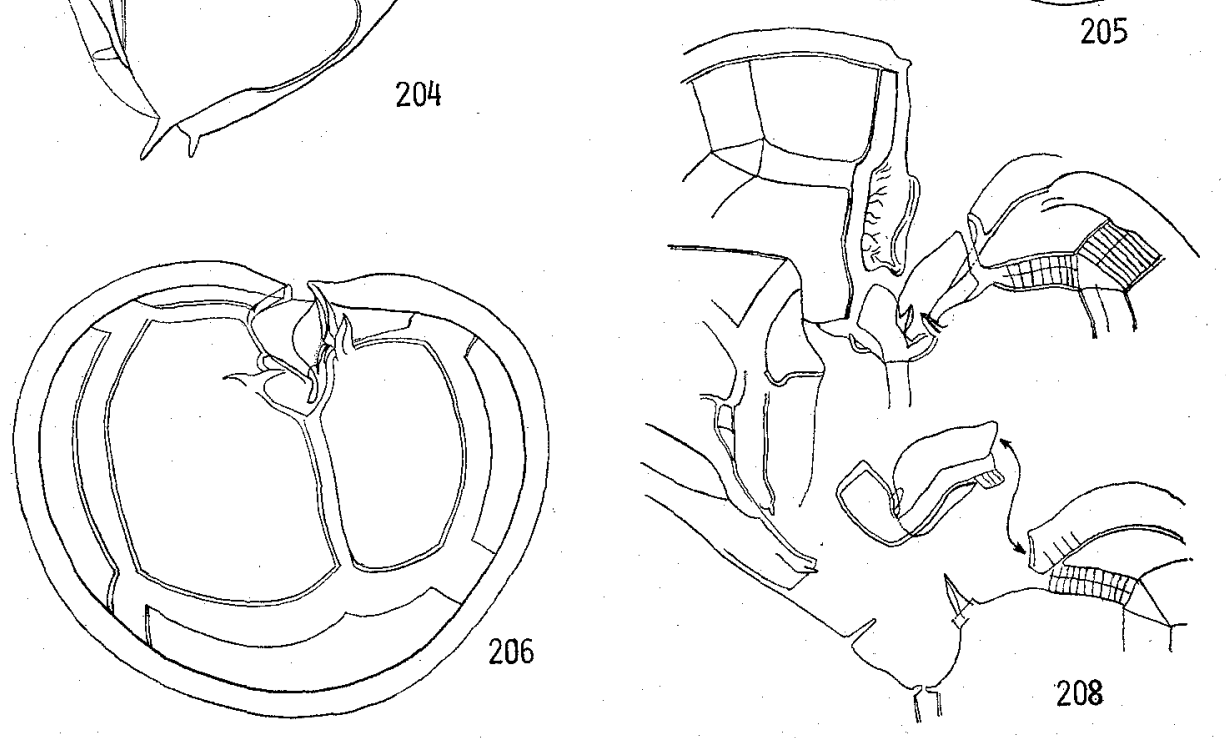

Fig. 31 (202-207): Peridinium isthumus n. sp. 202-Ventral view. 203-dorsal view. 204-Side view. 205-Apical view. 206-Antapical view. 207-Ventral pre-cingular plate, inner view. 208Ventral area and adjacent plates, dissociated. 
in ventral view rhomboidal with a pointed apex and a rounded antapex, of which median portion is indented. It bulges more dorsally than ventrally, and the equatorial cingular plane, which is broadly reniform, tilts down ventrally. The apex, then, lies at the center of the epitheca, but the antapices are displaced ventrally. Around the broadest part of the body lies the narrow, ascending girdle with distal displacement of its own width. The cingular list has short and equidistant ribs in its basal half. The narrow and deeply excavated ventral area extends posteriorly beyond the antapices and nearly to the center of the hypotheca, forming the posteromedian indentation of the body. It does not expands distinctly towards the right as in other species of the group, and bears along its left side a distinct list, which covers the deeper left half of the sulcal furrow and extends posteriorly beyond the hind end of the body. A short and curved right antapical spine bends medianwards, standing at the dextro-dorsal corner of the posterior sulcal plate. A similar but more straight left one is displaced more ventrally, bending also towards the ventral, and stands at a short distance laterally from the hind end of the left sulcal list. They bear a ventral and a dorsal side-lists of subequal size, but a lateral one is very indistinct.

The ventral plate pattern is 'para', but the right side of the irregularly hexagonal ventral apical is so small in length that two sutures are seen under lower magnification as if crossed at a point on the right of the plate.

The ventral plate pattern is 'para'. Difference in length of the lateral sides of the ventral apical plate is so great that the actual length of extremely short, right side of this plate was established on an isolated plate, which was given in Fig. 31-207. The triangular left ventral precingular plate is about one half as long and broad as the similarly shaped right ventral of the same series. Mid-dorsal three plates including the hexagonal middle intercalary are subequal in length with one another. The left ventral postcingular plate is longer than wide, while the left ventral of the same series has breadth twice as large as the left ventral. The postcingular row of plates cover anterior one-third or a little less of the hypotheca. The left antapical is much smaller than the right antapical.

In ventral view of the body it is hardly possible to establish the structural relations of the ventral area or sulcal furrow owing to its remarkable depression. But exact shapes and interrelations between the four sulcal plates are brought forth when they are separated from their surroundings or from one another (Fig. 31-208). Regarding anterior three of them there may be no need of special descriptions here as they are typical in all respects of the genus. But it may be added here that the small transitional plate has a minute posterior elongation by which it extends to the left sulcal one. Exact shape of the posterior sulcal plate was hard to be established because of its exceedingly uneven surface. It is L-shaped and consists of a posterior transverse lobe, which is broader as a whole or only in its right half, and a longitudinally elongated left lobe, which has subequal breadth throughout its length, bearing along its entire median margin the broader posterior half of the left sulcal list. This left lobe can be established readily in ventral view of the body just along 
lateral base of the sulcal list from which the left antapical spine is separated by its breadth.

In ventral or antapical view of the body, the left antapical wing-complex appears as if standing partly on the left antapical plate and partly on the left lobe of the posterior sulcal plate. But when these two plates are separated from each other, the spine together with its three side-wings is confirmed springing from the antapical plate and no trace of its base can be sought on the sulcal plate.

The general thecal plates are covered with irregular and incomplete meshes, along which minute thecal pores are distributed. Together with the transitional plate, the left sulcal plate is deprived of this surface marking. The ventral pore is indistinct and has no flange around its opening.

Measurements: Length, 78-95 $\mu \mathrm{m}$. Transverse diameter, 70-86 $\mu \mathrm{m}$. Depth, 53-56 $\mu \mathrm{m}$.

Locality: Shimoda.

It seems highly probable that the present species might have often been misidentified to some larger species of Humilia such as P. pallidum or an allied one, with which this is in reality closely related in general features of the body. The main differences by which this is distinguished from any of that group are the plate pattern of the epitheca, conical hypotheca furnished with deeply excavated, narrow ventral area, short and poorly developed antapical wing-complexes, and particularly the remarkably elongated left lobe of the posterior sulcal plate. These characteristics are shown partly or vaguely in MARUKAwA's Fig. $59 \mathrm{j}$ of $P$. pallidum, drawn by YoNEDA, which then corresponds exactly with the present species and is raised in this paper to the rank of species.

In addition to this typical species, there has been found a form, closely related to this but differing mainly in its less covex thecal wall. Regarding the plate pattern of the epitheca, this corresponds to the typical species, but it differs in typically formed polygonal meshes of its thecal wall. Further, its two short but much stouter antapical spines are diverging distally instead of converging, and the median one of the three narrow side-wings of the left spine can be traced to the left sulcal list extending over the left lobe of the posterior sulcal plate. When the sulcal plate is separated from the left antapical plate, the major portion of this wing is confirmed to belong to the spine, lying over the left lobe with which it has no connection of any sort. But one can establish on the lateral surface of the sulcal list a narrow ridge corresponding in site, shape and size with the distal end of the side-wing. These structural relationships are hardly established without elaborate and minute observations or separating the sulcal plate from the others. The direct connection of the spine with the sulcal list leads us to suggest that this form is a typical species of Parapellucida, but the well formed left lobe of its posterior sulcal plate is typical of Paradivergentia. Further, the connecting side-wing is indistinct and narrow in its distal half lying over the left lobe. From these we are informed that this forms a connecting link between Parapellucida and Paradivergentia, suggesting closest mutual affinities of them or of the two subgenera, to which they belong respectively. 


\section{Peridinium gibberum n. nom.}

P. okamurai АвE, 1927, p. 403, Fig. 20.

Paulsen (1931) allocated the present species to his third section, Pellucida without paying due regards to the structural relations of the antapical wing-complex or the posterior sulcal plate. 'Two of the three side-wings of the left antapical spine stand in this species along the ventro-median edge of the left antapical plate. The spine together with its side-wings is separated completely from the left sulcal list by the elongated left lobe of the posterior sulcal plate, which extends ventrally to the left ventral postcingular plate. Further, the ventral area in this often forms on either side a small lateral expansion just at the base of this spine. All these structural features established as above clearly suggest its correct allocation to the Divergentia group.

Marukawa (1921) has the priority in regard to the specific name, $P$. okamurai.

\section{Peridinium globosum (GoURRET)}

Fig. 32 (209-214)

Ceratium globosum Gourret, 1883, p. 42, PI. 1, Fig. 4.

Peridinium (divergens) longipes Karsten, 1907, p. 418, Pl. 43, Fig. 6 a, b.

Peridinium longipes, Okamura, 1912, Pl. 4, Fig. 57 a-c; Marukawa, 1921, Pl. 5, Fig. 62 a-c (reproduced from OKAMURA).

Peridinium divergens, in part, Hensen, 1911, Fjg. B 5.

KARSTEN (1907) was the first who gave detailed figures of this species. But, GOURRET's species agrees very well with it in its pentagonal midbody, elongated apical horn, two remarkably long, slightly undulating and strongly diverging antapical spines and its straightly cut hind end of the body between the two antapical spines. Further, in his Fig. 4 is drawn the longitudinal flagellum springing from the left of the flattened hind end. All these structural features given by Gourret correspond exactly with those of KARsTen's and also of our Shimoda species, and are also unparalleled in the genus.

The midbody is in ventral view broadly pentagonal and is furnished with a pre-equatorial ascending girdle, an elongated apical horn, about two-thirds in length of the body, and two long and strongly diverging antapical wing complexes, each consisting of an undulating shaft of the spine and its three side-wings. The spine is subequal in length with the apical horn. The cingular section is ovoidal or ellipsoidal. The diameter of the body is greatest at the posterior cingular ridge, and a little smaller at the other cingular ridge. Characteristic is the shape of the ventral area, which is, roughly speaking, an isosceles triangle expanding similarly to either side at the two lower corners of this triangle where stand the characteristic antapical spines.

The hexagonal ventral apical plate tapers much more anteriorly than posteriorly, extending almost to the distal end of the apical horn. The dorsal apical is fairly 
small, extending not much posteriorly beyond the base of the horn. The transversely elongated, hexagonal middle intercalary plate covers larger dorsal median portion of the epitheca. By far the major portion of the cingular wall is covered with a single cingular plate, and the other two are exceedingly small, each lying at the ventral end of the girdle. Either of the two cingular lists is of considerable breadth and is furnished with equidistant ribs. The postcingular row of plates cover the anterior half or a little more of the hypotheca. Among its five component plates,
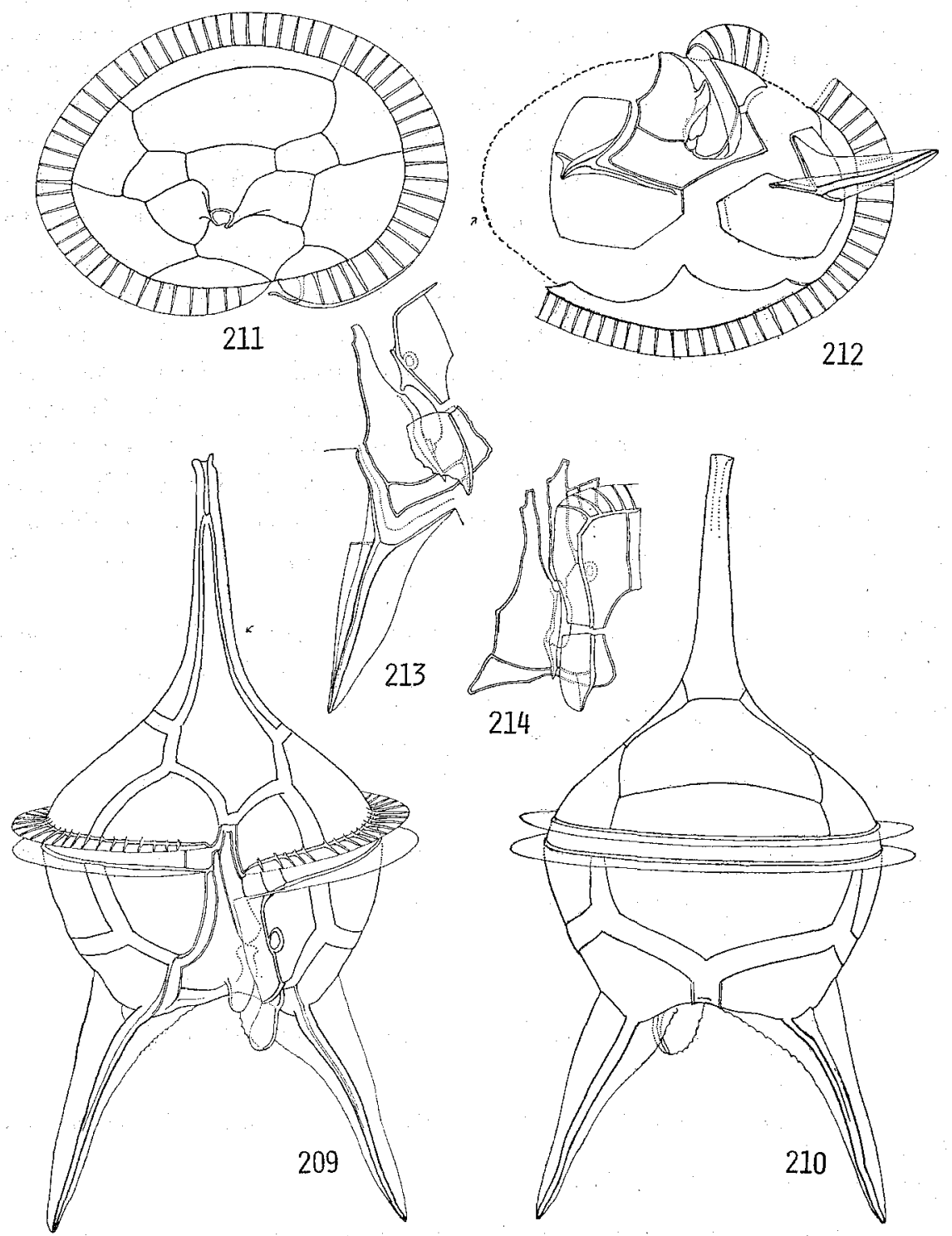

Fig. 32 (209-214): Peridinium globosum (GourreT). 209-Ventral view. 210-Dorsal view. 211-Apical view of epitheca. 212-Dissociated hypothecal plates. 213-Right antapical spine and plates of ventral area. 214-Left antapical spine and girdle-cingular list. 
the left ventral is about one half as broad as the right ventral and is displaced more posteriorly, conforming the distal displacement of the girdle. The plate pattern of the ventral area is typical of the Divergentia group. The right sulcal plate becomes strikingly broader posteriorly, and extends anteriorly with its attenuated neck to the epitheca. The J-shaped left sulcal plate is much smaller and subequal with or a little larger in length than the anterior sulcal one. On the left of the anterior sulcal lies the minute transitional plate, which has breadth subequal with the left ventral cingular plate. Extending between the two antapical spines, the posterior sulcal plate is L-shaped, consisting of a smaller left and a larger posterior lobe. This plate is highly variable in shape and size, particularly distinct in its posterior lobe. This can be established when one compares Fig. 32-214 with Fig. 9-54.

The ventral area is hardly excavated in the portion covered with the right and posterior sulcal plates, but the flagellar furrow is abruptly differentiated particularly in its posterior portion. The furrow occupies the smaller left half of the ventral area, and the flagellar pore is displaced much posteriorly. The right sulcal list is indistinct while the left is strongly formed, extending posteriorly remarkably beyond the hind end of the body. This, together with the well-formed flagellar wing, covers almost entirely the flagellar furrow. The greatest breadth of the ventral area corresponds exactly with the distance by which the two antapical spine is separated. The distance, on the other hand, is subject to individual variations conforming the lateral expansion of the posterior sulcal plate at the base of spine, which is variable as given above. Coupled with the least development of the sulcal furrow, this unusual lateral expansion of the ventral area at the base of the antapical spine naturally forms the characteristic, flattened hind end of the body.

The antapical spine has three side-wings of subequal size, of which the two ventral and dorsal (or posterior) stand basally along the edge of the antapical plate. In ventral view of the body, the median of the left antapical spine appears as if connected with the left sulcal list as in Pellucida, but in reality in this species the left wing-complex is completely separated from the sulcal list by the left lobe of the posterior sulcal plate.

Measurements: Length of midbody, 100-115 $\mu \mathrm{m}$. Breadth, 60-75 $\mu \mathrm{m}$. Depth, $43-54 \mu \mathrm{m}$. Length of antapical spine, $40-48 \mu \mathrm{m}$.

Locality: Shimoda.

\section{Group 2. Divergentia FAURÉ-FrEmIET (emend.)}

FAURÉ-Fremiet, 1908.

Section Divergentia Jörgensen, 1912; Lebour, 1925; Peter, 1928; PAulsen, 1931; Sahili.er, 1935; DiWALd, 1939.

Group divergens-crassipes LINDEMANN, 1924.

The present group is characterized by the asymmetrically expanded posterior sulcal plate coupled with two antapical horns.

The midbody is onion-shaped with a rounded cingular region or more often 
biconical, forming anteriorly a shorter or much elongated apical horn and posteriorly two shorter conical or elongated finger-shaped antapical horns. The antapical horn is correlated in length with the apical one, and it ends generally in a short spine which fails to develop when it is much elongated.

The ventral plate pattern is generally 'meta' but rarely 'para'. The middle intercalary plate is tetragonal or pentagonal, and exceptionally hexagonal.

The girdle is circular, ascending or descending. The ventral area either forms, as a whole, a narrow and deeply excavated sulcal furrow or is laterally expanded forming in its sinistro-anterior portion a more or less well-differentiated flagellar furrow. It extends posteriorly to the hind end of the body and expands in its middle more towards the right than towards the left. The left sulcal list is strongly formed, standing basally along the left edge of the flagellar or sulcal furrow. The posterior sulcal plate is differentiated into two lateral lobes, extending on the left to the left ventral postcingular plate. And it extends postero-laterally, covering a smaller or larger median basal portion of the antapical horn.

The present group was established by Fauré-Fremiet $(1908$, p. 221) for $P$. divergens, $P$. typus, $P$. obtusum, ? P. oblongum and $P$. kofoidi. He characterized it mainly by the antapical horn covered partially or entirely with the antapical plate. Among these five species, four species have the ventral plate pattern of 'ortho', and two species $(P$. oblongum and $P$. kofoidi) belonging to Oceanica after the principle of our subdivision, and two species (P.typus and P. obtusum) to Conica. Five years later, JöRGENSEN (1913) re-characterized the group by its pentagonal ventral apical plate coupled with the antapical horn, allocating it to the subgenus Metaperidinium, and included in it $P$. speciosum ( $=P$. divergens), $P$. curtipes, $P$. crassipes, $P$. grande and their allies. The definition of the group appears to be fairly well established in this case. Conforming to him, LeBour (1925) allocated her Divergentia section to the group Metaperidinium of the subgenus Peridinium, and confined its members only to $P$. divergens and $P$. curtipes. On the other hand, the definition of the section was enlarged errorneously by Peters (1928), and P. ovatum and P. cerasus, both of which are furnished with the antapical spine, were included in the section in addition to those listed above. Paulsen (1931) intended to settle the question by increasing useful records of new and known species of seemingly unusual and inconsistent characteristics, and by establishing a new section, Paradivergentia, for those with the ventral plate pattern of 'para'. He defined his eighth section belonging to Divergentia as "Metaquadra, rarement penta. Circulaires ou dextrogyres, à deux cornes creuses antapicales." And he included in this the following species; $P$. acutipes, $P$. crassipes, $P$. curtipes, $P$. divergens, $P$. brochi $(=P$. adriaticum) and $P$. crassum.

From these and other available facts, it may be concluded that the three species of $P$. divergens, $P$. crassipes and $P$. curtipes may be regarded as representatives of the present group.

It may be clearly established from the brief historical accounts given above that the present group was fairly well characterized by JörGENSEN and his definition has been generally accepted without serious emendation. The definition of 
the group generally accepted hitherto is simple and clear, but it needs some reexamination.

No one has ever allowed exceptions in the ventral plate pattern of Divergentia, but Lindemann (1924) recorded a case of 'para' in $P$. divergens and ABÉ (1927) saw a similarly patterned specimen of $P$. crassipes in Asamushi. The same pattern is found typically in $P$. solidicorne and its allies, which have been either allocated generally to Pellucida or gathered into Paradivergentia by Peters (1931). All of these species have undoubtedly an asymmetrically expanded posterior sulcal plate, judging from published figures and also from the author's observation. There are still some uncertainties, on the other hand, as to the taxonomical allocation of $P$. remotum and $P$. divaricatum, which have been figured as having the plate pattern of 'ortho'. They appear to have some characteristics suggestive of their allocation to the present group, but this can not be answered until further details of their thecal characters may be brought forth in future. In general structural features, $P$. granii is somewhat related to this group, but it differs profoundly in the ventral area, particularly in its posterior sulcal plate.

The well known species, $P$. divergens, from which the name of the present group is derived, is not yet well established generally. It was regarded by some of the earlier investigators as a collective species, and has been interpreted variously by different authors. Pouchet (1883) regarded it as a 'group species', allocating to it more than ten different forms, but all of them apparently belong to the Oceanica and Conica groups. Similarly, Schütt (1895), Bergh (1881) and KARsten (1907) fell into some misinterpretation in this regard. Afterwards, some of them were separated into distinct species, and now two forms, one with a rounded body and the other with an angulated one, are left in that species. Both of them are regarded by some as corresponding to EHRENBERG's original figure of $P$. divergens, but there is no facility to examine it.

Whether the body of $P$. divergens is rounded or angulated is, however, by no means significant for the purpose of drawing generalized characterization of the Divergentia group. These two forms agree, so far as published figures inform us, in the structural relations of their ventral area. Their sulcal furrow extends dorsally beyond the two conical antapical horns, indenting deeply the postmargin of the body. Their ventral area expands in its middle towards the right. Further, in some of published. figures of them is illustrated, without any elucidation, the characteristic posterior sulcal plate expanding asymmetrically towards the left beyond the left sulcal list.

Basing on these, we contrived to re-examine published figures, and found that $P$. crassipes and $P$. curtipes also have similarly formed ventral area, and $P$. elegans is an ordinary member of this group. From these and other established facts we were led to conclude that the clearly asymmetrical posterior sulcal plate should be esteemed in the characterization of Divergentia much more than any other structure.

The ventral area expands in the typical case towards the right in its middle, and the anterior half of its right edge is fairly oblique, often bearing a narrow right sulcal 
list there. MANGIN's figure of $P$. divergens is peculiar in this regard, because its ventral area is reversed in the right-and-left relation (1910, pl. 7, figs. 11-15). Further, the same author gave a figure of $P$. crassipes (pl. 8, fig. 1), in which is illustrated the posterior sulcal plate expanding bilaterally instead of asymmetrically towards the left. Not a single case of the former has ever been recorded by any other author, and the latter is without doubt due to the author's misinterpretation or misdrawing. This posterior sulcal plate is, in typical cases, asymmetrical in shape extending with its left lobe towards the left and then anteriorly around the hind end of the left sulcal list, and it separates the left antapical spine from the sulcal list. This left lobe of the plate can readily be established in ventral view of the body, because it lies invariably outside of the sulcal or Alagellar furrow.

The posterior sulcal plate is fairly constant for a given species but shows a wide range of variations within the group in regard to its size, shape and bilateral differentiation. Fig. 35-230 \& 233 are the ventral view of $P$. crassipes, in which the ventral plate has its elongated left lobe of subequal breadth. The plate of $P$. elegans in which the ventral area is most highly differentiated in the group, is strikingly larger and is constricted into a smaller right and a much larger left lobes, and each expands posterolaterally along the base of the antapical horn. P. tumidum is an intermediate between them in these regards.

Similar accounts may be given regarding the structural relations within the ventral area and between it and the antapical horn. The ventral area in P. crassipes and its allies is more or less deeply indented as a whole and extends dorsally beyond the antapical horn, covering its major median surface. The posteromedian indentation of the body may be, therefore, interpreted as formed partly by dorsal elongation of the sulcal furrow and partly by the conical bulging of the thecal wall. This sulcal portion of the horn can be distinguished from the rest in ventral view of the body by a narrow list standing basally around the posterior sulcal plate. Contrary to these short-horned species, the long-horned species such as $P$. tumidum and $P$. elegans have a more widely opened sulcal furrow. In the former of them, the flagellar furrow is more distinctly differentiated than in $P$. crassipes, occupying the smaller left half of the ventral area which is still indented as a whole though much less deeply. In the latter, the sulcal depression is slight, while the general ventral depression of the body is so markedly formed that they can not be distinguished from each other, and the flagellar furrow is sharply differentiated into a smaller portion. By means of the presence of this less differentiated and wider sulcal furrow and stronger limitation of the flagellar furrow to a smaller region, the posterior sulcal plate comes to lose its bordering list and is, then, less differentiated from the antapical plate. In the species, the sulcal portion of the antapical horn is confined to its smaller basal half, and can be established as such in ventral view of the body only by a weakly formed bulge of the thecal wall around the posterior sulcal plate. The bulge is indistinct, but has taxonomic and practical importances, because it is invariably illustrated in every published figure of species, even if some of other important structures are not given sufficiently, thus helping us in the separation of the present group from Oceanica in 
which the basal-and-distal differentiation of the horn is not formed.

We have to give here a brief note on Paulsen's (1911) Fig. $11 \mathrm{c}$ of P. pellucidum which clearly consists of at least more than two different forms or species. His species has no antapical horn but is furnished with very short antapical spines. In the figure is illustrated the ventral area extending around the hind end of the left sulcal list as in Paradivergentia. But in other figures, the ventral plate pattern is 'meta'. If all of these are exactly drawn, this PAulsen's form is interesting in suggesting close relationships between Protoperidinium and Mesoperidinium. We are not certain as to the taxonomical allocation of this Paulsen's form. But, it may be suggested that that is more closely related to Divergentia than to Paradivergentia.

The shape and length of the antapical horn is associated with variations in the structural relation of the ventral area. The present group can be subdivided into two sections; one of them has short and conical antapical horns extending not much beyond the ventral area and the other has much elongated or finger-shaped horns.

To the former may be allocated the following ones among recorded species; $P$. asymmetricum Karsten, $P$. crassipes Kofom, $P$. curtipes Jörgensen, ? $P$. divaricatum Meunier, $P$. divergens Ehrenberg, $P$. pulchellum Karsten, $P$. acutipes Dangeard, $P$. adriaticum Broch, $P$. angustum Dangeard, $P$. bidens Karsten, $P$. brochi Kofold and Swezy, $P$. inflatum Okamura, $P$. areolatum Peters, $P$. solidicorne Mangin and $P$. spinulosum SchILler.

Among these, the cingular region of the body flares strongly in the first six species while rounded in the others. The ventral plate pattern is 'meta' except the last three in which it is 'para'. Their short apical horn is not well differentiated from their midbody. The ventral area is narrow and deeply indented as a whole, forming a distinct sulcal furrow. MEUNIER's $P$. divaricatum shows, so far as published figures are concerned, characters partly of Conica and partly of the present group and its plate pattern is peculiarly 'ortho' according to Lebour (1925). But it is allocated to this in this paper for the time being until further morphological details are worked out more exactly in future.

Reviewing through published figures of these, we are informed of the fact that they can be classed into three groups, represented by $P$. crassipes, $P$. adriaticum and $P$. spinulosum respectively. And of the fifteen recorded the first six form a group related to $P$. crassipes. Among them $P$. asymmetricum can hardly be characterized so far as illustrated by KARSTEN, and $P$. pulchellum is another uncertain species, related partly to $P$. curtipes and $P$. crassipes and partly to $P$. divergens. On the other hand, $P$. curtipes and $P$. crassipes, which were separated from $P$. divergens but are still often confounded with it, are two forms of a single species on the basis of our studies. In addition, $P$. pustulatum $\mathrm{KARSTEN}$ is also an uncertain form but closely related either to $P$. divergens or $P$. curtipes. And $P$. curvicorne KARSTEN appears to be a distinct one so far as illustrated. Consequently, we have only four species, $P$. crassipes, $P$. divergens, $P$. curvicorne KARSTEN and $P$. divaricatum to be regarded as valid species.

Among the second group are included the next six species of the fifteen. Most 
of them are, however, only insufficiently studied and are hardly distinguished from one another, differing mainly in the length of their conical antapical horn. So far as they are illustrated and as we have examined a few of them, their specific distinction seems to be sceptic.

The other three species form the third group and are dealt with in this paper as a single species.

From these considerations it is suggested here that we have here five species and a group of related forms represented by $P$. adriaticum to be allocated to the first section.

The latter or second section may be represented by the following species; $P$. grande Kofoid, $P$. tesselatum Karsten, $P$. tumidum Okamura, $P$. fatulipes Kofoid, $P$. elegans Gleve and ? P. remotum Karsten.

Among them, the antapical horn becomes longer in the order given above. And there seems to be a parallel relation between the length of the apical and antapical horns and the breadth of the ventral area, as a longer-horned species is furnished generally with a more widely expanded ventral area and a more strongly differentiated flagellar furrow. Judging from the shape of the hypotheca, P. remotum KARSTEN appears to belong to this. But we are still now uncertain as to its taxonomical allocation because of its unusual plate pattern ('ortho') and undetailed published figures of this species.

It is highly probable that $P$. tesselatum is a form of $P$. tumidum. And we were led to regard $P$. fatulipes as an over-grown form of $P$. tumidum, because KoFom's description was prepared in all probability on a single, extremely over-grown specimen, and stronger divergence of the two antapical horns is associated with greater breadth of the sutural zone.

We have then in the second section only three species of $P$. tumidum, $P$. elegans and $P$. grande.

It may be interesting to note in this place that the antapical spine seen generally in the first section fails to develop completely in an exceedingly long-horned species of this, such as $P$. elegans, while a structure comparable to the side-wing of the spine is formed along a distal half of the horn of a medium-horned species, $P$. grande. In a corresponding distal portion of the horn in P. tumidum and P. elegans are established many longitudinal ridges which may be interpreted as a morphological equivalent of the structure distinctly formed in $P$. grande.

These two sections differ more or less apparently from each other in some characters as considered above. But they form an uninterrupted series in regard to the structural relations within the ventral area. This is the reason why we do not regard them in this paper as two distinct sections.

There are some reasons to suggest that the semisulcal horn strongly formed in the first section may be a morphological equivalent of the minute conical elevation seen rarely at the base of the antapical spine in Humilia and Pellucida. On the other hand, the structural differentiations within the ventral area are more advanced in the second section than in the first one. There are some parallel variations or struc- 
tural differentiations between the second section of this group and Conica of Veroperidinium. All these facts and considerations lead us to suggest that the second section is a higher type than the first one.

The closest relative of the present group is undoubtedly Paradivergentia which may be regarded as having been derived from an ancestor common with this. The present group is rather more directly related to Pellucida, particularly to some of Parapellucida. On the other hand, this is related to the subgenus Veroperidinium, through its Tabulata group, particularly through the Tatrica section in which the posterior sulcal plate is deemed to be asymmetrical in shape and expansion.

\section{Key to species}

1. The body is pentagonal in ventral view, forming posteriorly two short, conical antapical horns, and its thecal wall flares along the girdle

A. The antapical horns are straightly elongated

a. The horn extends only slightly beyond the edge of the sulcal furrow...... P. crassipes

b. The horn extends beyond the edge as far as the sulcal furrow indented $P$. divergens

B. The antapical horns are strongly curved laterally. P. divaricatum

C. The antapical horns undulate $P$. curvicorne

2. The body is somewhat onion-shaped, forming posteriorly two short horns which are feebly differentiated from the midbody

A. The antapical horn is hollow to its tip where it often bears a short spine angustum-adriaticum group

B. The antapical horn is of considerable length ending distally in a distinct spine or increasing thickness of its thecal wall to pass distally into a solid spine P. solidicorne

3. The midbody is concave biconical passing anteriorly into a long apical horn and forming posteriorly two, equally elongated, conical or finger-shaped antapical horns A. The antapical horn is conical

a. Length of the horn is subequal with depth of the sulcal furrow at the hind end of the midbody.... P. grande

b. The length is a little greater than the depth................... spinulosum

B. The antapical horn is finger-shaped

a. The length of the horn is ca. 1.5 times greater than the depth of the postmedian indentation of the midbody .......................... tumidum

b. The length is more than twice as great as the depth............. elegans

\section{Peridinium spinulosum SCHILLER}

Fig. 33 (215-222)

Schiller, 1911, p. 3, Figs. 3 A, B. 
P. solidicorne Mangin, 1922, p. 80, Fig. 23; Dangeard, 1927, p. 7, Fig. 5; Schiller, 1929, p. 408, Figs. 26 a, b, 27 a-e; Diwald, 1939, p. 169, figs. 8 a-c, 10 a-f.

P. areolatum Peters, 1928, p. 33, Fig. 8 a-e.

The midbody bulges more dorsally than ventrally and is elongated pentagonal in ventral view, bulging broadly at the girdle, and tapers anteriorly to an apical elongation and posteriorly to two conical antapical horns which often end in a solid cone and invariably bear distally a winged or wingless short spine. The cingular section of the body is broadly reniform with a ventral flattening, and the equatorial and ascending girdle has its distal displacement of its own width. Fairly narrow and deeply indented is the ventral area which extends posteriorly to the middle of the semisulcal horn.

The ventral apical plate is irregularly hexagonal of various breadth, and the

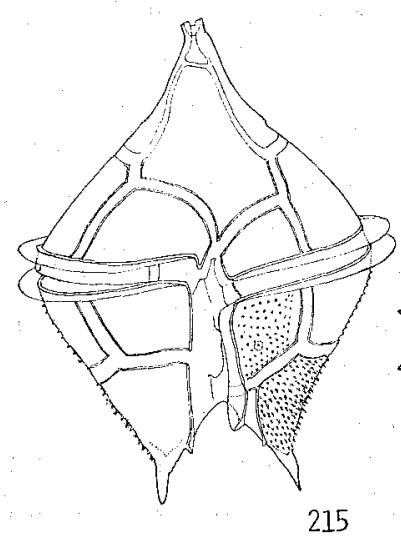

215
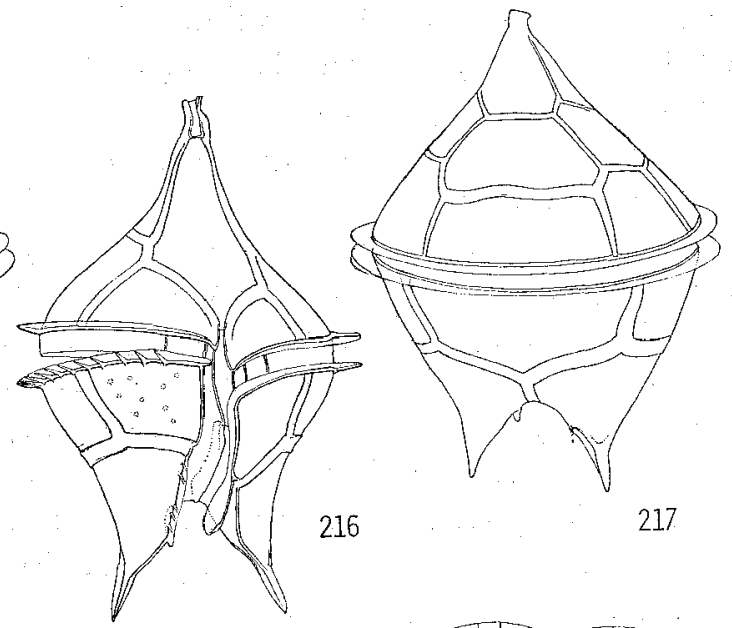

217
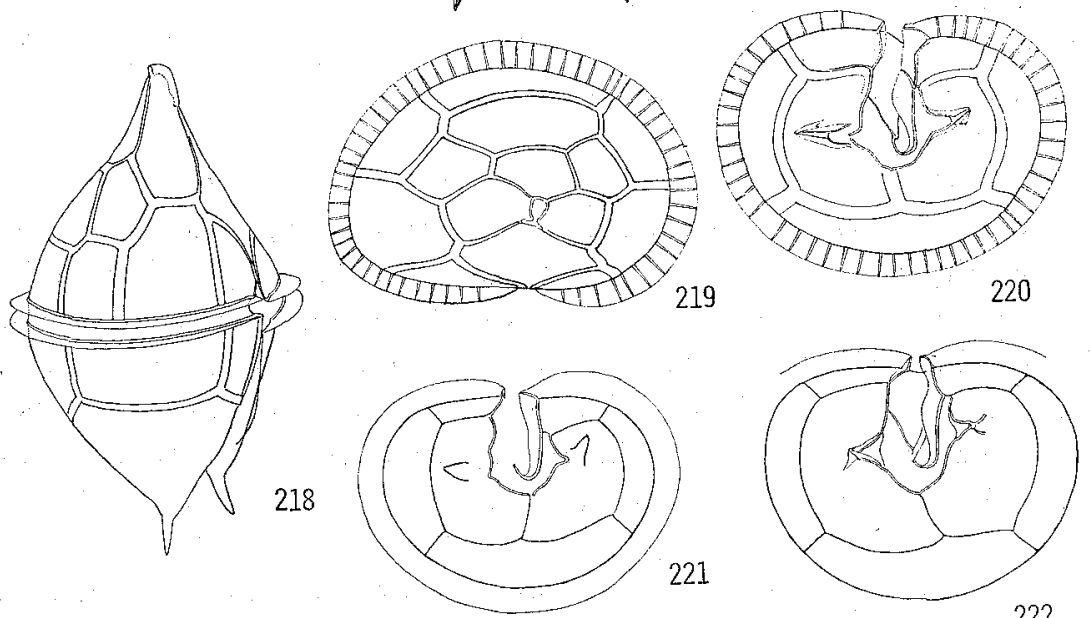

222

Fig. 33 (215-222): Peridinium spinulosum ScullLer. 215, 216-Ventral views, the girdle is partially disjoined. 217-Dorsal view. 218-Side view. 219-Apical view. 220-Antapical view. 221, 222Hypothecal plate patterns of other specimens. 
smaller left and larger right ventral precingular plates are similarly broader than long. The mid-dorsal intercalary plate is trapezium-like hexagonal, covering the middle one-third in length of the dorso-median part of the epitheca. The postcingular row of plates expands posteriorly nearly to or beyond the middle of the hypotheca. In the row, the left ventral component is a little narrower but inversely longer than the right ventral. Ventral two of the three cingular plates are remarkably small in size, lying at the ventral end of the girdle.

Sharply differentiated from the general thecal surface, the sulcal furrow either has subequal width throughout its major length or increases slightly its width posteriorly. The right sulcal list is indistinct, while the left sulcal one is much broader, extending posteriorly beyond the postmargin of the body. Differentiation of the flagellar furrow from the sulcal one is indistinct. The narrower left lobe of the Lshaped posterior sulcal plate lies along median base of the left antapical horn. Shortly separated from the plate stands on its either side the antapical spine furnished with or without three exceedingly narrow side-wings. These side-wings often have no direct connection with the plate, and more often median two of them extend towards anteroand postero-median directions respectively and are decurrent distally along the median edge of the antapical plate upon which the spine stands. A minute triangular patch thus formed between the two side-lists has very often no bordering structure of any sort along the suture between the posterior sulcal plate and the antapical one. The ventral area, then, often appears in antapical view as if forming a small lateral expansion at the base of the horn. This seeming lateral expansion is formed variously and symmetrically or asymmetrically in different specimens (Fig. 33).

The thecal plates often have in well-grown specimens minute spinules all over their surface. They are longer in the hypotheca than in the epitheca. In addition, we can sometimes see the minute ventral pore furnished with a circular flange lying on the left ventral postcingular plate.

Measurements: Length exclusive of antapical spine, $82-90 \mu \mathrm{m}$. Transverse diameter, 54-65 $\mu \mathrm{m}$. Depth, 40-45 $\mu \mathrm{m}$.

Locality: Shimoda.

Though differing in its ventral plate pattern, the present species is most closely related to $P$. adriaticum and its allies, from which this differs, in addition, in its hexagonal middle intercalary plate, stronger elongation of the body and apical horn and in its less expanded ventral area. This may be, therefore, regarded as forming a connecting link between Divergentia and Paradivergentia, lying closer to the former in regard to the structural relations of its hypotheca and the shape of the body. In regard to the shape of the middle intercalary plate and the rightward expansion of the ventral area, published records and our observations inform us that they are subject to individual variation.

Three closely related forms, have been known: $P$. areolatum, $P$. solidicorne and $P$. spinulosum. Among them, the first appears to be identical with the second in all respects except the tetragonal middle intercalary plate, which was described by Schiller in $P$. solidicorne. The third was distinguished from the other two by its 
minute spinules scattered all over its thecal surface. But just a corresponding from was found in Shimoda and confirmed to be identical with $P$. solidicorne in all other respects, suggesting their specific unity.

\section{Peridinium angustum DANGEARD}

Figs. 34a, b (223-229)

Dangeard, 1932, p. 343, Fig. 6 g-i.

There has been recorded a group of Peridinium-species allied to one another in their short pentagonal body, broadly rounded along the girdle and tapering anteriorly to a hardly differentiated apical horn and posteriorly to two short conical antapical horns. They have been interpreted variously by different authors, being allocated by some collectively to a single species but divided by others into several distinct species. Among them is $P$. angustum, to which the present form is most closely related in its body shape and its least developed antapical horn.

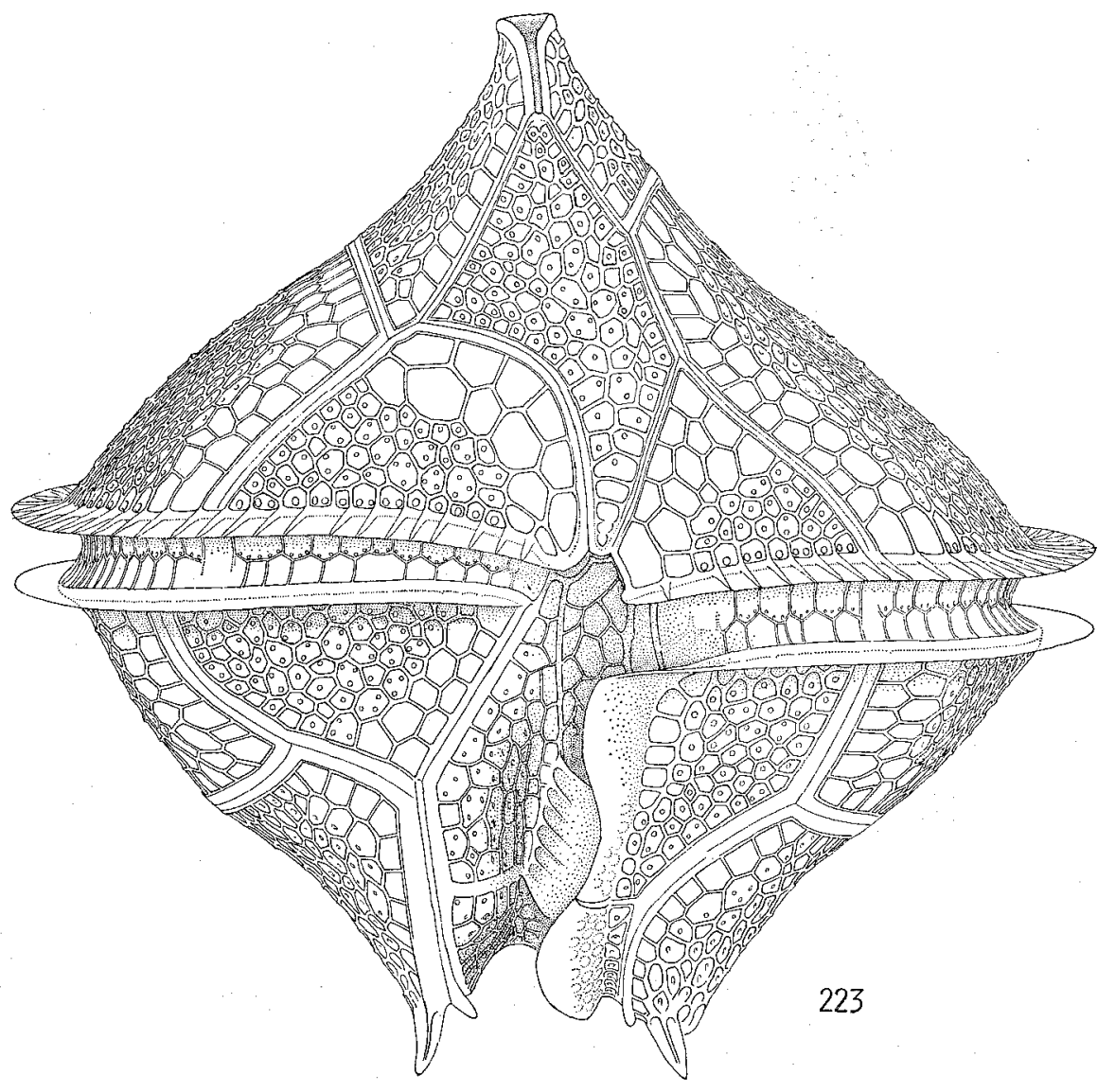

Fig. 34a (223): Peridinium angustum Dangeard. Ventral view. 

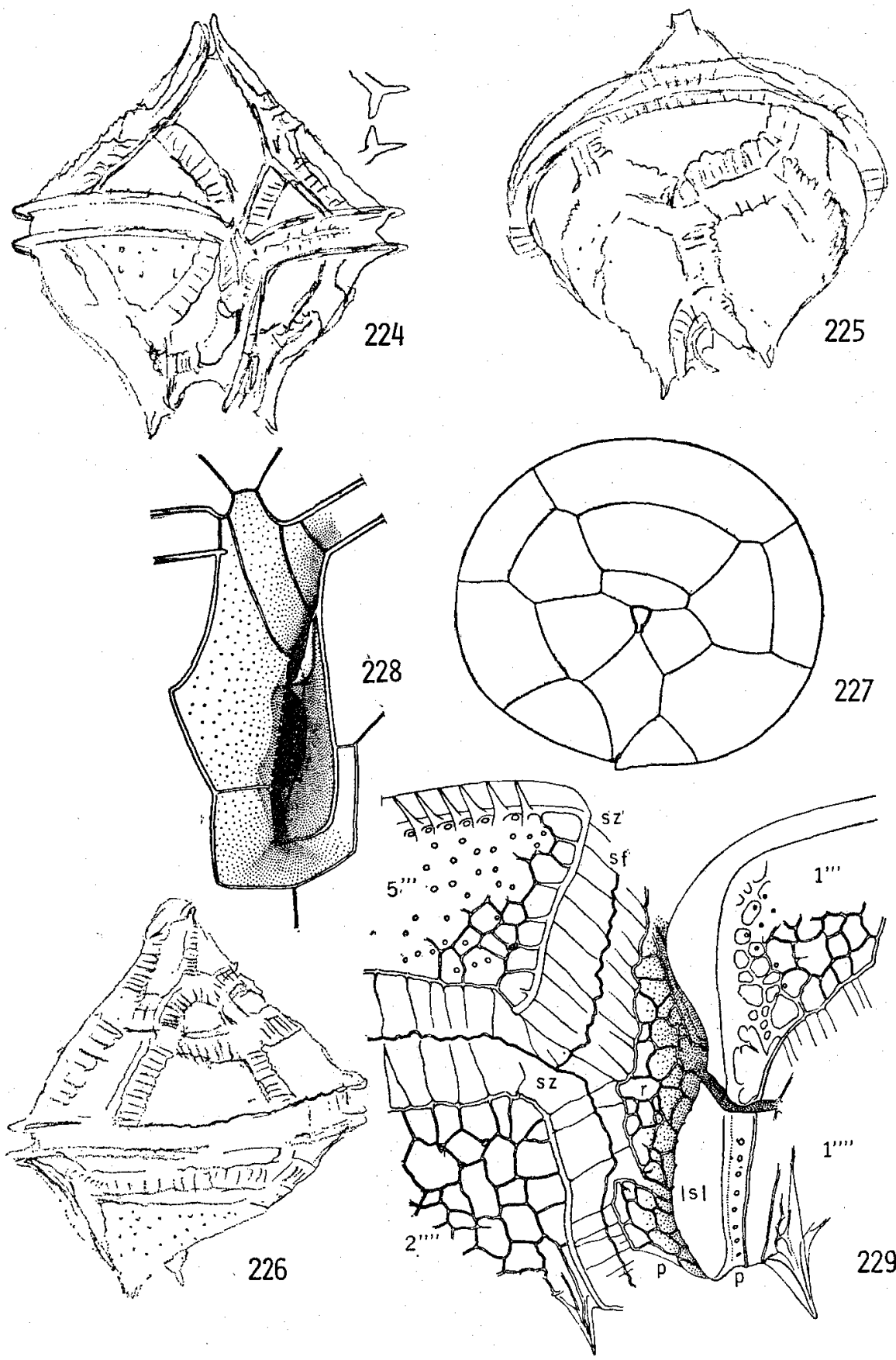

Fig. 34b (224-229): Peridinium angusium Dangeard. 224-226-Pencil sketches of ventral, posterodorsal and side views of other specimens. 227-Epithecal plate pattern. 228-Ventral area. 229-Ventral area and its surrounding region. sz-sutural zone. sf-sutural fissure. 1sl-left sulcal list. 
The body is broadly pentagonal in ventral view, forming posteriorly two exceedingly short antapical horns, but is rhombic in side view bulging more dorsally than ventrally. It is slightly longer than broad, and its thecal wall flares along the girdle and bulges posteriorly on either side to form a minute, conical antapical horn, bearing distally a short spine. The ventral area is as a whole deeply excavated but particularly remarkably in its left half, and expands slightly towards the right in its middle region or posterior half, extending posteriorly beyond the antapices to the center of the hypotheca forming the indented postmargin of the body. The right sulcal list is indistinct, while the left sulcal one is much broader and conspicuous. The ascending girdle is equatorial or slightly post-equatorial having distal displacement of its own width. The cingular section is irregularly ovoidal bulging more dorsally than ventrally and tilts down ventrally.

The pentagonal ventral apical plate expands more towards the right than towards the left, and shortly separated from the ventro-lateral precingular 6". The horizontal suture by which they are separated is so short and the striated sutural zone is formed so strongly in this species that two diagonal sutures appear with medium magnification to meet at a point on the right of the ventral apical plate. The tetragonal or hexagonal middle intercalary plate is smaller in length than the dorsal apical or postcingular plate. In the hypotheca, the postcingular row of plates covers a little more or less of its anterior half. Among its five components, the ventral left is a little longer but much narrower than the ventral right.

The ventral area is deeply excavated as a whole, and is typical of the group in the structural relations within or around it. Together with the left sulcal list, the flagellar wing is strongly formed and can readily be established in ventral view of the body. The posterior sulcal plate occupies the major breadth of the deeply indented postmargin of the body, expanding posteriorly almost to the tip of the antapical horn, where a very short spine stands. Generally three narrow ridges or side-wings are formed along the spine and can be traced basally to the surface meshes of the ant* apical plate.

The transitional plate is exceedingly small. A fairly narrow strip of plate is seen along lateral base of the posterior half of the left sulcal list. In well-grown specimens, a striated sutural zone is formed between this and the left antapical plate. This strip is the left lobe of the posterior sulcal plate. There is an indistinct ridge along the left wall of the flagellar furrow, extending diagonally between the anterior end of the flagellar pore and anteriorly the proximal end of the posterior cingular ridge. We often found proximal part of the transverse flagellum lying also diagonally in front of this ridge which corresponds with the anterior edge of the left sulcal list (Fig. 34a).

The thecal plate is covered with polygonal meshes which are remarkably larger, extending along one side of some sutures, under which is formed the striated growth band. Minute thecal pores are scattered all over the surface of the thecal plate except the striated portion. There is a close set of pores along the outer base of cingular list. Another pores are seen arranged along the middle of the cingular wall. This characteristic arrangement of them on the thecal wall is associated with the 
non-development of the striated band along either side of the girdle. A sutural addition is formed equally or differently on either side of a sutural cleft, and has upon its surface weakly undulating transverse striations of irregular intervals. These striations correspond, in most cases, in arrangement with the meshes lying along the inner side of the sutural addition. The striated band of growth passing obliquely across the thecal wall is much broader than the sutural addition.

Dimensions : Length, 68-80 $\mu \mathrm{m}$. Transverse diameter, 65-72 $\mu \mathrm{m}$. Depth, $60-65 \mu \mathrm{m}$.

Locality: Asamushi.

\section{Peridinium crassipes KOFOID}

Fig. 35 (230-236)

Koford, 1907, p. 309, P1. 31, Figs. 46, 47; PAulSeN, 1908, p. 57, Fig. 73; 1931, p. 65, Fig. 36 A-G; Mangin, 1910, p. 50, Pl. 8, Figs. 1-5; Okamura, 1912, Pl. 4, Fig. 63 a-c; Marukawa, 1921, Pl. 6, Fig. 65 g-i; Fauré-Fremjet et Purgaudeau, 1922, Fig. 11; Lindemann, 1924, p. 230, Figs. 80-86;

Abé, 1927, p. 407, Figs. 26, 27; Peters, 1928, p. 42, Figs. 11 a-h; Dangeard, 1932, p. 345, Fig. 7 a-f; Böнm, 1933, p. 308, Fig. 4 a-c; Schiller, 1935, p. 233, Fig. 221 a-g; Diwald, 1939, p. 173, Figs. 8 d-e, 21 a-b.

Peridinium divergens SchưtT, 1896, Fig. 23 a-b; KArsten, 1907, Pl. 23, Fig. 10 a-b.

$P$. divergens v. bidens Karsten, 1907, Pl. 50, Fig. 10.

? P. asymmetricum Karsten, 1907, p. 418, PI. 53, Fig. 2.

P. crassipes f. typica BRoch, 1910, p. 194, Fig. 9.

P. crassipes $\mathrm{f}$ autumnalis Broch, 1910, p. 194, Fig. 10 a-c.

P. cuttipes Jörgensen, 1912, p. 8; Lebour, 1925, p. 128, Fig. 39; PAUlsen, 1931, p. 64.

Much discussion has often been given as to the specific distinction or unity of $P$. crassipes and $P$. curtipes or of $P$. crassipes and $P$. divergens. The former two are so closely related with each other in many respects, differing mainly in the absence or presence of a well-formed proximal arch of the girdle. Peters (1928) proposed to take $P$. curtipes as a synonym of $P$. crassipes, because he found many intermediate forms in regard to the development of the arch. And PAULSEN (1931) insisted on their specific distinction, allocating PETers' form to $P$. curtipes. With regard to the similar question about $P$. crassipes and $P$. divergens, we shall not give here discussion nor consideration because we have not found in Japan any specimens corresponding exactly with published figures of $P$. divergens, which differ in some or other points according to different authors, and further we could not examine EHRENBERG's original figures of the species.

So far as our observations are concerned, both $P$. crassipes and $P$. curtipes are fairly common either in Asamushi or in Shimoda and also in some other regions. And by finding some intermediate forms in addition to their typical ones, we came to the conclusion agreeing with Peters' (1928). So far as they are concerned, it may be granted to conclude that the proximal arch is very often coupled with broad sutural zone and ventral displacement of the left antapical horn. In specimens of the crassipestype, stronger ventral displacement of the left horn is associated with more prominent arch of the girdle, and the ventral thecal wall of the hypotheca and cingular region 


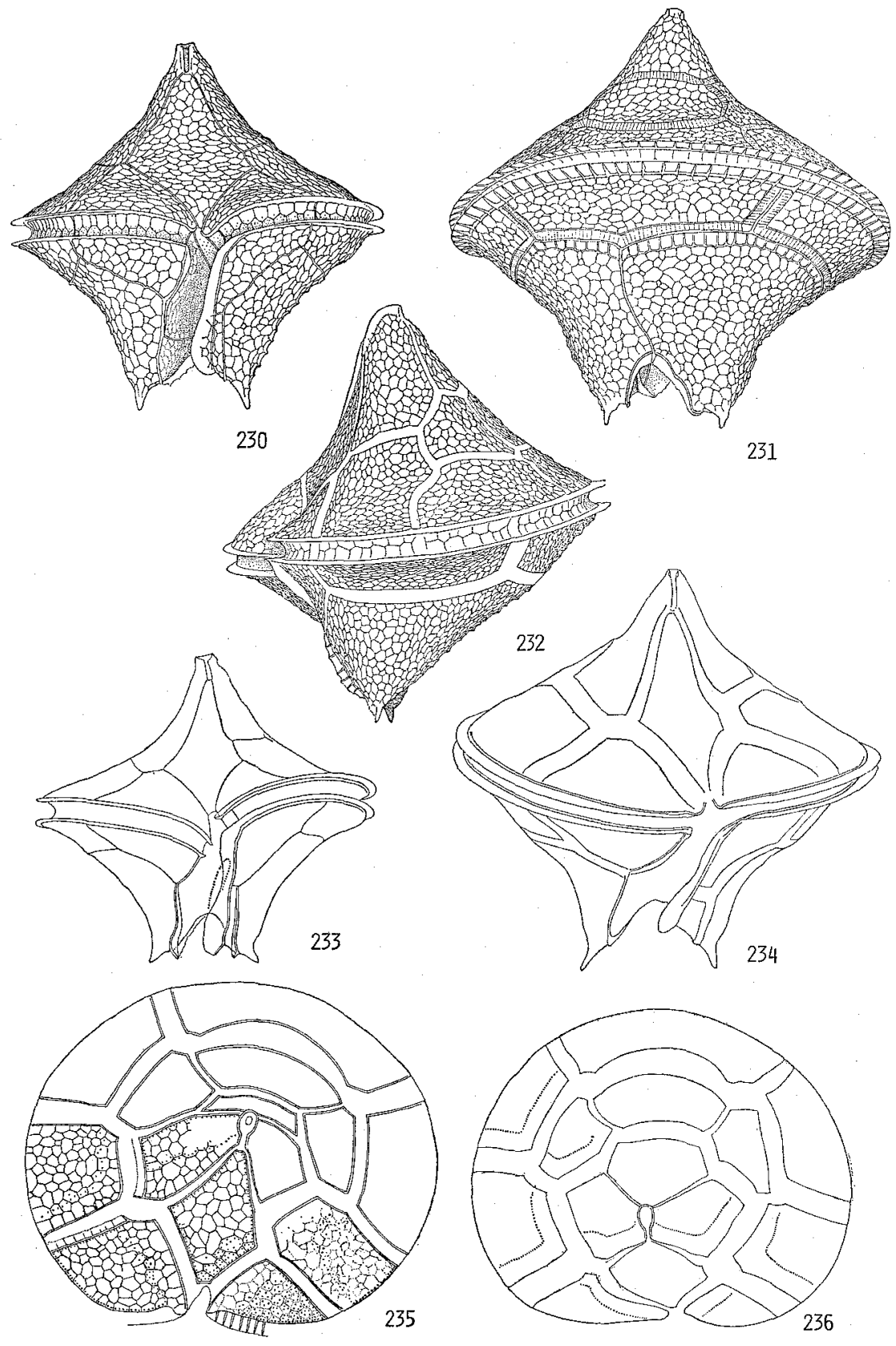

Fig. 35 (230-236): Peridinium crassipes Koford, 230-Ventral view. 231-Dorsal view. 232-Side view. 233, 234-Ventral views. 235-Apical view. 236-Epithecal plate pattern. 
bulges more remarkably on the left of the sulcal furrow than on the opposite side. And these asymmetries in the hypotheca are more remarkable in broadly sutured specimens than in younger ones. In specimens of curtipes-type, all of these structures are fairly well symmetrically formed. It is to be recollected here that not only Koforn's original figure but also most of published figures of $P$. crassipes are the postero-ventral view of body. Judging from these, it may naturally be suggested that the ventral asymmetries are exaggerated in this direction of observation. Detailed studies on the asymmetrical distribution and growth of the sutural zones in the ventral of the hyotheca suggest that the increase in the breadth of that zone is deeply associated with strengthening of the proximal arch of the girdle. All these facts and considerations explain the occurrence in nature of the various intermediate forms. It seems then hardly possible for us to draw a line of sharp specific demarcation between the arched and nonarched forms. But we have some reasons to believe that these two forms show some differences in their seasonal and geographical distribution. From these, $P$. crassipes and $P$. curtipes are regarded in this paper as two varieties of a single species.

The girdle with a proximal arch may be regarded as forming a descending spiral. But, this often leads us to a wrong conclusion. The types of the cingular distal displacement are to be established on the basis of relations between two ventral ends of the girdle. In other words, whether the cingular spiral is ascending or descending is correlated partly with the relative lengths of median ends of the two ventral precingular plates, and partly with the form of the truncated hind end of the ventral apical plate. The median ends extend posteriorly beyond the ventral apical plate. The present species is highly variable in these regards, as its girdle is ascending, circular or descending and every one of them is seen coupled with the proximal arch. The hind end of the ventral apical plate is truncated either horizontally or obliquely to either side, and the two ventral precingular plates extend beyond this similarly or differently. Consequently, various combinations of these bring forth all the possible types of the distal displacement of the girdle.

In this species is noted a remarkable irregularity in its sutural growth in the epitheca. As may be surmised from Fig $35(235,236)$, growth of the intra-precingular sutural zone is greater on the ventral side in some specimens while on the dorsal side in others, and that of the inter-serial one differs not only on either side of the intercalary series of plates of a single specimen but also between two different ones. This irregularity naturally results in partial differences in the increase of the epithecal surface, presumably bringing forth some degrees of variations in the concavity of its surface. This suggestion may be supported by the occurrence of high variability in the surface concavity of the body in natural populations. That the growth of the sutural zone in this species is clearly established in the fact that the cingular section in well-grown specimens very often extends around its edge and that four depressions agree in site with the four intra-postcingular sutural zones.

The cingular section is broadly reniform or almost circular with a faint or distinct 
but narrow ventral depression.

The plate pattern of the epitheca in the present species is highly variable as pointed out by Peters (1928) and some others. Two types of the pentagonal ventral apical plate are found; one smaller and the other much larger in breadth. Similarly, almost every component of the three circular rows is subject to individual variation in its size. The region where the highest variation took place is the mid-dorsal portion. The middle intercalary plate is mostly trapezoidal but rarely pentagonal. In a single case, it is irregularly octagonal and coupled with the unusually triangular dorsal apical plate. The postcingular row of plates covers a little less than the anterior one-third of the hypotheca.

Typical is the structural relation of the ventral area in this species, expanding towards the right in the posterior half and towards the opposite direction with the left lobe of the posterior sulcal plate. This ventral area is deeply excavated as a whole but distinctly in its left half except the left lobe of the posterior sulcal plate which has subequal breadth throughout its length. The left sulcal list is distinct, while the right sulcal one is fairly small in breadth, standing basally in its posterior half around the posterior sulcal plate. The left antapical horn has, then, on its median surface a set of a broader and a narrower list, standing along either side of the left lobe.

The distal ends of the antapical horns extending beyond the sulcal furrow are very short, and either extend parallel with each other or strongly diverge distally, bearing a minute spine furnished with or without several indistinct side-ridges. These ridges can be traced basally to the general polygonal meshes of the antapical plate.

The thecal plate is covered with the polygonal meshes, which are entirely absent in the transitional and the left sulcal plates.

Dimensions: Length, 90-120 $\mu \mathrm{m}$. Transverse diameter, 90-120 $\mu \mathrm{m}$. Depth, $67-110 \mu \mathrm{m}$.

Locality: Asamushi, Shimoda.

\section{Peridinium grande KOFOID}

Fig. $36(237-241)$

Kofoid, 1907, p. 174, Pl. 5, Fig. 28; Karsten, 1907, p. 418, Pl. 52, Fig. 4 a, b; Dangeard, in part, 932, p. 349, Fig. 9 а; Вӧнм, in part, 1933, p. 314, Fig. 6 a.

Koford (1907) recorded the present species from the east region of the Pacific, giving a figure in dorsal view, in which is illustrated a pre-equatorial girdle and two conical antapical horns. He correctly regarded this as a Divergens type. This suggestion is clearly supported by a faint bulge of the thecal wall at the middle of median surface of its antapical horn. Ventral view of this species was given by KARsTEN (1907). Dangearo (1932) and BöHm (1933) appear to have confounded this with either $P$. fatulipes or $P$. elegans. Paulsen's $(1931$; fig. 3a) is entirely different, 
belonging apparently to $P$. elegans.

This is in ventral view star-shaped, flaring remarkably at the girdle and forming posteriorly two large and strongly diverging antapical horns. Its equatorial girdle forms a descending spiral by means of its proximal arch, and its cingular section is broadly reniform with a midventral depression and tilted at $30^{\circ}$ ventrally. The

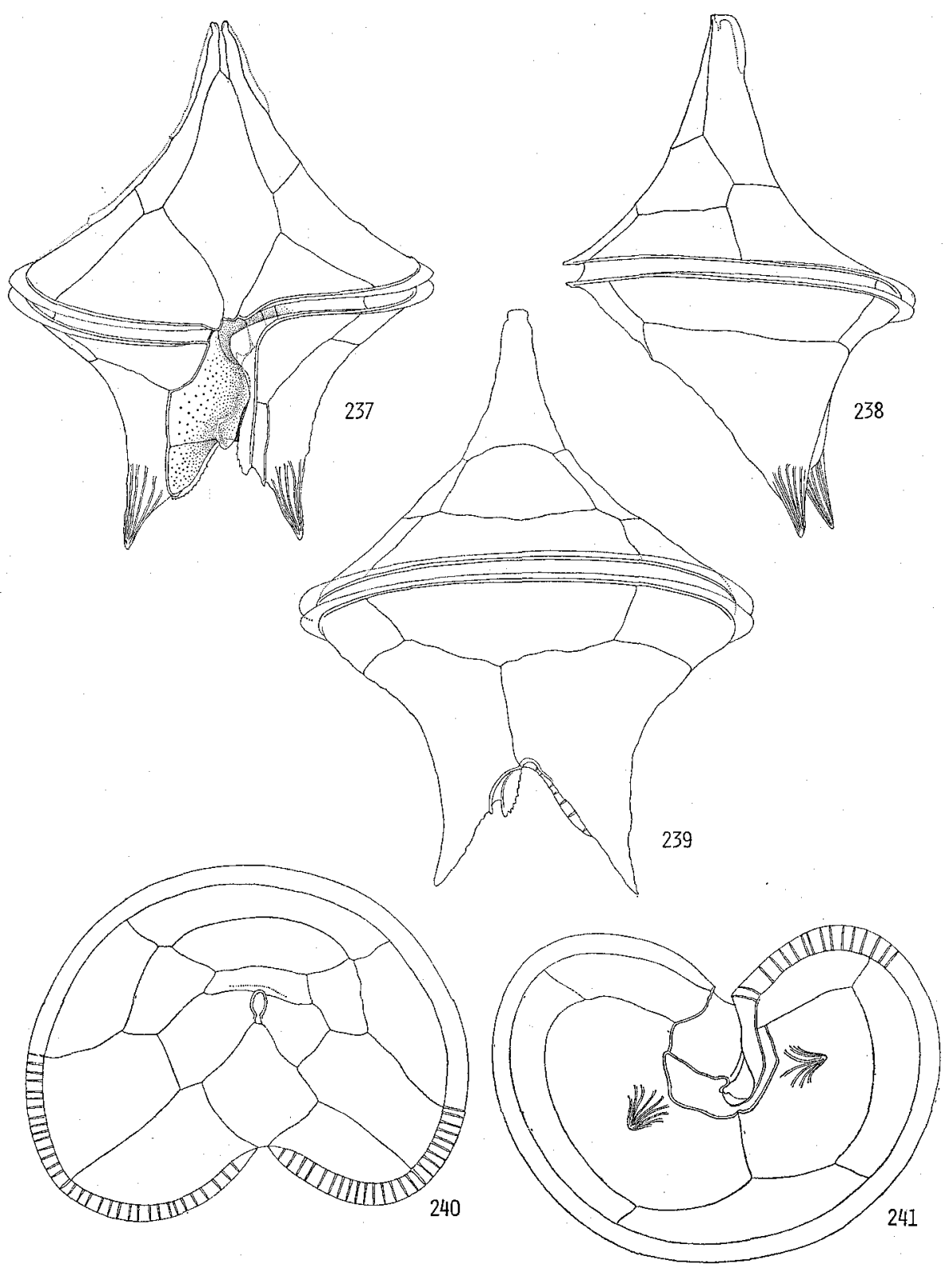

Fig. 36 (237-241): Peridinium grande Koford. 237-Ventral view. 238-Side view. 239-Dorsal view. 240-Apical view. 241-Antapical view. 
epitheca is convexed conical, merging distally to a conical apical horn. Similarly its hypotheca tapers posteriorly into two conical horns of semisulcal type, the distal half of which has on its surface many longitudinal ridges converging towards its pointed end.

The ventral area expands fairly remarkably in its posterior two-thirds, and is deeply excavated as a whole except at the elongated left lobe of the posterior sulcal plate. This furrow extends dorsally beyond the bases of the antapical horns, as in other species, to form a deep postero-median indentation of the body and two horns on its either side. The thecal wall forms, then, around the ventral area an angular bulge which can be seen in ventral view on the median surface of the antapical horn.

Arrangement of the thecal plates was illustrated partly by KoFoID, KARSTEN and Dangeard. The ventral apical plate is elongated pentagonal, tapering more anteriorly than posteriorly. The left apical is smaller than the right apical, either of them extending posteriorly nearly to or slightly beyond half-way between the apex and the girdle. Among the middorsal three plates, the apical $3^{\prime}$ is the greatest and the precingular $4 "$ is the smallest in length, and the trapezoidal middle intercalary is intermediate in this regard. The postcingular row of plates covers the anterior onefourth or a little less of the hypotheca. Its left ventral component is much longer but narrower than the right ventral one, and has a narrow and truncated hind end.

The right ventral postcingular plate has diagonally cut median margin, by means of which the ventral area is remarkably compressed at the girdle. In the left half of the sulcal furrow lies the flagellar pore which is hidden partly behind the flagellar wing and partly in the flagellar furrow. The right sulcal list is very indistinct, lying basally in its posterior portion around the posterior sulcal plate. This plate is reversely L-shaped, consisting of a large rectangular right lobe and a slender and curved left one of subequal breadth.

The two conical antapical horns are either subequal in size or the left is a little smaller than the right. They diverge in ventral view distally (ca. $40^{\circ}$ ), and often the left inclines more ventrally than the right. Their major distal portion is covered with 11-16 longitudinal ridges which can be traced basally to the general large meshes covering the thecal wall. A narrow list can often be established along the intra-apical suture.

Measurements: Length, 130-150 $\mathrm{m}$. Transverse diameter, 105-110 $\mu \mathrm{m}$. Depth, 75-95 $\mu \mathrm{m}$.

Locality: Shimoda.

\section{Peridinium tumidum OKamura}

Fig. 37 (242-248)

Okamura, 1907, p. 133, Pl. 5, Fig. 37; Marukawa, in part, 1922, Pl. 6, Fig. 69 d, e.

? $P$. divergens typisch BerGH, 1881, p. 234, Fig. 41.

? P. tesselatum Karsten, 1907, p. 417, Pl. 50, Fig. 11 a, b.

? P. remotum, in part, KARSTEN, 1907, p. 417, Pl. 53, Fig. 5 a.

Peridinium sp. Hensen, 1911, Fig. B 6. 
KofoID (1907), giving only a ventral view of a well-grown specimen, recorded $P$. fatulipes more closely allied to $P$. elegans than to our present one in regard to its elongated apical and antapical horns. In the same year, OKamura (1907) described $P$. tumidum giving its three insufficiently drawn figures. This latter is most closely

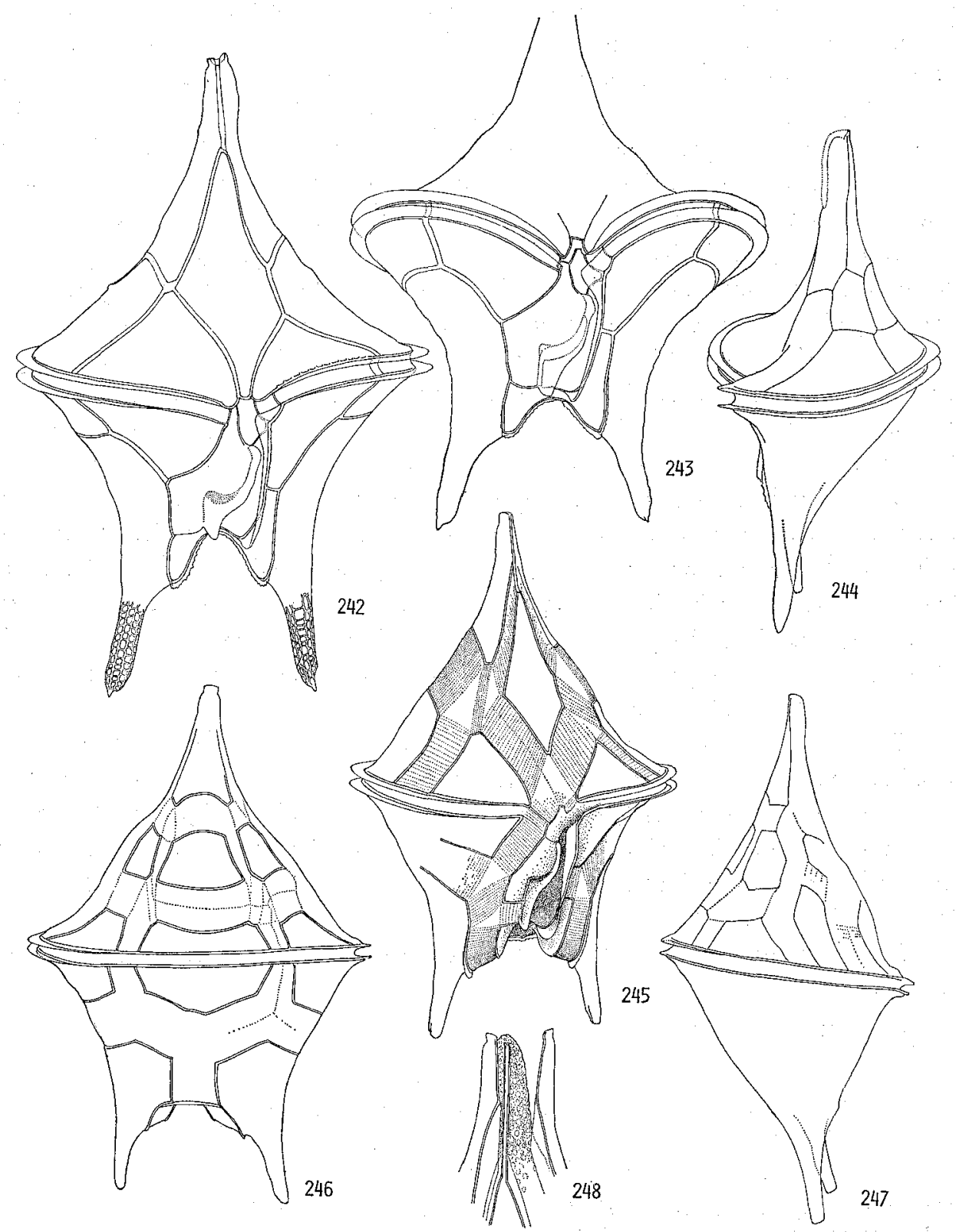

Fig. 37 (242-248): Peridinium tumidum Oxamura. 242-Ventral view. 243-Detailed thecal structure in ventral view. 244-Side view. 245-248: Well-grown specimen. 245-Ventral view. 246Dorsal view. 247-Side view. 248-Separated apical plates in the apical end. 
related to ours, but its antapical horn diverge distally much more strongly than ours. It is related in this regard to Korom's species, from which it differs in its shorter apical and antapical horns and its more strongly swollen mid-body. In 1921, Marukawa recorded $P$. tumidum also in Japan, giving five figures drawn by Yoneda, two (d, e) clearly corresponding with OKamura's species and the other three with different two species. All of these given hitherto were invariably overgrown specimens. Not a single figure of younger specimen in which one can establish ordinary form of the species was ever published.

From these given above, it is apparent that $P$. tumidum differs from $P$. fatulipes in its swollen mid-body and shorter apical horn. We found in Shimoda younger and well-grown specimens, somewhat related to either of them. The younger one is related regarding its epitheca to $P$. fatulipes but its apical horn is shorter, while the grown one is allied to $P$. tumidum in regard to its swollen mid-body and short apical and antapical horns. Either of them has less diverging antapical horns than these recorded species. But some observations suggest that the antapical horns in the present species shows a certain range of their distal divergency in correlation with the growth of the sutural zone, though we have not seen a single case of strikingly diverging antapical horns as figured by Okamura.

From these facts and considerations given above and the oceanic conditions in which Oxamura's and the present form was found, it may be allowed to suggest that the present one may be identified with OKamura's rather than with KoFOID's.

The mid-body is in ventral view somewhat elongated pentagonal, flaring distinctly along the girdle and tapering anteriorly to an apical horn and posteriorly to two finger-like antapical horns. The ventral depression is particularly distinct in the cingular region, forming the cingular section distinctly reniform with a broadly triangular ventral indentation. As the cingular section tilts up dorsally, the apical horn is displaced dorsally, while the antapical horns ventrally. The girdle along which the thecal wall flares remarkably is circular with respect to its two ventral ends, but forms a descending spiral by means of its proximal arch. The antapical horns are fairly thicker in their proximal one-third. Their distal two-thirds are fingershaped with pointed or rounded distal ends and are distally diverging $\left(20^{\circ}-23^{\circ} 3\right)$. In younger specimens, the thecal wall is fairly convex both in the epitheca and hypotheca. But the thecal wall of grown specimens is less concave or rather convex around the middle of the epitheca or hypotheca.

The elongated ventral apical plate tapers not much anteriorly, owing to remarkable length of the ventral slit of the apical pore, which lies along a distal onefourth of the epitheca. The triangular left ventral precingular is a little smaller than the similarly shaped right ventral of the same series, but the latter is in reality tetragonal because of its very short anterior side by which it borders on the right apical plate. Between the two ventro-lateal precingulars, the left is a little narrower than the other, and either of them forms, together with the lateral apical plate lying above it, an elongated or narrow zone extending from the apex to the girdle. It is to be recollected in this regard that a similar peculiarity can be established in $P$. 
elegans of this subgenus and also in $P$. sinuosum and its allies of Veroperidinium. The trapezoidal dorsal intercalary plate lies at posterior two-thirds of the epitheca. The lateral and dorsal postcingular plates are fairly small in length, covering an anterior one-fourth or a little less of the hypotheca. The other two ventrals of the same series expand twice or more posteriorly. Among them, the left is a little narrower but longer than the right.

The ventral area of this species expands strongly towards the right in its posterior two-thirds, and the sulcal furrow, occupying the major portion of the ventral area, lies within the ventral depression of the body and is differentiated from the general thecal surface only faintly by an angular bulge of the thecal wall. This differentiation or the angular bulge is more distinct in older bodies than in younger ones. As in $P$. elegans and $P$. sinuosum, the flagellar furrow is $\mathrm{J}$-shaped and sharply confined to the smaller left half of the sulcal furrow. The left sulcal list is not distinct, standing along the left edge of the flagellar furrow, and along the opposite edge is seen the strongly formed flagellar wing, extending much posteriorly beyond the elongated and characteristically twisted flagellar pore.

On the right of the minute and somewhat rectangular transitional plate lies the anterior sulcal plate which is exceedingly small in length in accord with elongation of the flagellar pore. The posterior sulcal plate is broadly constricted at the hind end of the left sulcal plate into two lateral lobes, each of which has the maximum breadth at the median base of the antapical horn.

The thecal plates are covered with polygonal meshes which are particularly small and thickly arranged into 9-13 longitudinal rows in distal major part of the antapical horn.

Measurements: Length, 130-145 $\mu \mathrm{m}$. Transverse diameter, 80-90 $\mu \mathrm{m}$. Depth, $55-65 \mu \mathrm{m}$.

Locality: Shimoda.

The present species is rarely seen in summer planktons in Shimoda, and can be distinguished from the previous by its finger-like antapical horn. It is highly probable that BERGH's 'divergens typisch' corresponds apparently with this. Judging from the structural differentiation of the ventral area and the peculiar plate pattern of the epitheca, the present species is more closely related to $P$. elegans than to $P$. grande. There are some reasons to doubt about specific distinction of $P$. tumidum Okamura from $P$. tesselatum KARsten and $P$. remotum Karsten. In $P$. tumidum it is established that in accord with growth of the sutural zone the postero-median indentation of the body becomes less distinct and the two antapical horns are set wider apart. If these changes go on much further than we have ever established in the present species, such structures as illustrated on the latter two species may be brought forth.

\section{Peridinium elegans Cleve}

Fig 38 (249-254)

Gleve, 1900, p. 16, Pl. 7, Fig. 15 (16); Okamura, in part, 1907, Pl. 5, Fig. 38 a. 
P. divergens gramulatum KARsten, 1907, Fig. 17 a-b.

P. fatulipes Okamura, 1912, Pl. 4, Fig. 8 a-c; Marukawa, 1921, P1. 6, Fig. 67 a-c

P. grande Marukawa, 1921, PI. 6, Fig. 68 a-b; Paulsen, 1931, p. 68, Fig. 39; in part, Böhm, 1933, p. 313, Fig. 16 b.

Peridinium sp. Hensen, 1911, Fig. B 6, 8.

CLEVE (1900), finding an elegantly elongated large form in samples from the Indian Ocean and the tropic part of the Atlantic, identified it with MurRay and Whitring's variety of $P$. divergentia, and separated it into a distinct species, $P$. elegans. But his figures were so insufficiently drawn that some of later investigators wrongly identified CLeve's species with KoFoID's $P$. grande or $P$. fatulipes, or some others failed to distinguish these two different but closely allied species. Our present form collected from Shimoda corresponds in all respects exactly to CLEVE's original form.

The midbody is in ventral view star-shaped, flaring strikingly at the girdle and furnished with three, slender finger-shaped apical and antapical horns of subequal length. Its cingular portion is so strongly compressed in axial direction and its surface is so remarkably concave in its either half that the thecal wall bulges strikingly along the girdle to form a circular edge of about $30-40^{\circ}$. Ventral part of the midbody is broadly indented into a triangular depression which is particularly distinct
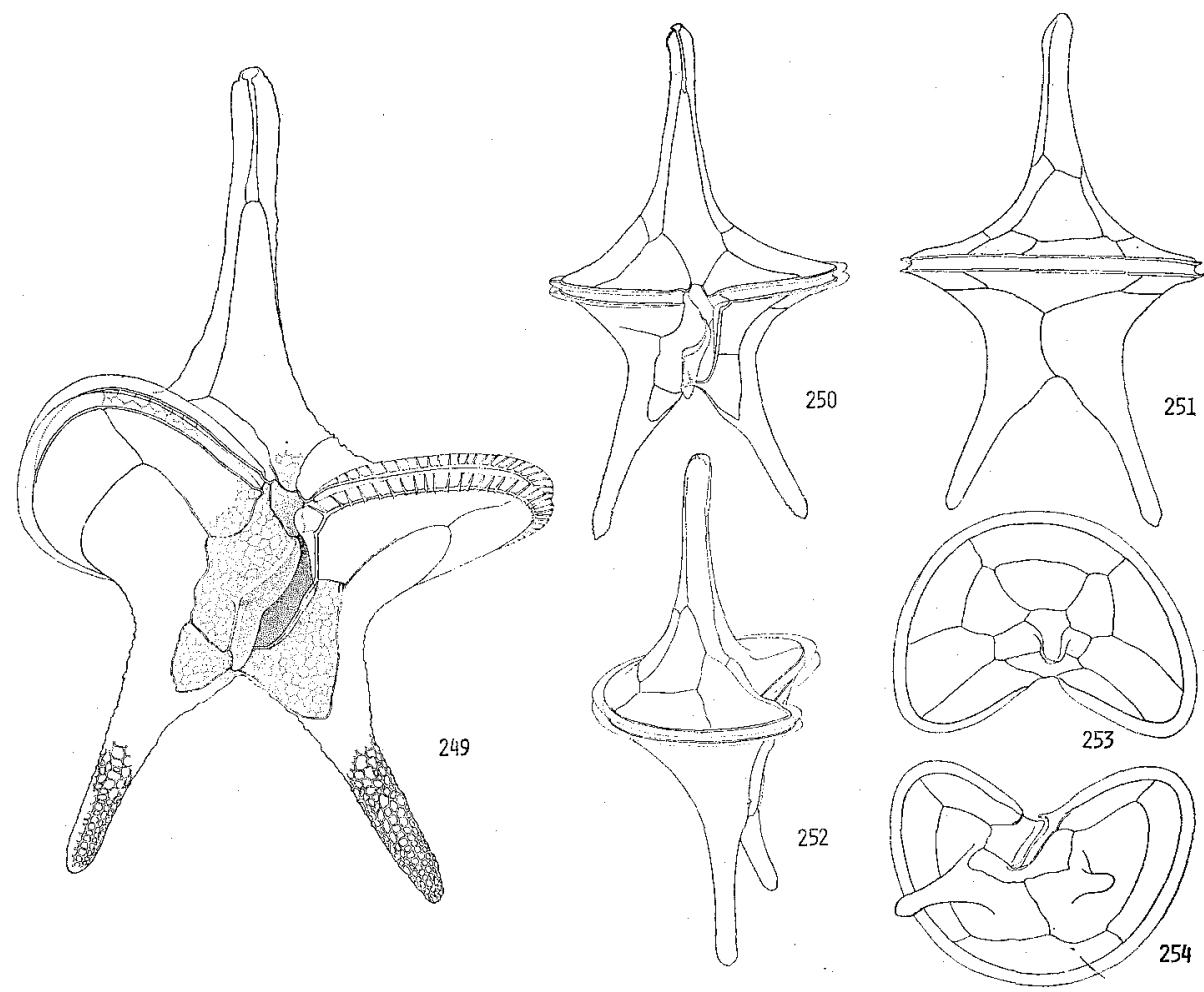

Fig. 38 (249-254): Peridinium elegans GLeve. 249-Ventral view. 250-254-Ventral, dorsal, side, apical and antapical views of the same specimen. 
in the cingular region. The cingular section of the body is, then, typically reniform with a broadly triangular depression occupying its entire ventral breadth. The equatorial girdle runs horizontally for the major length, forming a small proximal area by which its proximal end is displaced more posteriorly than its distal end.

Anteriorly the flattened concave conical epitheca tapers gradually to form a finger-shaped apical horn which bulges faintly at the distal end where it bends ventrally bearing a minute apical pore and an elongated apical slit. The hypotheca is similarly flattened, merging posteriorly gradually into two finger-shaped antapical horns which diverge distally forming an angle of $45^{\circ}$ between them.

The ventral area expands strikingly in its larger posterior portion not only towards the right but also towards the opposite direction. It expands further posterolaterally covering basal median one-third of the antapical horn, where it is slightly thicker than the rest. The sulcal furrow can hardly be distinguished from the ventral depression of the body, presumably owing to the strong development of the ventral depression of the body and the unusual wider opening of the sulcal furrow. On the contrary, the flagellar furrow is sharply differentiated into a small portion of the ventral area, represented only by the left sulcal plate. As a consequence of exceedingly weak development of the sulcal furrow, the linear bulge of the thecal wall formed along the outer boundary of the ventral area is indistinct in this species, but can be established, though faintly, on the median base of the antapical horn.

The strongly elongated pentagonal apical plate tapers much more anteriorly than posteriorly, but along the distal one-fourth or a little more of the epitheca lies the ventral slit of the apical pore, by the length of which the plate is separated from the apex. The lateral apical plates cover anterior two-thirds or a little more of the epitheca, and the dorsal apical is a little shorter, hardly extending beyond the middle of it. The middle intercalary plate is tall trapezoidal, lying at the dorsal base of the apical horn. The dorsal precingular plate lying below this is rarely splitted into unequal two halves. The plate pattern of the epitheca in this species shows some peculiarity, similar to that established in $P$. sinuosum. The two ventro-lateral precingular plates are fairly small in breadth, particularly remarkably in the left of them, which is displaced more ventrally than the other. This is clearly correlated with the asymmetry in the shape of the cingular section and also with the strongly formed ventral depression of the body. In the hypotheca, most of the postcingular plates cover only its narrow subcingular portion, but the left ventral plate of the series extends much more posteriorly than others.

Among the four sulcal plates, the anterior one is the smallest, extending posteriorly beyond the girdle as far as its breadth. The transitional plate is much smaller. The flagellar pore is strongly elongated and strikingly twisted, lying diagonally in front of the middle of the ventral area, and opens towards the left with its anterior end and obliquely ventrally with the other end. The narrow flagellar trough is about one-half as long as the pore. Along the entire length of the pore and trough stands the flagellar wing which extends posteriorly beyond the trough or the right sulcal plate. The left sulcal list is subequal in breadth with this flagellar wing or a 
little narrower, and is narrower posteriorly than anteriorly. Together with other facts, these structural differentiations within the ventral area of this species lead one to suggest some relationships between the present species and $P$. sinuosum, either of which is presumably the highest type of the subgenus to which it belongs. The irregularly shaped right sulcal plate has subequal breadth throughout its posterior major portion but is tapered fairly abruptly in its anterior end. The posterior sulcal plate is deeply constricted at the flagellar trough into a smaller right and a much larger left lobes. Its left lobe is twice or thrice as large as the other, and has a broadly truncated anterior end, subequal in breadth with the flagellar furrow.

The thecal wall is covered with polygonal meshes which are much smaller and more distinct in the distal half of the antapical horn where they are arranged more or less regularly into 10-14 longitudinal lines. And the thecal surface is often more strongly corrugated in this portion. Together with the transitional plate, the left sulcal plate has no surface marking.

The distal divergency of the antapical horns is fairly constant $\left(40^{\circ}\right)$ so far as our materials are concerned. Measurements on published figures inform us that the angle formed by them is smallest $\left(20^{\circ}\right)$ in MarukawA's $P$. grande while greatest $\left(50^{\circ}\right)$ in Okamura's $P$. fatulipes. And Cleve's $P$. elegans and Paulsen's and Böhm's $P$. grande are intermediate $\left(30^{\circ}\right)$ between the two in this regard. And all these just cited are undoubtedly identical with GLEVE's original species, yet display such a wide range of variation in the distal divergency of the antapical horns. Specific unity of these can be verified by their closely allied body form and also by the slight bulge of the thecal wall at the median base of their finger-shaped antapical horn. Further, in most of these published figures is illustrated the corrugated surface of the antapical horn.

Measurements: Length, 225-240 $\mu \mathrm{m}$. Transverse diameter, 120-130 $\mu \mathrm{m}$. Length-breadth ratio of body, 1.8 (1.7-1.9). Depth, 76-78 $\mu \mathrm{m}$.

Locality: Shimoda.

\section{Subgenus 3. Veroperidinium PAULSEN (emend.)}

The body is variously shaped and furnished with or without the antapical spines or horns. The apical horn is often formed but in most cases scarcely elongated. The ventral plate pattern is exclusively 'ortho', and the intercalary series consists partly of two, partly of three and rarely of a single plate. Often the series has much more numerous plates. The posterior sulcal plate, coming typically in all of marine species and in most of fresh-water species on both sides, but presumably exceptionally in a part of fresh-water species only on the left to contact with the ventral postcingular plate, expanding in most cases bilaterally beyond the two middle sulcal plates.

Studies of earlier literatures inform us that some of the earlier investigators such as Bergh (1881), Pouchet (1883, 1885), Paulsen (1908) and Jörgensen (1913) suggested to divide the genus into two on the basis of presence or absence of the 
antapical wing-complex. And the species without the structure were allocated to the genus Peridinium by BERGH (188I) but to the subgenus Euperidinium of the genus Peridinium by Paulsen (1908). Bergh's Peridinium or Paulsen's Euperidinium agrees in the inclusion of Divergentia.

Jörgensen (1913) was the first who distinguished Divergentia from the rest and established a new subgenus, Orthoperidinium, for the majority of Euperidinium and included in that the three groups of Tabulata, Conica and Oceanica. He based his principle of subdivision on the ventral plate pattern of the epitheca, and this was followed by other investigators because of its simplicity and practical convenience. His distinction of Orthoperidinium from the others is correct in the main. But it is to be recollected that he confined the genus only to these species with three intercalary plates, and separated at the same time those with two intercalaries to a new genus, Archaeperidinium, in disregard of their ventral plate pattern. JöRGENSEN's principle of subdivision was re-examined and emended by PAuLsen (1931), and yet he followed JöRGENSEN in the distinction of Archaeperidinium from the rest.

From these it is apparent that some of these former investigators laid greater stress upon the number of plates in the intercalary series rather than upon types of the ventral plate pattern of the epitheca. And no one has ever correctly estimated the taxonomical insignificance of the variability in the number of plates in the intercalary series, which has generally been established.

In the present subgenus are then included all the species with the bilaterally expanded posterior sulcal plate and the fresh-water species of supposed asymmetrical expansion. We can see in them remarkably wide ranges of variations in the number of the intercalary plates, in the form of the body, in the development and type of the antapical horn, in the shape and development of the posterior sulcal plate and further in the differentiation of the sulcal furrow from the ventral area. It is owing to this diversity of the major thecal characters.

The present subgenus is subdivided into six groups according to their natural affinities as follows:

PAulsen (1931), characterizing his second subgenus Veroperidinium, only with the three intercalary plates, subdivided it into eight sections as follows: Pellucida, Humilia, Pyriformia, Tabulata, Paradivergentia, Divergentia, Oceanica, and Conica. Of these, the first three are allocated in this paper to Protoperidinium and the fifth and seventh to Mesoperidinium, based on the peculiarities of their ventral area. The other three are those grouped by JöRGENSEN (1913) into one of his subgenera, Orthoperidinium and commonly manifest, so far as our detailed morphological studies reveal, some structural features not only in the ventral of the epitheca but also in and around the ventral area. The same author's Avellana section of his Archaeperidinium also manifests the same characteristics so far as the regions just cited are concerned, but disagrees with the other three only in its two intercalary plates.

We have, however, to allude here to a probable exception. The structural peculiarity of the ventral area has often been clearly illustrated in many of published figures of large species of the Conica section owing to the distinct, bilateral expansion 
of their posterior sulcal plate. All species of the Oceanica and some of the Tabulata we have examined also show the structure typically. But published figures are to some extent uncertain as to their trustworthiness in manifesting exact structural relations in their ventral area. In some species of Tabulata, certain structures illustrated in their ventral area can not be interpreted unless their posterior sulcal plate was interrupted on the right from contact with the postcingular plate by posterior elongation of the right sulcal one. This relationship is, however, not established yet but was accepted, though sceptically, as such in this paper, because we have not examined a single case of those species illustrated as having the peculiarity. They have to be dealt with in this paper as more closely related to Mesoperidinium than to the present subgenus if the illustrated structural relationships were established. But owing to the uncertainty they are allocated in this tentatively to Tabulata.

\section{Group 1. Tabulata Ehrenberg (emend.)}

The body is small globular or angulated, having no distinct apical and antapical horns nor typically formed antapical wing-complex. The intercalary plate ranges in number from zero to four or more. The ventral area is excavated as a whole. All the recorded fresh-water species are included.

Section 1. Tatrica n. sect.

The hypotheca is more or less distinctly angulated. The ventral area is often broad, expanding to one or both sides. The posterior sulcal plate is distinctly asymmetrical both in shape and in expansion, and is in all probability interrupted from contact with the right ventral postcingular plate by posterior elongation of the right sulcal plate.

Type species: Peridinium tatricum Woloszynska

Section 2. Tabulata n. sect.

The hypotheca is generally rounded but rarely angulated. The ventral area is narrow and more or less symmetrical in shape. The posterior sulcal plate is small, coming laterally into contact with both of the two ventral postcingular plates.

Type species: Peridinium tabulatum (Ehrenberg) Clap. et LaGhu.

\section{Group 2. Avellana PAulseN}

The body is biconical or globular, bulging along the girdle, and without apical and antapical horns. The intercalary plate is rarely single but typically two or three in number. The ventral area is strongly compressed bilaterally, forming a deep longitudinal furrow of subequal breadth, and the typically symmetrical and exceptionally asymmetrical posterior sulcal plate lies in its hind end.

Type species: Peridinium avellanum MEUnIER 
Group 3. Monovela n. gr.

The body is pyriform with rounded posterior and pointed anterior ends. The intercalary plates are either two or three in number. The ventral area is not excavated except its sinistro-anterior portion, and is narrow in its inter-cingular portion, expanding bilaterally in its postcingular major portion. The posterior sulcal plate is transversely elongated triangular. A large flagellar wing extends obliquely towards the left, and this is the sole surface extension of the hypotheca.

Type species: Peridinium monovelum ABÉ

\section{Group 4. Perrieri Fauré-Fremiet}

The body is strongly compressed either in axial direction or dorso-ventrally. The intercalary series comprises larger right and smaller left plates.

Type species: Peridinium perrieri Fauré-Fremiet

\section{Group 5. Oceanica JörgensEN}

Two shorter or longer simple antapical horns are formed. The intercalary series has rarely two but mostly three plates. The ventral area is short and narrow and is deeply excavated as a whole, extending posteriorly to the median base of the antapical horn.

Type species: Peridinium oceanicum VANHÖFFEN

\section{Group 6. Conica Jöraensen}

The body is rarely biconical, often globular or cake-shaped and mostly pentagonal or star-shaped with two, smaller or larger, pseudomorphous antapical horns ${ }^{(1)}$, bearing distally a minute spine. The intercalary series consists of exceptionally two but regularly three plates. In the case of three, the middle plate is transversely elongated hexagonal. The ventral area consists of a narrower anterior and an abruptly broader posterior portions, and the posterior sulcal plates, occupying the latter, is U-shaped showing a wide range of variations in its lateral expansion. Differentiation of the flagellar furrow from the sulcal one is in most cases distinct.

Type species: Peridinium conicum (Gran) Ostenfeld et Schmidt

With regard to the ventral plate pattern, the present subgenus is well established, hardly allowing any exception. The posterior sulcal plate expands typically to both sides in all of the marine species and in one-half or more probably of the freshwater species judging from published figures and also from our observations on a few species. On the other hand, in some of published figures of fresh-water species is illustrated the right sulcal plate as if extending posteriorly to the hind end of the ventral area and between the posterior sulcal and right ventral postcingular plates.

(1) The simple horn is covered entirely to its base with the antapical plate on all sides. 
Assuming them as correctly drawn, the fresh-water species are divided in this paper into two sections according to the difference just considered. These two sections, however, correspond with each other in so many other major structural features that they are to be regarded forming a single group rather than being separated into different groups.

The present subgenus displays a wide range of variation in the shape of the body. In Tabulata, Avellana and Monovela, the body is in the main globular or alike without forming an anterior or posterior elongation. In the first of them, which consists for the majority of fresh-water species, the girdle is equatorial or postequatorial, and the hypotheca is either rounded or angulated and furnished with or without a single median or two bilateral spines. And often, the hypotheca has several spines springing from its general thecal plates. In Perrieri, the body is strikingly compressed in axial direction or dorso-ventrally. Two long and finger-like simple antapical horns are formed in Oceanica, and two shorter and conical pseudomorphous ones are seen in most of Conica. In the former group, the horn is sharply differentiated basally from the ventral area, while that in the latter is covered along its median surface to its tip with the posterior sulcal plate.

We have to pay special attention to the fact that the hollow antapical horn can be established regularly in the three groups of Divergentia, Oceanica and Conica, all of which differ from one another in the intrinsic nature of their horn. The first two of them agree in their elongated conical or finger-like antapical horn. That of Oceanica is formed entirely with the general thecal plates, and is in this regard morphologically equivalent of the apical horn. But that of Conica differs profoundly because only its median half is covered to its tip with the posterior sulcal plate. In other words, the sulcal furrow takes half share in Conica in the formation of the antapical horn. Furthermore, the sulcal furrow of Oceanica agrees in extent with the ventral area and is sharply differentiated from its surroundings, but that of Conica can not be sharply distinguished from the ventral depression of the body. This latter can correctly be appreciated when one supposes that either of the sulcal furrow or ventral depression, when it extends dorsally beyond the postmargin of the body, comes to indent the postero-median portion of the hypotheca to form on either side a hornlike process. The sulcal depression is regarded in Conica to cover the entire surface of the ventral area even if one can not distinguish it from the midventral depression of the body. Naturally, the median half of the antapical horn in Conica is in reality of sulcal nature, differing profoundly in its intrinsic nature from its lateral half. And the antapical horn in this case may be elucidated to have been formed by the dorsal elongation and lateral expansion of the sulcal depression.

These relations can be elucidated when one arranges species of Conica according to increasing size of their antapical horn. In smaller and less advanced species, the postero-median part of the body is indented only slightly and the antapical horns are hardly formed. The length and distinctness of the horn increase as the postero-median indentation becomes wider and more remarkable. And, thus the typically conical horn of $P$. conicum is formed. On the other hand, the sulcal 
depression expands strikingly bilaterally instead of growing longer dorsally in $P$. sinuosum in which the antapical horn is hardly differentiated.

Divergentia is intermediate in these regards between Oceanica and Conica: Its antapical horn is covered partly or mostly along its median surface with the posterior sulcal plate. Two portions of different nature are then distinguished, one distal corresponding to the simple horn and the other basal to the pseudomorphous horn.

The length and shape of the epitheca is correlated with the development of the antapical horn. In hornless species, the apical horn is hardly differentiated from the midbody, and the epitheca has generally convex surface as that of the hypotheca. In long horned species the concave conical epitheca elongates anteriorly as long as the antapical horn. And in these with the short and thick antapical cone, the flat conical epitheca does not form distally differentiated apical horn.

The ventral area of this subgenus is fairly constant throughout the groups in its structural relations, displaying, on the other hand, a wide range of variations not only in shape but also in structural differentiation. In Tabulata, Avellana, Oceanica, Perrieri, and also in most species of Conica, the ventral area is excavated more or less deeply as a whole. That of Tabulata can be divided into two forms: one with small and subequal breadth throughout its length and the other expanding more or less distinctly bilaterally or to one side. The former is coupled with the rounded hypotheca and a small and symmetrically shaped posterior sulcal plate, and the latter is often associated with the angulated hypotheca and a larger and asymmetrically expanded posterior sulcal plate. Although great many of fresh-water species have been recorded and a surprisingly wide range of variations have been established as regards to their plate pattern especially of the epitheca, hardly any was established about the structural differentiation of the ventral area and its variations with exception of a few species. So far as published figures indicate, there are at least two types of their ventral area as described above, and one of them was confirmed also by us as such in this paper. But, the variation in shape of the ventral area is so great in these fresh-water species and we are so entirely ignorant about the structural relations within their ventral area that it is hardly possible to know whether or not these are intermediate types of the ventral area.

The ventral area of Avellana forms a narrow and sharply differentiated furrow with a slight constriction near its hind end. In this regard, Avellana is most closely related to the Tabulata section. The posterior sulcal plate of them is small and fairly simple in shape, hardly expanding laterally beyond the two middle sulcal plate. But that of Conica is much complicated in shape and expands laterally variously, in some slightly beyond the middle two and in others so strikingly as to cover the entire breadth of the hypotheca. It is U-shaped consisting of two lateral lobes and a narrow median neck formed by posterior elongation or displacement of the left sulcal plate. In all species, the ventral area is divided into a narrower anterior and a broader posterior portions. And two portions are excavated similarly in smaller and less advanced species, but there appears to be a correlation between 
increase in size of or stronger lateral expansion of the posterior sulcal plate and stronger limitation of the sulcal furrow to a smaller portion. In an extreme case such as seen in $P$. sinuosum, the small right and the extraordinary huge posterior sulcal plates lie entirely outside of the sulcal furrow which is sharply restricted to the left half of the anterior narrower portion.

The peculiarly flattened species, $P$. perrieri ( $=P$. excentricum), is unparalleled in the genus in its unequal two intercalary plates, and then has been variously interpreted as to its taxonomic allocation. Our thecal analysis of its ventral area informs us of the fact that this species is clearly related on one hand to Monovela or Avellana and on the other hand to Conica, judging from structural relations of its ventral area and the characteristic shape of its posterior sulcal plate. The ventral plate pattern of 'ortho', common to them, supports this suggestion. P. compressum and P. grenlandicum agree with each other in their peculiar flattened body, bilaterally expanded posterior sulcal plate and distinct differentiation of the sulcal furrow from the ventral area, but differ from each other in the ventral plate pattern. They are related to $P$. perrieri in the two unequal intercalary plates.

In all of the Avellana, Monovela, Oceanica and Conica groups, two or three intercalary plates are established. And this series of plates show a striking variation in the number of its component plate in the Tabulata group. Contrary to this, corresponding variation has not been established in the other two subgenera. This strongly supports our suggestion that too much taxonomic importance can not be given to the difference in number of the intercalary series.

\section{Key to groups}

1. No antapical horn is formed

$1^{\prime}$. The fresh-water forms

$2^{\prime}$. The marine forms

A. Scarcely excavated ventral area expands bilaterally just or a little below the girdle and the flagellar wing is of considerable breadth........ Monovela

B. The ventral area of small and subequal breadth is deeply excavated as a whole

a. Asymmetrically curved hind end of the dorsal apical plate is coupled with two intercalary plates .................................... Avellana

b. Straightly elongated dorsal apical plate is coupled with three intercalary plates ..................................................... Tabulata

C. The ventral area abruptly expands bilaterally in its posterior region where it occupies the entire breadth of the ventral depression of the hypotheca...... Monovela (?)

D. The body is strongly flattened in dorso-ventral or antero-posterior direction Perrieri

2. Two longer or shorter antapical horns or similarly shaped structures are formed 
A. The horn stands entirely outside of the ventral area.............. Oceanica

B. The horn is covered along its median half and to its tip with the posterior sulcal plate Conica

\section{Group 1. Tabulata EHrenberg (emend.)}

Faurí-Fremiet, 1909; Lebour, 1925; Peters, 1928; Paulsen, 1931; Schiller, 1935; Diwald, 1939.

A fresh-water species, $P$. tabulatum, has long been generally regarded as a type species of this group. EHrenberg was the first to establish the Tabulata group for the species and its allies. But his followers differ remarkably from one another in the characterization of the group. FAURE-FrEmIET (1909) included in it many species differing from one another in the structural relations of the hypotheca. They are $P$. anthonyi, $P$. lenticulatum, $P$. crassipes var. tatihouensis, $P$. ovatum (Рouchet), $P$. pellucidum var. crassum and $P$. pellucidum var. acutum. The majority of them were described for the first time by the author who apparently laid a special stress upon the girdle and shape of the dorsal intercalary plate. Excluding $P$. tabulatum from the group owing to its hexagonal middle intercalary plate, LeBour (1925) allocated $P$. claudicans and P. punctulatum to that group. PAulsen (1931), following these investigators, still esteemed the plate pattern and the girdle as of taxonomic importance, and consequently forcibly granted many exceptional cases allied partly to Oceanica and partly to Conica.

From this brief historial account, it is apparent that the Tabulata group is one of the least established in the genus and has been variously interpreted by different authors who excluded from their lists of species the majority of the freshwater ones, upon one of which was established the group. This is clearly due to unsurpassed difficulty in grouping fresh-water species on the basis of the plate pattern which shows nearly all sorts of variation. It is undoubtedly utterly unreasonable to settle the subdivision of the genus without due considerations on the fresh-water species.

The small globular or pear-shaped body is sometimes angulated, without forming an apical elongation and distinct antapical spines and horns, and has in most cases flattened ventral side. The equatorial or distinct post-equatorial girdle is circular or forms a descending spiral. The ventral area is either short and narrow or expands asymmetrically to one side in its postcingular portion, indenting the epitheca anteriorly and forming a deep furrow as a whole. Partly conforming to this variation, the hypotheca is rounded or irregularly angulated. The sulcal list is indistinct, and at the hind end of the body is rarely seen a single or two short spines. Further in some species, the hypotheca bears several spines along the hind end or postcingular part of the body.

The ventral plate pattern of the epitheca is 'ortho'. As to the number and arrangement of plates in the three circular rows of plates in the epitheca, a wide range of variations is known not only between different species but also within a 
a single species.

To this group may be allocated the majority of fresh-water species, and they can be divided into at least two sections, one with the ventral area presumably of Divergentia-type and the other with that of Conica-type.

Section Tatrica n. sect.

The ventral area is broad, expanding laterally or more often distinctly asymmetrically to one side. The posterior sulcal plate borders in all probability directly only on the left ventral postcingular plate but not on the right ventral of the same series.

Type species: P. tatricum Woloszynska.

Section Tabulata n. sect.

The ventral area is short and narrow, without expanding distinctly to either side. The posterior sulcal plate borders on either side on the two ventral postcingular plates.

Type species: P. tabulatum (EmRenberg).

With respect to the structural relations of the hypotheca especially of the ventral area, Tabulata is clearly comprised in Veroperidinium while Tatrica is most closely related to Mesoperidinium. In few cases among numerous recorded species some accounts were given about their ventral area, but we are still ignorant of the structure in the majority of them. But judging from some of the published figures, in which are given structures suggestive of a part of the structural relations within the ventral area, the two types of the ventral area are suggested. So far as published figures available at hand inform us, the third type can not be established. From these, it may be granted to conclude that the majority of the recorded fresh-water species can be allocated to either of the two sections basing on the structurel relations of the ventral area.

These two sections, however, cannot be sharply distinguished from each other by the plate pattern of the epitheca because of the wide range of its variations in both of them. But it may be allowed to suggest that the hexagonal middle intercalary plate is coupled more often (or almost exclusively) with the ventral area of the Gonicatype than with that of the Divergentia-type. From these and other facts, it may be suggested that Tabulata may be more advanced than Tatrica. Further, there are some reasons to believe that variations in the plate pattern of the apical and dorsal regions of the epitheca are generally greater in Tatrica than in Tabulata. In the former section, the intercalary series has generally two but often only a single plate, and the series rarely fails to develop. While in the latter section, the same series consists generally of three and often of two plates. This clearly supports the suggestion given above. A greater range of variations in the plate pattern of the epitheca are established in the fresh-water species rather than in the marine species. It may be due to their different habitats, as was suggested by BARrows (1918).

Together with Paradivergentia and Divergentia, the Tatrica section may be the one to be allocated to the subgenus Mesoperidinium, so far as the ventral area is concerned. These just cited may have, then, stronger natural affinity with one another 
than with any of others. But the Tatrica section is allocated in this paper to Veroperidinium because of its close relationship with Tabulata and lack of trustworthy descriptions or figures about its ventral area.

\section{Section 1. Tatrica $\mathbf{n}$. sect.}

The body is rotund, tapering to a minute apical elevation. Around the equatorial or postequatorial region lies a circular or descending girdle. The hypotheca, which is generally smaller in length than the epitheca, is rarely rounded but generally more or less sharply angulated. The ventral area is broad as a whole or expands strikingly towards the left, and the angulate form of the hypotheca is related with this symmetrical or asymmetrical posterior expansion of the sulcal furrow.

The ventral plate pattern of the epitheca is invariably 'ortho', but the three circular series of plates in the epitheca show a wide range of variations in their plate formula is shown as follows:

$$
4-5^{\prime}, 0-2 \mathrm{a}, 6-7^{\prime \prime}, 5^{\prime \prime \prime}, 2^{\prime \prime \prime \prime} \text {. }
$$

The posterior sulcal plate is in all probability remarkably asymmetrical in shape, expanding more towards the left than towards the opposite direction. It borders broadly on the left ventral postcingular plate but is interrupted completely or incompletely from contact with the right ventral of the same series by posterior elongation of the right sulcal plate.

In the majority of published figures of fresh-water species almost none has ever been illustrated about the structural relations within the ventral area. In some of them in which the structure is shown vaguely or partly, the ventral area is illustrated as if furnished with an asymmetrically expanded posterior sulcal plate. In two figures of $P$. tatricum Woloszynska, reproduced by Schiller (1935), are illustrated four plates within the ventral area and around the flagellar pore similarly as those of the marine species. Two of them, presumably corresponding to the anterior and left sulcal plates, have similarly the surface markings. The other two, consisting of a smaller anterior and a larger posterior ones, correspond to the left and posterior sulcal plates. If the figures are exactly drawn and our suggestion is correct, the posterior sulcal plate is interrupted in the species from direct contact with the right ventral postcingular plate. In addition a similar or exactly corresponding structural relation in this portion can be established more or less clearly in some other species such as $P$. goslaviense WoloszYnSKA, $P$. elpatievskyi G. ENTz and $P$. dzieduszyckii WoLOSZYNSKA.

We have some reasons to suggest that the asymmetrical shape or expansion of this plate is correlated generally with the corresponding irregularity of the ventral area or of the hypotheca. So far as illustrated in published figures, the posterior half of the ventral area expands in many species towards the left, but there is not a single case expanding towards the opposite direction. This portion is apparently covered with the posterior sulcal plate. Judging also from published figures, it is apparent that the cingular wall consists generally of five plates. 
We have to recollect now the fact that the plate pattern of the epitheca of fresh-water species has generally been believed to be subjected strikingly to individual variations. There arises naturally then a question if not such variations occur within the ventral area of fresh-water species. Judging from WoLoszynska's Fig. $8 \mathrm{c}$ and $\mathrm{d}$ (after Schilcer 1935), the posterior sulcal plate of $P$. tatricum v. spinulosum extends to the right ventral postcingular plate (Fig. c) or terminates in front of it (Fig. d). It is not certain whether or not these two different cases can be seen within a single species, and further we are in doubt if either of them is due to misinterpretation. This will be solved in future. But anyhow, it may be said with certainty that there is sometimes a case in which the exact shape of the posterior sulcal plate can be established only with much difficulty.

Though we have not yet studied the thecal morphology of any species of this type, careful examinations of published figures lead us to the suggestion that to this section are to be allocated the following as valid: $P$. tatricum Woloszynska, goslaviense Wolosz., P. elpatievskyi (Ostenfeld), P. africanum Lemm., P. dieduszyckii Wolosz., P. marchicum Lemm., P. steinmanni Wolosz., P. umbonatum Stein, P. quadridens Stein, P. cunningtonii Lemm., P. penardii Lemm. Doubtful species: $P$. caudatum Playfair, $P$. geminum Playfair, $P$. inconspicuum Lemm. and $P$. intermedium Playfair.

\section{Section 2. Tabulata JörGENSEN}

The body is globular or ovoidal with or without forming the apical elongation, and bulges more dorsally than ventrally. The cingular section is generally rounded semicircular or reniform without a distinct ventral depression. The girdle is circular or distinctly descending. The hypotheca is rounded posteriorly and is rarely furnished with a single median spine or two symmetrically arranged ones standing on either side of the hind end of the sulcal furrow.

The ventral plate pattern is 'ortho'. And the intercalary series consists generally of three but rarely of four or two plates. A single intercalary plate is known exceptionally in $P$. polonicum. In the case of three plates, the middle one is generally hexagonal but often pentagonal. In the case of two, they are either separated or juxtaposed. The girdle is covered with three plates.

Disregarding the general thecal characteristics, the species, $P$. tabulatum, is characterized by its rounded body furnished with a midventral and longitudinally extended sulcal furrow of small and subequal breadth. In this regard the following species are most closely related to $P$. tabulatum: $P$. aciculiferum Lemmermann, $P$. anglicum West, $P$. cinctum Ehrenderg, $P$. bipes Stein, P. hieroglyphicum var. ovatum Playfair, $P$. lubieniense Woloszynska, $P$. volzii Lemmermann, $P$. westii Lemmermann and $P$. willei Huitfeldt-KaAs.

The ventral area in all of them is slightly constricted just in front of its hind end, and the smaller posterior-most portion thus differentiated is covered with a single plate and the anterior larger portion consists of three plates. These four plates partly or vaguely illustrated in some or published figures correspond exactly to the 
four sulcal plates established in our marine species. It was verified by the author in $P$. cinctum and $P$. bipes collected from Tokyo. In $P$. cinctum, the precingular part of its ventral area is covered with a L-shaped anterior sulcal plate. The right and left sulcal plates lie on either side of the flagellar pore. And the posterior sulcal plate occupies the entire breadth of the ventral area, covering its posterior onethird or a little more.

Review of published figures leads us to suggest that the following species have the ventral area organized as just considered above: $P$. australe Playfair, $P$. gatunense NygaARd, $P$. gracile Lindemann, $P$. lomnickii Woloszynska, $P$. marsonii Lemmermann, $P$. nasutum Mangin, $P$. polonicum Woloszynska, $P$. striolatum Playfair and $P$. trochoideum (Stein) Lemmermann.

In addition to these given above, $P$. quinquecorne may be allocated to this section, though its ventral area has not been investigated sufficiently owing to its extreme minuteness in size of its flagellar furrow and scarcity of the materials.

\section{Peridinium cinctum (MÜLleR) EHRENBERG}

Fig. 39 (255-259)

Schiling, 1913, p. 46, Fig. 52 a-d; LindeManN, 1918, p. 161, Figs. 134-139; 1925, p. 187, Figs. 184187; ENTZ, 1927.

Our present form corresponds to var. irregulatum of LiNDEMANn (1925) with respect to the plate pattern of its epitheca. It may be no use to give here full accounts about the arrangement of the thecal plates and the general structural feature of this well known species, as they have been sufficiently described by some investigators. But, we feel constrained to note that the thecal plates of this form were examined minutely by us by separating them from one another.

The cingular wall consists of five plates, two lying on the ventral, two on the lateral and one on the dorsal side of the body. Among them, the dorsal and two ventral ones correspond in basal length and also in position to the dorsal and two ventral precingular plates respectively. The lateral one lies along two small precingular plates $\left(2^{\prime \prime}+3^{\prime \prime}\right.$ or $\left.5^{\prime \prime}+6^{\prime \prime}\right)$.

The ventral area is in the main longitudinal, deeply indenting the epitheca anteriorly but extending to the center of hypotheca posteriorly. The middle intercingular portion is weakly oblique conforming stronger distal displacement of the girdle. Its precingular portion has a subequal width throughout, while the postcingular portion is slightly constricted laterally just below the distal end of the girdle and broadens posteriorly from there. The major portion of the ventral area except the precingular part is deeply excavated, and the flagellar pore lies in its middle or at the distal end of the girdle. The right and left sulcal lists are subequal in breadth with each other and throughout each of them, and have similar minute and irregular marginal serrae. Either or both of them have regularly or irregularly arranged ribs, while a little broader cingular list has regularly equidistant ribs. 

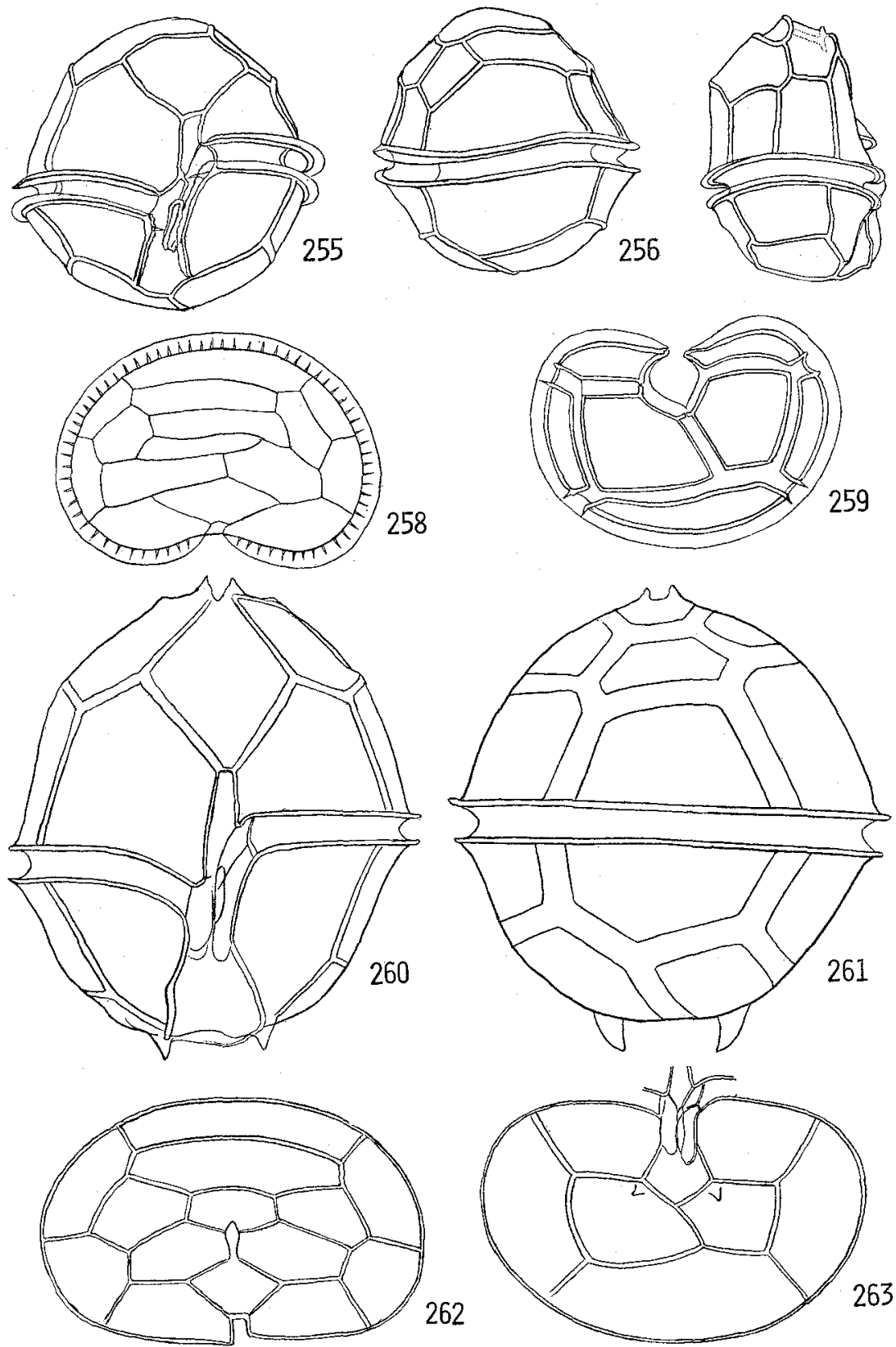

Fig. 39 (255-259): Peridinium cinctum (MüLler) EHrBg. 255-Ventral view. 256-Dorsal view. 257--Side view. 258-Apical view. 259-Antapical view.

(260-263): Peridinium bipes Stern. 260-Ventral view. 261-Dorsal view. 262-Plate pattern of epitheca. 263-Plate pattern of hypotheca. 
The sulcal wall consists of four plates. There is in the precingular part a Lshaped minute plate, expanding towards the left at the proximal end of the girdle. This plate is divided into two portions, since a diagonal ridge, extending from the proximal end of the anterior cingular ridge to the flagellar pore, divides this into a longitudinal dextral and an oblique postero-sinistral portion. Its sinistral portion is more deeply concave than the antero-dextral, forming a short diagonal furrow leading the cingular furrow to the flagellar pore. A minute jut is seen at the hind end of this, extending dorsally to form an anterior wall of the tubular part of the flagellar pore. The other dextral part extends anteriorly beyond this, and can be traced posteriorly to the flagellar pore. These two portions differ from each other in the surface marking, and correspond in position to the anterior sulcal and the transitional plates of the marine species respectively. But, in spite of repeated efforts, we have failed to separate these two portions from each other. Consequently, we have to verify the fact that this plate corresponds exactly with the anterior sulcal plate of marine species.

The right sulcal plate is a little smaller than the anterior one, and is broader posteriorly than anteriorly, bearing a narrow and stout flagellar wing along the posterior major portion of its median margin. This plate extends anteriorly beyond the distal end of the girdle twice as far as posteriorly. There is on the left of the flagellar pore a little larger and J-shaped left sulcal plate which is broader anteriorly than posteriorly. The posterior sulcal plate, the largest among the quartet, is subject to individual variation in size, but is regularly pentagonal, with a small and deep notch in its antero-median portion just at the flagellar pore. Along the left edge of this notch stands a minute list, the posterior continuation of the left sulcal list. Further, interesting is the fact that in this species a small chute-shaped plate was seen lying longitudinally along the bottom of the flagellar pore. It is more deeply concave anteriorly than posteriorly and opens anteriorly to meet the posterior of the anterior sulcal plate. From the depth of this minute furrow spring the two flagella.

The thecal plate is generally covered with irregular meshes. In the cingular plates these meshes are mostly elongated longitudinally to cover the entire width of the girdle. Among the sulcal quartet, the left sulcal and the pore plates are regularly free of the surface meshes, and the sinistral lobe of the anterior sulcal plate is variously reticulated and often entirely free of them.

Measurements: Length, 50-55 $\mu \mathrm{m}$. Transverse diameter, 45-53 $\mu \mathrm{m}$. Depth, 35-37 $\mu \mathrm{m}$.

Locality: Tokyo, Komaba.

\section{Peridinium bipes STEIN}

Fig. 39 (260-263)

Lindemann, 1925, p. 173, Figs. 124-125; non Sahilding, 1913, non Lindemann, 1918.

The ventral area in this species is longitudinal throughout its entire length and 
has a subequal breadth in its anterior major portion. It expands laterally in the posterior half of its postcingular portion, where it is covered with the posterior sulcal plate. The structural relations within the sulcal furrow and the arrangement of the sulcal plates are similar with those of the previous species. A minute spine is often drawn in published figures on the left of the flagellar pore springing from the left sulcal edge. This is in reality not a spine but the hind end of the left sulcal list which is more distinct in this species than the right sulcal list. The two short antapical spines standing on either side of the hind end of the ventral area spring from the ventral edges of the antapical plates, but often fail to form a shaft of the spine.

Measurements : Length, $45-60 \mu \mathrm{m}$.

Locality: Tokyo.

\section{Peridinium volzii LeMmermanN}

LEMMERMANN, 1905, p. $166 ; 1910$, p. 675, Figs. 14-17.

The body is ovoidal in ventral view but bulges more dorsally than ventrally or its ventral side is broadly flattened. Its epitheca exceeds the hypotheca in length, and the deeply indented post-equatorial girdle forms a descending spiral with distal displacement of its own width. The sulcal furrow weakly bends at the distal end of the girdle, extending anteriorly only slightly beyond its proximal end, and has subequal breadth throughout its length.

The rhombic ventral apical plate is narrow, tapering more posteriorly than anteriorly. All the precingular plates cover a posterior half of the epitheca, and among them the middorsal $4^{\prime \prime}$ is broadest, covering dorsal major breadth of the epitheca. Together with the dorsal apical, two lateral intercalaries are arranged transversely in a line. The hexagonal middle intercalary is subequal in transverse length with the dorsal precingular plate.

The posterior half of the postcingular portion of the sulcal furrow is covered with the posterior sulcal plate, and two smaller right and left sulcal ones lie on either side of the flagellar pore.

The thecal plate is covered with polygonal meshes.

Measurements: Length, $45 \mu \mathrm{m}$. Transverse diameter, $40 \mu \mathrm{m}$. Depth, $30 \mu \mathrm{m}$. Locality: Tokyo.

In the plate pattern of the epitheca, the present form is related more or less closely to $P$. bipes, $P$. volzii or $P$. willei. But this can be distinguished from the first of them by lack of the antapical spine and from the other two by its apical pore. From $P$. tabulatum this differs in its hexagonal middle intercalary plate. Among these, the closest relative of this is $P$. volzii, with which this might have been identified if the apical pore was overlooked. In this regard, we found in Asamushi a small variety of $P$. thorianum, in which the apical pore, together with the apical trough, completely failed to develop. Occurrence of such an unusual variation may be explained only when one takes into considerations the unusual oceanic conditions 
of Mutsu Bay. Presuming parallel variations, the present form is regarded in this paper as a variety of $P$. volzii.

\section{Peridinium willei HuITfELDT-KAAS}

Lemmermann, 1910, p. 653, Figs. 10-13; Schilling, 1913, p. 45, Fig. 51; Lebour, 1925, Pl. 21, Fig. 2 a-d; Lindemann, 1925, p. 185, Figs. 175-178.

The plate pattern of the ventral area is cinctum-type.

Measurements: Length, 54-65 $\mu \mathrm{m}$. Transverse diameter, $48-53 \mu \mathrm{m}$.

Locality: Tokyo.

\section{Peridinium quinquecorne $\mathrm{AB}$}

Fig. 40a (264-272)

ABÉ, 1927, p. 410, Fig. 30.

In 1927, the author described the present species, finding two incomplete specimens in summer planktons from Asamushi. In the next summer we could examine a few living specimens of this, and got variously grown specimens with incomplete or complete structures. In spite of the effort to study its thecal morphology, relations within its ventral area were not brought to light so sufficiently as to establish taxonomic allocation of this species. But, we have some reasons to conclude that the present one is clearly a Peridinium-species, though it shows some peculiarities suggestive of its more or less close relationships with some other genera such as Goniaulax and Diplopsalis-group.

The present species shows a wide range of variation in its body form. The body of younger specimens is angular polygonal in ventral view, flaring at the girdle. Its triangular epitheca has angular shoulders at half-way between the apex and girdle. The apical horn is either hardly differentiated or more or less abruptly formed. The hypotheca is also hexagonal contracting posteriorly in ventral view. Besides these, a less angulated form was often seen furnished generally with broader sutural zone. In these with exceedingly broader sutural zones, the body is nearly ovoidal, flaring weakly along the girdle and the apex is hardly differentiated. A similar variation can be also established in the shape of the cingular section. The body of younger specimens is strongly flattened in dorso-ventral direction, forming a thin fusiform cingular section with a minute midventral depression. But the cingular section of those with broader sutural zones is reniform and that of extremely grown ones is somewhat rectangular with rounded corners and convex dorsal and concave ventral sides.

The girdle is deeply impressed, forming a weakly descending spiral with distal displacement of one-half or a little less of its width. It is in typical cases post-equatorial but often equatorial. This variation appears to be correlated with different growth rate between the epitheca and the hypotheca. The narrow cingular list has minute marginal serrae, each accompanied with a rib. The hypotheca has typically 


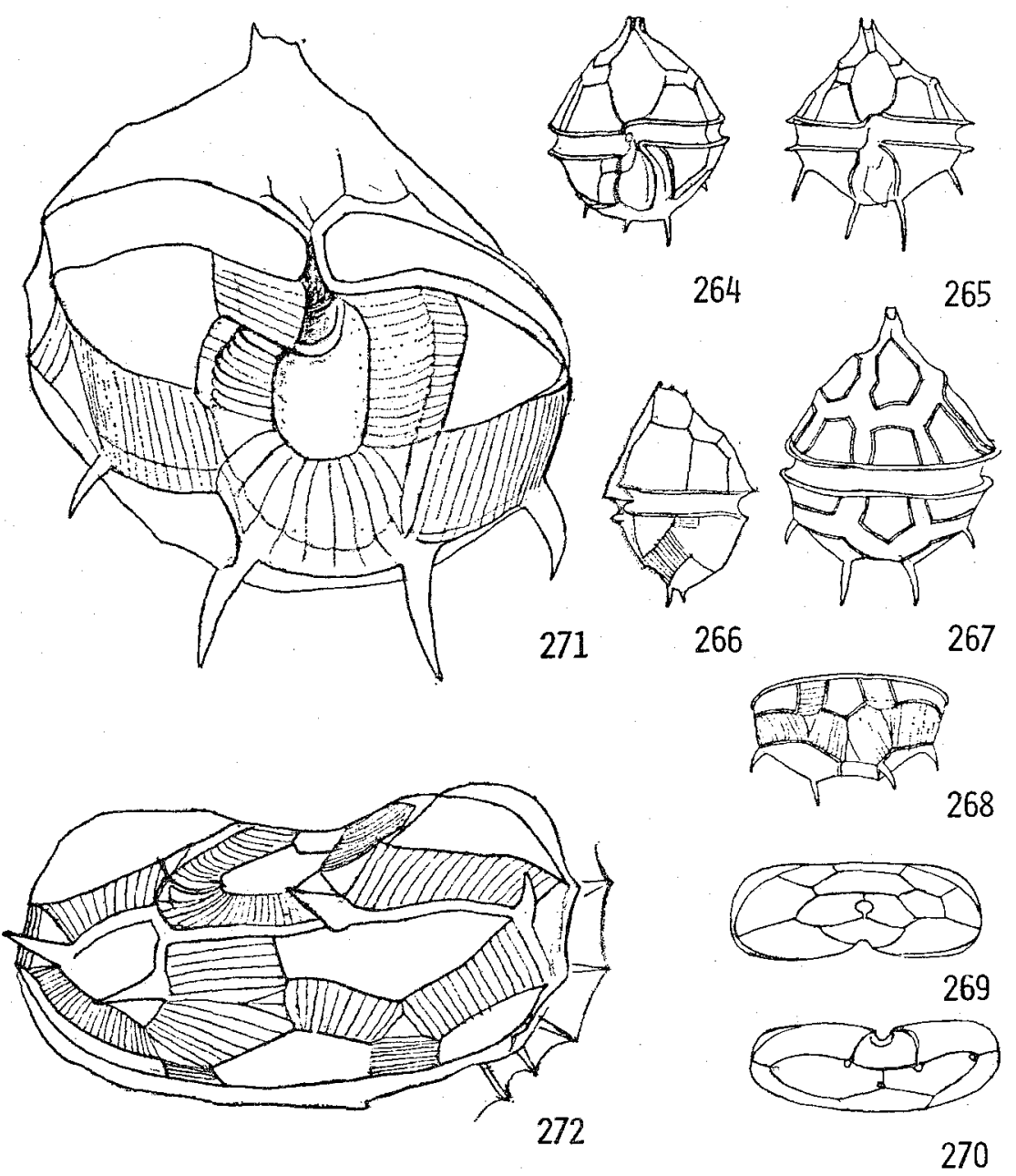

Fig. 40a (264-272): Peridinium quinquecorre AkÉ. 264, 265--Ventral views of two specimens. 266-Side view. 267-Dorsal view. 268-Dorsal view of hypotheca. 269-Plate pattern of epitheca. 270Plate pattern of hypotheca. 271-Postero-ventral view showing detailed structure of the hypotheca. 272 -Antapical view of the same specimen.

four but often three short spines arranged transversely along its hind margin. They are subequal in length, or the left median or two median ones of them are longer than the other laterals. Their length appears to be reversely correlated to the size of the body, because a larger specimen is generally furnished with shorter spines. The hypotheca is in some younger specimens about one half $(0.53)$ as long as the epitheca and is distinctly angulated at the antapical spines, while that of well-grown specimens is as long as the other half and broadly rounded posteriorly. Almost every intermediate form between these two can be established, suggesting their unity. Ventral median portion of the hypotheca is broadly excavated, and this depression extends posteriorly nearly to the center of the hypotheca. 
The ventral apical plate tapers more abruptly anteriorly than posteriorly, and its posterior portion is covex on either side, contracting abruptly to its distal end where it is truncated obliquely conforming the anterior edge of the ascending girdle. This peculiar shape of the ventral apical plate reminds us of the corresponding plate in the Avellana group. The two lateral apicals expand dorsally for a short distance beyond the apex as in the Diplopsalis-group. A wide range of variations is seen in the dorsal plate pattern of the epitheca. In addition to a large heptagonal middle, a single small pentagonal plate is seen on the left of this or two are arranged symmetrically on its either side. We rarely saw a specimen with three intercalary plates, among which the median is pentagonal and the left is the largest while the right is the smallest. It is interesting in this case that a small pentagonal plate, the dorsal apical, lies between the apex and the middle dorsal. From this, it may be granted to suggest that the two or three dorsal plates arranged transversely along the middle of the dorsal epitheca may be regarded as the intercalaries. The precingular series has, in every case, seven plates, among which the two ventrals cover almost entire ventral breadth of the epitheca while the middorsal has a small breadth.

In the hypotheca, the two lateral postcingulars have small length, subequal with the breadth of the girdle. The pentagonal dorsal of the same series is small in breadth, but extends posteriorly twice as long as the laterals. The two ventral postcingulars cover almost entire ventral surface of the hypotheca lying outside of the sulcal furrow. The left of them has a concave median edge, forming a triangular extension along the proximal end of the girdle. The median two of the four antapical spines stand on either side of the hind end of the ventral area, springing from the antapical plates. The lateral of them stands at lateral extremity of the antapical plate. The small fifth spine is formed often between the two medians springing from the dorso-median corner of the right antapical plate.

The ventral area expands towards the left just below the girdle and has a considerable breadth throughout its major length. It is excavated as a whole but more deeply anteriorly than posteriorly. In all specimens we have examined, this structure is always surrounded with a broader or narrower striated sutural zone. Owing to this, the structural relations within this structure were hardly worked out. But it may be said with certainty that its posterior major portion is covered with a single large plate which extends anteriorly on the left nearly to the proximal end of the posterior cingular ridge but on the right not so far, terminating at a short distance from the distal end of the cingular ridge, and further that there is a deeper furrow extending somewhat diagonally from the ventral apical plate posteriorly beyond the distal end of the girdle. Along the right of this furrow is clearly established a minute plate, and along the bottom or rather along dextral wall of the furrow opens the flagellar pore. And a different small plate is seen covering the sinistral wall of the furrow. Though we failed to establish the anterior sulcal plates owing to the minuteness in size and striking bilateral compression of that part of the flagellar furrow, all of these structural relations just given suggest that the present species is most closely related 
to some of fresh-water species of Peridinium.

So far as our materials indicate, the sutural zone is generally formed fairly remarkably. It is fairly narrow in the epitheca and is subequal in extreme cases in breadth with the girdle. But it is most strongly built around and between the two antapicals, where it is in extreme cases twice as broad as the girdle. A more or less broader sutural zone has flattened surface, but in unusually overgrown specimens, the thecal wall is concave along the sutural zone, particularly distinctly on the lateral of the hypotheca. It is due to this peculiarity that a grown specimen has invariably a thicker and somewhat rectangular cingular section than a younger one.

From this very common occurrence of broad sutural zone in this species, its rapid growth and subsequent rapid multiplication may be suggested. This appears to contradict the extremely rare occurrence of this in the planktons of Asamushi, but is apparently supported, on the other hand, by the fact that we often found in the same planktons an elongated mass of hyaline substance filled with an irregular row of several or more empty thecae of this species. This latter fact is clearly suggestive of the fact that the present species is fairly abundant in that sea and some copepods feed selectively on this organism. The apparent rare occurrence of this in the plankton may be due to too large meshes of the plankton-net used to collect them.

The surface of the thecal plate is without any marking. And the content of the body appears to be yellowish brown owing to oil droplets contained.

Measurements: Length, 28-40 $\mu \mathrm{m}$. Transverse diameter, 23-36 $\mu \mathrm{m}$. Depth, 5-26 $\mu \mathrm{m}$. Length of hypothecal spine, $1.5-7 \mu \mathrm{m}$. Width of girdle, $4 \mu \mathrm{m}$.

Locality: Asamushi.

The present species is unparalleled in the marine species of the genus regarding some of its thecal structures, showing closer relationships with some of the freshwater species of the same genus and also with Goniaulax. Judging from published figures, the present species might have been often recorded but misinterpreted as Goniaulax triacantha KoFOID because of their close resemblance in size and form of the body and in their antapical spines. From that, the present species differs profoundly in the plate patterns of both epitheca and hypotheca. KoFoID (1911) included in that species at least three different forms including GLEVE's P. hyperboreum and the present one. Finding also CLEVE's form in Asamushi, we could establish specific distinction of these Pacific and Arctic species, which shall be discussed in other paragraphs.

In the two laterally arranged antapical plates, the present species is undoubtedly a typical species of the genus Peridinizm. The three apical plates and varying number of the intercalary plates in the present species appear to suggest its relationship with either the Diplopsalis group or some of fresh-water species, particularly with the Tabulata group. In these regards, the closest relative of this may be $P$. lomnickii var. splendida Wolosynska (1916) or P. dyboweskii Wolosz.

If this suggestion is verified, it may be interesting to recollect that the present 
species is the sole marine species in the Tabulata group, and that the records of the present one presumably have been distributed mainly in northern seas of both the Atlantic and the Pacific Oceans.

\section{Peridinium triquetra (STEIN) LeBour}

Lerour, 1925, p. 109, P1. 18, Figs. 2 a-f.

Heterocapsa triquetra Bètschli, 1889, p. 1007, PI. 52, Fig. 1; Delagk et Hrìouard, 1896, p. 382, Fig. 563; LindemanN, 1928, p. 88, Fig. 75.

The body is irregularly biconical with bluntly pointed two ends. A relatively broad cingular furrow lies along the equatorial region, forming in its proximal end a distinct arch, by means of which it forms a descending spiral. The cingular section tilts up dorsally, and then the rounded apex is displaced somewhat dorsally while the antapex lies on the dextro-ventral of the center of the hypotheca and is either pointed or rounded.

According to LEBour (1925), the present species has two intercalary plates and the ventral apical plate is completely separated from the girdle. But in our materials, the intercalary row consists of three plates, of which the middle is hexagonal, and the ventral apical plate extends to the girdle. A narrow midventral plate lying just above the proximal end of the girdle was interpreted by LeBOUR as a precingular plate. A corresponding plate can be also established in our materials, and we have been led to suggest it as the ventral apical plate because of its characteristic situation and relations to its surroundings. Two small plates lying side by side and just above it are the lateral apicals. In the hypotheca, the intra-antapical suture lies on the left of the antapex. The cingular wall consists of at least five plates.

With all our effort we have failed to work out the structural relations of the ventral area which has a subequal breadth throughout its posterior major portion and is triangulately pointed posteriorly. Yet, there are some reasons to believe that this larger portion of the ventral area is covered with a single plate, and the flagellar pore lies just in the intra-cingular region. From these it is suggested that the ventral area of this, is related in structural relations to that of $P$. quinquecorne.

Measurements: Length, 25-28 $\mu \mathrm{m}$. Transverse diameter, 18-22 $\mu \mathrm{m}$. Depth, $12-18 \mu \mathrm{m}$.

Locality: Asamushi.

Heterocapsa triquetra has long been an insufficiently established species. According to SaHÜtT's figure reproduced by PAUlSEN (1908, Fig. 32), this species has an elongated horn-like structure at the hind end of its biconical body. LEBour's form has a little smaller conical bulge. Bütschli's (1889), Delage and Hìrouard's (1896) and some others' figures of this also agree with SchüтT's in shape and size of the body. And all of these agree with one another partly in the ventral plate pattern of the epitheca.

There is on the right of the ventral apical plate of our form a small trapezoid plate, which is also illustrated in Bütschur's figure (Pl. 52, Fig. 1) and Lindemann's 
(Fig. 75), but not in others' including Lebour's. From this and also others, our present form agrees most closely with BüTsCHLI's but not with LeBouR's, suggesting either high variability or heterogeneous property of this species. This suggestion may be supported by the facts that Lindemann (1924) ascertained some varieties and formae of this species, that in Asamushi were found two other small forms, agreeing in size and some structures with the present one but distinguishable from it in the plate patterns of their epitheca, and that in one of these two we found two juxtaposed intercalary plates just as those figured by LeBour (1925) and a pentagonal posterior sulcal plate occupying entire breadth of the ventral area.

\section{Group 2. Avellana PAULSEN}

Paulsen, 1931; Abé, 1936.

The body is globular, rounded polygonal or biconical with a more or less distinct, circular bulge along its equatorial or pre-equatorial girdle. No distinct apical horn nor antapical spine is formed. The girdle forms a descending girdle whose proximal end elegantly bends posteriorly merging into the sulcal furrow. The hypotheca is broadly rounded or pointed posteriorly. The ventral area is in typical cases deeply excavated as a whole, extending almost to the center of hypotheca. It is generally laterally compressed in its anterior portion, broadening slightly in the middle, and expands to either side in its hind end, forming a faint constriction just in front of it.

The rhombic ventral apical plate has the greatest breadth in its anterior portion, from where it tapers more or less abruptly towards the apical trough, and is convex on either side of its posterior major portion, particularly more strongly on the right than on the left in its hind end. This plate, then, appears as if bending in its hind end somewhat obliquely towards the left. The apical trough is unusually elongated dorsally in typical cases, extending into the triangular, tetragonal or pentagonal dorsal apical plate. The intercalary series consists generally of two subequal plates but rarely of three or a single one. On the ventral side of the hypotheca, the two ventral postcingular plates are subequal in size and shape, extending posteriorly to the small posterior sulcal plate. The ventral two of the three cingular plates extend laterally as far as the ventral pre- or postcingulars. In the ventral area, the right and left plates lie symmetrically on either side of the elongated flagellar pore which extends anteriorly hardly beyond the proximal end of posterior cingular ridge. The posterior sulcal plate is in typical cases small pentagonal, expanding laterally only slightly beyond the two middle sulcal plates, but very rarely more towards the left than towards the opposite direction.

The thecal plate is either hyaline or crowded with rounded or polygonal poroids, and the cingular wall is corrugated.

The following species are included in this group: Avellana Meunier, P. robustum Meunier, $P$. rotundatum ABé, $P$. thorianum Paulsen; $P$. clavus Asé, $P$. hemi- 
sphericum AвÉ; P. achromaticum Levander, $P$. levanderi ABÉ, P. pietschmanni Böhm, $P$. punctatum (GLeve) ABÉ (=P. Abei PAULSEN) and P. ventricum ABÉ.

These species can be divided into two types, one with a globular and the other with a biconical body. Among eleven species cited above, the first six belong to the former and the next five to the latter.

Steiniella punctata CLEve has long been regarded as an uncertain species. It is elongated biconical and furnished with a descending girdle and a longitudinal sulcal furrow extending posteriorly almost to the pointed hind end of the hypotheca. In these and some other structures, it agrees with $P$. Abei Paulsen. Careful study of published figures of these two species led us to the conclusion that they are in all probability one and the same species. The difference, if we are forced to point out, is the seemingly smaller length of the ventral area of $S$. punctata. But in KozoID's figure no account is given in this regard. The other to be considered here in relation to $S$. punctata is Murrayella intermedia PAviLLARD which agrees very closely with that in general structural features except greater length of its antapical horn. This latter species manifests, so far as illustrated by Dangeard (1932, Banyuls, fig. 12 a-c), some characteristics more of Goniaulax than of the present group. Allocation of MEUNIER's $P$. robustum may be verified by its characteristic ventral area and its corrugated general thecal plates and cingular wall illustrated in his figures reproduced by LeBOUR (1925, Text-fig. 36 e). But its specific distinction from $P$. thorianum appears to be uncertain, although his form has three instead of two intercalary plates. About the allocation to this section is certain in other species, $P$. pietschmanni BöHM, but its specific distinction from $P$. thorianum, is uncertain.

The Avellana section was established for the first time by Paunsen (1931) for these species with two symmetrically arranged intercalary plates. But the number and arrangement of the intercalary plates is not of taxonomic importance after the principle of subdivision proposed in this paper.

Judging from the structural relations within the sulcal furrow or ventral area, the present group is related closely on one hand to the Tabulata group through its Tabulata section and on the other hand to the Conica group through some biconical species of this and $P$. biconicum of that group. One of the closest relatives of $P$. thorianum in Tabulata is $P$. lubieniense which differs from the other mainly in its ventral apical plate and in the general contour of its ventral area. On the other hand, P. biconicum may be allocated to Avellana if its posterior sulcal plate is symmetrically shaped, and $P$. munobis might have been regarded as a member of Conica if its ventral postcingular plates do not extend nearly to the antapex. These brief considerations may be enough to support our suggestion that Tabulata, Avellana and Conica have deep natural affinity among them.

There has never been recorded a single case of catenation in Peridinium. But it is interesting in this regard to know that $P$. clavus and $P$. hemisphericum have some peculiar structures suggestive of their catenation. This, however, has not been established as yet, and is still sceptic. 
Key to species

1. The body is globoid with bulgy girdle

A. A larger form (more than $50 \mu \mathrm{m}$ in length) Peridinium thorianum

B. Smaller forms (30-50 $\mu \mathrm{m}$ in length)

a. The apex is bluntly pointed while the antapex is acutely rounded $\mathrm{a}^{\prime}$. The girdle is equatorial.................................. rotundatum $\mathrm{b}^{\prime}$. The girdle is pre-equatorial ..................... thorianum var. planiceps

b. The apex is rounded and the antapex is feebly indented........... avellana 2. The body is plano-concave

A. Distal one-third of the epitheca is flattened. $P$. hemisphericum

B. Distal one-third of the hypotheca is flattened P. clavus

3. The body is biconical

A. The girdle is pre-equatorial. P. ventricum

B. The girdle is equatorial P. punctatum

4. The body is small pentagonal with a narrow posterior indentation

A. The postero-median indentation is distinct, and the intercalary row has regularly three plates P. achromaticum

B. The indentation is small and indistinct, and the row consists of two plates P. levanderi

\section{Peridinium thorianum PAULSEN}

Paulsen, 1905; 1908; Jörgensen, 1913; Lebour, 1922; 1925.

DaNGEARD, 1927; ABÉ, 1936.

\section{var. planiceps n. var.}

Fig. $40 \mathrm{~b}(273-275)$

This small variety differs from the typical species mainly in its remarkably pre-equatorial girdle and its apical trough, not extending dorsally into the dorsal apical plate.

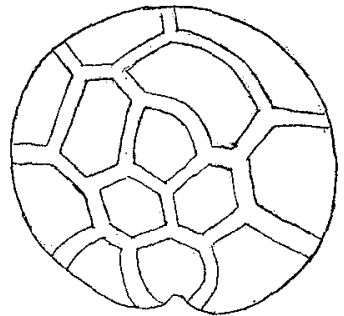

273

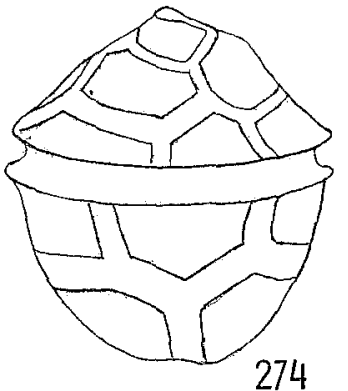

274

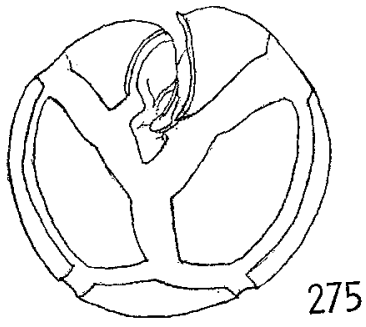

275

Fig. 40b (273-275): Peridinium thoriamum var. planiceps n. var. 273-Apical view. 274-Dorsal view. 275 -Antapical view. 
Measurements: Length, 40-48 $\mu \mathrm{m}$. Transverse diameter, 37-45 $\mu \mathrm{m}$. Depth, $35-42 \mu \mathrm{m}$.

Locality: Asamushi.

\section{Peridinium clavus ABÉ}

AвÉ, 1936 b, pp. 661-7, Figs. 33-51.

Together with $P$. hemisphericum, the present species is interesting in showing remarkable variations in the plate patterns both of its epitheca and hypotheca. In the former paper the author gave four plate patterns of its epitheca. And there is a fifth one in which the dorsal apical plate borders on the left directly on the left ventrolateral precingular plate as that of P. hemisphericum illustrated in Fig. 28.

Locality: Asamushi

\section{Peridinium achromaticum LEVANDER}

Levander, 1902, p. 49, Figs. 1-2; Ostenfeld, 1908, p. 165, Pl. 5, Figs. 29-30, 40-43; Paulsen, 1908, p. 62, Fig. 80; Lebour, 1925, Pl. 22, Fig. 1 a-g; ABÉ, 1927, p. 412, Fig. 31 A-F; WoloszynskA, 1928, P1. 12, Figs. 5-9.

In all of published figures of this species is illustrated the two ventral postcingular plates extending to the hind end of the body. This suggests its allocation to Avellana rather than to Conica. The narrow ventral area of this small species is often described but insufficiently known. It is excavated as a whole, somewhat wider posteriorly than anteriorly, and pointed dorsally at the hind end. It is guarded on either side with narrow lists of subequal breadth, which are usually interrupted at the hind end of the ventral postcingular plate. The subequal right and left sulcal plates lie on either side of a longitudinally elongated flagellar pore, and occupy the major middle portion of the ventral area. The right sulcal plate does not extend anteriorly to the epitheca. Along the median of the inter-cingular part of the ventral area lies a small anterior sulcal plate which is a little larger than the transitional one. The triangular posterior sulcal plate covers the hindermost and broadest part of the ventral area, expanding laterally hardly beyond the two middle sulcal plates, and is separated from the flagellar pore by a short flagellar trough which is subequal in breadth with the flagellar pore. Furthermore, the two ventral cingular plates agree with the two ventral preor postcingular plates in their lateral extremities.

All of these characteristics just given are typical of the Avellana group.

Locality: Asamushi.

\section{Peridinium aequilimbus n. nom.}

Peridinium levanderi ABÉ, 1927, p. 413, Fig. 32 A-H.

This small biconical species agrees with $P$. achromaticum in regard to the struc- 
tural relations within the ventral area and its posteriorly elongated ventral postcingular plates. But its antapex is more strongly tapered. Its sulcal furrow has subequal width throughout its anterior major length and expands laterally more or less abruptly at its hind end where it is pointed dorsally. The ventral apical plate is also typical of the Avellana group in its shape, expanding more towards the right than towards the opposite direction in its hind end. Usually the apical trough extends dorsally beyond the apex into the rhombic dorsal apical plate, but often it does not indent the plate. Rarely was seen a specimen without the apical pore and apical trough. The thecal plate is crowded with minute and indistinct poroids.

Measurements: Length, $30-40 \mu \mathrm{m}$. Transverse diameter, 27-34 $\mu \mathrm{m}$. Depth, 24-32 $\mu \mathrm{m}$.

Locality: Asamushi, Miyako.

Lemmermann has priority over the specific name, $P$. levanderi, which, however, was revealed as a form of Goniaulax spinifera.

\section{Peridinium rotundatum ABÉ}

ABÉ, 1936, p. 655, Figs. 16-21.

Locality: Asamushi.

\section{Peridinium hemisphericum ABÉ}

Авє, 1936, p. 657, Figs. 22-32.

Locality: Asamushi

\section{Peridinium punctatum (Cleve)}

Steiniella (?) punctata Cleve, 1900 , p. 18, Pl. 8, Fig. 4.

Murrapella punctata (CLEVE) KoFoId, 1907, p. 192, Pl. 9, Fig. 58.

Peridinium biconicum ABÉ 1927, p. 416, Fig. 34 A-H; BöHM, 1931, p. 194, Fig. 14.

P. Abei Paulsen, 1931, p. 73; ABÉ, 1936 a, p. 667, Figs. 52-61.

CLeve (1900), finding a biconical species closely allied to Ceratium biconicum Murr, and WhitT. in a sample from $48^{\circ} \mathrm{N}$., $24^{\circ} \mathrm{W}$. (August 1899), regarded it as belonging to the genus Steiniella. He gave a figure of its ventral view, in which is illustrated a descending equatorial girdle, a narrow sulcal furrow extending posteriorly almost to the antapex and a correspondingly elongated left ventral postcingular plate. Furthermore, a longitudinal sutural zone is shown along the left of the plate, and it bends in its hind end abruptly obliquely towards the left as if extending around an areolated, small posterior sulcal plate. In the epitheca, a short, transverse sutural zone is figured in a portion just corresponding to the anterior end of the left ventral precingular plate, suggesting the ventral plate pattern of 'ortho'. All of these characteristics shown in CLEve's figure and interpreted by him as above 
are established also exactly in our biconical species, suggesting their taxonomic unity.

Seven years later, GLEve's species was re-recorded by KofoId (1907) from the West Pacific, and his figure resembles CLEVE's so closely in all respect but for its oblique sulcal furrow that the latter may be regarded as reproduced from the former after some emendation. But for the oblique sulcal furrow, Koforn's may be identified as ours. And there are some reasons to believe that the diagonal furrow in KofoID's is due to his misinterpretation or misdrawing. Measurements of these three forms also suggest their unity.

Measurements:

\begin{tabular}{l|c|c}
\hline & Length & Diameter \\
\hline GLEVE & $110 \mu \mathrm{m}$ & $60 \mu \mathrm{m}$ \\
KoFoID & $65-155 \mu \mathrm{m}$ & $40-73 \mu \mathrm{m}$ \\
ABÉ & $70-105 \mu \mathrm{m}$ & $48-80 \mu \mathrm{m}$ \\
\hline
\end{tabular}

Locality: Asamushi, Miyako, the Inland Sea, $48^{\circ}$ N. $24^{\circ}$ W. (Atlantic), Temperate seas in Pacific.

\section{Peridinium ventricum ABÉ}

ABÉ, 1927, p. 418, Fig. 35 A-G.

This medium-sized biconical species was described in 1927 from Asamushi, and was found also in Shimoda. In the materials from Shimoda, we often found a specimen with three intercalary plates instead of two. Due allocation of this species to Avellana is supported clearly by the characteristic plate patterns in both of its epitheca and hypotheca, its descending girdle furnished with corrugated wall and the shape and the structural relations of its ventral area or sulcal furrow, all of which are clearly illustrated in the figures given in this and former papers.

Measurements: Length, 50-60 $\mu \mathrm{m}$. Transverse diameter, 40-55 $\mu \mathrm{m}$. Depth, $36-50 \mu \mathrm{m}$.

Locality: Asamushi, Shimoda.

The body is globular or nearly so and has a bluntly pointed apex and the equatorial circular girdle. Its hypotheca is broadly rounded posteriorly, and has no surface extension except the large, fan-shaped flagellar wing, extending obliquely towards the left. The ventral area is of considerable width in its posterior major portion where it expands similarly laterally, but is fairly narrow in its intra-cingular region. It is scarcely excavated and its hindermost part expands a little farther laterally beyond the middle and tapers posteriorly more or less abruptly to a pointed end.

\section{Group 3. Monovela ABÉ}

AвÉ, 1936, p. 669-670. 
The rhombic ventral apical plate tapers more posteriorly than anteriorly, extending diagonally to sinistro-posterior direction. The apical trough is short and is deflected with its ventral end obliquely towards the right. The intercalary series consists of either two or three plates. In the case of the two, they are subequal or the left is larger than the right. The two ventral postcingular plates are subequal in size and shape, terminating similarly in front of the hind end of the body. The narrower anterior portion of the ventral area is covered almost entirely with the anterior sulcal plate. Together with a small, elongated and strongly curved flagellar pore, a similarly shaped left sulcal plate lies diagonally along the bottom of an indistinct flagellar trough. The posterior sulcal plate is generally much broader than long and is V-shaped with a broadly rounded notch anteriorly. This ventral area has hardly any marginal list nor surface extension except the flagellar wing.

In the present group are included the following species: P. asymmetricum (АВÉ), P. mutsuensis ABÉ, P. monovelum ABÉ, P. monospinum PAUlsen (=P. constrictum ABÉ) and ? P. minutum KoFoID, and $P$. fusiformis n. sp. is described in this paper.

Judging from the plate pattern of the epitheca, particularly in its dorsal half and that of the ventral area, the present group is not to be regarded as an advanced type. On the contrary, disappearance of the sulcal furrow from the major portion of the ventral area suggests the present one as a higher one. The present group is closely related to Avellana in the former respect and to some of Conica in the latter.

\section{Key to species}

1. The body is similarly rounded at its two ends, and the ventral area is more strongly convex on the left than on the right

A. The body is globoid

a. Together with the dorsal apical, two intercalary plates are separated from the lateral apicals by a diagonal ridge.

Peridinium asymmetricum

b. No diagonal ridge is formed.............................. mutsuensis

B. The body is longer than broad and is pointed at two ends.....P. fusiformis

2. The body has pointed apical end, or the ventral area is convex on its two sides

A. The body is globular with a differentiated apical process

a. A smaller form $(23-43 \mu \mathrm{m}$ in length) ........................ minutum

b. A larger form $(50-70 \mu \mathrm{m}$ in length $)$...................... monospinum

B. The body is somewhat pentagonal with pointed anterior and slightly flattened posterior ends......................................... P. monovelum

\section{Peridinium fusiformis n. sp.}

Fig. 41 (a-g)

This minute species is rugby-ball shaped with bluntly pointed two ends and 
the equatorial circular girdle. Its cingular section is irregularly reniform without a distinct ventral depression. The depth of the body is a little larger in the right than in the other half.

The rhombic ventral apical plate and the apical trough extend diagonally in opposite direction in general as in this group. The two subequal intercalary plates are juxtaposed. The precingular plates become smaller in length from ventral to dorsal. The two ventral postcingulars extend posteriorly almost to the antapex. The ventral area is elongated, bending towards the left in its middle region, and the flagellar pore is also similarly shaped. The posterior sulcal plate is small and pointed posteriorly.
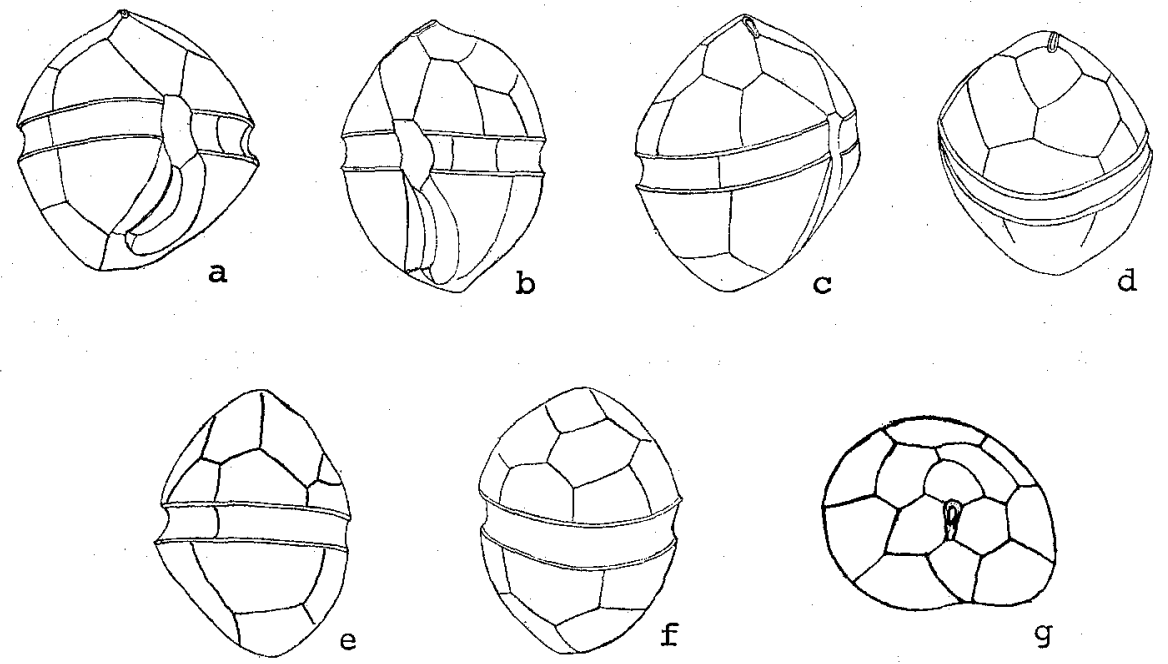

Fig. 41: Peridinium fusiformis n. sp. a-Dextro-ventral view. b-Sinistro-ventral view. c-Oblique side view d-Antero-dorsal view. e, f-Sinistro-dorsal views. g-Apical view.

Dimensions: Length, $32 \mu \mathrm{m}$. Transverse diameter, $29 \mu \mathrm{m}$. Depth, $23 \mu \mathrm{m}$. Locality: Asamushi.

The present species is found very rarely in the summer planktons in Asamushi, and is most closely related in all respects to $P$. asymmetricum, from which it can be differentiated in peculiar shape of its body, its larger dorsal precingular plates and lack of the apical diagonal ridge. The other closest relative of this is $P$. mutsuensis which differs from the present one in its plate pattern.

\section{Peridinium asymmetricum (ABÉ)}

ABÉ, 1936, p. 671, Figs. 62-64.

Sphaerodinium asymmetrica AsÉ, 1927, p. 391, Figs. 11 A-D, 12, 13.

Locality: Asamushi. 


\section{Peridinium mutsuensis $\mathrm{ABE}$}

ABE, 1936, p. 672, Figs. 62-65.

Locality: Asamushi.

\section{Peridinium monovelum ABÉ}

ABÉ, 1936, p. 673, Figs. 66-74.

Locality: Asamushi.

\section{Peridinium monospinum PAULSEN}

Paulsen, 1908, p. 42, Fig. 49 a-d; Lebour, 1925, p. 107, Pl. 16, Fig. 3 a-h. Peridinium constricta ABE, 1936, p. 676, Figs. 75-83.

\section{Group 4. Perrieri FAURÉ-Fremiet}

FAUR'́-Fremiet, 1909.

Section Excentrica PAULsen, 1931.

Group Excentrica ABÉ, 1936.

There has generally been a consideration that species with two intercalaries differ profoundly from those with three of them. Following this, LeBour (1925) allocated $P$. excentricum to Archaeperidinium. On the other hand, PAULSEN (1931) established the Excentrica section for this and $P$. grenlandicum because of their asymmetrically formed epitheca. Before them, FAURE-Fremtet (1909), verifying the peculiarity in the species, which he misinterpreted as a new species, P. perrieri, and proposed to create a new group Perrieri for it.

Finding abundant materials in Shimoda, we contrived to study the general thecal morphology of $P$. excentricum and found that this species is undoubtedly an ordinary member of Veroperidinium, more or less closely related to Tabulata or Avellana.

On the other hand, our re-examinations of $P$. compressum led us to the conclusion that the species is in reality a Peridinium species belonging also to Veroperidinium. The body of PAULsEN's species is remarkably compressed antero-posteriorly, while that of $P$. compressum is strikingly flattened dorso-ventrally. Irrespective of this difference, these two species are so closely related with each other in their general thecal morphology that it is hardly justifiable to separate them into different groups.

Coupled with the peculiar flattening of the body, which is unparalleled in the genus, the left of their two intercalary plates is unusually much smaller than the other.

However, there is another species to be considered. In $P$. grenlandicum, the left one of its two intercalaries is also much smaller than the other, and is ventrally displaced, peculiarly coming into contact with the pentagonal ventral apical plate. 
Judging from Woloszynska's figures, this species is undoubtedly to be allocated to Veroperidinium, and regarding the right sulcal plate it is more closely related to Avellane than to $P$. excentricum or to Tabulata or Monovela in the shape and general plate pattern of the ventral area. On the other hand, there is still some uncertainty, as represented in the inconsistency between her Figs. 13 and 14, about structural relations of the ventral area, particularly of its posterior sulcal plate. From these facts and considerations given above, WoloszynskA's species is allocated to the present group in this paper.

The ventral plate pattern of 'ortho' or exceptionally of 'meta' is coupled with two juxtaposed intercalary plates consisting of a smaller left and a much larger right ones. The right sulcal plate extends anteriorly to the epitheca, and the posterior sulcal plate is a lower type in its shape in Veroperidinium, expanding symmetrically to either side. The body is generally flattended strikingly in dorso-ventral or anteroposterior direction or exceptionally compressed weakly dorso-ventrally. No apical nor antapical elongation is formed.

To the present group are allocated then the following three species as valid: $P$. compressum AвÉ, $P$. excentricum Paulsen and $P$. grenlandicum Woloszynska. In this regard, these two species differ from Avellana in which the two intercalaries are subequal in size and shape and from some of Monovela in which the left intercalary is much larger than the right. The ventral area of $P$. excentricum is excavated as a whole as some of Conica, while that of $P$. compressum is scarcely indented except its sulcal furrow just in some higher forms of Conica and also as in Monovela. On the other hand, their posterior sulcal plate is broadest in the median region where it is pointed dorsally or posteriorly and comes narrower bilaterally as found in Monovela. Furthermore the left sulcal list is indistinct while the flagellar wing is more distinctly formed. Thus, they are closely related on one hand with each other and on the other hand partly with some of Conica but closely with Monovela. And then they can not be allocated to either of them.

\section{Peridinium compressum (ABÉ)}

Congruentidium compressum ABÉ, 1927, p. 420, Fig. 36 A-E.

This peculiarly flattened species was found only in Asamushi and not a single record of this has ever been reported from any other sea. Its body is so strongly flattened and its content is so hyaline and colourless that it was exceedingly hard for us to establish exact plate pattern and structural relations of its thecal wall. This led us in the former paper (1927) to some misinterpretations or insufficient interpretations about its thecal morphology, and this also forced us to re-describe the species here.

The body is pentagonal in ventral view, bearing a minute spine on either end of its large postmargin. It bulges generally more ventrally than dorsally but often similarly to either direction. The body is flattened dorso-ventrally as a whole but 
particularly strongly along its longitudinal (lateral) and transverse (posterior) ridges where the thecal wall is sharply folded and by which the body surface is sharply divided into the ventral and dorsal halves. This flattening of the body is, however, subject to individual variation to some extent. And then, the cingular section is irregularly fusiform with a stronger convex side on the ventral, and tilts up ventrally instead of dorsally. The ascending girdle is not excavated distinctly. The ventral area indents the epitheca anteriorly, and is narrow for a short distance below the girdle and then becomes wider posteriorly, ending in front of the postmargin of the body.

On the ventral of the epitheca, the rhombic apical plate tapers somewhat more anteriorly than posteriorly. The triangular lateral apical plate occupies anterior two-thirds or a little less of the lateral portion of the ventral surface, and expands laterally to the very margin of the longitudinal ridge of the body, along which it can be disjoined from the dorsal apical. The posterior one-third is covered with a ventral (median) precingular plate which expands laterally almost to the longitudinal ridge, along which is seen an exceedingly narrow ventral margin of its adjacent plate $\left(2^{\prime \prime}\right.$ or $\left.6^{\prime \prime}\right)$. On the dorsal of the epitheca are arranged eight plates in three series or transverse rows. The anterior one-third or a little less is covered with the dorsal apical plate which has an irregularly concave postmargin and agrees in lateral extremities with the two lateral apicals lying on the other side. A smaller left and a larger right intercalary plates are arranged transversely along the postmargin of the dorsal apical. The left of them expands directly to the left longitudinal ridge but the other is separated slightly from the right longitudinal ridge. Between these and the girdle lie three small precingular plates $\left(3^{\prime \prime}, 4^{\prime \prime}\right.$ and $\left.5^{\prime \prime}\right)$. At the postero-lateral corner of the dorsal surface is a minute plate $\left(2^{\prime \prime}\right.$ or $\left.6^{\prime \prime}\right)$ which extends anteriorly to the dorsal apical plate and is sharply folded near its ventral margin along the lateral ridge, lying for the major part on the dorsal surface and only partially on the ventral surface.

The hypotheca is also divided by the ridges into two halves, but differs from the epitheca in that the ridges lie invariably across the thecal plates and never along the sutures. Either of the two lateral postcingular plates is folded longitudinally along its ventral one-third or one-fourth, and the antapical plate also expands ventrally for a short distance beyond the lateral and posterior ridges, forming a small, flattened conical bulge at the base of a minute antapical spine.

The cingular wall is covered for the major length with a single, band-like plate, folding sharply at the lateral ridges. The other two cingular plates are small rectangular, lying at either end of the girdle.

The ventral area consists of a narrower anterior and a bilaterally expanded posterior parts. The former occupies anterior three-fifths of the ventral area, lying somewhat diagonally with its hind end deflected towards the right. Its left half is deeply excavated, forming the flagellar furrow, but the other half is hardly indented. Along the right of this furrow lies diagonally the short and exceedingly narrow flagellar pore, subequal in length with the flagellar trough. The posterior two-fifths 
expands postero-laterally on either side and is broadly rounded posteriorly but pointed at the intra-antapical suture. This part is more deeply indented anteriorly than posteriorly, conforming the flagellar furrow anteriorly. A narrow left sulcal list stands basally only along the median edge of the left ventral postcingular plate, extending somewhat obliquely towards the left. Along the opposite edge of the flagellar furrow is seen a much broader flagellar wing, extending also strongly obliquely towards the left. The right sulcal list is hardly formed, presumably owing to disappearance in this species of the sulcal furrow from the right sulcal plate. Around the posterior part of the ventral area is also seen no marginal list. But an indistinct, narrow one is often formed along the transverse hind end of the body.

The right sulcal plate extends anteriorly to the epitheca, lying entirely outside not only of the flagellar furrow but also of any sulcal depression. The left sulcal is about one half as large as the right sulcal, and it borders with its entire median margin on the flagellar pore and the flagellar trough, which have similar length. The transitional plate is exceedingly small in breadth. The posterior sulcal plate has its greatest breadth, thrice as large as that of the anterior half of the ventral area, and is pointed laterally and broadly rounded posteriorly.

We have hardly found a specimen without sutural zones of perceptible breadth. In some, the sutural zones are of considerable breadth, differing remarkably between different sutures. As was illustrated in any of our figures given, these zones lying transversely between two different rows of plates generally have greater breadth than those extending longitudinally within each of the rows. But, the intra-antapical suture has exceptionally a large breadth. We have hardly. been able to establish a sutural zone of definite breadth between any two of the four apical plates. From this irregular distribution of the sutural growth or the difference of growth-rate of the body between the longitudinal and transverse directions, it is undoubtedly suggested that the body may be elongated more and more remarkably as the sutural zone grows broader. This suggestion is strongly supported by the facts that the length-breadth ratio of the body is somewhat various between different specimens and that a broadly pentagonal specimen has generally narrower sutural zones than an elongated one.

The body content is granular but entirely colourless. A large vacuole is seen in the right half of the body. When actively swimming, this organism is erected with its apex upwardly and hardly shows active rotation of the body. The thecal wall appears to be hyaline but is crowded closely with minute and weakly differentiated poroids. It has small and subeuqal thickness throughout entire surface of the body except often along the posterior transverse ridge and at the tip of the antapical horn. A narrow and distinctly serrated list is sometimes formed along the ridges passing across the antapical plate.

Measurements: Length, 59-65 $\mu \mathrm{m}$. Transverse diameter, 52-67 $\mu \mathrm{m}$. Depth, 13-21 $\mu \mathrm{m}$.

Locality: Asamushi. 


\section{Peridinium excentricum PAULSEN}

Paulsen, 1908, p. 51, Figs. 64 a-f; Marukawa, 1922, Pl. 4, Figs. 51 g-i; Lebour, 1925, p. 108, P1. 18, Figs. a-d.

P. decipiens van BreEMeN, 1908, p. 187, Figs. 12 a, b, d.

P. perrieri FAURÉ-Fremtet, 1909, p. 228, Fig. 14, Pl. 16, Fig. 16.

\section{Group 5. Oceanica JöRGENSEN}

Section Oceanica Jörgensen, 1913; Lebour, 1925; Peters, 1928; Paulsen, 1931; Sahtllek, 1935; Diwald, 1939.

The body flares more or less remarkably either along entire length of the girdle or particularly distinctly on either side of the body, tapering anteriorly into a longer or shorter apical horn and posteriorly into two subequal, simple antapical horns. Its circular or descending girdle is equatorial or postequatorial, forming an ellipsoidal, ovoidal, reniform or circular cingular section of the body, which variously tilts up dorsally. The sulcal furrow generally has a subequal small breadth throughout its length or rarely is compressed bilaterally in the middle and is deeply excavated as a whole. It lies either along the ventro-median of the hypotheca, opening straightly ventrally or displaced more or less towards the left, opening obliquely towards the left. The left sulcal list has a subequal small breadth throughout its length, while the right sulcal list is much narrower and bears generally marginal serrae. A third list, similar in structure with the left one, is developed around the posterior sulcal plate lying in the hind end of the sulcal furrow where it slightly expands bilaterally.

The rhombic ventral apical plate tapers much more remarkably anteriorly than posteriorly. The intercalary row of plates rarely consists of two juxtaposed or separated plates but generally of three, the middle of which is tetragonal, pentagonal or hexagonal. The dorsal and two ventral postcingular plates expand generally nearly to the postmargin of the body. A small oblong or similarly shaped posterior sulcal plate borders on either side directly on the pointed hind end of the ventral postcingular plate.

The present group was established by Jörgensen (1913) who characterized it by the hollow antapical horns coupled with the rhombic ventral apical and tetragonal middle intercalary plates. Following his principle of subdivision, LEBour (1925) included nine species in this. The present group was re-examined and then re-defined by Paulsen (1931) who agreed with Lebour (9125) in the inclusion of the four following species; $P$. depressum, $P$. oblongum, $P$. oceanicum and $P$. saltans. Other three species of $P$. bulla, $P$. robustum and $P$. verrucosum, cited by LeBour were translocated by PAULSEN from this to the Tabulata group. Just an inversed allocation was proposed by them in regard to $P$. claudicans. It is peculiar and interesting that Paulsen (1931), Sariller (1935) and Diwald (1939) agreed in allocating to the present group $P$. elegans and $P$. grande, either of which differs profoundly from the present group in the structures of the ventral area and also in the ventral plate 
pattern, resembling only in its elongated antapical horn.

Judging from this brief historical account, it is apparent that the characterization of this group has been done, as in general in the genus Peridinium, mainly on the basis of seeming structure of the antapical horn, without giving any consideration on the other, more important structure, the ventral area. This naturally has brought forth the taxonomic confusion or inconsistency given above.

The plate pattern The ventral plate pattern is fairly well established in this group so far as published figures, literatures and our observations are concerned. In the major cases, the ventral apical plate is rhombic, tapering much more anteriorly than posteriorly. A single case of 'para' was recorded by DANGEARD (1927) on $P$. depressum. But his figures do not seem so accurately and correctly drawn as to allow us to verify taxonomic allocation of his form. In spite of this least variability of the plate pattern in the ventral half of the epitheca, some variations have often been recorded in the other half of $P$. depressum, $P$. oblongum and $P$. oceanicum. All of these species have three intercalary plates, and the shape of the middle intercalary is fairly well established in some, while it is subject to individual variation in others. Further, the relations between the lateral plates of the series and some lateral plates of the precingular series are, according to Peters (1928), also variable in $P$. depressum. In addition to these, two species were found bearing two juxtaposed or separated intercalary plates respectively. They are in all other respects correct members of the Oceanica group and can not be allocated to any other. This contravenes against the prevailing principle of subdivision of the genus, and clearly supports our principle proposed in this paper.

Hardly has ever been discussed the plate pattern of the hypotheca, particularly the ventral area of this group. Reviews of published figures inform us of the fact that the ventral two postcingular plates in the species of this group extend posteriorly with their pointed end similarly to the posteromedian end of the body. On the dorsal side of the hypotheca, the dorsal postcingular plate expands also nearly to its postmargin. We have been left in dense ignorance on the structural relations within the sulcal furrow of this group owing to its deep indentation and lateral compression. But it was brought to light in this paper that the right sulcal plate extends anteriorly to the epitheca, and the posterior sulcal plate borders in typical cases on either side on the ventral postcingular plate, expanding laterally hardly or slightly beyond the two middle sulcal plates.

The girdle and the midbody The girdle forms either a circular or a descending tract but never an ascending spiral. The cingular plane is ellipsoidal, ovoidal, reniform or circular according to the variations in the strength of its tilt and also in the dorso-ventral flattening of the midbody. These two characteristics just considered are variable within a certain range singly or concomitantly in some while well established in other species. Together with these, the bulge of the thecal wall along the girdle has effects upon the form of the midbody. When a weak tilt of the cingular plane is correlated with a distinct bulge of the thecal wall along the girdle, the midbody in ventral view is strongly angulated at the girdle. But when a stronger 
tilt is associated with a weak bulge, the midbody is rounded on either side. These are the difference established between $P$. oceanicum and $P$. oblongum.

The cingular section is generally bilaterally symmetrical in shape, but is distinctly asymmetrical in $P$. depressum and $P$. oblongum in which the depth of the section is smaller in the left half than in the other half of the body. This may be due to strikingly oblique opening to the ventral depression of the body in them.

The antapical horn All the species in this group have shorter conical or elongated finger-like antapical horns, corresponding in length to the apical horn. The hollow antapical horn is also seen in some of the Divergentia group. But the structure of the present group is characterized by its sharp differentiation from the sulcal furrow and lack of its distal spine. On the other hand, the sulcal depression expands along the median base of the antapical horn in the Divergentia group. This difference helps us much in practice in diagnosing a given species under low magnification and also an insufficiently drawn species in literatures.

The antapical horns stand remarkably asymmetrically on either side of the sulcal furrow in $P$. oblongum while fairly well symmetrically in $P$. oceanicum. A similar but much less distinct asymmetry can be established also in $P$. depressum. This characteristic structure has never received due considerations and discussions, but is in reality a feature of morphological importance as well as of taxonomic significance.

Highly variable is the length and distal divergency of the two remotely set antapical horns in $P$. oblongum. Similar variations are also reported on $P$. depressum. But in other species such variations have not been established.

Among published figures of this group we can very often see forms furnished with hardly differentiated and stumpy antapical horns, and they are variously allocated to $P$. claudicans, $P$. oblongum and $P$. ventricosum. But it has not been the case with our materials. So far as our materials are concerned, the differentiation of the antapical horn from the midbody is fairly characteristic for a given species within a certain range of variations, and serves together with other characters for specific distinction.

The ventral area The sulcal furrow agrees in extent with the ventral area which abruptly and deeply excavated as a whole. It lies longitudinally along the ventro-median of the hypotheca or slightly displaced towards the left, opening ventrally or obliquely towards the left, and extends in most cases dorsally beyond the postmargin of the body, forming there a narrow and deep indentation, sharply differentiated from the base of the antapical horn. The ventral area or sulcal furrow has in typical cases subequal width throughout its anterior major length, expanding in its hind end bilateral-symmetrically or more towards the right than towards the left. This broader portion is hardly established in ventral view of the body because it lies between the median bases of the two antapical horns. The left sulcal list has a considerable breadth throughout its length, subequal with the cingular list. Its free margin is entire. The right sulcal list has a similar breadth or is much narrower, bearing marginal serrae. It is to be noted here that this list has in $P$. depressum a distinct notch near its anterior end just as in some higher forms of the 
Humilia group of Protoperidinium. There is a third list, subequal in breadth and structure with the right sulcal one, standing basally around the broader posterior part of the sulcal furrow. This often extends laterally along the ventral edge of the antapical plate.

The flagellar pore lies longitudinally or somewhat diagonally along the middle of the postcingular part of the ventral area, and is often distinctly displaced posteriorly. The flagellar trough is subequal with or a little smaller in breadth than the flagellar pore, but has generally much smaller length. These two structures have, in common, along their right edge a narrow flagellar wing.

In $P$. depressum, the precingular or intercingular part of the sulcal furrow is divided into bilateral halves by a minute longitudinal ridge, springing from the proximal end of the anterior cingular ridge and standing along the suture between the transitional and anterior sulcal plates. This clearly serves to lead the proximal end of the cingular furrow to the flagellar pore. On the other hand, the distal end is sharply differentiated from the sulcal furrow. Posteriorly, the sulcal furrow is much less distinctly formed in the part covered with the posterior sulcal plate.

The right sulcal plate has a considerable and subequal breadth throughout its posterior major length and tapers more or less abruptly anteriorly, extending to the epitheca. The left sulcal plate is generally J-shaped but sometimes reversely L-shaped in $P$. depressum, and the flagellar trough lies along its postero-median margin.

The posterior sulcal plate is generally oblong and expands laterally symmetrically or asymmetrically beyond the two middle sulcal plates. But this abrupt expansion of the ventral area is often indistinct. In any case, the ventral postcingular plates extends posteriorly similarly to this plate. In $P$. depressum, this posterior sulcal plate is either $\mathrm{U}$ - or V-shaped, consisting of subequal or unequal two lobes. There is in its antero-median part a small notch, which corresponds exactly to the flagellar trough. The left lobe is longer than the right and has a subequal breadth or tapers distally. In either case, it extends to the left ventral postcingular plate with its truncated distal end in typical cases. But these two plates are variously set apart from each other in many specimens and furnished with narrower or broader sutural zones. This separation is particularly distinct in case the left lobe is pointed distally, and the distance between them corresponds in the main to the breadth of the sutural zones. This clearly suggests secondary remotion of the sulcal plate during growth of the body.

The sulcal furrow of $P$. consimilis $\mathrm{n}$. sp. and $P$. valgus $\mathrm{n}$. sp., both of which are furnished with two intercalary plates instead of three, is compressed laterally at the hind end of the ventral postcingular plates. In the latter species, the posterior sulcal plate is remarkably asymmetrical in shape, consisting of a broader right and a narrower and distally contracted left lobes as in $P$. depressum. Judging from this, $P$. depressum may be one of the lower types in the Oceanica group.

Distribution and development (growth) of the sutural zones within and around the ventral area were established on $P$. depressum, as was given in previous paragraphs and partly illustrated in Fig. 45 (297). A broad sutural zone is built around 
the ventral area except along its left anterior edge. And the sulcal furrow grows wider asymmetrically towards the right by sacrifice of this zone. The transitional and four sulcal plates are least disturbed during sutural growth of the body, keeping as a whole the closest relationship with the proximal end of the girdle.

Judging from these structural features considered above, among recorded species the following seven are regarded as valid for the Oceanica group; P. claudicans PAULsen, $P$. complanatum Karsten, $P$. depressum Bailey, $P$. oblongum (Aurivillius), $P$. oceanicum Vanhöffen, $P$. polymorphum Lindemann and $P$. saltans Meunier. To these are added in this paper following three new species: $P$. carus, $P$. consimilis and $P$. valgus.

Relationships Both of the Divergentia group of Mesoperidinium and the Oceanica group of Veroperidinium are characterized similarly by the hollow antapical horn. But they differ profoundly from each other in the structural relations within the ventral area and also in the relations between the ventral area and the antapical horn, suggesting their probable different origins. The present group is more closely related to Tabulata or Avellana with respect to the ventral area or sulcal furrow. Among the species of the present group, $P$. consimilis appears to represent the lowest type judging from its two intercalary plates, short antapical horns edging in a solid tip and its asymmetrically shaped posterior sulcal plate.

\section{Key to species}

1. The antapical horns, standing closely with one another in their proximal ends, strongly diverge distally

A. The horn is straight.....................................Peridinium valgus

B. The horn is strongly curved laterally ............................ saltans

2. The antapical horns stand more or less distantly from each other

A. The sulcal furrow is dinstinctly displaced towards the left....P. oblongum

B. The sulcal furrow is submedian

a. The body strongly flares along the girdle

$a^{\prime}$. The cingular tract is in ventral view convex anteriorly on the left and posteriorly on the right of the ventral area......P. depressum

$\mathrm{b}^{\prime}$. The cingular tract is convex posteriorly on both sides............. P. complanatum

b. The body not strongly flares along the girdle

$a^{\prime}$. The body is much broader than long forming anteriorly no apical differentiation ...................................... consimilis

$b^{\prime}$. The midbody is in ventral view pentagonal with subequal length and breadth and furnished with short antapical horns

a". The horns are set wide apart from each other......P. claudicans

$b^{\prime \prime}$. The horns are not strongly separated from each other........ P. polymorphum

$\mathbf{c}^{\prime}$. The similarly shaped midbody is furnished at both ends with 
distinctly elongated horns P. oceanicum d'. The small midbody is longer than broad, and the two short antapical horns are distinctly separated bilaterally. $P$. carus

\section{Peridinium consimilis $\mathrm{n}$. $\mathrm{sp}$.}

Fig. 42 (276-281)

This granii-like species is interesting in that it forms a connecting link between the Oceanica and Conica groups.

In ventral view the body of this small pentagonal species forms posteriorly two short and sharply pointed conical horns but does not differentiate anteriorly an apical elongation, and bulges more or less broadly along the equatorial circular girdle which is deeply indented. Its cingular section is horizontal and circular or nearly so with a faint ventral flattening. The conical epitheca has its concave surface either all over its length or only around its middle, or is weakly convex along its whole length. At the center of this epitheca lies a bluntly pointed apex. The dome-shaped hypotheca bulges more dorsally than ventrally, and has the two concave conical horns on the ventral of its center. Distal thinner portion of these horns are solid in most cases but does not bear a differentiated spine.

The sulcal furrow is deeply indented as a whole but is strongly compressed bilaterally at its posterior two-thirds just at the hind end of the ventral postcingular
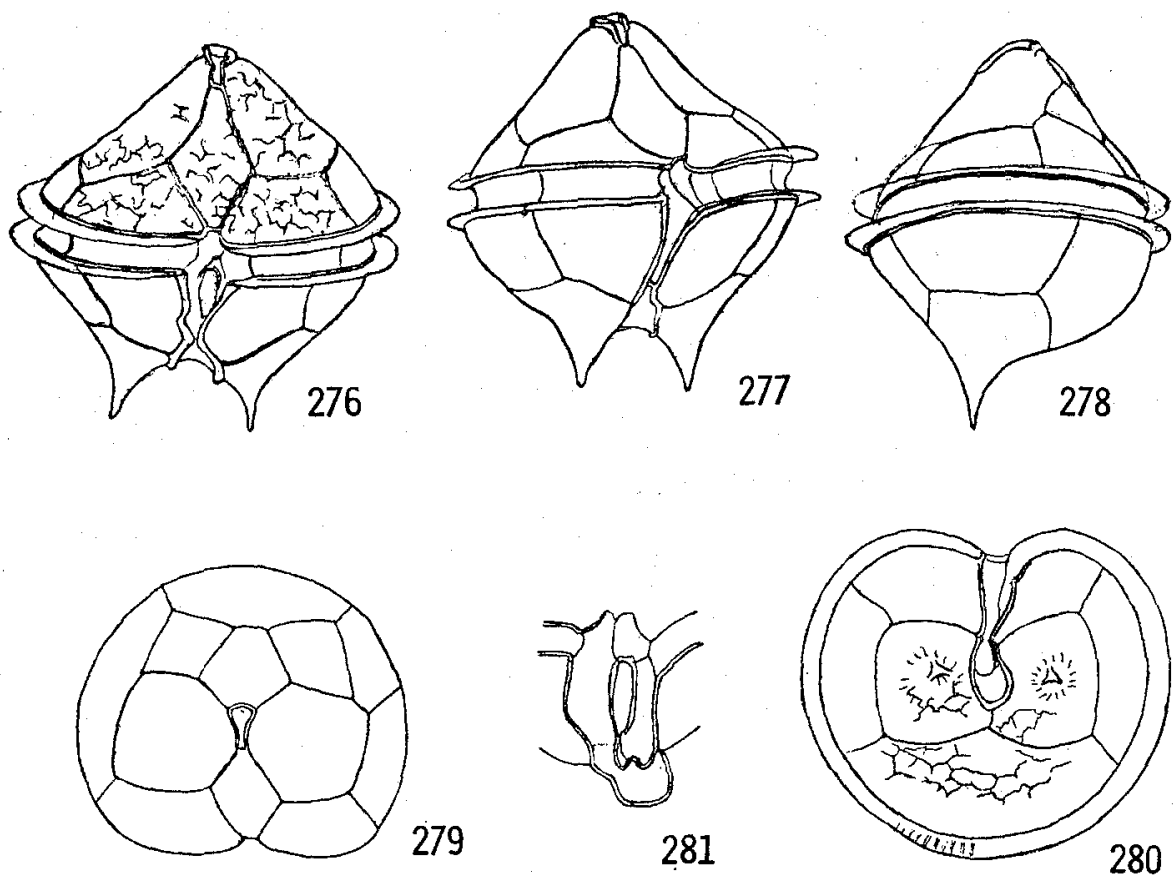

Fig. 42 (276-281) : Peridinium consimilis n. sp. 276-Ventral view. 277-Dextro-ventral view. 278Side view. 279-Apical view. 280-Antapical view. 281-Ventral area. 
plate. It extends dorsally to the center of the hypotheca, deeply indenting the postero-median margin of the body. The sulcal list is indistinct on either side.

The rhombic ventral apical plate is fairly small in breadth, tapering more anteriorly than posteriorly. On either side of this lie two, unusually large lateral apical plates, which cover anterior two-thirds or a little more of the ventrl-lateral surface of the epitheca. Similarly the pentagonal dorsal apical is elongated posteriorly, and two rhombic intercalary plates lie on either side of this dorsal apical and are separated completely from each other. The precingular plates are peculiarly six instead of seven in the specimens examined, and all of them have a similar length covering posterior one-third of the epitheca. Among them, the dorsal $\left(4^{\prime \prime}\right)$ and right $\left(5^{\prime \prime}\right)$ ones are the largest in basal length.

In the hypotheca, all of the five postcingular plates are much elongated, covering anterior half or a little more of its surface. Among them, the dorsal is the largest both in breadth and in length, extending almost to the postmargin of the body. The antapical horn lies in the center of an antapical plate, and its distal portion is triangular in cross section owing to its three side-ridges.

The ventral two of the three cingular plates agree in their lateral extremities with the ventral postcingular plates. The transitional plate is small pentagonal, lying mostly within the sulcal furrow.

It was hardly possible to establish the structural relations within the sulcal furrow without flattening that part of the thecal wall because of the strongly bilateral compression and deep indentation of the furrow. With all our repeated contrivances we failed to bring out exact shapes of the four sulcal plates owing to their strongly uneven surface. But it can be said with certainty that the ventral area of this species is Veroperidinium-type and not Protoperidinium-type.

The flagellar pore lies longitudinally, extending between the posterior cingular ridge and the lateral constriction of the sulcal furrow. Lying on the right of this, the right sulcal plate extends anteriorly to the epitheca. The left sulcal plate extends posteriorly beyond the right sulcal, bearing along its postero-median margin a narrow and short flagellar trough. The minute, pentagonal anterior sulcal plate does not much indent the epitheca. It is the posterior sulcal plate whose exact contour was hardly established. This plate is very irregular in shape and has irregularly concave surface. It borders with its right anterior end on the right ventral postcingular plate, and has a tapering left end, with which it extends to the right ventral postcingular plate.

The thecal plate is covered with polygonal meshes, which are often incompletely formed and discontinuous in the epitheca. A close set of irregularly arranged ribs is seen along marginal major breadth of the cingular list.

Measurements: Length, 53--58 $\mu \mathrm{m}$. Transverse diameter, 45-50 $\mu \mathrm{m}$. Depth, $42-45 \mu \mathrm{m}$.

Locality: Asamushi, Shimoda. Extremely rare.

With $P$. granii, the present species is so closely related in general shape of the body that we may be led to misinterpret this, if we fail to pay due considerations 
on details of their thecal structures. The present species differs from $P$. granii not only in the plate pattern of the epitheca but also in the structures of its ventral area. Judging from literatures it seems highly probable that some investigators might have confused these two different species, supposing the antapical spine to be highly variable in development.

Together with the hollow antapical horn, the asymmetrically formed posterior sulcal plate clearly defines closer relationships of this with Oceanica than with Conica. From species of the former group, the present one can be distinguished by its small size, its least developed apical and antapical horns, and strongly compressed sulcal furrow. In the latter Conica group, there are several small species somewhat related to the present one in body contour. But from them, the present one can be separated at once by its two, bilaterally displaced intercalary plates, simple antapical horn and narrow sulcal furrow.

\section{Peridinium valgus $\mathrm{n}$. sp.}

Fig. 43 (282-284)

In a spring plankton from Asamushi, we saw an interesting form, closely resembling $P$. saltans described by Meunier (1910) from west coast of Nova Zembla. No other investigator has ever redescribed that.

Our species has a broadly rhomboid or rather biconical midbody, bulging more dorsally than ventrally and also more or less remarkably along the girdle. Its convex conical epitheca tapers more or less abruptly to a short apical horn. And

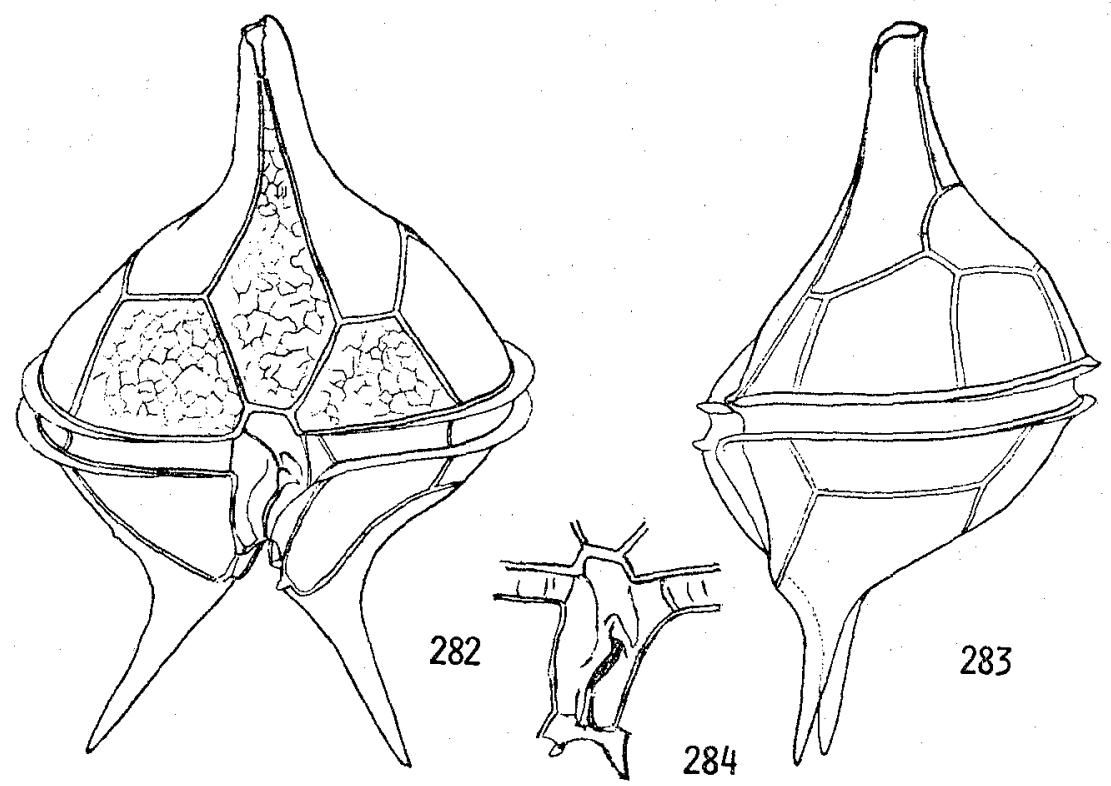

Fig. 43 (232-284): Peridinium valgus n. sp. 282-Ventral view. 283-Side view. 284-Ventral area. 
the two, gently tapering antapical horns strikingly diverge distally (ca. $60^{\circ}$ ), standing symmetrically just on the lateral of the median sulcal furrow. They are subequal in length and size, but the left of them is deflected very slightly ventrally. The apical horn stands at the center of the epitheca while the antapical horns are displaced to ventral one-third of the hypotheca. The cingular plane is broadly reniform, slightly broader than deep, and tilts up dorsally $\left(20^{\circ}\right)$. Its mid-ventral depression is indistinct.

The girdle is equatorial or post-equatorial, forming a circular tract. The deeply excavated sulcal furrow is peculiarly widest at the intercingular part, and is compressed bilaterally in its posterior two-thirds.

The ventral apical plate is elongated anteriorly, and the trapezoidal left ventral precingular plate is smaller than the similarly shaped right ventral of the same series. The intercalary series consists of subequal two plates, lying juxtaposed. In the hypotheca, the ventral postcingulars are triangular, extending similarly to the base of the antapical horns.

A small and narrow flagellar pore lies diagonally in the middle of the ventral furrow, and is accompanied with a small flagellar trough. Lying on the right of them, the right sulcal plate extends anteriorly to the epitheca. The anterior sulcal plate has a subequal breadth throughout its major length, and broadly indents the epitheca anteriorly. The left sulcal plate is much smaller than the right sulcal one, but does not much extend posteriorly beyond it. The posterior sulcal plate expands laterally beyond the two middle sulcal plates and has irregularly uneven surface. The transitional plate is a little longer than broad, and the two ventral cingular plates extend laterally as long as the ventral pre- or postcingular plates.

The thecal plate is covered with distinct polygonal meshes. The cingular wall has also irregular transverse striae.

Measurements: Length, 105-113 $\mu \mathrm{m}$. Transverse diameter, 68-72 $\mu \mathrm{m}$. Depth, 53-57 $\mu \mathrm{m}$.

Locality: Asamushi.

Only three specimens of this were found. In regard to the striking dorsal bulge of the midbody and the closely set and strongly diverging antapical horns, the present form is unparalleled in the Oceanica group except $P$. saltans Meunier which is described only insufficiently and is entirely unknown about its size. Disregarding the size, his species differs from the present one in its three intercalary plates and strongly curved, much longer antapical horns. In spite of these differences, we have still doubts about their specific distinction. But, we shall regard this in this paper as a distinct species until their intermediate forms suggesting their unity are brought to light.

\section{Peridinium complanatum KARSTEN}

Fig. 44 (285-289)

Karsten, 1905, Pl. 53, Fig. 4 a, b. 
P. parallelum BROCH, 1906, p. 153, Fig. 3. PAUlsen, 1908, p. 53, Fig. 68.

? P. antarticum (SGhiller) Karsten, 1905, Pl. 19, Figs. 1-4.

P. depressum, in part, LeBour, 1925; PETER, 1928, Fig. 17 e-f.

This short-horned form was distinguished into a distinct species by some investigators such as Karsten (1905, 1906), Broch (1906), PAulsen (1908) and others, while it was regarded on the other hand as a variety of $P$. depressum by LeBour (1925) and Peters (1928). But so far as our materials are concerned, we have not yet found any specimen intermediate between $P$. depressum and $P$. complanatum regarding obliquity of the cingular plane, and length of the apical and antapical horns. In addition to these differences, the sulcal furrow lies at the mid-ventral part of the hypotheca in the present form while it is displaced more or less distinctly towards the left in $P$. depressum. In other words, the right antapical horn is displaced from the sulcal furrow more laterally than the left one in $P$. depressum, while the two antapical horns stand

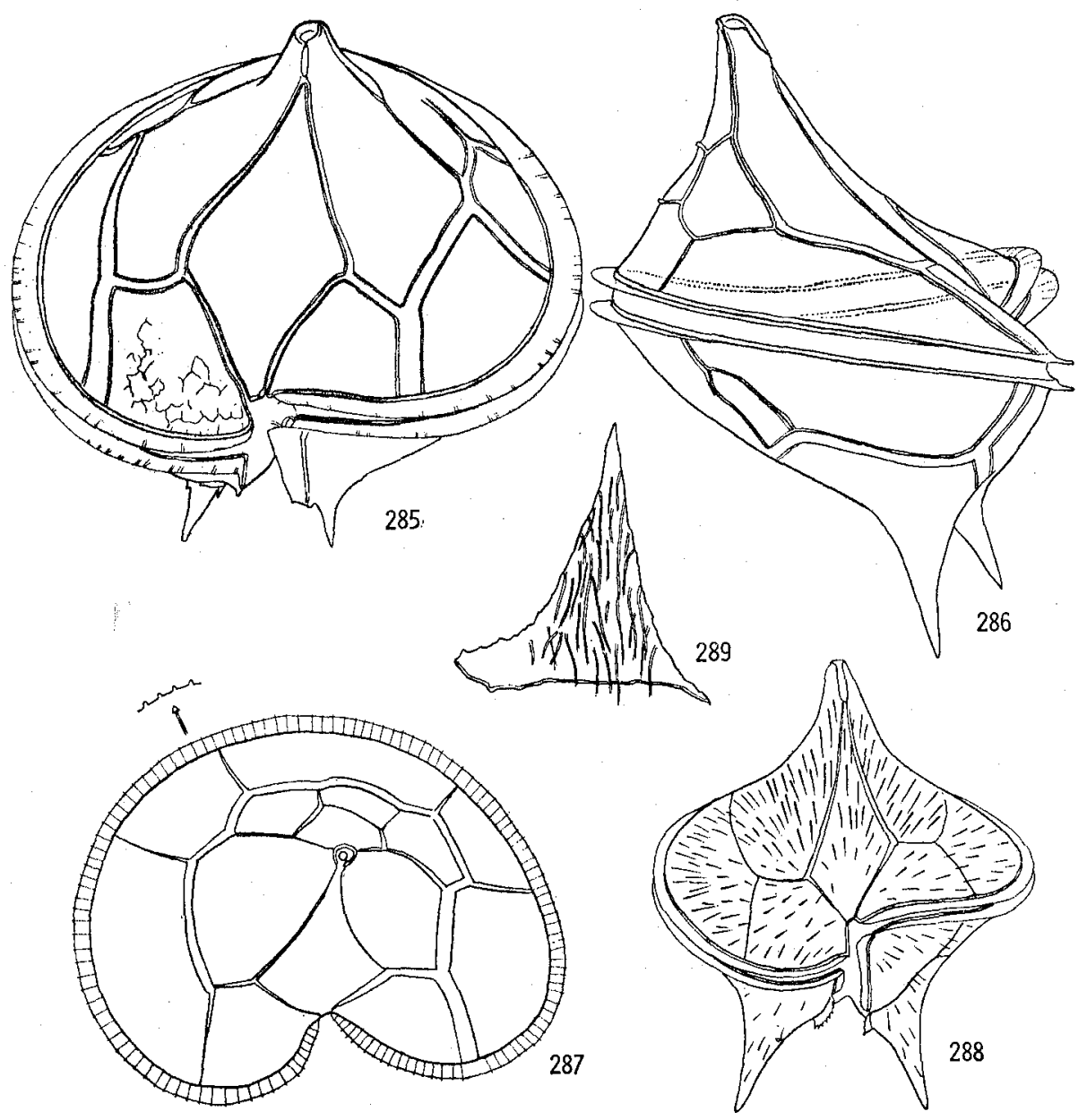

Fig. 44 (285-289): Peridinium complanatum KARSten. 285-Antero-ventral view. 286-Side view. 287-Apical view. 288-Ventral view. 289-An isolated plate furnished with fine tubules. 
symmetrically on either side of the furrow in the present form. Furthermore, the left half of the cingular section is much smaller than the other half in $P$. depressum, while this bilateral difference is much smaller in the present form. These differences just considered are clearly illustrated in published figures of them but have not been taken into consideration by former investigators in the unity or separation of these two forms. All the investigators who discussed the taxonomic unity of them, have disregarded these differences, pointing out only the difference in the structure of their antapical horn.

Similar differences are generally established among $P$. claudicans, $P$. oblongum and $P$. oceanicum. Of these three forms are to be regarded as distinct species, it may be justified to suggest specific distinction of this from $P$. depressum.

Measurements: Length, $110 \mu \mathrm{m}$. Transverse diameter, $110 \mu \mathrm{m}$.

Locality: Asamushi. Very rare.

\section{Peridinium depressum BAILEY}

Fig. 45 (290-297)

Paulsen, 1908, p. 53, Fig. 67; 1931, p. 68; Mangrn, 1910, Pl. 7, Figs. 6-9; Okamura, 1912, P1. 4, Figs. 60 c, d, 61, 62; Lebour, 1925, p. 119, Pl. 23, Figs. a-f; Dangeard, 1927, p. 2, Fig. 1 A-C; 1932, p. 341, Fig. 3 a; Peters, 1928, in part, p. 63, Figs. 17 a-d, 18 a, 20; BöHм, 1933, p. 311 , Fig. 5 a-b; Schiller, 1935, p. 250, Fig. 251 a-t; Drwald, 1939, p. 179, Fig. 1.

P. divergens v. reniforme BerGH, 1881, Fig. 45; Pouchet, 1883, in part, P1. 20-21, Figs. 24-27.

P. kofoidi Fauré-Fremiet, 1908, p. 224, Textfig. 11, Pl. 16, Fig. 12.

P. marinum Lindemann, 1925, p. 98, Figs. 7-12.

This is one of the commonnest species in Japan as well as in other parts of the world. Much discussion has been given about the thecal morphology of this species, and there is now a prevailing suggestion that the antapical horn in this species is highly variable in structure, forming in some a hollow while in others a solid distal end. But for the reasons given in relation to the previous species, we are now inclined to believe their specific distinction.

In $P$. compressum, the midbody also bulges so strikingly along the girdle and the cingular plane is so strongly oblique that the body in side view is parallerogramic with its greater diagonal along the body axis. In contradiction to $P$. complanatum, the apical and antapical horns are much longer, and the left half of the cingular plane is smaller in depth than the other half. This latter character is coupled with a remarkable arch of the girdle in its proximal quarter and also with a large midventral depression of the body, which is particularly distinct in the cingular region and opens not directly ventrally but somewhat obliquely towards the left. The sulcal furrow is displaced towards the left, instead of lying in the midventral part, setting the right antapical horn more apart from it than the left antapical horn. And this left antapical horn is smaller in thickness and length and inclines more ventrally than the right one. All of these peculiarities give to this species the characteristic features by which we can distinguish it at a glance from all other 
species of the genus.

Peters (1928) discussed the dorsal plate pattern of the epitheca extensively, giving four types different from one another in the relations between the lateral intercalary and ventro-lateral precingular plates. These four may be reduced
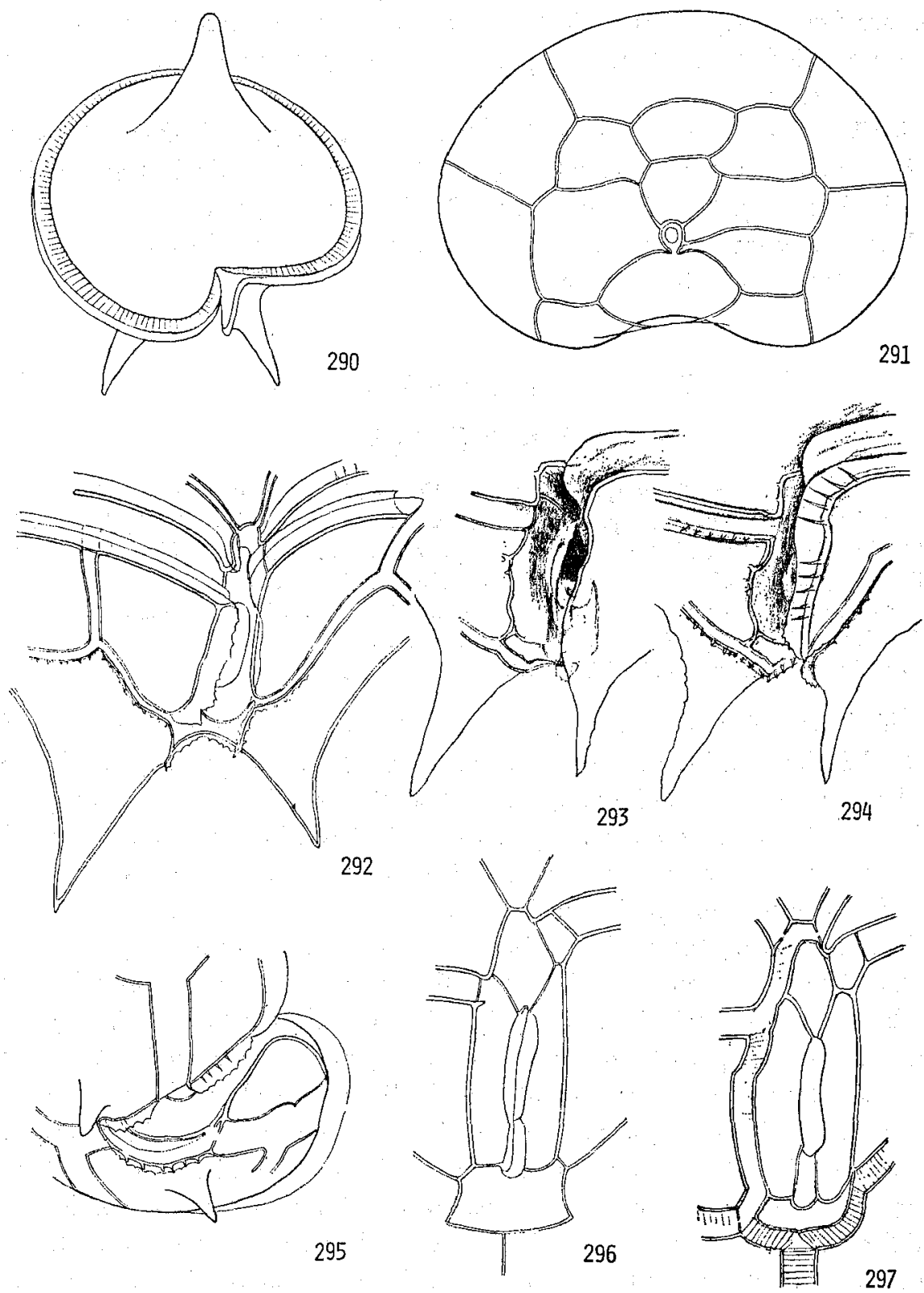

Fig. 45 (290-297): Peridinium depressum BaIly. 290-Anterior ventral view. 291-Plate pattern of epitheca. 292-Ventral area and adjacent plates (dextro-ventral view). 293-Ventral area depicted without appendages (sinistro-ventral view). 294-The same with appendages. 295-Dextroantapical view. 296, 297-Ventral area of ordinary (296) and well-grown (297) specimens. 
to three if the right precingular plate in his Fig. $20 \mathrm{~d}$ is presumed to consist of $5^{\prime \prime}$ and $6 "$. Then, two symmetrical and one asymmetrical types are comprised in Peters" forms. And all of these three are also established in our materials. In addition to these variations, we saw a single case of five apical plates, and PEters (1928) recorded a case of six precingular ones. Further we found a large specimen bearing an additional triangular plate among the two postcingular ( $3^{\prime \prime \prime}$ and $4^{\prime \prime}$ ) and right antapical plates. A full account was given in a previous paragraph about the structural relations within the ventral area of this species. One has to recollect now that the posterior sulcal plate of this species is variable in its leftward expansion, reaching the left ventral postcingular plate in some while separated from it in others.

From these given above, it may be allowed to suggest that the plate pattern is at least partially unestablished as yet in this species as in some others. But we feel constrained to point out that the two lateral apical plates are subequal in total breadth with the two ventral precingulars. In this regard, $P$. compressum agrees with $P$. complanatum, and this character helps us in practice in distinguishing them from others.

Strange is the fact that we rarely saw a huge, thick-walled and deeply coloured specimen with numerous, fine thread-like structures arranged in radial directions within the body. These structures can be traced from the thecal wall for a considerable length into the body. In one case, we found a group of very fine tubules springing from the inner surface of an isolated antapical plate. They are rigid and flexible, yielding to pressure, and each of them can be established to spring from a thecal pore of that plate. On the other hand, they can be broken to pieces instead of disjoining from the thecal plate by applying a needle or pressure from above the cover glass. And they agree with the radial structures within the grown specimens in their arrangement and diameter. From these it is clear that these fine tubules consist of materials different from that of the thecal wall, and they are formed as secondary addition during growth of the body in which they are seen. We are entirely ignorant of their morphological and physiological significance. But it may be allowed to suppose that they serve at least partly as an inner thecal wall of an over-grown specimen.

In Asamushi, we often found a cyst of this species.

Measurements: Length, 140-190 $\mu \mathrm{m}$. Transverse diameter, 90-145 $\mu \mathrm{m}$.

Locality: Asamushi, Shimoda, the Inland Sea.

\section{Peridinium claudicans PAULSEN}

Fig. $46(298,299)$

Paulsen, 1908, p. 55, Fig. 71 ; 1931, p. 67, Fig. 38 A-E; Barrows, 1919, P1. 19, Figs. 5-6; Lindemann, 1924, p. 228, Figs. 63-65; Lebour, 1925, p. 123, Pl. 25, Fig. 1 a-d.

Peridinium sp. FAuré-Fremiet, 1908, p. 224, Text-fig. 11, Pl. 16, Fig. 11.

P. oceanicum f. claudicans MeUnIER, 1919, p. 17, Pl. 15, Figs. 22, 23. 
P. oblongum Lebour, 1925, Pl. 24, Fig. 1 a-c.

P. oblongum var. inaequale Dangeard, 1927, p. 9, Fig. 7 A-G.

P. oblongum var. latidorsale DangeARd, 1927, p. 10, Fig. 7 D-E.

P. oblongum var. symmetricum DANGEARD, 1927, p. 8, Fig. 5 A-F.

P. ventricosum MANGIN, 1922, p. 80, Fig. 213.

Judging from PAulsen's figures, $P$. claudicans has a smaller left and a larger right antapical horns, set apart asymmetrically from the sulcal furrow, and its midbody bulges fairly remarkably dorsally. In Asamushi and Shimoda were found two forms of similar size and shape, differing mainly in the dorsal bulge. In one of them, the pentagonal midbody is strongly flattened similarly on either side and is furnished with symmetrically formed sulcal furrow and antapical horns. In the other, the midbody bulges more dorsally than ventrally and the sulcal furrow and antapical horns are asymmetrical in arrangement. This latter form, then, corresponds exactly to Paulsen's originl species.

Measurements: Length, 90-115 $\mu \mathrm{m}$. Transverse diameter, 50-75 $\mu \mathrm{m}$. Depth, 20-38 $\mu \mathrm{m}$.

Locality: Asamushi, Shimoda.

We have some doubt about specific distinction between $P$. oceanicum and $P$. oblongum so far as published figures are concerned. Many of former investigators apparently interpreted these two species variously, and at the same time had given figures of them wrongly drawn regarding some or other structures. But so far as our materials are concerned, the present species has characteristics worthy of specific distinction from $P$. oblongum.

\section{Peridinium oceanicum VANHÖFFEN}

Fig. 46 (300-302)

Cleve, 1900, p. 17, PI. 7, Figs. 17, 18; PAulsen, 1908, p. 54, Fig. 69 a-c; Mangin, in part, 1910, Pl. 7, Fig. 3.

P. oceanicum f. arupinensis Broch, 1910, p. 190, Fig. 7.

P. oceanicum var. oblongum Lindemann, 1924, Figs. 56-61.

P. oblongum, Fauré-Fremiet et O. du Puigaudeau, 1924, Fig. 9; Böhm, 1933, p. 315, Fig. 7 a-c.

From $P$. oblongum, the present species has generally been distinguished mainly by its angulated cingular portion, concave conical epitheca and two antapical horns standing less remoted from each other. But, whether the cingular portion is angulated or rounded is clearly correlated mostly with weakly or strongly tilted cingular plane and partly with difference in directions of view. So far as our materials are concerned, the present species shows a definite range of variations in the tilt of its are cingular plane. This is also supported by some of published figures. The concavity of its epithecal surface depends somewhat upon the less tilted cingular plane. That the two antapical horns of this species is less separated from each other than those of $P$. oblongum is clearly due to their least separation from the sulcal furrow. As described regarding $P$. oblongum, the right antapical horn of that species is more 


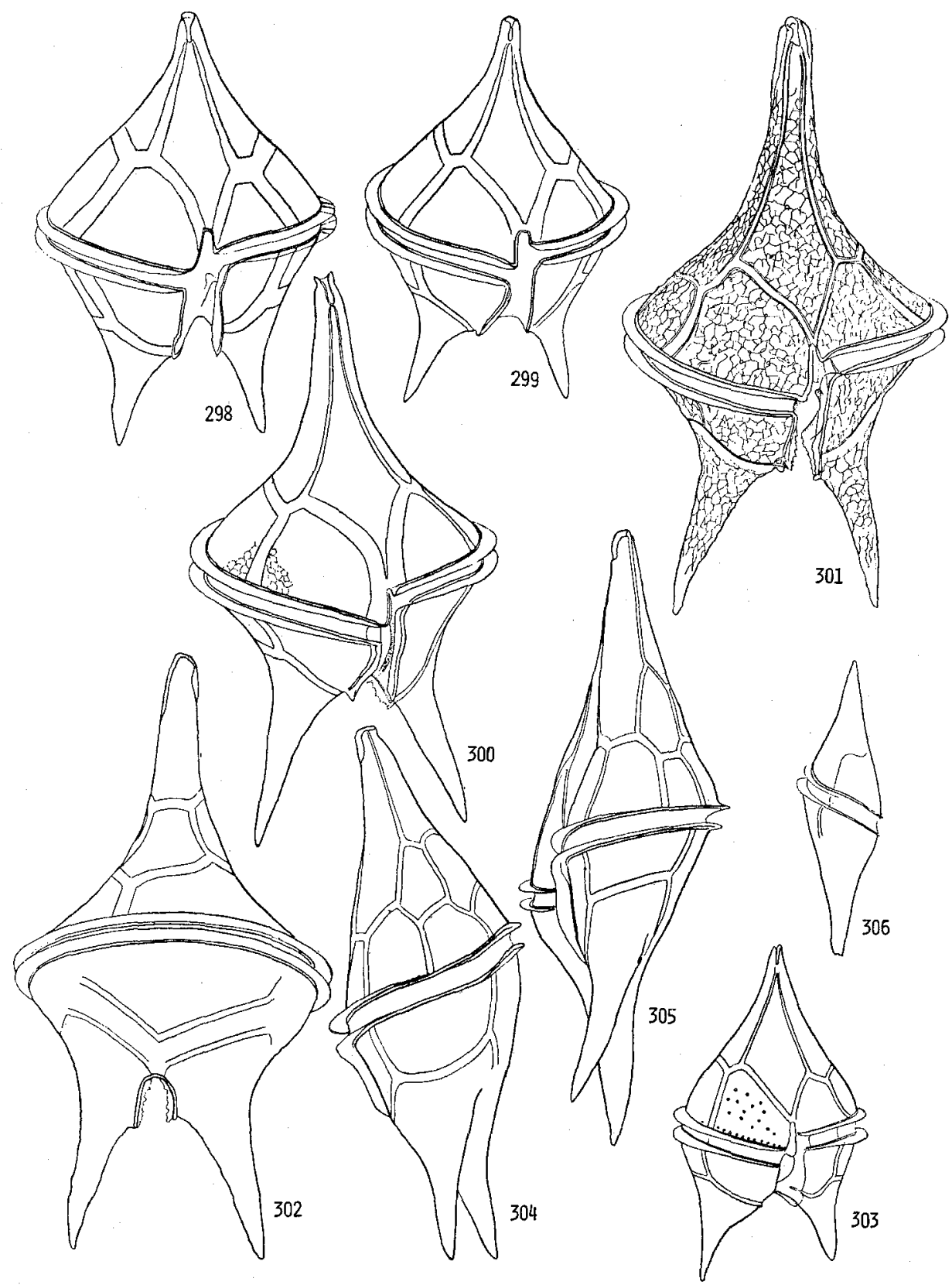

Fig. 46: (298-299): Peridinium clandicans Paulsen. 298, 299-Ventral views.

(300-302): Peridinium oceanicum VAnfö́fFen. 300, 301-Ventral views. 302-Dorsal view.

(303-306): Peridinium carus n. sp. 303-Ventral view. 304-306-Side views. 
laterally removed from the sulcal furrow than the left one. Correlated to this symmetrical arrangement of the two antapical horns in the present species, its sulcal furrow is sub-median, lying either just along the ventro-median or slightly displaced towards the left side.

Structural characteristics concerning the epitheca and cingular plane are fairly variable, while those of the hypotheca appear to be well established and worthy of specific characterization of this, helping us much in practice in identifying species.

In ventral view, both of the epitheca and hypotheca are concave conical. The midbody is flattened dorso-ventrally, and the thecal wall flares at the girdle strikingly laterally but not distinctly towards the ventral and dorsal directions. Along the midventral of the body is the ventral depression which extends anteriorly beyond the girdle, lying for the majority within the hypotheca. The girdle forms a descending spiral with distal displacement of two cingular widths. In postero-ventral view the girdle appears as if forming a distinct proximal arch, but such is not the case in ventral or antero-ventral view of the body. The cingular plane tilts up dorsally about $15^{\circ}-$ $20^{\circ}$.

The median or submedian sulcal furrow is deeply excavated as a whole and has a subequal width throughout its length. It extends dorsally beyond the postmargin of the body, forming there a small but deep indentation. Its posteriormost portion lying between the girdle is a little wider, expanding abruptly laterally, and to this the two ventral postcingular plates extend. The left sulcal list has entire margin and is broader than those standing along the dorsal and right edge of the furrow and bearing marginal serrae. The left antapical horn is a little smaller in length and thickness and is inclined more ventrally than the right. It stands just on the left of the sulcal furrow, while the right antapical horn is slightly displaced laterally from the furrow. But this asymmetry is so indistinct that it can hardly be established under lower magnification. These two horns diverge distally $30^{\circ}-40^{\circ}$.

The rhombic ventral apical plate extends with its elongated neck almost to the tip of the apical horn. The middle intercalary plate is either tetragonal or pentagonal so far as our materials are concerned. The ventral cingular plates extend laterally as far as the two ventral pre- or postcingular plates. And the transitional plate is broader than long. In the hypotheca, the two ventral postcingular plates extend similarly posteriorly to the medium base of the antapical horn, and the dorsal of the same series expands also posteriorly almost nearly to the postero-median indentation of the body.

Measurements: Length, 155-165 $\mu \mathrm{m}$. Transverse diameter, 75-80 $\mu \mathrm{m}$. Depth, $50 \mu \mathrm{m}$.

Locality: Asamushi.

66. Peridinium carus n. sp.

Fig. 46 (303-306) 
Togethter with $P$. compressum, we found in a collection from Asamushi, a small $P$. oceanicum-like species, differing in some or other points from any of recorded species.

This small species has an elongated body merging anteriorly into a conical apical horn and forms posteriorly two small conical antapical horns. The midbody is flattened dorso-ventrally and the cingular plane tilts up dorsally (ca. $30^{\circ}$ ). The thecal wall is elegantly rounded along the girdle, and the left antapical horn is shorter than the other. The girdle forms a descending spiral with distal displacement of its own width. The sulcal furrow is somewhat asymmetrical, opening obliquely towards the left but not so distinctly as in P. oblongum.

The two ventral precingular plates differ from each other remarkably in size but are similarly longer than broad. The two ventral postcingular plates differ similarly in breadth. The middle intercalary is broadly hexagonal. Lying between the ventral pre- and postcingulars, the ventral cingular plate agrees with them in lateral extension. The ventral area slightly expands laterally in its hind end covered with the posterior sulcal plate.

The thecal plate is scattered with minute pores.

Measurements: Length, 85-93 $\mu \mathrm{m}$. Transverse diameter, 45-48 $\mu \mathrm{m}$. Depth, $20 \mu \mathrm{m}$.

Locality: Asamushi. Extremely rare.

From $P$. claudicans, the present species differs in its much smaller size and slender body. Judging from published figures and literatures, it seems highly probable that some of former investigators might have confused this with $P$. claudicans, and that the present species may be found not only in the north Pacific but also in northern parts of the Atlantic Ocean. The present species is distinguished from either $P$. oceanicum or $P$. oblongum by its much smaller size and shorter antapical horns. Regarding the tilt of the cingular plane, this is closely related to $P$ : oceanicum from which this differs in lack of angular bulge of the thecal wall along the girdle. In respect to the asymmetry in the hypotheca, this is more closely related to $P$. oblongum than to $P$. oceanicum, forming a connecting link between them.

\section{Peridinium oblongum (AURIVILLIUS)}

P. divergens Ehrbg. var. oblonga Aurivillius, 1898, p. 96.

$P$. oceanicum, in part, Bergh, 1881, Pl. 15, Figs. 39, 40; MAngrn, in part, 1910, Pl. 7, Fig. 4, 5; PAulsen, 1931, p. 60, Fig. 39; Dangeard, 1932, p. 341, Fig. 3 b; Böнm 1933, p. 316, Fig. 8 a-b.

P. divergens var. typica Pouchet, 1883, p. 436, Pl. 20-21, Figs. 20, 21.

$P$. oceanicum var. oblongum PAulsen, 1908, p. 55, Fig. 70; OKamura, 1912, Pl. 4, Fig. 59, a-b; ABE,, 1927, Fig. 21 A-D.

P. diabolus Okamura, 1907, P1. 5, Fig. 39.

P. elegans var. KARSTEN, 1905, p. 132, P1. 19, Figs. 5. 6.

$P$. gracile Karsten, 1907, p. 417, P1. 50, Figs. a-b.

P. murrayi Kofold, 1907, Figs. 29.

Whether the present species is distinct from or united with $P$. oceanicum has not been well established, and is still held in a state of confusion because of their close resemblance, or rather their intermediate forms and insufficient characteriza- 
tion bringing forth some difficulties and confusions. Aurrvillius, finding the present form in Skagerrak, characterised it in 1898 as follows: "Umkreis-von den Stacheln weggeschen-elliptisch (die Gürtelpartie als nicht... winklig hervorstehend). Die Hinterhorner sind mit einem kleinen Zahn nach innen an der Basis versehen, divergieren aber weniger als bei der var. depressa. Es lauft die vordere Hälfte kegelformig in das Vorderhorn aus. Die ganze Oberfläche ist even und Querfurche bildet, wie bei var. depressa einer niedrigen Spiral. Die Farbe ist rosenrot."

Judging from these and his figures, the midbody of his species is in ventral view broadly rounded laterally at the girdle, tapering anteriorly into an elongated apical horn, and forms posteriorly two subequal, widely removed and more or less abruptly differentiated antapical horns. Its cingular plane is strongly tilted up dorsally. And the postero-median indentation due to the sulcal furrow is slightly displaced towards the left.

Aurivillius' characterization is far from complete, bringing forth some confusions and inconsistencies in literatures published afterwards. Presumably placing taxonomic stress upon either of 'the rounded cingular part' or 'the less divergent antapical horns', some regarded a rounded form and others took a slender form as corresponding to AuriviLurus' species.

In such a form in which the cingular plane tilts up dorsally so strikingly as this and $P$. oceanicum, the shape of the midbody in ventral view is correlated mostly to the depth and tilt of the cingular plane and partly to whether the thecal wall is concave or convex along the girdle. Consequently, Auriviliuus' definition regarding this structure is not to be brought under a sweep discussion, and can be verified only from BERGH's figures.

The antapical horns in $P$. oblongum are less divergent only by comparison with those of $P$. depressum but not with those of $P$. oceanicum. If we do not take this into consideration, we may be led into confusion.

The only trustworthy basis upon which one can define AuriviluIus' original species is Bergh's figures which correspond in all respects exactly with PAULSEN's (1931) and Börm's $P$. oceanicum and at the same time with the present one.

In typical cases, the cingular wall is broadly rounded or elegantly convex along the girdle in $P$. oblongum, while it bulges more or less remarkably or concave along it in $P$. oceanicum. The cingular plane tilts up dorsally $30^{\circ}-60^{\circ}$. The apex and antapices are then strikingly displaced towards the opposite directions in the two halves of the body and the cingular section has a considerable depth. As in $P$. depressum, the thecal wall bulges more ventrally in the right half than in the other half, bringing forth in ventral view a characteristic distal arch of the girdle.

The antapical horn is either short conical or elongated finger-shaped, corresponding in length with the apical horn. As well as the apical horn, these antapical horns are more or less abruptly differentiated from the midbody, and are subequal in length or the left of them is slightly shorter than the other. In any case, the antapical horn of this is always more slender than that of $P$. oceanicum. They are almost parallel in direction of their extension or more or less strongly diverge distally $\left(20^{\circ}-40^{\circ}\right)$. In 
any case, the left antapical horn stands just on the left of the sulcal furrow, while the right one is slightly or strikingly displaced laterally from the sulcal furrow. In other words, the sulcal furrow is remarkably displaced towards the left, and the postmargin of the body is seen asymmetrically only on the right of the furrow. The sulcal furrow lying thus asymmetrically is deeply excavated as a whole and opens strongly obliquely towards the left instead of straightly ventrally. This asymmetry in the hypotheca is so distinct in this species that it helps us much in practice in identifying $P$. oblongum even under small magnification.

KoFOID (1907) distinguished P. murrayi from the present species on the basis of its 'more divergent antapical horns' (ca. $60^{\circ}$ ). We found a form in Shimoda just corresponding with his. In both of them, the asymmetry in the hypotheca can readily be established. On the other hand, there are reasons to believe probable occurrence of high variability in the distal divergence of the antapical horns in this species.

In addition to the typical form, we often saw in Asamushi and more abundantly in Shimoda a slender form more or less closely related to $P$. oceanicum or rather to PAulsen's (1908) var. oblongum. They are intermediate between oceanicum and the typical form of $P$. oblongum, but are allocated in this paper to the latter because of the asymmetry in the hypotheca. The dorsal intercalary plate is tetragonal or hexagonal.

Measurements: Length, 130-147 $\mu \mathrm{m}$. Transverse diameter, $70-80 \mu \mathrm{m}$. Depth, $45-50 \mu \mathrm{m}$.

Locality: Asamushi (rare), Shimoda, Misaki.

\section{Group 6. Conica JöRGENSEN}

Scction Conica Jörgensen, 1913; Lebour, 1925; Peters, 1928; Paulsen, 1931; Schiller, 1935; DrWALD, 1939.

The body in this group is highly polymorphic, ranging from a typically biconical form to a star-shaped one, according to the development of the posterior sulcal plate and sulcal furrow and also to the differentiation of the flagellar furrow from the sulcal one. The epitheca is conical or nearly so without forming an elongated apical horn. The hypotheca is, on the contrary, reversed conical, broadly rounded or dorso-ventrally flattened, but mostly forms two conical antapical horns, entire median surface of which is covered with the posterior sulcal plate. The circular or descending girdle is equatorial or postequatorial, forming an ovoidal or reniform cingular section lying horizontally or tilting up dorsally.

The ventral area is differentiated into a narrower anterior and a broader posterior halves, and is excavated as a whole or partially in its whole anterior half or its left half. This sulcal furrow, lying in most cases within the ventral depression of the body, extends dorsally forming a smaller or larger postero-median indentation of the body.

The rhombic ventral apical plate tapers similarly to both directions, and the 
middle of the three intercalary plates is in typical cases transversely elongated hexagonal or bordered with six plates but often pentagonal and rarely tetragonal. The two ventral postcingular plates are generally broader than long, extending posteriorly similarly to the posterior sulcal plate. In the ventral area, the right sulcal plate extends anteriorly to the epitheca, and the U-shaped posterior sulcal plate expands laterally abruptly beyond the two middle sulcal plates to meet the ventral postcingular plates and posteriorly to the tip of the pseudomorphous antapical horns which bear a minute spine at the tip. This plate shows a wide range of variation in size, shape and structural differentiation, bringing forth the polymorphic hypotheca of this group. The ventral cingular plates agree with the ventral pre- or postcingular plates in their lateral expansion.

\section{Histrical account on the characterization of group}

Jörgensen (1912) was the first who distinguished the Conica Section in the subgenus Orthoperidinium by the following characteristics; the middle intercalary plate is hexagonal, apical horn is generally absent, girdle is circular and antapical horns are either absent or only poorly developed. LEBOUR (1925) placed the section also under the group Orthoperidinium of the genus Peridinium, laying much stress upon the shape of the intercalary plate. And PAULSEN (1931), taking some other characteristics into consideration, characterized his tenth spection as follows. "Ortho hexa, plus rarement penta ou quadra. Circulaires ou sinistrogyres. Forme vue du devant carres ou rhomboide, sans corne apicale mais le plus souvent a deux cornes antapicales creuses."

These investigators cited above characterized this group mainly by the combination of the ventral and dorsal plate patterns. But sometimes, it is fairly difficult in practice to define exact contour of these plates in broadly sutured specimens. One often misinterprets or misdraws the plate pattern. Judging from some of very incomplete published figures and descriptions it also might have often been the case with some of earlier investigators. PAUlsen (1931, p. 46) acknowledged many exceptional cases in his subdivision of the genus Peridinium.

Another characteristic of this group to be considered is the circular or descending girdle coupled with the conical epitheca which does not elongate to form the apical horn. But the combination of these characteristics is unworthy to define the group, because corresponding combination may be found not only in the present group but also in some species of the Avellana and other groups.

Further, Jörgensen and PAULSEN agreed in taking into consideration the shape of antapical part of the body, which is highly polymorphic in this group. This structure is, according to our study, not only of taxonomic importance but also of morphological significance, but they did not enquire further into details of it.

From these uncertainties and inconsistencies we are led to conclude that it is not the definitions they had given but the species they allocated to this group that in reality characterizes the present group. 
JöRGENSEN originally placed in this group the following four species; $P$. conicum, $P$. conicoides, $P$. subinerme and P. punctulatum. And Lebour (1925) contends to include in it sixteen species, while Paulsen (1931) fifteen species as valid, in addition to the first three species of Jörgensen. They agreed in the opinion that this group includes the following five species: $P$. pentagonum, $P$. leonis, $P$. achromaticum, $P$. anthonyi and $P$. divaricatum. LeBour admitted another eight species; $P$. willis, $P$. faeröense, $P$. trochoideum, P. fimbriatum, $P$. nudum, $P$. tabulatum, $P$. elongatum and $P$. yserense. PAuLsen (1931) acknowledged six different species including Jörgensen's $P$. punctulatum, $P$. biconicum, $P$. inaequale, $P$. munobis, and $P$. obtusum (KARsten, not FAuré-Fremiet and LeBour).

Re-examination of these species allocated by Lebour and Paulsen led us to acknowledge the fact that these authors differ not only from each other but also from JörGENSEN in the characterization of the present group. Their inconsistent opinions as to the characterization of the group seem to be natural so far as they concern themselves only with these characters incompletely analysed and inadequately elucidated and some of them proved to be subjected to individual variation. The inconsistencies may be also due to the wide range of variations in the structural relations of the antapical part of the body, coupled with the very dissimilar appearances of that part which even a single individual may present in different directions of view. And also the want of accuracy in the manifestation of the structural relations of the ventral area in published figures makes the interpretation of old literatures and of published figures exceedingly difficult.

In order to settle these inconsistencies and further to avoid confusions, it seems most important and necessary to revise first the general characteristics of those four species originally placed in this group by Jörgensen. Of the original four species, $P$. conicum and $P$. conicoides are well defined while the others are less established. We have examined all these four species in addition to some others to find that seeming similarity or dissimilarity of their antapical part has no fundamental bearing on the structural relations of their ventral area which has a remarkable uniformity throughout them. Revision of published figures of them and careful examinations of the four species which we have collected from various sea areas around Japan led us to reveal the facts that all of them have the ventral area excavated as a whole and abruptly expanded bilaterally in its posterior region where the posterior sulcal plate covers, extending to the tip of the antapical horn and bordering directly on both sides on the ventral postcingular plates, and that these structural relations are illustrated more or less exactly but without due accounts in all of published figures of them. Furthermore, we were led to acknowledge the facts that the deeply excavated sulcal furrow forms posteriorly a shorter or longer $\mathrm{U}$ - or $\mathrm{V}$-shaped ridge lying along posterior (or dorsal) margin of the posterior sulcal plate and extending in some of them from tip to tip of the antapical horns, and that there is along the dorsal of this a second, much less distinct ridge extending often from tip to tip but lying invariably across ventro-median part of the antapical plates. The sulcal furrow often extends to this secondary ridge which is most distantly separated from the pos- 
terior sulcal plate at the intra-antapical suture. There is then a U- or V-shaped area between these two ridges. This structure lies in all cases along the indented postmargin of the hypotheca and is differentiated more or less distinctly from the general body surface and also from the sulcal furrow. This is also illustrated in some of published figures but not elucidated at all.

One of the earlier investigators, GrAN (1902), had already clearly figured this posterior sulcal plate in the cases of $P$. pentagonum and $P$. conicum, but it seems highly probable that he might have mistaken this in the former species for ventral continuations of the two antapical plates, judging from the fact that the ventral posterior part of the hypotheca is divided in his figure $15 a$ into two by a longitudinal median line. On the other hand, this plate is correctly drawn in the latter species by the same author, and also on $P$. subinerme by PAULSEN (1908). In addition to these, there have been published by other observers many more or less convincing figures of these and other species, which seem to indicate vaguely or apparently the existence of the expanded posterior sulcal plate. According to DANGEARD's original figures, the peculiarly biconical species $P$. biconicum, which is very similar in body shape to $P$. abei of the group Avellana and was admitted by PAULSEN as a member of this group, seems to be furnished with the narrow and short ventral area, and its posterior sulcal plate was clearly illustrated by PAULSEN (1931) in his figure $44 \mathrm{D}$. This latter fact supports PAULSEN's above opinion, because this plate in his figure is deeply V-shaped consisting of a narrower left and a broader right lobes both of which apparently coming laterally into contact with the ventral postcingular plates. Notwithstanding these very obvious illustrations, not only these observers just described but also almost all investigators who have described and illustrated any of the species of this group, have shirked to elucidate this peculiar structural feature.

There were a few who paid attension to the peculiarity seen in the structural relations of the ventral area of some species belonging to this group. In regard to the ventral area of $P$. subinerme, LEBOuR described as follows: "Hind part of the longitudinal furrow lying in a sharp depression whose borders coincide or nearly so with the suture which lies round the furrow..." And the "hind part" in his description means undoubtedly the posterior, expanded part of the ventral area corresponding to the posterior sulcal plate. According to Peters (1928), "Die verhaltnissmässig kurze Längsfurche" of $P$. multistriatum "konnte man vielleicht als ein Unterscheidungsmerkmal anführen;..." And the 'Längsfurche' in this case and also in most of the descriptions about $P$. pentagonum corresponds to the narrower anterior part of the ventral area covered with the anterior three sulcal plates.

Before going further into subdivision of the group, we have to minutely examine the major thecal characters of the group, because the present group is together with the Pellucida group of Mesoperidinium, one to be regarded as of the most highly advanced type in the genus, and at the same time it includes numerous species manifesting in many points unusually wide ranges of variations. To prevent confusion it must be mentioned here that 'the higher form' mentioned in the following means one 
furnished with a larger posterior sulcal plate and 'the lower form' with a smaller one.

\section{Plate pattern of the epitheca}

In lower forms of this group as well as in general in the genus, the epithecal plates are so arranged as to lead us to think it more convenient and also natural to group those of circular rows or of lateral arrangements into different series, as it has been proposed by KoFoID and followed by most of the recent observers. In other words, the sutures in the epitheca are not generally differentiated into definite longitudinal and transverse ones. But there occurs a peculiar arrangement or plate pattern in this group especially in the case of higher forms such as $P$. pentagonum and P. sinuosum (Figs. 60-412, 63-426) in which the plates are so arranged as to make it more convenient or natural to group them into six meridional groups, each comprising two or three plates of different circular series. These six meridional groups shall be called here, for the sake of brevity, ventral $\left(1^{\prime}+1^{\prime \prime}+7^{\prime \prime}\right)$, ventro-lateral $\left(2^{\prime}+2^{\prime \prime}, 4^{\prime \prime}+6^{\prime \prime}\right)$, dorso-lateral $\left(1 \mathrm{a}+3^{\prime \prime}, 3 a+5^{\prime \prime}\right)$, and dorsal $\left(3^{\prime}+2 a+4^{\prime \prime}\right)$ meridional groups. And the meridional sutures which separate those groups of plates extending from apex to girdle, are fairly straight in apical view. And they shall be called "collective sutures" in this paper. These collective sutures are usually differentiated from those shorter ones, connecting them transversely. They may be regarded as to form three pairs, to wit ventral, lateral and dorsal ones. And we intend here to call such a specialized form of plate structure as "adjusted plate pattern" in contrast to the ordinary one.

There are some intermediate forms between the two, and it can said in this regard that the epithecal plate pattern of the higher forms has characters of more adjusted as compared with that of the lower forms. In other words, the peculiarity in the epithecal plate pattern is correlated distinctly with exceedingly stronger lateral expansion of the posterior sulcal plate.

$P$. multistriatum, $P$. punctulatum, $P$. subinerme and $P$. obtusum have the ordinary pattern (Figs. 47, 46, 54,57), in which the collective sutures are very zigzag, bending sharply at every corner of the plates they pass by. $P$. conicoides, $P$. petersi, $P$. bifurca, $P$. conicum, $P$. leonis, and $P$. furcata form the second type in which the collective sutures are less zigzag, but not so straightened as in the third type which is represented by $P$. pentagonum. The ventral pair of the collective sutures in every case appears to be fairly straight especially in ventral view, and either or both of the other two are fairly zigzag either or both in apical and in side views. Peculiar is the fact that there are two forms in the plate pattern of $P$. furcata, one with fairly straight collective sutures and the other with more zigzag ones (Fig. 53-365). Coupled with this difference, the former form has two kinds of sutures as in the typically adjusted pattern, while the sutures of the latter are not differentiated. This, together with the diversity described by PAULSEN (1931) on P. leonis, seems to suggest probably the rare occurrence of such sorts of variability in the group. It must be mentioned here that the lateral collective sutures of this second type extend bilaterally 
so as to divide the epitheca into subequal dorsal and ventral halves. The differentiation between the meridional collective and the transverse individual sutures is very prominent in $P$. deficiens which may be regarded as forming a connecting link between the second and the third type in regard to the epithecal plate pattern.

Shape of the mid-dorsal intercalary plate has been considered as one of the characters of the greatest taxonomic importance and generally as hexagonal. Paulsen (1931) described further some variations, although one of these seems to be due to his understanding. According to our observations, following species have the middle intercalary plate of hexagon or rather of trapezoidal hexagon, touching basally three precingular plates; $P$. multistriatum, $P$. conicoides, $P$. punctulatum, $P$. subinerme, $P$. bifurca, $P$. conicum, $P$. deficiens, $P$. obtusum, $P$. leonis, $P$. pentagonum and $P$. simuosum. And the typical trapezoidal plate, separated completely from the dorsolateral precingulars, $3^{\prime \prime}$ and $5^{\prime \prime}$, is seen in $P$. petersi, $P$. furcata, $P$. deficiens and $P$. expansa. The pentagonal plate, touching only one of the two dorso-lateral precingulars, is seen in $P$. multistriatum, $P$. bifurca, $P$. pentagonum and $P$. bidentaia. From these facts, it may be said with certainty that the middle intercalary plate is variable in shape at least in the following six species, viz. $P$. deficiens, $P$. furcata, $P$. multistriatum, $P$. bifurca, $P$. pentagonum and probably $P$. conicum. Further careful studies upon larger numbers of individual and upon wider range of materials, may prove more frequent occurrence of these variations in wider range of species. The shape of this plate, however, is correlated largely: with adjustment of the plate pattern.

The posterior sulcal plate attains its highest development in $P$. pentagonum, $P$. bidentata, $P$. expansa and $P$. sinuosum, and is coupled with typically adjusted plate pattern, the third type of the epitheca. The ventro-lateral meridional zone is in them very narrow and displaced much ventrally, and fairly straight are the collective sutures except the dorsal one which bends distinctly only at the apical-intercalary suture. And peculiar and interesting is the fact that an apparent fusion of plates is seen in some highly specialized species not only in the epitheca but also in the hypotheca. In the epitheca, the fusion takes place generally between allied components of a single meridional zone but not generally between those of different zones belonging to the same circular row. A similar but somewhat different case is observed in $P$. deficiens in which the fusion occurs between two apicals which belong to a one and the same meridional zone, conforming the peculiar arrangement of its meridional collective sutures. These seem to suggest the fact that the components of a meridional zone in the case of those highly specialized species are not only morphologically but also physiologically more closely related with one another than with adjacent plates belonging to different zones of a single circular row. And to our greatest surprise we found a peculiar case in which the posterior suilcal plate fused with the two ventral postcingular plates, thus forming a huge $\mathrm{U}$ shaped plate covering entire ventral surface of the hypotheca (Fig. 56-387).

The fusion of plates or contrary appearance of an excessive plate is not rare in Peridinium. Published literatures indicate that this abnormality appears to occur more frequently in the fresh-water species than in the marine forms. The fusion is 
said to occur mostly in the epitheca and only very rarely in the hypotheca. Peters (1928) found an abnormal specimen of $P$. depressum in which the precingular series consists only of six plates. And his figure $20 d$ indicates that the precingulars $5^{\prime \prime}$ and $6^{\prime \prime}$ are fused to form a single large plate. So far as our obsrevations are concerned, $P$. clavus ABÉ (1936) is the most interesting species in this regard. Variations in number of plates occur not only in all the three series of the epitheca but also in the antapical series of the hypotheca. Broci (1910) failed to see an actual fusion of the plate in his materials, saying, "Bei keiner der untersuchten Arten habe ich Verschmelzungen unter den Platten beobachten können; eine nähere Untersuchung hat auch die immer eine feine Grenzlinie gezeigt, wo ich zuerst geglaubt hatte, dass eine Verschmelzung vorläge." Such a misinterpretation due to a hasty conclusion as was apprehended by him may be not uncommon. But the closer observation revealed an actual occurrence of the fusion of plates as well as the appearance of an excessive plate by means of splitting of an old plate. The left-hand one of BRoch's Fig. II is very interesting in the point that the left ventral postcingular plate is not differentiated from the posterior sulcal plate, while the opposite $5^{\prime \prime \prime}$ is distinctly separated from the latter by a wide sutural zone. Taking his description into consideration, this figure may be interpreted as indicating that there is at least a remarkable asymmetry in the development of the sutural zones on either side of the ventral area of his form $(P$. conicum). The asymmetry is discussed in another paragraph of this paper, but it is to be noted here that the left ventral postcingular plate might had been so incompletely separated in his form from the posterior sulcal plate that he had to desist from drawing a sutural line at the place where the two plates border on each other. The posterior sulcal plate differs originally from the postcingular plate. And yet these two kinds of plates in our form are fused with each other to form a single plate. Our efforts to separate them was fruitless. And occurrence of this unusual fusion between them can be accounted for, only when one considers the facts that the posterior sulcal plate is almost completely differentiated in the section Pentagona from other three sulcal plates or from the longitudinal furrows s. str., and that the three ventral plates among which the fusion took place are distinctly demarcated in $P$. pentagonum var. depressum by a bilateral ridge separating them from all the other dorsal plates. These facts appear to support the suggestion that the lateral ridge of the hypotheca is homologous with the collective meridional suture of the epitheca.

Parallel with these variations in the epithecal plate pattern, there occurs a remarkable bilateral asymmetry in the cingular section. This is especially distinct in the higher forms in which is seen a large ventral flattening of the body or increase in extent and depth of the ventral depression of the body. This may be discussed in a later paragraph.

\section{Cingular displacement and torsion of the body due to growth}

The lower forms have mostly a circular or approximately such girdle, and its distal displacement becomes stronger in higher forms. The circular girdle in a strict sense is very scarce, and in most cases, the girdle forms a seemingly ascending 
or descending spiral in consequence of an asymmetrical posterior extension of the median parts of the two ventral precingular plates. In accord with this variation, the posterior end of the ventral apical is obliquely truncated in either direction. In either case, the girdle runs horizontally for the most part without forming a spiral tract, and generally there is a minute posterior extension of the right ventral precingular at the distal end of the girdle, which extends posteriorly in most cases slightly beyond the postero-median end of the left ventral precingular, thus bringing forth such a slight disagreement between the two ends of the girdle as is to be interpreted as forming a descending spiral. And the actual distal displacement, when it exists, seems to vary slightly even within a single species, in some forming an ascending and in others completely circular or descending spiral (Fig. 35-230, 233). A distinctly ascending girdle is found in $P$. petersi, $P$. deficiens and in some of $P$. furcata. $P$. conicum and all species of the pentagona section are furnished with a distinctly descending girdle, but strength of the distal displacement seems to vary in different species and also within a single species. And among those higher forms, the distal displacement is smaller in some forms such as $P$. obtusum and $P$. leonis and is largest in $P$. sinuosum. A specimen with broader sutures has a stronger distal displacement, when we compare 393 with 395 in Fig. 57 and further 405 with 408 and 409 in Fig. 59. And stronger proximal arch of the girdle is accompanied with stronger distal displacement, and that is also followed by stronger ventral displacement of the left antapical process. These linked variations may be due to torsion of the body brought forth by unequal growth of the sutural zones in lateral halves of the body. The left antapical spine or process is generally more ventrally displaced than the right one in higher forms in which the two antapices are separated more or less widely from each other. And this asymmetrical ventral displacement appears to be correlated with growth of the sutural zone. Extended discussion on the distribution and growth of the sutural zone was given by Peters (1928). But he did not allude to the zone lying in and around the ventral area. According to our observations, the asymmetrical ventral displacement of the two antapices is mostly due to the difference in growth of the zone on either side of the ventral area. As shall be detailed in a later paragraph, the growth of the sutural zone causes to separate the right-hand antapex more distantly from the right ventral postcingular plate than the left-hand antapex from the left ventral postcingular plate. This may be, in other words, because the ventral displacement of the left-hand antapex is strengthened by the growth of the body.

This asymmetrical displacement can be seen, though in much smaller degree, also in the cases of lower forms of this group, in which the postmargin of the body is shorter than that of the higher forms. And a similar displacement and its different variabilities occurring among the different species as well as within a single species can be seen in most of the other groups of the genus Peridinium.

\section{Asymmetry in the cingular section and torsion of the body axis}

The body of Peridinium has generally a ventral flattening or depression which 
varies in size, depth and extent in different species. And in relation with this fact, the cingular section is generally circular, oval or reniform. There appears to exist another fact which has close relation with the shape of the cingular section. That is a dorso-ventral flattening of the body. And these two factors define the shape of any horizontal section of the body acting singly or in combination. In the case when the ventral depression is strong enough, the cingular section may be differentiated into bilateral lobes.

In the lower forms with the ordinary or least adjusted epithecal plate pattern such as P. multistriatum (Fig. 47-309) or P. punctulatum (Fig. 49-329), the ventral left half of their cingular section is more acutely rounded than the corresponding part of the right, and the greatest depth of the body lies just on the right of their dorsoventral median plane of the body, corresponding, on the dorsal side, to the right end of the dorsal precingular 4". A similar but more distinct relation exists also in other higher forms such as $P$. subinerme (Fig. 54-371), Peridinium sp. and P. conicum (Fig. 55-375). Among them, the flattening of the body increases in the order here described, and in P. leonis (Fig. 58-401, 402) the lateral lobe of the cingular section as well the ventral-lateral meridional zone is narrower in the left half of the body than in the other half. Such asymmetrical development of the cingular section is fairly well distinct in $P$. deficiens (Fig. 56-385). In the pentagona section, the ventral depression is so prominent that the cingular section is <-shaped instead of reniform. And the flattening of the body seems to occur more strongly in the higher forms such as $P$. conicum, $P$. bidentata, $P$. pentagonum, $P$. expansa and $P$. sinuosum. The bilateral halves of the cingular section thus formed are subequal in length in $P$. pentagonum (Fig. 59-411), while the left half is smaller in length and breadth in $P$. sinuosum. (Fig. 63-427) and its allies.

Apparently in connection with the strong flattening and consequent asymmetry of the body, there occurs, as described partly in a previous paragraph, the peculiarity in the plate pattern of the epitheca. In the lower forms with broader cingular section, the ventro-lateral meridional zones of the epitheca have zigzag sides (collective sutures) and a considerable width, and the right-hand one of these two is often broader than the other. On the other hand, those of $P$. sinuosum are very narrow and have fairly straight sides. There are many intermediate forms between the two in this regard. A considerable decrease in width of these zones occurs irregularly in $P$. leonis, $P$. bidentata and $P$. pentagonum. In them, the decrease is more prominent in the left-hand zone and also in their upper half than in their lower one.

In company with a stronger dorso-ventral flattening of the body, there appears a peculiar torsion of the body axis in most of the higher forms of the Pentagona section. In consequence of the wide and deep ventral depression, the body is strongly flattened especially in its apical and antapical portions, in which a more or less distinct bilateral ridge is formed. In the epitheca, the thecal wall is folded more or less sharply along the antero-lateral margins of the ventral depression, thus forming an oblique ridge on either side of the body, which extends from apex to 
girdle. The ridge is more distinct anteriorly than posteriorly, and coincides anteriorly with the lateral collective suture and posteriorly with the elongated ventrolateral precingular plate. A similar ridge is also seen in the hypotheca in which it is most distinct between the antapices or rather along the hind margin of the posterior sulcal plate and becomes more indistinct anteriorly. These ridges can be seen in almost every higher form of this group but most distinctly in $P$. sinuosum. Fig. 63 (426) is an apical view of $P$. sinuosum, and only a part of the theca lying along these ridges was figured. In the figure, is represented an apical or median part of the epithecal ridge, where the folding of the thecal wall is so sharp as to form a distinct bilateral ridge, and $b_{1} b_{2}$ indicate similarly a sharp antapical ridge. In apical view, these apical and antapical ridges do not run generally parallel either with each other or with a supposed bilateral thecal plane passing through the ventro-lateral ends of the body. Rarely one of them lies parallel with the supposed plane, but it invariably accompanies the oblique extension of the other. In any case, these two ridges cross each other at an angle of $15^{\circ}-20^{\circ}$. There is another characteristics to be considered here. In apical view, the right-hand ridge of the epitheca is fairly straight while the opposite one bends more or less distinctly in its anterior part just on the left of the dorsal apical plate.

And a similar torsion of the body axis can be seen in $P$. pentagonum, $P$. bidentata and $P$. expansa, and in all these cases the angle the two ridges form is about $15^{\circ}$, and generally the apical ridge is more strongly oblique than the antapical one. This diversity in the directions of flattening of the body at its both ends leads us to infer morphological significance of this structure.

In locomotion, the organism moves forward taking a spiral course, and the rotation may occur in any direction. But as was pointed out by KoFoID (1906) "in the Dinoflagellates generally the rotation is predominantly from left over to right." But according to Peters (1929), the organism usually changes its direction of rotation after a few turns in one direction. Among nine species he observed, Peridinium subinerme and $P$. pentagonum belong to this group. The former species is said to rotate more often with its left side in front, and his Fig. 14 indicates also that the latter species moves along a spiral course always with its left side of the body in forward or in downward locomotion. And calculation indicates that the radius of the spiral course along which the organism moves is in the latter species about two times as large as the dorso-ventral diameter of the body. The lower forms of the present group have a circular cingular section, and may be able to rotate or move with ease in any direction. But in a higher form such as any member of the section Pentagona, it seems more natural to assume, as confirmed experimentally by Peters, the organism to move along a spiral course with its ventral convex side always towards the center of the circle or towards the axis of the spiral cylinder. The stronger dorso-ventral flattening of the body coupled with large and deep ventral depression, more or less sharp bending of the body in the left half, and the more acute sinistro-ventral end of the cingular section than the opposite end coupled with the asymmetrical flattening of the body, serve to support morphologically 
Peters's conclusion.

Admitting these as valid, the reversed obliquity of the apical and antapical ridges is, then, strongly suggestive of the fact that the apical ridge may serve in locomotion to make greater the radius of the spiral course of that part and the antapical ridge makes it smaller. This may be said in other words that the body may be held always obliquely with its apex dorsal. It is obvious from the large ventral depression of the body that the organism also may take this posture naturally when it is subject to passive sinking as a result of the gravitation. This suggestion may be supported by the fact that the tilting angle of the body axis in locomotion is, according to Peters, about $40^{\circ}$, and further that invariably the cingular section is horizontal or tilts down ventrally and not a single case is known throughout the group in which it tilts down dorsally.

These peculiarities both in the epitheca and hypotheca are highly characteristic to this group and may serve to separate its higher forms from the lower and also the present group from the others, but they are not so diversely well defined in most cases as to characterize its every form or species.

\section{Ventral area and antapices}

The most radical and also distinct characteristic of the present group is, it seems to us, to be sought among the size, shape and extent and degree of lateral expansion of the posterior sulcal plate, because it is highly polymorphic in different species and yet fairly constant in a given species in such a degree as to serve to separate it from others, and further it is very deeply related with the shape of the hind end of the body, which is very characteristic for a given species. Therefore, the shape and size of the posterior sulcal plate and the relation of this to its surroundings are not only of taxonomical importance but also may serve as the most reliable key to identify a given species in practice.

The posterior sulcal plate covers the posterior half of the ventral area which displays a marked polymorphism in the present group, and then the characterization of this group or of its every species can not be considered without referring to the structural features of the ventarl area. Therefore, it is not the posterior sulcal plate but the ventral area that serves to characterize every species. The ventral area of $P$. multistriatum and of $P$. sinuosum lies respectively on either end of a series of variations. In the former species and its allies, the ventral area corresponds in extent with the sulcal furrow, while in the latter and its relatives, the latter structure is limited only to a small part of the former. The restriction increases inversely to the expansion or widening of the posterior sulcal plate.

Before going further into the discussion of these features, here is given a detailed description of the ventral area of Peridinium sp. and $P$. conicum for the benefit of understanding, because not only the ventral area of these species but also their body are large enough for our easy observation and analysis and that every component plate of their ventral area exhibits typical characteristics of the group in a moderate degree. 
With an adequate pressure on the cover glass, we can often isolate in a block the entire sulcal plates together with the ventral precingular or cingular plates. This block of plates has a strikingly uneven surface, and consequently is to be strongly flattened under the cover glass causing some or most of the components to separate from one another. Figs. 9-52 and 55-381 show the ventral group of plates thus prepared, and Fig. 9-51 shows a shematized plate pattern of the ventral area and its surroundings.

The ventral area of these species consists of a narrower anterior and a broader posterior part and has four plates as in general in the genus, in addition to the small transitional plate which lies at the proximal end of the girdle. The anterior sulcal plate $(a)$ is irregularly quadrangular or fan-shaped lying obliquely in the intercingular part of the ventral area. It slightly indents the epitheca anteriorly, and borders on the flagellar pore with its dextro-posterior end. And its posterior portion expands towards the left over the left sulcal plate (1), but is separated a little from the left ventral postcingular $1^{\prime \prime \prime}$ by a short suture. The reversely L-shaped left sulcal plate (1) covers the left half of the narrower inter-postcingular part of the ventral area, and broadly and deeply indents the posterior sulcal plate posteriorly, bearing along its short posteromedian margin of a flagellar trough. A little smaller right sulcal plate ( $r$ ) lies slightly anterior to the left, covering the opposite half, and extends anteriorly to the epitheca with its narrow extension across the distal end of the girdle, bearing along its median margin a narrow flagellar fin (ff) which stands basally along the right brim of the flagellar pore and also of the flagellar trough. The elongated and elegantly curved flagellar pore lies obliquely between these two plates, with its posterior part half hidden behind the right sulcal plate. The flagellar pore is not a mere aperture or cleft formed between the two plates, but has a short canal leading into the body. The wall of the canal consists of inner extensions partly of the anterior and mostly of the right and left sulcal plates. Its left wall is illustrated partly in Fig. 65-439. In consequence of the posterior elongation of the left sulcal plates, the posterior sulcal plate ( $\mathrm{p}$ ) is broadly and deeply encroached in its antero-median portion. This broadly U-shaped posterior sulcal plate expands laterally beyond the above lying two plates, into a smaller left and a larger right (in Peridinium sp.) or into two subequal lobes (in $P$. conicum, Fig. 55-381). Its two lobes border anteriorly on the left and right ventral postcingular plates, and laterally and dorsally on of the two antapicals. Their lateral margins are subparallel with each other either in natural posture or when isolated and flattened. Its postmargin lies along the antapical $\mathrm{U}$-shaped ridge of the body but is fairly straight when it is flattened.

It may be convenient to consider here about the sulcal furrow in relation to the ventral depression of the body. None of the former observers who described skeletal morphology of Peridinium has ever distinguished the sulcal furrow or the sulcal furrow from the ventral area and also from the ventral depression of the body. The sulcal furrow used in this paper is a deeper part of the sulcal furrow, connecting the flagellar pore with the proximal end of the girdle and its posterior continuation. Its boundary may not be sharply defined generally, as it occupies either the whole extent or only 
a part of the ventral area. The sulcal furrow is a larger longitudinal depression confined mostly within the ventral area but rarely expanding posteriorly but never laterally beyond the boundaries of the ventral area.

The present group displays some interesting variations in this regard. In most of the groups in the genus Peridinium, the ventral area is more or less sharply demarcated from the general body surface and corresponds in extent with the sulcal furrow. The ventral area in most species of the lower forms of this group is excavated as a whole as in the other groups. But in the higher forms, the posterior sulcal plate expands laterally beyond the sulcal furrow in various degrees, and at the same time the stronger depression is limited inversely to a smaller anterior portion of the ventral area. In $P$. sinuosum, the sulcal furrow is sharply limited only in the left half of the anterior narrower part of the ventral area, and the posterior sulcal plate lies entirely outside of the sulcal furrow. Peridinium bifurca and $P$. conicum are intermediate in this regard. The ventral area in these cases is deeply excavated as a whole and has its greatest depth in its median portion passing over the flagellar pore and extending between the girdle and the postmargin of the body. Then, the major median part of the posterior sulcal plate lies within the furrow. But, a small anterior part of the plate, where it borders on the ventral postcingular plate, expands beyond the furrow, though still lying, within the general ventral depression of the body together with the median part of either of the ventral postcingulars.

As stated in the former paper (1936), the sulcal furrow of $P$. excentricum extends posteriorly for a short distance beyond the ventral area. A corresponding structural feature can be seen more or less distinctly in some species of this group. A careful observation reveals the fact that the antapical ridge, which bears a narrow list, runs for the most part across the ventro-median parts of the antapical plates lying for the most part at a short distance from the posterior sulcal plate. This small portion of the antapical plates between the posterior sulcal plate ventrally and this ridge dorsally lies within the ventral depression of the body or in its dorsal continuation. This relation may be clearly seen in Fig. 93 in which all the four sulcal plates are lost. This peculiar portion may be called "post-sulcal area" in this paper. The structure always lies at the hind end of the body, extending between the two antapices, but in some of the lower forms it can not be seen at all. Its size, length and shape are characteristic in the main of a given species. In the lower forms, it lies outside the sulcal furrow but within the ventral depression of the body, and this may be also true of some of the higher forms. This structure in these cases appears to serve for the dorsal elongation of the sulcal furrow.

Here must be remarked an interesting fact that the left lobe of the posterior sulcal plate is distinguished from the left sulcal plate by the posterior continuation of the left sulcal list, but by no means from the ventral postcingular plate. On the other hand, the right lobe is not demarcated from the right sulcal plate and also from the right ventral postcingular. From these facts, it may be said with certainty that the posterior sulcal plate is more distinctly differentiated from the left sulcal plate than from the right sulcal and also from the two ventral postcingular plates. 
This seems to answer the facts that the sulcal furrow s. str. is more abrupt at the postmargin of the left sulcal plate than that of the right sulcal plate, and that the left sulcal plate is differentiated from the right and posterior sulcal plates by their different surface markings.

The polymorphism of the ventral area and also of the antapical part of the body in this group is brought about partly by the variations in shape, size and extent of this posterior sulcal plate, and partly by the variations in the differentiation of the sulcal furrow from the sulcal furrow. When the posterior sulcal plate is small, expanding laterally only slightly beyond the intra-postcingular part of the ventral area as in $P$. multistriatum, the hind end of the body is rounded or has two minute prominences standing near by. On the contrary, when the lateral expansion of the plate is very striking as in $P$. sinuosum or its allies in which the plate covers entire width of the ventral posterior half of the hypotheca, the two antapices are distinct and widely set apart. In the former case, the sulcal furrow is not distinctly differentiated, and corresponds in extent exactly with the sulcal furrow or ventral area, while in the latter case it is limited to the small anterior left region of the latter. And we can see almost every intremediate type between these two forms in regard to the size of the posterior sulcal plate, the shape of the hind end of the body and the differentiation of the sulcal furrow s. str. from the ventral area. In $P$. punctulatum, $P$. subinerme, $P$. petersi and $P$. conicoides, the posterior sulcal plate is a little larger than that of $P$. multistriatum, expanding laterally in symmetrical or asymmetrical manner, and yet the plate lies entirely within the sulcal furrow. In $P$. conicum, the plate is still larger and its antero-lateral portions extend beyond the sulcal furrow. The furrow disappears from the right sulcal plate in $P$. pentagonum in which the posterior sulcal plate is much larger and lies for the most part outside the posterior continuation of the sulcal furrow. And finally the furrow disappears completely from the posterior sulcal plate in $P$. sinuosum. This distinct range of variations suggests that the posterior sulcal plate in the higher forms of the present group is deprived largely or entirely of its morphological significance as a sulcal member. And the same may be suggested from the fact that the plate itself in the higher forms exhibits characteristics more of the general body surface than of the ventral area.

The antapical process is absent in some species of the lower forms, which have invariably a small or large $U$ - or V-shaped antapical ridge. In the others, the ridge bulges out more prominently in its ventro-lateral parts to form the two antapical processes which are compressed laterally. Consequently, these two antapical bulges may be taken in ventral view as the distinct horns contracting to a pointed end with or without a minute distal spine. There is often a narrow, hyaline or sparsely ribbed list standing basally along the antapical ridge. In case the plate is much larger, the lateral arms of the $V$-shaped ridge opens wider apart and the list disappears again.

Distribution of the sutural zone in and around the ventral area is peculiar and very interesting. The structure can least established within the ventral area especial- 
ly in its anterior narrower part, and between any two plates of the anterior three sulcal members and transitional plate (Fig. 58-366). It is formed, however, weakly along the anterior margin of the posterior sulcal plate, but this is not so wide, even in an extremely megacytic specimen, as to bring forth perceptible change in shape of the ventral area. Contrary to these, a broad sutural zone is formed regularly along the right and posterior margins of the ventral area, extending anteriorly across the distal end of the girdle, and then turns towards the left around the anterior end of the anterior sulcal plate. Posteriorly it extends around the posterior sulcal plate and is confluent distally with the suture between the left ventral postcingular and left antapical plates. This irregular development of the suture in megacytic specimens causes to displace the sulcal plates as a whole towards the sinistro-anterior direction. In megacytic specimens, the ventral area remains, then, in close contact only with the proximal end of the girdle and with the left ventral postcingular plate. We are, then, forced to accept the conclusions that the megacytic growth occurs asymmetrically on either side of the ventral area so as to keep the sulcal plates always in closest relationships with the proximal end of the girdle, that the structural relations within the ventral area are least disturbed by the megacytic growth, and that the interrelations between the two middle and anterior sulcal plates which are arranged directly around the flagellar pore remain almost unchanged throughout the growth. And the peculiarity in the distribution of the intercalary zones in and around the ventral area, may be elucidated when we understand the fact that where there occurs no sutural growth the structural relations of that part of the body remains unchanged, that the normal conditions of water currents within the longitudinal furrow can be continued as long as the normal structural relations within the furrow are maintained and that if the structural relations within the sulcal or flagellar furrow are disturbed, the normal water conditions may be destroyed, bringing the affected organism to its final death.

This peculiar and characteristic development of the sutural zones in and around the ventral area has not received any adequate study. But it is not impossible to find published figures in which this peculiarity is illustrated. One of the most interesting example is that figured by KoroID (1907, Pl. XXX, Fig. 41) in regard to P. multistriatum, and his species can not be identified without thorough knowledge about the arrangement and establishment of the sutural zone in and around the ventral area.

There are some reasons to believe that the irregular development of the sutural zone around the ventral area is decidedly correlated with the stronger ventral displacement of the left-hand antapex in comparison to the right-hand one. A broad sutural zone separates in ventral view the two antapices equally from the posterior sulcal plate. But the bilateral lobes of the posterior sulcal plate are separated in most cases differently from the girdle, because the sutural zone between the right lobe and the right ventral postcingular plate is generally much broader than that between the left lobe and the left ventral postcingular. This latter fact forces to separate the right-hand antapex more dorsally than the other one. 
In the girdle, the sutural zone is established between the cingular plates but never along their anterior or posterior side. In far advanced megacytic specimens, during the megacytic growth, the pre- or postcingular plate grows larger along the base of the cingular list, forming there a thinner marginal leaf, with which the plate expands into the girdle closely along the inner surface of the cingular plate. And this marginal leaf grows broader and finally these of the pre- and postcingulars come to meet along the middle of the girdle. Therefore, the cingular wall of an extremely megacytic specimens consists of a thick double layer consisting of an outer cingular plate and an inner layer composed of an upper and a lower halves each springing from the pre- and postcingular plates. These relations may be established by the fact that the width of the girdle is fairly well fixed throughout the entire course of the megacytic growth.

In connection with the establishment of a wide sutural zone around the anterior end of the ventral area, the sulcal furrow extends in the megacytic specimen anteriorly beyond the ventral area and covers postero-median ends of the ventral apical and two ventral precingular plates. And the depressed part of these plates corresponds in position and extent to that backed with a thin marginal leaf of the anterior sulcal plate.

\section{Characterization of the group}

One of the least advanced form of this group is either P. munobis or P. multistriatum which appears to be related to the group Avellana in the body shape and the extent of the ventral area. But its epithecal plate pattern, circular girdle, asymmetrical development of the ventral area and its two antapical spines, clearly distinguish this from that group. The other closest relative of the present group is Divergentia in which the sulcal furrow is also wide. So far as our observations are concerned, the posterior sulcal plate of that group is peculiarly reversed L-shaped, consisting of a broader median lobe and a slender left extension, and contiguous on the left with the left ventral postcingular plate but separated on the right from the right ventral postcingular one. The ventral area, then, does not show in that group a rightward abrupt expansion at the posterior sulcal plate. By this character these two groups are separated from each other.

From examinations of a wide range of materials and published figures, it is concluded that the present group is to be regarded as the most highly specialized one among the groups of the genus so far as the structural differentiation of the ventral area is concernsed. There are many more or less convincing facts to support this interpretation. And the most important facts are these. The ventral depression of the body, the ventral area and the flagellar furrow are differentiated from one another in their extent in the higher forms, while the latter two of the three agree in the lower forms of this and also in most of the other groups. The development of the postsulcal area appears to strengthen this differentiation. The expanded posterior sulcal plate is sharply differentiated in the higher forms from the other sulcal 
members, especially distinctly from the anterior and left sulcal plates, and provided with characteristics more of the general body plate than of the sulcal ones. There occurs the peculiar simplification of the epithecal plate pattern in the higher forms, and in its extreme cases the actual fusion of plates takes place between members of different circular series. The differentiation of the posterior sulcal plate becomes so striking in some that it fuses with the ventral postcingular plates of entirely different origin.

\section{Subdivision of the group}

All the species to be allocated to this group can be arranged according to the development of their posterior sulcal plate, which is coupled on one hand with stronger differentiation of the flagellar furrow from the sulcal one and on the other hand with disappearance of the sulcal furrow from the posterior sulcal plate. These variations are associated directly with variations in the shape of the hypotheca, particularly of its hind end. Taking these into considerations, we have been led to subdivide the present group into three sections in which are manifested some parallel variations of major thecal characters.

Section 1. Multistriata $n$. sect.

The body is biconical, globoid or pentagonal with or without posterior indentation. The ventral area is more or less deeply indented as a whole, and the posterior sulcal plate is small in breadth, lying within the sulcal furrow and expands laterally only slightly beyond the two middle sulcal plates.

To this are allocated the following recorded species as valid: $P$. anthonyi FauréFremiet, $P$. biconicum Dangeard, $P$. conicoides Paulsen, $P$. multistriatum Kofom, $P$. munobis Abé, $P$. punctulatum Paulsen and $P$. subinerme PAUlsen. And four new species, $P$. furcata, $P$. paulseni, $P$. petersi and $P$. rhombiformis, are described in this paper.

Besides these, there is another group of insufficiently defined species, somewhat closely related to them. In this are included the following four species: $P$. elongatum Meunier, $P$. fimbriatum Meunier, $P$. nudum Meunier and $P$. yserense Meunier. All of them agree with one another in their exceedingly small biconical or globular body, rhombic ventral apical and hexagonal middle intercalary plates, two subequal ventral postcingular plates extending posteriorly to the postmargin of the body and in their deeply excavated sulcal furrow which is wider posteriorly than anteriorly. All of these structural features led us to suggest their allocation to the Conica group rather than to the Avellanan group. This suggestion is supported by the fact that the sulcal furrow of the latter forms a characteristic S-shaped tract leading anteriorly to the girdle, while that of the former is straightly elongated. These vaguely known minute species may be, then, regarded as forming a connecting link between the Avellana group and higher forms of the Conica group. 
Section 2. Conica n. sect.

The body is in ventral view pentagonal or rather star-shaped with a broad postero-median indentation between two conical antapical horns. The median majority of the ventral area is excavated, and the ventral depression of the body is indistinct. The posterior sulcal plate is of considerable size, expanding remarkably bilaterally and partly beyond the sulcal furrow.

Two species of $P$. conicum Gran and $P$. deficiens MEUNIER are included in this section, and a new species, $P$. bifurca is described de novo in this paper.

Section 3. Pentagona n. sect.

The body is in ventral view pentagonal or star-shaped with two wiedly separated antapical horns or processes. The posterior sulcal plate covers the major or entire breadth of the hypotheca and lies largely or entirely outside of the indistinct sulcal furrow but within the ventral depression of the body, and the flagellar furrow is more or less distinctly differentiated.

In this are included following four recorded species and two new species: $P$. bidentata n. sp., P. expansa n. sp., P. leonis Pavillard, P. obtusum (Karsten) FauréFremiet, $P$. pentagonum Gran and $P$. sinuosum (LemmermanN) Jörgensen.

Detailed accounts and discussions about the Conica group are given in a previous paper of the author.

\section{Section 1. Multistriata n. sect.}

The species included in this section has a small biconical or pentagonal body furnished with a more or less circular girdle and a small posterior sulcal plate. The hind end of the body is rarely rounded and without any protuberance nor spine, but generally has a short and slightly or deeply indented postmargin between two small antapical prominences. The girdle is generally circular or nearly so.

The plate pattern of the epitheca is typical and the collective meridional sutures are more or less distinctly zigzag and rarely differentiated from the transverse ones. The left ventral meridional zone is more or less smaller in width and displaced more ventrally than the right ventral in every case.

In the hypotheca, the lateral and dorsal postcingular plates are generally very narrow. The ventral area and the longitudinal furrow s. str. agree completely both in shape and in extent. The postmargin of the body is U-shaped and does not form, in lower forms, any of antapical processes nor horns bilaterally. But the body wall swells generally in the higher forms on either side of the larger posterior sulcal plate to form a low conical prominence furnished with or without a distal spine.

Key to species

1. The body is globular with pointed apex....................Peridinium anthonyi 
2. The body is biconical with pointed two ends

A. The girdle is pre-equatorial...................................... munobis

B. The girdle is equatorial ....................................... biconicum

3. The body is biconical with bluntly rounded or shortly truncated antapex

A. The hind end is rounded and the body is much broader than long

P. punctulatum

B. The hind end is truncated and the body is subequal in length and breadth

a. The ventral area expands in its posterior region subequally to both sides .................................................. P. multistriatum

b. The ventral area expands in its hind end more strongly and abruptly towards the left ..................................... rhombiformis

4. The body is pentagonal with indented postmargin

A. The antapices are pointed distally

a. The ventral area expands just below the girdle abruptly towards the left $P$. conicoides

b. The ventral area expands in its hind end about two times more towards the left than towards the right P. subinerme

c. The ventral area expands similarly to both sides but asymmetrically at the posterior part towards the right than towards the left

$P$. petersi

d. The ventral area expands similarly to both sides at subequal altitude and is deeply indented at the postmargin $P$. furcatum

B. The antapices are flattened bilaterally P. paulseni

\section{Peridinium munobis ABÉ}

ABE, 1927, P. 414, Fig. 33 A-B.

\section{Peridinium multistriatum KoFOID}

Figs. 47, $48(307-325)$

KoFID, 1907, pl. XXX, Figs. 40, 41.

P. punctulatum Paulsen, 1931 (not 1908).

Peridinium multistriatum was recorded for the first time by KoForD in San Diego, but has been generally regarded as a doubtful species because of complete failure of its ratification since then. Peters (1928) suggested that Koford's species might be a grown example of $P$. subinerme. But closer inquiry on our Asamushi specimens and further careful studies of literatures concerning these two species, led us to conclude that Korom's is a distinct species, clearly distinguishable from $P$. 

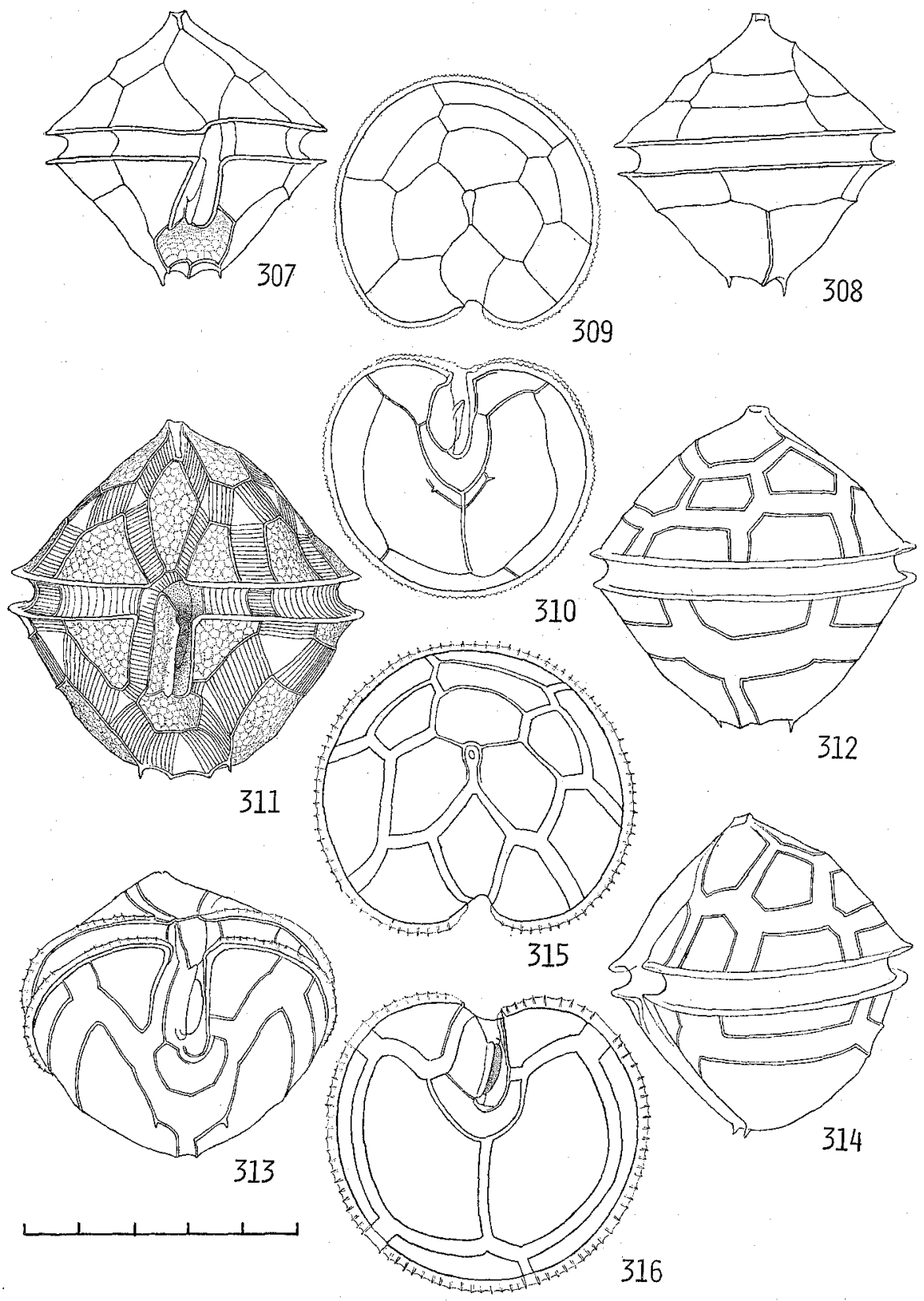

Fig. 47 (307-316): Peridinium multistriatum KoroId (1). 307-310-A young specimen. 307-Ventral view. 308-Dorsal view. 309-Apical view. 310-Antapical view. 311-Ventral view of a broad sutured specimen. 312-Dorsal view of another with obliquely displaced, pentagonal middle intercalary plate. 313-Postero-ventral view of a broadly sutured specimen with a short posterior sulcal plate. 314-Side view. 315-Apical view of a different specimen with sutural zone of moderate width. 316-Antapical view of the same. 

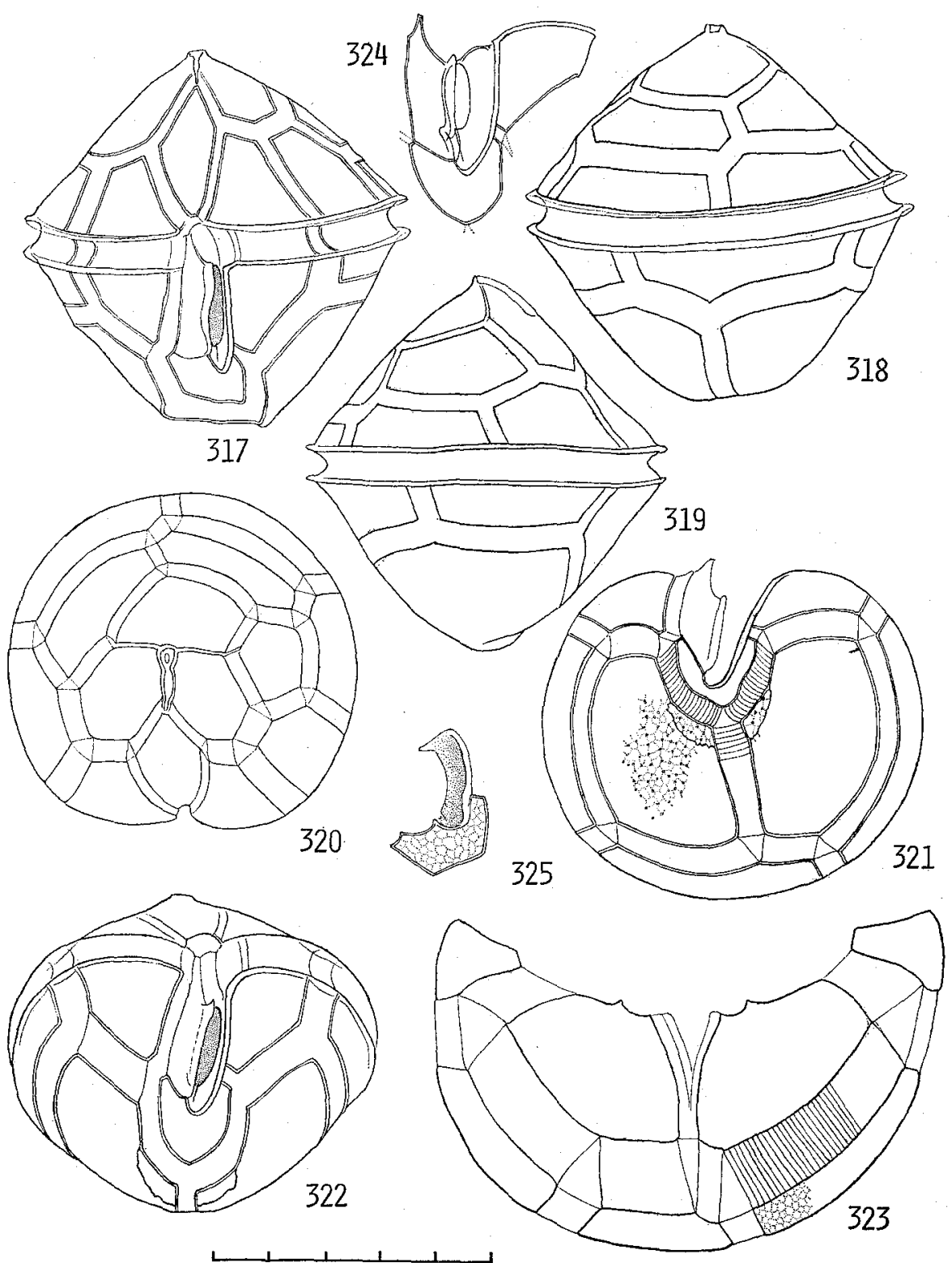

Fig. 48 (317-325): Peridinium multistrisium KoFoID (2). 317-Ventral view of a larger form with a W-shaped posterior sulcal plate and rounded antapex. 318-Dorsal view. 319-Side view. 320Apical view. 321-Antapical view of an isolated hypotheca, showing surface reticulations and post-sulcal area. 322-Postero-ventral view of a broadly sutured specimen with a V-shaped posterior sulcal plate. 323-Posterior three sulcal plates isolated together with left ventral postcingular plate. 324-A W-shaped posterior sulcal plate isolated in company with left sulcal plate. 325--An isolated left and posterior sulcal plates. 
subinerme. From the species to which this is most closely related, this can be distinguished by its smaller posterior sulcal plate and also by its less flattened body. $P$. conicoides is quite different from this in its peculiarly expanded ventral area. The present species seems to correspond to P. punctulatum (PAulsen, 1931, not 1908), judging from its epithecal plate pattern and body shape, and Paulsen's Figure $43 \mathrm{~B}$ agrees with our Fig. 47-313 in regard to their ventral area and the distribution of the sutural zone around it. And our Fig. 47-312 corresponds to his Figs. G and $D$ in regard to the small intercalary plate.

We found in Asamushi several small or a little larger forms of a rhombic species furnished with narrower or broader sutural zones and invariably with the small posterior sulcal plate. They show some differences in the convexity of the thecal wall, shape of the posterior sulcal plate, width of the sutural zones, and in the structure of the antapical part of the body. On the other hand, they agree with one another in their plate pattern both of the epitheca and hypotheca. And in spite of the differences, it seems best to consider all of them identical with one another and also with KoFom's species owing to close similarity of our broadly sutured specimens with his. Careful examination of Koroin's figures led us to conclude that $P$. multistriatum has the narrow rhombic ventral apical plate, the transversely elongated dorsal 2 and 4 ", the small but bilaterally expanded posterior sulcal plate and two minute processes along the postmargin of the body in addition to the two small but distinct antapical spines. And further its ventral area can be divided into a narrower and longer anterior and a smaller but bilaterally expanded posterior portions. Judging from these structural relations, his species answers very well to ours in every respect, justifying our identification.

The body of the smallest and presumably of the youngest individual (Fig. 47-307, 310 ) is rhombic in ventral view and has the equatorial girdle, straight sides, the faintly differentiated apex, and a minute antapical spine on either side of a short postmargin of the body, and the last structure has a faint median protuberance at the posterior end of the inter-antapial suture. The deeply impressed girdle forms a weakly descending spiral, and is guarded with hyaline low lists furnished with closely arranged marginal serrae each with a minute marginal rib. The cingular section is broadly reniform or oval. The left ventral part of the section is more acutely rounded than the right ventral. In other broadly sutured specimens (Fig. 47-311-314), the thecal wall is more or less convex both in the epitheca and hypotheca, and the antapex is not so acutely angulate as the youngest. In most of the specimens, there are two small median protuberances along the postmargin of the body, each standing on either side of the broad inter-antapical sutural zone. The variation in number of the median process is due to longitudinal splitting of a faint ridge formed along the inter-antapical suture in consequence of the growth of the sutural zone. There is a third form in which the short postmargin of the body is not furnished with any spine nor with median protuberance (Fig. 48-317-322).

The epitheca is divided into subequal plates and the mid-dorsal three plates 
are displaced a little towards the left side of the body. Consequently, these five plates lying on the left side of the epitheca, are smaller respectively than their corresponding one seen on the right side. The left ventral precingular $1^{\prime \prime}$ is smaller than the right $7^{\prime \prime}$ both in height and basal length. These features can be surmised also from Korom's figures. The epithecal plate pattern exhibits a minor variation. The median intercalary plate is transversely elongated hexagonal and subequal in length and width with the underlying precingular 4". These strikingly flattened two mid-dorsal plates, which are illustrated apparently also in KoForD's figure, serve to characterize this species in most cases, but we saw a single individual in which the median interclaary was smaller and irregularly pentagonal (Fig. 47-312).

The apex lies in the center of the epitheca and the apical trough extends, in the youngest individuals, to the ventral apical plate, but terminates in well-grown individuals at a short distance from there (Fig. 47-307). In KoForD's figure is illustrated a much shorter apical trough, terminating at a greater distance from the ventral apical plate. But this may be a natural result of over-growth of the intercalary zones.

The ventral postcingulars are obliquely elongated pentagonal, and the left of them is subequal with or smaller than the right, each corresponding in its width and length with the ventro-median precingular. The dorsal postcingular is smaller in width than the two laterals, and is displaced slightly towards the right. And these three postcingulars cover anterior one-third of the hypotheca. The antapicals are subequal in size, or the left is a little smaller than the right.

The ventral area is narrow, extending posteriorly to the center of hypotheca, and expands slightly bilaterally in its posterior half. It is deeply excavated as a whole, but the depth lies in its anterior left half (Fig. 47-311). In broadly sutured individuals, the ventral area does not extend to the center of hypotheca, as is noted by KoFoID, owing to the broad sutural zone lying around the posterior sulcal plate. KoroIo's figures seem to elucidate these relationships clearly, but his description. does not.

The ventral cingular plate corresponds in its lateral margin with the ventral pre- and postcingulars, and the minute transitional plate lies at the proximal end of the girdle. The four sulcal plates are typical in arrangement. The anterior, right and left sulcal plates lie within the narrower and deeper anterior part of the ventral area. This anterior deeper part bears a narrower right and a broader left sulcal list and the left one of them elongates posteriorly standing along the ventral and hind margin of the left sulcal plate. The other broader posterior part is covered with the posterior sulcal plate which is fairly constant in size but exhibits some variations in shape. As can be surmised from Fig. 47-307, this plate is broadly W- or V-shaped. In either case, it has a smaller right and a deeper left notch in its anterior margin, and its left lobe thus formed extends more anteriorly than the right, and the difference in shape of this plate is not associated with presence or absence of the antapical spine.

The small V-shaped postsulcal area forms a fairly flattened or concave surface 
lying on the ventral side of the body, and is distinguished distinctly from the sulcal furrow. The shape or length of this area is various in different specimens, and its dorsal ridge is so faint in some that it can be seen only with difficulty.

Surface of the thecal wall is covered with polygonal meshes with or without nodal minute spines. Among the sulcal members, the meshes can be seen in the right and posterior sulcal plates, but the other two and the transitional plates are left free from it. The cingular plates have transverse parallel striae.

Dimensions: Body length, 50-67 $\mu \mathrm{m}$. Transverse, diameter, 47-68 $\mu \mathrm{m}$. Dorsoventral diameter, $45-57 \mu \mathrm{m}$. Width of girdle, 5.5-6 $\mu \mathrm{m}$. Ratio in width of antapex to cingular section, $0.2-0.30$.

\section{Peridinium punctulatum PAULSEN}

Fig. 49 (326-330)

Paulsen, 1908, p. 61, Fig. 79 a-e; Mangin, 1910, Pl. 8, Figs. 677; Marukawa, 1921, p. 27, Pl. 7, Fig. 76 i-k; Lebour, 1925, p. 123, Fig. 37.

P. multipunctatum FAURé-Fremiet, 1908, p. 226, Fig. 12, Pl. 16, Fig. 11.

P. subinerme, in part, PAulsen, 1908, p. 60, Fig. 78 d, f; Peters, 1938, p. 52.

The body is in side view broadly biconical with pointed anterior and rounded posterior ends. The epitheca is convex conical, and the apex lies at its center. The circular or slightly descending postequatorial girdle runs horizontally around the subequatorial part of the body, where the thecal wall bulges distinctly. Along the ventro-median of the body lies a weak ventral depression which extends posterodorsally beyond the antapex. The cingular section is then broadly reniform with a weak indentation or flattening on the ventral, and the thecal wall forms two indistinct bulges on either side of the hind end of the sulcal furrow. The hypotheca is inferior in length to the epitheca, and along its ventro-median lies the deeply excavated sulcal furrow of small breadth, which extends posteriorly to the center of hypotheca but anteriorly hardly beyond the girdle. This furrow is strongly compressed bilaterally in its anterior half lying between the postcingular plates but becomes slightly wider in the other posterior half, and is bluntly pointed dorsally.

The rhombic ventral apical plate is fairly small in breadth, and the two ventral precingular plates are similarly broader than long. The pentagonal dorsal apical plate is of considerable size, expanding posteriorly almost to half-way between the apex and girdle, and is deflected towards the left. Lying between a smaller left and a much larger right intercalary plate, the middle intercalary is transversely elongated pentagonal, and together with the dorsal precingular plate it is also displaced towards the left. The three dorsal and lateral postcingular plates cover anterior one-fifth of the hypotheca, while the other two ventral plates of the same series extend posteriorly similarly to three-fifths. The posterior sulcal plate is deeply $\mathrm{V}$-shaped, consisting of a broader right and a narrower left lobe. Together with the cingular plates, the other sulcal plates are typical of the Conica group in their arrangements. 


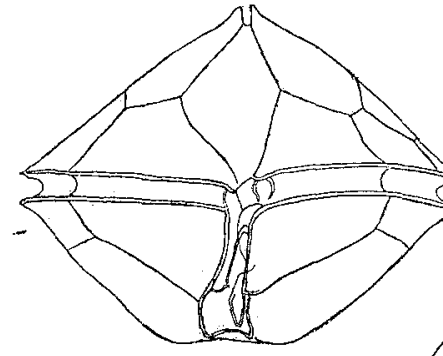

326
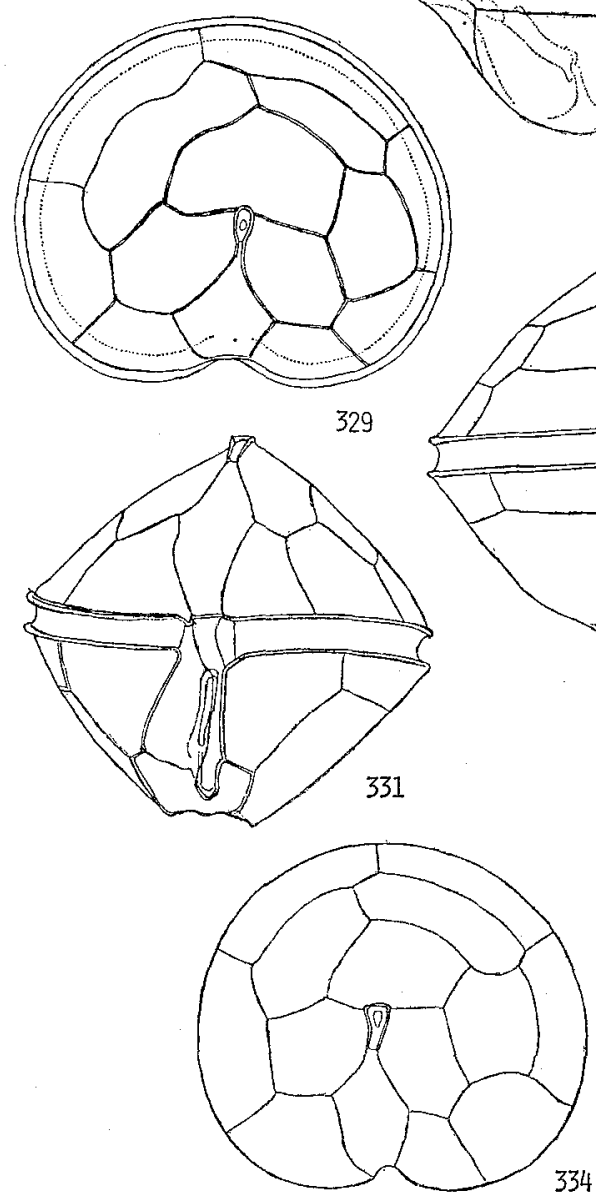

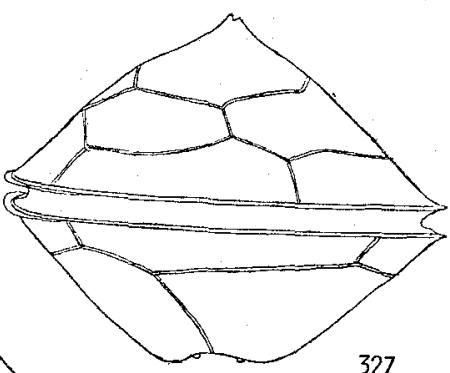

327

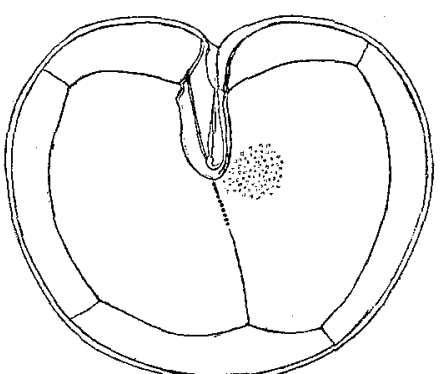

330

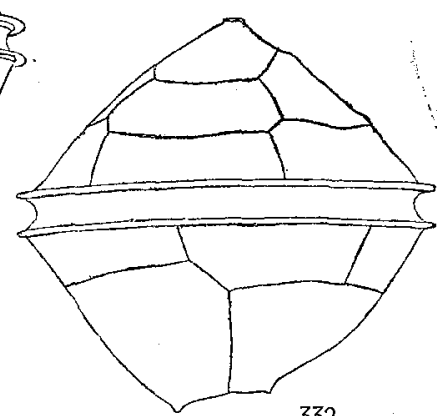

332

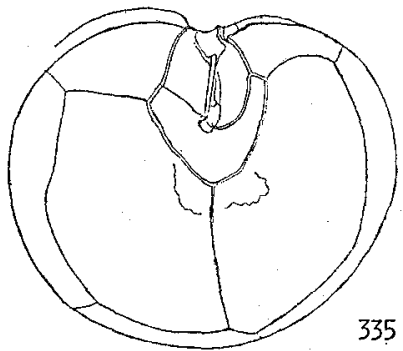

Fig. 49 (326-330): Peridinium punctulatum PAuLsen. 326-Ventral view. 327-Dorsal view. 328Side view. 329-Apical view. 330-Antapical view showing partially closely crowded minute points in the thecal surface.

(331-335): Peridinium rhombiformis n. sp. 331-Ventral view showing posteriorly expanding ventral area. 332-Dorsal view. 333-Side view. 334-Apical view. 335-Antapical view. 
The thecal plate is closely crowded with minute points. The postsulcal area is hardly differentiated.

Measurements: Length, 90-80 $\mu \mathrm{m}$. Transverse diameter, 65-72 $\mu \mathrm{m}$. Depth, $70-73 \mu \mathrm{m}$.

Locality: Shimoda.

PAULSEN (1908) described this species, giving eight figures which represent at least three different forms, one (Fig. 79 a-e) with a fairly narrow sulcal furrow and rounded antapex and the other two $(f, h: g)$ with a wide sulcal furrow and two pointed minute antapices. The former corresponds exactly with the present one in every respect, and is then regarded in this paper as worthy of receiving the specific name. Peters (1928) also apparently confused these rounded and angulated forms. MARukawA (1921) recorded the present species from Okhotsk Sea, giving its three figures.

\section{Peridinium rhombiformis n. sp.}

Fig. 49 (331-335)

P. punctulatum, in part, PAulsen, 1908, p. 60, Fig. $79 \mathrm{~g}$.

P. subinerme Lebour, 1925, p. 114, PI. 22, Fig. 2 a-f; in part, Peters, 1928, p. 52.

The body is in ventral view broadly pentagonal with a short concave postmargin, angulated at its either end, but is in side view broadly rhombic, pointing similarly at both ends. The apex and antapices lie at the center of the epitheca and hypotheca respectively. The equatorial girdle forms a circular furrow, and the horizontally formed cingular section is broadly reniform or sub-circular with a small indistinct ventral depression. Its epitheca is low and somewhat swollen conical, and the hypotheca is sub-conical, forming distally a distinct $\mathrm{V}$-shaped ridge of considerable size, which lies around the dorso-lateral margin of the posterior sulcal plate or of a small, similarly shaped postsulcal area. The thecal wall forms at either end of this ridge a minute conical bulge, the antapex.

The ventral area is broader posteriorly than anteriorly. Its narrower part, occupying its anterior two-thirds in length, increases its width posteriorly expanding towards the right, while the other broader part has at its ventral end its greatest width, one-third or a little less of the greatest transverse diameter of the body. The other posterior portion expands abruptly bilaterally beyond the anterior portion, contracting dorsally (or posteriorly). Its greatest breadth is then at its ventral end about one-third of the greatest transverse diameter of the body at the girdle. This ventral area is more or less deeply excavated as a whole, but particularly distinctly in its anterior left half, forming there an indistinctly differentiated flagellar furrow which extends posteriorly beyond the right sulcal plate. There is then an angulated transverse fold of the thecal wall along the anterior edge of the posterior sulcal plate.

The rhombic or rather elongated pentagonal ventral apical plate tapers more posteriorly than anteriorly, and is broadly truncated posteriorly. The left ventral of the precingular series is smaller in breadth than the right ventral of the same series, 
but they have subequal length. Among the other three apicals, the pentagonal dorsal is deflected with its broad hind end towards the left, covering anterior onethird or a little more of the middorsal of the epitheca. Together with this and the dorsal precingular $4^{\prime \prime}$, the transversely elongated, hexagonal middle intercalary is also displaced towards the same direction. Contrary to this, the dorsal postcingular plate is strongly displaced towards the opposite direction. This and the other two lateral postcingular plates have similarly small length subequal or a little larger than the width of the girdle, while the two ventral ones of the same series expand posteriorly beyond the middle of the hypotheca. The structural relations or plate pattern within the ventral area is typical of the Conica group, and the posterior sulcal plate is $\mathrm{V}$-shaped, consisting of a broader right and a narrower left lobe, expanding bilaterally beyond the two middle sulcal plates but a little more towards the left than towards the right.

The thecal plate is covered with faintly formed meshes, and the incompletely formed postsulcal area is smaller in breadth than the ventral area.

Measurements: Length, $80 \mu \mathrm{m}$. Transverse diameter, $77 \mu \mathrm{m}$. Depth, $70 \mu \mathrm{m}$.

Locality: Shimoda.

Our present form corresponds exactly with one of the three forms of PAunses's $P$. punctulatum (1908, Fig. $79 \mathrm{~g}$ ) regarding the size and shape of the sulcal furrow. In the same author's $P$. subinerme (1908, Fig. 78), the posterior sulcal plate is much larger than in the present form. From $P$. punctulatum, the present form differs in its more widely opened and more highly differentiated ventral area. The ventral area of them is, then, more highly differentiated in the order of $P$. punctulatum, the present form and $P$. subinerme.

\section{Peridinium conicoides PAULSEN}

Figs. 50, 51 (336-348)

Pautsen, 1908, p. 59, Fig. 75.

Marukawa, 1921.

Lebour, 1925, p. 112, PI. 20, Fig. 2 a-d.

The leftward abrupt expansion of the broadly excavated ventral area at immediately below the girdle characterizes this small species. The body is in ventral view rhombic or pentagonal with four convex sides and a slightly concave short postmargin. The epitheca is swollen conical, and the hypotheca is deeply excavated along its midventral region by the broad sulcal furrow, forming posteriorly a Ushaped antapical ridge which lies transversely between the two minute and solid antapical spines which stand each on an indistinct hollow conical swell of the body wall. The left one of them lies more ventrally than the other, and this asymmetry seems to be strengthened when the sutural zone becomes broader. The circular or very faintly descending girdle is equatorial and has deeply concave wall and narrow side-lists. The cingular section is broadly reniform or somewhat three-lobed especially in broadly sutured specimens. The epithecal plates are bilaterally symmetrical 

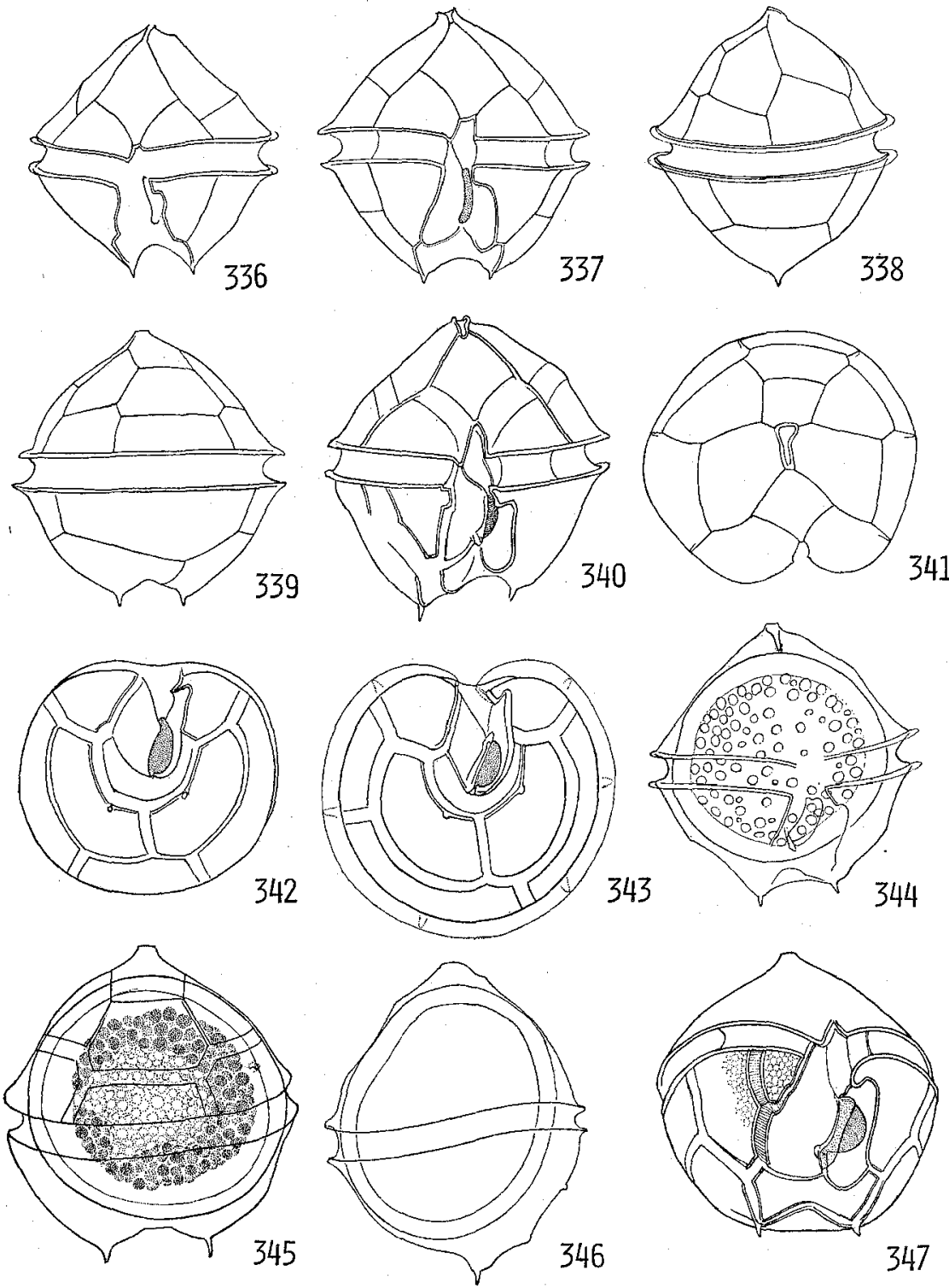

347

Fig. 50 (336-347): Peridinium conicoides PAULSEN. 336-Ventral view of a small specimen. 337-The same of a larger one with convex sides. 338-Side view. 339-Dorsal view. 340-Ventral view of a broadly sutured specimen with a median extension of the ventral postcingular plate lying on either side of ventral area just below the girdle. 341-Apical view of a large specimen showing characteristic (rounded pentagonal) shape of its cingular section. 342-Antapical view of a different one with a small, symmetrical dorsal postcingular plate. 343-Antapical view of a larger specimen with a large, asymmetrical dorsal postcingular plate. The six ribs in the cingular list indicate lower ends of inter-precingular meridional sutures. 344-A small specimen having a large cyst. 345-Dorsal view of a larger specimen with a large cyst. Granules are stained with iodine solution. The sutual zone in the epitheca displays a peculiar differentiation. 346-Side view of the same specimen. 347-Postero-ventral view of the same, showing the thecal plates in and around the ventral area and an additional postcingular plate on the right of ventral area. 

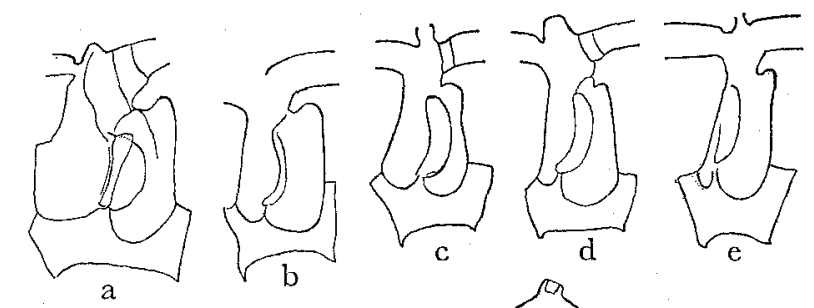

\section{8}

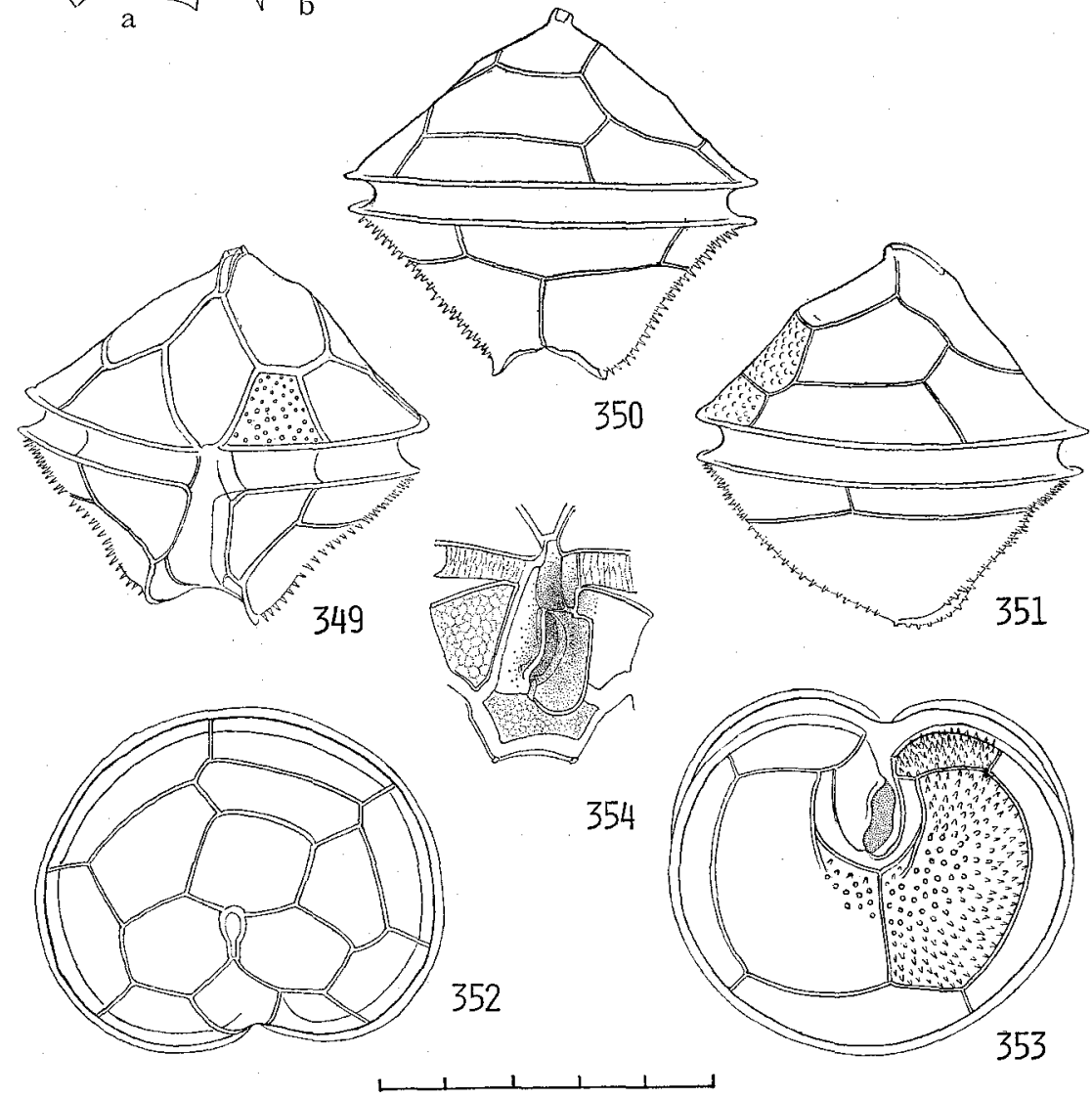

Fig. 51 (348): Peridinium conicoides. 348-Five different shapes (a-e) of ventral area.

(349-354): Peridinium paulseni n. sp. 349-Ventral view. 350-Dorsal view. 351-Side view. 352Apical view. 353-Antapical view. 354-Ventral area.

in arrangement. Among the three pairs of the meridional collective sutures, the ventral pair is most distinctly straightened while the dorsal is most zigzag. The tall pentagonal dorsal apical plate is the smallest, while the lateral apicals are the largest in the epitheca. The three intercalary plates are subequal in size, and the middorsal $2 \mathrm{a}$ is generally trapezium-like hexagonal. The precingular plates, all of which are subequal in their basal length, decrease their height from ventral to dorsal. But strictly speaking, these in the right half of the body are slightly larger respectively than the corresponding one in the left half. Connected with this, the middorsal three plates are displaced slightly towards the left side of the body. 
The plate pattern of the epitheca is fairly constant, while that of the hypotheca is subject to individual variation. One of the most characteristic features of this species is the shape of the left ventral postcingular plate which has a rectangular median extension just at the proximal end of the girdle. The lateral and dorsal three postcingular plates are of considerable size, occupying anterior two-fifths of the hypotheca. There are at least three types in regard to the size and lateral expansion of the dorsal postcingular plate, so far as our observations are concerned, one with a small plate lying symmetrically just below the dorsal precingular 4" (Fig. 50-342), one with a larger one extending asymmetrically towards the left (Fig. 50-338), and the other towards the opposite direction (Fig. 50-343). And there appears to be the fourth type in which a large plate expands symmetrically, judging from LeBour's Figure 2a (Plate XX).

Another variability of extreme rare occurrence is seen in the right ventral postcingular plate. This plate has generally elegantly curved median margin (Fig. 50337), but rarely was seen a minute and short rectangular extension in its antero-median portion extending into the ventral area, and this corresponds in shape and position to that of the left ventral postcingular (Fig. 50-340). In one case, we saw a large swollen theca with a large resting cyst in it, and an additional minute plate on the right of its ventral area and separated from the plate $5^{\prime \prime \prime}$ by a broad suture (Fig. 50-345). The differentiation of this plate may be partly due to the over-growth of the body but not related directly with the formation of the thick-walled resting cyst, because that the separation of the plate must have occurred before the commencement of its cyst formation, unquestionably further before the beginning of the megacytic growth of this individual.

Another interesting and also characteristic feature of this species is its ventral area which affords us a clear and most convenient practical base for the taxonomic distinction of this. The ventral area is narrow just below the girdle owing to the median extension of the left ventral postcingular plate, and expands abruptly towards the left in its middle region, and further bilaterally at the posterior sulcal plate. The structure is subject to individual variation not only in shape but also in size, as is illustrated in Fig. 50-337, 340, 343. This variability may be partly due to the development of the sutural zones in and around the ventral area, and partly due to differences in lateral expansion or widening of the sulcal furrow, accompanied with inversely decreasing of its depth. On the other hand, we can not but admit the fact that there are in reality some actual differences in size of its component plates. The sulcal furrow agrees in the extent mainly with the ventral area, but expands peculiarly beyond it just below the girdle over the median extension of either the left or right ventral postcingular plate. The left sulcal plate is also characteristic in shape, curving towards the left in its middle, and extends anteriorly to the posterior end of the median extension of the left ventral postcingular plate. The median (distal) end of the extension corresponds, then, to the oblique proximal end of the posterior cingular ridge seen in other species. The broadly $\mathrm{W}$-shaped posterior sulcal plate is deeply indented at the hind end of the left sulcal plate, and expands bilaterally beyond the two plates lying just above it in a similar degree or more towards the left than towards 
the right.

The thecal wall is covered with fine polygonal meshes. And a similar but smaller meshes can be also seen in the posterior and faintly in the right sulcal plates. But the cingular wall is different; it is minutely corrugated, and in surface view there is a double row of longitudinally elongated meshes.

We have often seen a large resting cyst within the cyst wall or free from it (Fig. $50-344,346)$. It is spheroidal or slightly flattened obliquely in antero-dorsal posteroventral direction, and in such a flattened one one can see on its surface a longitudinal slight depression corresponding in position to the ventral furrow of the theca. Its thick wall is pomerian red in formalin-preserved materials and not stratified. Its content is filled with small spheroidal granules which stain dark with iodine solution and lie around a central large transparent region. The cyst is found very often in a theca provided with the broad sutural zones, but not rarely it is seen formed within a theca without them. In the former case the theca is more or less swollen distinctly while in the latter it is more angulate. This seems to suggest the independent occurrence of the cyst formation from the megacytic growth of the thecal wall. According to Schütt (1887, 1895), Schiling (1891) and Hurer and Nipkow (1922, 1923), the resting cyst of fresh-water species is not rare while that of the marine is extremely scarce. But in the winter plankton of Asamushi, the cyst of this species is not rare.

Dimensions: Body length, $41-53 \mu \mathrm{m}$. Transverse diameter, 39-50 $\mu \mathrm{m}$. Dorsoventral diameter, $38-42 \mu \mathrm{m}$. Width of girdle, $4-5 \mu \mathrm{m}$. Ratio in transverse diameter of antapex to cingular section, $0.25-0.34 \mu \mathrm{m}$. Diameter of cyst, 37-42 $\mu \mathrm{m}$. Dorsoventral diameter of flattened one, 32-36 $\mu \mathrm{m}$. Thickness of cyst wall, 2.0-2.2-2.5 $\mu \mathrm{m}$.

Locality: Asamushi.

\section{Peridinium paulseni n. sp.}

Fig. 51 (349-354)

P. subinerme Paulsen, 1931 (non 1908), p. 71, Fig. 42.

This small and broadly rhombic species has an equatorial and slightly descending or circular girdle and a distinct postero-median depression formed by dorsal extension of the sulcal furrow. The antapical spine is absent. Surface of the thecal plates is closely crowded with minute processes which are more prominent in the hypotheca where they grow in length into spines.

The epitheca is low conical with flat ventral and slightly swollen dorsal sides, and is divided into subequal plates. The left ventral precingular $1^{\prime \prime}$ is a little smaller than the right ventral $7^{\prime \prime}$. All the precingular plates are fairly small in length, covering lower one-third or less of the epitheca. The ventral apical is narrow, while the dorsal pentagonal apical is of considerable size. The dorsal meridional triplet is displaced to the left in consequence of unequal development of the bilateral plates. 
The girdle is equatorial and deeply excavated, and has low hyaline side-lists which bear marginal ribs at regular intervals. The cingular section is broadly reniform or oval with ventral flattening. Each of the two ventral cingular plates corresponds in length with the basal length of the pre- or postcingular plate lying just above or below it.

The hypotheca has also flat ventral and swollen dorsal sides, and the decply impressed sulcal furrow extends posteriorly to the center of hypotheca, excavating its antapical median region. The sulcal furrow extends dorsally beyond the ventral area, forming on its either side an indistinct antapical prominence which is compressed bilaterally and represented in antapical view with an oblique ridge extending dorsally beyond the posterior sulcal plate.

In the postcingular series, the left ventral is a little smaller than the right ventral as in the precingulars, both extending posteriorly similarly, and the other three postcingulars are short and transversely elongated, all slightly exceeding the girdle in length.

The posterior bilateral expansion of the ventral area deeply excavated as a whole is not distinct. The postsulcal area is incomplete dorsally as the antapical ridge is divided into bilateral halves by the dorsal extension of the sulcal furrow (Fig. 51-354). This peculiar structure reminds one of the corresponding structure in P. excentricum (ABÉ 1936a).

The left sulcal list is distinct. The U-shaped posterior sulcal plate expands similarly bilaterally, and the post-sulcal area has no dorsal demarcation.

Surface of the epitheca is closely scattered with minute processes which grow in length into short spines in the hypotheca.

Dimensions: Body length, $55 \mu \mathrm{m}$. Transverse diameter, $60 \mu \mathrm{m}$. Dorso-ventral diameter, $48 \mu \mathrm{m}$. Width of girdle, $5 \mu \mathrm{m}$. Ratio in width of antapex to cingular section, 0.27 .

Locality: Asamushi

There have been reported many marine and fresh-water species with fine spines or points scattered all over the thecal surface, such as $P$. excentricum, $P$. ovatum, $P$. punctulatum, $P$. obtusum, $P$. marielebourae, $P$. leonis of marine and $P$. anglicum, $P$. marssoni, $P$. lomnickii and $P$. godlewskii of fresh-water species. Of these marine species, the last four have somewhat large posterior sulcal plate, suggesting their correct allocation in the present group. And the species worthy of consideration here is $P$. punctulatum. Paulsen's species (1908, Fig. 79) seems to include at least two different forms, one with a short and narrow ventral area and the other with an elongated one accompanied with a distinct, large V-shaped antapical ridge ( $f, h)$, and his later (1931) and LEBour's species (1925) seem to correspond with the former of the two. And our present species is more closely related to the former of PAULSEN's, though indicating some intermediate characteristics in regard to the ventral area. We found two other forms in Shimoda, one corresponding exactly to PAuLSEN's and the other displaying differences, suggesting taxonomic distinctness of the present form. Consequently, it seems very advisable to reserve PAUlSEN's species name $P$. punctulatum for his former 
form (Figs. a-e).

Our present species can be separated at once from the two forms of Shimoda in the characteristic structural feature of its antapical part. The ventral area of $P$. punctulatum is strikingly compressed bilaterally and not furnished with the antapical ridges. And the other form of PAulsen's has a little broader ventral area differing much from that of $P$. punctulatum and also from our present species. Another one to be considered here is $P$. subinerme which was often confused with $P$. punctulatum PaulSEN. Many more or less different forms have been attributed to PAULsEn's original species, but we intend here to define the species only to his original species (1908), especially to the form collected from Skagerrak and placed ahead in his Figure 87, which is characterized by the asymmetrical expansion of the posterior sulcal plate. Paulsen's later species (1931, Fig. 42) may be the one corresponding to the present one. Both Lebour's (1925) and Peter's (1928) forms differ from Paulsen's former and also from the present forms in some or other points, especially in their plate pattern of the epitheca, and in the structural relations of their antapical part. And the other species to be distinguished from the present species is $P$. petersi n. sp. to which it is most closely related especially in the structural differentiation of its antapices. But it can be separated at once from the present species in its smaller dorsal and broader ventral apicals and its larger posterior sulcal plate of asymmetrical expansion, and complete development of the antapical V-shaped ridge.

\section{Peridinium petersi n. sp.}

Fig. 52 (355-359)

This small pentagonal species is characterized by asymmetrical expansion of the posterior sulcal plate, and its low and pointed antapices.

The body is in ventral view swollen pentagonal, bulging out more dorsally than ventrally, and has a slightly concave posterior margin. The equatorial and slightly ascending girdle is deeply impressed and has narrow and well ribbed lists. The cingular section is broadly reniform, tilting down ventrally. The ventral area, which expands asymmetrically in its posterior part and is very deeply excavated as a whole, extends dorsally beyond the center of hypotheca, indenting the posterior median part of the hypotheca broadly but not so deeply. In consequence of this, the hypotheca has on either side a sharply pointed and bilaterally flattened low antapical cone which bears a minute solid spine at the distal end. The antapical $\mathrm{V}$-shaped ridge thus formed bears a denticulated low list along its whole length. The apex lies in the center of epitheca or slightly dorsal to it, while the antapices are displaced a little towards the ventral.

The plate pattern of the epitheca is symmetrical in arrangement, and the two lateral apicals are large plates. The pentagonal lateral intercalaries are much larger than the trapezoidal middle whose transverse length is subequal with the dorsal apical lying just above it. The dorsal three precingulars are subequal in height and 


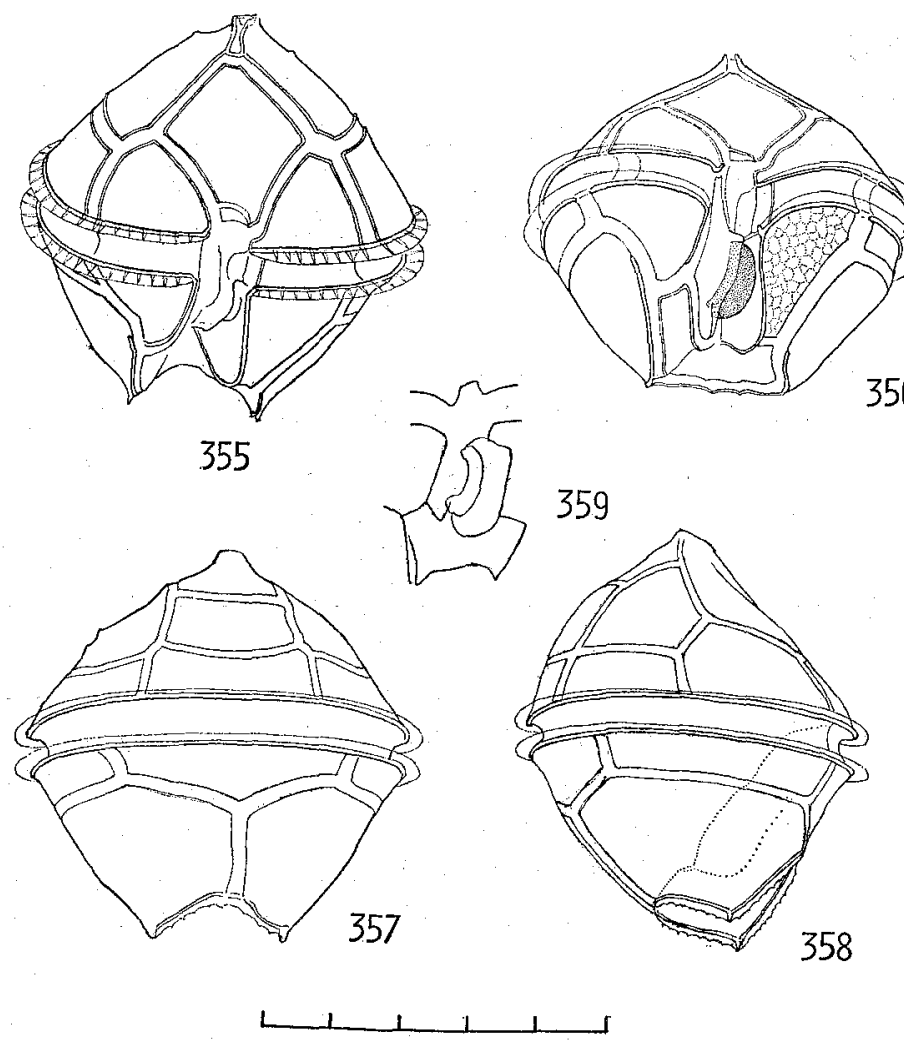

Fig. 52 (355-359): Peridinium petersi n. sp. 355-Ventral view. 356-Postero-ventral view showing a peculiar asymmetrical expandion of posterior sulcal plate. 357-Dorsal view. 358-Side view showing depth of longitudinal furrow with dotted line. 359-Ventral area.

size, and the ventro-lateral $2^{\prime \prime}$ and $6 "$ are twice as tall as these three. The ventral precingulars are subequal in shape and size. In the hypotheca, the dorsal and lateral three postcingulars have small length subequal with the breadth of the girdle, and the left ventral $1^{\prime \prime \prime}$ is much larger than the right ventral $5^{\prime \prime \prime}$, extending posteriorly nearly to the left antapex, while the other to half-way between the girdle and right antapex. The ventral cingular, precingular and postcingular plates agree in their lateral extremities. The transitional plate is narrow, lying half in the girdle and half in the ventral area.

The ventral area expands more towards the right than towards the left in its posterior part, in consequence of the asymmetrical expansion of the posterior sulcal plate. The plate is peculiarly L-shaped, being correlated to the asymmetrical posterior extension of the ventral postcingular plates. There is a serrated narrow list standing along the antapical $\mathrm{V}$-shaped ridge.

The thecal wall is covered with fine polygonal meshes, but the anterior and left sulcal plates are left free from the markings.

Dimensions: Body length, 56-60 $\mu \mathrm{m}$. Transverse diameter, 53-57 $\mu \mathrm{m}$. Dorsoventral diameter, $44 \mu \mathrm{m}$. Girdle width, $4-6 \mu \mathrm{m}$. Ratio in breadth of antapex to 
cingular section, $0.33-0.38$.

Locality: Asamushi

The present species can be distinguished from any of the recorded species by its peculiarly asymmetrical posterior sulcal plate coupled with the inversely elongated ventral postcingular plates.

\section{Peridinium furcatum n. sp.}

Fig. $53(360-367)$

This is a leonis-like but much smaller species furnished with circular girdle, slightly inclined cingular plane, wide sulcal furrow, slightly flattened antapical horns and extremely short postcingular plates. The cingular section is broadly reniform.

The epitheca is conical with flat or slightly concave sides in younger and faintly convex ones in broadly sutured specimens. The ventral slit of the apical pore often has an obliquely truncated distal end extending in sinistro-ventral direction. The hypotheca has in most cases more concave sides than the epitheca, and the two antapical horns are separated from each other for about 0.4 transverse diameter of the body. The equatorial circular and relatively wide girdle, which is deeply impressed and guarded with well-ribbed low lists, runs slightly aslant, tilting up dorsally. The ventral area is very narrow in its anterior part which is very short occupying less than its anterior half, and expands abruptly similarly to both sides at the posterior sulcal plate. It is deeply excavated as a whole especially in its anterior narrower part and extends dorsally beyond the center of hypotheca. The V-shaped antapical ridge lies along the lateral and dorsal margin of the posterior sulcal plate, extending across the antapical cone which is flattened along this ridge, and bears a very narrow list along its entire length and a stout rib or spine at the distal end of the cone. But in some specimens the antapical spine is absent.

There is often a marked differentiation between the meridional collective and the transverse suture in the epitheca, the former being marked with distinct ridges forming fairly straight six meridional sutures, while the latter is weak and faint and sometimes distinguishable only through the sutural lines (Fig. 53-365, 366). But the linear arrangement of the meridional ones is various in different individuals.

The epithecal plate pattern is fairly symmetrical, but there seem to be some distinct variations in its ventral half. The ventral apical plate is broad or narrow according to the smaller or larger upper widths of the two ventral precingulars, and the plate has a broadly truncated posterior end. Much smaller dorsal apical is also variable in transverse length. The lateral intercalary plates are larger than the trapezoidal or hexagonal middle 2a. All the precingulars are fairly small in length, decreasing their length from ventral to dorsal, and the largest ventrals do not extend anteriorly beyond the middle of the epitheca. The lateral and dorsal postcingular plates are very small in length, hardly exceeding breadth of the girdle. The ventral postcingular plates extend posteriorly similarly to half-way between the girdle and 
the antapex. The huge and subequal antapical plates cover the posterior majority of the hypotheca.

The ventral cingular plates agree in lateral expansion with the pre- and post-

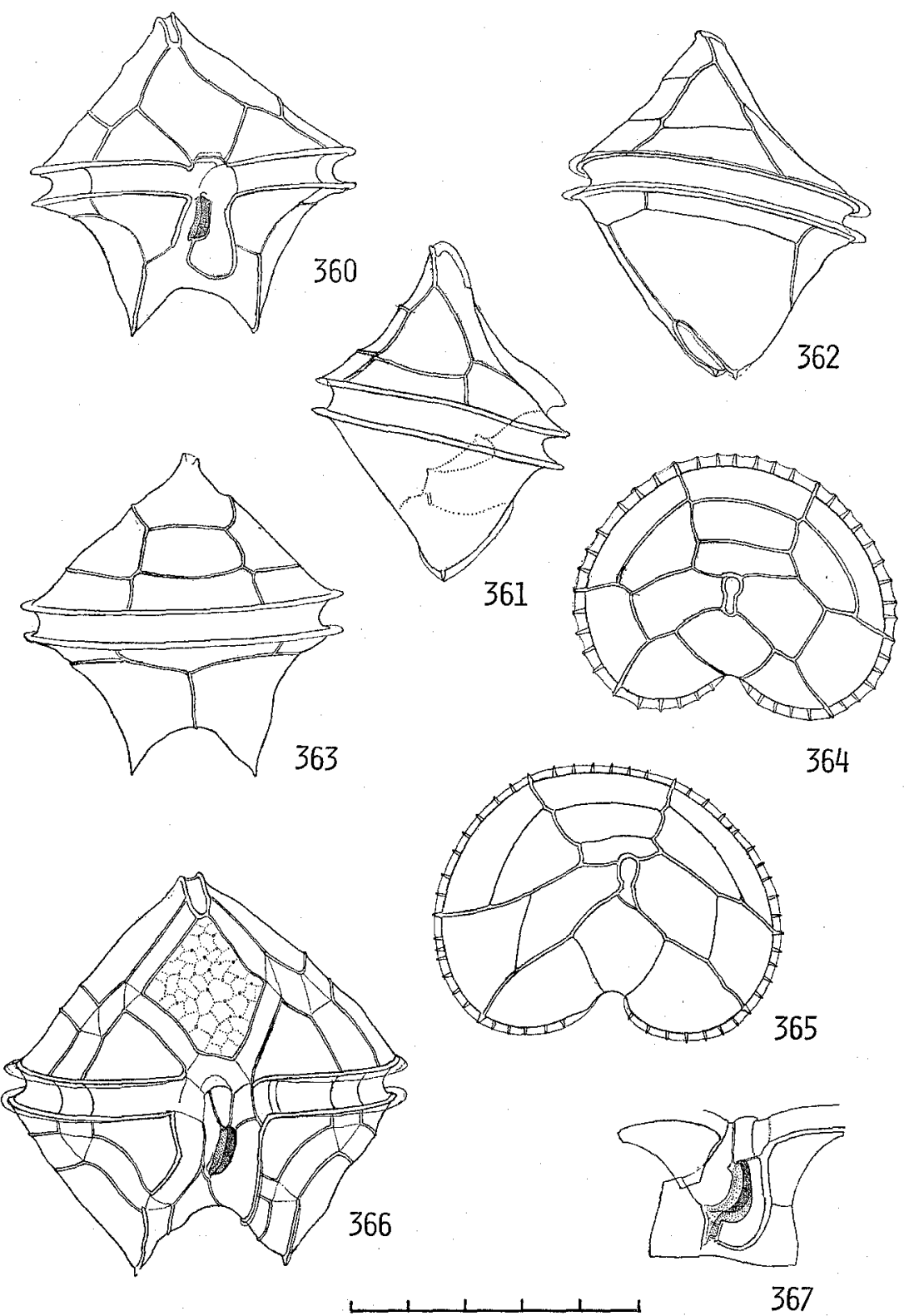

Fig. 53 (360-367): Peridinium furcatum n. sp. 360-Ventral view of a young specimen. 361-Side view of the same showing depth of longitudinal furrow. 362-Oblique dorsal view of another specimen. 363-Dorsal view. 364-Apical view of a specimen with a larger dorsal apical and smaller ventral precingulars. 365-Apical view of another with a smaller dorsal apical and larger ventral precingulars. 366-Ventral view of a broadly sutured specimen. 367-Isolated ventral part of a hypotheca, partially disjoined. 
cingular plates. The anterior margin of the left ventral postcingular plate is very oblique at the lower end of the transitional plate. The arrangement and interrelations of the four sulcal plates are typical as illustrated in Fig. 53-367. The small and rectangular anterior member is slightly larger than the transitional plate, and the $\mathrm{J}$-shaped left sulcal plate lies far more posteriorly than the right, deeply indenting the posterior sulcal plate, and bears the short flagellar trough along its truncated posteromedian margin and a distinct left sulcal list along its left and posterior margin. The posterior sulcal plate is very characteristic in shape, being broadly and deeply constricted at the hind end of the left sulcal plate to form a smaller left and a larger right lobe (Fig. 53-366). The left lobe increases its width gradually towards the left, while the other abruptly at the flagellar trough. This pecuriality is partly associated with the unusual position of the flagellar trough, namely between the left and posterior sulcal plates instead of between the two middle sulcal plates. Notwithstanding the difference in size and shape of the two lobes, the two antapical horns do not show marked difference in direction of extension in younger individuals, but distinct asymmetry occurs in broadly sutured ones. Along the V-shaped antapical ridge, which continues ventrally to the ventral postcingular plates, is a low hyaline list with or without a minute spine or rib at the tip of the antapical cone.

The thecal wall is covered with fine or somewhat coarse polygonal meshes with minute nodal spines, and the same is true of the posterior and right sulcal plates.

Dimensions: Body length, 55-67 $\mathrm{m}$. Transverse diameter, 55-68 $\mu \mathrm{m}$. Dorsoventral diameter, $45 \mu \mathrm{m}$. Width of girdle, 5-6 $\mu \mathrm{m}$. Ratio in width of antapices to cingular plane, $0.35-0.4$.

Locality: Asamushi

This small pentagonal species is closely related to $P$. conicum in its body form, epithecal plate pattern, and especially in its broad but bilaterally flattened antapical horns, but differs from it in its distinctly smaller size, circular girdle, strikingly narrow postcingular plates, smaller anterior part of the ventral area, wider antapical depression and in its peculiarly shaped posterior sulcal plate. From $P$. leonis this can be distinguished by its narrower pre- and postcingular plates, larger dorsal apical plate, broader body, circular girdle, and especially distinctly by its larger antapical plate and peculiarly shaped posterior sulcal plate. Furthermore, its markedly narrow postcingular plates and its strikingly shorter anterior part of the ventral area coupled with the symmetrical (bilateral) expansion of the posterior sulcal plate, are enough to separate this from $P$. subinerme and other allied species. From $P$. petersi this can be separated in the posterior subequal extensions of its ventral postcingular plates.

\section{Peridinium subinerme PAULSEN}

Fig. 54 (368-374)

Paulsen, 1908, Fig. 78 a-c f (not d-e).

not Paulsen, 1931; Lebour, 1925; Peters, 1928; Schiller, 1929. 
This species name has been applied presumably to various small forms of the Conica-group by different authors, owing to the lack of sufficiently detailed morphological study of the group. Our Asamushi-species corresponds exactly with that originally figured by PAULSEN, which were re-illustrated by him in the "Nordisches Plankton" (1908, Fig. 78). This may be justified when one compares Fig. 54-368 with Paulsen's Fig. 78c.

The rhombic body is slightly flattened from apex to antapex, and has convex sides and small antapical indentation. The pointed apex lies in the center of epitheca, while the antapices are displaced slightly towards the ventral in accord with the short ventral area which terminates in front of the center of hypotheca (Fig.
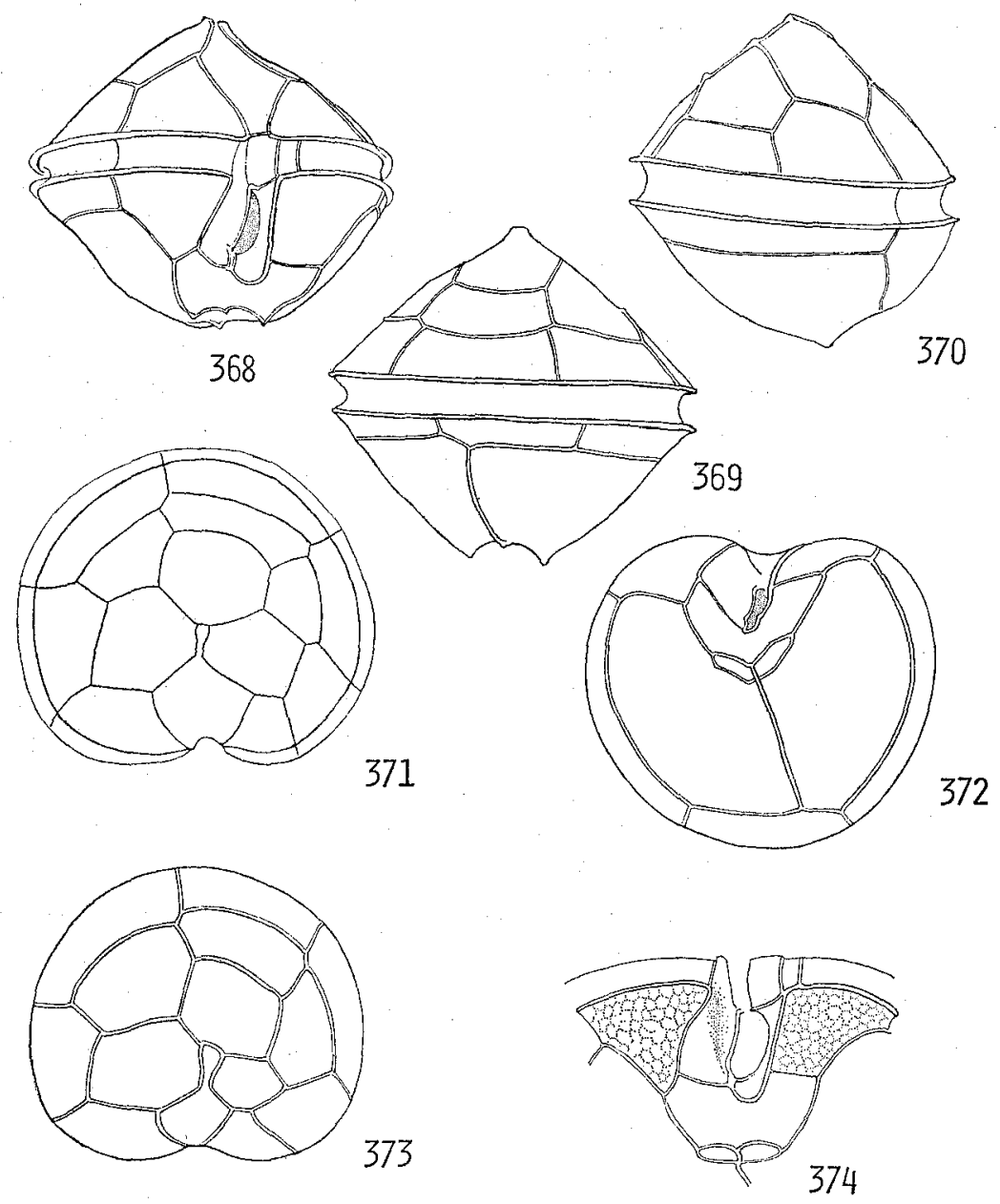

Fig. 54 (368-374): Peridinium subinerme PAulsen. 368-Oblique ventral view. 369-Dorsal view. 370-Side view. 371-Apical view. 372-Antapical view. 373-Apical view of a different specimen showing a distinctly asymmetrical plate pattern. 374-Partially disjoined and strongly flattened ventral part of an isolated hypotheca. 
54-368, 374). The epitheca is low conical, and the cingular section is broadly reniform or oval with a ventral flattening. The girdle is circular or faintly descending, and guarded with narrow lists. There is a minute conical horn or rather a pointed process on either end of the antapicla ridge which bears neither solid spine nor distinct list. These two antapical processes are separated from each other twice as wide as the breadth of the girdle. And there is, in ventral view, another smaller elevation of the ridge at the inter-antapical suture (Fig. 54-368, 369).

The plate pattern of the epitheca of our species (Fig. 54-371) corresponds with that of PAulsen's Iceland specimen (Fig. $f$ ) in every detail. The ventral plate pattern is somewhat asymmetrical. Upper margin of the left ventral precingular is much shorter than that of the right ventral. The apicals are subequal in size or the ventral and left members are smaller than the others (Fig. 54-373). In accord with the leftward displacement of the middorsal three plates, lying in the left half of the epitheca, these plates are smaller than those seen in the other half. The left ventral postcingular has wider posterior margin than the right ventral in harmony with leftward stronger expansion of the posterior sulcal plate (Fig. 54-373). The dorsal and lateral postcingular plates are very small in length, hardly exceeding the breadth of the girdle. A larger right and smaller left antapicals cover the major part of the hypotheca. Every ventral pair of the pre- and postcingular series agree with one another in their lateral extremities.

The ventral area is very irregular and characteristic. The left side of its anterior region is longitudinal, bearing a narrow list, while its right side is quite oblique. The anterior region is deeply excavated especially distinctly in its left half. The posterior region expands abruptly towards the left twice as far as towards the right, and the longitudinal furrow continues posteriorly to the median part of this and dies out laterally.

The small rectangular transitional plate is a little smaller than the similarly shaped anterior sulcal plate. The right sulcal plate is much larger than the left-sulcal one. The posteiror sulcal plate is inversely trapezoidal and has a small but deep notch in the middle of its larger anterior margin, and expands towards the left twice as much as towards the opposite direction. The post-sulcal area is small, extending between the two minute antapical processes, and has a slight median constriction at the interantapical suture (Fig.5 4-372, 374). The polygonal surface marking of the thecal wall is seen not only in the genreal thecal plates but also in the right and posterior sulcal plates, but is completely absent from the left and anterior sulcal ones.

Dimensions: Body length, $47-50 \mu \mathrm{m}$. Transverse diameter, 50-55 $\mu \mathrm{m}$. Dorsoventral diameter, $44-47 \mu \mathrm{m}$. Width of girdle, $4-5 \mu \mathrm{m}$. Ratio in breadth of antapex to cingular section, $0.21-0.22$.

Locality: Asamushi

Paulsen's species (1908) seems to include two different forms. One of his Skagerrak specimens (Fig. $78 \mathrm{a}-\mathrm{c}$ ) has the ventral area exactly answering to that of our present species. But the other (Figs. d, e) seems to differ from that in the shape of the left ventral precingular plate, and the figure exhibits some structures hardly 
possible to be interpreted. His Iceland specimen (Fig. f) seems to answer to his Figure a, judging from the shape of the left ventral precingular plate. And our present species corresponds to the first Skagerrak form of his, although its body is more elongated. And in addition to these, his work (1931, Fig. 42) shows a third type with broadly excavated antapical part of the body, suggesting its specific distinctness. We believe it advisable to reserve the specific name $P$. subinerme for one of his forms, represented by his Figures a-c. LEBour's (1925) species differs clearly from PAULSEN's original one in its symmetrical epithecal plate pattern, broader postcingular row of plates, and presumably symmetrical (bilateral) expansion of the posterior sulcal plate. Peters' (1928) species may be another to be distinguished from Paulsen's and also from our species, because of its different plate pattern of the epitheca, lateral expansion of its posterior sulcal plate in reversed direction and its pre-equatorial girdle. MartikawA's species (Fig. 74; g, h, i, pl. VII) is quite different from these just described and from our species, especially in the structural differentiation of its antapical part.

\section{Section 2. Conica n. sect.}

This section is characterized by its large posterior sulcal plate expanding partly beyond the sulcal furrow.

The plate pattern of the epitheca is semi-adjusted. The collective meridional sutures are less zigzag, and the lateral pair of them divides the epitheca into subequal ventral and dorsal halves. The ventro-lateral meridional zones do not differ from each other much in width, and are nearly symmetrical in extension. The girdle is circular, ascending or descending, and the cingular section is broadly reniform. The antero-lateral small portion of the posterior sulcal plate is distinctly elevated lying outside the sulcal furrow which extends dorsally beyond the center of hypotheca, forming the postero-median indentation of the body, along the dorsal and lateral sides of which lies the large V-shaped antapical ridge. The broadly U-shaped posterior sulcal plate expands bilaterally slightly or much distinctly beyond the two middle sulcal plates and covers the posterior half of the ventral median part of the hypotheca. Of the three species, $P$. deficiens exhibits some distinct peculiarities but has other characteristics suggestive of its correct allocation in this section.

\section{Peridinium sp.}

Fig. 9 (52)

P. conicum, in part, Вöнм, 1933.

The present species is so closely related to $P$. conicum that this has been often confounded with it, but extended morphological study of these two forms suggests the correctness of their separation.

The body is in ventral view pentagonal with convex sides and a distinct and narrow postero-median concavity, and in side view it is rhombic with horizontal or 
slightly diagonal girdle. The antapical horn is flattened bilaterally and broadly or acutely rounded but never pointed distally in side view. Its actual tip is always displaced much ventrally, so that the hind end of the body is in side view bluntly truncated in oblique direction.

Both of the conical epitheca and bifurcated hypotheca have in most cases distinctly concave sides, and the ventral area is much narrower than that of $P$. conicum. The concavity is weaker in broadly sutured specimens, and the distance between the tips of the two antapical horns appears to be subject to individual variation, due partly to the development of the sutural zones in and around the ventral area. The depth of the sulcal furrow is distinct, but is in inversed relation to wider opening of the furrow or larger distal divergence of the antapical horns. Consequently, the postmargin of the body is much more deeply convex in the specimen with less diverging horns or narrower sulcal furrow. On the other hand, the concavity of the furrow seems to be also associated with the shape of the antapical horn itself, judging from the facts that the broadly sutured specimen has the antapical horns more broadly rounded than those of the narrow sutured, and that these specimens with more rounded antapical horns generally have wider ventral area. With every possible combination of these variable characteristics, we can see many intermediate forms lying between a broadly sutured and swollen specimen with widely separated antapices, and a much angulate one with strongly convex sides and sharply differentiated antapical horns. The deeply impressed circular or slightly descending girdle is equatorial, and the cingular section which is horizontal or slightly tilts down ventrally, is broadly reniform or oval with ventral depression.

The apical trough has along its lateral and dorsal sides hyaline low lists which continues often further ventrally along the anterior margin of the lateral apical plate.

The antapical horn of this species differs from that of $P$. conicum in its rounded end in side view and its more flattened median wall. The large V-shaped antapical ridge and postsulcal area are nearly the same in both species in their structural relations. Though the structural relations of the ventral area of this species were described in a previous paragraph, a few words still remain here to be added. Each sulcal plate in this species differs in shape from corresponding one of $P$. conicum, though admitting some variabilities in each species. The left sulcal plate is more strongly elongated transversely in its posterior half in this species than in $P$. conicum, apparently in association with the deeper excavation of this part of the ventral area. The posterior sulcal plate in this species is more broadly and asymmetrically constricted into larger right and much smaller left lobes. Each of them has much narrower anterior end partly in accordance with the narrower postero-median end of the ventral postcingular plate, and the right lobe extends more anteriorly than the left one.

The distinctly serrated left sulcal list stands basally along the ventral margin of the left sulcal plate, and has subequal width throughout its major length. The right 
sulcal list is indistinct. There is another one, standing along the V-shaped antapical ridge, and this continues further ventrally and anteriorly along the antero-median margin of the antapical plate. This antapical list is fairly variable in width and furnished in most cases with marginal ribs but never with a single distinct spine at the tip of the antapical horn.

The plate pattern of both epitheca and hypotheca is much the same with that of $P$. conicum. But the present species can be separated from that in its much shorter pre- and postcingular plates. Except the ventral postcingular plates these two rows of plates cover respectively a basal or upper one-fourth or nearly so of the epitheca or of the hypotheca. They are mostly about twice as long as the width of the girdle in this species but much longer in $P$. conicum.

The epithecal plate pattern is fairly regular and symmetrical in arrangement both in the ventral and dorsal halves, and the six meridional collective sutures are fairly straight. An indistinct hyaline list is often seen standing along the collective suture, and it is usually broader in its anterior half. The ventral apical is broadly rhombic, and the dorsal apical is smaller in comparison to that of $P$. conicum. The mid-dorsal intercalary $2 \mathrm{a}$ is trapezium-like hexagonal but rarely pentagonal.

The postcingular row is subequal with or rather much smaller in width than the precingular, and the large subequal antapical plates cover by far the major part of the hypotheca. Between the ventral postcingulars, the left is longer but narrower than the right. This disparity in their posterior extension is answered by the inverse anterior extension of the two lateral lobes of the posterior sulcal plate.

The quadruplet of the ventral area is especially liable to split from its surroundings in a block or in company with the ventral postcingulars and the epithecal ventral three plates. It was on this species that the complete analysis of the ventral area. was carried out for the first time (Fig. 9-52). By pressing the separated block of plates, we can define the actual size, extension and inter-relations of the four sulcal plates. The sulcal members thus prepared are illustrated, and their detailed elucidations were given in previous paragraphs. Sometimes a slight pressure from above the cover glass for the purpose of splitting the theca along the girdle cause separation and subsequent loss of the sulcal quadruplet from the hypotheca. And the hypotheca thus obtained shows us very obviously the exact shape and extent of the large and deeply $V$-shaped postsulcla area extending along the ventro-median margin of the antapical plates.

The theca is covered with minute reticulations, and the polygonal meshes of the cingular plates are much larger than these of the ordinary plates.

Dimensions: Body length, 55-80 $\mu \mathrm{m}$. Transverse diameter, 62-92 $\mu \mathrm{m}$. Dorsoventral diameter, 55-82 $\mu \mathrm{m}$. Width of girdle, 5-6 $\mu \mathrm{m}$. Ratio in width of antapices to cingular section, $0.27-0.32$, in a extreme case, 0.18 .

Locality: Asamushi

Böнm (1933) distinguished 'two different phenotypes' in $P$. conicum taken from the Adriatic Sea, but did not elucidated them enough. Judging from his descriptions, 
they seem to differ in size of the body and relative width of the ventral apical plate. His calculations indicate that the relative breadth of the body is smaller in his smaller form. His distinction is not based on any structural relation worthy of consideration here, but his figures appear to indicate that he might have confused the present form with $P$. conicum. It seems highly probable that his Figure $3 \mathrm{~b}$ may be sure of this form, judging from its deeply excavated postmargin of the body coupled with rightward stronger expansion of its posterior sulcal plate. The present species can be distinguished from $P$. conicum by its smaller pre- and postcingular plates, stronger inflation of the body wall along the girdle, rounded antapical horns in side view and by the asymmetrical expansion of its smaller posterior sulcal plate. It was generally admitted that $P$. conicum is highly variable in the body shape and two seasonal forms have been distinguished. And the present and the next species appear to answer the two. But our morphological study revealed that this smaller form has some characteristics worthy of its specific separation.

SGFILler's $P$. conicum var. bilobata (=P. conicum $\mathrm{f}$. bilobaia MEUnIer) is apparently related to the smaller form in size of the body and also in its antapical cones standing side by side, but rather more closely to $P$. conicum judging from its elongated body, its larger precingulars and its pointed antapical cones.

\section{Peridinium conicum GRAN}

Fig. 55 (375-381)

Gran, 1902; Paulsen, 1908; Broch, 1910; Lebour, 1925; AbÉ, 1927; BöHm, 1933, in part.

P. conicum (GRAN) f. asamushi ABé, 1927.

P. divergens v. pyramidale KARSTEN, 1907.

This well-known species was first described by GRAN in 1900, and his figure 74 is accurate in the main in regard to its morphological features, while his description (1902) is very insufficient for the definition of this species, and the number of similar pentagonal species such as those described in this paper was added afterwards. Admitting some misinterpretations, BROCH (1910) gave a fairly extended and accurate definition of this species, and we intend to add here some other remarks on their thecal morphology especially of its ventral area.

The body is in ventral view pentagonal with flat or concave sides and a narrow and deep postero-median indentation. Between the two antapical horns which are convex conical, the left is a little smaller than the other deflected ventrally. They are pointed distally. The equatorial girdle has along its sides well-ribbed lists, and forms a descending spiral with a distinct proximal arch and distal displacement of 0.5-1 girdle width. The cingular section is reniform with a broad ventro-median depression and weakly tilts down ventrally. The sulcal furrow is narrow and distinct in its anterior narrower part but becomes indistinct in its posterior part especially in its peripheral or lateral regions. The bilateral parts of the posterior sulcal plate extend beyond the sulcal furrow covering the convex median sides of the antapical 

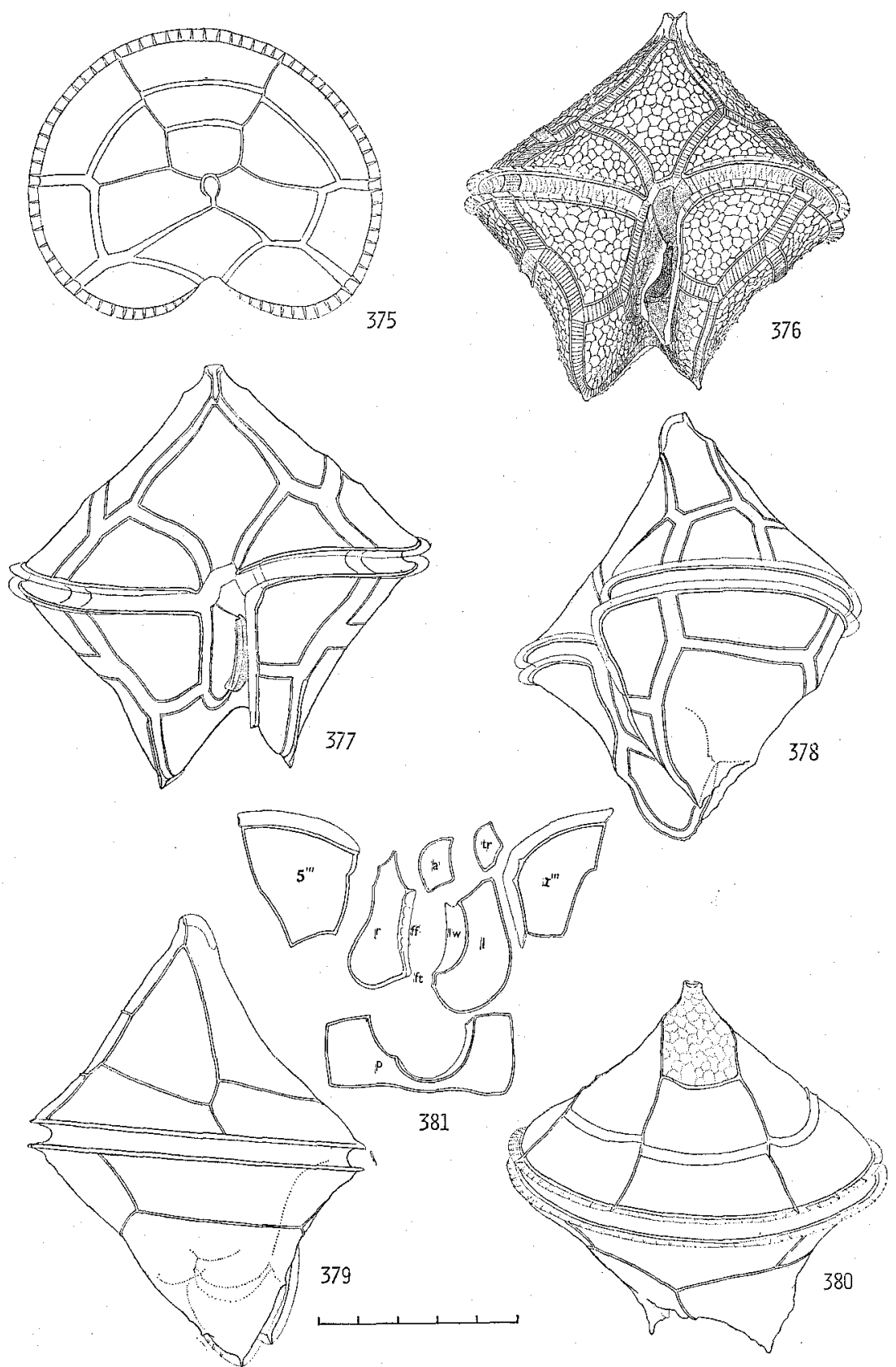

Fig. 55 (375-381): Peridinium conicum Gran. 375-Apical view. 376-Postero-ventral view of a broadly sutured specimen showing structural differentiation of ventral area. 377-Ventral view of another specimen. 378-Oblique postero-lateral view of the same, showing diagonal flaring of antapical horns. 379-Side view of a larger young specimen showing asymmetrical extension of antapical horns. 380-Antero-dorsal view of a different one. 381-Separated sulcal plates and ventral postcingulars. For the abbreviations, see the explanation to Figs. $9(51,52)$. lw-left wall of the flagellar pore. $\mathrm{ff}$-Flagellar fin. $\mathrm{ft}$-Flagellar trough. 
cones. This posterior sulcal plate, together with the post-sulcal area, is demarcated laterally and dorsally by the antapical ridge which bears a narrow and sometimes denticulated list with or without a stout rib at the pointed tip of the antapical cone. The left sulcal list is broader than the right sulcal one.

All the meridional collective sutures in the epitheca are fairly straight, and the lateral pair of them extends in such a direction as to divide the epitheca into subequal ventral and dorsal halves. Together with the bilateral intercalaries, the three lateral and ventral apicals are fairly large plates, and the small dorsal apical is tall pentagonal. The mid-dorsal intercalary is either trapezoidal or trapezium-like hexagonal, and very rarely it is divided into two (ABÉ, 1927). The dorsal three precingulars are subequal both in length and width covering lower one-fourth or more of the epitheca, while the other ventral four are larger in length but smaller in width covering lower one-third or more of the epitheca. The left ventral precingular 1 " is smaller than the right 7 ".

The right and left ventral postcingular plate differ in width in harmony with the two corresponding precingulars, extending similarly posteriorly to half-way between the girdle and antapex. The other three lateral and dorsal postcingulars cover the anterior one-third of the hypotheca.

The thecal wall of the ventral area was successfully analyzed often into its components as illustrated in Fig. 53 (381). The antero-median corner of the left postcingular plate where it borders on the small transitional plate is very oblique. The anterior sulcal plate is a little larger and obliquely fan-shaped. The right sulcal plate is broadest in its posterior part just in front of its hind end and bears along its median (dorsal) mragin a narrow flagellar fin, while the subequal J-shaped left sulcal plate lies more posteriorly than the right, deeply indenting the posterior sulcal plate. The flagellar trough is short and narrow, lying between the postero-median ends of these two plates. The posterior sulcal plate has a strikingly large ventral notch, by which it is differentiated into subequal two lateral lobes. This posterior sulcal plate is so conspicuous and can be seen so readily in ventral view of the body that not a single published figure failed to illustrate this plate, but no one has ever elucidated this correctly in his description. These two lobes expand similarly anteriorly or the left extends beyond the right only slightly. This bilateral asymmetry is more pronounced in these specimens with stronger proximal arch of the girdle or with broader sutural zone, and is correlated with the ventral deflection of the left antapical horn.

The V-shaped antapical ridge runs with its lateral arm diagonally across the horn, bearing a narrow list along its entire length, and its two arms lie along the lateral margin of the posterior sulcal plate, but its median portion lying between the tips of the antapical horns is displaced dorsally, passing diagonally across the ventro-median corner of the antapical plate, and thus forming there the post-sulcal area between this ridge and the posterior sulcal plate. This area may be regarded as a dorsal continuation of the ventral area or rather of the sulcal furrow. Contrary to this, the flagellar furrow is restricted only within the anterior narrower part of the ventral area and a median small portion of the posterior sulcal plate. 
It will be interesting to note here that in most cases the right-sulcal list is interrupted at shortly below the girdle, where the median margin of the right postcingular plate is slightly indented. A similar but more conspicuous structure can be seen invariably, according to our observations, at the corresponding place of all the species of the Pellucida group and some of other groups.

The thecal wall is covered with irregular and rather coarsely polygonal meshes with or without minute spines at the nodes. The same marking is also seen in the posterior and right sulcal plates, while the other two sulcal members and the transitional plate are left free from it. The cingular wall has a seemingly different kind of marking, which varies in different individuals. In any case, what can be seen in the cingular wall is a modified form of the ordinary marking.

Dimensions: Body length, 96-104 $\mu \mathrm{m}$. Transverse diameter, 84-90 $\mu \mathrm{m}$. Dorsoventral diameter, $66-80 \mu \mathrm{m}$. Width of girdle, 5-6 $\mu \mathrm{m}$. Ratio of distance between tips of antapical processes to body breadth, 0.32 .

Locality: Asamushi, Shimoda.

Gran's original figures, which were cited later by PAULSEN (1908) agree well with ours. But his as well BRoGH's and Borm's appears to differ from ours in their distinctly smaller precingular plates and smaller transverse diameter of the body at the girdle. Measurements indicate that the proportion of breadth to length of the body as well as the ratio in length of the ventral precingular plates and the epitheca increases in the following order; Broch's (0.8:0.25), BöHM's (0.83:0.29) and GRAN's (0.89:0.31). KARSTEN's variety pyramidale has a much broader body and agrees in this regard with our Shimoda form in which the two ratios are 1.0 and 0.3 respectively. Lebour's form is intermediate in regard to the relative breadth of the body (0.85) but has much elongated precingular plates $(0.44)$. We were not certain whether or not some of these published figures are so accurately drawn that the measurements on them are trustworthy. If we presume their figures to be accurate, we are forced to accept the conclusion that there may be two different forms in the Atlantic species, one with smaller and the other with much larger precingular plates, and that ou. Pacific form may be separated from either of them in its broader body and its moderately large precingulars. We could not see in Shimoda as well as in Asamushi a specimen corresponding to the Atlantic form. And that MARUKAwA's figures agree well with ours appears to support our suggestion that the Atlantic forms are absent or at least extremely rare in the seas around Japan.

\section{Peridinium deficiens MeunieR}

Figs. 56 (382-387)

Meunier, 1919; Woloszynska, 1928.

$P$. deficiens is a very rare and peculiarly pentagonal minute species, furnished with postmedian girdle, truncated conical hypotheca, and peculiarly shaped ventral apical plate. Afterwards, the species was described by Woloszysska, but it is 
doubtful whether or not her species is identical with our form because of its well developed antapical cones. The conical epitheca has flat or slightly concave sides and the diagonal apical trough. Its broad and deeply excavated girdle is strikingly post-equatorial and has well-ribbed narrow lists. It is circular for the most part,

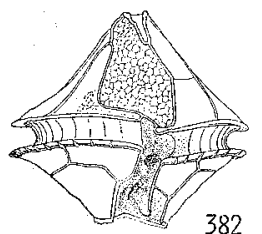

382

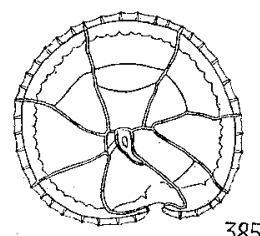

385
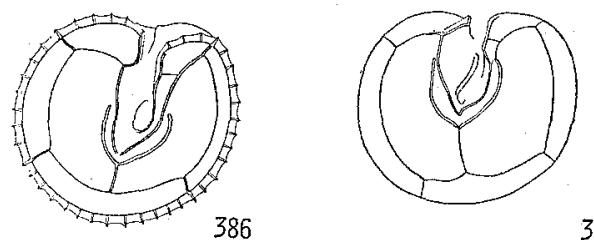

387

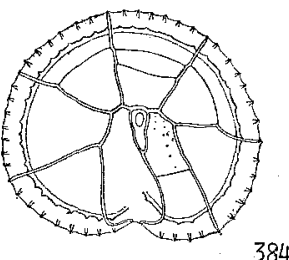

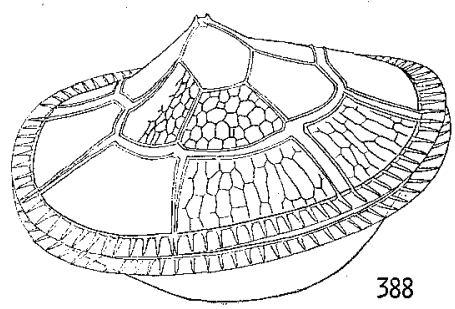
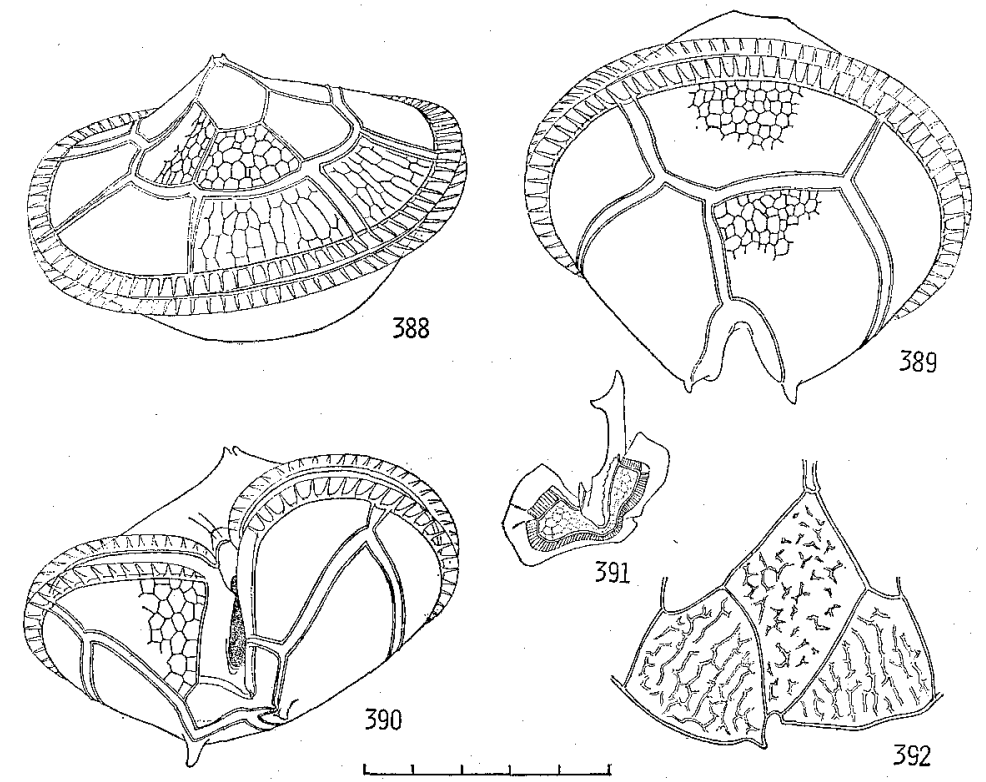

Fig. 56 (382-387): Peridinium dificiens Meunier. 382-Ventral view. 383-Side view showing depth of longitudinal furrow. 384-Apical view of a large specimen with narrow ventral apical plate. Bottom of cingular groove is illustrated. 385-Apical view of a smaller specimen with broader ventral apical plate and asymmetrical cingular section. Corrugated bottom of girdle is also illustrated. 386-Antapical view of a different one with much peculiar cingular section and large, symmetrical dorsal postcingular $3^{\prime \prime \prime} .387-$ Antapical view of another specimen with presumably ordinary cingular section.

(388-392): Peridinium obtusum (KARSTEN) FAurE-Fremiet (1). 388-Antero-dorsal view showing partially differentiated surface markings. 389-Postero-dorsal view. 390-Oblique postero-ventral view. 391---Isolated left sulcal and posterior sulcal plates. 392-Ventral three precingular plates of an isolated epitheca showing earlier developmental stage of surface marking. 
but forms by means of its weak proximal arch a slightly ascending spiral with distal displacement of 0.3 its own width. The hypotheca is about two-thirds in length of the epitheca and broadly truncated posteriorly, forming a large V-shaped antapical ridge.

The plate pattern is peculiar especially in the ventral half of its epitheca, owing partly to its strikingly reduced right apical plate or fusion of this with the ventral apical. There are, instead of six, eight meridional sutures extending from apex to girdle, and their distribution is characteristic. They are distinctly differentiated from the other shorter transverse ones and accompanied each with a distinct ridge. Except the left ventral one which extends directly from the distal end of the ventral slit of the apical pore to the girdle passing along the left of the ventral apical plate, the others converge anteriorly to form two bilateral groups, the left with three and the right with four branches (Fig. 56-834, 835). Of the eight meridional zones thus divided, three dorsal ones correspond in position and in their constituent plates with those of the other ordinary species, and the remaining five differ profoundly in their constitutions and in distribution of plates from the ordinary ventral three. Among them, the two ventro-lateral precingulars $\left(2^{\prime \prime}, 6^{\prime \prime}\right)$ and the right ventral precingular $\left(7^{\prime \prime}\right)$ form three distinct zones, and the other two zones include respectively two plates, one with the left apical and left ventral precingular plates, and the other with the ventral and right apicals.

The epitheca is, then, divided into eight meridional zones, one with three, four with two and three with a single plate, and only three of them extend anteriorly to the apical trough, the others terminating at different heights below the apex. And the transverse sutures in them are very indistinct, running mostly in horizontal direction. And that lying between the ventral and right apicals is oblique when it develops, but often these two plates fuse with each other completely. The arrangement and extent of these eight zones are highly variable, and two types are illustrated here in Fig. 56-384, 385. They are characterized by the facts that the dorsal three zones cover the dorsal half or a little less of the epitheca, that the left ventral zone has subequal width throughout its middle major portion and the others are also fairly characteristic in shape, that the apical trough lies between the ventral and left ventral zones and that the right and left ventral zones have respectively an extremely narrow median extension just above the girdle. On the other hand, they differ in the following points; the distance between every two divaricating points in the two lateral groups of sutures is subject to individual variation, the midventral zone is very variable not only in shape but also in size, and the median extensions of the two ventro-lateral zones are strikingly variable both in length and width.

The apical pore lies in the center of epitheca or slightly ventrally to it and has a narrow ventral slit, extending obliquely towards the left. The ventral apical plate is highly variable in shape and size and especially in its largest transdiameter just above the girdle. The anterior part of the ventral zone is wider (Fig. 56-384) or very narrow (Fig. 56-385), and complete fusion is effected often between its two component plates. The left apical plate covers the anterior half of the left ventral zone. 
The dorsal three precingular plates are fairly subequal in length and basal length, and occupy the lower one-third or more of that part of the epitheca. Of the three, the middle is a little smaller or contrary larger in length than the two laterals, and the middle intercalary plate is flat lens-shaped. Whether or not the dorso-lateral precingular plates touch the middle intercalary plate has been regarded generally as of taxonomic importance but has nothing to do in this species with the shape of the latter plate. The bilateral intercalaries are subequal in size or the left is a little smaller than the right. The dorsal apical is distinctly pentagonal. The precingulars $2^{\prime \prime}$ and $7 "$ are irregularly triangular of variable size, while the plate 6 " has a shortly truncated anterior end, all extending nearly to the apex.

It is impossible to establish the type of the ventral plate pattern of the epitheca in such specimens. But Fig. 56-385 affords us a matter with which we can draw a possible conclusion. Some careful and repeated examinations with high magnification revealed the facts that there are two very indistinct and oblique parallel lines passing across the anterior narrower part of the ventral zone, and that the ventral one of them consists of a very closely arranged double line, lying on the surface of the thecal wall, while the other dorsal one lies at a slightly deeper level, consisting of a more indistinct single line. This, together with the fact that marginal part of the ventral apical plate in other larger species was found extending below the margins of its adjacent plates, seems to support the interpretation that these ventral and dorsal lines correspond respectively to the upper and lower limits of the sutural cleft. If this suggestion is correct, the ventral one is to be taken into consideration in order to define the plate pattern of this portion. From this, it may be true that the right apical and right ventral precingular plates are contiguous with each other in this species. These structural relations led us to infer that the ventral plate pattern of this species is 'ortho' as in general in the present group.

The girdle has roughly corrugated wall (Figs. 56-382, 383). The cingular section is broadly ovoidal or reniform. And its bilateral halves are subequal or its left half is a little smaller and more acutely rounded than the other half.

The truncated conical hypotheca is deeply excavated in its ventral and posterior median portion, forming posteriorly the $\mathrm{V}$-shaped antapical ridge with a very narrow list along its entire length (Fig. 56-386, 387). The sulcal furrow is narrow just below the girdle and widens posteriorly so as to occupy the entire width of the truncated end. The ventral area, corresponding in extent in the main with this furrow, is very short and narrow in its post-cingular part where it is less in width than the girdle and expands laterally in its posterior half and extends dorsally beyond the center of hypotheca. The antapical ridge and the post-sulcal area lie around the dorsal margin of the ventral area. Both the ventral area and the antapical ridge are various to some extent in length, width and also in shape. The postmargin of body or the antapical ridge is fairly straight in side view, slightly tilting down ventrally, and does not form either the distinct median indentation nor the antapical horn. The postcingular row of plates covers mostly upper one-third or one-fourth of the hypo- 
theca. The pentagonal left ventral plate is a little larger, extending posteriorly to half-way between the girdle and the postmargin of body. The right ventral postcingular plate which is twice as large in transverse length as the left ventral, has a broader median half where it is subequal in length with the left ventral.

It was hardly possible to bring out exact structural relations of the ventral area owing to its small width and extraordinary depth. But we are sure of the fact that its structural feature is typical for the Conica group. This is clearly illustrated in Fig. 56-182 in which we can see the laterally expanded posterior sulcal plate deeply indented by the left sulcal plate.

The thecal wall is covered with fine polygonal meshes, and the same is true with the posterior sulcal plate. The cingular wall is corrugate as that of the Avellana Group.

Dimensions: Body length about, $42 \mu \mathrm{m}$. Transverse diameter, $44-50 \mu \mathrm{m}$. Dorsoventral diameter, $40-42 \mu \mathrm{m}$. Width of girdle, $5 \mu \mathrm{m}$. Ratio in width of antapex to cingular section, 2.1-2.25.

Locality: Asamushi

Meunier (1919) found $P$. deficiens on one occasion only in the Flemish coast, and LeBour (1925) suggested it as an abnormal one on the basis that there occurs apparent fusion of plate between the first and the fourth apicals. But as stated above, the present species displays a wide range of variation especially in its plate pattern of the epitheca. And the fusion of plate was suggested already by WoLoszYNSKA and is not rare in this group as described in other parts of this paper. So far as our observations are concerned, some variation occur more or less distinctly in every epitheca of this species, and yet the distribution or the manner of divarication of the meridional ridges is fairly constant in every case. In spite of these, its body shape and the structural relations of the hypotheca do not show marked variabilities. These facts appear to stand against LEBouR's opinion. But in this regard, we are very anxious to know about exact and detailed thecal morphology of $P$. inaequale Peters (not FAURÉ-Fremiet or LemMermanN) which is closely related in body shape to our present species. We have some reasons to believe that Peters' species may be divided into more than two different forms.

\section{Section 3. Pentagona n. sect.}

The present section is characterized mainly by wider opening of the sulcal furrow, complete differentiation of the posterior sulcal plate from the furrow, the highly adjusted plate pattern of the epitheca, or the usually huge posterior sulcal plate.

The body is in ventral view pentagonal with or without conical antapical horns and broad postmedian indentation. The cingular section of the body is reniform usually with but rarely without a broad and triangular ventral indentation brought forth by the ventral depression of the body, which expands anteriorly only slightly beyond the girdle and is confined mainly within the hypotheca where it is much wider 
than the sulcal furrow from which it can scarcely be differentiated and dies out laberally but can be traced to the antapical edge. The sulcal or rather flagellar furrow is, however, more or less sharply and distinctly differentiated from the depression and is confined in the anterior narrower part of the ventral cerea or only in its left half. The girdle is displaced distally 1-2.2 times of its width.

The plate pattern of the epitheca is highly adjusted. Of the four sulcal members, the posterior one expands symmetrically, covering the major or almost entire ventral breadth of the posterion half of the hypotheca. This posterior sulcal or posterior and right sulcal plates lying outside the flagellar furrow manifest structural flatures more of the general thecal wall than of the sulcal wall.

Dorso-ventral flattening of the body and bilateral asymmetry of the cingular section are associated partly with development of the ventral depression of the body and of the adjusted epithecal plate pattern and partly with the bilateral expansion of the posterior sulcal plate. As in $P$. deficiens of the former section, fusion of plates takes place also in $P$. expansa, one of the highest forms in this section.

$P$. pentagonum, $P$. bidentata, $P$. expansa, $P$. sinuosum and $P$. leonis are included in this section. It is not certain whether or not $P$. obtusum is to be included in this section. But the species certainly displays some characteristics suggesting its closest relationship with the species cited just above.

\section{Peridinium obtusum (KARSTEN) FAURÉ-Fremiet}

Figs. 56, 57 (388-397)

P. divergens v. obtusum KARSTEN, 1906.

P. okamurai MakukaWA, 1921, (not P. okamurai AвE, 1927).

P. marielebourae Paulsen, 1931.

Paulsen, 1931.

The present species may be found only sparsely in Mutsu Bay but abundantly not only in Shimoda Bay and its surrounding waters but also in the planktons collected from Misaki. This as well as MarukawA's description from a far southern station appears to indicate its fairly wide distribution in the seas around Japan.

When left undisturbed upon a flat surface, any specimen of this species takes, naturally, tilted postures such as illustrated in our Fig. 56-389, 390, or more often such as shown in Fig. 57-397. It is due to its distinctly oblique cingular plane, and this often leads us to a misinterpretation in regard to its body shape. Karsten's three figures (pl. 23, Fig. 12 a, b and c) correspond respectively in every respect exactly to our Figs. 56-389 and 57-396, 399. It appears to me highly probable that the "abgerundete stumpfe apikalseite" of KARsten's form, which PAULSEN emphasized in separating $P$. marielebourae from KARSTEN's, may be due to his misinterpretation. Another structural feature to be considered here is the longitudinal striations in the thecal plates, figured by FaURÉ-Fremiet and KARSTEN. In the figures given by them, distribution of these striations is not limited to the precingular plates, while 


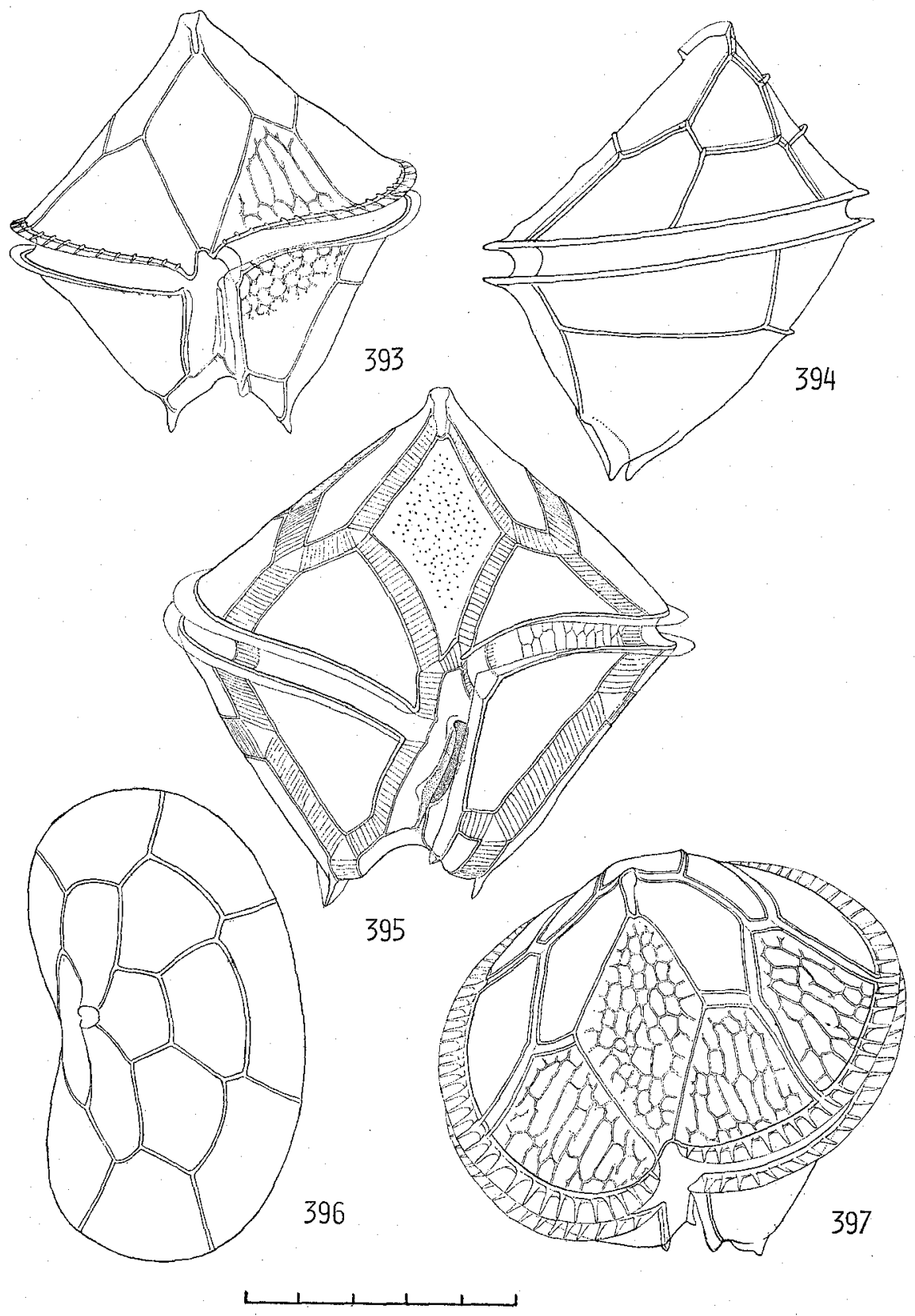

Fig. 57 (393-397): Peridinium obtusum (Karstev) FaurÉ-Fremiet (2). 393-Ventral view of a young specimen. 394-Side view of a larger one. 395-Ventral view of a megacytic form showing the distrigution of pores in ventral apical plate. 396-Dorsoapical view of another specimen. 397Ventro-apical view of a young specimen. 
such is the case with our form. We wonder if such a difference in the distribution of the striation does exist between the Atlantic and the Pacific forms. Assuming that such may be the actual condition, our Pacific form is so closely related to the Atlantic one in other points that they are in all probability identical with each other. Although it is quite certain that LEBour might have seen the present form, her figures differ apparently from these considered above and also from our form.

Marukawa described P. okamurai in Shinozima, Aichi Prefecture and characterized it giving its three figures, as follows; "Girdle is left handed, no antapical spine exists. Antapex is rounded. Surface is incompletely reticulated or covered with wavy lines. Body breadth is larger than its length. Body length is $97 \mu \mathrm{m}$, and its transverse diameter is $100 \mu \mathrm{m}$. This may be distinguished provisionary as a new species." But his Fig. $80 a$ corresponds exactly to Karsten's Fig. $12 b$ and also to our Fig. 57-395, suggesting the identity between his and the present form, in contradiction to his descriptions. This suggestion is supported by the facts that the longitudinal striation of his is distinctly limited to precingular plates as in our form, that the other two apical and antapical figures indicate that this form has also small and subequal three anterior intercalary plates, all subequal in size with its dorsal apical, and the small but distinctly expanded posterior sulcal plate corresponding to that of our present form in size and manner and extent of lateral expansion, and that his and our present forms are found in the same current.

To avoid further confusions which may arise as a result of insufficient definition of a given species, it will be best to give here a fuller account of our Pacific form.

The body in ventral view is pentagonal with four straight sides and a short and distinctly concave postmargin, and is in side view parallelogrammic. On either side of the postmargin lies a small antapical cone, furnished with a minute and solid distal spine. Ventral deflection of the left antapical cone is not distinct, and the two cones are subequal in size and in direction of extension. The cingular plane is distinctly tilts down ventrally $\left(\mathrm{ca} .30^{\circ}\right.$ ), and the girdle forms a slightly descending spiral, displaced distally about $1-2$ girdle widths.

The epitheca is distinctly conical with the pointed apex and longer ventral and shorter dorsal sides. The cingular plane is very oblique lying across the middle of the body, so that the apex lies on the dorsal of the center of epitheca, while the antapices are displaced in the opposite direction. The cingular section is broadly reniform with a deep ventral depression. The dorso-ventral diameter of the body appears to differ in different specimens. The girdle, which is deeply indented and guarded with broad and well-ribbed lists, forms a distinctly descending spiral with distal displacement of 1-2 girdle widths. The distal displacement varies according partly to the asymmetrical posterior extension of the two ventral precingulars, and partly to the development of the sutural zones, and is affected by the ventral deflection of the left antapical cone, which becomes stronger as the growth of the body goes on. Irregularity in the development of the sutural zone appears to introduce 
some characteristic distortions of the body. The proximal arch of the girdle, which is very weak in Fig. 57-393, is much stronger in Fig. 57-395, and in the latter figure, there is the second distal arch which is entirely absent or hardly perceptible in the former. The ventral portion of the hypotheca bulges out more distinctly on the left of the ventral area than on the right, bringing forth stronger anterior displacement of the proximal part of the girdle, and it is followed by the ventral deflection of the left antapical cone. Sinistro-anterior displacement of the four sulcal components in a block as a result of the irregular development of the sutural zones, which was elucidated in another paragraph of this paper, and seeming widening of the ventral area which results from the structural change just mentioned, may be related to the development of the median asymmetrical bulge.

The two antapical cones are subequal both in size and direction of extension, and the left of them is displaced more ventrally in broadly sutured specimens.

The ventral area is deeply excavated in its upper two-thirds where it has small and subequal breadth and guarded on either side with a narrow list. The elongated flagellar pore lies in its middle region. The left sulcal list has smooth or minutely serrated margin (Fig. 56-390,391). The right sulcal list is very indistinct (Figs. 55390, 56-395). The posterior part of the ventral area expands abruptly towards both sides, doubling its width, and extends dorsally beyond the antapices to the center of hypotheca. The sulcal furrow is deep and distinct in the anterior narrower part of the ventral area and less distinct in the posterior part where the posterior sulcal plate can not be distinguished from other general thecal plates by any special boundary. The plate is demarcated, on the contrary, from the left sulcal plate by a rigde or a list. The deeply $V$-shaped and small antapical ridge has, so far as our observation is concerned, no list except the antapical spine which is buttressed often with three to several narrow triangular wings or side-ridges which are decurrent basally along the wrinkled surface ridges of the general polygonal meshes of the antapical plate.

The plate pattern of the epitheca is in most cases symmetrical in arrangement, and the collective meridional sutures are very zigzag. All the transverse and longitudinal sutures are often furnished with distinct ridges or very narrow lists (Figs. 56-338, 57-394). Together with the three subequal intercalaries, the pentagonal dorsal apical is distinctly small. The elegantly rhombic ventral apical is fairly narrow. The dorsal three precingulars are subequal in width and in length, covering lower one-third or nearly so of that part of the epitheca, while the other four ventral ones of the same series are a little longer occupying the lower half. And the left ventral precingular is smaller than the right ventral one. The arrangement, shape and relative size of these plates are fairly constant, except the middle intercalary which is irregularly pentagonal in some (Fig. 57-396) but trapezium-like hexagonal in most cases (Fig. 56-388).

The ventral postcingulars are subequal in length, covering upper three-fourths of the hypotheca. They correspond in transverse length to the two ventral precingular or cingular plates. They lie more or less symmetrically bilaterally in younger forms, but the left ventral is displaced more anteriorly in older ones in accord with the stronger distal displacement of the girdle. The other postcingular plates are 
generally much shorter but becomes longer from ventral to dorsal.

The structural relations and the plate arrangement in the ventral area are typical of the group. Fig. 56 (391) is the posterior sulcal plate which has uneven surface and is isolated in combination with the left sulcal plate. In this figure is seen the posterior continuation of the flagellar wing standing along the right side of the flagellar trough, and a little broader one along the median margin of the left lobe of the posterior sulcal plate, the latter being the posterior continuation of the left sulcal list. The posterior sulcal plate is deeply constricted at the hind end of the left sulcal plate into a smaller left and a larger right lobe. The plate is surrounded with an inner narrower and a broader outer marginal zone. The transversely striated inner zone corresponds to the inner half of the sutural zone lying around this plate. The outer, much thinner lamella has subequal width throughout its length and is completely hyaline. This is the marginal addition of the plate expanding closely along the inner surface of marginal parts of the plates lying around this plate, and serves to bring them into closer connection. The inner and outer zones correspond to Peters' 'Zuwachsstrefen' and 'Falzstreifen' respectively. Further discussion on this structure was given in other papers.

The thecal wall is covered with coarsely polygonal meshes. The transitional plate and the anterior three components of the ventral area are left free from the marking, but in some cases the right sulcal plate has faint reticulation. The marking consists of distinct ridges with minute spines at the nodes (Fig. 57-393), and every thecal plate is crowded with minute pores (Fig. 57-393). There are two other kinds of the marking, covering respectively the precingular and the cingular plates. In younger individuals (Fig. 56-392), the major thecal plates are scattered with groups of three short ridges radiating from the center, while the precingular plates have many, longitudinally arranged zigzag ridges of various length, each with short lateral branches at the angles. The latter is apparently a modified form of the former, being arranged and connected longitudinally in groups. In later stages of growth, these, connecting the original points, are completed, thus forming uninterrupted polygonal meshes in the former and longitudinally elongated larger meshes of irregular size in the latter. And their arrangement corresponds, in the region just above the girdle, partly to that of the ribs in the cingular lists. The cingular wall has transverse subequidistant ridges, corresponding partly to the ribs in the list. The majority of them ramify or send out one or two short lateral branches to connect them laterally.

Dimensions: Body length, 80-97 $\mu \mathrm{m}$. Transverse diameter, 75-90 $\mu \mathrm{m}$. Dorsoventral diameter of cingular section, $68-80 \mu \mathrm{m}$. Width of girdle, $5-6 \mu \mathrm{m}$. Ratio of distance between two antapices to cingular transdiameter $0.26-0.30$. The smallest individual measured $70 \mu \mathrm{m}$ both in length and in transdiameter.

\section{Locality: Asamushi}

The author recorded in 1927 a form similar to $P$. steinii and designated it as $P$. okamurai, but this name had been proposed for this form in 1921 by MARUKawa. Accordingly, he proposes in this paper to change the specific name okamurai to gibberum. 


\section{Peridinium leonis PAVILLARD}

Fig. $58(398-404)$

Paulsen, 1931.

The present species is in ventral view tall pentagonal with a deeply excavated postmargin, and parallelogramic in side view in consequence of dorsoventral flattening of the body and also due to a remarkable obliquity of its cingular plane.

The epitheca is conical with shorter dorsal and longer ventral sides. The narrow and deeply excavated girdle lies around the middle of the body, forming a descending spiral, displaced distally 1.0-1.5 girdle widths. The cingular section is broadly rounded semicircular with a ventral flattening. The hind end of the hypotheca is strongly flattened in dorsoventral direction, partly in consequence of a strikingly lateral expansion of the sulcal furrow in that part, and forms there a broadly U-shaped antapical ridge. The hypotheca tapers posteriorly into two hollow antapical cones which, lying each on either end of the antapical ridge, taper distally each to a short and solid antapical spine. These two cones are subequal in size, and extend similarly posteriorly.

The plate pattern of the epitheca is symmetrical in arrangement, and the middorsal intercalary is trapezium-like hexagonal. The dorsal apical is small pentagonal, and the ventral apical is rhombic with symmetrical, premedian lateral angles. A smaller left and a little larger right apicals are narrow, extending posteriorly beyond the middle of the epitheca. The apical trough which is covered with a distinct platelet has an apical pore in its broader dorsal part, and the distal end of its narrower ventral portion is often truncated obliquely (Fig. 58-401). The three dorsal precingulars are subequal in transverse length, covering lower one-third or less of the epitheca of that part. But the other four of the same series extend anteriorly to halfway between the girdle and apex. The right ventral precingular is a little larger than the left ventral one, expanding in its median half posteriorly beyond the left. In the arrangements and relative sizes of the plates in the epitheca, this species is closely related to the preceding but differs from it in its less zigzag collective meridional sutures and smaller width of the ventro-lateral meridional zones (Fig. 58-398, 399). The three dorsal and lateral postcingulars, which are subequal both in length and in width, cover an upper one-third of the hypotheca. The right and left ventral postcingulars cover upper two-thirds or a little more of the ventral surface of the hypotheca.

The deeply impressed girdle has narrow lists which bear minute and indistinct marginal ribs. The pentagonal transitional plate lies half in the ventral area and half in the girdle, and the proximal end of the posterior cingular edge corresponding to this plate to very oblique as in the preceding species. The flageller furrow is limited to the narrower anterior two-thirds of the ventral area, and the sulcal lists are indistinct. The posterior part of this is much larger than that of $P$. obtusum, being four times as wide as the narrowest part of the anterior part, and occupies almost entire width of that part of the hypotheca. The sulcal furrow is not distinct in this part extending dorsally beyond the antapices and nearly to the center of 
hypotheca, forming the antapical ridge along its dorsal margin. This part of the ventral area is not differentiated from the general thecal surface by any marginal list nor by the surface marking.

Fig. 58-404 is the isolated ventral half of a hypotheca, and was flattened strongly under the cover glass in order to bring out the structural features of the narrower
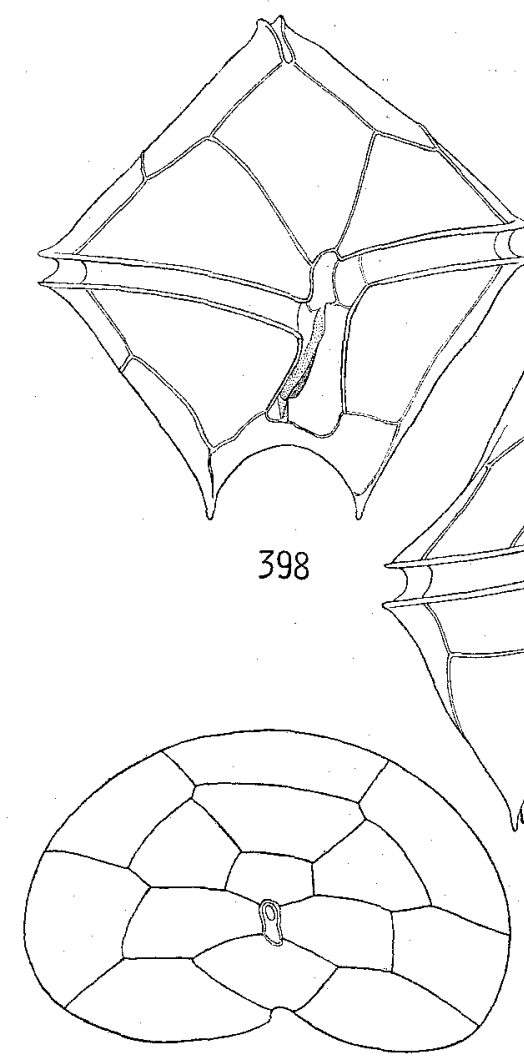

401

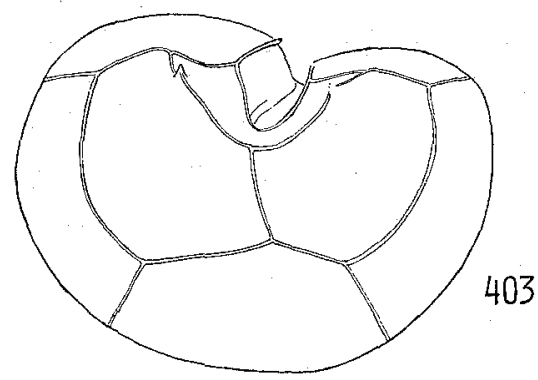

403

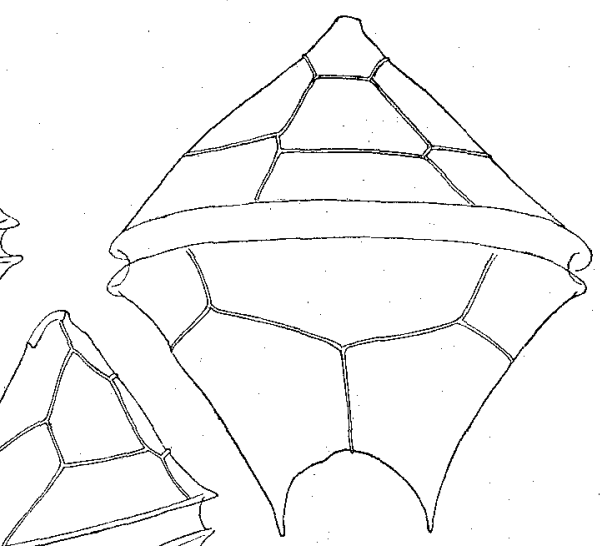

399

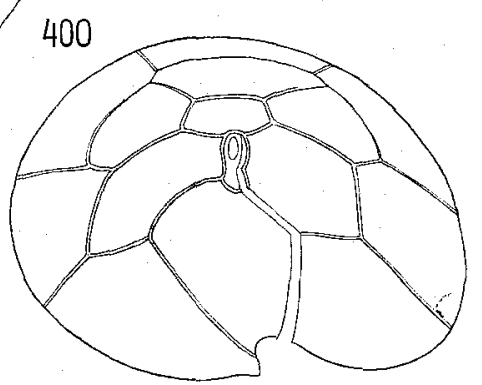

402

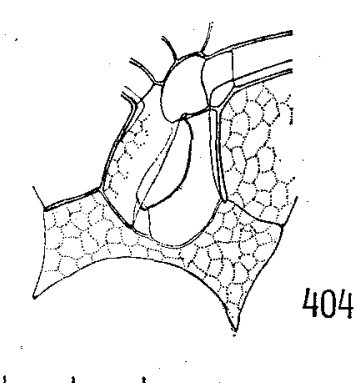

Fig. 58 (398-404): Peridinium leonis Pavildard. 398-Ventral view. 399-Dorsal view. 400-Side view. 401-Apical view. 402-Apical view of an isolated epitheca, partially disjoined. Apical pore plate is distinguished. 403-Antapical view. 404-Strongly flattened ventral part of a partially broken specimen. Longitudinal furrow is then strikingly widened. 
part of the ventral area, which are so clearly illustrated in the figure that there appears to be no need of further elucidation. The fan-shaped anterior sulcal plate in this species is very closely related in the shape and relations with its surroundings to that of pentagonum. On the other hand, the right and left sulcal plates exhibit some structural features suggestive rather of close relationships of this species with $P$. conicum or some other lower species of the present group. The posterior sulcal plate is broadly constricted into two subequal lobes which expand posterolaterally to the tip of the antapical cone. We have failed to see the post-sulcal area in this species, and the antapical spine has no side ridge or list.

The thecal wall is covered with rather coarsely polygonal meshes with minute spines at the nodes. And the same marking is found on the posterior sulcal plate and faintly along lateral margin of the right sulcal plate, while the anterior and left sulcal plates, together with the transitional plate, are left free from it.

Dimensions: Body length, $70-75 \mu \mathrm{m}$. Transverse diameter, 65-70 $\mu \mathrm{m}$. Dorsoventral diameter of cingular section, $50 \mu$. Width of girdle, 4-5.5 $\mu \mathrm{m}$. Ratio in width of antapices to cingular section, 0.3 .

Locality: Asamushi

Our present form is most closely related in body shape to leonis (PAULSEN 1931). On the other hand, it is not certain whether or not the species reported by Dangeard (1927, 1932), Lebour (1925), Sahiller (1929) and Paulsen (1931) are identical with one another, judging from their figures which differ from one another in some or in other points. They appear to agree only in the possession of oblique cingular plane, conical epitheda, descending girdle and two short and acutely pointed antapical cones each with a minute distal spine. Among them, Dangeard's (1932) and LEBOUR's species appear to be more or less closely related with each other, though Lebour's figure la suggests posterior extension of the longitudinal furrow to the deeply indented postmargin of the body, while Dangeard's Fig. 11 a exhibits a structure suggestive of leftward expansion of the posterior sulcal plate. But these figures are highly untrustworthy in regard to the structural differentiation of their ventral area, because those authors figured these parts of the body without laying much taxonomical significance upon them. DANGEARD's another figure (1927) is wholly obscured in regard to its ventral area and yet suggestive of some strong dorso-ventral flattening of the body and possession of the obliquely pentagonal middle intercalary plate and also of much larger postcingular plate. Paulsen's (1931) Fig. $41 \mathrm{~A}$ seems to be nearly or entirely identical with our species, judging from its plate pattern of both epitheca and hypotheca and the structural features of its antapical region.

\section{Peridinium pentagonum GRAN}

Figs. 59, 60 (405-413)

Gran, 1902; Paulsen, 1908; Meunier, 1919; Marukawa, 1921; Lebour, 1925; Conrad, W., 1926; KISSELEW, 1928. 
P. divergens, in part, BERGH, 1882.

P. conicum, in part, MarUKaWA, 1921.

Since GRAN's first segregation in 1902 of this large species from $P$. conicum, it has been recorded from various places by many observers, and yet its thecal morphology has never received any adequate and thorough study. And we know that we owe very largely to GRAN and also to MEUnIER, whose figures and descriptions are fairly accurate. And in essential, Gran's following diagnosis has stood but little additions to the present time. "Zell weniger symmetrisch als bei der vorrigen; Querfurche deutlich rechts drehend. Schalenansicht schief nierenformig, linke Zellhälfte schmaler und kleiner als die rechte, Gürtenansicht von vorne oder hinten fünfeckig, apikale Hälfte dreieckig mit fast geraden Seiten, abgestuzten spitze und breiter Basis, antapikale Hälfte trapeziformig. Antapikale Fortsätze sehr undeutlich, die zwei unteren (antapikalen) Ecken nur wenig hervortretend, in je eine kleine solide Spitze endigend. Die Längsfurche reicht nicht ganz bis zum unteren Ende der Zelle." In spite of Gran's brief description, it appears highly probable that he might saw its ventral groove extending posteriorly to the postmargin of the body. And in later time, Paulsen (1908) and Lebour (1925) have added scarcely any. Meunier (1919) gave a fuller and fairly accurate account about the general morphology of this species, which was cited by ConRaD (1926).

Fig. 59-405 is one of the smallest forms without distinct sutural zones, while Fig.

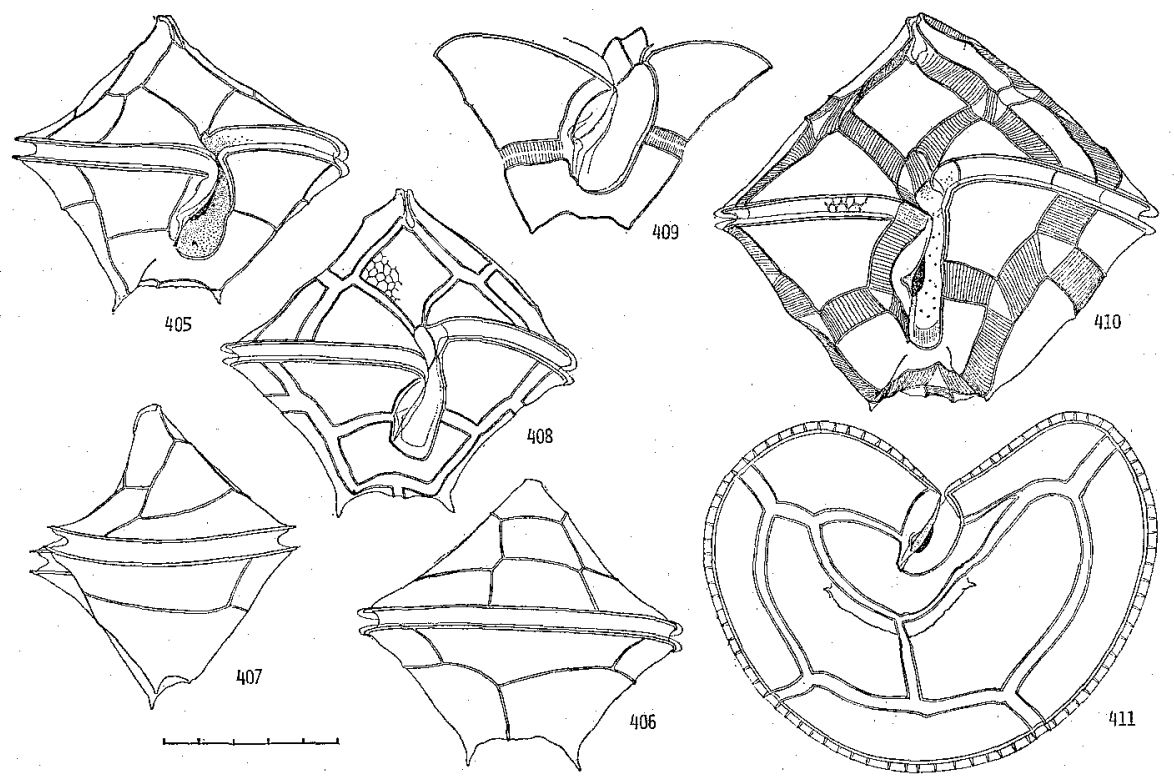

Fig. 59 (405-411): Peridinium pentagonum GRAN (1). 405-Ventral view of a young specimen. 406Dorsal view. 407 -Side view. 408--Ventral view of a larger specimen with broader sutural zones. 409-Isolated ventral part of hypotheca in another specimen of a more advanced stage. 410 Ventral view of an advanced megacytic specimen. 411-Antapical view of a huge specimen in a less advanced megacytic stage. 


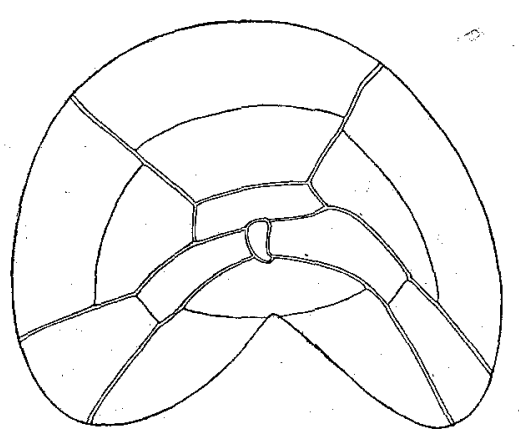

412

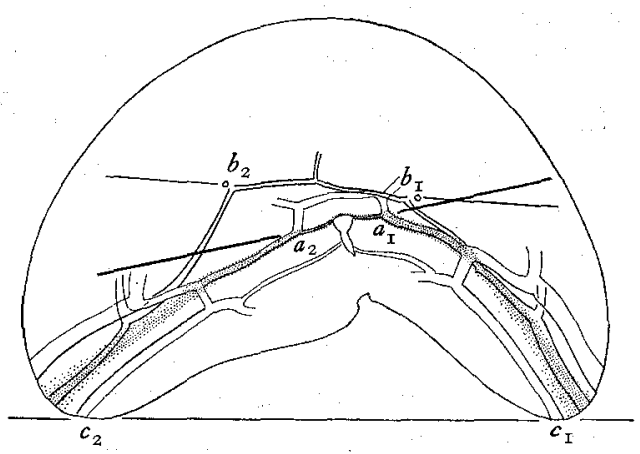

413

Fig. 60 (412-413): Peridinium pentagonum Gran (2). 412-Plate pattern of epitheca. 413-Bilateral circular ridge passing across the apex and the antapices, and torsion of body axis are ellustrated. The former structure is represented by dotted area in epitheca and by which double lines (sutural zone) in hypotheca.

59-410, 411 is of the largest, furnished with broad sutural zones, and Fig. 59-405 is intermediate in this regard. Careful comparison of them led us to point out the facts that both the epitheca and hypotheca are more concaved in the younger specimen than in the grown one and that the growth of the body brings forth more rapid increase in the length than in the breadth of the body. This latter fact may be established by measurement as the three specimens illustrated in Fig. 59-405, 408, 410 have each $0.88,0.91$ and 0.94 transverse diameter of body in length. A similar result was reported on $P$. conica by BöHm (1933, p. 309, table 2).

The body is broadly pentagonal in ventral view. Its postmargin is weakly convex, extending between the two minute antapical processes, and forms in antapical view a broadly expanded $V$-shaped ridge (Fig. 49-411). The antapical cones are subequal or the left one is a little smaller than the right, each tapering distally to a minute solid spine. There is, as stated by Meunier and Conrad, often but not always a slight median elevation of the ridge just at the hind end of the interantapical suture. It is split in broadly sutured specimens into two, each on either side of the sutural zone (Fig. 59-408, 410).

The distance between these antapices is about one-third $(0.3-0.27)$ of the transverse diameter of the body at the girdle, but the ratio appears to become smaller in broad sutured specimens. This may be elucidated when one consider the fact that increase of the transverse distance is represented by the width only of a single sutural zone while that of the transverse diameter of the body is affected by at least four ones.

The cingular section is distinctly reniform with a large triangular ventral depression. The characteristic difference between its bilateral halves was pointed out correctly by MEunier. Its left lobe is smaller both in length and in breadth than the other, and has a more acutely rounded ventro-lateral end. The ventral depression occupies the entire ventral surface of the body, extending from apex to postmargin, and in the bottom of which lies the flagellar furrow. In the epitheca, it covers the 
entire surface of its ventral three plates, bringing forth a more or less distinct sharp bending of the thecal wall along the very narrow ventro-lateral meridional zone as was described by MeunIER (Fig. 1). And in the hypotheca, the depression occupies by far the major part of the two ventral postcingulars and entire surface of the posterior sulcal plate (Fig. 59-411).

The girdle runs horizontally for the most part around the middle of the body and has a weak proximal arch, forming a distinctly descending spiral, displaced distally 1-2 girdle widths. It has deeply impressed wall and well ribbed side-list. Increase of this distal displacement goes parallel with growth of the sutural zones, as described in other parts of this paper.

In spite of the large size and common occurrence of this species, no one has ever paid special attention to the peculiar structural differentiation of its ventral area. The sulcal furrow is distinct and abrupt in the smaller antero-median part of the ventral area corresponding in the extent to the anterior and left sulcal plates, but indistinct and obscure in the median part of its broader posterior part or of the posterior sulcal plate. The plate is so distinctly expanded laterally that it occupies almost entire lower ventral half of the hypotheca. And its lateral portions lie outside the sulcal flagellar furrow and is hardly distinguished from the ventral postcingular or antapical plates by any structure such as list or abrupt folding of the thecal wall. On the contrary, this plate has along the suture between this and left sulcal plates a list along which the thecal wall is sharply folded forming anteriorly the flagellar furrow. Further, the right sulcal plate has no list nor sharp ridge along its lateral margin, adjacent to the right ventral postcingular plate, but is furnished along its left side with a broad list, flagellar fin, along which the thecal wall is so sharply folded that the flagellar pore is hidden mostly behind this plate. Thus, the sulcal feature in this species is seen only in the flagellar furrow, and this is strongly compressed bilaterally at the distal end of the girdle, where it bends in <-shaped, and from where it widens posteriorly. The flagellar furrow is, then, distinctly differentiated from its surroundings and has a distinct left sulcal list and a much broader flagellar fin along its lateral edges, extending posteriorly nearly to the postmargin of the body, and occupies anterior $0.77-78$ of the ventral median part of the hypotheca.

The ventral end of the apical trough is often obliquely truncated. The plate pattern of the epitheca of this species illustrated by GRAN (1902) and LEBour (1925) is accurate in the main, although it slightly differs between the two authors. And that of our specimens is illustrated in Fig. 59-408. One of the most strikingly characteristic features of this is the dorso-ventral compression of the ventro-lateral meridional zones, which was clearly figured by Gran but has not been adequately studied by him and other authors. The author has never seen such a plate pattern of this species as illustrated by LeBour, in which these two zones expand distally as in these of some lower forms of this group.

Together with the next species, the present species displays a typically adjusted plate pattern in the epitheca (Fig. 60-412). Subdivision of the epitheca is very characteristic but irregular. The three dorsal meridional zones cover more than the dorsal 
half of the epitheca, while either of the ventro-lateral meridional zones is very narrow and does not widen much towards the girdle. Among the six zones, the triangular ventral one is the largest in basal length, occupying the entire breadth of the ventral depression of the body. The left dorsal one widens much distinctly ventrally, compared with the right dorsal zone. Correlated with this, the left lateral collective suture bends ventrally in its anterior portion more strongly than the right ventral one. Partly associated with this asymmetry, the left ventral meridional zone has subequal small width throughout its length bending distinctly in its anterior portion, but the right ventral one is less curved and widens distally in its lower half. The width of these ventro-lateral zones at the apical-precingular suture is subequal with the length of the apical trough, but the lower end of the right-hand zone is larger while that of the left-hand zone is decidedly smaller than a double width of the former. It may be interesting in this regard to note here that the asymmetry in the distal widening of the zones, which is fairly distinct in this species, can be seen in $P$. leonis though less distinctly. The dorsal pair of the meridional collective sutures is fairly straight except a sharp bending at the apical-intercalary suture.

These irregularities and peculiarities in these ventro-lateral meridional zones are seen not only in our specimens collected from Asamushi, Shimoda and the Inland sea, but also illustrated more or less apparently in Gran's original figure and also in Marukawa's Fig. 73e which was drawn from a specimen collected from the Japan Sea. From these, the structural features considered above are to be regarded as universal occurrence in this species, and the Atlantic and our Pacific forms are to be comprised in a single, well-unified species.

In the hypotheca, the meridional and transverse sutures are not so well differentiated as in the epitheca. But the meridional ones lying along the lateral margins of the ventral postcingular and posterior sulcal plates are fairly straight extending from girdle to antapices. These collective sutures of the hypotheca, postmargin of the body and ventro-lateral meridional zones of the epitheca encompass the ventral depression of the body.

The rhombic ventral apical plate is longer than wide and has four subequal sides. The lateral apical plates are elongated, extending posteriorly to half way between apex and girdle. The dorsal apical is broadly pentagonal and much larger in comparison to that of $P$. sinuosum. The left ventral precingular plate is a little smaller than the right ventral precingular which extends more posteriorly than the left in accord with the distal displacement of the girdle. All the three dorso-lateral and middorsal precingulars cover lower one-third of that part of the epitheca. Among them, the left dorsal $3^{\prime \prime}$ is the largest and the right dorsal $5^{\prime \prime}$ the smallest in basal length. The middorsal intercalary is in most cases to be regarded as hexagonal because of its bordering posteriorly on the dorsal three precingular plates. But practically it is trapezoidal or nearly so owing to the fairly straight extension of the dorsal pair of the collective meridional sutures (Fig. 60-412). But there are some variations, in which the plate is irregularly pentagonal, bordering posteriorly only on two plates and the collective sutures are fairly zigzag. 
The left ventral postcingular plate which is smaller in width but larger in length than the right ventral, covers the upper left half of the ventral surface of the hypotheca, while the right ventral one extends posteriorly beyond halfway between girdle and right antapex. The postmargins of these two plates are slightly oblique lying similarly, or the left is slightly anterior than the right. The posterior sulcal plate is deeply constricted into two lateral lobes, of which the smaller left expands more anteriorly while the larger right more towards the right. These three plates cover by far the major but not entire ventral width of the hypotheca (Fig. 59-409, 411). The ventral pairs of the cingular, pre- and postcingular plates agree generally in this genus with one another in their lateral extremities, but disagreement occurs exceptionally in this and the next species. The ventral postcingular and cingular plates expand laterally beyond the ventral precingular plates, and further to the middle of its adjacent one. The lateral and dorsal postcingulars cover upper one-fourth to one-third of the hypotheca, and the former is in its ventral end about one half as long as the ventral postcingular plate.

The inner structural details of the flageller furrow was hardly possible to work out, and a part of it was illustrated in Fig. 59-409 which is an isolated ventral half of the hypotheca. The posterior sulcal plate was illustrated, however, invariably in every published figure without adequate elucidation and sometimes even with some mistakes. Its extent was already accurately illustrated by GRAN, but it is thought that he misinterpreted the natural features of this plate because this area in his figure is divided into two by a median longitudinal suture, suggesting as if they were ventral continuations of the two antapical plates. That of LeBour's figure 1 $a$ (pl. XX), on the other hand, is too small for the present species if we have to presume it as accurately drawn. Her figures show another disagreement with our Pacific species because all the lateral and dorsal postcingular plates of her species are much larger than those of ours. These differences, we believe, may be due to their misinterpretation and not due to the actual existence of such inconsistencies between the Atlantic and Pacific forms.

The postmargin of the body is much flattened dorsoventrally owing partly to the distinct ventral depression of the body and partly to the strikingly lateral expansion of the posterior sulcal plate. The antapical ridge is broadly expanded Vshaped, and the similarly shaped post-sulcal area has subequal width throughout its entire length. The dorsal margin of the post-sulcal area corresponds with the antapical ridge and consists of thickened short ridges of the surface polygonal meshes arranged end to end.

The thecal wall is covered with coarse and irregular polygonal meshes with nodal minute spines. The posterior sulcal plate can not be distinguished from the general thecal plates by its surface marking, and the right sulcal plate has a faint one in its lateral half. The left and anterior sulcal plates, together with the transitional plate, are free from the marking. Among them, the left one is porulate sparsely all over its surface, while the anterior and transitional plates have crowded pores 
in the anterior and middle parts respectively.

Dimensions: Body length, 75-80-110 $\mu \mathrm{m}$. Transverse diameter, 85-115-127 $\mu \mathrm{m}$ Dorso-ventral diameter, 52-56-80 $\mu \mathrm{m}$. Girdle width, 4-5 $\mu \mathrm{m}$. Ratio in width of antapex to cingular section, $0.32(0.27-0.34)$.

Locality: Asamushi, Shimoda, the Inland Sea and the Japan Sea.

\section{Peridinium bidentatum n. sp.}

Fig. 61 (414-418)

This minute pentagonal species appears to resemble $P$. leonis, but its plate pattern in the epitheca and the structural relations of its ventral area exhibit much closer relationships to $P$. pentagonum.

The body is in side view parallelogrammic and in ventral view pentagonal with broadly and deeply concave postmargin. There is at either end of the antapical ridge a conical antapical cone which tapers distally to a pointed end provided with

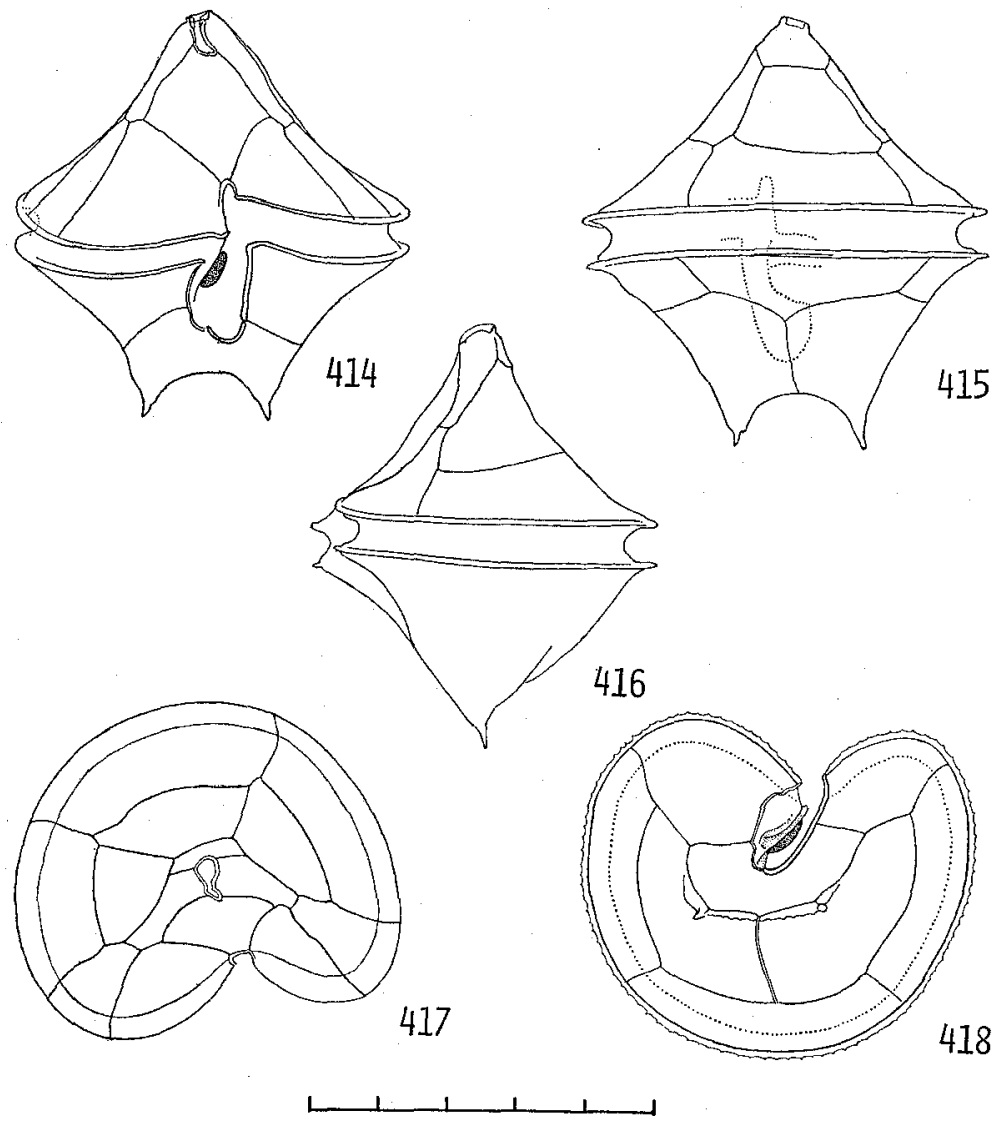

Fig. 61 (414-418): Peridinium bidentatum n. sp. 414-Ventral view. 415-Dorsal view. 416-Side view. 417-Apical view. 481-Antapical view. 
a minute solid spine. Both the epitheca and hypotheca have slightly concave sides. The relatively wide and deeply impressed girdle has narrow and minutely denticulated lists, and runs horizontally across the middle of the body, forming a descending spiral with distal displacement of its own width. The narrow and small flagellar furrow extends posteriorly beyond half-way between the girdle and postmargin of body.

The ventral depression of the body is distinct but less than that of $P$. pentagonum. Consequently, the cingular section is more broadly reniform, and its left half is smaller than the other. The antapical ridge is nearly straight in antapical view.

The meridional subdivision of the epitheca is fairly distinct, but the meridional sutures are not differentiated from the transverse ones. The subdivisoin is the same in the main with that of $P$. pentagonum, but it is characterized in this species by the facts that the sutures in the epitheca undulate, that the collective meridional ones are slightly zigzag and that the two ventro-lateral meridional zones are narrowest in their middle point and expand similarly towards the girdle. In the hypotheca, the ventral postcingular plate expands more distinctly laterally in this species than in $P$. pentagonum. In these regards the present species is intermediate between $P$. pentagonum and $P$. sinuosum.

The plate pattern of the epitheca is very similar to that of $P$. pentagonum, but exhibits slight differences. The ventral apical is longer than wide. The lateral apicals are elongated obliquely ventrally. They are subequal in size and the left of them is a little broader in its anterior part than the right one. The dorsal apical is broadly pentagonal. The left ventral precingular plate is much smaller than the right ventral which extends much posteriorly beyond the left. The distinctly elongated ventro-lateral precingulars are subequal in their size and shape. Their basal margin is about four times as long as their upper margin. Among the other three precingulras, the dorsal $4 "$ is the largest in basal length and displaced a little towards the right. And the left dorsal precingular is a little broader than the right dorsal. The middle intercalary is irregularly pentagonal, bordering posteriorly on the two precingulars $4^{\prime \prime}$ and $5^{\prime \prime}$. This plate may be presumably variable in shape as in the corresponding plate of $P$. pentagonum.

The hypotheca is characterized by the bilateral extension of its antapical ridge. This structure appears to be related apparently to the almost complete disappearance of the sulcal furrow from the posterior sulcal plate.

The large posterior sulcal plate occupies entire breadth of lower two-fifths or more of the ventral surface of the hypotheca, and its lateral anterior margins are distinctly oblique. The post-sulcal area is very narrow, extending transversely between the two antapices, and is demarcated dorsally by the antapical ridge which runs parallel to the post-margin of the posterior sulcal plate.

The thecal surface is covered with fine polygonal meshes, and the posterior sulcal plate also has the same marking.

Dimensions: Body length, $60 \mu \mathrm{m}$. Transverse diameter, $56 \mu \mathrm{m}$. Dorso-ventral diameter, $48 \mu \mathrm{m}$.

Locality: Asamushi 
The present species is related to $P$. leonis in its body shape and its sharply pointed antapical cone standing on either end of its deeply concave post-margin, but the differences in the plate pattern and in the structural relations of their ventral area serve in practice to separate them. From all the allied species of $P$. pentagonum, this may be separated in its smaller size and deeply excavated post-margin.

\section{Peridinium expansum n. sp.}

Fig. $62(419-422)$

There is a group of small pentagonal species, more or less closely allied to $P$. sinuosum and scattered very sparsely throughout all oceans. They are much smaller than that species, to which they are so closely related in the structural features of their ventral area and in the plate pattern of the epitheca that they might have been confounded with $P$. pentagonum or $P$. sinuosum, or more probably have been regarded as varieties or formae of them. Their thecal wall is generally thin and often exhibits some abnormalities such as fusion of plates. P. latissimum Koford, $P$. pentagonum $\mathrm{f}$. depressum AвÉ and the previous species, P. bidentatum belong to this group. And we saw in Asamushi two different forms which agree with each other in their thecal morphology, but they are known only very incompletely because of extreme scarcity of the materials.

One of the two is illustrated in Fig. 62-419, 421. The body is tall pentagonal with straight sides and a short and straight postmargin. The antapical cones are subequal or the left is a little smaller than the right, each tapering distally to a small solid spine. Its relatively wide girdle runs horizontally for the most part around the middle of the body and forms a descending spiral furnished with well-ribbed lists. Shape of its cingular section is nearly the same with that of the next form (Fig. 62-422). The large and distinct ventral depression is larger and deeper than that of $P$. pentagonum but less than that of $P$. sinuosum. The plate pattern of the epitheca is well 'adjusted' but not so distinctly as in $P$. sinuosum, and rather closely related to that of $P$. bidentatum. Its ventrolateral meridional zones are narrow and very similar to these of $P$. pentagonum. The dorsal apical is broadly pentagonal, and the middorsal meridional zone is displaced a little towards the right. The ventral apical is rhombic tapering more anteriorly than posteriorly. The dorsal three precingulars are subequal in length and cover lower one-third or less of that part of the epitheca. The middle intercalary $2 \mathrm{a}$ is trapezoidal.

The posterior sulcal plate covers the entire width of the posterior ventral half of the hypotheca. Similarly the two ventral postcingulars cover, together with the sulcal plates, entire width of the anterior half (Fig. 62-419). The lateral and dorsal postcingular plates cover anterior one-third or one-fourth of the hypotheca. The flagellar furrow is wide and resembles in shape and relative size that of the previous species. It seems curious that we could not see the right sulcal plate in this form. But this does not mean, we believe, absence of this plate in this species. The 
antapical ridge is straight or weakly undulate.

The thecal wall is covered with coarse polygonal meshes which are also seen in the large posterior sulcal plate. The left and anterior sulcal and transitional plates are left free from the marking. The cingular wall is also reticulated.

Dimensions: Body length, $65 \mu \mathrm{m}$. Transverse diameter, $70 \mu \mathrm{m}$. Ratio in width of antapicse to cingular section, 0.26 .

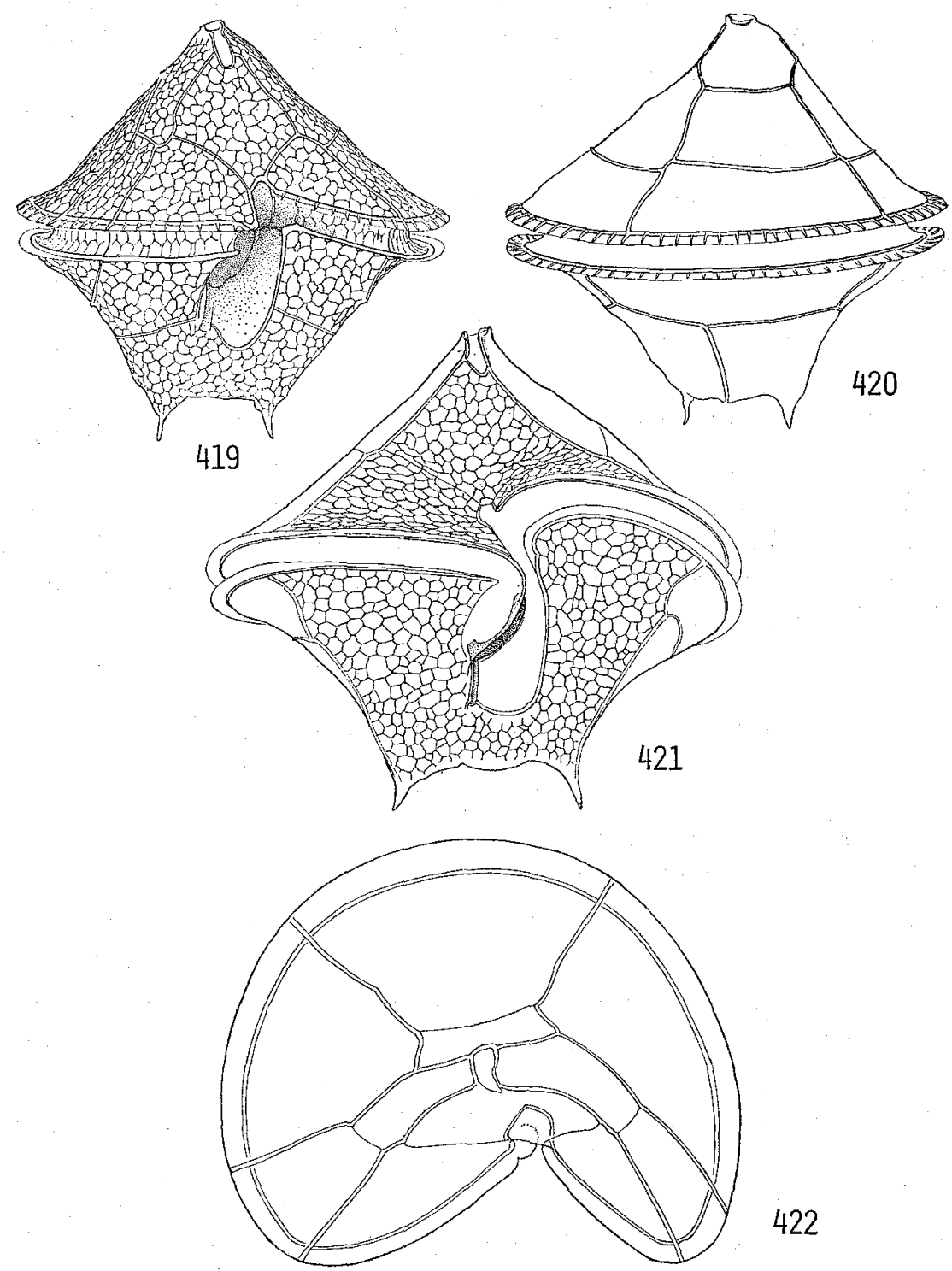

Fig. 62 (419-422): Peridinium expansum n. sp. 419-Ventral view. 420-Dorsal view. 421-Ventral view of presumably a different form. Surface marking is drawn only on ventral parts. 422Apical view of the same. 
There is a slightly larger form, more closely related to the previous form than to $P$. pentagonum in regard to the size and shape of the body, the plate pattern or the meridional subdivision both of the epi- and hypothecae, and also in the structural relations of the ventral area (Fig. 62-421).

Peculiar is the fact that in this form fusion of plates is seen in both of the epitheca and hypotheca. This peculiarity may be regarded as a result of extreme, structural differentiation between the collective meridional and transverse sutures, generally seen in the present group. In the epitheca, the three dorsal precingular plates fuse each with one of the three intercalary plates lying just above them (Fig. 62-422). And in the hypotheca, the fusion takes place in its ventral half between the posterior sulcal plate and two ventral postcingular plates. In order to clear the doubt whether or not they are actually fused, we examined with oil immersion lens the place where the suture is to be seen normally. But the effort was fruitless.

Dimensions: Body length, $75 \mu \mathrm{m}$. Transverse diameter, $85 \mu \mathrm{m}$. Dorso-ventral diameter, $55 \mu \mathrm{m}$. Ratio in width of antapices to cingular section, $0.35 \mu \mathrm{m}$.

Locality: Asamushi

The smaller form of this species is most closely related to $P$. sinuosum in general morphological features but is separated from that in its smaller size and much smaller transverse diameter. On the other hand, the larger one is related partly to $P$. sinuosum but more distinctly to $P$. pentagonum in regard to the shape of the antapical ridge. And further, the smaller and larger forms are distinguished from eath other only in the size of the body and the shape of the antapical ridge, resembling so much in other structural features that it seems to be highly advisable to distinguish them collectively from either $P$. pentagonum or $P$. sinuosum.

\section{Peridinium sinuosum (LEMMERMANN) JÖRGENSEN}

Figs. 63-65 (423-440)

$P$. divergens var. sinuosum Lemmermann, 1899.

P. divergens var. pentagonum KARSTEN, 1909.

This huge and broadly pentagonal species has concave sides, two widely separated, small antapical processes each at either end of a fairly straight and large postmargin of the body, and the equatorial girdle which forms a descending spiral by means of its proximal arch. The length of the body and the distance between the two antapices are respectively 0.7 and 0.3 of the transverse diameter of the body at the girdle. The cingular section is large and flattened hemicircular with broadly triangular ventral depression which is so large and characteristic that it covers almost entire ventral surface of the body, and in addition the greatest depth of the depression lies just on the left of the median dorso-ventral plane of the body. In relation to these structural differentiations, the left lobe of the cingular section is shorter and narrower than the other half. The two lobes decrease their width distally, and the distal end is more acutely rounded in the left than in the right. The 


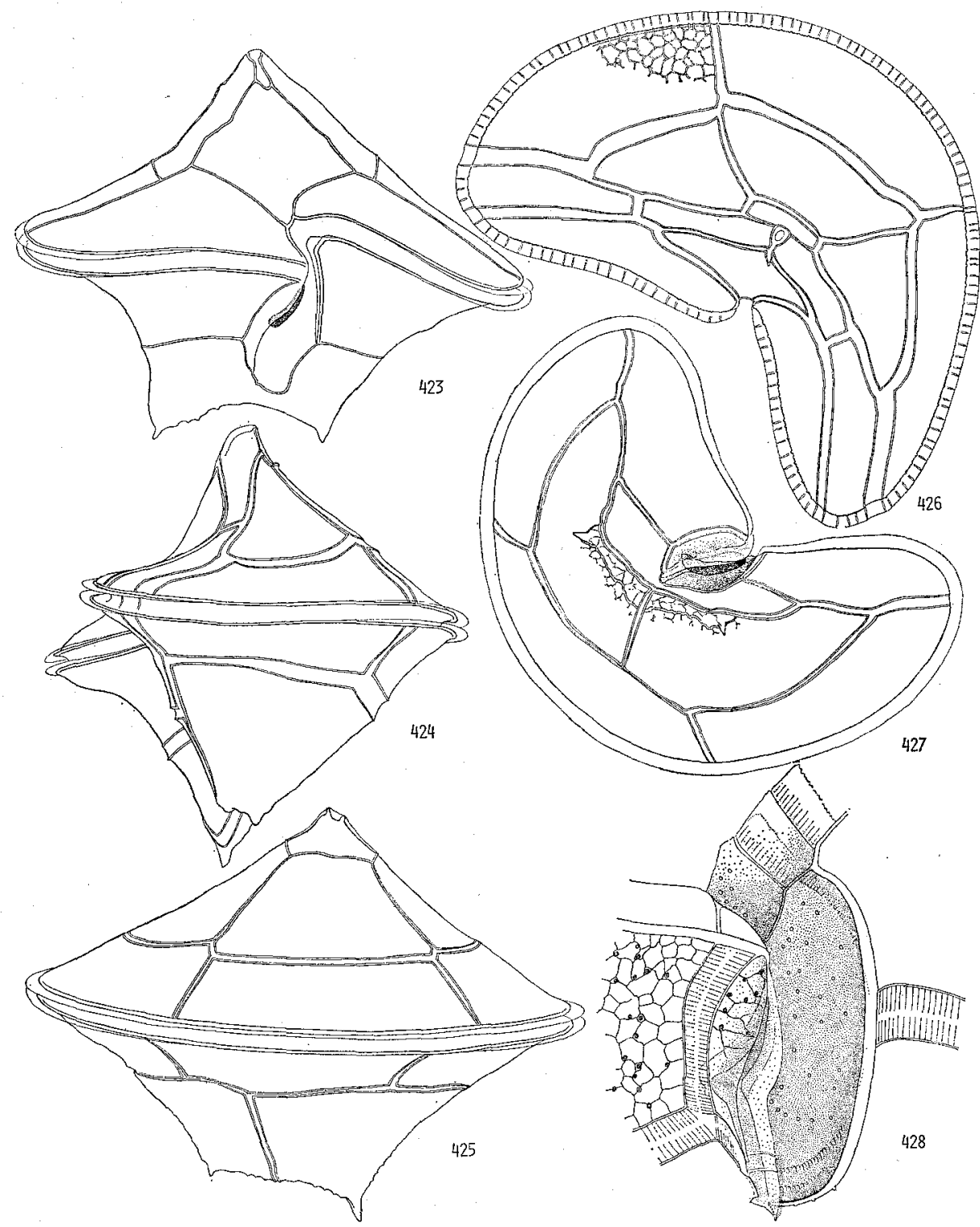

Fig. 63 (423-428): Peridinium sinuosum (Lemm.) Jörgensen (1). 423-Ventral view of a young specimen. 424-Dorsal view of somewhat grown specimen. 425-Side view. 426-Apical view of another specimen. 427-Antapical view of a smaller one showing post-sulcal area. 428-Midventral part of hypotheca drawn with higher magnification, considerably pressed.

greatest dorso-ventral diameter of the body at the girdle is in its median region just on the right of the flagellar furrow. This sturcture appears to be associated with an asymmetrical ventral inflation of the body wall on either side of the furrow (Fig. 63-426). 
The epitheca is in ventral view low conical with more or less concave sides. The concavity is stronger ventrally than dorsally and in the right than in the other half. The apex leans then slightly to the right. Further this inclination appears to be strengthened by a slight rightward displacement of the apex (Fig. 63-423, 425).

The girdle runs horizontally for the most part and has a weak distal and a stronger proximal arch, by means of which it forms a descending spiral, displaced distally 1.5-2 its widths. It is decply impressed, and the cingular lists bear subequidistant marginal ribs.

The hypotheca is reversed trapezoidal with distinctly concave sides and a long postmargin. In association with the extraordinary bilateral expansion of the posterior sulcal plate, the posterior half of the hypotheca is so strongly flattened dorsoventrally that the postmargin of the body forms an almost straight transverse ridge. On either end of this is a more or less prominent process or rather a small swelling of the body wall-with a well-differentiated, short and solid distal spine. The left swelling is usually smaller than the right, and often so much reduced in size that there is hardly any perceptible swelling there.

In consequence of the peculiar flattening of the body and an unparalleled development of the dorsal epithecal plates, the plate pattern of the epitheca is very characteristic, and the ventral two pairs of the meridional collective sutures run fairly straightly (Fig. 63-426). The ventral meridional zone agrees in extent with the ventral depression in the epitheca. Together with the middorsal one, the two dorsolateral meridional zones cover more than the dorsal half of the epitheca. Then, the ventro-lateral zone is much reduced in breadth, lying along antero-lateral border of the ventral depression of the body in the epitheca, and is in apical view very narrow in its anterior two-thirds but a little wider in its lower portion. The left ventral zone curves a little in its anterior portion, while the right ventral is fairly straight. They are subequal in width and in distal expansion.

The short and narrow apical trough is sharply differentiated into an expanded dorsal and a narrow ventral part, and its ventral end is truncated or more often deflected obliquely towards the left.

The rhombic ventral apical plate is about 0.3 transverse diameter of the body in breadth and is truncated obliquely in its posterior end. The left ventral precingular is smaller than the right ventral which expands posteriorly much beyond the other. The broadly pentagonal dorsal apical is very small, and the dorso-median collective sutures have a sharp bend at the postero-lateral corner of this plate. The middorsal intercalary plate is trapezoidal hexagon in shape as it has on either side a short and obliquely truncated posterior corner with which it borders on the dorso-lateral precingular $3^{\prime \prime}$ or $5^{\prime \prime}$. The dorsal precingular is regularly trapezoidal. The left dorsal precingular $3^{\prime \prime}$ is larger in basal length than the right dorsal of the same series, both expanding more ventrally than dorsally. And these three precingulars cover the lower one-third or a little more of the epitheca. The narrow lateral apical has a subequal. width throughout its length, hardly exceeding the length of the apical trough, and it is shorter than the right apical. The ventro-lateral pre- 
cingular plate, which covers the lower half of the zone, is larger in length and width than the lateral apical, and has a subequal width in its lower two-thirds where it is twice as broad as its anterior end. Its lower end lies just at the acutely rounded distal end of the lateral lobe of the cingular section.

In the hypotheca, the plates may be separated into a ventral and a dorsal group, one bordering on the other along the postmargin of the body and also along the ventro-lateral meridional ridges of the body wall extending from antapices to girdle. The left ventral postcingular plate is longer but narrower than the right ventral, and they cover the upper ventral half of the hypotheca. The posterior sulcal plate, which is completely differentiated from the flagellar furrow, covers the remaining posterior half. This plate is deeply constricted into a smaller left and a larger right rectangular lobe (Fig. 63-427), and their anterior margins are horizontal or slightly oblique. These three plates, together with the flagellar furrow, cover the depressed ventral surface of the hypotheca so completely that it may be hardly possible to see in ventral view any of the lateral precingulars or of the antapical plates. The posterior sulcal plate is not differentiated not only by surface subsidence or texture but also by any marginal list from either of the two ventral postcingulars. The other three postcingulars are subequal in length and cover anterior two-fifths of the hypotheca. The two antapicals are subequal in size. The bilateral longitudinal ridge of the hypotheca lying, together with the antapical ridge, around the ventral depression of the body, is more distinct posteriorly than anteriorly, and the antapical ridge is fairly straightened in accordance with the stronger dorso-ventral flattening of the antapical part of the hypotheca. The antapical spine is removed dorsally from the hind margin of the posterior sulcal plate by the width of the post-sulcal area, which is subequal throughout its length.

The ventral cingular plates coincide with the ventral postcingulars in their lateral end. The irregularly pentagonal transitional plate lies partly in the girdle but mostly in the ventral area (Fig. 63-428).

In the most conspicuous and striking features of this species are the sharp differentiation of the flagellar furrow and the unparalleled lateral expansion of the posterior sulcal plate. The smaller antero-median part of the ventral area varies also in shape and size as illustrated in Fig. 64-432, 434 in which the shape and size of the right and left sulcal plates, the flagellar pore and the flagellar trough differ in every case. The flagellar furrow is sharply confined, as in the previous smaller forms, mainly within the left half of this portion covering the anterior and left sulcal plates and the flagellar pore, and is strongly compressed laterally (Fig. 63-428), bending into <-shape in ventral view at the distal end of the girdle, and extends posteriorly amlost to the postmargin of the body. It is hardly possible to establish exact shapes and interrelationships of these sulcal components lying within the deep furrow, unless they were disjoined from one another. In Fig. 63-428 is illustrated the major portion of the left sulcal wall, consisting of the left and anterior sulcal plates and isolated from the right sulcal and left ventral postcingular plates. The transitional plate is irregularly pentagonal lying partly in the furrow but mostly in the 
girdle. The anterior sulcal plate is larger than the transitional, but its exact shape is quite unknown owing to its strikingly concave surface, being hidden mostly behind the postero-median corner of the right ventral precingular plate. The large, sickleshaped left sulcal plate has an obliquely truncated postero-median side with which it borders on the flagellar trough and concave anteromedian margin of this plate. The large and elongated flagellar pore is strongly twisted along its longitudinal axis, opening towards the left in its anterior end where it lies just beneath the median margin of the right sulcal plate, but sinistro-ventrally in its posterior end where it is deflected further deeply and towards the right. It extends from the distal end of the posterior cingular ridge, posteriorly along a weak spiral course, but its length and the degree of its axial torsion is subject to individual variations. The flagellar trough is subequal with or a little smaller in length than the flagellar pore. It indents often posteriorly the posterior sulcal plate, and anteriorly it deepens into the flagellar pore (Fig. 63-427). The structural relations of the right sulcal plate, together with the right-hand wall of the flagellar pore, are illustrated in Fig. 64-432, 434. The plate is in surface view an irregularly elongated with or without a narrow posterior extension. Along its median margin is the broad flagellar fin, widest at the posterior end of the flagellar pore and narrower anteriorly than posteriorly. It continues further posteriorly beyond this plate, standing basally along the median margin of the right lobe of the posterior sulcal plate. In other words, the flagellar fin consists of two portions, each belonging to the right and posterior sulcal plates.

The plate may be divided into three parts, comprising the plate proper, lateral larger or main portion of the plate lying outside of the flagellar furrow, the flagellar fin and the dorsal or interior extension. The plate proper (Fig. 64-435) is flat or slightly, convex in its lateral major portion but indented along the flagellar fin and especially distinctly at the posterior end of the flagellar pore forming there a deep pocket-like depression (Fig. 64-435, 437, 438). Along the right of the flagellar fin is a narrow list (d-d) which is called in what follows 'submedian list'. It is erected and becomes thicker but lower anteriorly. It can be traced posteriorly to the pocket $(\mathrm{Pb})$ and anteriorly to the posterior cingular ridge. There is then a narrow area lying between this and the flagellar fin (Figs. 64-435, $437 \mathrm{sm}$ ). The thecal wall bends along this submedian list more strongly anteriorly $\left(70^{\circ}-80^{\circ}\right)$ than posteriorly $\left(20^{\circ}-\right.$ $30^{\circ}$ ), and forms there a submedian furrow which is spearated from the flagellar furrow by the flagellar fin. Although the plate proper (Fig. 64-435 Pp) terminates anteriorly at the posterior edge of the girdle (Arrow B), this submedian portion (sm) extends, together with the interior extension $(a-b)$, further anteriorly across the girdle, bending sharply at the postcingular ridge (B). This anterior extension can not be seen in surface view unless the plate is isolated, because of its unusual position along the inner margin of the sharply folded and overhanging thecal wall at the distal end of the girdle. The flagellar fin (bb-cc) stands basally along the median margin of the plate and extends towards the left. The plate is sharply folded along the base of this fin to form the interior extension, which is irregularly sigmoide in side view and has a subequal width throughout its major length, forming the right-hand wall 

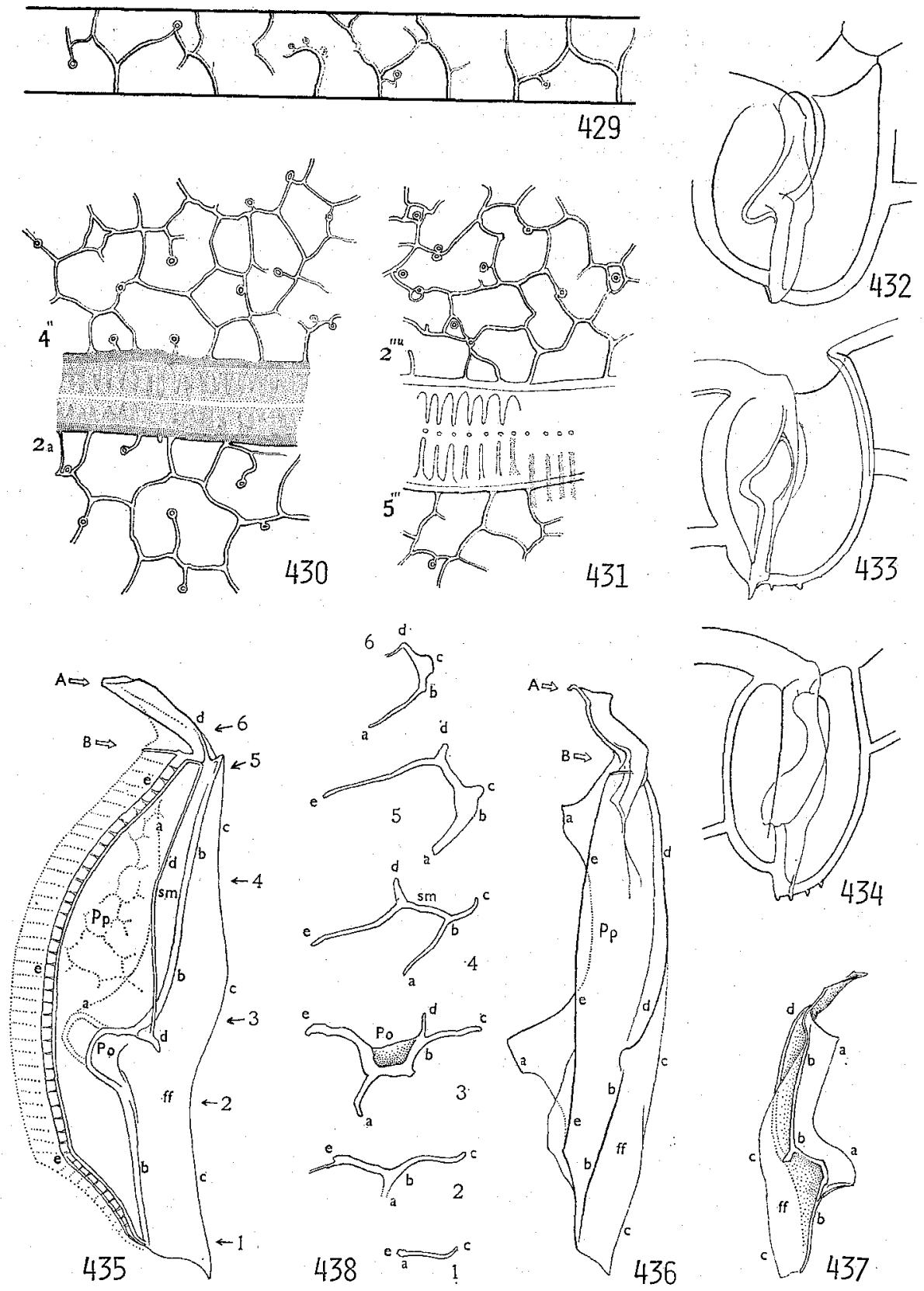

Fig. 64 (429-438): Peridinium sinuosum (LEMm.) Jörgensen (2). 429-Surface view of a part of girdle. 430-Suture between middorsal intercalary and precingular $4^{\prime \prime \prime}$. 431-Suture between postcingular $5^{\prime \prime \prime}$ and antapical $2^{\prime \prime \prime}$. 432-434-Three different shapes of anterior narrower part of ventral area, furrow s. str.. 435-Surface view of isolated right sulcal plate. 436-Oblique right side view of the same. 437-Left side view (free hand sketch). 438-Transverse optical sections (in antapical view) of the same at various heights.

$\mathrm{a}-\mathrm{a}$-Distal free margin of interior extension. $\mathrm{a}-\mathrm{b}$-Width of interior extension. $\mathrm{b}-\mathrm{b}-$ - Base of flagellar fin. b-c-Width of flagellar fin. c-c-Distal free margin of flagellar fin. d-dSubmedian list. d-e-Width of right sulcal plate proper. e-e-Lateral margin of plate. $\mathrm{ff}-$ Flagellar fin. po-Pocket. pp-Plate proper. sm-Submedian region. Arrow A indicates distal end of anterior extension of plate. Arrow B indicates anterior end of plate proper. 
of the flagellar pore (Fig. 64-435 bb-aa). In Fig. 64 (438) is illustrated a series of transverse optical sections in antapical view of this plate, and each of the numerals given in it indicate the level of the optical section. At the hind end (1), the plate consists mostly of the flagellar fin (a-c) and has no interior extension. At a little anterior level (2) just below the pocket $(\mathrm{Pb})$ is seen the interior extension (a-b) beginning to rise and at this point the flagellar fin has the largest width. In the third is shown the section cut through the pocket. It is irregularly Y-shaped with two upper arms, each representing the flagellar fin and the plate proper. There, the submedian list has the largest breadth, standing close by the flagellar fin, and the thecal wall is very thick at the pocket, the bottom of which forms a part of the wall of the flagellar pore. It may be due to this structure that one can see very distinctly the posterior end of the flagellar pore in ventral view of the body. The interior extension springs from the bottom of the pocket and is thicker than its middle portion. At a further anterior level (4), the plate is folded along the base of the submedian list, set apart from the flagellar fin, and the interior extension is broad but thin. At the anterior end of the flagellar pore (5), the folding of the plate is more distinct, the median half of the plate including the interior extension is thicker than elsewhere, and further the flagellar fin (c) becomes rudimentary. At the distal end of the girdle (6), the plate proper disappeared, and the submedian portion and the interior extension form collectively the right-hand wall of the inter-cingular part of the flagellar furrow. The plate in this portion is very narrow, its width being represented in the figure by the distance between $a$ and $b$. Anterior extension of the flagellar fin is very rudimentary (c) there.

From these described above, it is known that the structural differentiation of this plate is much more complex than we have ever deduced from other available facts. And the following characteristics are considered as worthy of special interest; the right sulcal plate expands towards the right beyond the distal end of the girdle, a small pocket is seen on the surface of the plate at the posterior end of the flagellar pore, and the interior extension forms the right-hand wall of the flagellar pore. And it may be said with certainty that these structural features may be also seen in other species of the Pentagona section.

Another point to be considered here is the distinct axial torsion of the flagellar pore. As indicated by the stronger folding of the interior extension in its anterior portions, the flagellar pore opens leftwards in its anterior end but is distorted much ventrally in its hind end. Measurements tell us that the angle of the folding is about $50^{\circ}$ just at the hind end of the flagellar pore, and about $30^{\circ}$ at the anterior end. And the angle is still smaller in the intercingular part of the flagellar furrow where it is about $10^{\circ}$. The series of angles shown here may be regarded as representing inversely the strengths of axial torsion of the flagellar pore in different heights.

Surface of the thecal wall is rugged in accord with the coarse polygonal meshes, and minute pores are scattered sparsely along the bordering ridge of the meshes or lie at the ends of their short branches extending into larger polygonal fields. And rarely a pore is confined in a small polygon without apparent connection with its en- 


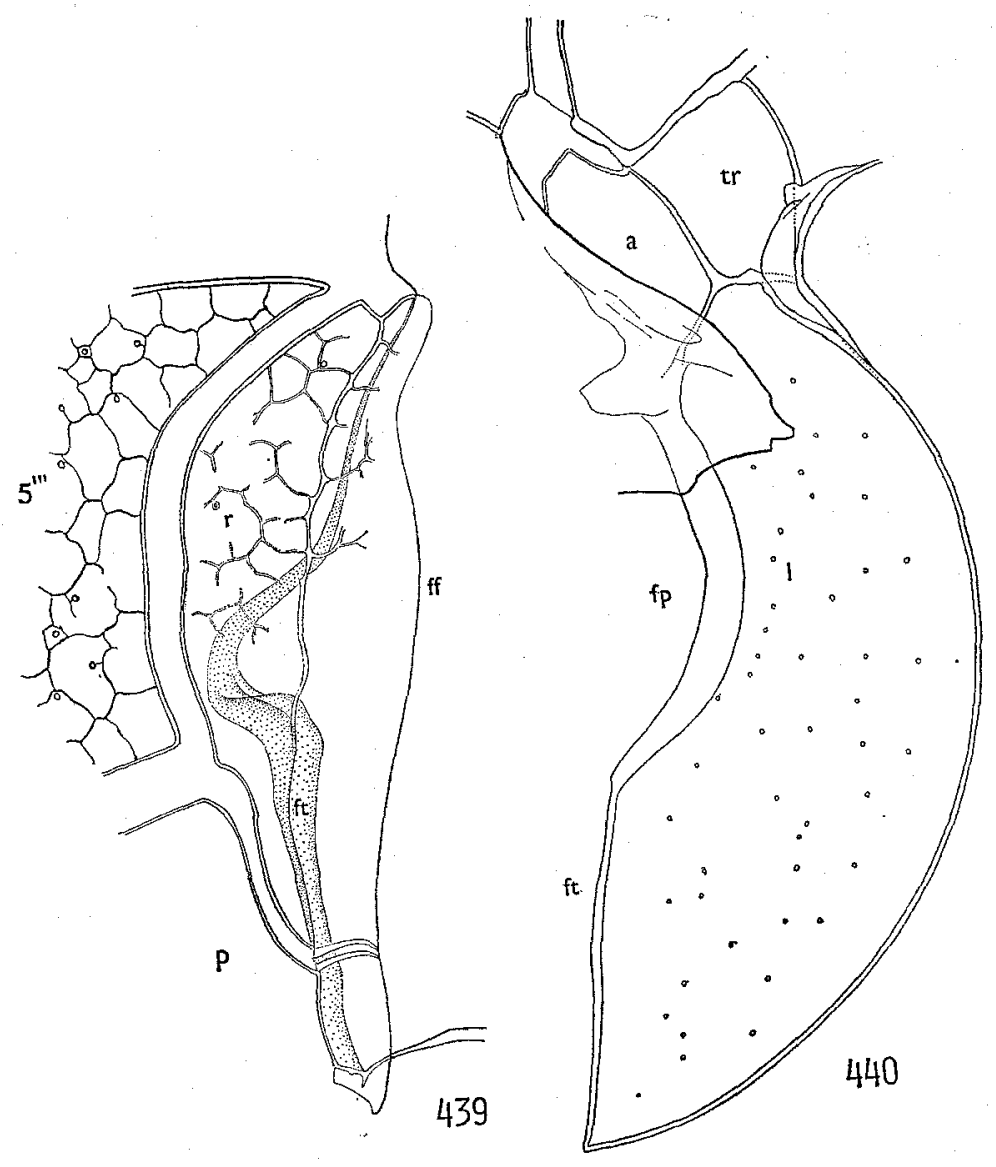

Fig. 65 (439-440): Peridinium sinuosum (Lemm.) Jörgensen (3). 439-Right sulcal plate and its flagellar fin. 440-A series of plates covering left half of longitudinal furrow. For abbreviations, see explanation to Figs. $9(51,52)$ and 64 .

circled ridges (Fig. 64-430, 431). The surface ruggedness is more conspicuous in the posterior part of the body. The surface marking of the posterior sulcal plate can not be distinguished in any way from that of the other thecal plates, while that of the right sulcal plate consists of several incomplete meshes and located in its anterior half. The cingular plates differs in this regard. Its marking consists of branched or curved transverse ridges extending alternately from its either side, and two or three neighbouring ones are connected with one another in most cases, bearing the pores at their turning points or at the terminals of their short branches (Fig. 64-430). The left and anterior sulcal plates as well the transitional plate are entirely lacking in the surface meshes (Fig. 65-440). The left sulcal plate has sparsely scattered pores all over its surface, while the anterior one has crowded ones in its median part just above the flagellar pore, and the transitional is entirely free from the perforation.

Dimensions: Body length, 110-130 $\mu \mathrm{m}$. Transverse diameter, $160-170 \mu \mathrm{m}$. 
Dorso-ventral diameter, $80-95 \mu \mathrm{m}$. Ratio in transverse length of antapical ridge and cingular section, 0.27-0.34.

Locality: Asamushi, Shimoda and the Inland Sea.

This huge pentagonal species, together with the previous much smaller forms, might have been confounded and often combined with $P$. pentagonum. $P$. pentagonum $P$. bidentata, $P$. expansa and $P$. sinuosum are so closely related with one another that there is a possibility of looking upon them as representing different developmental stages of a single species. On the other hand, they differ so much from one another in so many respects that it appears best to keep them distinct at any rate provisionally until further evidences may come to hand. Judging from Karsten's diagnosis (1906, p. 149) and his figures (pl. XXIII, Fig. II: a, b), P. divergens var. pentagonum appears to be in accord with the present species. His form differs from GRAN's original figure in its much larger and straight postmargin of the body. $\mathrm{He}$ regarded $P$. divergens simusum LemM. (1899) as a synonym of his. Although it is impossible at present to sce LemmermanN's original figures, we have to follow him, assuming KARSTEN's identification is correct and his figures coincide with LEMMERMaNN's. From $P$. pentagonum the present species can be distinguished by its larger size, stronger flattening of the body, smaller dorsal apical plate and longer and less convex postmargin of the body correlated with the extraordinary lateral expansion of the posterior sulcal plate. $P$. divergens var. excavatum KARSTEN may be separated from ours in its more deeply convex and shorter postmargin of the body.

In regard to the differentiation of the posterior sulcal plate from the flagellar furrow, the present species appears to be most highly advanced in all the described species. All the former observers who studied $P$. pentagonum in which the differentiation is less, regarded the flagellar furrow as the ventral area itself, and shirked the difficulty to uncover the true nature or structural relations of the posterior sulcal plate which was illustrated or noted by them without exception.

\section{REFERENCES}

AвÉ, T. H. 1927: Report of the biological survey of Mutsu Bay. 3. Notes on the protozoan fauna of Mutsu Bay: Peridiniales. Sci. Repts. Tohoku Imp. Univ., Ser. 4, 2 (4), 383-438.

1936a. Report of the biological survey of Mutsu Bay. 29. Notes on the protozoan fauna of Mutsu Bay. II. Genus Peridinium: Subgenus Archaeperidinizm. Sci. Rep. Tohoku Imp, Univ., Ser. 4, $10(4), 639-686$.

- 1936b. Report of the biological survey of Mutsu Bay. 30. Notes on the protozoan fauna of Mutsu Bay. III. Subgenus Protoperidinium: Genus Peridinium. Sci. Rep. Tohoku Imp. Univ., Ser. 4, 11 (1), 19-48.

1940. Studies on the protozoan fauna of Shimoda Bay. Genus Peridinium: group Globula. Sci. Rep. Tokyo Bunrika Daigaku, Sect. B, No. 82, 27-38.

1941. Studies on the protozoan fauna of Shimoda Bay. 1. The Diplopsalis group. Records of Oceanogr. Works in Japan, 12 (2), 121-144.

Apstern, C. H. 1896. Das Stisswasserplankton-Methode und Resultate der quantitative Untersuchung. Lipsius \& Tischer, Kiel u. Leipzig.

AurivituIus, G. W. S. 1898 . Vergleichende tiergeographische Untersuchungen über die PlanktonFauna des Skagerraks in den Jahren 1893-97. K. Sv. Vet. -Akad. Handl., 30 (3), 1-427.

BaIley, J. W. 1855. Notes on new species and localities of microscopical organisms. Smithsonian 
Inst. Contrib. Knowl., 7 (3), 1-16.

Bergh, R. S. 1881a. Der Organismus der Cilioflagellaten. Eine phylogenetische Studie. Morphol. Jahrb., 7 (2), 177-288. $60-76$.

1881b. Bidrag til Cilioflagellaternes Naturhistorie. Vid. Medd. Nat. For. i. Kjobenhavn,

1882a. Der Organismus der Cilioflagellaten. Morphol. Jahrb., 7, 177-288.

1882b. Über die systematische Stellung der Gattung Amphidinium. Zool. Anz., 5, 12-16.

Barkows, A L. 1918. The significance of skeletal variations in the Genus Peridinium. Univ. Cal. Publ. Zool., 18 (15), 397-478.

Вӥнм, А. 1931a. Peridineen aus dem Persischen Golf und dem Golf von Oman. Arch. Protistenk., 74, 188-197.

1931b. Zur Verbreitung einiger Peridineen. Arch. Protistenk., 75, 498-501.

1933. Neue Peridineen aus der Adria. Arch. Protistenk., 80, 351-354.

BRoch, H. 1906. Bemerkungen über den Formenkreis von Peridinium depressum. Nyt. Mag. Naturvidensk., 44, 151-157.

1910a. Das Plankton der Schwedischen Expedition nach Spitzbergen, 1908. K. Sv. Vet. Akad. Handl., 45 (9), 25-64.

- 1910b. Die Perdinium-Arten des Nordhafens bei Rovigno im Jahre 1909. Arch. Protistenk., 20, 176-200.

1910c. Neue Studien über das Plankton am Eingang zur Ostsee. Swedish Hydrographic Investigations.

Bürschl, O. 1885a. "Dinoflagellata" in "Protozoa" (1880-89), in "Bronn's Klass. u. Ordn. des Tierreichs", 1, 906-1029.

—_ 1885b. Einige Bemerkungen über gewisse Organisationsverhältnisse der sog. Cilioflagellaten und der Noctiluca. Morph. Jb., 10, 529.

ClaparÈde, E. \& Lachmann, J. 1858-59. Études sur less Infusoires ét les Rizopodes. Mém. Inst. Nat. Genèv, 5, 1-260, 6, 261-482.

Cleve, P. T. 1900a. Plankton from the southern Atlantic and the southern Indian Ocean. Öfvers. K. Vetensk.- Akad. Förh., 8, 919-938.

1900b. Plankton from the Red Sea. Öfvers. K. Vetensk.-Akad. Förh., 9, 1025-1038.

1900c. Notes on some Atlantic Plankton-Organisms. K. Svenska Vetensk.-Akad. Handl., $34(1), 1-22$.

- 1900d. Report on the plankton collected by the Swedish expedition to Greenland in 1899. K. Sv. Vet.- Akad. Handl., 34 (3), 1-21.

1900e. The plankton of the North Sea, the English Channel and the Skagerrak in 1899. Kongl. Sv. Vet.- Akad. Handl., Stockholm, 32 (2), 1-77.

ConRAD, W. 1926. Recherches sur les Flagellates de nos eaux saumatres. 1e Partie. Dinoflagellates. Arch. Protistenk., 55, 63-100.

Daday, E. 1883. Über eine Polythalamie der Kochsalztumpel bei Deva in Siebenbürgen. Z. Wiss. Zool., 40, 465.

Dangeard, P. 1923. Coloration vitale de l'appareil vacuolaire chez les Péridiniens Marins. C. R. Acad. Sci. Paris, 177, 978-979.

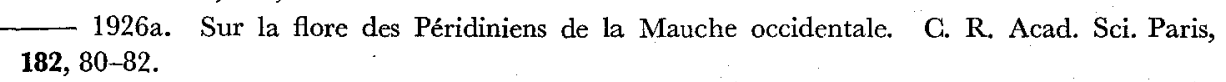

984-986.

1926c. Description des Péridiniens testacés recueillis par la Mission Charcot pendent le mois d'août 1924. Ann. Inst. Océanogr., 3 (7), 307-334.

1927a. Péridiniens nouveaux ou peu connus de la Croisière du "Sylvana". Bull. Inst. Océan. Monaco, 491, 1-16. 1927b. Notes sur la variation dans le genre Peridinium. Bull. Inst. Océan. Monaco, 507,

1927c. Phytoplancton de la croisière du "Sylvana", mission Comte J. de Polignac Louis 
Gain. Ann. Inst. Océanogr., 4 (8), 287-405.

Dangard, P. 1932a. Phytoplankton recuelli a Banyuls-sur-Mer. Arch. Zool. expér. et générale, 74, 317-355. $72,58$.

Delage, Y., \& Hèrouard, E. 1896. Traitè de Zoologie concrète. I. La cellule et les Protozoaires. Schleicher, (1) 1-584.

Drwald, K. 1939 . Ein Beitrag zur Variablilität und Systematik der Gattung Peridinium. Arch. Protistenk., 93 (1), 121-184.

ENTZ, G. jr. 1926. Beiträge zur Kenntnis der Peridineen. 1. Zur Morphologie und Biologie von Peridinium Borgei Lemmermann. Arch. Protistenk. 56, 397-416.

Fauré-Fremiet, 1908. Etudes descriptives des Péridiniens et des infusoires Giliés. Ann. Sci. Nat., Zool., 7, 209-243.

1909. Etude descriptive des Peridiniens et des infusoires ciliés du plancton de la Baie de la Itougue. Ann. Sci. Nat. Zool, 7 (9), 209-243.

Fortr, A. 1922. Riecerche sur la fiora pelagica fitoplancton di quarto dei mille (Mare Ligure). Venezia, C. Ferrari.

Gourret, P. 1883. Sur les Péridiniens du Golfe de Marseille. Ann. Mus. Hist. Nat., Marseille; Zool. 1, 1-144.

Gran, H. H. 1902. Das Plankton des Norwegischen Nordmeeres von biologischen und hydrographischen Gesichtspunkten behandelt. Norg. Fish Invest., 2, 1-222.

1915. The plankton-production in the North European waters in the spring of 1912. Bull. Plank. 1912. Conseil Perm. Intern. Expl. Mer, Copenhagen, 1-142.

Hensen, V. 1911. Das Leben im Ozean nach Zählungen seiner Bewohner. Übersicht und Resultate der quantitativen Untersuchungen. Ergebn. Plankton-Exped. Humboldt-Stiftung, 5, 1-402.

Höıl, K. 1928. Oekologie der Peridineen. Pflanzenforschg., 11, 1-105.

Huttfesd-Kass, H. 1900. Die limnetischen Peridineen in Norwegischen Binnenseen. Vid. Skr. math. nat. Kl. Christina, 1900, 1-7.

Jörgensen, E. 1912. Bericht über die von der schwedischen hydrographisch-biologischen Kommission in den schwedischen Gewässern in den Jahren 1909-10 eingesammelten Planktonproben. Svenska hydrog. -Biol. Komm., 4, 1-20.

Karsten, G. 1905. Das Phytoplankton des Antarktischen Meeres nach dem Material der deutschen Tiefsee-Expedition 1898-99. Wiss. Ergebn. d. Deutsch. Tiefsee-Exped. "Valdivia", 2, 1-219.

- 1906. Das Phytoplankton des Atlantischen Meeres nach dem Material der deutschen Tiefsec-Expedition 1898-99. Wiss. Ergebn. d. Deutsch. Tiefsee-Exped., 2, 137-219.

- 1907. Das indische Phytoplankton nach dem Material der deutschen Tiefsee-Expedition, 1898-1899. Wiss. Ergebn. d. Deutsch. 'Tiefsee-Exped. 'Valdivia', 2, 221-548.

KLeBs, G. 1884. Ein kleiner Beitrag zur Kenntnis der Peridineen. Bot. Z., 42, 721-733.

Koford, C. A. 1906a. Dinoflagellata of the San Diego Region. 1. On Heterodinium, a new genus of the Peridinidae. Univ. Calif. Publ. Zool., 2, 341-363.

1907a. Dinoflagellata of the San Diego region, III. Descriptions of new species. Univ. Calif. Publ. Zool., 3, 299-340.

1907b. Reports on the scientific results of the Expedition to the Eastern Tropical Pacific, in charge of Alexander Agassiz, by the U.S. Fish. Commission Steamer "Albatross", from October, 1904, to March, 1905, Lieut. Commander L. M. Garretr, U. S. N., commanding, 9. New species of dinoflagellates. Bull. Mus. Comp. Zool., Harvard-College, 6, 161-207.

- 1907c. The Plates of Ceratium with a note on the unity of the genus. Zool. Anz., 32, 177183.

1907d. On Ceratium eugrammum and its related species. Zool. Anz., 32, 25-28.

1908a. Exuviation, autotomy and regeneration in Ceratium. Univ. Calif. Publ. Zool., 3, $299-340$.

[909a. On Peridinium steini Jörgensen, with a note on the nomenclature of the skeleton of the Peridinidae. Arch. Protistenk., 16, 25-47. 
Kofold, C. A. 1909b. Mutations in Ceratium. Bull. Mus. Comp. Zool., Harvard, 52, 211-257.

- 1911a. Dinoflagellata of the San Diego region. IV. The genus Gonyaulax, with notes on its skeletal morphology and a discussion of its generic and specific characters. Univ. Calif. Publ. Zool., 8 (4), 197-286.

- 1911b. On the skeletal morphology of Gonyaulax catenata (Levandek). Uriv. Calif. Publ. Zool., 8, 187-194.

1911c. Dinoflogellata of the San Diego Region. V. On Spiraulax, a new genus of the Peridinida. Univ. Calif. Publ. Zool., 8, 295-300.

Kofoid, C. A. \& J. R. Mighner, 1911. New genera and species of Dinoflagellates. Bull. Mus. Comp. Zool., 54, 267-302.

Kofoid, G. A., \& T. Skogsberg, 1928. The Dinoflagellata : The Dinophysoidae. Mem. Mus. Comp. Zool., Harv., 51, 13-760.

Koford, C. A., \& A. M. Adamson, 1933. The dinoflagellata: The family Heterodiniidae of the Peridinoidac. Mem. Mus. Comp. Zool., Harv., 54, 1-136.

Lebour, M. V. 1922. Plymouth Peridinians. I. Diplopsalis lenticula and its relatives. J. mar. biol. Ass. U. K., 12, 795-812.

1923. Plymouth Peridinians. IV. The plate arrangement of some Peridinium species. $J$. mar. biol. Ass. U. K., 13, 266-270.

1925. The Dinoflagellates of northern seas. Plymouth, Marine Biol. Lab., 172.

Lemmermann, E. 1899. Ergebnisse einer Reise nach dem Pacific. Plankton algen. Abh. Naturw. Ver. Bremen, 16, 318-398.

1904. Das plankton Schwedischer Gewässer. Arch. Bot., 2, 1-209.

1907. Gonyaulax palustris, ein neue Suisswasser-Peridinee. Beih. Bot. Zbl., 21, Aht. 2, 296-

300.

1910a. Algen in Kryptogamenflora der Mark Brandenburg Algen I (Schizophyceen, Flagellaten, Peridineen). 3,563-682. $49-51$.

I Indemann, E. 1918. Mitteilungen über Posener Peridineen. Z. nat. Verein. Prov. Posen, 25 (1).

1924a. Mitteilungen über nicht genügend bekannte Peridineen. Arch. Protistenk., 47, 431-439.

- 1924b. Der Bau der Hulle bei Heterocapsa u. Kryptoperidinium foliaceum (Stein) $\mathrm{n}$. nom. Bot. Arch., 5, 114-120.

1924c. Über finnische Peridineen. Arch. f. Hydrob., 15, 1-4.

1924d. Peridineen des Alpenradgebietes. Bot. Arch., 8, 297-303.

1924e. Vom Plankton des Golfes von Neapel. Schriften für Süsswasser- u. Meereskunde.

$11 \mathrm{pp}$.

— 1925a. Neubeobachtungen an den Winterperidineen des Golfes von Neapel. Bot. Arch., 9, 95-102.

- 1925b. Peridineen aus Seen der Schweiz. Bot. Arch., 10, 205-208.

1925c. Peridineen des Oberrheins und seiner Altwasser. Bot. Arch., 11, 474-481.

1928a. Neue Peridinee. Hedwigia, 68, 291-296.

1928b. Peridineae. Die nat. Pflanzenfam., Engler-Prant1, 2, 3-104.

1928c. Vorlaufige Mitteilung. Arch. Protistenk., 63, 259-260.

1929a. Experimentelle Studien uiber die Fortpflanzungeserscheinugen der Suisswasserperidineen auf Grund von Reinkulturen. Arch. Protistenk., 68, 1-104.

1923. Über Peridineen einiger Seen Süddeutschlands und des Alpengebietes. Schriften f. Siisșwasser- und Meereskunde, 1, 3-7.

Mangin, L. 1911. Modifications de la cuirasse chez quelques Péridinéiens. Intern. Rev. d. Gesammt. Hydrobiol. u. Hydrogeogr., 4, 44-54.

__ 1911a. A propos de la division chez certains Péridiniens. Vol. Publ. en Souv, de Louis Oliver, $1-5$. 
Mangrn, L. 1911b. Modification de la cuirasse chez quelques Péridiniens. Int. Revued. ges. Hydrobiol. u. Hydrogeogr, 4, 44-54.

1911c. Sur 1'existence d'individus dextres et senèstres chez certains Péridiniens. C. R. Acad. Sci. Paris, 153, 27-32.

1911d. Sur le Pleridiniopsis asymmetrica et al. Peridinium paulsenii. Ibid, 153, 644-699.

1912. Phytoplancton de la croisière du René dans l'Atlantique, (Septembre 1908). Ann. 1'Inst. Océanogr. Monaco, 4, 1-63.

1913. Sur la flore planctonique de la rade de Saint-Vaast-la Hougue 1908-12. Nouv. Arch. Mus. d'Hist. Nat., Paris, ser. 5, 147-241.

1922. Phytoplancton Antarctique. (Expéd. Antarctique de la "Sotia" 1902-1904) Mém. Acad. Sci. Inst. France, 57, 134.

Marukawa, H. 1921a. Plankton list and some new species of copepods from the northern waters of Japan. Bull. de l'Inst. Océanographique, No. 384.

1921b. Fuyu-Seibutsu Kensaku Zusetsu, Part II (Explanatory diagrams of the plankton organisms. II. Peridineae). Tokyo.

Meunier, A. 1910. Microplankton des Mers de Barents et de Kara. Duc d'Orléans Campagne Arctique de 1907 (Bruxelles, Bulens), 355.

- 1919. Microplankton de la mer Flamande. Part III. Les Péridiniens. Mém. Mus. Roy. Hist. Nat. Belgique, 8, 1-116.

Murray, G. \& F.G. Whitting. 1899. New Peridineaceae from the Atlantic. Trans. Linnean Soc. London, Bot., ser. 2, 5, 321-342.

Mǘller, O.F. 1773. Vermium terresstrium et fluviatilum seu animalium infusoriorum, helminthicorum et testaceorum, non marinorum seoincta historia. Heineck et Faber typis Martini Hallager et Lipsiae, 1 (1), 135.

Okamura, K. 1907. An annotated list of plankton microorganisms of the Japanese coast. Annot. Zool. Japan, 6, 125-151. $1-35$

Ostenfeld, G.H. 1903. Phytoplankton from the sea around the Faeröes. Botany of the Faeröes, 2. 558-612, Copenhagen.

1908. The phytoplankton of the Aral Sea and its affluents, with an enumeration of the algae observed. Wiss. Ergebn. Aralsee Exp., 8, 123-225.

1915. A list of the phytoplankton from the Boston Strait Celebes. Dansk. Bot. Ark., 2 (4), 1-18.

PAscher, A. 1924. Ueber die morpholog. Entwicklung der Flagellaten zu Algen. Arch. Protistenk., 42.

PAulsen, O. 1904. Plankton investigations in the waters around Iceland in 1903. Medd. Komm. Havudersög., Kjöbenhavn, 1, 1-39.

1908. Peridiniales. Nordisches Plankton, herausgegeb. v. Brandt \& Apstein, Kiel, 18, 1-124.

1911a. The plankton on a submarine bank. Biol. Arbejder til Eug. Warming (Kjöbenhavn, Hagerup), 231-239.

1911. Marine plankton from the East-Greenland Sea collected during the "Danmark Expedition" 1906-1908 III. Peridiniales. Medd. om Grönland, 43, 301-318.

_- 1912. Peridiniales ceterae. Bull. Planktonique, 1908-1911. Conseil Perm. Intern. Expl. Mer, Résumé Planktonique, part 3, 251-290, Copenhagen.

_. 1931. Étude sur le microplancton de la Mer d'Alboran. Trabajos del Inst. Espanöl. de Oceanografia, Madrid, 4, 1-108.

Pavillard, J. 1912. A propos du Diplopsalis lenticula Bergh. G. R. Acad. Sci. Paris, 155.

1916a. Recherches sur les péridiniens du Golfe du Lion. Trav. Inst. Bot. Univ. Montpellier, série mixte, mém. 4, 9-70.

Peters, N. 1929. Beiträge zur Planktonbevölkerung der Weddelsee nach den Ergebnissen der Deutschen Antarktischen 1911-1912. Beitrag III. Die Peridineenbevölkerung der Weddellsee mit besonderer Berücksichtibung der Wachstums und Variationsformen. Int. Rev, Hydrobiol., 
21, $1928 / 1929,17-146$.

Pouchet, G. 1883. Sur l'evolution des Peridiniens et les particularités d'organisation qui les rapprochent des Noctiluques. C.R. Acad. Sci. Paris, 95, 794-796. $28-88$.

1885a. Nouvelle contribution a l'histoire des Péridiniens marine. J. Anat. Physiol., 21,

1885b. Troisieme contribution a l'histoire des Peridiniees. J. Anat. Physiol., 21, 525-534.

SCHILLER, J. 1929. Über eine biologische und hydrographische Untersuchung des Oberflächenwassers im westlichen Mittelmeer im August 1928. Bot. Arch., 27, 381-419.

SchilLing, A.J. 1891. Die Süsswasserperidineen. Flora, 74, 220-299, 8-10.

1913. Dinoflagellatae (Peridiniae), in A. PAscher, Die Suisswasserflora Deutschlands, Osteerichs und der Schweitz, 3, 1-66, Gustav Fischer, Jena.

SchröDer, B. 1900. Das Phytoplankton des Golfes von Neapel. Mitt. a. d. Zool. Station z. Neapel, 14, 1-38.

1901. Das Phytoplankton des Golfes von Neapel nebst verglechenden Ausblicken auf das Atlantischen Ozeans. Math. Zoöl, Sta. Neapel, 14. 1-38.

ScHÜтT, F. 1892. Ueber Organisationsverhältnisse des Plasmaleibes der Peridineen. Sitzungsber. Akad. Wiss. Berlin, 24, 377-384.

- 1895. Die Peridineen der Plankton-Expedition. I Teil. Studien ibber die Zellen der Peridineen 170. V. Hensen, Ergebn. d. Plankton-Expedition d. Humboldt-Stiftung, 4, 1-170, Kiel \& Leipzig.

- 1896. Peridiniales, in EngLeR, Naturl. Pflanzenfam., Teil I, Apt. 1B, 1-30, Leipzig.

Stein, F. 1878. Der Organismus der Flagellaten nach eigenen Forschungen in systematischer Reihengolge bearbertet. Der Organisms der Infusionstiere, 3, 1-154.

_ 1883. Der Organismus der Infusionsthiere nach eigenen Forchungen in Systematischer Reihenfolge bearbeitet. Abt. III, Aälfte II. Die Naturgeschichte der arthrodelen Flagellaten, 1-30, Engelmann, Leipzig.

VANHÖFFEN, E. 1879a. Botanische Ergebnisse der von der Gesellschaft für Erdkunde zu Berlin, unter Leitung Dr. von DrygalsKi ausgesamtem Grönland-Exped. nach Dr. VANHöfFEN's Sammulungen bearbeitet. A. Kryptogamen. III. Peridineen und Dinobryeen. Bibl. Bot., 8, 25-27. 1897b. Fauna und Flora Grönlands. Grönland-Expedition der Gesellschaft fur Erdkunde zu Berlin, 2, 254-320.

Woloszynska, J. 1916. Polnische Süsswasser-Peridineen. Bull. Acad. sci. Gracovie, Classe Sci. Math. et Nat., Ser. B, 260-285, Oct.-Nov.-Dec. 1915.

1928. Dinoflagellatae der polnischen Ostsee sowie der an Piasnica gelegenen Sümpfe. Arch. d'Hydrob. et d'Ichtyol., 3, 153-278. 